\title{
Conservation Reserve Program (CRP) Contributions to Wildlife Habitat, Management Issues, Challenges and Policy Choices-An Annotated Bibliography
}
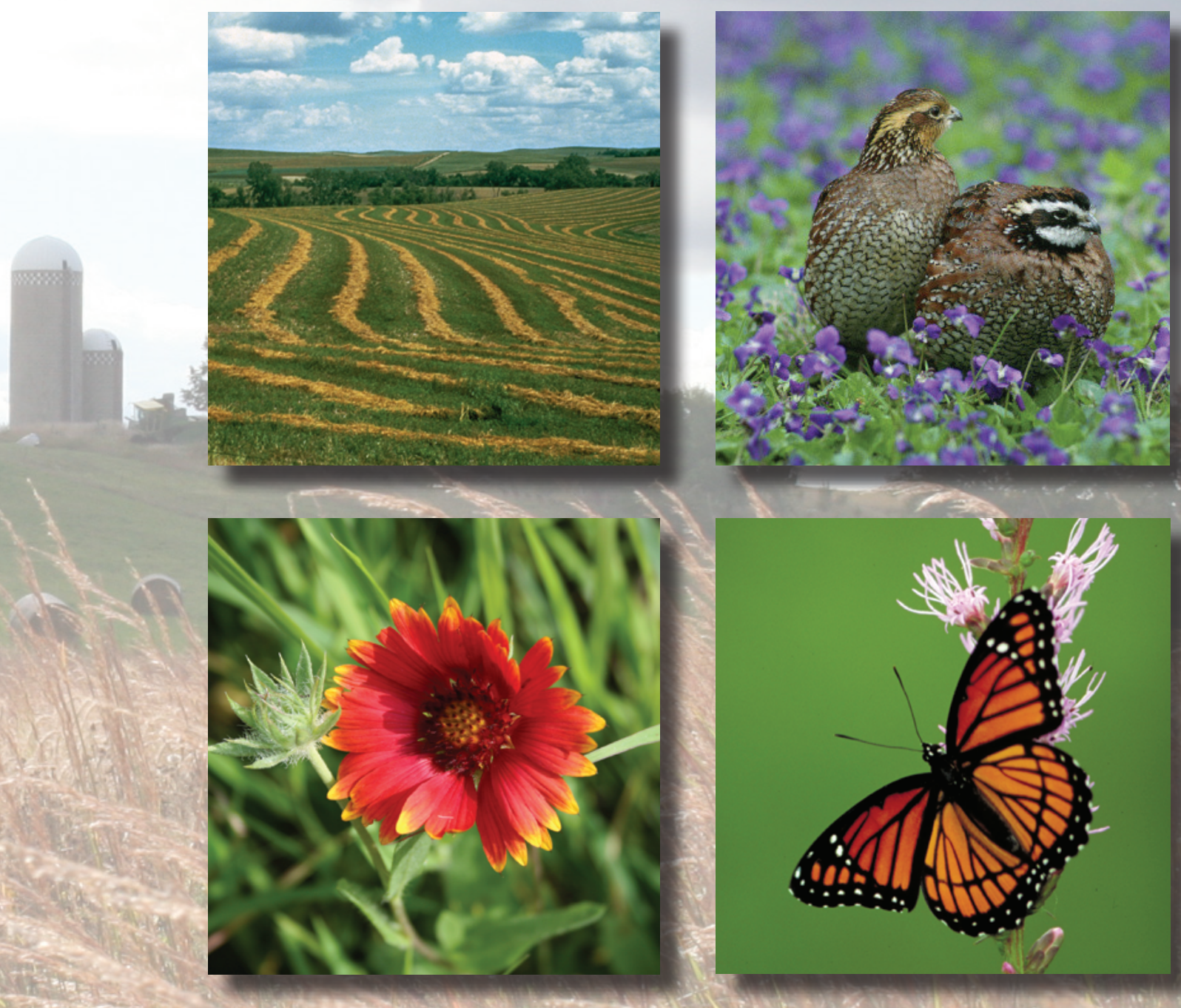

Scientific Investigations Report 2012-5066 
Cover photos: Harvested Conservation Reserve Program field, Mark Vandever, U.S. Geological Survey; Northern bobwhite quail, Steve Maslowski, U.S. Fish and Wildlife Service; Blanketflower, Mark Vandever, U.S. Geological Survey; Monarch butterfly, Dr. Thomas G. Barnes, U.S. Fish and Wildlife Service.

Report body photos: All photos were taken by the authors unless otherwise indicated. 


\section{Conservation Reserve Program (CRP) Contributions to Wild life Habitat, Management Issues, Challenges and Policy Choices-An Annotated Bibliography}

By Arthur W. Allen and Mark W. Vandever

Scientific Investigations Report 2012-5066 


\title{
U.S. Department of the Interior \\ KEN SALAZAR, Secretary \\ U.S. Geological Survey \\ Marcia K. McNutt, Director
}

\author{
U.S. Geological Survey, Reston, Virginia: 2012
}

For more information on the USGS - the Federal source for science about the Earth, its natural and living resources, natural hazards, and the environment, visit http://www.usgs.gov or call 1-888-ASK-USGS.

For an overview of USGS information products, including maps, imagery, and publications, visit http://www.usgs.gov/pubprod

To order this and other USGS information products, visit http://store.usgs.gov

Any use of trade, product, or firm names is for descriptive purposes only and does not imply endorsement by the U.S. Government.

Although this report is in the public domain, permission must be secured from the individual copyright owners to reproduce any copyrighted materials contained within this report.

Suggested citation:

Allen, A.W., and Vandever, M.W., 2012, Conservation Reserve Program (CRP) contributions to wildlife habitat, management issues, challenges and policy choices-An annotated bibliography: U.S. Geological Survey Scientific Investigations Report 2012-5066, 185 p. 


\section{Contents}

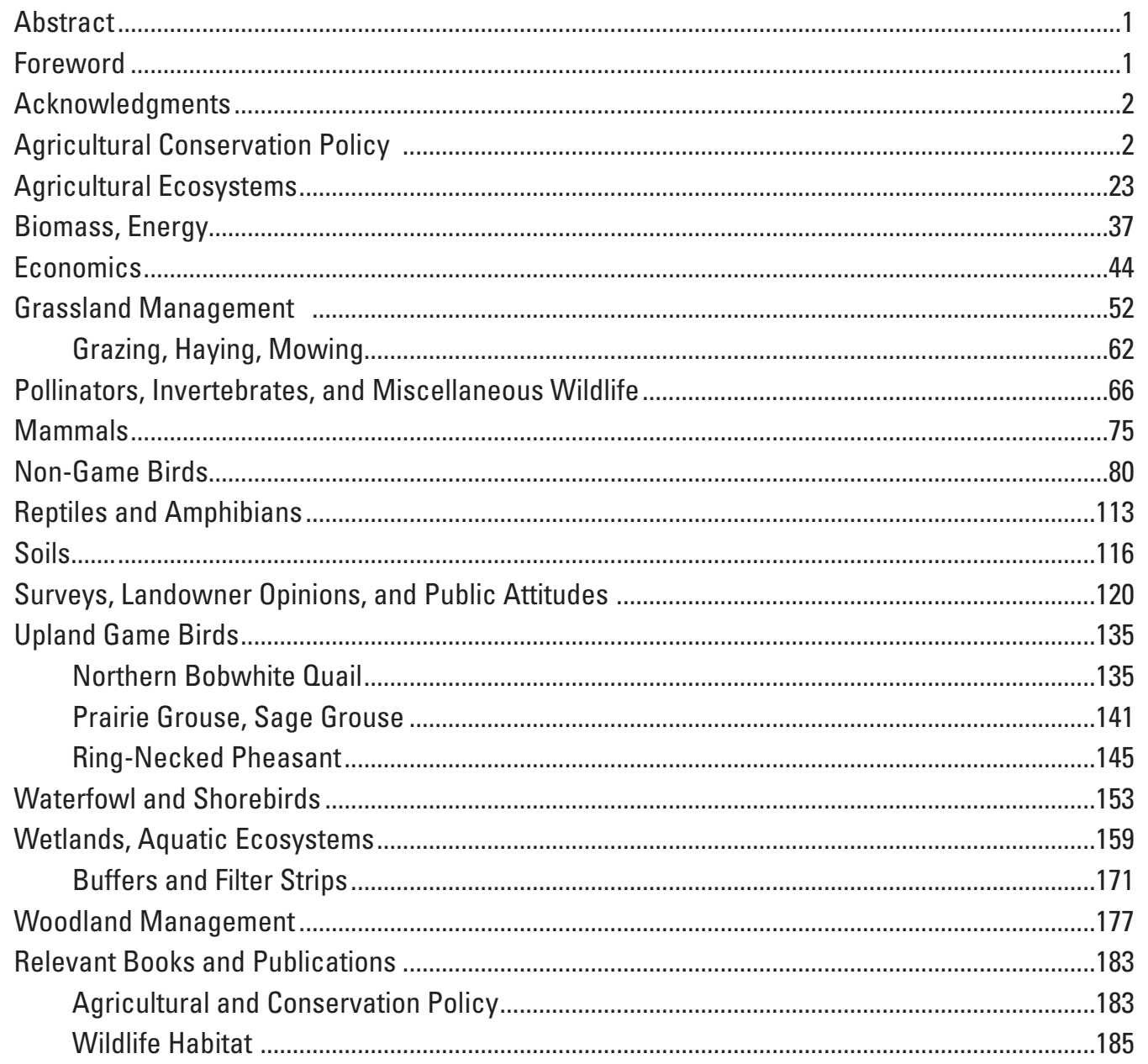




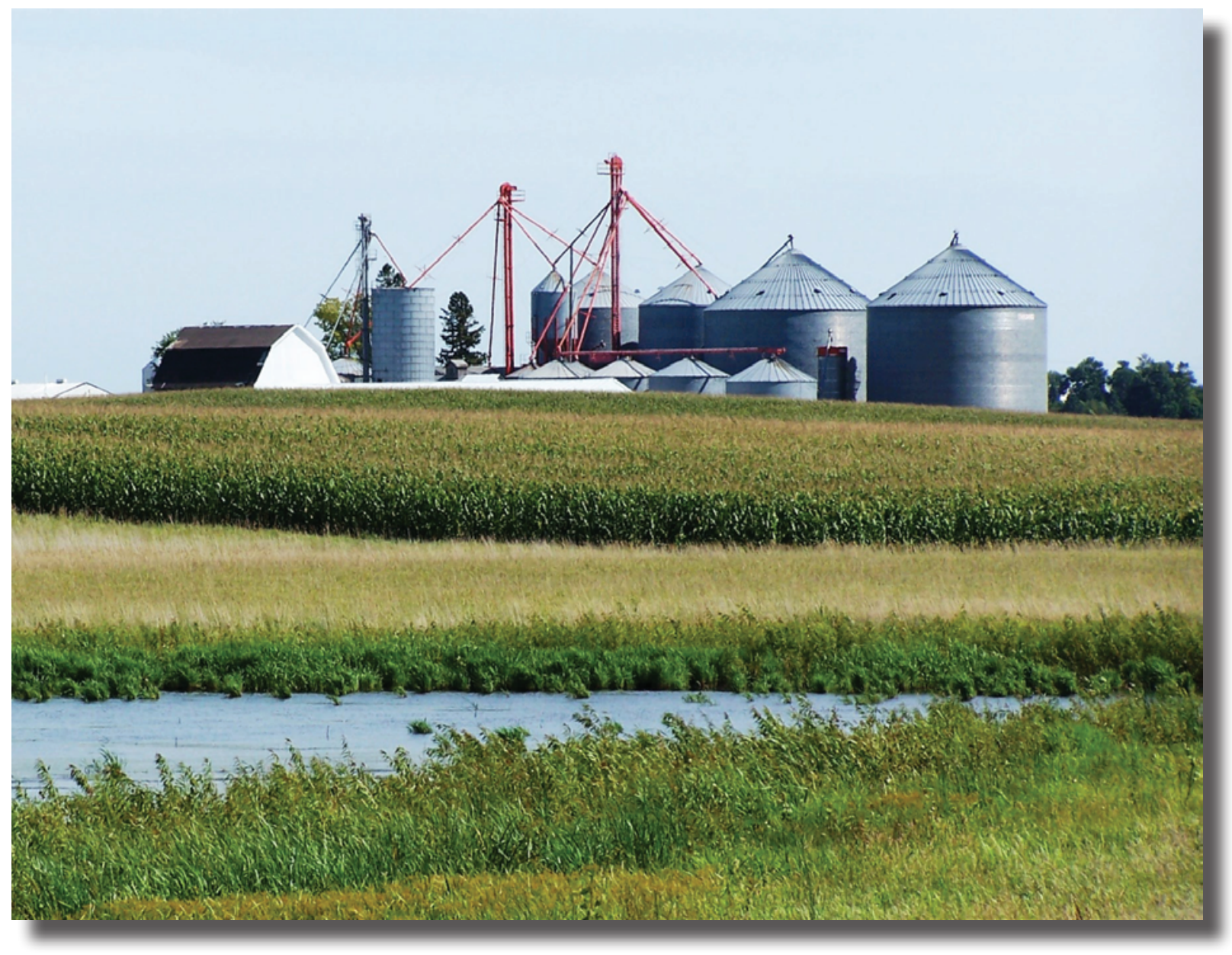




\title{
Conservation Reserve Program (CRP) Contributions to Wildlife Habitat, Management Issues, Challenges and Policy Choices-An Annotated Bibliography
}

\author{
By Arthur W. Allen and Mark W. Vandever
}

\section{Abstract}

The following bibliography presents brief summaries of documents relevant to Conservation Reserve Program (CRP) relations to wildlife habitat, habitat management in agriculturally dominated landscapes, and conservation policies potentially affecting wildlife habitats in agricultural ecosystems. Because the literature summaries furnished provide only sweeping overviews, users are urged to obtain and evaluate those papers appearing useful to obtain a more complete understanding of study findings and their implications to conservation in agricultural ecosystems.

The bibliography contains references to reports that reach beyond topics that directly relate to the CRP. Sections addressing grassland management and landowner surveys/opinions, for example, furnish information useful for enhancing development and administration of conservation policies affecting lands beyond those enrolled in conservation programs. Some sections of the bibliography (for example, agricultural conservation policy, economics, soils) are far from inclusive of all relevant material written on the subject. Hopefully, these sections will serve as fundamental introductions to related issues.

In a few instances, references may be presented in more than one section of the bibliography. For example, individual papers specifically addressing both non-game and game birds are included in respective sections of the bibliography. Duplication of citations and associated notes has, however, been kept to a minimum.

This bibliography is available online at http://pubs.usgs. gov/sir/2012/5066/.

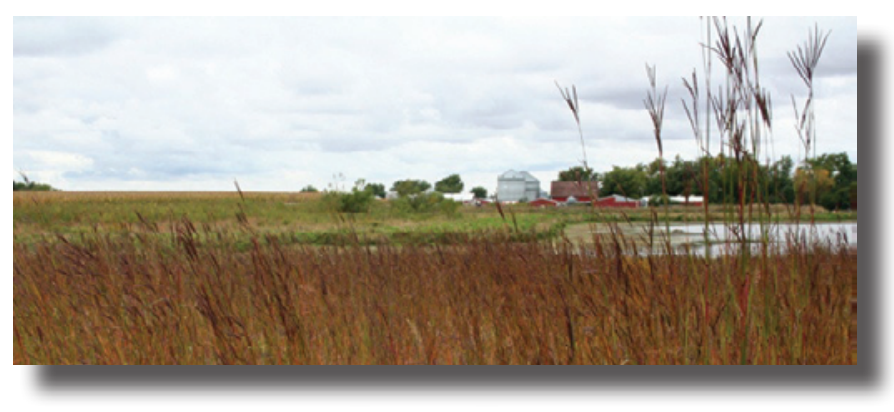

\section{Foreword}

While reviewing newer studies and editing the original draft of this document some conclusions became obvious.

Since the CRP was initiated in 1985, we have learned a great deal, but there is still a need to intertwine conservation and agriculture for the long term. The implications cited in this bibliography reach far beyond farms and watersheds, as all lands are working lands. Whether under the plow or CRP grass, they all are providing services and products. The millions of acres enrolled in the CRP, and smaller programs, have benefited wildlife of all kinds. If you have sustainable populations of targeted wildlife species, it's likely other species of wildlife are there with them. You cannot furnish ideal habitat for all species on any particular unit of land at any given time. Vegetative characteristics change. Objectives must be clearly defined. Desired results are most often not immediate. Grasslands support more beneficial insects than pest species. Properly managed, permissive use of CRP grasslands generally benefits habitat quality over the long-term. The ecological costs of putting existing conservation lands into corn production for ethanol exceed the environmental benefits realized. Little attention has been directed toward identifying conservation benefits to aquatic habitats. Renters of agricultural lands tend to have less concern about the future of the land they are farming than those who own it. Collaboration between agencies and programs brings greater benefits. The public, including the farm community, values environmental health and food quality; they want to protect it.

Generally, those enrolled in the CRP will be first to acknowledge improvement in the landscape, greater numbers and kinds of wildlife, cleaner water and air, less erosion, and satisfaction to see farmland serving better purposes.

The question is: can landowners keep their sensitive lands in conservation programs? Can conservation be made desirable and affordable to those who need it? The majority of papers included here document benefits of long-term evaluation of farm-conservation policy. It is information those who create farm policy can see, understand, believe in, and act upon. 
The CRP and other conservation programs are not about recreating what was, but what "can be"; they strive to ensure working lands provide products and profits with negligible long-term environmental impacts across the U.S. from field to sea. It can be done. It needs to be done.

Arthur W. Allen

Wildlife Biologist, (Ret.)

Policy Analysis and Science Assistance Group

Fort Collins Science Center

\section{Acknowledgments}

This work was funded jointly by the USDA, Farm Service Agency Economic and Policy Analysis Staff and Fort Collins Science Center under the U.S. Geological Survey. The authors would like to thank Clay Ogg and David Hoge for reviewing earlier drafts of this document.

\section{Agricultural Conservation Policy}

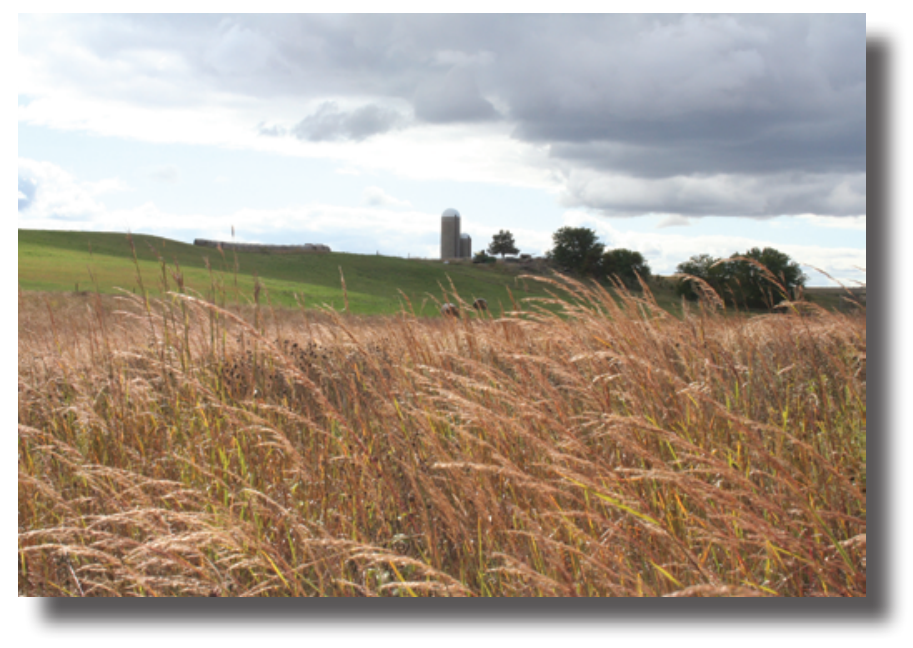

Allen, A.W., 1993, Wildlife habitat criteria in relation to future use of CRP lands, in Proceedings of the Great Plains Agricultural Council Annual Meeting, Rapid City, S. Dak., 2-5 June 1993, Proceedings: Washington D.C., U.S. Environmental Protection Agency, Great Plains Agricultural Council, p. 41-88

The report focuses on identification of strengths and weaknesses of the CRP as it developed and potential consequences on wildlife habitat if the CRP were terminated or reduced in scope. The report presents information on relations between the CRP, specific conservation practices, spatial considerations, planning, and management. The report centers on a discussion of the need to explicitly define CRP/wildlife objectives on regional and local scales. The report is based largely on information provided by state and federal biologists familiar with the program and local or regional issues.

Allen, A.W., 1994a, Regional and state perspectives on Conservation Reserve Program (CRP) Contributions to Wildlife Habitat: Fort Collins, Colo., U.S. Fish and Wildlife Service Federal Aid Report, National Biological Survey, National Ecology Research Center, 28 p.

A review of literature and information furnished largely by state and federal biologists on relations between the CRP and wildlife habitats within agricultural ecosystems. The report provides regional reviews of benefits and weaknesses of early CRP implementation. Discussions and comparison of needs by endemic grassland species and those more traditionally affiliated with agricultural land use are provided. Recommendations are presented addressing the need for elevated involvement of state wildlife agencies in technical assistance to U.S. Department of Agriculture (USDA) agencies and contractees, increased flexibility in conservation practices, and greater recognition of regional and local priorities in program implementation.

Allen, A.W., 1994b, Wildlife benefits of the Conservation Reserve Program-A national perspective, in When Conservation Reserve Program Contract Expire-The policy options, Washington, D.C., 1994, Proceedings of the Soil and Water Conservation Society Conference: Ankeny, Iowa, Soil and Water Conservation Society, p.18-20.

This paper is a brief summary of CRP benefits to game and non-game species. A discussion of limitations of the program and recommendations for increasing effectiveness of USDA conservation programs in enhancing habitat quality associated with agricultural ecosystems is presented.

Allen, A.W., and Vandever, M.W., eds., 2005, The Conservation Reserve Program - Planting for the future-Proceedings of a National Conference, Fort Collins, Colo., June 6-9, 2004: U.S. Geological Survey Scientific Investigations Report 2005-5145, 248 p.

Twenty-nine papers supplemented with moderator comments and appendices furnish differing perspectives on social, economic, and ecological effects of the CRP. Opinions expressed range from stating that the CRP has caused the downfall of U.S. agriculture to stating that the program represents the best in integration of agricultural and environmental policies. The focus of the conference, however, was on refinement and future direction of the CRP, particularly in relation to 16 million acres of contracts expiring in 2007 and 2008.

A wide range of stakeholders that includes USDA, Soil and Water Conservation Society, Ducks Unlimited, Pheasants Forever, Wildlife Management Institute, International Association of Fish and Wildlife Agencies, National Cattlemen's Beef 
Association, Farm Bureau, American Seed Trade Association, and the National Grain and Feed Association offer perspectives and recommendations for the future of the program. Reports on monitoring of USDA conservation programs and aspects of CRP effects and management options are presented by representatives from the U.S. Fish and Wildlife Service (USFWS), U.S. Geological Survey (USGS), USDA Natural Resources Conservation Service (NRCS), USDA Economic Research Service, Oklahoma State University, Mississippi State University, University of Illinois, Kansas Department of Wildlife and Parks, Colorado Division of Wildlife, and Environmental Defense.

Allen, K., 1990, Reflections on the past, challenges for the future-An examination of U.S. agricultural policy goals, in Allen, K., ed., Agricultural policies in a new decade: Washington, D.C., Resources for the Future, p. 3-23

The development of agricultural policy has become a process of mutual accommodation with large numbers of narrow provisions being fitted together to become broad-based legislation which often contains inconsistencies and few clues to real goals of policy. Agricultural policy is forced to address many more issues than farm prices and incomes. Food, fiber, trade, environmental health, rural macroeconomic, and foreign policies have all become important constituents in formulation of agricultural policies. The primary objective of farm groups remains price/income support and market stability. Overall goals of agricultural policies have broadened in response to a political environment in which non-farm interests are becoming increasingly aware and recognize that agricultural programs are at least partially responsible for detrimental environmental effects.

Environmental interests will become increasingly important to the largely urban Congress. Demographic changes in population will continue to result in changes in consumers' tastes and preferences. Concerns about chemical residues in foods and their injection into the environment are a major issue and will continue to be so. The public wants to support farmers but is increasingly disenchanted with subsidies that go mainly to the largest, wealthiest operators. Farming and agricultural service industries together contributed only about 8 percent of the personal income in non-metropolitan areas in 1986. Raising farm prices for select agricultural commodities is an inefficient way to promote rural economic activity. Economically diversified rural communities offer greater employment opportunities to farmers who wish to continue farming but have difficulties meeting financial commitments. Small, marginal changes can yield significant results in the long run. Long-term goals of agricultural policies should be promotion of a healthy, competitive agricultural sector and viable, diverse rural communities.

Berner, A.H., 1989, The 1985 Farm Act and its implications for wildlife, in 1988/1989 Audubon wildlife report: New York, N.Y., National Audubon Society, p. 437-465.
Over the last 50 years changes in land use and agricultural production have significantly affected wildlife inhabiting agricultural landscapes. Specialization and intensification of agricultural production are responsible for severe declines in distribution and quality of wildlife populations and their habitats. Federal commodity programs have contributed to much of the decline. Regulations have encouraged development of unsafe habitat by allowing late-seeding and early destruction of vegetative cover on retired acres during the nesting season.

The 1934 Cropland Adjustment Act was the first retirement program with the purpose of stabilizing the market and farm economy. Planting cover on retired acres was not required. The 1936 Agriculture Conservation Program created the Soil Conservation Service (SCS) and the Agricultural Stabilization Conservation Service (ASCS) and required farmers to plant grass or grass-legume cover on set-aside lands. The Soil Bank (1956-72) provided annual and multi-year set-aside (Conservation Reserve) programs with 3, 5, and 10 -year options.

Due to the annual nature of these programs and wide variety of agricultural management practices, little guidance on appropriate management of retired lands was furnished or required. The option of more restrictive, beneficial management guidelines are left to state and county committees comprised of local farmers which has, too often, resulted in environmentally questionable management practices. Many committees allow late seeding of cover crops or require no cover, and permit or require destruction of established cover in the fall.

Acreage reduction programs (ARP) pay farmers to annually idle land to reduce production of commodity crops. Regulations that once required reducing soil loss now require highly erodible croplands be farmed under an approved Soil Conservation plan that "substantially" reduces soil loss. The USDA predicts that crop surpluses will exist at least through 2000. More than 20 million acres per year are expected to be retired in ARP annually. Because ARP agreements are annual, farmers are not willing to pay to seed perennial grass-legume cover crops. Agricultural Stabilization Conservation Service committees generally opt to maintain maximum flexibility in establishing cover requirement, crop seeding dates, and rates and dates of cover destruction; consequently, there are minimal natural-resource benefits.

Pheasant populations have substantially increased when ARP acres are planted early to annual cover crops (typically small grains) and maintained to multi-year covers. Presently, however, ARP encourages practices proven to be detrimental to wildlife. Pheasant production in Minnesota averages 30 percent lower in years with an ARP when compared to years without the program. Minor modifications in administration could increase the value of these lands to wildlife. Recommendations to reduce negative impacts include seeding to annual cover crop (small grains) and not disturbing these plantings for at least 90 days. In areas where winter cover may be critical, a portion of acres in ARP should be seeded to cover crop such as forage sorghum and left undisturbed throughout winter. Cover 
for three or more years would provide maximum benefits to wildlife.

Berner, A.H., 1984, Federal land retirement program-A land management albatross, in Transactions of North American Wildlife and Natural Resources Conference, 49, Boston, Mass., March 23-28, 1984, Proceedings: Washington, D.C., Wildlife Management Institute, p. 118-130.

The acreage-reduction portion of Soil Bank and Feed Grain Program did not require the seeding of grass-legumes on retired acres. This lack of seeding resulted in loss of wildlife habitats associated with agricultural ecosystems. Annual programs have emphasized administrative flexibility in commodity control to the detriment of soil and wildlife conservation. Most acres in these programs are fallow or disked by the end of July to the detriment of both game and non-game species. Agricultural Stabilization and Conservation Service regulations require most fields be planted late (after June 15) and covers destroyed by mowing, disking, or plowing before grain matures (usually mid July). Present land-retirement programs are narrow in scope and deal exclusively with controlling production of domestic commodities. Policies tend to encourage conversion of non-cropland to cropland even if those lands are highly erodible. Uncertainties of program structure across years make planning difficult; therefore, farmers tend to prepare all acres for planting - this exposes even retired acres to erosion. Recent annual land-retirement programs (1961-1983) have aggravated soil erosion and wildlife habitat problems and encouraged unwise use of land. Long-term retirement options, resulting in grass-legume stands, virtually eliminate soil erosion and provide secure wildlife covers associated with farmland landscapes.

Block, D.R., 1993, Absentee enrollment and land quality in Conservation Reserve Program, in Nellis, M.D., ed., Geographic Perspectives on the Social and Economic Restructuring of Rural Areas, Proceedings of the Commission on Changing Rural Systems, Manhattan, Kans., 4-6 August, 1992: Manhattan, Kans., Kansas State University, p. 100-109.

The CRP has transferred several billion dollars to about one percent of the nation's farmers. Much of the social benefit of the CRP is based on characteristics of lands enrolled in the program. The paper reports on comparison between enrollment patterns among absentee and local landowners in Rock and Brown Counties, Nebr. The author concludes among lands eligible for CRP enrollment (that is, center pivot irrigated land) that absentee land ownership was not a significant variable in predicting enrollment in the program. Mean erosion susceptibility of absentee-owned pivots is almost identical to that of locally owned pivots. This leads to the conclusion that absentee owners are not farming in a manner more detrimental than local landowners. Mean erosion susceptibility rankings enrolled by local and absentee owners were nearly identical.

Brown, D.J., Spontak, D.M., Tibbets, M.N., Connolly, A.R., and Baccus, J.T., 2008, Enhancing the Farm Bill's conservation potential through land prioritization: Journal of Wildlife Management, v. 73, no. 4, p. 620-625.

The report describes a Geographic Information System (GIS) method to prioritize land for inclusion in agricultural conservation programs. The procedure is based on identification of lands of high conservation value (HCV) using habitats of greatest conservation need. Priority zones are delineated around HCV lands to identify high and low priority working lands (land in agricultural production) for potential inclusion in conservation programs. The authors believe the method developed encompasses broad conservation goals, has high adaptive potential, is economically and socially feasible, and is potentially applicable throughout the United States. Alternatives for identification of HCV lands and development of GIS data layers are described. Methods for definition of working land priority zones are described - these may include home range size for wildlife species of concern, percentage of landscape in HCV lands, or creation of a 1-mile (mi) buffer (1.6 kilometers [km]) priority zone surrounding existing $\mathrm{HCV}$ lands. A strong argument for using the third option is the method could be used nationwide as the Public Land Survey system (36 $\mathrm{mi}^{2}$ townships and $1 \mathrm{mi}^{2}$ sections) covers 75 percent of the U.S. landscape and all of the farm belt states. Various options for information layers are described.

Burger Jr., L.W., 2006, Creating wildlife habitat through federal farm programs - An objective-driven approach: Wildlife Society Bulletin, v. 34, no. 4, p. 994-999.

The author states USDA conservation programs have tremendous potential to affect wildlife habitats on private land and have contributed to sustaining some regional populations of wildlife. However, he argues that for Farm Bill programs to realize consistent long-term improvement in quality of habitat, planners must have a better understanding of species-specific habitat requirements and ecological processes. Wildlife biologists must also have a better understanding of the conservation programs, practices, and knowledge of landowner needs and eligibility requirements. Comprehensive planning at the farm scale is needed to optimize potential benefits to wildlife from conservation programs. Too often landowner selection of conservation practices is program driven; this results in less than optimum benefits to wildlife. Identification of landowner conservation objectives and their application at the farm scale is more likely to produce longer term benefits resulting in sustainable populations of wildlife.

While many benefits of USDA conservation programs have been realized, the failure to optimize benefits is a function of how programs have been designed and delivered across 
levels of organization from the Washington to county levels. Benefits to wildlife cannot be realized if goals are not programmatic or are not statutory objectives of conservation policies. Conservation programs may also fail to produce wildlife profits at regional and local levels due to state and local interpretation of programs rules and objectives. The quality and kind of technical assistance provided by county level USDA offices will have a strong influence on the future of wildlife populations in agriculturally dominated landscapes.

Planners and policy makers must understand that the well-being of local populations of wildlife is influenced not only by local conditions and land use but also by the structure and composition of the landscape at larger spatial scales. Therefore, long-term conservation planning should be undertaken at watershed, region, and even continental scales. However, implementation of current farm bill programs and selection of conservation practices is program driven; landowners enroll in specific programs and in subsequent management practices often driven by requirements unique to that program. These management practices may or may not meet participant objectives as the practices are simply required by the program. The reasons for this include a lack of clearly defined conservation objectives, poor understanding of programmatic options available, poor understanding and excessive work burdens on local USDA staff providing guidance to operators, and brief, limited sign-up periods which tend to result in USDA staff recommending simplistic prescriptions using "canned" alternatives. Field office personnel may also lack technical knowledge necessary to formulate effective conservation plans. Creative solutions to delivery of conservation planning may require partnerships between USDA and non-governmental organizations such as Ducks Unlimited, Pheasants Forever, and others. State wildlife agencies need to pursue cooperative arrangements for assistance in resource planning to local USDA offices.

Burger Jr., L.W., McKenzie, D., Thackston, R., and Demaso, S.J., 2006, The role of farm policy in achieving large-scale conservation-Bobwhite and buffers: Wildlife Society Bulletin, v. 34, no. 4, p. 986-993.

Payments to farm operators under USDA conservation programs far outweigh the collective investment of the North American Wetlands Conservation Act, Endangered Species Act, Pittman Robertson Act, and Conservation Investment act with potential to alter land use on large spatial scales. However, the past effectiveness of these programs has varied by program, practice, region, and wildlife species affected and effects have ranged from positive to negative. These programs can be more effective if explicit goals are identified as part of large-scale conservation initiatives such as the North American Waterfowl Plan and the Northern Bobwhite Conservation Initiative. While USDA conservation programs have been designed to achieve broad conservation objectives, available policy options often have not been designed to address specific wildlife goals identified in comprehensive, multi-agency regional and national initiatives. In the 1996 Farm Bill, wildlife was elevated to co-equal status with soil erosion and water quality, but wildlife still does not carry the weight of other objectives in relation to conservation compliance. An overview of how the CRP, specifically Conservation Practice 33 (Habitat Buffers for Upland Birds), is being used to address specific goals and objectives to enhance habitat for these species is presented.

The authors describe the Northern Bobwhite Conservation Initiative as a case study for refinement of USDA conservation programs to achieve specific wildlife goals. The goal is to restore range-wide populations to an average density equivalent to that which existed in 1980; this would require management on 32.8 million hectares ( 81 million acres) of farm, forest, and rangeland. Recommended management practices would change primary use on only 6 to 7 percent of this land. The underlying assumption upon which this initiative is based is that insufficient native herbaceous grasses and forbs, primary covers for nesting and brood habitat, limit bobwhite populations across the range of these grasses and forbs. Conservation buffers and field borders in uplands were identified as key practices that could achieve this goal in agricultural ecosystems. Conservation Practice 33 was the first continuous CRP practice specifically designed to meet habitat and population goals under a national species recovery plan. It was also the first CRP practice to specifically require monitoring to determine population response. Habitat buffers are typically 30-120 feet (ft) wide and seeded with native warm-season grasses, legumes, and shrubs, or vegetated through natural succession. Contracts are 10 years in length and require periodic disturbance through disking, prescribed fire, or application of selective herbicides. In the first year 29,588 hectares (73,113 acres) were enrolled in 35 states. CP33 will likely succeed because it addresses producer economic needs, provides multiple wildlife and environmental benefits, and is based on scientific goals identified in largescale conservation initiatives.
Christensen, J., 2003, Auditing conservation in an age of accountability: Conservation in Practice, v. 4, no. 3, p. 12-19.

A discussion of need for monitoring and documentation of conservation program performance using the Nature Conservancy as an example of an agency using monitoring to enhance success in reaching program objectives. In addition to being fundamental for accountability, measuring and auditing can be essential in learning and improving program performance. The author suggests that investors in conservation organizations and the public in general will demand more accountability in program success, not only from NGOs but from government agencies as well. Interactive measures of program performance are suggested, but purposes of measures are to focus attention on the most important aspects of the program. Monitoring should be limited to a set of key measures to assist managers and investors in making better decisions. 
Monitoring should be ongoing with a plan that communicates what is learned so data can be used for adapting strategies to improve program performance.

Claassen, R., Hansen, L., Peters, M., Breneman, V., Weinberg, M., Cattaneo, A., Feather, P., Gadsby, D., Hellerstein, D., Hopkins, J., Johnson, P., Morehart, M., and Smith, M., 2001, Agri-environmental policy at the crossroads - Guideposts on a changing landscape: Washington, D.C., USDA Economic Research Service, Agricultural Economic Report No. 794, 66 p.

Agricultural policies implemented over the last 20 years have played an important role in reduction of soil erosion, protection/restoration of wetlands, and creation of wildlife habitat. Emerging agri-environmental issues, evolution of farmincome policies, and limits imposed by trade agreements may point toward reformulation of agri-environmental policies. This report identifies types of policy tools available and design features that enhance effectiveness of current programs. Agrienvironmental payments are analyzed in depth as a potentially important tool for future policies. Agri-environmental payments to producers who achieve desirable environmental performance or use environmentally sound practices have been proposed but have been subject to only limited formal analysis. Such payments may be useful in addressing environmental issues and elevating farm income. In a multi-objective policy, there is considerable risk of conflict among objectives. Consistency between income support and environmental objectives has been enhanced through compliance mechanisms but continued coordination among all farm programs is needed to minimize contradictory or duplicative efforts.

Performance-based payments may be advantageous because only environmentally relevant actions are subsidized and producers have flexibility to select low-cost alternatives. One-size-fits-all solutions are unlikely to be successful as solutions to agro-environmental problems. Performance-based payments will focus activity on practices most effective in a given resource setting and reduce costs by allowing selection of least cost alternatives. These methods may involve high costs for planning and enforcement because farm or field specific plans must be devised. Incentives to expand crop production can undermine agro-environmental program performance. Payments for good performance, or practices, can encourage expansion of crop production onto previously uncropped areas, while the absence of a sodbuster-type provision can result in greater losses of uncropped land.

Claassen, R., Breneman, V., Bucholtz, S., Cattaneo, A., Johansson, R., and Morehart, M., 2004, Environmental compliance in U.S. agricultural policy—Past performance and future potential: Washington, D.C., USDA Economic Research Service, Agricultural Economic Report No. 832, $50 \mathrm{p}$.
This article is a discussion of compliance incentive characteristics and potential for expanding compliance approach to address nutrient runoff from crop production. Farm commodity programs in the 1970s and early 1980s probably encouraged crop production on sensitive lands increasing environmental damage associated with agricultural production. Since 1985, U.S. agricultural producers have been required to practice soil erosion conservation practices on highly erodible cropland and to preserve wetlands as a condition of farm program eligibility. Compliance provisions link farm payments with environmental objectives by requiring farmers in selected Federal agricultural programs (for example, price support loans, income support payments) to implement soil conservation systems to remain eligible for participation. Soil erosion rates have been reduced on lands subject to compliance as well as on land not subject to compliance. About 25 percent of erosion reduction was attributed to Conservation Compliance. Compliance incentives have probably deterred conversion of highly erodible noncropped land and wetlands to production. Annual rate of soil erosion on U.S. cropland estimated to have declined by nearly 40 percent between 1982 and 1997. About one quarter of the decline can be attributed to compliance provisions. Nearly 90 percent of erosion reduction between 1982 and 1987 occurred on farms receiving government program payments. Other factors that include technology, information, and markets also had an important influence on triggering reduction in rates of erosion. Compliance may have been a factor in wider adoption of farming practices (for example, conservation tillage) that may reduce erosion.

Authors suggest compliance may be a better alternative to using conservation payments to protect lands because compliance sanctions are activated only when a violation occurs. Authors believe that, under favorable market conditions, from 7 to 14 million acres of highly erodible land or wetlands could be converted to production. Compliance incentives may discourage producers from expanding crop production onto these lands. Compliance mechanisms are believed less likely than subsidies to produce unintended outcomes and may be particularly effective when subsidy programs are difficult or expensive to use. The majority of cropland with high potential for wind erosion and nutrient runoff problems is located on farms in government payment programs. Existing government payment programs have potential to affect a broader set of agricultural conservation issues but will be effective only where payments exceed the cost of required conservation actions.

Council for Agricultural Science and Technology, 1990, Ecological impacts of federal Conservation and Cropland Reduction Programs: Ames, Iowa, Task Force Report No. $117,28 \mathrm{p}$.

Overproduction in agriculture first became a major problem following WWI. Food and fiber were produced for the war effort, but markets diminished following the end of war. This pattern was repeated following WWII. World demand is a major factor influencing domestic production and prices. 
Overproduction of commodities also is due to increases in technology and productivity per acre. Between 1930 and 1980, farm production rose by almost 150 percent. If CRP reaches its goal of 45 million acres, the reduction in soil erosion is estimated to be 850 million tons per year. Other CRP benefits are cited as reduction in soil erosion, improved ground and surface-water quality, reduction in nitrate and pesticide use, and decrease in commodity surpluses. Ideas are presented to lessen negative effects of ARP, to extend the period a field may be idled from 1 to $3-5$ years, to not permit the fallowing of fields that do not furnish vegetative cover, require ASCS to consider wildlife when setting rules for seeding and destruction of cover, and include natural resource professionals on ASCS committees.

Dahlberg, K.A., 1992, The conservation of biological diversity and U.S. agriculture - Goals, institutions, and policies: Agriculture, Ecosystems and Environment, v. 42, p. 177-193.

The modernization and transformation of agriculture over the past several decades has led to increasing genetic depletion of farm habitats and rural landscapes. Ways to modify policies to enhance diversity in agricultural landscapes include making changes in current set-aside policies, credit programs, and rangeland management practices. Water and energy should receive priority, but aesthetic values and diversity of rural landscapes should also be considered in design of agricultural policies. The overarching goal should be to achieve a more diversified lower-input agricultural system.

Agricultural practices and efforts in conservation biology affect each other. American agriculture has gone from small-scale, diversified production based on local marketing systems dependent largely upon human and animal labor to large scale monoculture systems dependent on cheap energy and large markets. The size of rural populations and number of farm and farmers in the U.S. population continues to decline. Pressures to expand production have led to more monocultural production and the elimination of habitat for wildlife and pest predators through simplification of the agricultural landscape. These changes have generally also resulted in an increase in soil erosion and groundwater pollution. An important part of seeking new policy direction will be to educate the public regarding the value and importance of rebuilding a strong, diverse rural America.

Davidson, J.H., 2003, The Federal Farm Bill and the environment: Natural Resources \& Environment, v. 18, no. 1, p. 3-5, 36-39.

The article furnishes a review of the evolution of farm policy with an emphasis on development of environmental programs. The article's critical review of USDA environmental programs administered under the Farm Bill(s) concludes that most programs are ineffective in realizing sustainable natural resource management and agricultural production because they contribute to pollution and resource degradation. Although well intended, farm policy and environmental programs (CRP and Environmental Quality Incentives Program (EQIP) in particular) suffer from their temporary nature, continued focus of benefits to the largest operations, and apparent signals to farmers to intensify production on existing fields or bring new fields into production. The failure to protect family farms is identified as perhaps the biggest failure of current farm policy. The economic effect of USDA farm policy continues to enhance the capacity of larger farms to absorb smaller operations. The conclusion is also drawn that farm programs fail to encourage production methods most consistent with a healthy environment. The Farm Bills have failed to reverse long-term declines in farm jobs, off-farm jobs, and the general quality of rural life. The temporary nature of most environmental programs is seen as a major risk and limitation to these programs' long-term effectiveness in addressing environmental quality and the impacts of agricultural production.

Although critical, the article concludes that environmental programs administered under the farm bills have been a good start in addressing environmental issues born from agriculture. Farm price and income supports must be decoupled from the amount of grain or other commodity produced. Financial support for agriculturalists should be based not just on commodities but to all crops produced with an emphasis on crops that generate conservation benefits such as a return to more diverse and healthy rotation of crops and greater use of grasslands. The author also recommends all farm operations should be required to demonstrate compliance with a wholefarm conservation plan to be eligible for income support. The Conservation Security Program (CSP) is identified as having the greatest potential for environmental benefits and being the sharpest deviation from the precedent set by other farm bill environmental programs and may become the foundation for future farm support legislation.

Dimitri, C., Effland, A., and Conklin, N., 2005, The 20th century transformation of U.S. agriculture and farm policy: Washington D.C., U.S. Department of Agriculture, Economic Research Service, Economic Information Bulletin No. 3, 28 p.

The article provides an analysis of historical data on farm structure and developments in farm policy on farmers and the U.S. economy. American agriculture and rural life have undergone substantial transformation in the 20th century. The agricultural sector of the 21 st century is concentrated on a small number of large, specialized farms in rural areas where less than 25 percent of the U.S. population now lives. Production agriculture has become a smaller player in the national and rural economies. While farming-dependent counties once comprised most of the rural economy, only 20 percent of nonmetro counties were considered farming-dependent in 2000. Since 1900, the number of farms has declined by 63 percent, while farm size has increased by 67 percent. Farm families 
have had both incentive and opportunity to seek off-farm work, which has made rural areas increasingly attractive to non-farm industries. Growing public interest in food safety and environmental quality has expanded markets for specialized products and influenced agricultural environmental policy. American agriculture has increasingly become part of a global market, with at times, volatile effects on the farming economy. Farm price and income-support programs have been the core of U.S. agricultural policy since 1933. These programs have been adjusted in response to economic, political, and social pressures. Authors conclude that the extent to which farm policy meets contemporary objectives for maintaining the well-being of farm households and improving the agricultural economy remains a matter for debate.

Doering, O., 1992, Federal policies and incentives or disincentives to ecologically sustainable agricultural systems, in Olson, R.K., ed., Integrating sustainable agriculture, ecology and environmental policy: Binghamton, N.Y., Haworth Press Inc., p. 21-36.

Sustainable agriculture involves less use of off-farm inputs while introducing new management and cropping systems that make better use of on-farm resources. Until recently, federal farm policies have not been concerned with environmental issues but reflected goals of increased farm income and low cost food for the nation. Federal policies had other goals, such as improving rural conditions, increasing rural income, improving farming operations, and conserving natural resources as part of the base of agricultural productivity. At times these policies have been in conflict. Future policies must be concerned with the environmental impact of agriculture.

Five-year average data on amount of increase in input prices (1950-1985): land 710 percent, pesticides 45 percent, fertilizer 88 percent, labor 387 percent, fuel 372 percent, and machinery 921 percent. Increase in quantities of farm inputs 1950-1987: fertilizers and pesticides 426 percent, pounds per acre (lb/ac) nitrogen (N) 950 percent, and phosphate 136 percent. Labor decreased 71 percent.

Government commodity programs in the past have rewarded farmers for producing the primary commercial food and feed grain crops and have encouraged farmers towards monocultures. Since World War II, fertilizers and pesticides have become comparatively cheaper compared to labor, fuel, and machinery encouraging greater use. The CRP has reduced environmental problems, but the program does not address sustainability or environmental concerns relative to acres remaining in production and the long-term use of CRP acres. What is required is a much more strongly held view by the general public that they have interest in long-term decisions about land use and resources.

Dunn, C.P., Stearns, F., Guntenspergen, G.R., and Sharpe, D.M., 1993, Ecological benefits of the Conservation Reserve Program: Conservation Biology, v. 7, no. 1, p. 132-139.
An overview of unintentional, yet significant, ecological benefits of CRP that include: reversal of landscape fragmentation, maintenance of regional biodiversity, increased habitat for wildlife, and regional changes in carbon (C) flux. The authors believe overall program costs would be more than offset by benefits from: increased net farm income, soil productivity improvements, enhanced water quality, and revenue from recreational activities if these benefits could be accurately documented. Dollar benefits derived from program are difficult precisely quantify. Other ecologically desirable benefits include: reduced sedimentation in lakes, rivers, streams; reduced non-point source agricultural runoff, improved water quality, and retention and development of wildlife habitat. Documenting the economic and social benefits should be completed in order to maintain and improve the program studies.

General Accounting Office, 2002, Agricultural ConservationState advisory committees' views on how USDA programs could better address environmental concerns: Washington, D.C., U.S. General Accounting Office, 76 p.

Based on input from state conservation committee members, sixty-two percent of respondents indicated loss of wildlife habitat on farms and ranches was a moderate or major concern. Over half believed that loss of native species was of moderate or major concern. Almost 50 percent felt that CRP was from very to extremely effective in addressing state environmental and resource concerns. Nearly 53 percent felt CRP was from very to extremely effective in protecting or improving wildlife habitat. Over 35 percent felt there was enough NRCS technical assistance to meet program needs while 58 percent felt there was less than enough assistance provided than needed. Fifty-eight percent of respondents felt CRP had somewhat or very positive effects on economy of rural communities. Nearly 20 percent of respondents believed CRP had negative effects on local economies. Fifty percent felt that CRP needs more emphasis in protecting or improving wildlife habitat.

General Accounting Office, 2003, Agricultural ConservationUSDA needs to better ensure protection of highly erodible cropland and wetlands: Washington, D.C., Committee on Agriculture, Nutrition, and Forestry, U.S. Senate, U.S. General Accounting Office, GAO-03-418, 106 p.

Investigation reveals that NRCS has not consistently implemented conservation provisions of the 1985 Food Security Act. The result is an increase in the possibility that some farmers continue to receive federal payments while their soil continues to erode at rates higher than permissible or that they convert wetlands to cropland. A nationwide survey reveals that almost 50 percent of NRCS field offices do not implement/ enforce conservation provisions as required because they lack 
sufficient staff, recommended management does not emphasize conservation provisions, or staff are uncomfortable with enforcement role. Field offices consistently did not check on enforcement, see if recommended problems were corrected, or enforce wetland violations. Weak oversight of field offices impairs implementation of conservation provisions. Also, NRCS disproportionately emphasized tracts with little erosion potential (for example, rangeland, pasture) and noncompliance leading to inflated compliance rates. The General Accounting Office (GAO) concluded that NRCS field offices could not conduct timely reviews during critical erosion periods or furnish higher administrative levels with up-to-date information. The Farm Service Agency (FSA) was found to often waive noncompliance determinations without adequate justification. The resulting GAO recommendations were to: increase level of oversight of field offices on compliance reviews to improve accuracy and completeness, conduct compliance reviews on more representative tracts of land, develop and implement automated data system for reviews, and insure that FSA supports noncompliance issues and withholds benefits to operators in violation of conservation guidelines and provisions.

Government Accountability Office, 2006, Conservation Security Program - Despite cost controls, improved USDA management is needed to ensure proper payments and reduce duplication with other programs: Washington D.C., Committee on Appropriations, U.S. Senate, U.S. Government Accountability Office, GAO-06-312, 96 p.

The report investigates rising costs associated with implementation of the CSP. The primary factor leading to rising costs was identified as the availability of little information on how the program would be implemented at time of inception in 2002; this resulted in conservative estimates of costs. Estimates of participation level, number of acres enrolled, and amount and types of payments made were underestimated. As details became clear costs rose. Government Accountability Office concludes that costs could be brought under control by addressing weaknesses in internal controls and inconsistencies in the wildlife habitat criteria used by state offices to determine eligibility for the highest CSP payment level.

NRCS cost-control efforts may be undermined by inconsistencies in the wildlife-habitat-assessment criteria used by state offices for determination of the highest tier of payments. Evaluation criteria were variable - this contributed to differences in Tier III participation and payments among watersheds. Some state offices developed and applied criteria for fiscal year 2005 that were inconsistent with national guidance. These discrepancies diminished NRCS' ability to ensure that CSP is achieving intended wildlife habitat objectives. As of February 2006, NRCS had not reviewed their wildlife habitat assessment criteria and did not have plans to do so.

To improve implementation of the CSP, GAO recommends the NRCS should review and field check wildlife-habitat-assessment criteria used in each state office to ensure consistency. In addition, it was recommended that NRCS develop an automated system to minimize or prevent duplication of payments and a process to review existing CSP contracts to ensure duplicate payments are not made.

Government Accountability Office, 2006, Agricultural conservation-USDA should improve its management of key conservation programs to ensure payments promote environmental goals: Washington, D.C., Testimony before the Committee on Agriculture, Nutrition, and Forestry, U.S. Senate, GAO-07-370T, $11 \mathrm{p}$.

Farmers and ranchers own about 940 million acres (about half the area of the United States); therefore, they are among the most important stewards of the nation's soil, water, and wildlife resources. This GAO report describes weaknesses in NRCS management of the EQIP and CSP. The GAO determined the NRCS process for providing EQIP funds to states was not clearly aligned to the program purpose of optimizing environmental benefits and may not be directing funds to states with the most significant environmental issues. NRCS does not have a viable plan to link long-term, outcome-oriented performance measures to the funding allocation process. NRCS did not have a process to prevent, or identify, when duplicate payments were made to operators under different programs. The GAO recommends that NRCS ensures factors and weights used in EQIP financial formulas are documented and linked to program priorities, continue monitoring of performance measures to refine financial assistance formulas, and develop a comprehensive process to identify and prevent duplicate payments between CSP and other conservation programs.

Gersmehl, P.J. and Brown, D.A., 2004, The Conservation Reserve Program-A solution to the problem of agricultural production?, in Janelle, D.G., Warf, B., and Hansen, K., eds., Worldminds - Geographical Perspectives on 100 Problems: Boston, Mass., Kluwer Academic Publishers, p. 381-386.

The report furnishes a critical look at the 1985 Farm Bill, the CRP, and the issue of slippage. Authors are critical of environmental study results attributing benefits to the CRP because only few spatially isolated studies have been used to derive benefits on larger scales. Authors believe scaled-up fallacies have given an artificial assessment of environmental benefits derived from the CRP. The authors state the CRP on the Great Plains is a "well-regarded failure" because the favorable effects of the program are offset by the widespread creation of new cropland during the same time periods of high enrollment. The authors estimate a slippage increase of nearly 4 million hectares of new cropland in between 1992 and 1997 
when CRP acreage in 15 Great Plains states increased to 9.5 million acres. In absence of data to the contrary, the authors believe new lands would be at least as erosion prone and would potentially offer poor habitat for wildlife. The abundance of geographically suspect field-scale studies has overwhelmed other opinions resulting in the Federal government to expand the CRP to control "food surpluses." A multi-scale approach is required to correctly expand field level studies to larger scales. Authors believe policy makers will have to recognize that a change in farm-scale incentives and policies is essential to finding solutions on a national scale.

Goodwin, B.K. and Smith, V.H., 2003, An ex post evaluation of the Conservation Reserve, Federal Crop Insurance, and other government programs-Program participation and soil erosion: Journal of Agricultural and Resource Economics, v. 28, no. 2, p. 201-216.

For the most part, policy makers and evaluations of federal farm programs have given little attention to interactions between various programs potentially affecting erosion of soils. Effective design of federal agricultural policies must take into consideration interdependence of farm programs and the overall attainment of soil erosion goals. This study concludes that the CRP significantly reduced erosion in areas where farmers participated. However, the analysis also reveals that federal crop insurance and disaster relief programs have had little impact on rates of soil erosion. Incomesupport programs have encouraged production on other lands more susceptible to soil erosion. Estimates are CRP has significantly reduced annual soil loss by an average of about 1.02 tons per acre (tons/ac). At the same time, increases in proportion of farm revenues resulting from federal payments between 1982 and 1992 were estimated to have increased erosion by about 0.55 tons/ac.

Gray, R.L., and Teels, B.M., 2006, Wildlife and fish conservation through the Farm Bill: Wildlife Society Bulletin, v. 34 , no. 4 , p. 906-912.

Authors provide a synopsis of the history of Farm Bill contributions to wildlife habitats and conservation since the 1985 Bill and creation of the CRP and other conservation programs. Descriptions and benefits of key programs: CRP, Wetlands Reserve Program (WRP), Wildlife Habitat Incentives Program (WHIP), EQIP, Grassland Reserve Program, and CSP are provided, as well as descriptions of Swampbuster and the Conservation Effects Assessment Project (CEAP). Authors describe the importance of these programs in meeting environmental and fish and wildlife conservation goals associated with the 70 percent of the U.S. land base held in private ownership.
Gregory, S., Allen, A.W., Baker, M., Boyer, K., Dillaha, T., and Elliott, J., 2007, Realistic expectations of timing between conservation and restoration actions and ecological responses, in Schnepf, M., and Cox, C., eds., Managing agricultural landscapes for environmental quality — Strengthening the science base: Ankeny, Iowa, Soil and Water Conservation Society, p. 115-146.

How many months, years, decades, or lifetimes must we wait to see consequential evidence of conservation success? The needs and costs of conservation and restoration are constantly debated, sometimes with information. Frequently missing from deliberations are realistic estimates of the time required before desired environmental outcomes are realized. Often expectations about timing and effectiveness are unrealistically short. The objectives of this paper are to present information relative to timeframes over which conservation and restoration outcomes in agriculturally dominated landscapes are likely to be realized, definitions of success, and how conservation policies can be designed and evaluated to yield reasonable measures of effectiveness. The report presents examples of restoration and conservation issues in agricultural systems related to water temperature, water chemistry, pollutants and waste, aquatic communities, and terrestrial wildlife.

Conservation and restoration are closely related but discrete processes. Dissimilarity between these concepts has enormous consequences in how the success of an ecological response is defined. Conservation attempts to maintain functional and ecological ecosystem components to sustain existing resources. Ideally, conservation maintains performance of the existing system. Restoration is an attempt to repair ecosystem processes to reestablish functions that have been diminished or eliminated. Exact restoration may take decades, or longer, to see meaningful response. Desired outcomes generally arrive more quickly under conservation objectives. Monitoring designs are intricate and expensive because they must measure ecologically complex processes, often over an extended period of time.

The purpose of USDA conservation programs is not to restore ecosystems but to lessen undesirable environmental effects of agricultural production. Wildlife response to the CRP, and other conservation programs, has been geographically and ecologically far-reaching. Terrestrial wildlife response to conservation practices closely follows establishment and physical characteristics of vegetation planted. Wildlife response in terms of number and types of species will vary as vegetation characteristics change through time. Consequently, measurement objectives must be clearly defined. Evidence shows wildlife species have prospered where conservation practices have been designed to address regionally prevalent erosion issues. For example, whole field CRP enrollments planted to grasses in western states have decreased wind erosion and benefited grassland wildlife that are dependent on an extensive area of suitable habitat. In wetter regions, grass filter strips, riparian buffers, and field borders have diminished rates of soil 
erosion while benefiting wildlife adapted to higher levels of habitat interspersion.

Restoration of aquatic habitats is difficult to evaluate because effects can be influenced by physical, biological, and chemical factors on multiple spatial scales, from small site to inputs from the entire watershed. Conservation practices in a watershed will differentially influence the depth and timing of responses of physical habitats and aquatic species. Consequently, correlations between a specific practice and ecological responses are difficult to obtain. The maintenance connectivity of wetlands in a watershed, restoration of riparian vegetation, removal of obstacles, and placement of instream structure have been shown beneficial to aquatic species. Species affected and times of response to these practices can be variable through time and the watershed requiring judicial definition of success for conservation practices and policies. Farm policy, political administrations, landowner dynamics, and agency personnel could change many times before a watershed demonstrates true recovery.

Measurable responses to long-term restoration and conservation programs are challenging to evaluate and report. A lack of evaluations, particularly for aquatic responses, is a consequence of the continually limited funding amount that is dedicated to assessment and represents a failure by those who formulate farm conservation policies to recognize the importance of monitoring to improve program performance. Unfortunately, often this lack of data on measurable, economic response has been incentive to further limit funding. Successful conservation policies can be supported only when their effectiveness in known. To gain such knowledge requires a commitment to gather immediate as well as long-term data. Time frames of conservation and restoration must be clearly defined for policy makers to understand that results may not be immediate. Practical timeframes for conservation policy to become effective must be taken into account in policy design.

Hansen, L., 2007, Conservation Reserve Program-Environmental benefits update: Agricultural and Resource Economics Review, v. 36, no. 2, p. 1-14.

Long-term retirement of cropland under the CRP has furnished scores of environmental benefits. Over time, environmental goals have become leading objectives of the program. This article presents an attempt to quantify some of the benefits of the program on a regional and national basis. Supporting methodology and assumptions of the analysis are presented. Based only on wildlife viewing and hunting for ring-necked pheasants (Phasianus colchicus), the authors estimate wildliferelated benefits of the CRP are approximately $\$ 737$ million per year (million/yr). The value of improved hunting of pheasants is about $\$ 87$ million/yr, 12 percent of the total benefits. The sum of the CRP's total benefits is estimated at $\$ 1.32$ billion per year (billion/yr). Conservation Reserve Program benefits in the Corn Belt are nearly twice those of the Southern Plains. The Corn Belt, Lake, and Southern plains regions hold about 35 percent of all CRP acreage and account for over 60 percent of environmental benefits. In contrast, Mountain and Northern Plains regions have 45 percent of the CRP area but account for only 12 percent of estimated benefits. Authors conclude that the estimated environmental benefits compensate for 75-85 percent of CRP costs. This is a conservative estimate because not all environmental benefits borne from the CRP have been included in this analysis. Many benefits remain unquantifiable and unknown. The authors conclude there is strong evidence the environmental benefits of the CRP exceed the costs of the program. In addition, they state that any assessment of the CRP should recognize the program brings additional economic benefits through favorable effects on other farm programs.

Hays, R.L., and Farmer, A.H., 1990, Effects of the CRP on wildlife habitat - Emergency haying in the Midwest and pine plantings in the southeast, in Transactions of North American Wildlife and Natural Resources Conference, 55, Denver, Colo., March 16-21, 1990, Proceedings: Washington, D.C., Wildlife Management Institute, p. 30-39.

A multi-state evaluation of emergency haying of CRP in 1988 documents impacts on the quality of habitat furnished by the program. Although a relatively small percentage of CRP fields (less than 20 percent) were hayed in 1986/1987, haying in many cases exceeded legal limits of percentage of field eligible for haying. Mowing for weed control was generally extensive in CRP fields with 82 percent of sampled fields having more than 75 percent of field area mowed. Fifty-five percent of these fields had been mowed entirely. It was estimated that about one-third of hay was cut during the period when about half of avian nests were still being incubated. Authors conclude emergency use probably had significant negative impacts on availability and quality of habitat in CRP.

Hays, R.L. Webb, R. P., and Farmer, A.H., 1989, Effects of the Conservation Reserve Program on wildlife habitat-Results of 1988 monitoring, in Transactions of North American Wildlife and Natural Resources Conference, 54, Washington, D.C., March 17-22, 1989, Proceedings: Washington, D.C., Wildlife Management Institute, p. 365-376.

Results of a multi-state evaluation of CRP contributions to wildlife habitat are discussed. The highest amount of persistent vegetation cover was recorded in CP2 (warm season grasses) fields. The highest pre-greenup average visual obstruction reading (VOR) was in CP2. Percentage of herbaceous cover made up of grasses was not different between $\mathrm{CP} 1$ (introduced grasses) or $\mathrm{CP} 2$ conservation practices. Ring-necked pheasants (Phasianus colchicus) may be more limited by winter food and cover than by nesting cover near some CRP fields. The planting of woody vegetation and food plots should be encouraged. CRP appears to be providing good nesting habitat for pheasants and fair nesting habitat for meadowlarks (Sturnella spp.). Improvement in habitat quality for cottontail rabbits (Sylvilagus floridanus) was not detected. 
Winter cover values appear to be greater on CP2 than within CP1. Unless high-quality winter cover is developed on more CRP fields themselves, it seems likely that winter food will only contribute to usable pheasant habitat in years that have mild winters. It appears that CRP could provide a greater contribution to the quality of pheasant habitat if planted in association with other covers in short supply such as winter cover and winter food.

Heard, L.P., Allen, A.W., Best, L.B., Brady, S.J., Burger, W., Esser, A.J., Hackett, E., Johnson, D.H., Pederson, R.L., Reynolds, R.E., Rewa, C., Ryan, M.R., Molleur, R.T., and Buck, P., 2000, A comprehensive review of Farm Bill contributions to wildlife conservation, 1985-2000: Madison, Miss., USDA Natural Resources Conservation Service, Wildlife Habitat Management Institute, Technical Report USDA/NRCS/WHMI-2000, 208 p.

The report provides a comprehensive review of literature describing wildlife responses to USDA programs established under the Conservation Titles of the 1985 and 1990 and 1996 Farm Bill amendments. Annotated literature and summaries are provided for the CRP, WRP, WHIP, and EQIP. In general, wildlife has showed a positive response to these programs. Precise quantifiable relations between Farm Bill conservation programs are, however, difficult to achieve and generally lacking. Programs are making significant contributions toward conservation on fish and wildlife resources. Most literature discussed pertains to CRP studies. Less documentation for other programs exists due to lack of scientific investigations focused on these programs.

Heard, L.P., Allen, A.W., Best, L.B., Brady, S.J., Berger, W., Esser, A.J., Hackett, E., Helinski, R.R., Hohman, W.L., Johnson, D.H., Reynolds, R.E., Rewa, C., and Ryan, M.R., 2001, The history, status and future needs of fish and wildlife management on private lands as related to USDA agricultural programs, in Transactions of North American Wildlife and Natural Resources Conference, 66, Washington, D.C., March 16-20, 2001, Proceedings: Washington, D.C., Wildlife Management Institute, p. 54-67.

The report provides an overview of past USDA conservation programs and effects on wildlife in agricultural ecosystems. It also presents a synopsis of present USDA conservation program (CRP, WRP, Conservation Reserve Enhancement Program (CREP), WHIP effects on wildlife populations. Recommendations are made for future refinement of conservation programs to benefit environmental quality and wildlife associated with agricultural lands.

Hovorka, D., 2007, Hidden treasures-The Conservation Security Program and wildlife: Washington, D.C., National Wildlife Federation, $40 \mathrm{p}$.
The report describes an overview of the structure of the CSP as well as some of the benefits to wildlife and their habitats brought by the program. Case studies of wildlife benefits provided by the CSP in the Chesapeake Bay, California, Georgia, Minnesota, Missouri, Nebraska, and Texas are presented. The author concludes that approximately 50 percent of CSP payments in 2006 will furnish direct or indirect benefits to wildlife and their habitats. However, benefits appear to be much lower in some states. For example, only 26 percent of payments in Nebraska support practices that benefit wildlife habitats. A major finding is that the CSP provides substantial benefits to wildlife, but these vary between states and could be substantially improved.

Key findings of the report include a recommendation that Congress should enhance funding for the CSP to provide nationwide opportunities for enrollment in the program. USDA should fund new practices at the same rate furnished in other USDA conservation programs. All CSP Tier II and III contracts should address wildlife habitat and the emphasis on wildlife issues should be elevated in Tier I contracts. USDA should ensure CSP standards provide consistently high levels of benefits to wildlife. Monitoring of the effectiveness of conservations practices should be a fundamental part of the program to ensure funds are being spent appropriately and conservation practices are achieving desired results.

Ikerd, J., 2002, New Farm Bill and U.S. Trade Policy—Implications for family farms and rural communities: Paper presented at "Grain Place" Farm Tour and Seminar, Aurora, Nebr., accessed July 27, 2002, at http://web.missouri. edu/ ikerdj/papers/FarmBill.html.

The author advises government programs to focus on using "public funds" to create "public benefits," not to subsidize wealthy landowners and corporate investors. The author furnishes a lucid argument detailing why current U.S. farm policy fails to meet the needs of individual farmers and is continually drifting toward providing benefits only to large corporate farms with consequential further disassociation from environmental quality and the public good.

There are few places left in the U.S. where prices of farmland are not affected by potential residential values. Land prices will continue to rise regardless of what happens to agriculture. Multinational agribusiness now controls much of the new technology and increasingly investments and technologies earn their greatest returns somewhere other than in America. American farmers are no longer competitive in world markets; they are heavily subsidized, but government payments have done nothing to address the real problems in American agriculture. Ten percent of agricultural producers, including many large corporate operations, have been receiving more than two-thirds of all commodity payments. The 2002 Farm Bill is not designed to meet the needs of farmers but the needs of the Agricultural Establishment comprised of corporate agribusiness, commodity organizations, USDA, and Land Grant Universities. The main objective of these 
members of the Agricultural Establishment is maintaining high levels of production. Profits come from margin and volume, not farm-level price. Limited demand domestically translates into high levels of exports, which are possible only if commodity prices are "competitive," which means low. Multinational agribusiness corporations increasingly dominate the Agricultural Establishment.

Much of the current public support for agricultural programs is based on the belief that the programs help smaller, independent farmers; unfortunately, there is little truth in this assumption. Congress must find ways to focus agricultural programs to provide public benefits with these public funds. This goal must become the focus of public farm programs. American farm policy should be targeted toward long-run sustainability capable of meeting the needs of the present while leaving better opportunities for the future. Agricultural policy must be based on concepts that are ecologically sound, economically viable, and socially responsible. American agricultural policy must be based on benefits to the public beyond economic benefits to farmers. Benefits should be limited to individually owned and operated farms and family farms with the realization that no one has the right to degrade the natural environment.

Johnson, J., and Maxwell, B., 2001, The role of the Conservation Reserve Program in controlling rural residential development: Journal of Rural Studies, v. 17, p. 323-332.

The report describes a model for the prediction of land use; the model is used to determine what influence the CRP may have on urban sprawl and sustainability of rural communities. Model results showed that the projected mean rural residential growth rate was about 50 percent the growth rate with CRP as compared to without the program. The preservation of ecosystem integrity increased with the presence of CRP. In some cases, CRP may have significantly impacted the economic and social character of the community. Authors propose modifications of the program to support the establishment of within-production field-scale ecological refuges that would meet conservation objectives yet permit a viable level of agricultural production.

R.E., and Antle, J.M., 1990, Interaction between environmental and agricultural policies - Opportunities for coordination and limitations for evaluation: American Economic Review, v. 80, p. 197-202.

Agricultural policy has well-documented impacts on farmers' production decisions policy thus affects the environment. There is growing public perception that existing agricultural policies are linked to agricultural pollution. Existing agricultural and environmental policies can have either positive or negative effects on non-point source pollution. Agricultural policy can be used to mitigate pollution if properly designed and implemented. Agricultural production and environmental impacts depend on highly location-specific environmental conditions. Generalizations about the environmental impacts of agricultural policies are easy to make but should be avoided.

Keeney, D. and Kemp, L., 2003, A new agricultural policy for the United States: Minneapolis, Minn., North Atlantic Treaty Organization Advanced Research Workshop on Biodiversity and Rural Sustainability, November 2002, Institute for Agriculture and Trade Policy, $23 \mathrm{p}$.

The report is an admirable presentation of agriculture and policy evolution resulting from industrialization of the U.S. commodity based agricultural industry. The report contains overviews of economic, social, and environmental implications from changes in agricultural structure. The report's conclusions are based largely on evidence that while current production philosophies harm their own resource base and appear environmentally unsustainable, modern U.S. agriculture continues to be supported by policies furnishing major returns to suppliers and the largest of producers. Authors conclude that governmental initiatives and programs focused on one specific environmental problem (for example, erosion, wildlife), will be unsuccessful in finding solutions to problems. Although supported by the public, current approaches to control water pollution and other environmental impacts of agriculture are modest, poorly enforced, poorly funded, and lack long-term commitment. The report documents the public's support for farming, potential social and environmental benefits, and the public's willingness to pay for environmentally sustainable agricultural sector. The report describes, and strongly supports, potential benefits of implementation of the CSP created in the 2002 Farm Bill. Authors believe that if successful, the CSP has potential to reduce agriculture's environmental impacts, diversify agriculturally-dominated landscapes, improve farm income, and become the model that could form the foundation for a national green payment program displacing a significant portion of the failing commodity policies the USDA. (Also published in Light, S.S. ed., 2004, The role of biodiversity conservation in the transition to rural sustainability: Washington, D.C., IOS Press, 342 p.)

Kelly, C.R., and Loden, J.A., 1995, Federal farm program conservation initiatives - Past, present, and future: Natural Resources \& Environment, v. 9, no. 3, p. 17-19.

From its New Deal beginnings, farm policy has been primarily designed to stabilize commodity prices and to support farm income. Natural-resources capital, on which agriculture is dependent, has not been the primary concern of those who have guided federal farm policy for the past 60 years. Conservation initiatives have largely served to gain political support or otherwise assist in achieving economic objectives. Although economic well-being will continue to be a predominant concern of federal policy, conservation is likely to assume a greater importance because agricultural impacts are receiving 
greater attention. Budgetary constraints and international competition will accelerate market-orientated policies diminishing the program's tradition role in supply management. Paying farmers for adopting conservation practices is likely to expand and to replace other mechanisms for supporting farm income.

A political problem that may result from green-payments is that recipients of green payments are not likely to be the same farmers favored by current income transfers. Current programs favor larger and midwestern farmers. Green payments are likely to be greatest where environmental problems are greatest and nearest to population centers; this may result in shifts to coasts and major watersheds. Furthermore, green payments may not provide benefits to small farmers because it can be argued that attention should be greatest to those who farm the most land. There is no guarantee that green payments would provide sufficient income to satisfy farmers.

Kleiman, D.G., Reading, R.P., Miller, B.J., Clark, T.W., Scott, M., Robinson, J., Wallace, R.L., Cabin, R.J., and Felleman, F., 2000, Improving the evaluation of conservation programs: Conservation Biology, v. 14, no. 2, p. 356-365.

Evaluation of conservation program effectiveness is essential for improving the performance of these programs. However, evaluations have been rare because of resistance by participants, difficulty, and lack of funding. The author recommends an external peer review of long-term complex conservation programs every five years and an annual internal review. Measures of success must include biological and social measures and application of new knowledge. The authors furnish an example of program evaluations and advice on organization of effective assessment of programs. It is essential that goals and objectives are well defined with precise identification of what is to be evaluated. Criteria for success must be adequately identified for an evaluation/monitoring program to evolve to, so that conservation programs can ultimately provide the greatest benefits.

Conservation program evaluations should assess success and failure in terms of goal achievement and accountability for outcomes. Quality of performance and dissemination of findings to appropriate staff/agencies involved and public should be fundamental goals of conservation program evaluation. Program evaluations should include assessment of program substance (what was accomplished) and process (how effectively the program has, or is, functioning). Because they involve living systems and change, most conservation programs should be viewed as a continuous feedback loop rather than linear program with a clear start and finish. Socioeconomic and political interests are often the foundation for most conservation programs; therefore, these factors must be considered in program assessments. Interdisciplinary approaches to conservation that address both biological and social science have best chance for success. Too many programs fail to educate the public or confront sociopolitical issues.

A major challenge facing conservation is conflict among conservation scientists, government agencies, and non-government organizations competing to "own" a conservation problem or solution. The key measure of program's success is its ability to develop a strategy to mobilize financial, political, and technical support.

Lambert, D., Sullivan, P., Claassen, R., and Foreman, L., 2006, Conservation-Compatible Practices and Programs-Who Participates?: Washington, D.C., U.S. Department of Agriculture Economic Research Service Report No. 14, 43 p.

Farming and conservation practices adopted by the 2 million farmers in the U.S. can have major impacts on the health of ecosystems directly and indirectly affected by agricultural production. The effectiveness of farm conservation programs depend on the willingness of farm operators to participate. Factors other than profits and environmental considerations (for example, farm ownerships status, off-farm employment) can influence participation in conservation programs. Conservation programs based on the assumption that long-term profit is the sole driving force behind farm practices will not appeal to all farmers. In many cases, offsite environmental issues may not be adequately addressed by on-farm conservation practices capable of improving long-term profits.

The report offers examination of business, operator, and household characteristics of farms adopting conservationcompatible practices. Operators of small farm operations and operators not primarily focused on farming are found to be less likely to adopt management-intensive conservation practices and are less likely to participate in working land-conservation programs than operators of large enterprises whose primary occupation is farming. Results suggest that farm size, commodities produced, and operator motivation are associated with use of various conservation practices, but these relationships vary. The authors conclude that both types of programs have differing appeal to operators and each may be needed to address total conservation needs of the diverse agricultural industry. Flexible incentive structures are needed to accommodate farm-operator goals such as ease of application and appropriateness to individual operations. Conservation compliance, improved levels of technical assistance, availability of information (for example, benefits of crop rotation) can all be used more effectively to provide conservation benefits. The farm commodity program (price supports), often criticized for encouraging more intensive use of agricultural lands, may have a beneficial effect on conservation because participants in these programs are more likely to have adopted conservation-compatible farming practices than are farm operations involved in production of nonprogram crops.

Operators of small enterprises focused on non-farm occupations are less likely to adopt practices requiring additional time or expense. Conservation practices like grass waterways, riparian buffers, and planting erosive lands to grass-dominated covers result in a cost for installation and lost future production opportunities. Younger operators, whose primary occupation is farming, are more likely to install working land 
structures compatible with agricultural production. Operators of larger farms are more likely to participate in working land programs such as the EQIP but only a small percentage of the operation is typically enrolled in conservation programs.

Land-retirement programs (for example, CRP) are more commonly used among smaller, retired, and "lifestyle" farm operations. Whole farm enrollments (where farm income is replaced by conservation program payments) are generally older and more dependent on non-farm sources of income. Approximately 50 percent of CRP participants fall into this classification. Partial farm enrollment in CRP (individual fields or portions of fields) tends to be on larger farms with farming the primary occupation.

Authors believe that the availability of expert advice and technical assistance may assist in adoption of specialized conservation practices. For conservation practices that do not pay for themselves, incentives will be necessary to encourage adoption. For farm households dependent on farming as the primary source of income, working-land programs can make beneficial conservation practices affordable. A sliding scale of financial assistance could increase adoption by smaller farm operations. Working land-conservation programs may not furnish equal amounts of wildlife benefits as do retirement programs (for example, CRP). Authors conclude that the retirement of contiguous fields from production can provide broader environmental benefits than may be accomplished through working land approaches. Land-retirement programs can be an integral part of a working land approach to conservation. Authors conclude that future conservation programs have the greatest potential when viewed as a combination of working and retirement program options.

Leathers, N., and Harrington, L.M.B., 2000, Effectiveness of Conservation Reserve Programs and land "slippage" in southwestern Kansas: Professional Geographer, v. 52, no. 1, p. 83-93.

Authors define slippage as occurring when the number of acres enrolled in a reserve program is not met by an equivalent reduction of acreage production. Slippage occurs when the amount of land enrolled in a reserve program is offset by additional land outside the program being brought into cultivation. The paper addresses slippage effect on CRP in southwestern Kansas from 1988 to 1994. At one extreme, conservation programs were 100 percent successful in removing land from production, but slippage resulted in reserve programs being nearly useless. Land in southwest Kansas is relatively flat with newly cultivated land often having equivalent or higher susceptibility to erosion than land being enrolled in the CRP. Authors conclude that there is a great deal of spatial and temporal variability and that analysis of potential effects should be done at the county level to evaluate effectiveness of CRP performance.

Slippage occurs in part because not all farmers take part in farm programs. As participants reduce number of acres planted to meet eligibility requirements, nonparticipants often increase acreage in production in anticipation of higher prices for crops produced. CRP participants may also contribute by putting idle land in production. In the Great Plains this is often land left fallow or land with a high incidence of crop failure. A summary of earlier studies (cited in the paper) led authors to conclude: programs directed at reduction of a single commodity are especially vulnerable to slippage, low participation rates contribute to a program's ineffectiveness, use of land reserves is subject to failure regardless of whether one crop or cropland in general is targeted, variability in slippage is influenced by availability of land easily brought into production; program enforcement affects slippage rates, long-term programs are slightly less effective than short-term programs, and production incentives for nonparticipants also affect slippage.

In southwest Kansas, slippage rates varied between counties and years. Rates were near 0 in some counties and 99 percent in other counties. In 1993, when the CRP accounted for most land in conservation programs, slippage rates decreased. Average annual slippage for 14 counties in the study was 53 percent. Although 100 percent effectiveness may be too much to expect from conservation programs, slippage rates of 50 to 100 percent are unacceptable. During the years when CRP alone accounted for most land in reserve, the program was effective in reducing the number of acres in production proportionate to acres enrolled in the program in three counties but varied between 1 and 75 percent in remaining 11 counties. Authors conclude that CRP was more effective than were other conservation programs, but the CRP was unable to completely overcome failures of previous programs. Authors cite limitations of USDA record keeping as a constraint in evaluation. County and regional evaluations are needed to refine program performance and evaluation.

Miranowski, J.A., and Bender, R.L., 1982, Impact of erosion control policies on wildlife habitat on private lands: Journal of Soil and Water Conservation, v. 37, no. 2, p. 288-291.

Policies designed to maintain soil productivity and improve water quality tend to enhance upland habitat for wildlife with varying degrees of effectiveness. Generally, wildlife needs have been subordinate to other resource and conservation priorities addressed in agricultural policy. The dichotomy between private and public interest has been the major problem underlying all policies relating to wildlife and their habitats. The benefits of erosion-control policies and programs should incorporate social and economic benefits to wildlife/ habitats in analysis of impacts. A discussion of potential benefits of inclusion of wildlife is included in an evaluation of a linear program model using analysis of the Iowa River Basin.

Nassauer, J.I., Corry, R.C., and Cruse, R.M., 2002, Alternative future landscape scenarios-A means to consider agricultural policy: Journal of Soil and Water Conservation, v. 57, no. 2, p. 44-53. 
Each time a Farm Bill is a passed, new policy implies new future alternative scenarios for agriculturally dominated landscapes. The report's authors state that it is difficult to perceive future landscapes and it is only in retrospect that people can see how much things change. This paper addresses policy implications to agricultural dominated landscapes through potential changes in two watersheds in Iowa. Three alternative futures are compared using 1994 conditions as the baseline. Scenarios include: (1) increasing agricultural production is primary goal, (2) water-quality improvement is key goal, and (3) biodiversity enhancement is primary objective. Implications of alternative federal agricultural policies for ecological functions, hydrological functions, economic return, and public acceptance are discussed. Consequences of alternative futures are discussed and show that effects of policy decisions can have dramatic effects. Authors conclude it is possible to have a healthy, agriculturally dominated landscape that furnishes beneficial environments and services.

Pimentel, D., Berger, B., Filiberto, D., Newton, M., Wolfe, B., Karabinakis, E., Clark, S., Poon, E., Abbett, E., and Nandagopal, S., 2004, Water resources-Agricultural and environmental issues: Bioscience, v. 54, no. 10, p. 909-918.

Growing demands on global supply of water threaten biodiversity (in both terrestrial and aquatic ecosystems), food production, and other vital human needs. Agriculture consumes about 70 percent of freshwater used worldwide. It takes 264 gallons (gal) (1,000 liters [L]) of water to produce 2.2 pounds (lbs) (1 kilogram $[\mathrm{kg}])$ of cereal grain and 11,360 gal (43,000

L) of water to produce $2.2 \mathrm{lbs}$ of beef. In the United States, 2.5 acres ( 1 hectares) of corn with a yield of $1,636 \mathrm{lb} / \mathrm{ac}$ requires about 1.6 million gallons $(6,000,000 \mathrm{~L})$ of water during the growing season. Only about 17 percent of the world's cropland is irrigated, but it accounts for 40 percent of the world's food production. Irrigated agricultural production accounts for about 40 percent of the freshwater withdrawn in the United States and more than 80 percent of the water consumed.

New supplies of water are more likely to develop from conservation, recycling, and improved efficiency in use rather than from development of new, large projects. Population growth and associated increased use of water will severely reduce water availability and create additional stresses on biodiversity in the entire global ecosystem. Conflicts surrounding water issues are escalating among new industrial, agricultural, and urban sectors.

Population growth, agriculture, and other water uses are mining groundwater resources faster than they can be recharged. The capacity of the Ogallala aquifer has decreased by 33 percent since about 1950, with a water withdrawal three times faster than the recharge rate. Similar problems exist throughout the world. The rapid depletion of groundwater poses a serious threat in world agricultural regions. An estimated 1 percent of the storage capacity of world's reservoirs is lost each year to siltation of the basins.
Approximately 40 percent of freshwater in the United States is deemed unfit for drinking or recreation due to contamination by microorganisms, pesticides, and fertilizers. Agricultural production in the United States is projected to expand to meet increased needs of the population, which is expected to double in the next 70 years. Increased crop and livestock production during the next 5 to 7 decades will significantly increase the demand on all water resources, especially in western, southern, and central states.

Authors suggest that because farmers are primary users, they should be the chief target for incentives to conserve water. Options include implementation of water- and soilconservation practices such as cover crops and crop rotations. Water subsidies that encourage wasteful use by farmers, industry, and the public should be eliminated. Furthermore, governmental policies should be directed toward protection of forests, wetlands, and natural ecosystems to enhance conservation of water.

Plantinga, A.J., Alig, R., and Cheng, H., 2001, The supply of land for conservation uses-Evidence from the Conservation Reserve Program: Resources, Conservation and Recycling, v. 31, p. 199-215.

Using 1987-1990 data on CRP enrollment, the authors estimate grassland-supply functions for conservation lands in nine USDA farm production regions (excluding the Pacific region due to low enrollment at time of analysis). Subsequent to 1986 and prior to 1991 , the CRP operated similarly to a competitive market for conservation lands. Competitive markets are characterized by many buyers and sellers who accept the price of goods as offered. With the CRP, the rental rate (set by USDA) is analogous to a price for land conservation. Study results suggest that low rental rates (less than $\$ 40$ per acre per year $[/ \mathrm{ac} / \mathrm{yr}])$ contribute to very little land enrolled except in the Northern Plains region. Significant acreage enrollment can be expected in the Mountain region (approaching \$60/ac/yr). Annual rental payments of greater than $\$ 80 / \mathrm{ac} / \mathrm{yr}$ will result in enrollments in the Lake States, Corn Belt, and Southern Plains regions. Even at relatively high payments, little land can be expected to be enrolled in the Appalachian, Delta, Northeast, and Southeast regions. The authors discuss implications for meeting other types of conservation objectives by enrolling agricultural lands in conservation programs.

Pretty, J., 2002, People, livelihoods, and collective action in biodiversity management, in O'Riordan, T., and StollKleemann, S., eds., Biodiversity, sustainability and human communities: Cambridge, UK., University Press, p. 61-86.

In an almost entirely farmed landscape, nature is as much a product as it is an input. The assumption that conservation of natural resources is only possible through exclusion of human interference is erroneous. Modern development of ecosystems was based on simplification, but modernism led to arrogance 
about social ties with the natural world and the assumption that technology will furnish universal solutions to environmental problems. Regulations and economic incentives are commonly used to encourage changes in behavior. Although such incentives may be effective in changing management practices, they rarely result in a positive change in attitudes and farmers commonly revert to old practices when regulations are no longer enforced. When people are organized in groups and their knowledge is sought in answers to environmental problems, they are more likely to sustain desirable activities following project completion. Five core components of successful biodiversity programs promote sustainable management of natural resources: conceptualization of sustainability being of high social value, recognition that rural people can improve agro-ecological understanding, increased understanding derived from farmers engaging in their own experimentation supported by professionals, ideas for improvement in management are more likely to spread from farmer to farmer rather than group to group, and recognition that social learning process should be an important focus for all natural resource management programs.

Ray, D.E., De La Torre Ugarte, D.G., and Tiller, K.J., 2003, Rethinking U.S. agricultural policy-Changing course to secure farmer livelihoods worldwide: Knoxville, Tenn., Agricultural Policy Analysis Center, University of Tennessee, $59 \mathrm{p}$.

Authors put forth the case that a deliberate shift in American agricultural policy in the 1990s resulted in depressed crop prices, due to the elimination of several traditional safeguards for managing supply and supporting prices. The report explores why changes in agricultural policy in the 1996 Farm Bill resulted in declining farm revenues; the report also introduces a policy blueprint that could raise crop prices and contribute to a worldwide healthy agricultural industry. Prices of primary agricultural imports have declined by over 40 percent since 1996. Farmers in the United States continue to be forced out of the industry despite the large infusion of government payments intended to compensate for lower prices. The authors conclude that government must help manage excess capacity if prices are to be held at levels to benefit both producers and consumers.

Even with enormous sums of federal funding provided to farmers as emergency payments, many small farm operations continue to fail and disappear. These payments have not closed the gap between production costs and market prices and further reinforce the bias in U.S. agriculture for bigger, less diversified farms. Although the number of farms and farmers continues to decline, the amount of cropland in production remains fairly constant. Unchecked, this trend will result in an agricultural industry dominated by large, highly mechanized farms. Through contract production, large agribusiness firms may control many of the remaining small farms. The authors believe that no one policy instrument is key to resolving this crisis, but a set of options and policies may increase market prices to sustainable levels. Used effectively, the authors believe, these options could reduce U.S. government outlays by more than $\$ 10$ billion/yr and contribute to a healthy agricultural industry on a global scale. These options include greater use of short- and long-term set-aside programs, farmerowned food security reserves, and price supports. Authors advocate greater use of CRP to curb excess productive capacity. Both short- and long-term acreage retirement would reduce excess production and improve environmental performance. Short-term set-aside programs would induce farmers to idle a portion of their working cropland.

Reichelderfer, K., 1990, Environmental protection and agricultural support-Are trade-offs necessary? in Allen, K., ed., Agricultural policies in a new decade: Washington D.C., Resources for the Future and National Planning Association, p. 201-230.

Traditional means of supporting farm income tend to exacerbate environmental problems. Under current programs, agricultural and environmental protection reflect conflicting societal preferences. Public reaction to environmental problems suggests that the non-farm population believes it has a right to a clean, safe, and healthy environment, which may be infringed upon by farming activities. Long-run environmental goals of the American public conflict with the short-run profit objectives of individual farmers. The adoption of new technologies requires capital investment, high-adjustment cost, increased operating costs, or some forfeiture of yield, any of which can reduce farm income, at least in the short run. Efforts must focus on increasing the cost-effectiveness of current or reduced levels of funding to meet policy objectives. The Farm Bill has furnished consistency between environmental and agricultural policy objectives, but it could be better. For over 50 years, programs supporting commodity prices and the transfer of income to the farm sector have formed the core of U.S. agricultural policy. Until recently, these programs included no explicit conservation objectives. Main objectives of agricultural policy are to support farm income and ensure a stable and reasonably priced food supply. These multiple objectives are achieved through a system of farm programs that insulate the farm sector from the market economy by artificially supporting certain commodity prices and managing their supplies. Each mechanism used to achieve farm and supply control has unique secondary and unintentional effects on environmental quality.

Riddel, M., and Skold, M., 1997, Cropland retirement and supply control in the Great Plains: Journal of Production Agriculture, v. 10, no. 1, p. 106-110.

Supply control has been an important component of agricultural commodity policies for the past 60 years. The primary instrument to provide supply control through agricultural legislation has been cropland annual and long-term (for example, 
Soil Bank, CRP) retirement. Authors conclude that annual cropland retirement programs for wheat have no effects on the amount of wheat produced in the Great Plains, and that long-term programs, such as CRP, have only limited supply control effectiveness. Rationale for continuing CRP includes increased reliance on the program for supply control. However, effectiveness for CRP to control wheat supply from the Great Plains is, at best, limited. Within the Great Plains CRP enrollment, approximately 57 percent of 34.6 million acres is enrolled in the program. Wheat was approximately 50 percent of base reduction in Great Plains accounting for 36 percent of total long-term land retirement in the Great Plains.

The Great Plains has experienced increased yields over the entire life of land-diversion programs due to greater use of chemical and physical inputs, better management practices, and improved cultivars. But Great Plains yields vary by 38 percent during the period of analysis - this makes effects of land retirement programs difficult to determine. Authors conclude that increasing trends in production, yield, and acres under production outweigh the consequences of reductions in wheat derived from short- and long-term setaside programs. To be effective, supply control programs must be more directly linked to output rather than how much input is used in production. Since long-term land-retirement programs are relatively ineffective for supply control, other benefits such as reduced soil erosion, wildlife habitat, and water quality must be used to a greater degree to justify such programs.

Roberts, M.J., and Bucholtz, S., 2005, Slippage in the Conservation Reserve Program or spurious correlation? A comment: American Journal Agricultural Economics, v. 87 , no. 1 , p. $244-250$.

Authors put forward the argument that slippage due to CRP reported by $\mathrm{Wu}$ (see below) is not supported by the data and method used by the author to estimate unintended stimulus by the program to convert non-cropland to cropland. The authors conclude that Wu's assertion is erroneous. Wu presents the idea that slippage might arise through a price-feedback effect caused by shift in crop prices due to CRP enrollment due to substitution of land from noncropping to crop production. Wu's findings are based on the regression of data across crop-reporting districts - the data relate new cropland to CRP enrollment. These authors state that Wu's data cannot be used to estimate slippage arising from a price feedback effect and conclude that there is no convincing evidence of slippage due to CRP. Roberts and Bucholtz completed an additional analysis and found a net-slippage estimate that is statistically indistinguishable from zero. The authors conclude, however, that even their model and estimates are not reliable and suggest future estimates could be derived using data representing a longer and more frequent sample period.
Robertson, G.P., and Swinton, S.M., 2005, Reconciling agricultural productivity and environmental integrity-A grand challenge for agriculture: Frontiers in Ecology and the Environment, v. 1, no. 3, p. 38-46.

Current trends point to continued human population growth and higher levels of consumption as the global economy expands. The main challenge of agriculture in coming decades will be to produce sufficient food and fiber for a growing population at acceptable costs to the environment. This challenge requires an ecological approach to agriculture production that is largely missing from current management and related research. Crop and livestock production must be managed as ecosystems with decisions based on environmental costs and benefits. Too little is known about important ecological interactions in agricultural systems and landscapes and about the economic and social values of ecosystem services associated with agriculture. Sustainable agriculture must be managed for multiple services (in addition to food production) that will require ecological and social research, public education, and innovative agricultural policies.

Agriculture is the world's largest industry whose future impact depends on how effectively we understand and manage both the social and ecological elements of ecosystems dominated by the industry. Agricultural ecosystems are as ecologically complex as most other ecosystems on earth. Row crop agriculture is essentially a form of early ecological succession in which intentional disturbance annually sets back succession. Management typically focuses only on the production of marketable commodities but this production comes at the expense of other ecosystem services and long-term productivity of agriculture itself. Clean air, water, wildlife habitat, C storage, pollination, and disease suppression are all services important to human health, ecosystem health, and long-term sustainability of agriculture itself. Active management for maintaining environmental services associated with agriculture is a concept receiving too little attention in the past and is supported by too little science. Science should provide options and a sound basis for decision-making by producers, consumers, and those making policies. It is important for the public to be aware that choices have alternative consequences and that choices can be optimized. A focus on full ecosystem services is missing in ongoing research related to agricultural production and ecology.

Understanding how organisms are distributed and ecological process within and across landscapes is crucial for designing management practices that optimize trade-offs. Solutions to problems in one part of the landscape may become a problem elsewhere when management is based on reactive problem solving rather than ecosystem management. Social research in agricultural ecosystems is just as needed as is ecological research. Economic analysis and other social sciences are needed to evaluate environmental services associated with agriculture and promote their importance to society. Agriculture must adopt a systems-oriented outlook that incorporates social and environmental services. This will require input from social 
science and economists and a strong approach toward education of the public about their future and trade-offs between management decisions.

Effective management of agricultural ecosystems requires ecosystem understanding of properties and processes that include human needs. Socioeconomic research in agricultural ecosystems is as much needed as is ecological research. The long-term environmental costs of agriculture will be avoided only if policy recognizes and rewards environmental stewardship early in the process. Challenges to be faced include identification of ecosystems services furnished and affected by agriculture, understanding trade-offs between options, valuing ecosystem services so they can be prioritized and linked to policy decisions, and creating an environmentally literate public. Agricultural policy must adopt a more forwardlooking, systems-oriented outlook towards management of agricultural ecosystems.

Robertson, G.P., Broome, J.C., Chornesky, E.A., Frankenberger, J.R., Johnson, P., Lipson, M., Miranowski, J.A., Owens, E.D., Pimentel, D., and Thrupp, L.A., 2004, Rethinking the vision for environmental research in U.S. agriculture: Bioscience, v. 54, no. 1, p. 61-65.

Authors conclude that environmental research related to agriculture is largely reactive, focused on problems at small scale (for example, field, farm) and conducted within narrow disciplinary boundaries. This approach fails to resolve most of the more serious environmental issues associated with agricultural production. Economic and social costs of agricultural production are high and mostly external to producer decisions. Solutions to environmental issues have not been adopted for lack of incentives or other socioeconomic reasons, or solutions have been inadequate because they fail to fully consider the complexity of agricultural ecosystems. Often, how well solutions work is unknown because there have been inadequate follow-up assessments and monitoring. Appropriate incentives must go beyond production of food and fiber to address environmental benefits increasingly demanded by the public. Basic environmental research associated with agriculture must address the system at multiple scales and locations and be based on development of environmental performance standards. Descriptions of environmental services and understanding how they can be quantified and appropriately valued is an emerging research need with important implications for agriculture and land-use planning.

Ribaudo, M.O., Hoag, D.L., Smith, M.E., and Heimlich, R., 2001, Environmental indices and the politics of the Conservation Reserve Program: Ecological Indicators, v. 1, p. 11-20.

Use of Environmental Benefits Index (EBI) helped the USDA increase and broaden the CRP's environmental benefits beyond erosion reduction, which was the primary focus of the early program. The paper provides examples about how integration and assessment for the purpose of managing public resources requires more than natural science disciplines. Social science can help explain how public values influence what information is collected and how it is interpreted. Examples are furnished to show how EBI was used to integrate science, politics and social values.

Schertz, L.P., and Doering III, O.C., 1999, The making of the 1996 Farm Act: Ames, Iowa, Iowa State University Press, $190 \mathrm{p}$.

An insightful assessment of the trials and tribulations in the formulation and passage of the Federal Agriculture Improvement and Reform Act of 1996. Although seen as some as the beginning of the end of federal transfers of funds to farmland producers by 2002, the authors correctly foresaw continuation of such support to the agricultural community. Of particular interest are perceptions about the growing political power that environmental interests have in shaping new legislation based on mounting evidence of the negative impacts of agricultural production on the landscape and environmental services.

Soil and Water Conservation Society, 2006, Conservation Effects Assessment Project-Final Report from the Blue Ribbon Panel Conducting an External Review of the U.S. Department of Agriculture: Ankeny, Iowa, Soil and Water Conservation Society, $25 \mathrm{p}$.

A blue ribbon panel of academic, state, tribal, and nongovernmental organization leaders furnishes review and recommendations for improvement in the USDA CEAP. The panel concludes that a coherent and science-based assessment and evaluation system is urgently needed to ensure that conservation programs produce environmental gains that taxpayers and agricultural producers expect. The underlying conclusion provided by the panel is that the current direction of CEAP must change. The panel questions the validity of generalized estimates of environmental effects derived from simulation models and extrapolation of data derived from conservation practices. Quantifying effects and evaluating effectiveness are very different types of results. The panel concludes simulations cannot, and should not, be seen as a substitute for on-the-ground monitoring designed to determine if anticipated conservation benefits are being furnished.

The panel recommends that Congress mandate that at least one percent of funding for each authorized program, about $\$ 40$ million, be specifically set aside to support monitoring and evaluation of USDA conservation programs. It is recommended collaborative efforts be expanded between governmental and nongovernmental agencies around geographically specified outcomes such as soil quality, water quality, wildlife habitat and air quality. Development of approaches to "smart monitoring" and assessment of unmet needs and opportunities 
are needed. The panel also recommends that the USDA look more to regional-level assessments rather than a broad-scale, national-level evaluation.

The panel believes the most important, and troubling, piece missing from the existing CEAP is the absence of plans for on-ground monitoring of changes in environmental indicators and outcomes. There is an urgent need for USDA to strengthen plans for on-ground monitoring to evaluate progress toward specific environmental goals. Simulation models and extrapolations of data cannot be a substitute for on-the-ground monitoring. It is likely that additional funds and staff resources will be needed to support necessary monitoring and inventory systems. On-ground monitoring need not be overwhelming and should be based on a suite of indicators that can be used to tell a story of what is happening in the environment as a consequence of conservation practices and policies. The fundamental unit of assessment should be based upon watersheds or other salient geographic scales. The national scale currently being used as a foundation for CEAP was determined by the panel to be unsatisfactory due to the lack of ability to describe local benefits of conservation policies.

Soil and Water Conservation Society, 2004, Realizing the promise of the Farm Security and Rural Investment Act of 2002: Ankeny, Iowa, Soil and Water Conservation Society, $36 \mathrm{p}$.

The report furnishes a summary of progress on implementation of the 2002 Farm Security and Rural Investment Act as well as four major recommendations to make the Farm Bill live up to its full potential. The report requests that Congress provide full funding for all USDA conservation programs. Unfortunately, the 2005 presidential budget does not keep that promise.

Full support of conservation technical service infrastructure is cited as the single greatest opportunity to realize the full potential of the 2002 Farm Bill. USDA should produce a plan to construct a viable technical-services infrastructure for the 21 st century. Funds from the Commodity Credit Corporation $(\mathrm{CCC})$ should be used to a greater degree to fund conservation. Conservation programs must be structured to meet the challenge of managing agricultural impacts on the environment. The CSP should become the primary agricultural conservation program across the country. The report presents numerous detailed recommendations on realizing the full potential of the 2002 Farm Bill and making conservation a top priority for USDA and improvement of environmental quality.

Stem, C., Margoluis, R., Salafsky, N., and Brown, M., 2005, Monitoring and evaluation in conservation-A review of trends and approaches: Conservation Biology, v. 19, no. 2, p. 295-309.

Monitoring and evaluation furnish public and internal accountability that demonstrates the impact of programs, which has become increasingly important in the current climate of budgetary constraints. Effective projects incorporate well-designed monitoring and evaluation, but monitoring and evaluation often suffer from a failure to take advantage of lessons already learned from previous monitoring efforts. Monitoring efforts require different approaches that must be based on consistent language and incorporation of aspects in addition to biological variables. Qualitative and social variables are necessary to provide comprehensive assessments of conservation-program effectiveness.

Evaluation approaches vary by stakeholder interests, and often serve overlapping purposes that include knowledge generation, program improvement, accountability, resource allocation, and impact assessment. To understand our environment and protect resources, managers need to be able to measure what they are trying to preserve or enhance. Monitoring changes in wildlife populations is generally too time consuming and expensive to be feasible for most program and site-level assessments. In addition, multiple years of data are typically required for a reliable assessment of changes in animal populations. A more practical alternative of rapid assessment is characterization of vegetation types and species but this approach is often limited in approach and reliability of results is imperfect. Approaches to measuring the effectiveness of conservation programs are best when preceded by a strong planning process and clear identification of goals and objectives as well as by measures to gauge progress toward achieving those goals.

The monitoring of conservation has traditionally focused on quantitative indicators of biological health. but engaging stakeholders in project management and assessment of social, economic, political, and cultural aspects and impacts of a program are essential. Conservation takes place in a complex context influenced by human populations. It is important to involve key stakeholders in monitoring processes because stakeholders may offer greater and unique insights to what is actually happening as a consequence of conservation practices.

The authors conclude by recommending there is a greater need for collaboration among conservation interests. Diverse, numerous approaches to monitoring and evaluation only lead to confusion, duplication, and competition, usually for limited funds. It would be beneficial to seek greater agreement on short lists of potential indicators for common conservation goals. Strategic selection of programmatic indicators of success that clearly relate to goals and show progress toward desired conservation objectives should be a principal goal of monitoring and evaluation.

Taylor, M.R., 2001, The emerging merger of agricultural and environmental policy - Building a new vision for the future of American agriculture: Virginia Environmental Law Journal, v. 20, no. 1, p. 169-190.

Agriculture is one of society's most pervasive and consequential environmental interventions. As environmental values have become part of mainstream public concern, fundamental 
questions are asked about impacts of agriculture on the environment and welfare of society. Consequently, agriculture will continue to be a legitimate subject of public policy. Conservation and environmental protection have moved to the center of farm-policy debates. Over the past decade, USDA has annually spent on average about $\$ 13.5$ billion on economic assistance for farmers with peaks as high as $\$ 28$ billion/yr in response to emergency conditions. Americans continue to culturally identify themselves with farms and farmers, and a substantial majority of Americans believe it is in the country's interest to preserve small-family farms. U.S. farm policies have played an important role in the emigration of families from the farm community. Agricultural policy is global, and the impact of U.S. policies has to be understood and evaluated from both global and domestic perspectives. The 1985 Farm Bill brought conservation and environmental issues into the farm-bill debate and created linkages between farmconservation practices and the economic support that operators received from the government. The importance of the 1996 Freedom to Farm Act is that it furnished an opportunity to devise policies linking financial assistance to the achievement of other objectives, including environmental quality. Public dollars will continue to be invested in agricultural support with an emphasis on maintaining environmental quality and sustainable farming practices. Farmers and society at large share common interests in ensuring sustainable land use by lessening the environmental impacts of agriculture. Farmers are, however, unlikely to respond to issues (for example, wildlife habitat) that influence their farm's future productivity if there are no economic returns or incentives.

Theobald, D.M., Spies, T., Kline, J., Maxwell, B., Hobbs, N.T., and Dale, V.H. 2005, Ecological support for rural land-use planning: Ecological Applications, v. 15, no. 6, p. 1906-1914.

Enhanced decision making about rural lands requires consideration of how ecological information can enhance planning and policy needs. Ecologists must understand tradeoffs between various environmental and social objectives and the importance of integrating local knowledge with landscape level information. Authors describe four primary challenges in improving rural land-use planning: the mismatch between spatial and temporal scales in which ecological processes occur; scales and tempos of land use and planning; the need to develop comprehensive land-use framework to extrapolate results of ecological studies to larger landscape context; and development of environmental indicators to directly inform local, rural land-use planning.

Four factors affect development in rural landscapes: urbanization; conversion of natural areas to agriculture or intensive forestry; abandonment of agricultural land; and exurban or rural development of resorts, second homes, vacation homes, or ranchettes. Exurban development is increasingly stimulated by environmental and recreation amenities. Ecological consequences of land-use change are rarely considered.
Improvement in access to scientific information could help identify potential changes resulting from land use. Realistically, it may take decades to centuries to clearly demonstrate consequences of natural resource policies.

Complex policies at all levels of government regulate natural-resource use throughout the United States, but consideration of ecological effects of land-use change generally does not fit well within traditional governmental hierarchy. Policy makers often lack high-quality regional-scale information about existing ecological conditions and potential implications of land-use change. Although governments, in particular the federal government, want to judge success of environmental policies based on quality outcomes, adoption of "performancebased" environmental policy have been hampered by lack of reliable scientific information.

Landowners must be involved and empowered if landuse planning is to be effective. Planning must be regional, but problems are exacerbated as planning areas become large. Major problems arise from the lack of institutional establishment to conduct eco-regional or cross-ownership planning. It is often difficult to demonstrate the effects of individual landuse changes which may have significant impact on long-term ecological issues. A significant challenge is to integrate data from a variety of agencies into a cohesive, consistent database to make information accessible and useable. Credibility of projects or programs is at risk if sufficient amounts of data showing results do not meet stakeholder expectations. Farmers and ranchers often have abundant knowledge of ecological conditions and use of natural resources in local areas. This information is often richer than information furnished by governmental agencies. Integrating this information is critical to improve the quality of decisions.

Authors conclude there are few examples of organized and systematic efforts to evaluate and learn from applied projects in regional land-use planning. There is a mismatch of spatial and time scales where ecologists have the greatest understanding and those upon which land use occurs. Systematic evaluations of how land-use decisions are influenced by ecological information is needed. Improving the relevance of ecological science requires critical evaluation. The critical component of adaptive management is missing in land-use planning, monitoring, and evaluation.

U.S. Department of Agriculture, 2001, Food and Agricultural Policy_ Taking stock for the new century: Washington, D.C., U.S. Department of Agriculture, 120 p.

Meeting society's demands for improved environmental quality requires a broad definition of output, including environmental amenities represented by rural landscapes, wildlife, wetlands, and improved water/air quality. Currently, 92 cents of every dollar spent on conservation payments are associated with idling environmentally sensitive land. Farming no longer anchors most rural economies. The economic foundations in seven out of eight rural counties are now dominated by mixes of manufacturing and other non-farming activities. 
How farming and agricultural policies address environmental issues is a matter of both public and private concern. While agricultural production has doubled over the past 50 years, farm numbers dropped by more than two-thirds. Program crops were grown on almost every farm in the 1930s but account for only 20 percent of total value of all agricultural sales today.

Farmers and farm households have goals representing differing stages of business development. The smallest economic sales class of farms ( 27 percent) view farming as a primary occupation and the rest are either retired or consider farming as a secondary occupation. In 2001, there were 175,000 commercial farms with sales above $\$ 250,000 /$ year. This group of producers ( 8 percent of all farms) accounts for 68 percent of total farm output. Sixty-two percent of farmers combine non-farm income with farm income or are retired and view farming as in investment opportunity and a way to enjoy rural life. About 650,000 farms consider farming the primary occupation and share goals with both commercial farms and rural-residence farms. Commercial farms account for 68 percent of production and 29 percent of land use. Most farms fall in the rural-residence category and occupy 71 percent of land owned by farmers.

Public expectations reflect concerns about environmental preservation and enhancement. Government price-support programs have encouraged unneeded output from the most efficient producers and have pushed surpluses higher and prices lower. Current program benefits still are directed to specific commodity producers resulting in only 40 percent of farms being recipients. In 1999, 47 percent of payments went to large commercial farms, which contributed nearly half of commodity production and had average household income of $\$ 135,000$. The impact of income from any source on land values depends on whether that income is viewed as permanent or transitory. Private farmers and ranchers own and manage two-thirds of the Nation's land. Stewardship costs are borne by land managers, but benefits serve society at large. Meeting society's demands for environmental quality demands a broad definition of agricultural output to include environmental amenities. Conservation programs can provide incentives and compensate land managers for all products, including environmental benefits. Conservation programs are an important source of income for small or intermediate ruralresidence farms. Issues of growing public concern include open space, nutrient management, pesticide use, greenhouse gas emissions, water quality, wildlife habitat, pathogens, and antibiotic resistant bacteria. The greatest challenges in formulating the next generation of conservation policy are to address multiple environmental problems, support rural communities, and make efficient use of funds. The benefits and costs of removing land from production must be in balance with conservation and environmental performance on lands that remain in production.
U.S. Government Accountability Office, 2004, Environmental indicators-Better coordination is needed to develop environmental indicator sets that inform decisions: Washington, D.C., U.S. Government Accountability Office GAO-05-52, $115 \mathrm{p}$.

Despite decades of activity and billions of dollars spent, the United States is incapable of producing a comprehensive picture of environmental or natural-resource conditions or trends. Challenges include selecting the most appropriate indicators and sustaining a balanced long-term effort to obtain data of sufficient quality that link environmental outcomes to obtain a comprehensive assessment of environmental conditions. Individual federal agencies are missing opportunities to improve data quality by not integrating work with similar objectives.

Environmental indicators are powerful tools for communicating information on complex environmental issues - these tools make information comprehensible and accessible. The development of indicators requires investments of time and resources as well as sustained leadership and commitment. It is not a short-term process. Issues that present challenges to the development of indicators include assuring that a sound process is used. The development of indicators can be an intensive political process; therefore, it should be a collaborative course of action. Obtaining data of sufficient quality is a major challenge. Coordinating and integrating various indicator sets is necessary to maximize results. The federal government lacks an organizational framework to provide a consistent basis for working with state or non-governmental sources of information. A major difficulty is linking management actions and environmental resources and trends that address the time lag between management actions and measurable results. To address this issue, a focused long-term commitment is needed.

Indicators must be measurable, relevant, of appropriate geographic scale, understandable, based on data that are available and of sufficient quality, reflect appropriate temporal scale, and yield information that is comparable to other sources of data. In the United States, for example, hundreds of agencies collect water-quality data, but there is not enough information to furnish a comprehensive assessment at the national level because various ways are used to collect the data. The lack of coordination, communication of common goals, and integration of data constrains the effectiveness of monitoring efforts and is a long-standing problem yet to be solved.

Warner, R.E., Etter, S.L., David, L.M., and Mankin, P.C., 2000, Annual set-aside programs-A long-term perspective of habitat quality in Illinois and the Midwest: Wildlife Society Bulletin, v. 28, no. 2, p. 347-354.

Authors conclude that although the CRP has been beneficial, its future is uncertain because of its high cost. Long-term conservation strategies must include grassland preserves and 
development of relatively sustainable farming systems that accommodate needs of grassland dependent species. Shortterm contracts must be at least 3 years and support vegetative cover that is present from year to year. The relative benefits of native versus introduced grasses are presented as being unknown. The authors believe there is growing evidence that fields of cool-season grasses or forage legumes may be more attractive to nesting birds than are CRP grasslands planted to native species. Emphasis on native species may not be warranted when, for the typical landholder, seeding of native species requires specialized equipment and several years for the stand to become established.

\section{Wu, J., 2005, Slippage effects of the Conservation Reserve} Program-Reply: American Journal Agricultural Economics, v. 87 , no. 1 , p. 251-254.

In response to the review, reanalysis, and criticism stated by Roberts and Bucholtz (see above) Wu states conceptual problems with his original analysis (see below) do not exist. He argues their central point of regional variation in CRP acreage being a non-influencing external variable is inconsistent with CRP implementation rules and data. Wu believes their misidentification of slippage effects arise from acceptance of a wrong assumption that the CRP has no impact on cropland values and price feedback effect is affecting only a small region. Wu points out the analysis of Roberts and Buchotz indicates a slippage rate in the Corn Belt ranging between 13 and 45 percent. Wu provides further arguments defending conclusions drawn in his original analysis.

Wu, J., 2000, Slippage effects of the Conservation Reserve Program: American Journal Agricultural Economics, v. 82, no. 4, p. 979-992.

An unintended impact of conservation easements in agricultural ecosystems is the entry of non-cropland into crop production. This slippage effect is believed to result in 20 acres of land put into production for each 100 acres of land enrolled in the CRP offsetting water and wind erosion benefits by 9 percent and 14 percent respectively. Substantial slippage effects described in this analysis suggest the issue should be targeted in future conservation policies. The author suggests relaxing program rules to allow inclusion of non-cropland that offers large environmental benefits, but would otherwise be converted to crop production, would reduce slippage effects and improve performance of conservation programs. Reduction of slippage effects would improve environmental performance of land retirement programs and increase supply control of commodities produced.

Yost, M, 2005, The quest for quantifying Conservation Reserve Program benefits, in Transactions of the North American Wildlife and Natural Resources Conference, 69, Spokane, Wash., March 16-20, 2004, Proceedings: Washington, D.C., Wildlife Management Institute, p. 20-29.
The report contains a discussion by the Associate Administrator of the FSA about the importance of farmland conservation and FSA attempts to improve the CRP and the need to document and quantify environmental benefits brought by the program. A discussion of how the CRP has evolved is presented. The argument is made that to insure future funding and the existence of the program, results will have to be measured and communicated beyond the agricultural and conservation communities. The author states that agencies that cannot effectively show results of their programs cannot justify budget requests and will be less likely to be funded. Descriptions of existing and proposed FSA funded projects to assess the environmental effects of the CRP are provided.

Zinn, J., 1993, The next generation of U.S. agricultural conservation policy: Ankeny, Iowa, Soil and Water Conservation Society, $40 \mathrm{p}$.

White paper based on results from National Soil and Water Conservation Society forum (March 14-16, 1993) of stakeholders and interest groups to assess how current agricultural policies are working. The paper provides detailed summaries of current strong and weak points pertaining to the effects of agricultural policies on environmental issues. Regional focus-group results present a summary of problems and potential solutions to agriculturally related environmental issues.

\section{Agricultural Ecosystems}

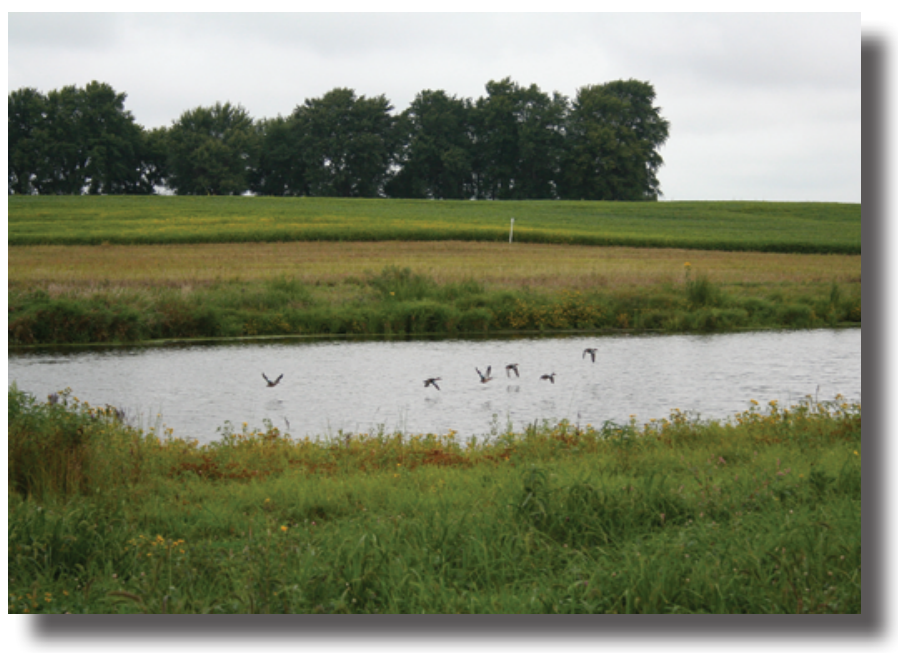

Allen, A.W., 1995, Agricultural ecosystems, in LaRoe, E.T., Farris, G.S., Puckett, E.E., Doran, P.D., and Mac, M.J., eds., Our living resources-A report to the Nation on the distribution, abundance, and health of U.S. plants, animals, and ecosystems: Washington, D.C., U.S. Department of the Interior, National Biological Service, p. 423-426. 
A summary of the historical effects of agricultural production on the quality and distribution of wildlife habitats is presented. The brief report includes a discussion of preliminary results of multi-state monitoring of grassland characteristics in undisturbed fields in Southern Plains and Midwestern CRP fields. An overview of CRP benefits to wildlife populations associated with agriculturally dominated landscapes is presented.

Banks, J.E., 2004, Divided culture-Integrating agriculture and conservation biology: Frontiers in Ecology and Environment, v. 2, no. 10 , p. 537-545.

High-production agriculture with associated simplification of ecosystems, dependence upon chemical inputs, and emphasis on yield often appears at odds with conservation, but they share a common ecological foundation. Communication and cooperation between the two fields is vital to lessening environmental impacts associated with agriculture. Holistic approaches to incorporating landscape perspectives are needed to define better integration of conservation and agriculture. A better understanding of how spatial scale interacts with biotic and abiotic processes is needed. Real progress in reaching a more sustainable level of agriculture will require a shift from large-scale agriculture, heavily dependent upon chemical inputs, to medium-scale farming with greater reliance on nature-mimicking processes. The ultimate challenge is to maximize yields while minimizing environmental costs. The greatest opportunities for improving relations between agriculture and conservation are gathering information across several spatial scales, understanding values and motives of stakeholders, defining biotic and abiotic forces and cycles at the landscape level, and understanding how policies and incentives influence relations between production and conservation at various scales.

Boody, G., Vondracek, B., Andow, D.A., Krinke, M., Westra, J., Zimmerman, J., and Welle, P., 2005, Multifunctional agriculture in the United States: Bioscience, v. 55, no. 1, p. 27-38.

Potential changes in farming practices are evaluated in two Minnesota watersheds to determine how changes in farm policy may affect environmental, social, and economic outcomes. Authors conclude that environmental and economic benefits from farming can be attained through change in agricultural land management without increasing public costs. Benefits include improved water quality, healthier populations of fish, increased $\mathrm{C}$ sequestration, decreased greenhouse gas emissions, and greater farm profitability. Policy transitions that emphasize environmental functions and products in addition to food production are essential. Suggestions for redirecting farm payments toward "green box" issues could lead to substantial environmental change and public benefits.
Minnesota residents indicate they are willing to provide incentives for significant changes in environmental benefits associated with agricultural production. Members of the public who were surveyed indicate a desire to develop public policy, research, education, and marketing strategies to promote greater diversification of food and fiber production that will lead to environmental and social benefits. Many current government programs and land-grant university systems focus too closely on too few crops and reinforce production of traditional commodities. Local institutions need to change along with farmers. Focus groups state that present commodity programs discourage diversification in farming. U.S. farm policy should support agricultural diversity and nonmarket ecosystem services. Future programs should reward farmers for environmental benefits. Authors conclude that we cannot afford to sacrifice future agricultural productivity for the sake of short-term increases in commodity production. Dealing with worldwide food shortages will require a future agriculture that produces rather than consumes ecosystem benefits.

Brady, S.J., 1985, Important soil conservation techniques that benefit wildlife, in Technologies to Benefit Agriculture and Wildlife-Workshop Proceedings: Washington, D.C., U.S. Congress, Office of Technology Assessment, OTA-BP-F34, p. 55-62.

Relations between increasing row-crop production, rates of soil erosion, nonpoint sources of water pollution and decreasing wildlife associated with farmlands are presented. Two principal reasons for degradation of wildlife habitats are identified as intensive use and management of agricultural lands and extensive cultivation of ever-enlarging fields resulting in demise of needed vegetative covers. Important soil-conservation management practices (for example, conservation tillage, grassed terraces, crop rotation) and their implications for wildlife are discussed.

Brady, S.J., and Flather, C.H., 2001, Estimating wildlife habitat trends on agricultural ecosystems in the United States, in Agriculture and Biodiversity-Developing indicators for Policy Analysis: Organization for Economic Co-operation and Development expert meeting, Zurich, Switzerland, November 2001, Proceedings: Zurich, Switzerland, Organization for Economic Co-operation and Development, p. $156-167$.

Wildlife response to the management of habitat exhibits great variability over time and space. There remains much to be learned about ecological process and functions, particularly as they relate to wildlife associated with agricultural ecosystems. Consequently, effective management of wildlife habitat remains a combination of both science and art. Land use is the principal factor determining the base level of abundance of indigenous species, which in most cases has a greater impact of species abundance than does management of land. Land 
use has both direct and indirect effects on wildlife. While use of land is relatively easy to document, assessment of wildlife habitat quality and wildlife numbers is more problematic. Population density is often an inaccurate estimator of habitat quality.

Authors present Natural Resources Inventory (NRI) data by USDA Farm Resource Regions and USGS hydrologic units. The effects of land use, cover type, spatial patterns, USDA conservation programs, and agricultural activities on wildlife are discussed. Authors conclude that the CRP has been one of the most beneficial programs for enhancement of wildlife in the United States, citing data that wildlife habitats created by the program are twice as large as the combined area of the National Wildlife Refuges System and all state-owned wildlife areas in the contiguous United States. The environmental effects of other USDA conservation programs (EQIP, WHIP) are discussed briefly. The authors note the effects of other conservation practices (conservation tillage, grass terraces, grass border strips, etc.) on lands remaining in active production of crops have beneficial effects to wildlife but are not immediately obvious or easy to quantify. The authors conclude by recommending a landscape-level approach to the quantification of wildlife-habitat indicators. As indicators of habitat quality are developed for monitoring purposes, they must be tested and refined based on empirically derived patterns of biodiversity and basic verification of the presence/ absence of a species on the landscape.

Brown, D.G., Johnson, K.M., Loveland, T.R., and Theobald, D.M., 2005, Rural land-use trends in the conterminous United States, 1950-2000: Ecological Applications, v. 15, no. 6 , p. 1851-1863.

Though land-use trends affect ecological systems, spatially explicit data on these changes are difficult to obtain. The authors provide an evaluation of land-use trends in the United States during the latter half of the 20th century. Agricultural land use has had important effects on ecological systems throughout the history of North American European settlement. Agricultural land has declined in the United States in the 20th century due to the conversion to other uses and abandonment of marginally productive land. The goal of the report is to summarize patterns of change in settlement and croplands in the United States between 1950 and 2000.

Although the focus of the report is on the eastern and southeastern United States, data are furnished for the entire country. Population gains in the last 50 years were smallest in the Northeastern forest region, Eastern Temperate forest region, and Great Plains. Western regions have grown at rates well above the national average. The agricultural heartland, including the Great Plains, experienced widespread population losses during this 50-year period. Other areas experiencing loss included the Mississippi Delta and the Appalachians. By 2000, 81 percent of the U.S. population resided in metropolitan areas.
Across the United States, cropland area decreased by 11 percent between 1950 and 2000. Decreases in cropland were most consistent in eastern regions; cropland declined by nearly 50 percent in the Northern Forest region. Cropland area stayed relatively consistent in the Corn Belt and Great Plains, although both regions experience substantial declines in human population. Declines in cropland areas can be partially explained by increases in productivity and intensification in remaining agricultural lands but decreases were most dramatic in metropolitan counties where cropland was lost to urban expansion. In northern forest regions cropland also went back into more natural covers. The Great Plains and other western areas did have pockets of agricultural expansion in the last half of the 20th century due to irrigation. These areas were primarily along the Columbia River, Snake River, and high plains of western Kansas. Cropland decreased by 22 percent east of the Mississippi River. The trends in exurban growth and conversion and abandonment of agricultural lands, especially in the eastern United States, have important ecological implications as they affect large areas and functioning of ecological systems.

Büchs, W., 2003, Biodiversity and agri-environmental indicators-General scopes and skills with special reference to the habitat level: Agriculture, Ecosystems, and Environment, v. 98 , p. $35-78$.

The author furnishes a discussion of biodiversity and habitat concepts in relation to development of environmental quality indicators in agricultural ecosystems. The presentation is based largely on the assumption that biodiversity equates to species richness. Requirements for use of indicators are presented (using mostly invertebrates as examples) as well as issues pertaining to development and use of indicators, baseline data, sample size, selection of species, and frequency of surveys. Using specific examples, the author shows biodiversity can be a misleading indicator of environmental quality. A discussion on the use of indicators by administrators is furnished which describes administrators' expectations that indicators are easy to assess, understand, and predictions are easy and can be expressed by numerical measures. Generally, an expectation is that one biotic indicator is able to represent an entire ecosystem. Administrators tend to aggregate data and favor reduction in number of indicators used. This tendency increases with administrative level, often resulting in use of highly aggregated indicators with weak representation of ecosystem characteristics or conditions.

Carpenter, J., Felsot, A., Hammig, M., Onstad, D., and Sankula, S., 2002, Comparative environmental impact of biotechnology-derived and traditional soybean, corn, and cotton crops: Ames, Iowa, Council for Agricultural Science and Technology, 189 p. 
Report furnishes a literature review on environmental impacts of biotechnology-derived soybean, corn, and cotton crops. In 2001, biotechnology derived seed was planted on 46 percent of global soybean acres, 7 percent of corn acres, and 20 percent of cotton acres. Of all biotech crops planted in 2001 (52.6 million acres globally), 77 percent were tolerant of specific herbicides, 15 percent resistant to selected insects, and 8 percent were resistant to both herbicides and insects. Major reasons for the adoption of biotech crops are lowered production costs, reduced crop injury, and flexibility in weed management. Biotech herbicide-tolerant soybean production has facilitated adoption of conservation tillage. No-till soybean acreage in the United States has increased by 35 percent since the introduction of herbicide-tolerant soybeans. No-till soybean acreage has also resulted in a decrease of soil erosion and dust and favored more efficient land use by more narrow-row spacing of crops. Biodiversity in the authors' state is maintained by adoption of biotech crops as soil microbes, beneficial insects, and bird populations - these methods were not different from those observed in conventionally tilled fields. Biotech varieties of corn and cotton allow a less persistent use of herbicides in the environment and reduce risks of herbicide run-off into surface waters. Adoption of biotech crops generally decreases production costs and enhances range of management options available for whole-farm planning.

A detailed review and discussion of potential impacts and benefits of biotech crops are presented. While the authors conclude that biotech crops have been economically, environmentally, and socially beneficial, they do recommend large-scale and farm-scale studies be completed to document long-term environmental effects related to the growing use of these crops.

Cassman, K.G., Dobermann, A., Walters, D.T., and Yang, H., 2003, Meeting cereal demand while protecting natural resources and improving environmental quality: Annual Review of Environment and Resources, v. 28, p. 315-358.

Food-production systems have a large influence on associated environmental quality. Lands used for crop production and pasture account for 38 percent of world land base. Irrigation accounts for 80 percent of all fresh water use on global scale. Conversion of natural ecosystems to agricultural production results in simplified agroecosystems with resultant reduction in bio-diversity and decreased availability of habitats. Maize, rice, and wheat account for about 60 percent of all human calories consumed either as direct food for indirectly as feed grains. Worldwide demand for cereal grains (largely for use in animal feeding) is projected to increase by about 1.3 percent annually until 2025 . Recent trends and future trajectories in crop yields, land, fertilizer use, C sequestration, and greenhouse-gas emissions in are discussed, as are key issues and challenges in meeting growing demands for foods. Authors conclude that lessening the expansion of cultivation into remaining natural ecosystems, more efficient use of $\mathrm{N}$, and techniques to improve soil quality will be key issues in agricultural sustainability. The authors also conclude that maintaining the sustainability of agricultural ecosystems will depend upon increasing the yield potential of cereal crops which is an elusive goal.

Authors believe a socially acceptable, proactive agriculture will be required to sustain demands for food and environmental quality on a global scale. Policies will have to be directed toward the intensification of production on existing prime agricultural land while avoiding further depletion of natural ecosystems. Substantial investment in research to support scientific advances of new technologies will be required.

Castrale, J.S., 1985, Responses of wildlife to various tillage conditions, in Transactions of North American Wildlife and Natural Resources Conference, 50, Washington, D.C., March 15-20, 1985, Proceedings: Washington, D.C., Wildlife Management Institute, p. 142-156.

The report provides a discussion of minimum tillage practices on wildlife use of agricultural fields, (primarily corn and soybeans). Three factors are major contributors to wildlife use of fields, food availability, vegetation structure, and disturbance. Under most circumstances, the availability of insects probably does not limit wildlife populations in agricultural fields. Preferred foods may be readily available in corn and soybean fields, but a lack of adequate cover or vegetation characteristics may prevent some species from using resources present.

Carroll, C.R., 1992, The interface between natural areas and agroecosystems, in Carroll, C.R., Vandermeer, J.H., and Rosset, P., eds., Agroecology: New York, McGraw-Hill, p. 365-383.

Farming systems generate weedy phenotypes including plants, animals, and pathogens that may become invaders of natural areas. Furthermore, crops may become important food sources for certain pest species, which contributes to the distortion of their impact on other populations of wildlife (for example, crows, jays, and raccoons whose enhanced populations seriously threaten other less abundant species of nesting birds). Landscapes dominated by agricultural production may have a significant effect on the ability of embedded natural areas to support endemic species. Natural ecosystems become fragmented, which increases boundary phenomena and results in the elevation of edge impacts. Loss of natural areas generally means that remaining patches are increasingly isolated; consequently, re-colonization is difficult - this increases the likelihood of local extinctions. Most of these impacts are cumulative and proceed as a consequence of many independent decisions made without regard to possible combined effects of changing land use.

In absence of active management, most small natural areas begin to degrade and become less representative of the original ecosystem. Small sites typically require more 
management effort per unit area than required for large areas. The long-term security of natural areas in agricultural landscapes will depend strongly on the way the land surrounding the natural area is used. Beneficial use of surrounding lands must be economically sustainable, socially equitable, and explicitly linked with management objectives in the embedded natural area. Design of agricultural areas should be clearly related to the ecological management goals of the natural area. Buffer zone activities should be able to be modified to meet new contingencies and sufficiently flexible so changes can be made without drastically disrupting local economy. Buffers should not be sensitive to rapid change in market prices, rising production costs, decreasing returns, nor should they rely on intensive use of agrochemicals, fire, or other methods that may strongly impact nearby natural areas.

Danielson, B.J., 1992, Habitat selection, interspecific interactions and landscape composition: Evolutionary Ecology, v. 6 , no. 5, p. 399-411.

The author describes three types of habitat: (1) source: reproduction exceeds mortality, (2) sink: limited reproduction but will not, on average, compensate for mortality, and (3) unusable: comprises the matrix of all habitats never exploited by the species. Patches of source and sink habitat are embedded in unusable habitat. By restoring landscapes to natural state, it is seldom possible to preserve population and community characteristics that have evolved under natural conditions. It may be possible to compensate for fragmentation where unusable habitats have increased by clustering patches of usable habitat and connecting patches with dispersal corridors. Spatial dimensions of landscape must be defined by the ecology of the species in question and management concern.

Doak, D.F., Marino, P.C., and Kareiva, P.M., 1992, Spatial scale mediates the influence of habitat fragmentation on dispersal success - Implications for conservation: Theoretical Population Biology, v. 41, no. 3, p. 315-336.

Habitat heterogeneity has different and conflicting effects on animal movement at various scales. Explicit consideration of scale is essential in discussion of habitat fragmentation and identification of optimal conservation strategies. A major impact of fragmentation is the disruption of animal dispersal. Fragmentation is dependent upon two scales: relative size of the habitat fragments and the spatial scale at which these fragments are arranged. When fragmentation is unavoidable, clustering habitat fragments may minimize dispersal mortality. The spatial scale of clustering must be defined. Clustering seems to have a positive influence on dispersal success. Scale effects risks of mortality, degrees of connectedness or independence among patches and the influence of environmental catastrophes.
Duelli, P., and Obrist, M.K., 2003, Biodiversity indicatorsThe choice of values and measures: Agriculture, Ecosystems, and Environment, v. 98, p. 87-98.

Ideally, a linear relationship exists between an indicator and this relationship accurately reflects an aspect of biodiversity under evaluation. Unfortunately, this is rarely the case, as it a difficult relationship to establish and problematic to prove. Motivations for assessing biodiversity aspects are based on different value systems. Because the total evaluation of biodiversity on even small areas is logistically and economically prohibitive, scientifically reliable and repeatable indicators must be identified. Use of biodiversity as an indicator requires clear definitions of terms, use, and objectives. There is no single indicator for biodiversity. Difficulties and concepts in choosing biodiversity indicators for several levels of assessment (protection of rare species, ecosystem functioning, pests and biological control) in agricultural ecosystems are discussed. To achieve greater reliability and acceptance, indicators must be tested to determine their correlation with the ecological values they are supposed to represent.

Egbert, S.L., Park, S., Price, K.P., Lee, R.Y., Wu, J., and Nellis, M.D., 2002, Using Conservation Reserve Program maps derived from satellite imagery to characterized landscape structure: Computers and Electronics in Agriculture, v. 37 , p. 141-156.

The report describes multi-seasonal Landsat thematic imagery used to produce maps of cropland and grassland for 1987 and 1992 for Finney County, Kansas. A spatial-analysis program was used to calculate number of patches, mean patch size, patch density, edge density, shape index, nearest neighbor distance, and interspersion index. Total grassland area and percent area in grassland as a consequence of CRP was also measured. Results imply species requiring large areas of contiguous grassland habitat have experienced gains in habitat quality. Maps of CRP using this methodology are cost-effective for mapping large areas and sufficiently accurate for use in modeling environmental effects of CRP. Techniques described in the study could be used in monitoring landscape changes over time as CRP enrollments and distribution change.

Farris, A.L., and Cole, S.H., 1981, Strategies and goals for wildlife habitat restoration on agricultural lands, in Transactions of North American Wildlife and Natural Resources Conference, 46, Washington, D.C., March 21-25, 1981, Proceedings: Washington, D.C., Wildlife Management Institute, p. 130-136.

Indicators of negative changes in farmland wildlife habitat quality include increased urbanization of agricultural land, enlarged size of farms, increasing acres devoted to row crops, decreased production of small grains, diminished area in wild/ tame hay and pasture, larger field size, continued loss of edge, fence rows, farmsteads, wetland, and idle lands. All these 
factors have contributed to reductions in numbers and diversity of wildlife. Agricultural policy is the primary influence on agricultural land use and farmland wildlife habitat. Native grasses, while taking more care and time to establish, provide excellent erosion control with significantly lower cost and energy expenditure than introduced species. Long-term benefits of native grasses over introduced, cool-season grasses are significant. In most cases, cutting for hay should be delayed until after July 15 when the majority of avian species have their young off the nests. Cost sharing for farmers that devote a minimum percentage of cropped acreage to permanent cover capable of supporting wildlife should be adopted. Authors suggest that 4 to 5 percent of the landscape in permanent cover probably is sufficient to bring benefits to many wildlife species associated with agricultural landscapes.

Felix, J., and Owen, M.D.K., 2004, Weed seedbank comparison in Conservation Reserve Program and adjacent fields under continuous cultivation: Weed Technology, v. 18, no. 1, p. $45-51$.

The report describes soil samples $(n=1,260)$ collected in 63 Iowa counties to describe weed seedbanks in CRP and adjacent fields under continuous cultivation. CRP fields were described as being planted to orchardgrass (Dactylis glomerata), smooth bromegrass (Bromus inermis), big bluestem (Andropogon gerardii), and switchgrass (Panicum virgatum). Cultivated fields were planted with either corn (Zea mays) or soybeans (Glycine max). Five annual grasses and 13 broadleaf weed species were identified in both CRP and cultivated fields. Weed species diversity was not significantly different between CRP and cultivated fields. Sweetclover (Medicago sativa) seed populations were consistently higher in CRP because it was included as part of cover seeding when stands were established. Overall, broadleaf weeds comprised 90 percent of the seedbanks in both types of fields. CRP grassland cover probably reduced weed seedbanks due to suppression of weeds and seed production. Annual seed production, differences in biology, and herbicide performance in cultivated fields may have contributed to higher production of weeds in these fields.

Study results describe larger seedbank of weeds in cultivated fields than found in CRP. Successful establishment of CRP grassland cover likely played a significant role in the reduction of weed-seed densities in program fields. Consequently, farmers returning CRP land to crop production are not likely to experience a shift in weed-species composition and may see lower populations of weeds than found in adjacent cultivated fields. The lower population density of weeds in former CRP could be an advantage to farmers switching to organic farming or reduced usage of herbicides.

Freemark, K., 1988, Agricultural disturbance, wildlife, and landscape management, in Moss, M.R., ed., Landscape ecology and management: Guelph, Ontario, Canadian Society for Landscape Ecology and Management Symposium, p. $77-84$.
The report provides a discussion of an investigation of bird-species richness and reproduction in forested habitats impacted by agriculture. Wildlife in agricultural landscapes is subject to disturbances such as habitat fragmentation and pesticides, which affect spatial and temporal distribution of wildlife. Understanding relations between landscape structure, disturbance, and distribution of wildlife is needed to develop better management strategies to minimize impacts and enhance the persistence of wildlife communities in agriculturally dominated landscapes.

Freemark, K., 1995, Assessing effects of agriculture on terrestrial wildlife-Developing a hierarchical approach for the U.S. EPA: Landscape and Urban Planning, v. 31, p. 99-115.

Given the intensive and extensive effects of agriculture, there is a need to develop a conceptual and scientific basis to promote sustainable agricultural practices that enhance environmental priorities associated with agricultural ecosystems. Retrospective analysis may provide insights into the range of possibilities for future landscape design and management scenarios in a given area. A major limitation of many previous studies of wildlife associated with farmland has been the focus on detailed studies of small plots with little regard to larger spatial scales.

Fry, G.L.A., 1991, Conservation in agricultural ecosystems, in Spellerberg, I.F., Goldsmith, F.B., and Morris, M.G., eds., The scientific management of temperate communities for conservation: Oxford, Great Britain, Blackwell Scientific Publications, p. 415-443.

Protected areas alone cannot achieve conservation goals such as the maintenance of biological diversity. Incorporation of conservation measures in farm management will demand clear recommendations based on sound theory and evidence gained through practical trials. Maintenance or enhancement of habitat quality for a wider range of plants and animals will require better understanding of ecological processes at site, field, and landscape levels. Lack of understanding of processes involved in animal distribution, ways in which species use corridors, and what constitutes barriers is a constraint in effectively designing and managing habitats. One limitation of many investigations of habitat and wildlife on farmland is a lack of regard for management of adjacent fields or the surrounding landscape. The abundance of many species comprising animal communities on farmland is controlled largely by few environmental factors. Both the timing and severity of agricultural practices are important factors governing the potential of agricultural lands as wildlife habitat. Extending the width of field margins farther into the cropped fields is one way of increasing habitat diversity on arable lands. In many situations management decisions will need to be implemented without thorough assessment of the impacts on wildlife. 
Gall, G.A.E., and Orians, G.H., 1992, Agriculture and biological conservation: Agriculture, Ecosystems and Environment, v. 42, p.1-8.

Agriculture is the dominant form of land management on all continents. There has been a dramatic increase in the intensity of management and capital investment in agriculture following WWII. Prior to the latter half of the 1940 s, agriculture was sufficiently inefficient that habitats were inadvertently provided for many species of wildlife. As management intensity increases, multiple uses of land decline. As prices of agricultural commodities increase, there is a corresponding decrease in recreational, aesthetic uses and values associated with agricultural lands. Adoption of more intensive agriculture on suitable lands enables more food to be produced per unit area. As a result, pressures on marginal agricultural land could be reduced, making the land available for conservation practices that contribute not only to on-site habitat but enhancement of downstream environmental quality.

Gilpin, M., Gall, G.A.E., and Woodruff, D.S., 1992, Ecological dynamics and agricultural landscapes: Agriculture, Ecosystems and Environment, v. 42, p. 27-52.

Many parts of society see conflict between conservation of biological resources and agricultural production. Agriculture is an essential element of society which can provide stewardship of biological resources, but interdisplinary efforts are needed in development of strategies for conservation. Agriculture and conservation are not mutually exclusive and can be positively linked on local, regional, and global scales. Governmental policies that support agriculture often deny true economic costs and environmental consequences.

Gliessman, S.R., 1984, An agroecological approach to sustainable agriculture, in Jackson, W., Berry, W. and Coleman, B., eds., Meeting the expectations of the landEssays in sustainable agriculture and stewardship: San Francisco, Calif., North Point Press, p. 160-171.

The underlying theme of this paper is "can research address questions of how agriculture can be more in balance with the natural environment and depend less upon costly chemical inputs?" A framework for long-term sustainability of agricultural systems and environmental values must be established. Agricultural ecology is based on the premise that the short-term, mainly economic focus of food production must be redirected toward long-term management based on cycles and interactions found in natural systems.

Hansen, A.J., Knight, R.L., Marzluff, J.M., Powell, S., Brown, K., Gude, P.H., and Jones, K., 2005, Effects of exurban development on biodiversity-Patterns, mechanisms, and research needs: Ecological Applications, v. 15, no. 6, p. 1893-1905.
Exurban development is a pervasive, rapidly growing form of land use understudied by ecologists which has large potential to alter biodiversity patterns over extensive areas. Exurban development, defined as low-density housing in landscapes dominated by native vegetation, is now the fastest growing form of land use in the United States. Since 1974, area in exurban land use has increased at rates in excess of area in urban or agricultural land use. Knowledge of exurban effects on land use and homeowner effects on biodiversity are poorly known, but potential impacts appear to be substantial. The richness of native species generally declines with increased exurban densities. Exotic species and native species adapted to human presence generally increase with the intensity of human development. These relations are generally nonlinear. Biodiversity trends are still likely responding to changes in development that began in the 1950s. Over time, exurban development often develops into suburban and urban forms of land use.

Higgins, K.F., Naugle, D.E., and Forman, K.J., 2002, A case study of changing land use practices in the northern Great Plains, U.S.A., An uncertain future for waterbird conservation: Waterbirds, v. 25, p. 42-50.

The northern Great Plains is one of the most economically depressed sectors of the United States. Current provisions of the Farm Bill are often weighted to commodity production; this furnishes incentives to bring more marginal land into production. High rates of wetland drainage in the northern Great Plains, especially in the prairie pothole region, remain a threat to wetland bird populations. Loss of wetlands and associated upland covers threaten production of the 50 to 80 percent of the continental waterfowl population produced here. Thirty-nine species of shorebirds use Prairie Pothole Region (PPR) wetlands during migration or as breeding habitat. Eleven additional species of obligate wetland-breeding birds rely on PPR wetlands for nesting. Wetland losses have had a negative impact on migratory habitats. Native mixed-grass prairies historically used for grazing are under social and economic pressure to be put in tillage. Until recently, loss of mixed-grass prairie had occurred more slowly than conversion of tallgrass ecosystems to agriculture. About 60 percent of all native mixed grass prairies in the Dakotas and Montana have been converted to cropland. The productivity of waterbirds has declined dramatically in response to grassland losses.

The conversion of grassland to cropland has increased grazing intensity on South Dakota rangelands. From 1977 to 19971.4 million hectares (3.5 million acres) were converted to cropland and other developments in South Dakota. Loss of native rangelands, combined with decreases in number of farm families and conversion to larger more efficient equipment, has led to "cleaner" farming practices wherein idle non-farmed areas are eliminated and small wetlands areas are drained. These changes are expected to continue as more operators shift from diversified grain and livestock operations to monoculture grain production. A continuing trend to replace small graincrops with soybeans and corn also has a negative effect on the quality of wildlife habitat. Development of drought-resistant, 
genetically modified soybeans has accelerated conversion of native grassland to cropland. New crop varieties have enticed producers to farm low-quality, drought-prone soils. Although wildlife benefits of the CRP have been impressive and well documented, data indicate native grassland continue to be tilled at the same time as lands are being enrolled in the CRP. More than one million acres have been converted to cropland in the Dakotas and Montana since 1985, despite conservation provisions of the Farm Bill. Since 1987, about 168,000 acres of grassland have been converted to cropland in eastern South Dakota due to western expansion of soybeans. Nearly 18 million acres of CRP in the northern Great Plains are almost the same area of native prairie converted to cropland in this area since the 1960s.

The loss of grassland and wetland habitats continues to expand westward. Current land use and demographic factors indicate that the habitat protection programs most likely to succeed are those that encourage livestock ranching. Authors believe the most effective approach to preservation of waterbird habitat in the northern Great Plains is a broad suite of short and long-term programs and incentives that encourage preservation of family ranching operations.

Jackson, D.L., and Jackson, L.L., 2002, The farm as natural habitat-Reconnecting food systems with ecosystems: Washington, D.C., Island Press, 297 p.

This book contains eighteen essays pertaining to common values shared by environmentally concerned non-farmers and agricultural producers. The essays address effects of agricultural policies (existent and proposed) on wildlife and environmental quality in agricultural ecosystems. Topics deal with sustainable agriculture, environmental restoration of agricultural ecosystems, and defining goals for landscape and ecosystem management. The text provides description and implications of industrialized agricultural effects on environmental quality and alternatives for ecosystem management in agricultural landscapes. An underlying theme throughout text is that farm policies need to address and promote nonmarket as well as market benefits in long-term policies.

Jeanneret, P., Schüpbach, B., and Luka, H., 2003, Quantifying the impact of landscape and habitat features on biodiversity in cultivated landscapes: Agriculture, Ecosystems and Environment, v. 98, p. 311-320.

There are no general models relating overall species diversity to landscape diversity. A single statistic containing all information about the assembly of objects that a landscape represents is an unrealistic expectation. Although biodiversity is conceptually defined, its measurement remains controversial and largely defined by specific objectives, organisms examined, financial constraints in sampling, and observation techniques. Authors suggest arthropods are good candidates to represent biodiversity. However, species richness of one single group or of a small set of organisms is not sufficient to measure the different composition of species and comparisons between habitats, the species diversity function in ecosystems, and the impact of environmental explanatory factors on biodiversity. One single taxonomic group likely does not represent more than one or two functions in ecosystems. Groups of species are unlikely to react in the same way as other groups of species to ecosystem changes. The assessment of species composition and assemblages is a more appropriate approach to quantifying influence of environmental changes in agricultural landscapes. Spatial and temporal distribution of suitable habitats is the key variable in assessment of biodiversity in agriculturally dominated landscapes. Constraints and limitations in definition and use of species used as indicators are presented. Habitats and landscape parameters have varying impacts on measures of biodiversity depending upon which evaluation species are chosen. Consequently, one single indicator cannot summarize the biodiversity response. The authors argue that examination of species assemblages allows for a more comprehensive assessment of habitat and landscape effects on biodiversity measures.

Kessler, W.B., Salwasser, H.C., Cartwright Jr., W., and Caplan, J.A., 1992, New perspectives for sustainable natural resources management: Ecological Applications, v. 2, no. 3, p. 221-225.

Management of public lands and resources requires knowledge about ecosystems, including interrelations of human values, activities, and patterns of use; closer partnerships with managers to complete large-scale studies; and adaptive management of public lands and resources. Managers must respond to more complex views of public lands and their roles in meeting human needs and aspirations. Managers need to define objectives that relate to ecological and aesthetic conditions of the land stating a desired future condition to sustain land uses and resource yields. Grasslands are sustainable in nature by dynamic forces such as fire, flood, and grazing. These forces continually change vegetation patterns and processes that have major effects on biological diversity, water quality, and other values. The public must be well informed about the conditions, capabilities, and options for lands and resources and share in the knowledge that professionals accrue through research and management experience. Science must take into consideration the values and needs of people rather than concluding and dictating conclusions about what is good or bad for society from a strictly scientific and technical perspective. Changes in perspectives must address cumulative effects of management and landscape fragmentation. Systems must be looked at as whole rather than individual parts. 
Kleijn, D., and Báldi, A., 2005, Effects of set-aside land on farmland biodiversity - Comments on Van Buskirk and Willi: Conservation Biology, v. 19, no. 3, p. 963-966.

Worldwide wildlife populations have suffered due to expansion and intensification of agricultural production. Policy developers in Europe and the United States have responded by initial attempts to reduce over-production and costs of price support and storage as well as specific attempts to address biodiversity and environmental quality. Long-term (for example, multi-year) removal of cropland from production has been a commonly used tool to reach these goals. The significant expenditures associated with this approach can, however, be justified only if scientific evaluations indicate that objectives are being met.

These authors furnish criticism of a meta-analysis evaluation of biodiversity benefits of set-aside land completed by Van Buskirk and Willi (2004) (see below for their response) in North American and Europe where Van Buskirk and Willi reported increases in biodiversity and a positive relationship between biodiversity and the age and area of set-aside lands. These authors further conclude the work by Van Buskirk and Willi was inadequate in design of assessment of ecological benefits of agri-environmental policies and suggest a more rigorous evaluation within the geographic, agronomic, and socioeconomic context of individual countries. An ambiguous definition of set-aside land and analysis of data from limited geographic areas are identified as flaws and limit the authors' ability to correctly extrapolate data to much larger geographic areas. While the criticisms of these authors focus on European conditions where agricultural land use has been the predominant form of land use for centuries, they stress the importance of agri-environmental policies being evaluated in the ecological and social context of the countries within which the policies are implemented. The authors caution against overextension in extrapolation of data and conclusions.

Koford, R.R., and Best, L.B.,1996, Management of agricultural landscapes for the conservation of neotropical migratory birds, in Thompson, F.R., III, ed., Management of midwestern landscapes for the conservation of neotropical migratory birds: St. Paul, Minn., U.S. Department of Agriculture Forest Service General Technical Report NC-781, p. $86-88$.

Thirty-eight neotropical migratory birds are common in Midwest agricultural landscapes. Most species depend on herbaceous or wooded habitats, which are declining as the average size of farms increases. Recommendations for improving diversity of avian habitats include: minimize cultivation, encourage moderate grazing, delay spring mowing of hay, increase acres in grassed waterways and roadsides, avoid nighttime mowing, encourage longer intervals between mowings, avoid fall mowing and annual mowing of grassed waterways and roadsides, retain fencelines, maintain idle land, and change configuration of idle land to enhance species richness and nesting success. An immediate short-term effect of tillage is the exposure of arthropods and other prey to foraging birds; a long-term effect is the reduction in abundance of litterdwelling arthropods. Conventionally tilled fields have lower arthropod abundance than no-till or idle areas. Herbicides can affect birds by reducing availability of seeds. Insecticides reduce abundance and diversity of foliage-dwelling arthropods. Strip cover, such as grassed waterways, terraces, fencerows, roadsides, and windbreaks/shelterbelts usually provide habitat more long-term than provided by areas enrolled in crop-retirement programs. Strip cover has decreased in recent years. Orientation of crop rows relative to grassed waterways influenced disturbance. Nest densities were greater when rows were parallel to waterways.

The authors recommend preservation of remnants of prairie and savannah. Large-scale restoration of these cover types is impractical, but remnants can be saved for education and research. Other recommendations include: increase presence of crop residues, continue and manage CRP, minimize tillage, diversify crops, encourage moderate grazing of pastures with prescription for species needs of those in most trouble, delay spring mowing of hay as long as possible, avoid night mowing, increase intervals between mowing, maintain idle land in blocks rather than strips, and increase species composition of vegetation. On terraces habitat, improvements can be made through flattening of back-slopes and improvement of grass stands and planting alternative vegetation. The burning of all ditches or roadsides areas in same year should be discouraged. Establishment of fencerows greater than 3 meters $(\mathrm{m})(10 \mathrm{ft})$ wide should be encouraged.

Krapu, G.L., Brandt, D.A., and Cox Jr., R.R., 2004, Less waste corn, more land in soybeans, and the switch to genetically modified crops-Trends with important implications for wildlife management: Wildlife Society Bulletin, v. 32, no. 1, p. 127-136.

Growing efficiency in corn harvest (greater than 99 percent under ideal conditions) and widespread replacement of corn and other crops by soybeans less capable of supplying nutritional needs of wildlife represent a growing risk to wildlife that are dependent upon waste grain for energy and weeds for the foods and cover they provide. Nearly 25 percent of total cropland in the United States is used to produce soybeans. In 2002, approximately 75 percent of soybean crop was planted with genetically modified (GM) herbicide resistant soybeans. Increased efficiency of weed-control results in a decline in the amount of weeds present - this represents a decline in foods and cover for wildlife in agricultural landscapes. Implications may be particularly severe on seeddependent wildlife of lower mobility, smaller home ranges, and migratory species with seasonally high nutritional needs. Prior to development of genetically modified (GM) strains, 
herbicides were less efficient or selective resulting in some weed species continuing to thrive in cropland. Genetically modified crops appear to be on the verge of greater acceptance by farm operators; this would directly or indirectly broaden negative impacts on wildlife that is dependent upon weeds. Aggressive control of weeds in CRP fields and other private lands further impact seed-eating wildlife when weed seeds and other high-quality grain foods are becoming less available across agriculturally dominated landscapes.

Authors suggest that more research is needed to determine impacts of weed control on CRP and other lands and that more studies are needed to better document effects of GM crops on quality of wildlife habitat across regions. Authors believe that beneficial effects of the CRP in providing perennial cover for wildlife may be negated by more highly efficient and intensive weed control on lands remaining in production. It is suggested that producers could be offered incentives to grow high-energy food plots, intentionally leave greater crop residues, and use less intensive weed-control methods to ensure that adequate sources of food are available for wildlife in landscapes dominated by row crop production.

Kuehl, A.K., and Clark, W.R., 2002, Predator activity related to landscape features in northern Iowa: Journal of Wildlife Management, v. 66, no. 4, p. 1224-1234.

Research in agriculturally dominated landscapes in northern Iowa provides further support for providing large blocks of grass-dominated cover. Corridors and moderately sized patches of habitat near large blocks of cover support elevated activity by predators. Focused management of cover within patches and exclusion or eradication of predators may still play a role in predator control, but the best long-run approach is landscape-level planning to furnish needed habitats of sufficient quality and quantity to lessen the impact of predator populations.

Milchunas, D.G., Vandever, M.W., Ball, L.O., and Hyberg, S., 2011, Allelopathic cover crop prior to seeding is more important than subsequent grazing/mowing in grassland establishment: Rangeland Ecology \& Management, v. 64, no. 3, p. 291-300

Sorghum is known to be allelopathic and is used in row crop agriculture rotations to suppress weeds and increase crop yields. The effects of grazing, mowing, and type of cover crop were evaluated in a previous winter wheat/fallow cropland seeded to grassland under the CRP in eastern Colorado. Prior to seeding, fallow strips were planted in alternating strips of sorghum or wheat as cover crops. Grazing treatments (no grazing, moderate to heavy grazing, and mowing) four years after planting, which were studied for three years, showed that strips previously in wheat had more annual and exotic species than sorghum strips. Sorghum strips showed greater abundances of perennial native grasses and native species. Grazing had relatively minor effects on basal and canopy cover of annual or exotic species versus perennial native grasses or native species. Mowing was a less effective weedcontrol practice than grazing. Common management practices for revegetation/restoration, commonly use herbicides and mowing as weed-control practices, and restrict grazing in all stages of development. Results suggest allelopathic cover crop selection and opportunistic grazing can be effective alternative grass establishment and weed control practices.

O'Connell, M.A., and Noss, R.F., 1992, Private land management for biodiversity conservation: Environmental Management, v. 16 , no. 4 , p. 435-450.

For the purpose of conservation, ecosystem diversity must be defined on the basis of geographically recognizable, mappable units representing commonly associated flora and fauna. Species profiting from habitat diversification are generally those least in need of conservation efforts. Managers have customarily enhanced local species diversity by maintaining numerous edges between habitat types, which is usually to the detriment of endemic species. Maintenance of diversity from regional and global perspective permits more flexibility in land-use options than a strategy that considers sites in isolation. Loss of a species from a specific site may not have detrimental effects on biodiversity if the species is regionally abundant. Regional biodiversity management does not preclude habitat manipulation to favor certain species; however, standards for private land management consistent with goal of conserving biodiversity are not simple to delineate. This paper provides specific steps and guidelines for identification of biodiversity priorities on private lands.

O’Neill, R.V., Hunsaker, C.T., Jones, K.B., Riitters, K.H., Wickham, J.D., Schwartz, P.M., Goodman, I.A., Jackson, B.L., and Baillargeon, W.S., 1997, Monitoring environmental quality at the landscape scale: Bioscience, v. 47, no. 8 , p. 513-519.

Authors argue that ethical environmental stewardship requires monitoring and assessment of landscape changes on a national scale. Individual owners make changes in landcover, but the impacts of these changes have cumulative impacts as spatial patterns change. Landscape changes have direct impacts on ecological processes. Determination of status and trends in patterns of landscape composition can be useful for understanding the conditions of ecological resources. The most important cause of declines in species numbers and diversity is loss of habitat. Authors present discussion on how remote imagery, GIS, and principles from landscape ecology can be used to monitor environmental quality over large regions. Descriptions to assess biotic integrity and diversity, watershed integrity, and landscape resilience and fragmentation are 
presented. The importance of landscape-scale assessments is highlighted by the frequency of political decisions made at the landscape scale. The authors point out that landscape-scale assessments will only be viable if developed on a foundation of sensitivity testing to determine reliability of methods supported by smaller scale field studies.

Parton, W.J., Gutman, M.P., Williams, S.A., Easter, M., and Ojima, D., 2005, Ecological impact of historical land-use patterns in the Great Plains - A methodological assessment: Ecological Applications, v. 15, no. 6, p. 1915 - 1928.

Authors report the use of historical county-level agricultural data to develop an ecosystem model for grassland, dryland cropping, and irrigated cropping to determine ecological effects of prevailing land use. Results indicate that cultivation of grasslands results in large losses of soil $\mathrm{C}$ and an increase in soil $\mathrm{N}$ mineralization for the first 20 years of cultivation followed by low soil $\mathrm{C}$ loss and $\mathrm{N}$ mineralization for 50 years after the initiation of cultivation.

Peterjohn, B.G., 2003, Agricultural landscapes - Can they support healthy bird populations as well as farm products?: The Auk, v. 120, no. 1, p. 14-19.

Intensification of agricultural production appears to underlie most declines in grassland bird species numbers and distribution. Conservation on a local scale can reverse local negative trends, but landscape-level patterns of population decline will require solutions that remain undefined. Our understanding of ecology and habitat requirements of many farmland species during the non-breeding season remains rudimentary, limiting the ability to develop effective conservation strategies. Until a more thorough understanding of the entire annual cycle of habitat use is provided, the risk of inefficient or ineffective conservation strategies remains high. Single-species management may not be an effective approach for the entire farmland bird community but may be needed for species of immediate conservation concern. Effective conservation of avian species associated with agricultural landscapes will require innovative solutions based on current agricultural practices. Reliance on reverting to less intensive agricultural practices across North America is an unrealistic expectation.

Some combination of variables including grassland species composition, structural diversity, patch size, habitat fragmentation, and management activities define relations between grassland birds and their habitat. Each species responds differently and studies at smaller spatial scales are needed to clarify these relations. Simple, all-encompassing conservation solutions will not reverse all declines in farmland bird populations. Recent declines in grassland birds probably reflect factors other than simple habitat loss and include fragmentation, increased mowing, and other detrimental practices associated with intensification of agricultural production.
The negative relationship between population trends of avian species and CRP (see Murphy 2003 in Grassland Birds; p. 171 of this report) is surprising and may reflect the fact that CRP fields constitute only 3.6 percent of the overall landscape and that negative factors operating on the remaining 96.4 percent of landscape have a greater influence on avian population trends. Five of seven negative associations reported by Murphy (2003) were for avian species associated with shrub-dominated habitats, and the two negative relations were for grassland species that regularly nest in less densely vegetated covers including row crops. The relatively small area of land devoted to CRP and its uneven distribution in the United States probably also had an influence on this relationship.

Pimentel, D., and Pimentel, M., 2003, Sustainability of meatbased and plant-based diets and the environment: American Journal of Clinical Nutrition, v. 78, p. 660-663.

Authors conclude that the heavy dependence on fossil energy used by the United States' food system is not sustainable. The United States' food-production system uses about 50 percent of the total area in the country, 80 percent of the fresh water, and 17 percent of the fossil energy. The United States' population doubled in the last 60 years and is expected to double again in 70 years. Differences in energy requirements needed to produce vegetarian and meat-based diets are discussed.

In the United States, more than 9 billion livestock are maintained to supply the animal protein consumed each year. These animals consume about 7 times more grain than consumed by the entire American population. The amount of grain fed to livestock is sufficient to feed about 840 million people who follow a plant-based diet. For each kilogram of animal protein produced livestock are fed about $6 \mathrm{~kg}$ of plant protein. The average fossil energy input for all animal protein production systems studied is 25 kilocalories (kcal) of energy per $1 \mathrm{kcal}$ of protein produced; this is more than 11 times that of grain protein production.

More than 99.2 percent of food in the United States comes from terrestrial production, whereas 0.8 percent comes from oceans or aquatic ecosystems. Continued use of land is of concern due to the rapid rate of soil erosion and degradation of associated ecosystems. Each year over 90 percent of cropland loses soil at 13 times sustainable rate of 1 ton/hectare/ year. Authors conclude the major threat to future survival and U.S. natural resources is rapid growth of human population.

Ribic, C.A., Warner, R.E., and Mankin, P.C., 1998, Changes in upland wildlife habitat on farmland in Illinois 1920-1987: Environmental Management, v. 22, no. 2, p. 303-313.

Authors developed an index to evaluate changes in agricultural ecosystems as they affect wildlife habitat. Indices at county level have potential to be used in multi-scale analysis 
to investigate effects of policy changes on large-scale areas and to develop regional documentation of agricultural impacts on upland wildlife and habitats.

Shackleton, R., 2009, Potential impacts of climate change in the United States: Washington D.C., Congressional Budget Office, Congress of the United States, $25 \mathrm{p}$.

The report presents a concise overview of the current understanding of potential effects of climate change in the United States. The synopsis of climate-change issues presents potential impacts including changes in weather patterns, precipitation, storms, ocean acidity, and sea level, as well as potential alterations to ecosystems and biodiversity, agriculture, fisheries, and human health. Climate-change responses to emissions and changes in land use are complex with both rapidly and slowly evolving responses. Uncertainly in projecting changes is great. Responses will not be uniform; they will vary across regions and seasons. A changing climate is likely to result in alterations of regional and seasonal temperatures, rainfall and snowfall, as well as change in frequency and severity of extreme events such as heat waves, droughts, and floods. Regional U.S. climates are expected to become more variable with more intense and frequents extremes of high temperature and rainfall.

Agricultural impacts are driven by changes in temperature and rainfall. Enhancement of plant growth resulting from higher concentrations of carbon dioxide, more destructive effects of ground-level ozone, and changes in susceptibility to fire and pests are potential consequences of global warming. Warming trends will be relatively greater at high latitudes in the Northern Hemisphere. Warming will be greater in the interior of continents. An average increase of $7^{\circ} \mathrm{F}$ (by the end of the 21 st century) in global temperature will shift average annual temperatures two states north. This means that North Dakota will have a climate similar to Nebraska of today. At the high end of estimated temperature change $\left(11^{\circ} \mathrm{F}\right)$ climate patterns would shift three states north. Kansas would be similar to Texas. Northerly regions of the United States would tend to warm most in the winter due to declining snow and ice cover. Most models project that almost any amount of warming will cause much of the Southwest to become more arid over the course of the 21 st century. Warmer winters in northern regions will be wetter. Summers will be drier in southern regions. Periods of intense rainfall will tend to be interspersed with longer dry periods. Rising sea levels will cause gradual, progressive inundation of shorelines; erosion of coastal wetlands will increase.

Risks to U.S. agriculture are described as comparatively modest. Farmers will have to adapt to changing climate conditions by shifting cultivation of specific crops northward and altering timing of planting. In some regions, changes in rainfall rather than changes in temperature will be more unfavorable. Northern regions may have longer growing season and greater precipitation, but southern regions are likely to be more sensitive to higher temperature and decreased rainfall. Declining supplies of water could affect agriculture in western states.

Studies generally conclude that warming and higher concentrations of carbon dioxide will boost global growth of forests. The area of shrub and steppe in the American southwest is expected to expand. Ranges of mixed forests in the northernmost regions and in colder boreal regions will shift northward and cover less land area. Treeline could shift 250 mi north over the course of the 21 st century. A greater risk of wildfires can be expected. Rising temperatures will shift geographic ranges of many fish species northward. Warmwater species are more likely to prosper and expand ranges. Western states will find it difficult to meet current levels of water demand.

Swanson, T.M., 1992, Wildlife and wildlands, diversity and development, in Swanson, T.M., and Barbier, E.B., eds., Economics for the wilds: Washington, D.C., Island Press, p. 1-14.

Diversity and economic development need not be mutually exclusive. Maintaining diversity of wild resources is a necessary condition for sustainability. Wild resources should be treated as an input to the development process and cannot be excluded. The conservation of biodiversity implies the need to conserve not only a given stock of wildlife but the capacity for the species to mix and evolve in an ongoing interactive process. In other words, the habitat must be provided that will meet the needs of the targeted species across the physical landscape as well as through time. It is important to integrate wildlife/biodiversity values into the economic process rather than shield them from it. Ultimately, the economic value of resources will be the key to their survival.

Szentandrasi, S., Polasky, S., Berrens, R., and Leonard, J., 1995, Conserving biological diversity and the Conservation Reserve Program: Growth and Change, v. 26, p. 383-404.

Effective protection of wildlife resources often will take place on land used primarily for purposes other than wildlife habitat. CRP lands currently are targeted to regions (for example, Midwest and Great Plains) having relatively few threatened and endangered species when compared to other regions of the country. This paper describes a method to retarget CRP enrollment to address threatened and endangered (T\&E) species' concerns in Oregon or other regions where there are greater numbers of these species. The justification for improved targeting of CRP is to enhance provision of important environmental benefits. Primary agencies involved in management and monitoring of CRP (USDA) do not have a traditional wildlife-oriented mission. Consequently, species preservation and habitat protection received minimal attention in program design. 
Tilman, D., Fargione, J., Wolff, B., D’Antonio, C., Dobson, A., Howarth, R., Schindler, D., Schlesinger, W.H., Simberloff, D., and Swackhamer, D., 2001, Forecasting agriculturally driven global environmental change: Science, v. 292, no. 13 , p. $281-284$.

Description of potential nonclimatic global environmental impacts of agriculture for the coming 20 to 50 years is presented. The forecasts presented are described not as predictions but estimates of environmental impacts, should agriculture continue on trajectories experienced over the past $35+$ years. Authors warn that unforeseen changes in population, economic growth, agricultural policies, climate and other factors may affect their projections. Agriculture affects ecosystems by use and release of resources that influence ecosystem functioning ( $\mathrm{N}$, Phosphorus $(\mathrm{P})$, water), release of pesticides, and conversion of natural ecosystems to crop production. These sources of global change may rival climate change in environmental and social impacts. About 70 percent of harvested crops are fed to livestock in developed countries. A 50 percent increase in population and demand for diets richer in meat are projected to double global food demand by 2050 .

The report states that global $\mathrm{N}$ fertilization is forecast to be 1.6 times greater than present amounts by 2020 and 2.7 times greater by 2050 . Phosphorus fertilization is forecast to be 1.4 times current amounts in 2020 and 2.4 greater by 2050 . Projected increases in $\mathrm{N}$ and $\mathrm{P}$ fertilization will have substantial environmental consequences that include eutrophication of surface waters, loss of biodiversity, and changes in species composition in terrestrial and aquatic ecosystems; groundwater pollution; increases in greenhouse gases; and acidification of soils and freshwaters. If past patterns persist, global pesticide production would be 1.7 times that of present levels by 2020 and 2.7 times greater by 2050 , resulting in elevated exposure to humans and ecosystems.

If trends continue, global cropland would increase by $350,000,000$ hectares (742 million acres) by 2050 . The majority of this would be in developing countries, primarily in Latin America and sub-Sahara Africa. It would amount to about half of all potentially suitable land for agriculture, which would lead to loss of about one third of remaining tropical and temperate forests, savannas, and grasslands. Conversely, agricultural land use in developed countries is projected to decline as the more productive land is farmed more intensively.

An environmentally sustainable revolution is needed based on the total costs and benefits of agriculture, including agriculture-dependent gains and losses in values of ecosystem services that include biodiversity, recreation, $\mathrm{C}$ storage, drinkable water, fisheries, and pollination. Use of cover crops and of buffers on drainages and surface waters need to be expanded. Comprehensive land-use planning is needed to minimize fragmentation and protect wetlands and surface waters. Methods to quantitatively forecast changes in ecosystem functioning are desperately needed.
Trenbath, B.R., Conway, G.R., and Craig, I.A., 1990, Threats to sustainability in intensified agricultural systemsanalysis and implications for management, in Gliessman, S.R., ed., Agroecology_-Researching the ecological basis for sustainable agriculture: New York, Springer-Verlag, p. 337-365.

Agricultural intensification typically results in a greater proportion of more intensively farmed available land, elevated levels of technological input, and more frequent use of land. In combination, these variables are often accompanied by damage to the natural resource base. Agricultural intensification may damage associated nonagricultural systems within or outside the farmed area as well as other agricultural systems downstream. Intensive exploitation of available areas has led to increases in productivity but also declines in wildlife populations associated with less intensive use. Where wildlife viability is dependent upon relatively large patches of lessdisturbed habitat, sensitive populations may disappear.

More frequent use of land is a common aspect of intensification that is potentially exhaustive of land capability. With shorter fallow periods between crops, natural-soil processes may be unable to regenerate fertility and there may be a buildup of pests. Both require greater use of agrochemicals to alleviate problems. Use of pesticides may lead to spectacular increase in yield, but experience shows that after a number of years of application, pesticides progressively lose effectiveness. This decline is due to an increased proportion of pest genotypes in a population becoming resistant to chemicals. If use continues, especially with higher dosages, the proportion of resistant genotypes increases rapidly to the point where existing pesticides must be replaced by new, more successful chemicals. Emergence of pesticide resistance reduces profitability through crop losses and need for different, inevitably more expensive chemical. The less obvious, and sometimes delayed, effects on the environment may be substantial, particularly to wildlife.

Van Buskirk, J., and Willi, Y., 2004, Enhancement of farmland biodiversity within set-aside land: Conservation Biology, v. 18 , no. 4, p. 987-994.

Although it may seem obvious that withdrawal of farmland from intensive production would provide benefits to wildlife and biodiversity associated with agricultural landscapes, there remain serious questions about the cost effectiveness and benefits of such programs. Some suggest set-aside programs are inefficient and relatively unsuccessful in providing wildlife habitat. Agroecologists monitoring these programs have reported conflicting results. Because these programs are costly, politicians may be unwilling to continue approving payments in North American and the European Union without clear evidence of program benefits. Because general conclusions about the impact of set-aside programs cannot be supported by a few isolated monitoring studies, the authors of 
this report completed a literature review of over 500 studies in agricultural landscapes.

The authors' meta-analysis indicates numbers of bird species, insects, spiders/harvestmen, and plants were significantly higher on set-aside land than on nearby control areas under conventional agricultural production. Authors believe their analysis unequivocally resolves controversy of biodiversity benefits of set-aside land at last at local level. Results of study show larger, more permanent units of land enrolled in set-aside have greater benefits than do smaller sites of short duration. Authors identify a need for more information on how land in these programs function in the context of the entire landscape and how species react to these programs.

van der Werf, J.P., and Petit, J., 2002, Evaluation of the environmental impact of agriculture at the farm level - A comparison and analysis of 12 indicator-based methods: Agriculture Ecosystems \& Environment, v. 93, p. 131-145.

This report furnishes an assessment of 12 indicator-based approaches to assessing the environmental impact of agriculture at the farm level. Indicators are alternative measures used to identify the status of a concern when, for technical or financial reasons, the impact cannot be measured directly. Indicators of environmental impact may be based on either farmer production practices or effects these practices have on the environment. Indicator methods of assessment should account for a range of objectives covering both local and global effects. Indicators based on environmental effects of farming practices are preferable to indicators based on farm practices as the link with the objective. Indices describing impact both per unit surface area and per unit of product are preferable. The method of assessment should be validated prior to use.

Veech, J.A., 2006, A comparison of landscapes occupied by increasing and decreasing populations of grassland birds: Conservation Biology, v. 20, no. 5, p. 1422-1423.

Twenty years of Breeding Bird Survey (BBS) data were used to identify stable, increasing, and decreasing populations of 36 grassland bird species in relation to physical features of the landscape adjacent to survey routes using USDA NRI data. Populations that were increasing were associated with landscapes that contained significantly more restored grassland and rangeland but less forest land and urban land than landscapes inhabited by decreasing populations. There was no significant difference in proportion of cropland within landscape of increasing and decreasing population, although cropland composed greater than 30 percent of many of these landscapes. Restored grassland typically was a very small proportion (less than 3.5 percent) of total land cover but was significantly more common in landscape of increasing than decreasing populations of grassland birds. Rangeland and CRP land held the greatest potential for having a positive effect on grassland birds. CRP was typically a low component of landscape composition (2.9-3.2 percent). The author concludes that the amount of grassland habitat within a landscape can affect population trends in grassland birds regardless of spatial configuration of individual grassland parcels.

Warner, R. E., 1994, Agricultural land use and grassland habitat in Illinois-Future shock for midwestern birds: Conservation Biology, v. 8, no. 1, p. 147-156.

During periods of intensive agricultural production, grasslands existed only as linear edges with resultant low density and diversity of grassland nesting birds. Nest densities and species diversity were highest where grassland was nearby, cover types were heterogeneous, and where corridors connected grasslands in surrounding landscape. The percentage of ring-necked pheasant (Phasianus colchicus) nests hatched annually from 1973 to 1981 was positively correlated with the amount of grassland per hen in spring, where grassland consisted of both edge habitats (including roadsides) and fields of hay and small grain. Nest densities and species diversity increased relative to the degree of spatial heterogeneity and to how well plots were connected to surrounding landscape by corridors. There is potential for enhancing use of grassy farmland edges by establishing filter strips, field borders, existing edges, and by locating hay and small grains near wider grassland corridors.

It is too simplistic to conclude all linear habitats compared to fields (blocks of cover) are predator traps. Nest destruction was high in years when both predators and nesting pheasants were concentrated in relatively little grass-dominated cover. Predation rates vary with predator-prey assemblages, density of birds in nesting habitats, and the extent to which other cover and prey attract predators away from relatively attractive nest sites. Overall, landscape-level phenomena affecting farmland wildlife populations are poorly understood at this time.

Weber, W.L., Roseberry, J.L., and Woolf, A. 2002, Influence of the Conservation Reserve Program on landscape structure and potential upland wildlife habitat: Wildlife Society Bulletin, v. 30 , no. 2 , p. $888-898$.

The report is an evaluation and quantification of CRP effects on Illinois agricultural-landscape composition within bobwhite quail (Colinus virginianus) range (southwestern and southern Ill.). Considering all land-cover types, CRP landscapes are characterized by smaller acreages, greater edge density and greater fragmentation compared to landscapes without CRP. Farmland enrolled in CRP tended to be located in areas with proportionately less row crop and more grassland and woodland than non-CRP landscapes. Landscapes surrounding CRP fields were more diverse than non-CRP landscapes. Enrollment criteria required CRP to be located in areas that were less productive and more likely to have smaller patch size and greater diversity than the composition of overall 
landscape. Multiple fields enrolled by landholders also might account for some aggregation. Basically, authors conclude that CRP is being established in landscapes that already contained grassland and woodland cover types.

To further enhance CRP benefits, land managers and wildlife biologists must collaborate to identify objectives and maximize landscape-level approaches to cover management. As enrollment criteria presently exist, opportunities to improve wildlife habitat are limited. Communication and information exchange between NRCS personnel and program participants needs improvement. Administration of CRP, as well as other conservation programs, need greater emphasis on landscape level planning to meet wildlife objectives.

Wu, J., Ransom, M.D., Nellis, M.D., Kluitenberg, G.J., Seyler, H.L., and Rundquist, B.C., 2002, Using GIS to assess and manage the Conservation Reserve Program in Finney County, Kansas: Photogrammetric Engineering \& Remote Sensing, v. 68, no. 7, p. 735-744.

This evaluation used soil, land use, groundwater, and other environmental layers in a GIS to evaluate distribution and planning for CRP enrollment. Aquifer thickness, coinciding with gas or oil fields, was closely associated with distribution of CRP. Soil, aquifer depth, physiography, or slope had little apparent relation to distribution of CRP. The data layer was developed using a soil erosion index used to identify areas best suited for enrollment of new CRP lands. Methods and approaches to identification of priority data themes and use of GIS in land-use planning for CRP and other conservation programs are discussed.

\section{Biomass, Energy}

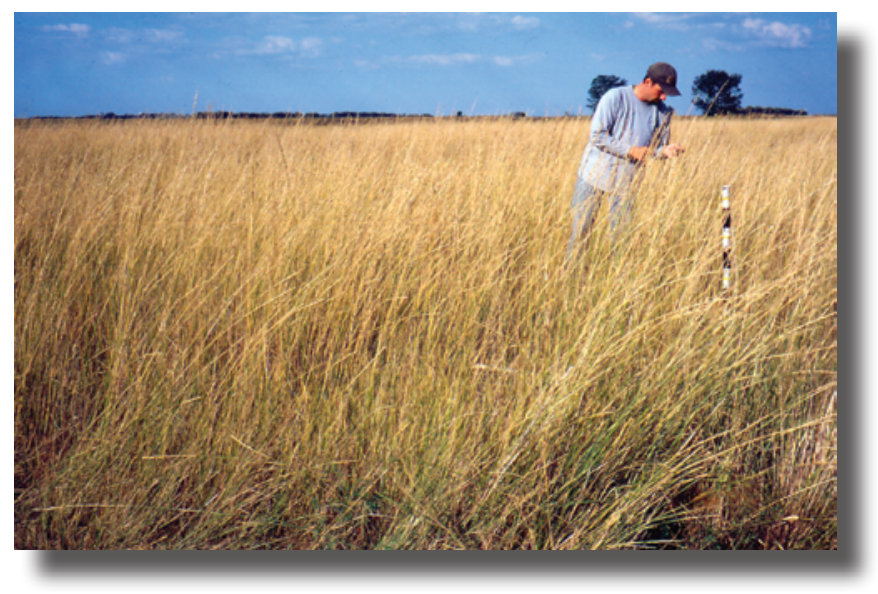

Adler, P.R., Sanderson, M.A., Weimer, P.J., and Vogel, K.P., 2009, Plant species composition and biofuel yields of conservation grasslands: Ecological Applications, v. 19, no. 8, p. 2202-2209.
In an investigation of the potential of CRP grasses as a source of biofuel, the report found that species richness and composition are key determinants in biomass and ethanol yields. As species composition increased, potential yields decreased. Warm-season grasses were evaluated from 34 sites in New York, Pennsylvania, New Jersey, Maryland, and Virginia. Grasses were dominated by switchgrass (Panicum virgatum), big bluestem (Andropogon gerardii), and Indiangrass (Sorghastrum nutans). Conservation grasslands with higher numbers of plant species had lower biomass yields and lower ethanol yield per unit of biomass. Biofuel yield decreased by 77 percent as plant-species richness increased from 3 to 12.8 species per square meter $\left(\mathrm{m}^{2}\right)$. Ethanol yields vary with plant species as a consequence of cell-wall chemistry affecting carbohydrate composition and efficiency of enzymatic hydrolysis. Plant-species composition affected concentration of lignin, cellulose, and hemicellulose in biomass; this affected the potential yield of conservation grasslands. Biomass yield per unit area also decreased in response to greater richness in plant species. Conservation grassland dominated by tall warmseason grasses had more aboveground biomass, few species of plants present, higher ethanol yield per unit biomass, and higher ethanol yield than for other sites. Authors conclude that sites with higher plant-species richness will yield undesirable fermentation characteristics diminishing ethanol yield.

Best, L.B., and Murray, L.D., 2005, Bird responses to harvesting switchgrass fields for biomass, in Transactions North American Wildlife and Natural Resources Conference, 69, Spokane, Wash., March 16-20, 2004, Proceedings: Washington, D.C., Wildlife Management Institute, p. 224-235.

One alternative use of CRP land as contracts expire is production of switchgrass (Panicum virgatum) for biofuel. Switchgrass appears to be a viable method of biofuel production due to its high production of biomass and its requirement of minimal maintenance once established. Switchgrass is harvested in fall and winter; breeding birds are not affected directly, but changes in vegetation abundance and structure may influence bird abundance and nest success the following spring. Winter abundance of avian species may also be affected. Authors believe that switchgrass production could furnish environmental benefits similar to the CRP, but removal of residual vegetation in harvested fields had a negative effect on nest success and nest/brood parasitism. Nest success was greater in unharvested fields (59 percent) than in total-harvested (40 percent) and strip harvested (33 percent) fields.

Because grassland-bird species differ in habitat needs, maintaining both harvested and nonharvested switchgrass fields would benefit the greatest number of species. This can be accomplished by leaving some fields idle during a harvest rotation. Harvesting switchgrass fields in alternating cut and uncut strips is believed to be more beneficial to the winter bird community than is harvesting entire fields. Because the establishment of extensive switchgrass fields for energy production may affect availability of foods, the authors further 
recommend establishment of food plots in biomass-production areas. A discussion of future research needs in relation to field size, field configuration, juxtaposition of habitats, and landscape-level effects is presented.

Bies, L., 2006, The biofuels explosion-Is Green Energy good for wildlife: Wildlife Society Bulletin, v. 34, no. 4, p. $1203-1205$.

A concise appraisal of biofuel types, production methods, energy costs, and potential environmental effects of growing demand for these products.

In early 2006, domestic ethanol production capacity was about 4.4 billion gallons per year. Approximately 95 percent of United States bioethanol comes from corn. About 20 percent of the U.S. corn production goes to ethanol. Iowa alone has two dozen ethanol plants with more under construction. Bioethanol can be created from cellulosic biomass derived from grasses, agricultural residues, straw, and woody biomass. Cellulosic ethanol production is often seen as more environmentally desirable due to lower greenhouse emissions and higher energy balance. Production and use of cellulosic ethanol results in fewer greenhouse-gas emissions and produces more energy per unit of input. A large portion of the economic and environmental costs in production of corn ethanol is the investment in fossil fuels needed to plant, tend, and harvest corn and convert it to ethanol. Three gallons of water are required to produce one gallon of corn ethanol. At this time, the processes to produce commercial cellulosic ethanol are not economically viable.

The extent of losses in wildlife habitat and other environmental impacts of biofuel production depend on the scale of production and the type of land used. Compared to land planted to corn, grasslands devoted to biomass production could still maintain some availability of habitat. Strip harvesting of switchgrass (Panicum virgatum) appears to offer viable options of a balance between production and perseveration of habitat values. Production methods of cellulosic ethanol are still in development. At present, the technology for processing a mixture of different grasses is unavailable. Potential effects of legislation, tax credits, and subsidies of production of biofuels are discussed. One can only conclude that biofuels are going to be a major source of agricultural production for years to come, and likely only going to get bigger. The author concludes that work must continue to evaluate and design biofuel production so it furnishes green energy and wildlife benefits.

Florine, S.E., Moore, K.J., Fales, S.L., White, T.A., and Burras, C.L., 2006, Yield and composition of herbaceous biomass harvested from naturalized grassland in southern Iowa: Biomass and Energy, v. 30, p. 522-528.

The paper addresses issues related to use of grass biomass for cofiring (burning herbaceous biomass with coal) to produce energy. Switchgrass (Panicum virgatum) is seen as an ideal energy crop due to relatively high yield with moderate to low inputs; adaptability to marginal soils; and favorable fuel characteristics of high net energy, ash content, and chemistry. However, other grasses may also be viable alternatives for production of biomass. Authors identify use of CRP lands for biofuel production as an alternative to returning these lands to production of commodity crops. Many CRP lands in Iowa have been planted to cool season grasses (for example, smooth brome [Bromus inermis]) but little is known of their potentials as a source of biofuel.

The authors sampled 10 sites planted to cool season grasses, and report that biomass yield varied within and among locations with yields ranging from 0.75 tons per hectare $(\mathrm{t}$ ha) (0.3 tons per acre $[\mathrm{t} \mathrm{ac}])$ to $8.24 \mathrm{t}$ ha $(3.3 \mathrm{t} \mathrm{ac})$. Average yield was $4.2 \mathrm{t} \mathrm{ha}(1.7 \mathrm{t} \mathrm{ac})$. The majority of biomass yield variation occurred within sites, not among them. Authors conclude that some locations are better than others for biomass production due to lower ash, sulfur, and chlorine content in vegetation. Chemical composition of sample vegetation is provided. The majority of cool season pastures sampled had higher levels of ash than recorded in switchgrass. The major component of ash is silica. Warm-season grasses typically have lower silica content than do cool-season grasses because they use water more efficiently. Authors conclude cool-season grasses (for example, smooth brome, orchardgrass [Dactylis glomerata], and tall fescue [Festuca arundinacea]) can serve as alternative sources of herbaceous biomass for fuel production. Biomass accumulation in cool-season grasses is greatest in spring and early summer while switchgrass and other warm-season species is greatest in late spring and summer. Authors suggest cool-season grasses could be harvested earlier in the season if stored supplies of switchgrass become limiting.

Higgins, K.F., Osborn, R.G., Naugle, D.E., and Bakker, K.K., 2005 , Contrasting the potential effects of biomass fuel, soybase fuel, ethanol, and wind energy developments on northern Great Plains Wildlife, in Transactions North American Wildlife and Natural Resources Conference, 69, Spokane, Wash., March 16-20, 2004, Proceedings: Washington, D.C., Wildlife Management Institute, p. 199-214.

Four renewable energy sources are receiving greater attention and being developed in the northern Great Plains: wind turbines, fuel from grass biomass (typically switchgrass [Panicum virgatum], ethanol from corn [Zea mays], and fuels from soybean [Glycine max]) products. Histories and social and environmental advantages/disadvantages of each method of energy production are discussed. Authors recommend construction of windplants near breeding, staging or wintering areas, migration corridors, or other areas with large concentrations of birds or bats should be avoided until further research is conducted. Although most past investigations report relatively small amounts of mortality due to turbines, these results should not be taken lightly due to the large number of windfarms being proposed for development. Perhaps one of the most negative impacts of wind power will be development 
of large, aboveground transmission lines which have been shown to cause significant avian mortality in areas with a high density of wetlands. Greater development of row crop acreage for ethanol and soy fuels has potential to accelerate conversion of wetland and native grasslands into croplands throughout the northern Great Plains. Development of drought-resistant, genetically modified soybeans has already accelerated conversion of remaining native prairie to cropland. Authors conclude that of the four approaches, only biomass fuels have potential to bring benefits to Great Plains wildlife. However, if remaining native grasslands and CRP grasslands are converted to biomass production, effects will be negative.

Hoover, S.L., and Morrison, M.L., 2005, Behavior of redtailed hawks in a wind turbine development: Journal of Wildlife Management, v. 69, no. 1, p. 150-159.

Authors describe flight behavior of red-tailed hawks (Buteo jamaicensis) and their flight/foraging characteristics in relation to topography and wind speed that may make them susceptible to mortality from collisions with wind turbines. Authors recommend that assessment of topographic features and weather variables (typical wind speed and direction) of the site and behavioral evaluations for common avian species be completed prior to installation of new wind farms to identify potentially dangerous situations and conditions. Windfarm managers can power down turbines at top of hazardous slopes when winds are strong and facing perpendicularly to the slope to lower likelihood of collision to lessen potential mortality to avian species.

Jarnevich, C.S., and Laubhan, M.K., 2011, Balancing energy development and conservation-A method utilizing species distribution models: Environmental Management, v. 47, p. 926-936.

Authors modeled Lesser Prairie Chicken (LPC; Tympanuchus pallidicinctus) habitat suitability using Maximum Entropy (Maxent) as a tool to assist energy development in Kansas. The LPC has experienced loss of habitat and population decreases and is considered an indicator of grassland conditions. Kansas is ranked third in potential wind energy and companies have established 6 wind facilities and proposed 44 more facilities. Avoidance from further negative impacts to wildlife (habitat loss and fragmentation) in areas developed for energy production are needed, but agencies often do not have the resources to delineate distribution of wildlife or suitable habitat at necessary scales.

Authors identified two land use/land cover classes (grasslands, CRP), areas of topographic relief, and anthropogenic variables (highways, transmission lines, etc.) as inputs. Grasslands represented pasture, rangeland, and lands with greater than 50 percent cover of trees or grasslands. Normalized difference vegetation index (NDVI) was used to provide estimates of vegetation productivity (low values indicative of fallow cropland, high values indicative of lush vegetation). Lek locations of both LPC and Greater Prairie Chicken (GPC; T. cupido) were collected by Kansas Wildlife and Parks and incorporated into the model.

Lek habitat suitability was positively correlated with increasing land cover use/classes. Average NDVI was the best indicator of habitat suitability across all models. Low NDVI values correlated with greater lek habitat suitability. Elevation was the third most important variable in all models except for mixed lek (LPC and GPC) models. Mixed leks models that included anthropogenic features showed distance from roads to be more important than standard deviation in elevation. Anthropogenic variables increased uncertainty in the models but generally had low relative contributions to habitat suitability.

Maxent models do not determine causal relationships, and while evidence of relationship between habitat suitability and anthropogenic variables exist and aid in siting energy development, the authors caution that additional testing is needed to confirm causal relationships.

Jensen, K., Clark, C.D., Ellis, P., English, B., Menard, J., Walsh, M., de la Toree Ugarte, D., 2007, Farmer willingness to grow switchgrass for energy production: Biomass and Bioenergy, v. 31, p. 773-781.

A survey of farmers in Tennessee to determine willingness to grow switchgrass (Panicum virgatum) for potential energy markets is reported. In 2005, a survey was sent to 19,684 Tennessee farmers with a reported income of over $\$ 10,000$. Response rate was 23.9 percent. Of those responding, 20.8 percent previously heard of growing switchgrass as an energy option. Only 29.6 percent of respondents indicated an interest in growing switchgrass if it were profitable. Producer opinions about switchgrass production are presented. The study results suggest that many farmers are still not familiar with switchgrass opportunities. The availability of technical assistance and poorly defined markets were factors limiting adoption of the practice. Land owners with off-farm income were more likely to convert land to switchgrass production. Control of soil erosion had no influence in interest in growing switchgrass but improvement of wildlife habitat quality did.

Johnson, G.D., Perlik, M.K., Erickson, W.P., and Strickland, M.D., 2004, Bat activity, composition, and collision mortality at a large wind plant in Minnesota: Wildlife Society Bulletin, v. 34, no. 4, p. 1278-1288.

Bat activity examined in southwest Minnesota indicates most mortality associated with turbines involves migrating bats. Most mortality was hoary bats (Lasiurus cinereus), although fatalities of other species were recorded. Authors conclude it is unlikely that resident bats would spend significant time foraging near wind turbines situated within interiors of crop fields, pastures, or CRP fields away from woodlands. A 
significant decrease in bat activity was recorded with increasing distance from woodland. Results of this and other studies cited lead authors to conclude that populations of breeding bats near wind plants are not highly susceptible to collision with turbines. However, mortality rates for migrating species are higher. Increased mortality due to safety lighting on turbines was not recorded.

Leddy, K.L., Higgens, K.F., and Naugle, D.E., 1999, Effects of wind turbines on upland nesting birds in Conservation Reserve Program grasslands: Wilson Bulletin, v. 111, no. 1, p. 100-104.

CRP grasslands without turbines and areas located 180 $\mathrm{m}$ (215 yards [yd]) from turbines supported 4 times higher densities of grassland birds than areas within $80 \mathrm{~m}$ (95 yd) of turbines. Authors recommend turbines be placed in cropland that supports lower densities of grassland passerines rather than placing them in CRP grasslands where greater numbers of birds are present. Associated human disturbance, turbine noise, and physical movements of turbines may have disturbed nesting birds.

McLaughlin, S.B., and Walsh, M.E., 1998, Evaluating environmental consequences of producing herbaceous crops for bioenergy: Biomass and Bioenergy, v. 14, no. 4, p. 317-324.

The choice of switchgrass (Panicum virgatum) for biomass production is based on potentially high yields, high nutrient use efficiency, and wide geographic distribution. Other attributes include positive effects on soil quality and stability, potential value as wildlife cover, and relatively low requirements for energy, water, and agrochemical inputs. Estimates of the efficiency of energy production show that switchgrass can exceed corn (bioethanol) by as much as 15 times. Carbon sequestration may exceed those of annual crops by as much as 20-30 times. These differences can have implications for both the rate and efficiency with which fossil fuels can be replaced by cleaner burning biofuels. Obvious environmental benefits of switchgrass production include improved soil conservation, enhanced energy gain, and reductions in emission of carbon dioxide.

Moreira, N., 2005, Growing expectations-New technology could turn fuel into a bumper crop: Science News, v. 168, no. 14, p. 218-220.

This is a short but informative article describing the potential use of biofuels. Various options and shortcomings of alternatives are presented. Green fuels are becoming more attractive as fuel prices climb and the end of an oil-based economy is projected in future decades. The Energy Policy Act of 2005 requires 7.5 billion gallons of ethanol and biodiesel to be part of the nation's fuel supply by 2012, providing 5.75 percent of the country's fuels supply. Ethanol is the most common plant-to-fuel product currently available. Green fuels have lower emissions of greenhouse gases, but these fuels do have negative consequences, which include high costs of energy required to produce them as well as elevated use of fertilizer and erosion of soil. Ethanol production from biomass currently requires more fuel-derived energy than it saves. Ethanol from corn consumes 29 percent more fuel than it saves. Estimates indicate that replacing the entire U.S. fuels supply with corn ethanol will require at least 60 percent of the nation's available cropland. Cellulosic biomass, rather than corn, appears to be a more environmentally friendly approach. Thermochemical production of biofuels (production of gas and eventual liquid of wood, grass, manure) cannot compete with petroleum on the open market.

Using waste plant material (corn husks, wood chips) may avoid these problems, but there is no commercially viable process yet to make large amounts of cellulosic biofuel. However, work is progressing on bringing down costs of fuel production from cellulase by using bioengineered organisms to break down cellulose and produce ethanol. In the United States, the greatest opportunities for competitive biofuels may lie in combining biochemical and thermochemical methods. The article quotes Larry Russo (Department of Energy) as saying "Agriculture in the 21 st century will become our oil wells."

Mulkey, V.R., Owens, V.N., and Lee, D.K., 2006, Management of switchgrass-dominated Conservation Reserve Program lands for biomass production in South Dakota: Crop Science, v. 46, p. 712-720.

Successful perennial grass-based energy production requires reliable establishment and persistence of grass, high yielding cultivars, and appropriate conversion technology. In some regions of the United States, switchgrass (Panicum virgatum) can produce up to 14 Milligram $(\mathrm{Mg})$ of dry matter (DM) per hectare of which over 60 percent is lignocellulose, the desirable component for biomass production. At similar stages of maturity, warm-season grasses have higher lignocellulose concentrations than cool-season grasses and legumes. Lignocellulose concentrations increase as switchgrass matures as a result of a decrease in the leaf-to-stem ratio. Growth characteristics and past descriptions of harvest effects on switchgrass yield are provided.

An investigation of management strategies for conversion of CRP land planted to switchgrass is presented. Objectives were to determine effect of harvest timing, $\mathrm{N}$ application rate effects on biomass production, and effects of harvest management on species composition and persistence. Authors recommend harvesting switchgrass once per year after a killing frost and applying low to moderate amounts of $\mathrm{N}$ to maximize energy yield. Older stands of switchgrass may be more sensitive to harvest timing than younger stands. Silica content is lowest in grass stems and highest in leaves; therefore, harvesting switchgrass with high stem content is desirable because biomass quality for combustion purposes is improved. Delaying harvest until after killing frost maximizes canopy cover 
length and decreased proportion of broadleaved weeds in harvested biomass. Switchgrass tends to be sensitive to frequent harvest. Authors conclude that in 9-yr-old stands, persistence of switchgrass declined rapidly when harvested annually during the growing season. Competition between switchgrass and other grasses and broadleaved weeds was also greater when switchgrass was harvested during growing season.

Murray, L.D., and Best, L.B., 2003, Short-term bird response to harvesting switchgrass for biomass in Iowa: Journal of Wildlife Management, v. 67, no. 3, p. 611-621.

An alternative to returning expiring CRP fields to row crop production is biomass production through growth of switchgrass (Panicum virgatum). Grass biomass is typically harvested during fall and winter thereby not directly affecting breeding birds during harvest. However, resultant changes in vegetation structure will have impacts on the quality of breeding habitat in the subsequent spring. Authors conclude that switchgrass biomass fields can retain breeding habitat value for some avian species and an interspersion of harvested and non-harvested fields would be the best alternative over total harvest of all fields or partial harvest of all fields. However, the number of avian species using biomass switchgrass fields may be reduced due to a greater dependence on herbicides and fertilizers to maximize production. Applications of agrochemicals may directly cause nest failures and reduction in habitat structure, which would diminish the quality of reproductive habitat. Switchgrass fields grown for biomass production will generally be of greater value to generalist avian species than those with more restrictive habitat requirements that are of management concern in Iowa (for example, sedge wren [Cistothorus platensis], grasshopper sparrow [Ammodramus savannarum], and northern harrier [Circus cyaneus]).

Murray, L.D., Best, L.B., Jacobsen, T.J., Braster, M.L., 2003, Potential effects on grassland birds of converting marginal cropland to switchgrass biomass production: Biomass and Bioenergy, v. 25, p. 167-175.

Report describes results of Geographic Information System analysis of converting row crop and CRP grass-dominated fields to biomass production and effects on 13 selected avian species in Rathun Lake watershed in Iowa. Bird-abundance values for each habitat were used to model avian abundance in watershed before and after conversion to biomass production. Scenarios using total harvest of fields and strip-harvest of fields were completed.

Authors conclude conversion to switchgrass (Panicum virgatum) biomass production would create habitat for some avian species of management concern (for example, bobolink [Dolichonyx oryzivorus], dickcissel [Spiza americana], and field sparrow [Spizella pusilla]). Abundance of these species increased under both total field and strip harvesting of biomass. A mixture of both total harvest and non-harvest would have the greatest benefits to the largest number of avian species. Rotations of fields in non-harvest status through harvest period would allow buildup of vegetation litter required by early-season ground nesting birds. Authors suggest that the establishment of row crop food plots in areas dominated by biomass production could mitigate loss of foods provided by typical row crop production. Future monitoring of switchgrass biomass production effects on avian populations is recommended.

Pineiro, G., Jobbagy, E.G., Baker, J., Murray, B.C., and Jackson, R.B., 2009, Set-asides can be better climate investment than corn ethanol: Ecological Applications, v. 19, no. 2, p. $277-282$.

To meet targets of the Energy and Independence and Security Act of 2007, corn production will need to increase by improving yields, replacing other crops, and bringing additional uncultivated land into production. The authors state that converting natural ecosystems and set-aside lands, including lands currently enrolled in the CRP, to corn can result in large shifts in $\mathrm{C}$ storage. Many past investigations suggest corn ethanol reduces greenhouse gas (GHG) emission by displacing use of fossil fuels, but most of these studies do not include the implications of changes in net $\mathrm{C}$ balance brought through changes in soil $\mathrm{C}$ content.

Evidence is furnished that $\mathrm{C}$ release from soil after planting corn for ethanol may completely offset $\mathrm{C}$ gains attributed to biofuel generation. The extent to which GHG emissions can be reduced through corn ethanol depends strongly on how and where the corn is produced. The authors' assessment of 142 prior investigations shows soil $\mathrm{C}$ sequestered by setting aside agricultural land was greater than $C$ credits generated by planting corn for ethanol on the same land. Because cropland soil has substantial potential to sequester $\mathrm{C}$ when restored to grassland, conversion of land under long-term cultivation to CRP has a more positive greenhouse gas balance than corn ethanol production.

When it becomes commercially viable, cellulosic ethanol from biomass is likely have the most beneficial GHG emissions balance of all production options. The authors conclude if grasslands are established on cropland the production of cellulosic ethanol does not reduce, and actually may increase, soil $\mathrm{C}$ stocks if corn were planted on the same land. Extending current CRP contracts or enrolling new lands in CRP appears to more economical strategies for sequestering GHG emissions than converting these lands to corn ethanol production.

Appropriate $\mathrm{C}$ accounting of biofuel production requires a complete analysis of impacts to the environment. Estimating the value and public costs of reducing GHG emissions through time is critical for evaluation of alternatives in U.S. Farm and Energy bills. The authors conclude cellulosic ethanol produced on set-aside land should provide the most efficient tool for GHG reductions. At present, conversion of CRP and other setaside lands is an inefficient and expensive alternative for mitigation of greenhousegases. The authors conclude conversion 
of CRP lands or other set-aside lands for production of ethanol should not be encouraged through greenhouse-gas policies.

Robel, R.J., Harrington, Jr., J.A., Hagen, C.A., Pitman, J.C., and Reker, R.R., 2005, Effect of energy development and human activity on the use of sand sagebrush habitat by lesser prairie chickens in southwestern Kansas, in Transactions North American Wildlife and Natural Resources Conference, 69, Spokane, Wash., March 16-20, 2004, Proceedings: Washington, D.C., Wildlife Management Institute, p. 251-266.

Lesser prairie chickens (Tympanuchus pallidicinctus) occupy xeric grasslands across much of the southern Great Plains dominated by sand sagebrush (Artemisia filifolia) or shinnery oak (Quercus havardii). In southwestern Kansas, populations have generally declined due to deterioration of sandsage habitat. This is largely due to the conversion to center-pivot irrigation for production of corn. While most of this development occurred in mid 1980s, prairie-chicken populations continue to decline. Low nest success and survival of chicks appear to be factors contributing to decline. Authors conclude the presence of anthropogenic features (for example, buildings, roads, wellheads, electric transmission lines) have reduced suitability of habitat beyond direct loss of habitat area to cropland. Vegetative characteristics between used and non-used areas were identical. The animals' avoidance of habitat is believed associated with movement and noise from infrastructure related to energy development and agriculture. Adult birds used habitat near roads, wellheads, buildings, and transmission lines less than areas further from those features. Negative impacts were greater for buildings and transmission lines than for wellheads and roads. Estimates of buffers around roads and energy features where habitat use is affected are given. Buffered areas representing habitat of lower quality represent 58 percent of the sand sagebrush habitat remaining in 2001. Loss of suitable habitat for nesting is believed to be even greater, leaving only 26 percent of remaining habitat available for nesting.

Roth, A.M., Sample, D.W., Ribic, C.A., Paine, L., Undersander, D.J., and Bartelt, G.A., 2005, Grassland bird response to harvesting switchgrass as a biomass energy crop: Biomass and Bioenergy, v. 28, p. 490-498.

Switchgrass (Panicum virgatum) grown as a biofuel has potential to furnish a cash crop for farmers and quality nesting cover for grassland birds. The study investigates how harvest of switchgrass for bioenergy impacts community composition and abundance of southwestern Wisconsin grassland bird species. Regrowth of vegetation following mid-summer harvest of switchgrass was not observed. Within harvested sites, residual vegetation was shorter and litter layer reduced in the year following harvest. Grassland bird species preferring vegetative cover of short height and low to moderate density were found in harvested areas (for example, grasshopper sparrow [Ammodramus savannarum], eastern meadowlark [Sturnella magna]). Unharvested switchgrass furnished tall, dense vegetation attractive to species such as sedge wren (Cistothorus platensis) and Henslow's sparrow (A. henslowii). Management plans that maintain some fields unharvested each year are recommended as a good compromise to maintain habitat for grassland avian species of management concern. August harvest furnished habitat the following year favoring species preferring vegetation of moderate height and low to moderate density. Authors believe a mid-August harvest would allow for at least 90 percent of nests to fledge.

Sanderson, M.A., Reed, J.C., and Reed, R.L., 1999, Harvest management of switchgrass for biomass feedstock and forage production: Agronomy Journal, v. 91, p. 5-10.

The paper describes harvest management recommendations for switchgrass (Panicum virgatum) as a biomass energy crop. Most research on perennial warm-season grasses for energy has emphasized a single harvest of very mature stands which is suitable for a biomass dedicated only to biomass fuels. Authors focus on an alternative that may allow use as forage as well as biomass source. Total seasonal yields decreased as frequency of harvest increased. Highest yields occurred with a single harvest in mid-September. Delay of harvest until November reduced yields. A single, mid-September harvest is recommended for maximum biomass yield in the south-central United States. A two cut (spring-autumn) alternative may allow farmers to use spring growth as forage and the regrowth for biomass but yield would be reduced. More frequent harvest would result in reduced yields - perhaps these yields would be so reduced as to not be economical for machine harvest for biofuel purposes.

Sanford, M.P., 2005, Extirpating the agriculture versus conservation dichotomy: Conservation Biology, v. 20, no. 1, p. 253-254.

Private farm and ranch lands are disappearing at an alarming rate. In the United States, more than 12 million hectares $\left(46,333 \mathrm{mi}^{2}\right)$ were converted to exurban development in the 1990s. Private lands in the United States cover 72 percent of the land base, support biodiversity equal to or exceeding protected areas, contain habitat for 60 percent for of threatened and endangered species exclusively, and represent habitat for nearly 95 percent of all threatened and endangered species. A failure by scientists and practitioners to embrace partnershipbased conservation on private lands remains. Factors affecting partnership-based conservation include public opposition/fear, negative prior experiences, lack of support from agencies/ institutions, and governmental policies. Agriculturalists and conservationists are often polarized on these issues.

The current conservation era is transitioning from limiting losses due to agricultural practices toward decreasing 
losses resulting from urban sprawl which will demand both local and global solutions. The author believes many past conservation efforts have failed due to the failure to recognize (1) the role of local communities in conservation and (2) local residents have one of the strongest influences on maintaining biodiversity and integrity of the land. Conservation is partly a social science which needs to continue a focus on elimination of barriers between professionals and landowners.

Secchi, S., Gassman, P.W., Williams, J.R., and Babcock, B., 2009, Corn based ethanol production and environmental quality - A case of Iowa and the Conservation Reserve Program: Environmental Management, v. 44, p. 732-744.

Increasing demands for corn ethanol has elevated concerns about environmental costs to lands in the CRP if they are returned to production. The authors investigate linkages between potential corn production on existing CRP. The investigation was competed using Iowa data because nearly 750,000 hectares (18.5 million + ac) are in CRP and the state produces more ethanol than any other. The Environmental Policy Integrated Climate model is used to investigate changes in distribution and abundance of CRP lands relative to potential changes in corn prices.

While the authors admit many variables affect decisions about enrollment, they estimate based on a price of $\$ 118.10$ / ton, almost 400,000 hectares (988,400 ac) of CRP, almost half the acreage in the state, would go back into production. As corn prices increase a greater percentage of CRP land would return to production. Authors estimate, at this price it would cost over $\$ 277$ million through higher payments to keep less than 70,000 hectares $(173,000 \mathrm{ac})$ from returning to production. The findings show lands leaving the CRP will be distributed according to land quality and productivity. Conservation benefits are likely to undergo substantial losses unless significant budget increases are provided. One consequence of changing land use may be more CRP in buffer strips, field borders, and grassed waterways rather than whole field enrollments. Higher payments are likely to be required to enroll or maintain whole fields.

Tilman, David, Hill, Jason, and Lehman, Clarence, 2006, Carbon-negative biofuels from low-input high-diversity grassland biomass: Science, v. 314, p. 1598-1600.

Authors conclude biofuels derived from low-input highdiversity mixture of native grassland perennials can furnish more useable energy, greater reductions in greenhouse gases, and less pollution from agrichemicals than can production of energy from corn ethanol or soybean biodiesel. High diversity grasslands provided 238 percent higher energy yields than monocultures after 10 years. Currently, biofuel production competes for fertile land needed for production of food and increases pollution due to greater dependence on chemical inputs to maintain productivity. Doubling of global demand for food and energy is projected in next 50 years and growing use of food crops for energy have elevated concerns about biodiversity loss as remaining natural lands are converted to these uses. Authors believe low input highly diverse grasslands to meet energy needs can be produced on abandoned agricultural lands and suggest with proper management these grasslands can produce a sustainable product, renew fertility of the soil and provide wildlife and cleaner water.

Usgaard, R.E., Naugle, D.E., and Osborn, R.G., 1997, Effects of wind turbines on nesting raptors at Buffalo Ridge in southwestern Minnesota: Proceedings of the South Dakota Academy of Science, v. 76, p. 113-117.

Authors report raptors (chiefly red-tailed hawk [Buteo jamaicensis], northern harrier [Circus cyaneus], and kestrel [Falco sparverius]) were absent from $32 \mathrm{~km}^{2}\left(12.5 \mathrm{mi}^{2}\right)$ wind plant facility despite presence of potentially suitable forested and riparian woodland nesting habitat. Although no direct mortality due to windmills was recorded, wind turbines may be indirectly affecting local populations of raptors by decreasing availability of nesting sites. Authors suggest key habitats believed important to raptors should be excluded from development of windfarms until more information is available.

Venuto, B.C., and Daniel, J.A., 2010, Biomass feedstock harvest from Conservation Reserve Program land in northwestern Oklahoma: Crop Science, v. 50, p. 737-743.

Six CRP grasslands were harvested for three consecutive years to determine biomass production in northwestern Oklahoma and describe effects on plant growth, and soil characteristics. CRP fields were planted to old-world bluestem (Bothriochloa spp.) monocultures and native mixed species comprised of big bluestem (Andropogon gerardii), Indiangrass (Sorghastrum nutans), silver bluestem (B. laguroides), sideoats grama (Bouteloua curtipendula), little bluestem (Schizachyrium scoparium), and sand lovegrass (Eragrostis trichodes).

Authors conclude, at least in the short-term, old world bluestem monocultures are a more productive source of biomass feedstock than are CRP fields planted to a mix of native species. Old world bluestem productivity declined more quickly over time than did productivity of native grass CRP fields. This implies greater long-term productivity for native species. Authors conclude an annual set-aside approach were implemented to extend overall productivity harvest yields would increase but total biomass available annually within the region would decrease. The consequence of this incorporation of rotations would require a greater amount of land to support a biomass processing facility. For a bioenergy industries to be viable from these CRP grasslands the authors conclude harvest strategies (resting/rotation) and nutrient replacement would be required to sustain productivity. There was no change in species composition or soil characteristics as a consequence of harvesting. 


\section{Economics}

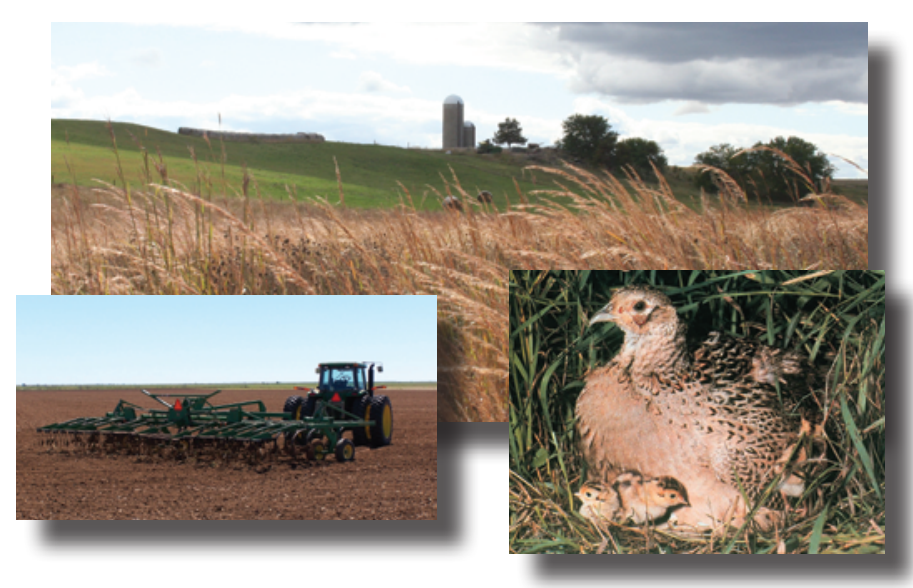

Adam, B.D., Hong, S.J., and Dicks, M.R., 2004, Effects of the Conservation Reserve Program on elevator merchandising margins in Oklahoma: Journal of Agricultural and Applied Economics, v. 36, no. 1, p. 83-96.

As a consequence of the CRP taking land out of production for 10 or more years, grain supplies available to elevators are reduced. Study results suggest the CRP has had negative effects on local elevator merchandising margins and profits but elevators adjusted to changes within one year. Authors conclude the program has had only minor national and regional economic impacts but reduced economic activities stemming from the CRP may be as high as 20 percent locally. Grain elevators have faced several sources of economic strain that include CRP, ARP set asides, modification in production due to technological changes, and competitive pressures associated with storage and merchandising capabilities. Effect of CRP on elevator economic stability varies but has been significantly reducing margins an average of 16 percent in 1989 in Oklahoma. Elevators were able to make economic or physical adjustments to CRP related declines in production in a relatively short period of time. However, these adjustments (for example, mothballing or sale of physical assets) may be costly to reverse if local productivity increases. These economic impacts should be considered as new agricultural policies are formulated. Authors recommend that agricultural policies be scrutinized carefully to adjust for local impacts on agribusiness because local negative effects can be substantial. Future research is recommended that addresses relationships between changes in land use, increasing size of farms, and losses in market share of local and regional agribusiness.

Bangsund, D.A., Leistritz, F.L., and Hodur, N.M., 2002, Rural economic effects of the Conservation Reserve Program in North Dakota: Fargo, N.D., Department of Agribusiness and Applied Economics, Agricultural Experiment Station, North Dakota State University, Agribusiness and Applied Economics Report No 497, 105 p.
While long-term crop retirement programs generally produce, in varying degrees, negative effects on those businesses and sectors providing agricultural inputs, those same programs generate positive economic effects in other areas of the economy. The CRP has greatly enhanced wildlife habitat in the northern Great Plains. Increased wildlife habitat has directly led to substantial increases in upland bird, waterfowl, and big game populations. Enhanced wildlife populations have in turn led to increases in wildlife-based recreation, primarily hunting, and to a lesser extent, wildlife viewing.

Few studies have attempted to include recreational revenues in the economic assessment of the CRP. Although this study examined gains and losses in rural economic activity due to the CRP, the analysis should be viewed cautiously, as assessing the program's net economic effects remains sensitive to several key factors and a number of assumptions were incorporated due to a lack of data. In addition, the analysis was based on a single point in time, and the results may not accurately predict future economic effects of the program. The future ability of rural areas to offset CRP-based agricultural losses with wildlife-related recreational expenditures will largely be dependent upon pheasant and waterfowl hunting. Pheasant and waterfowl hunting accounted for over 80 percent of all CRP-based hunting expenditures, and current data indicates even major increases in deer hunting expenditures will likely only offset small reductions compared to ring-necked pheasant and waterfowl hunting expenditures. Consequently, not all areas of North Dakota will be able to equally offset agricultural losses with recreational revenues. Future wildlife population levels, policies, and hunting trends, which affect pheasant and waterfowl hunting, will have the greatest effect on the level of recreational revenues captured in rural areas.

Collectively, resident hunter expenditures were a substantially higher source of new wealth than nonresident hunters. However, both resident and nonresident hunter expenditures are important sources of recreational revenues in most areas of the state. The future ability of rural areas to offset CRPbased agricultural losses will be dependent upon expenditures from both resident and nonresident hunters and factors, which substantially affect either group, will have implications on the amount of recreational spending captured in those rural economies. The degree to which CRP-based hunting revenues in rural areas are offsetting agricultural losses varied throughout the state. In several cases, hunting expenditures offset a substantial portion of the agricultural losses, while in other areas, the net economic loss from the program remains high. The net economic effects of the program in the western and central areas of the state were most favorable, since those areas had the highest levels of CRP-based hunting expenditures and relatively lower amounts of lost agricultural revenues. However, the net effect of recreational and agricultural revenues in eastern areas of the state was not nearly as favorable. Those areas captured little additional hunting-related expenditures from the program and had relatively high levels of lost agricultural revenues. In North Dakota, the net economic effect of losses in agricultural revenues and gains in hunting-based recreational 
revenues indicated the CRP is not the economic burden several in areas of the state previous research has suggested.

Cahill, K.N., Kucharik, C.J., and Foley, J.A., 2009, Prairie restoration and carbon sequestration- difficulties quantifying $\mathrm{C}$ sources and sinks using a biometric approach: Ecological Applications, v. 19, n. 8, p. 2185-2201.

Two southwest Wisconsin CRP fields and adjacent croplands were evaluated for $\mathrm{C}$ cycling and ecosystem characteristics. Greenhouse gas emissions have been targeted by the Kyoto Protocol yet no standardized or widely adopted methodology for quantifying $\mathrm{C}$ credits exist. Grasslands cover 20 percent of the earth's terrestrial surface and store 10-30 percent of its soil $\mathrm{C}$ stocks yet they do not receive the attention that forests do in the context of global change.

Study site entailed a CRP field previously in maize and enrolled into the program in 1987. Three treatments were evaluated: a warm season grass planting $\left(\mathrm{C}_{4}\right)$, a cool season grass planting $\left(\mathrm{C}_{3}\right)$, and a disk planted unfertilized continuous no-till rotation of crops (maize and soybeans). The most abundant grass in the $\mathrm{C}_{4}$ treatment was switchgrass (Panicum virgatum) and in the $\mathrm{C}_{3}$ treatment smooth brome (Bromus inermis). Both treatments had patches of non-seeded species in them and some seeded species failed to establish.

Total soil respiration was highest in the $\mathrm{C}_{3}$ treatment and not significantly different between the $\mathrm{C}_{4}$ and cropland treatment. Annual soil $\mathrm{C}$ flux was significantly higher than the $\mathrm{C}_{4}$ and cropland treatment. Forty of 45 estimates showed the $\mathrm{C}_{3}$ treatment to be a net annual source of $\mathrm{C}$ and fifteen out of 45 estimates showed the $\mathrm{C}_{4}$ treatment to be a $\mathrm{C}$ sink. Cropland treatment was estimated to be a $\mathrm{C}$ source. Both grassland treatments had significantly higher soil $\mathrm{C}$ in the top $5 \mathrm{~cm}$ of soil than the crop treatment.

Net ecosystem productivity estimates varied widely in magnitude and by methodology. Authors caution when using only one estimate for annual net primary production, belowground net primary production (ANPP, BNPP) or microbial respiration as the results may misrepresent the certainty assigned to the result. Authors also caution that great abundance of forbs planted in the CRP treatments may not be representative of a typical CRP planting. Forbs are important components of a diverse planting for wildlife habitat but involve a tradeoff by reducing $\mathrm{C}$ sequestration.

De La Torre Ugarte, D., and Helwinckel, C., 2006, Analysis of the economic impacts on the agricultural sector of the elimination of the Conservation Reserve Program: Knoxville, Tenn, Agricultural Policy Analysis Center, University of Tennessee, $18 \mathrm{p}$.

The CRP was not designed to be a supply management program but it clearly has an impact on supply and crop prices. As of 2006, the 34.7 million acre program has reduced planted and harvested acres of most farm programs. Changes in CRP enrollment will have impacts on markets should the program lose legislative or budgetary support. The Agricultural Policy Analysis Center estimates 37 percent of today's CRP acres will return to crop production as contracts expire by 2015 if legislation for budget priorities eliminates the CRP. It is estimated 71 percent of expiring acres ( 9 million acres) will be used to grow corn, soybeans, and wheat. Added acres devoted to these crops will reduce prices received by farmers to lower than USDA projected baseline prices resulting in an estimated $\$ 6.6$ billion loss in net market returns if CRP acres are returned to crop production. Increased plantings and lower prices will have a positive effect on export volume with corn exports estimated to increase by 183 million bushels, 7.7 percent above the USDA baseline projection. APEC estimates federal payments (direct payments, loan deficiency payments, etc.) for eight major program crops will rise nearly 34 percent ( $\$ 3.8$ billion) over USDA estimates. It is estimated from 20072015 the net effect of eliminating the CRP program would result in an additional cost to the government of $\$ 32.6$ billion.

Economic Research Service. 2004. Conservation Reserve Program: Economic and Social Impacts on Rural Counties. ERS Report to Congress. U.S. Department of Agriculture, Economic Research Service, Washington D.C. 143 p.

This report provides an evaluation of CRP on economic and social impacts on rural counties. Report concludes that high enrollment of CRP was associated with some loss of jobs in rural counties between 1986-1992 but the negative effect did not persist through the 1990s. Regional impacts of the CRP vary widely with both economic winners and losers. Economic effects were found to vary over time, geography, and economic trends affecting rural economies. No statistical significant evidence was found that high levels of CRP participation affected local government services or tax burdens. Proportion of whole-farm enrollees, relative to partial-farm enrollees did not have strong impacts on employment or provision of local government services. Rural counties with modest populations (small towns serving as local agricultural centers) were likely to lose jobs when 20 percent or more of the area's cropland was enrolled in CRP but job growth rebounded as time passed. More densely populated rural counties with diverse, local economies were rarely affected by CRP enrollment in either the short or long term. Counties with low population density (without small towns) were unaffected by level of CRP enrollment. Authors conclude that release of CRP back to production could have a small positive effect on national output but incomes of medium-income households (those receiving most of CRP payments) could decline.

Authors report because of the stable source of income provided by the program the CRP helped many financially vulnerable farm operators stay within their communities rather than leave in search of employment elsewhere. In addition, improvements in wildlife populations and provision of cleaner more scenically appealing environment, CRP may have made some rural communities more attractive places to live. 
CRP enrollment tends to be greatest in rural, agricultural areas with a long history of population decline. Post population trends were largely unaffected by high levels of CRP enrollment. Relative to consequences of technological advances, market trends and other federal policies, CRP effects on beginning farmer trends is minor. No statistically significant evidence was found that CRP participation encourage absentee ownership of farmland. While a full measure of the economic benefits associated with improved environmental quality and resultant recreation stemming from CRP is unavailable, conservative estimates are recreational activities exceed $\$ 700$ million/year.

Feather, P., Hellerstein, D., and Hansen, L., 1999, Economic valuation of environmental benefits and the targeting of conservation programs - the case of the CRP: Washington, D.C., USDA Economic Research Service, Agricultural Economic Report No. 778, 56 p.

Report documents how nonmarket valuation can be used in targeting CRP by examining environmental targeting to specific environmental benefits and recreational opportunities created by conservation programs. Ecosystem health and many recreation activities have substantial social and economic worth but typically have no explicitly identified price or market value. Report discusses development, application and alternatives in use of the EBI devised to score land parcels to determine potential environmental and economic benefits of individual contracts. Specifically discussed in this analysis are alternative applications to address greater attention to freshwater-based recreation, wildlife viewing, and ring-necked pheasant (Phasianus colchicus) hunting. Noteworthy findings include conclusion switching CRP targeting from soil erodibility to the EBI doubles benefits to freshwater-based recreation and wildlife viewing; CRP wildlife recreation benefits are significantly larger than fresh-water based recreation benefits. Natural resources near populated areas are likely to generate larger recreation use benefits simply because they are more easily accessible. Authors conclude valuation based targeting of CRP is feasible and may improve performance of the program, especially if public preferences are known and explicit.

Feng, H., Kling, C.L., Kurkalova, L.A., Secchi, S., and Gassman, P.W., 2005, The Conservation Reserve Program in the presence of a working land alternative- Implications for environmental quality, program participation, and income transfer: American Journal Agricultural Economics, v. 87 , no. 5 , p. $1231-1238$.

The United States has invested large amounts of money in agricultural conservation programs over the past century with the largest and most ambitious program being the CRP. Although the CRP has evolved to target an array of environmental issues the program operates strictly through land retirement. One issue that has not received much attention in evaluation is consequences of working land programs (for example, Environmental Quality Incentives Program, Conservation Security Program) that compete for the same parcels of land. As the 2007 Farm Bill approaches it will be important to understand the potential complementarities and conflicts between these types of programs (that is retirement vs. working land programs).

Increasingly farmers are faced with decisions to retire a piece of land, cultivate it with conservation practices, or not to participate in either type of program. This paper provides analysis and estimates of how these programs might affect the CRP in terms of land enrolled, income transfers to farmers, and the extent of environmental improvement as measured by $\mathrm{C}$ sequestration, reduction in soil erosion, and reduction of $\mathrm{N}$ runoff. Authors conclude compared to where land retirement is the only option the economic and environmental results of land retirement programs are very different when working land programs are available. The same unit payments for land retirement in presence of subsidies for conservation tillage will enroll only about 50 percent of acreage that can be enrolled in absence of working land programs.

Authors conclude working land and retirement program are mutually exclusive since a single piece of land can be enrolled in only one of these two options. Therefore, these types of programs compete and landowner decisions can have significant consequences for performance of each program. The authors point out one type of program is not superior to the other but the impact of one program on another is critical for conservation policy. Assessments of conservation program performance without taking these interactions into account could produce inaccurate performance and potential outcomes. Authors believe (based on simulation analysis) the presence of a working land program for conservation tillage would result in significantly lower signups for the land retirement program at a given rental rate. The presence of both a large working land and land retirement programs can result in more environmental benefits and income transfers than possible with only a land retirement program.

Fleming, R.A., 2004, An econometric analysis of the environmental benefits provided by the Conservation Reserve Program: Journal of Agricultural and Applied Economics, v. 36 , no. 2, p. 399-413.

Author investigates extent of crop acreage enrollment in the CRP and effects on environmental conditions. A spatial econometric model is used to assess if CRP enrollments are greater in counties with poorer environmental quality. Findings are in 7 of 10 regions evaluated, CRP enrollment is higher in counties with an environmental concern and the CRP is targeting environmental concerns that will lead to future improvement in environmental quality.

Author concludes in counties with higher productivity, thus higher economic returns from crop production, the CRP rental rate is not high enough to encourage operators to enroll in the program. Program expenditures have been 
highest in counties with poorer environmental quality suggesting enhancement of environmental quality as a result of the CRP. Even though CRP expenditures at the regional level may not indicate major environmental benefits extending from the program this does not mean there have not been beneficial micro or local impacts. Author concludes CRP has and will continue to benefit environmental conditions across the lower 48 states justifying expenditures and supporting continuation of agricultural conservation programs. Expansion of studies to document benefits to wildlife, soil quality/erosion, and water quality are suggested to document and assess the economic and social value of the CRP.

Gascoigne, W.R., Hoag, D., Koontz, L., Tangen, B.A., Shaffer, T.L., and Gleason, R.A., 2011, Valuing ecosystem and economic services across land-use scenarios in the Prairie Pothole Region of the Dakotas, USA, v.70, p.1715-1725

Authors quantify ecosystem services across three land uses (native prairie, CRP/WRP, and cropland) in the PPR of North and South Dakota by modeling four future land-use predictions and subsequent changes in ecosystem service values. Hypothetical land-use changes dubbed "aggressive conservation," "CRP mitigation," "market forces," and "extensive conversion" were evaluated for ecosystem and economic service tradeoff analysis. Some of the scenarios were purposefully designed to extend programs past their current contract periods to more fully capture the dynamics of the ecological impacts (that is $\mathrm{C}$ sequestration).

Aggressive conservation forecasts the effects of a 50 percent increase in CRP/WRP lands at the expense of cropland while preserving native prairie. CRP mitigation estimates the effects of mitigating conversion of native prairie to cropland by enrolling additional lands into CRP/WRP. Market forces estimate environmental and economic consequences of losing native prairie to cropland while maintaining CRP/WRP lands at current levels. Extensive conversion estimates effects of losing native prairie acreage compounded with a 25 percent reduction in CRP/WRP acreage.

Aggressive conservation would lead to gains in the PPR of $\$ 69$ million annually and $\$ 1$ billion over the twenty years and would substantially increase both soil and vegetation organic $\mathrm{C}$ and duck fledglings while reducing soil loss by 80 million Mg. CRP mitigation would sustain an estimated loss of nearly $\$ 200$ million annually or $\$ 2.5$ billion over twenty years. Authors indicate that CRP/WRP lands cannot entirely mitigate the loss of native prairie. The market-forces scenario estimated net annual losses valued at over \$281 million. Additional income from increased cropping could not offset decreases in $\mathrm{C}$ stocks. In the final scenario, extensive conversion showed enormous losses in C, soil and waterfowl tantamount to over \$271 million annually and \$4 billion over the twenty-year policy period.
Hansen, L., Feather, P., and Shank, D., 1999, Valuation of agriculture's multi-site environmental impacts-An application to pheasant hunting: Agricultural \& Resource Economics Review, v. 28, no. 2, p. 199-207.

Authors report ring necked pheasant (Phasianus colchicus) hunting benefits of the CRP were approximately $\$ 80$ million in 1991 in states where the program appears most critical to the provision of pheasant habitat. Using a multi-site demand model, national survey on recreation, and environmental data process through GIS environmental benefits of CRP acreage can be compared across locations permitting change in policies affecting design and operation of the program. Total consumer surplus associated with pheasant hunting was estimated at $\$ 184$ million/yr. Of this amount, $\$ 80$ million was attributed to environmental benefits brought by the CRP. Redistribution of CRP acreage to address other environmental priorities could reduce pheasant hunting benefits but economic losses would be more than offset by benefits brought by nonconsumptive wildlife recreation and water-based recreation.

Hodur, N.M., Leistritz, F.L., and Bangsund, D.A., 2002, Local socioeconomic impacts of the Conservation Reserve Program: Fargo, N. Dak., Department of Agribusiness and Applied Economics, Agribusiness and Applied Economics Report No. 476-S, 58 p.

Findings document a number of apparent benefits in Northern Great Plains of the CRP. Enhanced habitat for wildlife has contributed to growth in populations of upland game birds, growth in numbers of resident and non-resident hunters, and increase in recreation-related expenditures in rural areas. The program has helped stabilize revenue of participating landowners during a period when the region's farmers and landowners experienced adverse weather and poor market conditions. Program is very popular with ND landowners with continued participation expected to remain high. Some survey respondents, upon which report is based, attribute rural depopulation and general decline in farm and rural economy to CRP. However, most respondents indicated CRP did not affect transfer of property either to next generation or unrelated buyers. Other benefits attributed to the program include decreased soil erosion, improved water quality, and reduction in flooding. See Leistritz, Hodur, and Bangsund (2002) for an abbreviated presentation of study findings.

Hoppe, R.A., and Banker. D.E., 2006, Structure and finances of U.S. Farms - 2005 family farm report: Washington D.C., U.S. Department of Agriculture, Economic Research Service, Economic Information Bulletin, no. 12, 42 p.

In 2003, 98 percent of American farms were family owned and organized as proprietorships, partnerships, or family corporations. Very large family farms and non-family farms account only for a small percentage of all farms but 
account for a growing share of farm sales. Small family farms represent most farms in the country but produce only a modest share of farm output. Median income for farm households is 10 percent higher than median for all U.S. households with small farm households receiving a substantial portion of income from non-farm sources. Small family farms account for 91 percent of U.S. farms holding about 71 percent of farm assets including 70 percent of farmland. Consequently, these farms and operators potentially have a large role in the effectiveness of natural resource and environmental policy. Small farms account for about 82 percent of the land enrolled in the CRP and WRP.

Production has shifted largely to large and very large family and non-family farms since the 1980 s ( 9 percent of farms in 2003) and such farms now account for 73 percent of production. This trend is likely to continue due to growing share of operators 65 years old and older and negative operating profit margin of small farms. Medium sales and large sales farms received about 75 percent of commodity related governmental payments. Retirement, residential and low-sales small farms received 64 percent of conservation (CRP, WRP) payments in 2003.

Ibendahl, G., 2004, Risk-adjusted comparison of Conservation Reserve Program payments versus production payments for a corn-soybean farmer: Journal of Agricultural and Applied Economics, v. 36, no. 2, p. 425-434.

Author reports on simulation-model output to compare farming income to payments under CRP program. The study was conducted based on data from three farms in Kentucky. The report concludes that CRP payment provides a competitive return relative to active farming, especially in areas with poor productivity of soil. Author believes the CRP should be considered by many farmers as a management and economic option especially on those farms with variable soils and less productive lands.

Isik, M., and Yang, W., 2004, An analysis of the effects of uncertainty and irreversibility on farmer participation in the Conservation Reserve Program: Journal of Agricultural and Resource Economics, v. 29, no. 2, p. 242-259.

Authors examine determinants of farmer participation in the CRP. Option values play a significant role in farmer decisions to retire land having implications for the design and implementation of conservation programs by improving design and cost-effectiveness. With CRP participation, farmers face a decision between uncertain farm income due to fluctuating crop prices and yield, and uncertain payments from one signup period to another. A decision-making model based on data from 100 Illinois counties was developed analyzing land benefits, land characteristics, and owner attributes.

Study results indicate uncertainty and irreversibility of the CRP impact farmer decisions to participate in the program.
The bid cap has a positive impact on CRP participation, as do increases in production costs and decreases in crop revenues. Lands with higher EBI indices have higher probability of participation. Counties with higher proportions of cropland suitable for production tend to have lower enrollment rates in the program. Older farmers tend to participate more in the CRP than do younger farmers.

Success of land-retirement programs depends on appropriate design of rental payment, EBI instruments, and effective targeting of environmentally sensitive cropland. The program design should consider effects of costs to participants and uncertainty about outcomes. In environmentally sensitive regions, additional financial incentives would help increase participation in conservation programs.

Johnson, R.L., McKean, J.R., Sandretto, C.L., 1992, Increased recreational hunting can offset negative economic impacts of the Conservation Reserve Program: Washington, D.C., U.S. Department of Agriculture, Economic Research Service Technical Bulletin TB92-4, $23 \mathrm{p}$.

An input-out analysis using National Survey of Fishing and Hunting data completed for northeastern Colorado estimates negative economic effects of the CRP and an increase in small-game and migratory-bird hunting needed to offset it. Offsetting CRP-related employment loss would require recreation hunting to rise by 1.8 times, but offsetting the loss in sales would require an increase of 2.5. The negative impact and required offsetting rise in recreational hunting increases sharply if farmers who place land in CRP leave the region.

Keith, K.W, 2005, Perspectives of the National Grain and Feed Association, in Allen, A.W., and Vandever, M.W., eds., The Conservation Reserve Program-Planting for the future-Proceedings of a National Conference, Fort Collins, Colo., June 6-9, 2004: U.S. Geological Survey, Biological Resources Discipline, Scientific Investigations Report 2005-5145, p. 38-45.

Perspectives of the National Grain and Feed Association (NGFA) on the future of the CRP and suggested refinements of the program are provided. Recommendations the NGFA would like to see adopted include exclusion of whole-farm enrollment in CRP and reconsideration of the 25 percent cropland cap because of a dependence on inaccurate data and a tendency for CRP enrollment to become concentrated in specific geographic regions. Also recommended is a reduction in the overall enrollment cap for the CRP, as NGFA sees an increase in demand for more acres in production to address growing demands for production. NGFA believes there should be a greater focus on CRP addressing soil and water quality issues and would like to see some CRP lands put back into production prior to the large expiration of existing CRP contracts in 2007 and 2008. Overall, NGCA believes there are other opportunities to address conservation without idling land. Excerpts 
from several letters from grain-related industries from the Great Plains are presented that describe severe detrimental impacts of the CRP on local businesses.

Losey, J.E., and Vaughan, M., 2006, The economic value of ecological services provided by insects: Bioscience, v. 56, no. 4 , p. 311-323.

Authors estimate ecological services (dung burial, pest control, pollination, and nutrition for wildlife) provided by insects in the United States to be at least $\$ 57$ billion. Economic estimates for each service are: dung burial $\$ 0.38$ billion, pollination $\$ 3.07$ billion, pest control $\$ 4.49$ billion, and wildlife-related recreation $\$ 49.96$ billion. These are believed to be conservative estimates of the ecological values furnished by insects within the United States. Other environmental services provided by insects include suppression of weeds and other exotic herbivorous species, facilitation of dead plant and animal decomposition, and improvement of soil condition. The value of any of these services could add billions of dollars to these estimates.

The predominant benefit of insects is concentrating and moving nutrients through the food web. Economic and ecological benefits of dung beetles (primarily Scarabaeida) are discussed with benefits including improvement in soil, volatilization of $\mathrm{N}$, diminished fouling of forage, and control of livestock parasites and pests. Pollination is the most widely known benefit of insects, with 15 to 30 percent of diet within the United States directly or indirectly dependent upon pollination by insects. Available information suggests control of insect pests costs the U.S. economy billions of dollars each year. This is only a fraction of the economic impact if beneficial insects did not keep most pests below economically damaging levels. U.S. citizens spend over $\$ 60$ billion a year on hunting, fishing, and observing wildlife. Insects are a critical food source for much of this wildlife.

The authors conclude that an annual investment of tens of billions of dollars could be economically justified to maintain ecological services provided by insects. There has been a steady decline in beneficial insects associated with diminishing biodiversity accompanied by severe declines in the quality of environments heavily impacted by human activities. Authors recommend a diversity of plant species in restoration or conservation projects to support viable and diverse populations of insects. Authors recommend USDA conservation programs pay specific attention to insects and the roles they carry out in ecosystem functioning. Insects and their needs should be considered in land-management decisions. A diverse community of forbs should be included with any restoration projects.

Lynch, L., and Brown, C., 2000, Landowner decision making about riparian buffers: Journal of Agricultural and Applied Economics, v. 32, no. 3, p. 585-596.
Understanding farmer decision making in regards to property and conservation practices is crucial to effective conservation programs. Determination of conditions that influence farmer decisions when most benefits accrue to society (for example, establishment of riparian buffers) and not directly to the landowner is important in setting program incentives and policies. Authors conclude non-agricultural opportunity costs affect farmer decisions. If environmentally sensitive, but high-value, land is desired for enrollment additional incentives will be required. Upfront costs for adoption of conservation practices were important determinants in land owner decisions. Farmers were more sensitive to the cost-share rates to establish conservation practices than they were to relative incentive rates. Authors conclude increasing cost-share rates may be more effective in increasing enrollment in specific conservation practices than are increasing rental rates and upfront signing bonuses. Increasing cost-share rates may encourage more participation than does an increase in annual rental payments. Land values, rental rates, and crop prices affect farmer decisions about participation. In areas with high land values or low rental rates, additional incentives such as higher annual rates or signing bonuses may be needed to achieve enrollment goals.

Mortensen, T.L., Leistritz, F.L., Leitch, J.A., Coon, R.C., and Ekstrom, B.L., 1990, Socioeconomic impact of the Conservation Reserve Program in North Dakota: Society and Natural Resources, v. 3, p. 53-61.

Economic impacts of the CRP are estimated for North Dakota. Net reductions in production expenditures and household income totaled \$55 million of which about 62 percent occurred in the retail sector of the economy. The total impact of the program affected about 0.5 percent of the state's baseline economic activity. Local areas with high concentrations of CRP and businesses dependent on farm inputs may be affected the most. The most significantly impacted region had a 0.91 percent reduction in economic activity due to CRP. Positive economic impacts also were documented. Longer-term beneficial aspects could result from achievement of CRP conservation objectives. (See Bangsund and others, 2002, and Leistritz and others, 2002, for more recent analysis of economic effects of CRP on North Dakota economies.)

Parrish, D.R, 2005, The Conservation Reserve ProgramThrough the Farm Bureau Window-An outline, in Allen, A.W. and Vandever, M.W., eds., The Conservation Reserve Program - Planting for the future-Proceedings of a National Conference, Fort Collins, Colo., June 6-9, 2004: Reston, Va., U.S. Geological Survey, Biological Resources Discipline, Scientific Investigations Report 2005-5145, p. 37.

Perspectives of the Farm Bureau related to the CRP are presented. Support is described as being generally broad 
because the program provides stable source of income, opportunities to improve soil, air, water, and wildlife resources, but at times some view the program as a direct competitor for limited farmland and a threat to the economic stability of agricultural areas. Farm Bureau supports limiting CRP enrollment to 25 percent of cropland acres, maintaining base history, reevaluation of rental rates, control of noxious weeds on CRP acres, control of fire hazards, and leasing CRP for recreation but opposes emergency use of CRP acres and practices that jeopardize drainage or flood control. Farm Bureau would like to see a more landscape level approach to conservation policies as well as more integrated approach between various USDA conservation programs.

Pimentel, D., Acquay, H., Biltonen, M., Rice, P., Silva, M., Nelson, J., Lipner, V., Giordano, S., Horowitz, A., and D'Amore, M., 1992, Environmental and economic costs of pesticide use: Bioscience, v. 42, no. 10, p. 750-760.

Approximately 600 different types of pesticides are used annually in the U.S. Roughly 160 million ha/yr (greater than 395 million ac/yr) receive a heavy pesticide application, averaging $3 \mathrm{~kg} / \mathrm{ha}(2.7 \mathrm{lb} / \mathrm{ac})$. Without pesticides, pests would account for 10 percent of crop loss with specific crop losses ranging from 0 to nearly 100 percent. Despite widespread use of pesticides, insects, plant pathogens, and weeds destroy 37 percent of all potential food and fiber crops. Tenfold increase in insecticide use from 1945 to 1989 but total crop losses from insect damage have nearly doubled from 7 to 13 percent. Rise in insect damage is, in part, due to changes in agricultural practices. Natural predators play a major role in keeping populations of many insect pests under control. Pesticides directed toward pest species adversely affect these beneficial species disrupting natural biological control. Fungicides can contribute to pest outbreaks when they reduce fungal pathogens naturally parasitic on many insects. An estimated $\$ 520$ million/yr can be attribute to costs of additional pesticide applications and increased crop losses following destruction of natural enemies by pesticides applied to crops.

The three most common pesticides found in groundwater are aldicarb, and herbicides alachlor, and atrazine. Estimates are that nearly one-half of groundwater and well water in the United States has potential to be contaminated. Adding monitoring and cleaning costs the total cost of pesticide polluted groundwater is approximately $\$ 1.8$ billion/yr. High pesticide concentrations in water directly kill fish. Low-level doses kill susceptible fry and essential foods of fish are eliminated. Pesticides washed into aquatic systems by runoff and soil erosion cause few if any widespread pesticide poisoning dramatic enough to be observed. Therefore most poisonings go unrecognized and unreported yet have significant ecological impacts. A low estimate of annual losses is $\$ 24$ billion/yr. The actual cost is probably several times this amount.
Roberts, R.S., 1987, Rural population loss and cropland change in the Southern Plains-Implications for cropland retirement policy: Professional Geographer, v. 39, no. 3, p. 275-287.

A major obstacle constraining adoption and implementation of cropland retirement programs has been fear that such programs will threaten viability of rural communities. Author concludes short-term cropland idling under post-1960 pricesupport programs appears to furnish a greater threat to rural communities than do long-term cropland-retirement programs. Despite their intuitive appeal, cropland retirement programs have never been popular among farmers and have met stiff political opposition from regional and local rural interests. The combination of farm financial stress and continuing population loss from farming regions will continue to provide a basis for political contention. Author cites studies that determined the Soil Bank (1956-1972) did not increase downward trend in rural population losses and that the financial cushion furnished by the program actually allowed many farm families to remain farming or transition into off-farm jobs as a major source of income.

Based on an analysis of data from 1930 to 1970 , the author concludes that a small long-term negative impact on rural populations in the Southern Plains can be attributed to cropland retirement but massive structural shifts in the agricultural community have had a much greater effect on rural population change. There may be economic stress placed on individual farms, or farm supply and service businesses in rural areas, as a result of cropland retirement, but there is little evidence the changes have long-term effects on total rural and service center populations. The author further concludes, there is no major direct threat to rural population or retail change from change in cropland area.

Soutiere, E.C., 1984, Farm wildlife production-What does it cost?, in Transactions of North American Wildlife and Natural Resources Conference, 49, Boston, Mass., March 23-28, 1984, Proceedings: Washington, D.C., Wildlife Management Institute, p. 159-163.

Issues that negatively influence farmers' willingness to produce wildlife: harassment and problems associated with increased hunting pressure and demand, increased crop damage, and loss of income from diverted lands. Economic effects of delayed haying include lower tonnage as well as lower digestibility and protein content. Dairy cows fed late-cut hay will require 1.5-2 times more grain supplement containing an additional 5 percent protein.

Can it be expected that farmers will carry the cost of providing wildlife habitat? The answer is reflected in the continued removal of wetlands, idle areas, and fencerows. If the costs of wildlife are compared to the costs of agricultural products (grain, hogs) the costs of production on prime farmland are very high. Raising pen-reared birds is a comparative 
bargain at these prices. Compensation to the farmer for wildlife habitat would probably need to be at least equal to 75-80 percent of the market value of the yield per acre of crop normally produced on set-aside land. To obtain a meaningful increase in wildlife numbers it would probably require at least 5 percent of land area be devoted to wildlife habitat.

Any solution to production long-term of wildlife on farmland must include acceptance of farming practices that produce wildlife as a no-cost byproduct of production. Agencies need to aggressively advocate and demonstrate farming technologies that help both the farmer and wildlife. The best approach for farmland wildlife management is to deal with resources and programs that encourage sound land use for all resources over the long term. Wildlife's only hope on prime farmland is farm practices, programs, and policies that bring reduced costs or added income to the individual farmer.

Sulivan, P., Hellerstein, D., Hansen, L., Johansson, R., Koenig, S., Lubowski, R., McBride, W., McGranahan, D., Roberts, M., Vogel, S., and Bucholtz, S., 2004, The Conservation Reserve Program — Economic implications for rural America: Washington, D.C., U.S. Department of Agriculture, Economic Research Service, Agricultural Economic Report No. 834, 106 p.

The report estimates economic impacts of high levels of enrollment in the CRP in rural counties since the inception of the program. Results indicate no discernible impact by CRP on county population trends. Employment growth was believed to have been temporarily slowed in counties with high CRP enrollment, but negative effects were short lived. High levels of enrollment appear to have affected farm-related businesses over the long run but growth in other nonfarm businesses moderated the negative impact on total employment. If CRP had ended in 2001, study results suggest 51 percent of land in program would have returned to production. Spending on outdoor recreation related to CRP would have decreased by as much as $\$ 300$ million/yr in rural areas. Economic impacts of CRP on employment and income vary widely among regions having similar CRP enrollment due to local economic conditions.

Authors found no statistically significant evidence to support the assumption CRP encourages rural outmigration. Nor did high levels of CRP enrollment affect beginning farmer trends or absentee ownership of farmland. Nationally, it was estimated that economic effects of allowing CRP land to return to production would be very small with both positive and negative effects largely canceling each other out. However, economic effects could be more substantial locally where enrollment is high.

Van Buskirk, J., and Willi, Y., 2004, Enhancement of farmland biodiversity within set-aside land: Conservation Biology, v. 18 , no. 4, p. 987-994.
Although it may seem obvious that withdrawal of farmland from intensive production would provide benefits to wildlife and biodiversity associated with agriculturally dominated landscapes, there remain serious questions about the cost effectiveness and benefits of such programs. Some suggest set-aside programs are inefficient and relatively unsuccessful in providing wildlife habitat. Agroecologists monitoring these programs have reported conflicting results. Because these programs are costly, politicians may be unwilling to continue approving payments in North American and the European Union in absence of clear evidence reporting benefits of these programs. Because general conclusions about the impact of set-aside programs cannot be supported by few isolated monitoring studies the authors of this report completed a literature review of over 500 studies in agricultural landscapes. Of these, 127 reports met criteria of at least two treatments of lands-use types and measures of variation among replicates of at least one plant or animal taxon.

Authors report that meta-analysis indicates numbers of bird species, insects, spiders/harvestmen, and plants were significantly higher on set-aside land than on nearby control areas under conventional agricultural production. Authors believe their analysis unequivocally resolves controversy of biodiversity benefits of set-aside land at least at local level. The simple result of the study is that larger, more permanent units of land enrolled in set-aside have greater benefits than do smaller sites of short duration. Authors identify need for more information on how land in these programs functions in the context of the entire landscape and how species react to these programs.

Van Buskirk, J., and Willi, Y., 2005, Meta-analysis of farmland biodiversity within set-aside land-Reply to Kleijn and Báldi: Conservation Biology, v. 19, no. 3, p. 967-968.

In response to criticism by Kleijn and Báldi (2005) these authors defend their original investigation where they reported positive effects of set-aside land on density and species richness of birds, insects, spiders and plants. The authors state, in response to disparagement from Kleijn and Báldi, that their criticism is based only on their findings in Netherlands and that Kleijn and Báldi must realize variation from individual investigations is to be expected and local results reveal only part of the picture in the larger multi-national (127 studies assessed) evaluation. Van Buskirk and Willi argue that the level of heterogeneity in their study strengthens their results as it illustrates that biodiversity benefits of set-aside programs are quite general and at least a fraction of farmland biodiversity can be restored by temporarily setting aside land from conventional production. They suggest a reasonable initial plan would be to set aside a mosaic of plots, as large as possible, of different ages. This approach would have limited effects in a landscape dominated by traditional agriculture (for example, relatively small fields, production of multiple crops) but would be increasingly appropriate as the landscape became more dominated by modern, chemically-intensive industrialized farming. 
Williams, C.F., and Mjelde, J. W., 1994, Conducting a financial analysis of quail hunting within the Conservation Reserve Program: Wildlife Society Bulletin, v. 22, p. 233-241.

Upsurge in outdoor recreation has strained the public land system. Public hunting lands remain in short supply and growing demand for use. The greatest opportunities to supply quality hunting lie in development of opportunities on private land.

U.S. Department of Agriculture, 1993, Conservation Reserve Program-Cost-effectiveness is uncertain: Washington, D.C., U.S. General Accounting Office, GAO/RCED-93$132,14 \mathrm{p}$.

Precise balance between the costs and environmental benefits of CRP cannot be calculated because dollar value of the environmental benefits cannot be precisely assessed. The USDA has not quantified the effect on the environment of removing enrolled acres from production. USDA will pay more than $\$ 91$ billion to remove 63.5 million acres from production over ten-year life of program. Environmental benefits are perceived to be only temporary. USDA goals of program were to reduce commodity production, support farm income and lastly to provide environmental benefits. As a result of these priorities, land with fewer environmental benefits was initially allowed into the program. Other USDA programs (Conservation Compliance, Agricultural Conservation Program, and Small watershed Program) were identified as covering more acres of cropland, costing less, and providing more long-term environmental benefits. However, these programs are not intended to curb excess production and only indirectly support farm incomes. Advantage of these programs is they do not take land out of production. (Implications to wildlife; less land set aside in permanent cover = probability of lower overall wildlife benefits).

General Accounting Office, 1989, Farm programs-Conservation Reserve Program could be less costly and more effective: Washington, D.C., Committee on Agriculture, Nutrition, and Forestry, U.S. Senate, GAO/RCED-90-13, 79 p.

USDA could improve effectiveness of CRP by targeting cropland eroding at the highest rates where most contributions to surface water and groundwater contamination are greatest. CRP costs will be offset to some extent as farmers enroll acres otherwise used for growing crops covered by price and income support programs. USDA incurred additional cost in tree planting initiative by furnishing greater rental rates in 5 southeastern states. Higher rental rates were paid to all farmers whether or not they planted trees. USDA instructions to county offices allowed CRP rental rates in many areas to exceed local rental rates. Report recommends USDA implement competitive bid system and modify the 25 percent limit on acreage to allow more flexibility in program enrollment.

\section{Grassland Management}

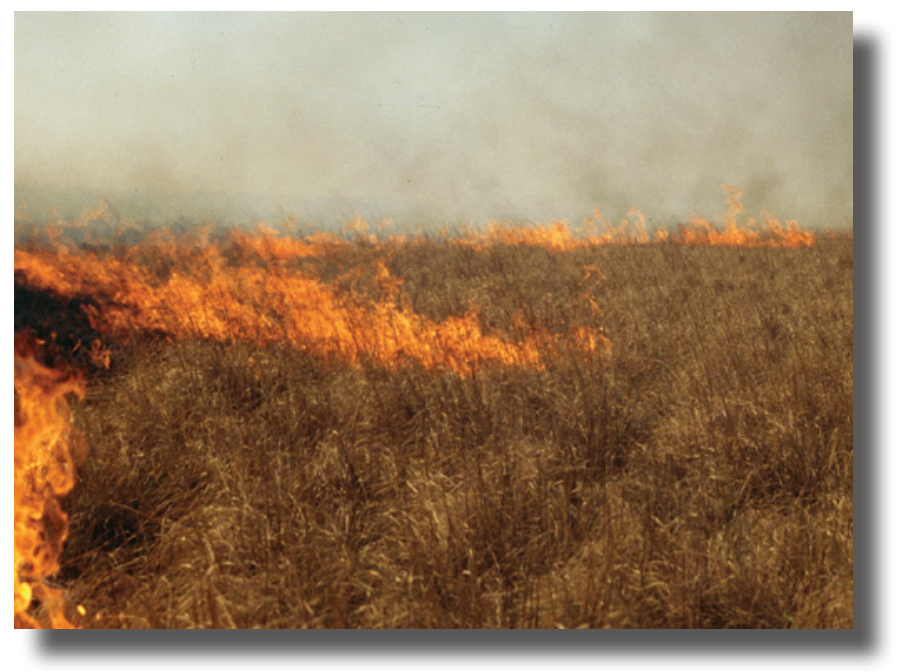

Baer, S.G., Kitchen, D.J., Blair, J.M., and Rice, C.W., 2002, Changes in ecosystem structure and function along a chronosequence of restored grassland: Ecological Applications, v. 12 , no. 6 , p. $1688-1701$.

Evaluation of change in vegetation, roots, and soil characteristics in 12-year-old CRP fields in Nebraska (Gage and Saline counties) planted to native warm season grasses (that is, big bluestem [Andropogon gerardii], little bluestem [Schizachyrium scoparium], sideoats grama [Bouteloua curtipendula], switchgrass [Panicum virgatum], and Indiangrass [Sorghastrum nutans]). The evaluation was completed across CRP fields of varying age ( $0-12 \mathrm{yr})$. Percent cover of grasses and forbs changed across time represented by CRP fields of varying age. Most recently planted fields ( 2 yr) contained legumes in seed mixture; legumes represented less than 1 percent of total plant cover in these grasslands. In fields less than 4 years old, vegetative cover was dominated by early successional annual species and planted grasses contributed less than 10 percent of total plant cover. Although species dominance varied, in fields greater than 6 years old grasses dominated plant cover and forbs were negligible. Root biomass and $\mathrm{C}$ storage in roots increased across time sequence. Total root biomass significantly was higher in grasslands restored for 10-12 years than in 2-year-old restored sites. Carbon storage in roots was greatest in grasslands restored for 10 or more years. Significant changes in soil physical and chemical properties occurred only within $10 \mathrm{~cm}$ (4 in) of surface.

The objective of CRP was not to restore native grasslands and pre-agricultural diversity. Near exclusion of forbs in CRP fields greater than 6 years old points to major difference between native tallgrass prairie and CRP (unmanaged) fields. Fields in this study were ungrazed and infrequently, or never, burned. Authors conclude, however, that revegetation of former croplands with historically dominant native grasses 
facilitates recovery of some key ecosystem properties and processes in trajectory toward reestablishment of native prairie.

Barker, J.R., Baumgarder, G.A., Turner, D.P., and Lee, J.J., 1996, Carbon dynamics of the Conservation and Wetland Reserve Programs: Journal of Soil and Water Conservation, v. 51 , no. 4 , p. $340-346$.

Data from Conservation and Wetland Reserve Programs analyzed to quantify $\mathrm{C}$ dynamics of cropland converted to grassland or forestland. Cropland converted to forestland gained $\mathrm{C}$ at a rate about 7 times greater than cropland converted to grassland. Maintaining existing CRP grassland will provide substantial $\mathrm{C}$ sequestration on a national scale due to large area enrolled in long-term set aside.

Berger, J.J., 1993, Ecological restoration and nonindigenous plant species-A review: Restoration Ecology, v. 1, p. $74-82$.

Merely re-creating the physical form or appearance of an ecosystem without restoring naturally occurring functions does not constitute complete restoration. The key question to ask is not whether one can eradicate an invading species but whether its establishment can be impeded, its growth restricted, and its reproduction restrained, thus keeping it from becoming a worse pest. Ecosystems most susceptible to invasion by nonindigenous plant species are generally those with breaks in the natural plant cover. Typically, mechanical or chemical weed removal or control is required before restoration can begin. An appropriate question is: can restoration prevent reinfestation of the ecosystem by the nonindigenous species? Restoration is not likely to be successful in excluding invading species once propagules of the invader are well dispersed throughout the system. Control rather than exclusion may be the more attainable goal. If restoration is not accompanied by a successful eradication or other on-going management program restored native flora will remain at risk.

Camill, P., McKone, M.J., Sturges, S.T., Severud, W.J., Ellis, E., Limmer, J., Martin, C.B., Navratil, R.T., Purdie, A.J., Sandel, B.S., Talukder, S., and Trout, A., 2004, Community and ecosystem-level changes in a species-rich tallgrass prairie restoration: Ecological Applications, v. 14, no. 6, p. $1680-1694$.

The objective was to examine differences in ecosystem characteristics between restored prairies and restored grasslands on adjacent agricultural fields in southern Minnesota to determine changes in plant community and ecosystem properties. Objectives were to examine how plant groups and ecosystem properties change through time, if ecosystem processes may be plant species dependent, and if ecosystem processes differ from lands in CRP.
Comparisons showed an increase in the proportion of native species after the first growing season. First growingseason restorations were composed mainly of annual and biennial plant species, many of which were non-native. Perennial native composites were common in the second growing season. By the third growing season a significant portion (38-57 percent) of vegetative cover became dominated by native warm-season grasses. Associated with increased cover of warm season grasses was an increase in belowground net primary production, litter mass, and $\mathrm{C}$ mineralization rates. Total soil $\mathrm{C}$ and $\mathrm{N}$ were not significantly different between native prairie and restored grassland on agricultural sites. Authors conclude, with time, vegetative diversity in restored agricultural sites (for example, CRP) can support community and system-level conditions comparable to native prairie.

Campa III, H., and Winterstein, S.R., 1992, Wildlife and vegetative response to diverted agricultural land in Gratiot County, Michigan: East Lansing, Mich., Department of Fisheries and Wildlife, Annual Report, December 1992, $26 \mathrm{p}$.

Several significant differences for vegetation variables (for example, percent canopy cover, height, total canopy, percent grass canopy, percent litter cover) among grasslands were reported, but none were found to be consistently related to field age. Older fields tended to be characterized by a greater percentage cover of grass and litter. Younger fields tended to have greater forb and live canopy cover. Younger fields supported greater avian densities and diversities. Avian productivity, however, was higher in older fields, which may have been result of older fields providing more suitable nesting sites due to greater diversity in vegetation structure.

Collins, S.L., Glenn, S.M., and Gibson, D.J., 1995, Experimental analysis of intermediate disturbance and initial floristic composition-Decoupling cause and effect: Ecology, v. 76 , no. 2, p. $486-492$.

This paper reports results of disturbance from long-term studies in tallgrass prairie (Konza Prairie Kansas). The hypothesis richness will be highest in communities with moderate levels of disturbance and at intermediate time spans following disturbance has been widely accepted. If disturbance occurs frequently, richness is assumed to decrease because species intolerant of disturbance become locally extinct. If disturbances are infrequent, richness decreases because dominant species outcompete weaker competitors. Richness should be greatest at intermediate frequencies of disturbance when conditions favor competitive species and those that tolerate disturbance. A second prediction of the intermediate disturbance hypothesis is that species richness will be highest at intermediate time spans following disturbance because late successional species will competitively displace early successional species lowering richness later in succession. 
Authors report significant decline in species richness with increasing disturbance frequency. Average number of species and number of grass, forb, and annual species were lowest on annually burned sites compared to unburned sites and those burned every 4 years. Species richness reached a maximum at an intermediate time interval since disturbance. A disturbance event can reduce or maintain species richness but does not in itself increase richness; it does, however, create conditions necessary for increased richness. Disturbance regimes are characterized by variation in size, frequency, and intensity of disturbance. Results indicate species richness is consistently lowest on frequently burned sites with lower fire intensity compared to infrequently burned sites where fires are hotter.

Coppedge, B.R., Engle, D.M., Fuhlendorf, S.D., Masters, R.E., and Gregory, M.S., 2001, Landscape cover type and pattern dynamics in fragmented southern Great Plains grasslands, USA: Landscape Ecology, v. 16, p. 677-690.

Cover and land-use change between 1965 and 1995 related to the CRP are discussed for an area of northwestern Oklahoma. The original grassland ecosystem has been fragmented by agricultural land use. Due to exclusion of fire, remnant grasslands have experienced invasion by eastern redcedar (Juniperus virginiana) having further negative consequences for endemic species of wildlife and remaining southern Great Plains grasslands. Even small amounts of encroachment by woody vegetation into remnant grassland can have substantial effects of these species. The authors conclude Oklahoma grasslands, as well as grasslands across the Southern Plains, will continue to lose their value to wildlife unless substantial modifications are made to existing land management policies and practices.

Coppedge, B.R., Fuhlendorf, S.D., Harrell, W.C., and Engle, D.M., 2008, Avian community response to vegetation and structural features in grasslands managed with fire and grazing: Biological Conservation, v. 141, p. 1196-1203.

The study reports management of tallgrass prairie in north central Oklahoma on avian community response. Grasses in the study area is dominated by big bluestem (Andropogon gerardii), little bluestem (Schizachyrium scoparium), Indiangrass (Sorghastrum nutans), and switchgrass (Panicum virgatum). Portions of pasture were burned each year to create a mosaic of grassland patches in varying stages of recovery from disturbance. Results indicate woody edges, ponds, and roads were more negative than positive influences on abundance of several grassland avian species. The study provides evidence of ecological advantages of rotating disturbance patterns in tallgrass prairie via patch-burning. Patch burning affected the avian community by decreasing abundance of the brown-headed cowbird (Molothrus ater), increased overall species richness, enhanced grassland obligate richness, and provided habitat for the Henslows's sparrow (Ammodramus henslowii) a species of management concern.

Fritcher, S.C., Rumble, M.A., and Flake, L.D., 2004, Grassland bird densities in seral stages of mixed grass prairie: Journal of Range Management, v. 57, no. 4, p. 351-357.

Authors believe seral stages of grassland may have effects on declining bird populations in grassland ecosystems, but resource managers lack sufficient information to assess how avian species are affected by changes in grassland composition. Report evaluates bird density, species diversity and species richness in four seral stages of western wheatgrass (Pascopyrum smithii), green needlegrass (Nasella viridula) associations in central South Dakota. Species richness did not differ between seral stages, but diversity was greater in early seral stages of grassland composition. Birds with habitat requirements of tall vegetation and residual cover were more abundant in later seral stages (for example, grasshopper sparrow [Ammodramus savannarum], bobolink [Dolichonyx oryzivorus]). Early seral stages were more beneficial to species needing short grass and sparse vegetative cover (for example, chestnut-collard longspur [Calcarius ornatus], horned lark [Eremophila alpestris]). Authors recommend management prescriptions furnishing a mosaic of seral stages to maximize grassland bird species diversity and abundance across the landscape. Authors conclude seral stage was an effective predictor of density for many grassland birds and its assessment can furnish a framework for development of management plans and prediction of effects of management decisions.

Gauthier, D. A. and Wiken, E.B., 2003, Monitoring the conservation of grassland habitats, prairie ecozone, Canada: Environmental Monitoring and Assessment, v. 88, p. 343-364.

Canadian prairie ecozone represents 5 percent of Canadian area and 16 percent of North American Great Plains. Authors estimate only 25-30 percent of Canadian grassland remaining habitats are concentrated in southeastern Alberta and southwest Saskatchewan. This report furnishes an overview of ecosystem, land cover, administrative, and conservation area databases useful for evaluation and monitoring grasslands in North America with a specific focus on Canadian prairie ecozone. Fragmentation of grasslands habitats and implications for grassland conservation are discussed. Authors recommend that monitoring programs incorporate quantitative and qualitative evaluations of habitat conditions that include amount of specific types of habitat, landscape patterns, indicators of habitat quality, spatial metrics, and rates of change in habitat conditions.

George, R. R., Farris, A.L., Schwartz, C.C., Humburg, D.D., and Coffey, J.C., 1979, Native prairie grass pastures as nest cover for upland birds: Wildlife Society Bulletin, v. 7, no. 1, p. 4-9. 
Lands seeded to pure stands of switchgrass (Panicum virgatum), Indiangrass ( Sorghastrum nutans), and big bluestem (Andropogon gerardii) and properly managed as warm season livestock forage provide suitable nest cover for ring-necked pheasants (Phasianus colchicus) and other upland nesting birds. In contrast, alfalfa and orchardgrass hay fields produced no successful nests due to early-season hay cutting. Switchgrass furnishes quality cover because it maintains leaves, resists burial/lodging by snow, and provides good residual spring cover. Passerine densities were highest in big bluestem. The three grasses listed above are recommended for warm-season livestock forage and wildlife nesting cover. Little bluestem is best nesting cover but it produces less forage and is more difficult to establish than other native grasses. Tall native grasses should not be grazed below 8-10 in. Grazed grasses should be left undisturbed as much as possible in order to provide maximum residual cover in spring. Prescribed burns every $4-5$ years will remove excess litter and prevent woody invasion.

Germano, D.J., Rathbun, G.B., and Saslaw, L.R., 2001, Managing exotic grasses and conserving declining species: Wildlife Society Bulletin, v. 29, no. 2, p. 551-559.

Evaluation of introduced grasses on fauna in San Joaquin Valley, Calif. Herbaceous cover of introduced grasses and forbs often creates an impenetrable thicket for small grounddwelling vertebrates. Authors believe some years moderate to heavy grazing by livestock is the best way to decrease the dense cover created by exotic grasses. Many plant and animals are adapted to relatively open habitats and are morphologically, behaviorally, and physiologically ill equipped to live in dense stands of grass. Control of exotic grasses may be possible by removing plants mechanically or by herbicides. These methods, however, generally are too costly to be effective over large areas.

Gibon, A., 2005, Managing grassland for production, the environment and the landscape - Challenges at the farm and landscape level: Livestock Production Science, v. 96, p. 11-31.

Agricultural systems are increasingly recognized by society and science as complex systems supporting a variety of environmental and social benefits. Written from a European perspective, this paper addresses issues appropriate to the future of grassland management and environmental issues in the United States. Grasslands are currently regarded as a land used to enhance and preserve based on growing recognition of their many environmental services. However, the scientific understanding required to achieve multifunctional benefits still remains poor. Spreading understanding of the need to consider grassland management beyond the grassland itself is needed at farm and landscape levels. The first requirement is a greater understanding of the diverse services grasslands provide and knowledge about the way their functions can conflict or complement other farm operations. Grasslands are increasingly recognized for their contributions to $\mathrm{C}$ sequestration, regulation of nutrients, soil quality, water cycle balance, flood reduction, and contributions to biodiversity.

As in the United States, European grassland has experienced huge reductions area and quality in the 20th century. High yielding row crops reduced area devoted to grasslands resulting in significant negative environmental impacts. There is a growing awareness of the need to care for grasslands on the farm and landscape level to maximize environmental services. Enhancement of semi-natural grassland and the recreation of landscape heterogeneity is being considered as a key in sustaining biodiversity across agricultural ecosystems. Aesthetics and natural heritage may lead to specific objectives with respect to grassland restoration and their spatial arrangement in the landscape. Pressure for delivery of environmental and public goods by agriculture has increased. Monitoring will be key in documentation of benefits, effectiveness of policies, and efficient adoption of desired management changes by fine tuning financial support to farmers. Success will require management at a variety of scales and cooperation with ecological sciences, economics, and social sciences.

Gill, D.E., Blank, P., Parks, J., Guerard, J.B., Lohr, B., Schwartzman, E., Gruber, J.G., Dodge, G., Rewa, C.A., and Sears, H.F., 2006, Plants and breeding bird response on a managed Conservation Reserve Program grassland in Maryland: Wildlife Society Bulletin, v. 34, no. 4, p. 944-956.

Paper describes plant and breeding bird responses to CRP grassland establishment and management in northeastern Maryland. Fields were planted with five mixtures of warm-season native grasses representing various growth-form heights with mowing and herbicide applications to control weeds and encourage stand establishment. In six years, plantspecies richness increased following a third season prescribed burn to remove excessive litter and control encroachment of woody vegetation. Several at-risk bird species (for example, grasshopper sparrow [Ammodramus savannarum]) colonized restored grasslands and established sustainable breeding populations. These populations declined in absence of burning but these fields did attract several shrubland associated species. Avian habitat preferences were determined more by vegetation structure than plant species composition. Authors recommend grassland management include rotation of prescribed fire and herbicide to favor desirable physical diversity in vegetation structure. No one management protocol will work for all targeted species.

Study results demonstrate eastern native grasslands can be "reassembled" on heavily degraded lands within a time frame of 2 to 4 years. "Reassembled" means increasing species diversity in a managed habitat so the area becomes capable of supporting sustainable populations of plant and animal species. In six years of management (for example, mowing burning), cumulative plant-species richness increased. 
Several at-risk bird species (for example, grasshopper sparrow [Ammodramus savannarum], dickcissel [Spiza americana]) colonized the restored grassland and established sustainable breeding populations. Large blocks of habitat were fundamental to the positive response by grassland obligate species in contrast to narrow linear grass-buffer strips (that is, CP21) which attracted very few grassland specialist bird species. Prescribed burning is identified as the least expensive management tool for maintaining grasslands. Switchgrass (Panicum spp.) was found to be too aggressive in this region and no longer recommended for native grassland seeding mixtures. Management of restored grasslands should include spatial and temporal rotation of prescribed fire and herbicide applications to sustain desirable vegetative physical structure rather than species composition.

The authors conclude mowing, during establishment, prescribed burning on a 3-year rotation, and application of herbicides for noxious weed control established and maintained a species rich grassland habitat valuable to grasslandobligate species. Results of this study demonstrate many of the management prescriptions recommended by USDA and others work. Conservation effort of CRP and CREP are valid approaches to benefit multiple conservation objectives.

Grant, T.A., Madden, E., and Berkey, G.B., 2004, Tree and shrub invasion in northern mixed-grass prairie-Implications for breeding grassland birds: Wildlife Society Bulletin, v. 32 , no. 3 , p. $807-818$.

Study reports investigation effects of invasion by aspen (Populus tremuloides), willow (Salix spp.) and other woody vegetation on avian grassland bird species habitat quality in north-central North Dakota. Grassland study area dominated by needlegrass- wheatgrass (Stipa-Agropyron) intermixed with smooth brome (Bromus inermis) and Kentucky bluegrass (Poa pratensis). Probability of occurrence of 11 of 15 species decreased as percent woodland, tall shrub, or brush cover increased. Grasslands became largely unsuitable for 9 species of grassland birds as woody cover exceeded 25 percent. Only vesper sparrow (Pooecetes gramineus), clay-colored sparrow (Spizella pallida), and common yellowthroat (Geothlypis trichas) occurred more frequently as woody cover increased. Savannah sparrow (Passerculus sandwichensis), bobolink (Dolichonyx oryzivorus) and grasshopper sparrow (Ammodramus savannarum) reached maximum occurrence in open treeless grasslands with probability of occurrence declining to 50 percent when woody cover ranged from 10-25 percent. Number of species negatively affected by woody cover increased as vertical structure changed to tall shrub and aspen woodland.

Authors judge even nominal increases in woody vegetation will compromise use of grasslands by several avian species. Occurrence of most woodland-sensitive species declined rapidly as woodland cover increased to only 5-20 percent. Recommend restoration efforts on grasslands be focused where woody cover is less than 20 percent for management to have most beneficial effects. Authors urge discontinuance of programs that encourage introduction of native and non-native trees and shrubs into northern Great Plains grasslands.

Henderson, D.C. and Naeth, M.A., 2005, Multi-scale impacts of crested wheatgrass invasion in mixed-grass prairie: Biological Invasions, v. 7, p. 639-650.

Crested wheatgrass (Agropyron cristatum) in the most widespread alien perennial forage grass across the North American Great Plains. The species has invaded native grasslands and raises concerns about its ecological impact. Intentionally introduced from Eurasia as a forage crop due to its ability to resist grazing and become established under drought conditions it has often spread into remaining natural grasslands. The species tends to out-compete native species and dominate communities for decades following establishment. Rate of spread can be as much as 1-2 m/yr (3-6 ft/yr). Because it is so adaptable, crested wheatgrass is intentionally seeded into semiarid regions to prevent invasion of even less desirable species like cheatgrass (Bromus tectorum) and knapweed (Centaurea spp.).

An assessment of impacts of crested-wheatgrass invasion is reported at multiple scales of evaluation. At population level, native cool season mid-grasses and forbs were less abundant in invaded grassland. Native cool season and warm season short grasses species abundance was not affected. At community and landscape levels, vegetative diversity was lower in invaded grasslands due to lower species richness and cover of forbs. At ecosystem level vegetation and litter biomass were greater in invaded grasslands but belowground organic matter, soil organic $\mathrm{C}, \mathrm{N}$, and $\mathrm{P}$ were not affected. Crested wheatgrass incursion into mixed-grass prairie communities appears to simplify composition of prairie landscapes. Crested wheatgrass pastures are less diverse and have less soil organic matter than native grasslands on formerly cultivated land. Once established, crested wheatgrass dominates vegetation composition and the seedbank. Control of crested wheatgrass requires suppression of seed production, elimination of existing plants, and introduction of native grass and forb seeds.

Hirsch, S.A. and Leitch, J.A., 1998, Impact of leafy spurge on post-Conservation Reserve Program land: Journal Range Management, v. 51, no. 6, p. 614-620.

Authors state leafy spurge (Euphorbia esula) infests some of the 1.2 million hectares (greater than 2.9 million ac.) of CRP in North Dakota. (However, no quantifiable data on presence of leafy spurge are presented.) Authors believe, once established, leafy spurge will out-compete established grasses. Resultant spurge monocultures will reduce benefits of the CRP and diminish economic returns to some post-CRP land use. Again, they offer no documentation of spurge replacing established grasses. Post-CRP impacts on grazing and 
crop production are estimated in the "absence of actual data." Authors speculate, using a North Dakota input-output economic model, that post-CRP economic losses on grazing lands (that is, CRP lands used for grazing after contract expiration) would be \$3.6 million annually. Authors believe if CRP lands facilitate spread of leafy spurge the ecological and environmental benefits of the CRP are overestimated. Justifiably, the authors advocated more precise inventories of spurge infestation to more accurately evaluate effects of the invasive species on land use and economic impacts.

Hofmann, M., and Isselstein, J., 2005, Species enrichment in an agriculturally improved grassland and its effects on botanical composition, yield, and forage quality: Grass and Forage Science, v. 60, p.136-145.

Effects of different management practices on botanical development and productivity of a species-poor, intensively managed grassland are reported for a 4-year period. Half of study plots were sown with a mixture of forb (wildflower) species to investigate effects of cutting regimes on vegetation composition, stand development and dry-matter yield. Frequent cutting resulted in the greatest number of established plants and three-times greater harvested dry-matter yield of introduced species when compared to infrequent cutting. Introduced forbs increased the crude protein concentration but decreased digestibility of forage. Although this investigation took place in Germany, the implications and discussion presented are applicable to grassland management issues in North America, particularly as they relate to lands enrolled in grass covers in USDA conservation programs.

The report documents that it is possible, under appropriate management, to establish a range of wildflower species into grasslands. All cutting treatments resulted in some degree of establishment of forbs. Stands subjected to more severe disturbance prior to seeding (for example, plowing) had the greatest response to forb establishment. Other studies cited show over-sowing by broadcast seeding without severe mechanical disturbance was ineffective. Greater biomass of seeded species in cut plots was result of higher number and growth of introduced plants. Appropriate management measures are necessary to ensure initial increase in vegetation composition is maintained over the long-term. Authors conclude herbage production can be maximized by increasing diversity in vegetation. This can be partly explained by establishment of $\mathrm{N}$-fixing legumes (for example, clover) as well as species with different temporal and spatial growth patterns than that of grass-dominated stands. Herbage from treated plots (mowed) with higher abundance of introduced forbs had higher $\mathrm{N}$ concentration than plots without such species. Authors conclude introduction of forbs can increase forage quality with respect to protein concentration but may lead to a reduction in digestibility.
Lee, K.H., Isenhart, T.M., Schultz, R.C., and Mickelson, S.K., 1999, Nutrient and sediment removal by switchgrass and cool-season grass filter strips in central Iowa, USA: Agroforestry Systems, v. 44, no. 2-3, p. 121-132.

In the short term, switchgrass (Panicum virgatum) and cool-season grass filter strips (smooth brome [Bromus inermus], timothy [Phleum pratense], and fescue [Festuca spp.]) removed about the same amount of sediment. Long-term effectiveness of cool season grass filter strips may be limited; however, due to sediment accumulation in this low stature, less resilient vegetation. Switchgrass may offer higher longterm effectiveness because it produces large amount of litter, has stiff stems, strong root systems, and growth pattern more uniform and erect than cool-season grasses.

Lemaire, G., Wilkins, R., and Hodgson, J., 2005, Challenges for grassland science-Managing research priorities: Agriculture Ecosystems \& Environment, v. 108, p. 99-108.

Although written for application in the European agricultural ecosystem, concepts presented are applicable to the agricultural/environmental situation in the United States as well. Production-oriented research in the last century made significant contributions to greater yields and productivity of the agricultural industry but these advancements have contributed to serious long-term negative effects on the stability of the world's land and water resources. Grasslands are an essential component of integrated land use affecting resource stability, biodiversity and global-level changes in environmental quality. The authors argue there is need for funding of research on land-use strategies and grassland management in particular. There is need for inter-disciplinary research with emphasis on large-scale, long-term land use on both regional and national scales. To be effective, some research projects will require funding for at least 10 years.

Grassland ecosystems have to be managed with multipurpose objectives related to their environmental, biodiversity, landscape ecology, agricultural, and social implications. The expansion of industrial agriculture largely has reduced the importance of grasslands in mixed farming systems. Because continued specialization of farming may be inescapable, new strategies of mixed-land use have to be promoted at landscape and regional levels. Implications for new approaches to research and management are discussed from perspectives of local, landscape, and regional scales. Grassland conservation and integration into a more diversified, sustainable agricultural land use must take into account the socio-economic forces that affect land use. The enhancement of conservation issues must be undertaken in an approach that recognizes the landscape as being an assembly of farmers who respond individually to their own social/economic constraints. Explicit contradictions between socio-economic goals of farmers and ecological goals of other components of society need to be recognized and defined. 
Madison, L.A., Barnes, T.G., and Sole, J.D., 2001, Effectiveness of fire, disking, and herbicide to renovate tall fescue fields to northern bobwhite habitat: Wildlife Society Bulletin, v. 29 , no. 2 , p. $706-712$.

Fields dominated by tall fescue (Festuca arundinacea) furnish poor habitat for bobwhite quail (Colinus virginianus) due to unsuitable vegetation structure, depleted vegetation composition, and a lack of food producing plants of sufficient quality. Fescue grass forms a dense sod that decreases bare ground and may prevent bobwhite from efficient movement and foraging. This study examined effectiveness of controlled burning, disking, and herbicide (Roundup ${ }^{\circledR}$ ) to improve habitat quality for quail. Spring herbicide application most effectively reduced fescue coverage. Fescue cover was reduced for one year following disturbance by fall, spring, and summer disking, but became similar to control plots and pre-treatment conditions by the second year post-treatment. Fall, spring, and summer burning did not prove to be effective in reduction of fescue.

Martin, A.R., Moomaw, R.S., and Vogel, K.P., 1982, Warmseason grass establishment with Atrazine: Agronomy Journal, v. 74, p. 916-920.

Competition from weeds is a major factor limiting establishment of warm-season grasses often delaying the first use for forage by 2 or $3 \mathrm{yr}$. Seeding year forage yields of big bluestem (Andropogon gerardii) and switchgrass (Panicum virgatum) were significantly increased following atrazine application. Warm season perennial grasses are particularly slow to become established from seed often requiring up to 4 years before they can be grazed or harvested for hay. Cool season weed species are especially competitive with native species.

Milchunas, D.G., Vandever, M.W., Ball, L.O., and Hyberg, S., 2011, Allelopathic cover crop prior to seeding is more important than subsequent grazing/mowing in grassland establishment: Rangeland Ecology and Management, v. 64, no. 3, p. 291-300

Sorghum is known to be allelopathic and is used in crop agriculture rotations to suppress weeds and increase crop yields. This study evaluated the effects of grazing, mowing, and cover crop in a winter wheat-fallow cropland seeded to grassland under the CRP in eastern Colorado. Fallow strips planted to forage sorghum as a cover crop and wheat strips with wheat stubble were treated as grazed moderate, grazed heavy, ungrazed, and mowed. After four years of grazing and mowing treatments, results showed that plots previously in wheat had more annual and exotic species than sorghum plots. Concomitantly, there were much greater abundances of perennial native grass and all native species in sorghum strips than in wheat cropped areas. Grazing treatments had relatively minor effects on basal and canopy cover composition of annual or exotic species versus perennial native grass or native species. Mowing was a less effective weed control practice than grazing. Results suggest that allelopathic cover crop selection and opportunistic grazing can be effective alternative grass establishment and weed control practices.

Murray, L.D., Best, L.B., Jacobsen, T.J., Braster, M.L., 2003, Potential effects on grassland birds of converting marginal cropland to switchgrass biomass production: Biomass and Bioenergy, v. 25, p. 167-175.

Report describes results of GIS analysis of converting row crop and CRP grass-dominated fields to biomass production on 13 selected avian species in Rathun Lake watershed in Iowa. Bird-abundance values for each habitat were used to model abundance in watershed before and after conversion to biomass production. Scenarios using total harvest of fields and strip-harvest of fields were completed. Authors conclude that conversion to switchgrass (Panicum virgatum) biomass production would create habitat for some avian species of management concern (for example, bobolink, dickcissel, field sparrow). Abundance of these species increased under both total field and strip harvesting of biomass scenarios. A mixture of both total harvest and non-harvest would have the greatest benefits to the largest number of avian species. Rotations of fields in non-harvest status through harvest period would allow buildup of vegetation litter required by early-season ground nesting species. Authors suggest establishment of row crop food plots in areas dominated by biomass production could mitigate loss of foods provided by typical row crop production. Future monitoring of switchgrass biomass production effects on avian populations is recommended.

Oberheu, D., Mitchell, R., Dabbert, B., and Davis, S., 1999, Observations of avian nesting activity in burned and nonburned weeping lovegrass CRP: Texas Journal of Agriculture and Natural Resources, v. 12, p. 14-17.

More than 1 million acres of weeping lovegrass (Eragrostis curvula) has been planted in Texas as part of the CRP. The planting has been criticized as being of little value to wildlife. Although numbers of nests found were small, this report documents nesting in weeping lovegrass by Cassin's Sparrow (Aimophila cassinii) a species in decline throughout its range. Nests of mourning doves (Zenaida macroura) and common nighthawk (Chordeiles minor) also were located in CRP lovegrass fields. Although not the best cover for wildlife due to a lack of structural diversity and insufficient thermal cover, weeping lovegrass may be the best multiple-use cover for soil conservation, and forage production on sandy soils in the southern High Plains. Because nesting seemed to be inhibited for at least two seasons following burning, the authors suggest application of prescribe fire should be conducted in a mosaic fashion to maintain diversity in vegetative cover. 
Porkorny, M.L., Sheley, R.L., Svejcar, T.J., and Engle, R.E., 2004, Plant species diversity in a grassland plant community_-Evidence for forbs as a critical management consideration: Western North American Naturalist, v. 64, no. 2, p. 219-230.

An evaluation of plant species diversity and composition in southwestern Montana grassland dominated by Idaho fescue (Festuca idahoensis) and bluebunch wheatgrass (Agropyron spicatum) is presented. Authors report that forbs represented a majority of species richness and biomass in the grassland community. Maintenance of diversity in vegetation composition should be a primary objective of land managers because increased diversity results in greater stability in vegetation community and decreases risk of invasion by undesirable species. Periodic sampling in spring and in summer at peak standing crop is recommended to better understand and define contribution of forbs in grassland community. Sampling in mid-summer captured only 76 percent of community diversity as compared to 95 percent when sampled in spring and summer. Management recommendations for maintenance of forb diversity are presented.

Renfrew, R.B., Ribic, C.A ., and Nack, J., 2005, Edge avoidance by nesting grassland birds - A futile strategy in a fragmented landscape: The Auk, v. 122, no. 2, p. 618-636.

An evaluation of edge effects is described for avian species (Savannah sparrow [Passerculus sandwichensis], grasshopper sparrow [Ammodramus savannarum], bobolink [Dolichonyx oryzivorus] and meadowlark [Sturnella spp.]) in grazed pastures in Wisconsin. Authors conclude edge avoidance by grassland passerines will not necessarily reduce predation in actively grazed pastures within fragmented agricultural landscapes. Authors recommend patches with larger core area will likely enhance productivity of these species. Removal of trees and shrubby hedgerows recommended when practical but this approach may be practical only when few wooded areas are nearby and removal increases connectivity of larger pastures or grassland covers. Presence of adequate height, density, and structural variability is believed key in conservation of grassland birds. Decreased rates of stocking could favorably maintain vegetation height density making it more difficult for predators to locate nests. Proper management of cattle may have as much an effect on grassland bird populations as management of patch and landscape characteristics.

Rucker, A.D., 2001, Conversion of tall fescue pastures to tallgrass prairie in southeastern Kansas - Kansas Department of Wildlife and Parks Annual Progress Report: Manhattan, Kans., Kansas State University, 56 p.

Conversion of existing stands of tall fescue (Festuca arundinacea) completed by removing cattle from fescue pastures, discontinuation of fertilization, and application of spring burning one year following removal of cattle. Study is focused on response of small mammals to changes in vegetation diversity and structure. Positive response and greater diversity of small mammals in restoration sites suggest greater diversity in plant species and structure had positive effects on mammal populations.

Ryan, M.R., 1986, Nongame management in grassland and agricultural ecosystems, in Hale, J.B., Best, L.B., and Clawson, R.L., eds., Management of nongame wildlife in the Midwest-A developing art: Chelsea, Mich., BookCrafters, p. 117-136.

Acquisition, reclamation, and proper management of grassland resources must become a priority to conserve the genetic diversity of native prairie flora and fauna. The role of agriculture in prairie wildlife conservation must be defined to develop effective management strategies. The remaining grassland tracts that are too small to show characteristic variability of natural prairie ecosystems may distort modern views of grasslands. Grasslands contain substantial habitat diversity, primarily in the horizontal plane. View of grassland ecosystem as a mosaic of habitat types influenced by soil moisture and grazing intensity are the primary controlling factors and set the stage for development of wildlife management goals and strategies. Opportunities to manage remaining prairie tracts of sufficient size to include all aspects of the prairie vegetation continuum are rare. Alternative is to manage smaller tracts as components of overall prairie mosaic. Goal of nongame grassland management should be conservation of wildlife species native to prairie habitats. Management actions must be defined on a state or region-wide level. If richness of species indigenous to prairie ecosystems is objective, the management plan must be developed on large scale and implemented through integrated management.

A large block of similar habitat will contain and conserve more species than a small unit. However, there is controversy around the question of whether a large tract will maintain more species than several small tracts that, combined, equal the area of the larger tract. Ranking of sites for selection: (1) sites, regardless of size, containing rare species or habitats that could support them; (2) large tracts containing a variety of habitat conditions furnishing a mosaic of habitat types; (3) clusters of small tracts that provide, or can be managed for, a variety of components of the prairie mosaic; (4) large homogeneous blocks of grassland; and (5) small highly isolated units of grassland. Monotypic seeded fields are less likely to be of value to nongame wildlife than multi-species fields.

Sampson, F., and Knopf, F., 1994, Prairie conservation in North America: Bioscience, v. 44, no. 6, p. 418-421.

Since European settlement, regional declines in area of native prairie range as high as 99.9 percent. In addition to 
direct loss to cropland, overgrazing and recreation add to the stress on remnant tracts of prairie. Fifty-five grassland species currently are threatened. Paper advocates inventory and monitoring of remaining prairie ecosystems, discouragement of establishment of woody plants and woody corridors within prairie dominated ecoregions, and realignment of administrative and ecoregion borders to increase efficiency in inventory and monitoring.

Seefeldt, S.S., Conn, J.S., Zhang, M., and Kaspari, P.N., 2010, Vegetation changes in Conservation Reserve Program lands in interior Alaska: Agriculture, Ecosystems and Environment, v. 135, p. 119-126.

Results of an investigation of plant communities within CRP fields established in Delta Junction, Alaska, is presented. The CRP fields included in the study were originally planted to smooth brome (Bromus inermis), red fescue (Festuca rubra), and the native common horsetail (Equisetum arvense). As time progressed, abundance of these species decreased being replaced by the native grass, bluejoint (Calamagrostis canadensis), native forbs, shrubs and tree species. Plant diversity in the CRP fields increased by more than 2 species per $1000 \mathrm{~m}^{2} /$ year. The authors conclude plant succession in the CRP fields is following patterns similar to that of natural systems despite multiple years of having been farmed. If these fields are left undisturbed, the resultant plant community would be indistinguishable from surrounding undisturbed bottomland forest. As frequency and abundance of woody species increase through time, it will be difficult to meet USDA compliance standard that CRP fields must be maintained in a condition that permits easy conversion to cropland. Authors believe that these CRP fields will be non-compliant 32 years after establishment in CRP, but the fields will be providing excellent erosion control and wildlife habitat. Although the CRP fields included in the study were not specifically evaluated for their quality as wildlife habitat, young CRP fields furnished "good" habitat for bison (Bison bison). The older, shrub-dominated fields were believed to furnish "good" habitat for moose (Alces alces).

Sieg, C.H., Flather, C.H., and McCanny, S., 1999, Recent biodiversity patterns in the Great Plains - Implications for restoration and management: Great Plains Research, Fall 1999, p. 277-313.

Public policies that focus on ecosystem protection and furnish private landowners with incentives to manage their property to meet conservation objectives are needed to assure long-term sustainability of Great Plains ecosystems. Ninetyfive percent of land in the U.S. portion of the Great Plains is in private ownership making private lands in this region particularly important to the conservation of imperiled species and habitats. Grassland nesting birds had the highest overall rate of loss. The proportion of grassland species that declined (greater than 44 percent) was greatest in the Southern Plains. An average of 9 percent of the wetland bird species have declined across the region between 1966 and 1996.

There is much uncertainty associated with plans to restore and maintain Great Plains biodiversity. For most aspects of biodiversity we lack a comprehensive understanding of past and current status as well as a relatively poor understanding of the role disturbances (drought, fire, grazing, flooding) played in shaping various prairie types and their landscape components. Less is known about how to incorporate disturbances into landscapes vastly altered by intensive land use, fragmentation, and the introduction of dozens of exotic species. Properly planned grazing regimes are appropriate components of a strategy to restore biodiversity throughout the Great Plains. Grazing systems should be tailored to a particular ecosystem and include variation in grazing duration and intensity. Restoration of fire in management plans should be considered with prescriptions based on historical patterns including burning at varying intervals in different seasons. Management designed to conserve biodiversity should focus on provision of habitats with varying successional and structural stages. Monitoring and evaluation of management actions will be critical in developing future management options and policy guidelines.

Tilman, D., Reich, P.B., and Knops, J.M.H., 2006, Biodiversity and ecosystem stability in a decade-long grassland experiment: Nature, v. 441, no. 1, p. 629-632.

Authors report on results and implications of a 10-year investigation of ecosystem stability finding year-to-year variation in abundances of plant species and productivity. Greater numbers of plant species led to greater temporal stability of annual aboveground plant production. Stability of ecosystem was found to be significantly greater at higher diversity levels of plant species and tended to increase as study plots matured. Authors conclude greater diversity in vegetation leads to greater ecosystem stability.

Vinton, M.A., and Goergen, E.M., 2006, Plant-soil feedbacks contribute to the persistence of Bromus inermis in tallgrass prairie: Ecosystems, v. 9, p. 967-976.

A greater understanding of factors supporting success and persistence of invasive plants in native ecosystems is needed. Over the past 30 years, grass smooth brome (Bromus inermis) and cool season $\left(\mathrm{C}_{3}\right)$ introduced and potentially invasive species have been spreading throughout North America's central grasslands resulting in displacement of native species including tallgrass species such as switchgrass (Panicum virgatum). Smooth brome was introduced in the 1880 s and was widely planted for forage and soil stabilization along roads and waterways. The presence of smooth brome is especially problematic in the Northern Plains and Midwest where 
it forms monocultures. This investigation reports smooth brome had greater tiller density, mass and canopy interception of light on $\mathrm{N}$ enriched soils suggesting smooth brome may have a competitive advantage on soils with higher rates of $\mathrm{N}$. Smooth brome was also found to have a higher C-N ratio and greater rate of decomposition than did switchgrass possibly contributing to more rapid cycling of nitrogen which may result in a competitive advantage that enables brome to persist in remnant or restored grasslands. The authors conclude the increased human-induce nitrogen deposition on terrestrial ecosystems will likely make control of smooth brome a continuing challenge.

Washburn, B.E., Barnes, T.G., and Sole, J.D., 1999, No-till establishment of native warm-season grasses in tall fescue fields: Ecological Restoration, v. 17, no. 3, p. 144-149.

A relatively new herbicide, Plateau may be especially useful in establishment of native warm season grasses because several key species and forbs are tolerant of the herbicide. Best control of tall fescue (Festuca arundinacea) was on plots with a spring burn followed by a single application of Plateau in early May. Glyphosate (Roundup ${ }^{\circledR}$ ) is a foliar-acting herbicide with no residual effects. Plateau has a $40-45$ day residual effect and plant uptake occurs both through leaf surfaces and roots. Plots treated with Roundup had few visible signs of native grasses. Spring burning followed by a pre-emergence application of Plateau at $12 \mathrm{oz} / \mathrm{acre}$ and seeding native grasses effectively eliminated tall fescue within a single growing season. This treatment also provided residual weed control that allowed native grasses to become established during the first growing season.

Wilson, S.D., and Gerry, A.K., 1995, Strategies for mixedgrass prairie restoration-Herbicide, tilling, and nitrogen manipulation: Ecological Restoration, v. 3, no. 4, p. 290-298.

Evaluation of converting crested wheatgrass (Agropyron cristatum) and smooth brome (Bromus inermis) to native species. Three levels of tillage, none, intermediate and complete. Plots sprayed with glyphosate had density of native seedlings 20 times that of unsprayed plots. Native seedling density was significantly higher in plots receiving the highest intensity of tilling. Native vegetation in north American prairie is frequently replaced with Eurasian grasses. One of greatest obstacles to seedling establishment is elimination of current vegetation. Most effective method for removing may be treatment with herbicides such as glyphosate. Tilling prior to seeding may provide sufficient time for seedlings to establish before the regrowth of introduced vegetation.
Wilson, S.D., 1989, The suppression of native prairie by alien species introduced for revegetation: Landscape and Urban Planning, v. 17, p. 113-119.

Introduced species did not aid revegetation. Plots seeded with introduced species did not produce significantly higher standing crop or below-ground biomass than did unseeded plots. Unseeded plots had the lowest frequency of bare ground. Allowing prairie to revegetate without sowing introduced species produced both the highest cover of bare ground and the greatest abundance of native species. Effect of sowing commercial seed mixtures of introduced species was to suppress native flora. Total frequency of native species was lowest where crested wheatgrass (Agropyron cristatum) and smooth brome (Bromus inermis) were sown indicating that these species dominate native as well as introduced flora.

Willson, G.D., and Stubbendieck, J., 1996, Suppression of smooth brome by Atrazine, mowing, and fire: The Prairie Naturalist, v. 28, no. 1, p. 13-20.

Neither burning nor mowing resulted in significant reductions of abundance of smooth brome (Bromus inermis). Sod seeded big bluestem (Andropogon gerardii) failed in all treatments. Restoration efforts to should be focused on enhancing the vigor of remnant warm-season grasses or suppress existing sod forming grasses before seeding native species. Authors recommend that the application of atrazine should be avoided if enhancement of forb diversity is a primary objective. Single mowing in May had no significant effect on smooth brome tiller density. The absence of significant effect of mowing may have been due to mowing above a majority of the tiller growing points.

Willson, G.D., and Stubbendieck, J., 2000, A provisional model for smooth brome management in degraded tallgrass prairie: Ecological Restoration, v. 18, no. 1, p. 34-38.

In warm season, grass-dominated pastures and native prairies smooth brome (Bromus inermis) is considered a highly competitive weed because of its rhizomatous sod-forming root system and prolific seed production. Brome exhibits two predominant periods of tiller emergence and development. Most active period is after flowering in June continuing into fall. The less active period of tiller emergence occurs from about mid-March through early May. Tiller elongation begins in early May in the central Great Plains and Midwest in response to greater day length.

Management: Clipping during its active period of growth will lower production of aboveground biomass of brome. Mowing and raking in an Illinois prairie in late April resulted in significant decrease in seasonal growth of brome. A 50-percent reduction in smooth brome tiller density was recorded after a prescribed burn in early May at time of tiller 
elongation. Early spring burns appear best to limit biomass production of brome. Herbicides also are effective in elimination of brome. Atrazine applied in late April at $1.9 \mathrm{lbs} / \mathrm{ac}$ reduced smooth brome by 91 percent and shifted dominance from cool to warm season grasses. Only atrazine was effective in reducing brome tiller density, possibly because the herbicide killed the whole plant. Burning at emergence does not affect secondary tiller (after treatment growth) density in years when precipitation is normal or below normal although in years with above normal precipitation brome increases dramatically. Burning during other three growth stages significantly reduces both tiller density and biomass, especially when repeated annually.

Two factors are particularly important in smooth brome management: post fire competition and seasonal timing of fire. A single, spring application of atrazine restored a pasture dominated by smooth brome when big bluestem (Andropogon gerardii) and Indiangrass (Sorghastrum nutans) comprised only 20 percent of pre-treatment vegetation. It appears that warm-season grasses must comprise more than 20 percent of species mix of degraded site before a prescribed burn will effectively reduce brome. Fire alone will not restore a degraded tallgrass site dominated by smooth brome. At severely degraded sites (CRP, former cropland) other methods must be used such as herbicide applications followed by seeding of warm season grasses. Annual spring burning can lower species diversity by eliminating, or preventing establishment of cool-season forbs. A single burn before tiller elongation that removes most litter may increase growth of brome due to increased light reaching growing leaves.

In situations where smooth brome is the dominant species and warm-season grasses are absent, burning will have no long-term negative effect on smooth brome and may actually increase its abundance. Burning of smooth brome during spring tiller elongation provides the most immediate and persistent reduction in both tiller density and biomass.

\section{Grazing, Haying, Mowing}

Allen, A.W., Cade, B.S., and Vandever, M.W., 2001, Effects of emergency haying on vegetative characteristics within selected Conservation Reserve Program fields in the northern Great Plains: Journal of Soil and Water Conservation, v. 56 , no. 2, p. 120-125.

This study compared vegetative characteristics of undisturbed and hayed CRP fields in North and South Dakota. Fields used in the study were of same age and planted with similar mixes of cool-season, introduced grasses and forbs. Emergency haying had little long-term effect on vegetation height/density, percent cover of live grass, or forb cover when compared to undisturbed fields. The presence of legumes primarily alfalfa increased in response to haying, whereas abundance of noxious weeds (predominantly Canada thistle
[Cirsium arvense]) decreased. Implications for long-term management of CRP grasslands to meet avian habitat requirements are discussed.

Boyles, S.L., Stoll, B.W., and Dobbles, T.L., 2001, The use of Conservation Reserve Program land for grazing cattle: Journal of Sustainable Agriculture, v. 18, no. 4, p. 113-120.

Evaluation of intensive rotational grazing of CRP grassland in Ohio is reported. Grassland was planted to orchardgrass (Dactylis glomerata), timothy (Phleum pratense), and red clover (Trifolium pratense) in 1987. Investigation evaluated potential of grazing CRP grasslands if the lands are removed from the conservation program at a seasonal annual stocking rate of $3.5 \mathrm{head} / \mathrm{ha}(1.5 / \mathrm{ac})$. Based on measures of nitrate and nitrogen run-off from grazed CRP met Environmental Protection Agency conservation compliance demands needed for participation in other USDA programs.

Cade, B.S., Vandever, M.W., Allen, A.W., and Terrell, J.W., 2005, Vegetation changes over 12 years in ungrazed and grazed Conservation Reserve Program grasslands in the Central and Southern Great Plains, in Allen, A.W. and Vandever, M.W., eds., The Conservation Reserve Program-Planting for the future - Proceedings of a National Conference, Fort Collins, Colo., June 6-9, 2004: U.S. Geological Survey, Scientific Investigations Report 2005-5145, p. 106-119.

Report describes changes, over a 12-year period, in vegetation composition and density in CRP grasslands as the result of no disturbance and emergency use (grazing) of well-established CRP grasslands. Introduced (CP1) and native (CP2) CRP fields were classified into introduced warm season grasses (for example, plains bluestem [Bothriochloa ischaemum], weeping lovegrass [Eragrostis curvula]), native warm season grasses (for example, Indiangrass [Sorghastrum nutans], switchgrass [Panicum virgatum], little bluestem [Schizachyrium scoparium]), and cool season grasses [for example, smooth brome (Bromus inermis), and intermediate wheatgrass (Thinopyrum intermedium).

All grass plantings exhibited an increasing dominance of grass cover over time with a corresponding reduction in the proportion of forbs in the stands. Results indicated that a single year of emergency grazing of CRP fields with wellestablished cover had minimal impacts on vegetation structure and composition two and four years after grazing. These results, however, do not apply to grazing of incompletely established fields or grazing in multiple sequential years. Selection of grasses for planting of conservation covers should be based on synchronous benefits for habitat, erosion control, and potential use as forage. Introduced grasses generally outcompeted native species and formed monotypic stands or developed stands so dense as to have minimal value as habitat for some species of wildlife. It is suggested management prescriptions for CRP fields should be based on clear objectives 
with measurable criteria for definition of success. Universal management guidelines across large spatial areas may simplify policy guidelines but fail to address differences among grass seedings and management objectives.

Collins, S.L., Knapp, A.K., Briggs, J.M., Blair, J.M., and Steinauer, E.M., 1998, Modulation of diversity by grazing and mowing in native tallgrass prairie: Science, v. 280, no. 5364 , p. $745-747$.

Long-term experiments on effects of $\mathrm{N}$ addition, mowing, and burning on tallgrass prairie lead to conclusion fire alone is not sufficient for restoration of biodiversity. Frequent burning dramatically increased dominance of warm season grasses but reduced plant species diversity. Grazing by bison or cattle is recommended for maintenance of vegetation diversity. Grazing increased abundance of forbs under conditions that would have otherwise promoted dominance of warm-season grasses. Richness of cool-season species was lowest on watersheds burned but not grazed. Richness of warm-season species was greatest on sites grazed and burned. Mowing prevented loss of cool-season grasses under conditions that otherwise would have led to elimination of these species. Increase in light penetration may be a major mechanism by which species richness is maintained.

Fuhlendorf, S.D., Zhang, H., Tunnell, T.R., Engle, D.M., and Cross, A.F., 2002, Effects of grazing on restoration of southern mixed prairie soils: Restoration Ecology, v. 10, no. 2, p. 401-407.

An analysis of grazing effects of cultivated lands reseeded to native grasses under CRP and native prairies never cultivated, but managed similarly, undertaken in Oklahoma. Vegetation monitored in study is typical of southern mixed prairie perennial species with dominant species varying depending on physical conditions and past land use. Common mid-grasses were sideoats grama (Bouteloua curtipendula), purple threeawn (Aristida purpurea), and silver bluestem (Bothriochloa laguroides). Dominant short grasses included blue grama ( $B$. gracilis) and hairy grama ( $B$. hirsuta). Less common tall grasses included little bluestem (Schizachyrium scoparium), yellow Indiangrass (Sorghastrum nutans), and big bluestem (Andropogon gerardii).

Management of domestic livestock on rangelands, including land planted to grasses but no longer actively part of the CRP program, can have variable effects on soil fertility, vegetation composition, and structure, thereby influencing the rate of recovery of restored grasslands. Grazing may also influence amounts, spatial pattern, and composition of nutrient accumulation in soil. Authors conclude that regardless of cultivation history, soils and vegetation on heavily grazed sites differed significantly from that on moderately grazed sites. On restored (CRP) sites soil $\mathrm{N}$ and $\mathrm{C}$ were higher with moderate grazing than with heavy grazing. On native prairie sites, grazing only minimally affected soil nutrients. Heavy grazing on formerly
CRP sites reduced litter accumulation and abundance and increased bare ground, which led to reduction in accumulation of organic matter and nutrients. Results of this study suggest heavy grazing on native mixed prairie has little influence but heavy grazing on restored mixed grasslands (CRP) actually reduces rate of soil nutrient and organic matter accumulation. Authors state data support USDA policies that limit grazing on CRP grasslands if the objective is restoration of grassland ecosystems or building soil $\mathrm{C}$ pools.

Gilley, J.E., Patton, B.D., Nyren, P.E., Simanton, J.R., 1996, Grazing and haying effects on runoff and erosion from a former Conservation Reserve Program site: Applied Engineering in Agriculture, v. 12, no. 6, p. 681-684.

Comparisons of runoff and erosion are made from a former CRP field with treatments including undisturbed CRP, twice-over rotational grazing, season-long grazing, haying, and burning. The experimental field was formerly in CRP and planted to 40 percent intermediate wheatgrass (Agropyron intermedium), 50 percent smooth brome (Bromus inermis), and 10 percent alfalfa (Medicago sativa). Runoff and erosion were based on simulated rainfall. No significant difference was found between season-long grazing and burned treatments. Similar amounts of erosion were recorded from twice over rotational grazing, season-long grazing and hayed treatments. Use of CRP for grazing or haying resulted in a significant increase in runoff when compared to leaving the site in undisturbed grass-dominated cover. Grazing and haying operations resulted in significantly reduced infiltration rates for surface waters. The authors determine, however, grazing and haying of this CRP site would not result in "excessive" erosion if adequate canopy and soil surface cover were maintained.

Ignatiuk, J.B. and Duncan, D.C., 2001, Nest success of ducks on rotational and season-long grazing systems in Saskatchewan: Wildlife Society Bulletin, v. 29, no. 1, p. 211-217.

Rotational grazing systems implemented to increase duck production in the Canadian prairie pothole region have had only limited success. A comparison of waterfowl production recorded in once-over rotational systems and season-long pastures in Saskatchewan failed to reveal differences in nest survival between grazing systems. Rotational systems could be more beneficial if they preserve or improve grassland areas, attract more ducks from less productive habitats, or increase duck survival. Strong evidence pastures have high success of nest compared to most other habitat types including small plots of planted cover. Conversion of cropland to pasture and retaining existing pastures was recommended to improve duck production.

Kantrud, H.A., 1981, Grazing effects on avifauna of North Dakota: Canadian Field Naturalist, v. 95, p. 404-417. 
Avian species richness tends to decrease in response to greater intensity of grazing, but total density of birds increased due to higher numbers of a few common species. Total bird density was always highest on idle or lightly grazed sites. In general, distribution and abundance of most grassland bird species in North Dakota have been negatively affected by agricultural activities. Fragmentation of grasslands by agriculture resulted in extirpation of some avian species, but cultivation of eastern tallgrass prairie has destroyed habitat for more bird species than in the shorter, western grasslands. Protection should be given to larger remaining areas of grassland representative of various types found throughout state. Long-term preservation of grassland habitat quality will require periodic management of vegetation.

Kantrud, H.A., and Kologiski, R.L., 1982, Effects of soils and grazing on breeding birds of uncultivated upland grasslands of the northern Great Plains: Washington, D.C., U.S. Fish and Wildlife Service Wildlife Research Report 15, 32 p.

Livestock grazing on lands set aside for wildlife can be used as a management measure to increase populations of game species and increase diversity of plant or animal species. Light to moderate grazing resulted in increased species richness. However, heavy grazing in the northern Great Plains significantly reduced species richness. Grazing by domestic livestock generally decreased average vegetative height and increased exposure of bare soil. In lightly grazed plots height of vegetation seemed to decrease because of shading effect of large amounts of litter. Increased avian species richness was associated with plots in which height of vegetation was not appreciably reduced and percentage of bare soil was not greatly increased by excessive grazing.

Luttschwager, K.A., 1991, Effects of two haying provisions on duck nesting in Conservation Reserve Program (CRP) fields in South Dakota: Brookings, S. Dak., South Dakota State University, M.S. thesis, $51 \mathrm{p}$.

This report provides an evaluation of 1988 and 1989 release of eastern South Dakota CRP fields for emergency haying on duck-nest density and success. Nest densities in idled (non-hayed) strips and non-hayed fields were significantly greater than recorded within hayed strips. Nest densities in idled and hayed blocks were similar. Nest success was lowest in idled strips, which apparently attracted predators as well as ducks. Author recommends leaving a minimum of 25 percent of hayed fields in non-hayed cover in contiguous blocks rather than strips.

McClaran, M.P. and Anable, M.E., 2006, Spread of introduced Lehmann lovegrass along a grazing intensity gradient: Journal of Applied Ecology, v. 29, no. 1, p. 92-98.
An evaluation of the spread of lovegrass (Eragrostis lehmanniana) in Arizona in relation to various levels of grazing intensity is presented. Lovegrass density increased with time but was not affected by grazing intensity. Native grasses decreased while relative abundance of lovegrass increased with time and grazing intensity. Lovegrass has been used commonly in the southwest to prevent soil erosion and to furnish forage for livestock where native grasses have declined. Lovegrass can become the dominant herbaceous cover within $15 \mathrm{yr}$ following planting with resultant lower faunal diversity associated with such stands. Authors conclude lovegrass will spread regardless of presence or absence of grazing and the only way to control the spread of the species is to reduce availability and distribution of seed from established plants.

McCoy, T.D., Kurzejeski, E.W., Burger Jr., L.W., and Ryan, M.R., 2001, Effects of conservation practice, mowing, and temporal changes on vegetation structure on CRP fields in northern Missouri: Wildlife Society Bulletin, v. 29, no. 3, p. 979-987.

During 1989-1995, 154 cool-season and warm-season grass CRP fields between 1 and $9 \mathrm{yr}$ old were monitored in Northern Missouri to describe differences and changes in vegetation. Within 3 to $4 \mathrm{yr}$, perennial grasses with substantial accumulation of litter dominated fields. Annual weed and legume component and abundant bare ground was characteristic of fields $3 \mathrm{yr}$, or younger. As fields aged, annual weeds declined and perennial grasses and litter increased reducing amount of bare ground. Once established, warm-season grasses (switchgrass monocultures) were taller and had more bare ground than cool-season grass plantings. Excessive height and density of vegetation in warm-season grass fields may limit use by many wildlife species, even those associated with tallgrass habitats. Mowing (vegetative material left in field vs. removal by emergency haying) had short-term effects on vegetation structure and led to accelerated succession and litter accumulation. Depending on species of wildlife of interest habitat quality can be expected to vary across time as fields age. Periodic management of CRP grassland recommended for setting back succession, increasing vegetation diversity, and enhancing habitat quality.

Renner, R.W., Reynolds, R.E., and Batt, B.D.J., 1995, The impact of haying Conservation Reserve Program lands on productivity of ducks nesting in the Prairie Pothole region of North and South Dakota in North American Wildlife and Natural Resources Conference 60, Proceedings: Washington, D.C., Wildlife Management Institute, p. 221-229.

Report provides a comparison of duck-nest success and production in hayed versus non-hayed portions of CRP fields. Duck production was higher on non-hayed portions of CRP fields. Authors suggest that haying effects on litter depth and vegetation structure may have detrimental effects on quality 
of nesting cover through entire year following haying of CRP cover. The report recommends haying be allowed no more than once every $5 \mathrm{yr}$ to maintain vegetation quality, habitat diversity and quality of nesting cover.

Rogers, W.M., Kirby, D.R., Nyren, P.E., Patton, B.P., and Dekeyser, E., 2005, Grazing intensity effects on Northern Plains mixed-grass prairie: Prairie naturalist, v. 37, no. 2, p. 73-83.

The effects of long-term (1988-2000) grazing on mixedgrass prairies in south central North Dakota are described. Authors did not detect difference in herbaceous basal cover between grazing intensities following 12 consecutive years of season-long moderate (50-percent removal) and heavy (80-percent removal of aboveground biomass) grazing. Stocking rate for moderate and heavy intensity grazing averaged 0.4 and 1.1 animal unit month (aum)/ha (1 and 2.75 aum/ac), respectively. Both intensities did, however, reduce aboveground herbaceous standing crop, total root biomass, and soil organic carbon. Grasses on study sites were dominated by Kentucky bluegrass (Poa pratensis), needle-and-thread (Hesperostipa comata), blue grama (Bouteloua gracilis), western wheatgrass (Agropyron smithii), and sun sedge (Carex heilophila).

Authors conclude that in Kentucky, bluegrass-dominated mixed grass prairie basal cover was relatively independent of grazing intensity. Grass cover and total aboveground herbaceous biomass was greatest in the non-grazed treatment. The study does not support the hypothesis that aboveground productivity is maximized at a moderate intensity of grazing. Root biomass was greatest in the non-grazed treatment with study concluding long-term moderate and heavy season-long grazing reduced root biomass in the upper soil profile.

Truett, J.C., 2003, Migrations of grassland communities and grazing philosophies in the Great Plains-A review and implications for management: Great Plains Research, v. 13, p. 3-26.

An assessment of implications of grazing by large herbivores on east-west migration of major grassland communities and discussion of changes in philosophies and implications of grazing regimes on grassland types and distributions are presented. The conclusion is that grazing does not necessarily "degrade" grasslands; it just alters structure and composition of the vegetative community. These changes are either favorable or detrimental to the extent they affect erosion of soil and the "desired" biological community. Author concludes increasing numbers of range scientists advocate grazing management shift from traditional model of light to moderate, uniform grazing to a regime based more on evolutionary grazing patterns. Such a management agenda would favor patchier grazing at various intensities to promote more diversity in grassland species, diversity in structural composition, and potential eastward expansion of short-grass ecosystems. The author bases his argument largely on the belief that such intensive grazing patterns may result in greater profitability for livestock producers and short-grass systems are intrinsically of more value than are mixed grass systems in Great Plains ecosystems.

Van Dyke, F., Van Kley, S.E., Page, C.E., and Beek, J.G., 2004, Restoration efforts for plant and bird communities in tallgrass prairies using prescribed burning and mowing: Restoration Ecology, v. 12, no. 4, p. 575-585.

Report provides description of mowing and burning management strategies for restoration and rejuvenation of tallgrass prairie (dominated by big bluestem [Andropogon gerardii], Indiangrass [Sorghastrum nutans], switchgrass [Panicum virgatum], and goldenrod [Solidago spp.]) in fragmented landscapes in Iowa. Many species of grassland birds are not area sensitive but are vegetation sensitive, responding to vegetation structure, diversity and habitat heterogeneity. Management treatments such as mowing and burning cannot change size, shape or areas of grassland but can alter grassland vegetation density and structure and can be important management tools. Response of vegetative and bird communities to management practices are discussed. Mowing did not affect species richness and diversity in plant communities but mowed sites were lower in total plant coverage and total forb coverage than burned or untreated sites. Untreated (unmowed and nonburned) sites had more coverage by shrubs suggesting mowing and burning did retard encroachment by woody vegetation.

Authors conclude that overall abundance and diversity of plants and birds were generally insensitive to management. Small fragmented sites may not respond in short term to management treatments nor be capable of supporting highly diverse communities regardless of how intensively they are managed. Diversity of native prairie communities can be enhanced only through long-term management, acquisition of large units of land capable of supporting stable populations, and intentional reintroduction of priority species. Management recommendations for increasing vegetative diversity are presented.

Warren, K.A., and Anderson, J.T., 2005, Grassland songbird nest-site selection and response to mowing in West Virginia: Wildlife Society Bulletin, v. 33, no. 1, p. 285-292.

Former hayfields and pastures are becoming a common component of the landscape in the eastern United States due to changing farming and land use practices as well as purchase of farmland for other uses. Authors report investigation of grassland bird nest site selection and success between idle and mowed pastures and hayfields. Dominant vegetation on study fields included orchardgrass (Dactylis glomerata), mountain oatgrass (Danthonia compressa), sweet vernalgrass (Anthoxanthum odoratum), quackgrass (Elymus repens), and timothy 
(Phleum pratense). Avian nests monitored included bobolink (Dolichonyx oryzivorus), eastern meadowlark (Sturnella magna), red-winged blackbird (Agelaius phoeniceus), and savannah sparrows (Passerculus sandwichensis).

Authors conclude management that increases vertical structure and density should be promoted for grassland birds through mowing, grazing, and prescribed burning to set back grassland succession. These management techniques are recommended to prevent encroachment of woody vegetation and excessive litter developing in undisturbed fields. Leaving blocks of cover idle for 1-4 yr is recommended to maintain overall diversity in vegetation composition.

Williams, D.W., Jackson, L.L., and Smith, D.D., 2007, Effects of frequent mowing on survival and persistence of forbs seeded into a species-poor grassland: Restoration Ecology, v. 15, no. 1, p. 24-33.

Enhancement of vegetation diversity in established communities is often difficult because established vegetation is resistant to colonization. Many attempts at restoration of tallgrass prairie have failed to achieve high diversity in species present. Survival of new or introduced species seedlings is generally restricted to larger openings in canopy due to greater availability of physical space, light, moisture, and nutrients. Authors report very frequent mowing in first and second year after introduction of forbs in established stands of grass to allow conditions favoring their establishment to enhance vegetative diversity in a 25 -yr-old prairie planting site in northern Iowa. Study site was initially dominated by smooth brome (Bromus inermis), Quackgrass (Agropyron repens) and planted to perennial $\left(\mathrm{C}_{4}\right)$ grasses consisting of big bluestem (Andropogon gerardii), little bluestem (Schizachyrium scoparium), switchgrass (Panicum virgatum), sideoats grama (Bouteloua curtipendula) and Indiangrass (Sorghastrum nutans) in 1973.

Forb seedlings in mowed plots grew larger and matured more quickly than did those in control plots (unmowed). Forbs in mowed plots had greater root and shoot mass than did those in control plots. Forbs in control plots began to decline as canopy of warm-season grasses increased. Four years after introduction, forbs twice as abundant in mowed plots as recorded in control plots. By year five, forbs were only half as abundant in unmowed plots as compared to treated plots. Seeded forbs in treated plots gradually increased in size over years becoming more visually dominant and eventually producing seed. Authors conclude addition of seed and a single year of managed mowing could turn species-poor grasslands into more diverse plant communities. Grazing may also be a useful approach in enhancement of vegetation diversity. In contrast to new seedings, succession/ restoration does not require intensive management beyond the first growing season.
Zukerberg, B., and Vickery, P.D., 2006, Effects of mowing and burning on shrubland and grassland birds on Nantucket Island, Massachusetts: Wilson Journal of Ornithology, v. 118 , no. 3, p. 353-363.

Paper reports results of management directed toward preservation and enhancement of early successional grasslands to maintain habitat quality for avian species dependent upon early stage grasslands. Habitat management was accomplished through burning and mowing (brush cutting). Over a 3-yr period songbird response varied among avian species as well as type of management applied. In shrublands mowing was the most effective method for restoring grassland habitat. Burning was reported to have little effect on abundances of shrubland birds and vegetation structure. Both burning and mowing were successful in restricting encroachment of shrubs into grasslands. Authors conclude effects of grassland restoration on generalist species will vary with management type and subtle habitat preferences of affected species. While several generalist species may inhabit the same habitat type differences in vegetative characteristics define the presence of each species. Habitat preferences for several species (for example, Eastern towhee [Pipilo erythrophthalmus], common yellowthroat [Geothlypis trichas], song sparrow [Melospiza melodia]) are described. Authors suggest a dynamic and diverse set of strategies should be integrated into management that furnishes some grassland areas in later stages of succession to maintain overall diversity in avian species.

\section{Pollinators, Invertebrates, and Miscellaneous Wildlife}

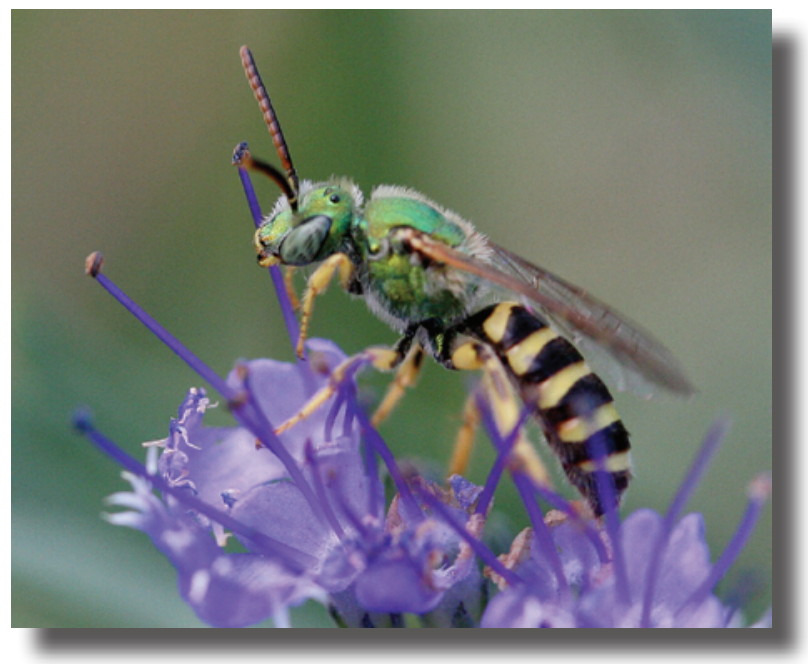

Photo credit: Sweat bee, David Leatherman

Aizen, M.A., Garibaldi, L.A., Cunningham, S.A., and Klein, A.M., 2009, How much does agriculture depend on pollinators? Lessons from long-term trends in crop production: Annals of Botany, v. 103, no. 9, p. 1579-1588. 
Animal pollination contributes to the integrity of most terrestrial ecosystems and has direct effects on biodiversity. The production and diversity of agriculture depends on biotic pollination. The productivity of many agricultural crops worldwide depends upon pollination by insects and other animals. Worldwide, the production and diversity of agriculture depends on biotic pollination particularly on the services provided by the honey-bee (Apis mellifera). The demand for pollination is rising at the same time pollinator populations are declining in abundance and diversity. Stocks of honey bees are experiencing many diseases. In North America, the number of managed honey-bee hives has declined almost 60 percent since the 1940s due to parasitic mites and other unidentified factors. Populations of wild pollinators species are also in decline, largely due to destruction of habitat, resulting in concerns that a potential global "pollination crisis" threatens food production.

While pollinator-dependent crops represent a larger proportion of total agricultural production in the developing world, future pollinator shortage is projected to result in expansion in cultivated area to compensate for lost production. Authors estimate that the percentage of cropland devoted to pollinator-dependent crops in the developed world increased from 18.2 percent in 1961 to 34.9 percent in 2006. In the developing world, pollinator-dependent crops increased from 23.4 to 32.8 percent in the same period. The developing world represents more than two-thirds of global agricultural production with production 50 percent more dependent on pollinators than that of developed countries. Losses of habitats and pollinator populations, particularly in the tropics, may accelerate deforestation and intensify pressures on remnant natural ecosystems as demand for agricultural land to compensate for these losses in production increases. The authors conclude that losses in pollinator benefits caused by human impacts will have direct effects on the quantity and diversity of food production. Attempts to compensate for these losses will accelerate habitat destruction and may cause even further losses in pollinators.

Bauer, D.M., and Wing, I.S., 2010, Economic consequences of pollinator declines-A synthesis: Agricultural and Resource Economics Review, v. 39, no. 3, p. 368-383.

The paper finishes a literature review of pollinator declines with resultant economic impacts, declines in ecological services, and concerns regarding global food security. Pollination is a priceless ecosystem service that furnishes a variety of benefits including food, fiber, plant derived medicines, genetic diversity, and overall ecosystem resilience. While recent declines in honey bees (Apis mellifera) have received much attention global declines in pollinator populations and species diversity raise concerns regarding risks to food security and economic development. Pollinator losses bring risks to ecosystem stability, biodiversity loss of pollinator species, and the plants they pollinate. Agricultural intensification, pests, disease, pesticides and habitat destruction have been linked to declines of both managed and wild insect pollinators. Even in plants that are wind and self-pollinated insect pollination can increase quantity and quality of production. Globally, 75 percent of primary crop species and 35 percent of crop production rely on some level of animal (insects, bats, birds) pollination. Within the United States, more than 50 percent of primary crops and 20 percent of crop production depend on animal pollination. Honey bee pollination in the United States has an economic value of $\$ 14.6$ billion/yr. Pollination by wild insects raises the economic value an unknown, but substantial, amount.

Wild pollinators are important for agricultural production whose importance varies by plant species, geographical location and time of year. Although most attention on pollinator declines has focused on impacts to agriculture implications reach into the structure of food webs, ecosystem health, and population dynamics of wild plants. Due to diminishing numbers and availability of honey bees, reliance on wild pollinators for agricultural production is projected to increase both globally and in the United States. The authors conclude wild pollination services will be under-provided without some type of government program or policy intervention. Loss of pollinator habitat is an issue of major concern. The authors further recommend development of conservation-based strategies for both on-farm and off-farm conservation of wild pollinator habitats.

Branson, D.H., 2005, Effects of fire on grasshopper assemblages in a northern mixed-grass prairie: Environmental Entomology, v. 34, no. 5, p. 1119-1113.

Grassland fires are capable of having positive or negative effects on grasshopper (Gomphocerinae) population densities. The timing and intensity of fire can have an important influence on population characteristics. The objective of this study was to examine effects of a late-fall wildfire on grasshopper density and community composition in a mixed-grass prairie. Common grasses on study sites included blue grama (Bouteloua gracilis), western wheatgrass (Pascopyrum smithii), and needle and thread grass (Hesperostipa comata). Authors report no statistically significant effect of fire on numerical species richness or an impact on grasshopper community structure. Mean grasshopper density was $5.2 / \mathrm{m}^{2}$ in burned plots and $5.4 / \mathrm{m}^{2}$ in unburned plots. Although fire did negatively affect grasshopper population densities, effects were short-lived.

Burger, L.W. Jr., Kurzejeski, E.W., Dailey, T.V., and Ryan, M.R., 1993, Relative invertebrate abundance and biomass in Conservation Reserve Program plantings in northern Missouri, in Church, K.E., and Dailey, T.V., eds., Quail IIINational Quail Symposium: Jefferson City, Mo., Missouri Department of Conservation.

CRP fields were planted to a red clover (Trifolium pratense)/timothy (Phleum pratense) mix and dominated by red clover had highest recorded levels of invertebrate 
abundance and biomass. Mean abundance and biomass of invertebrates in CRP fields were four times that of soybean fields. CRP fields could provide quality brood habitat if structural characteristics are consistent with quail brood foraging needs. Incorporation of a legume in CRP planting may produce higher invertebrate densities and improve value of these fields to avian broods.

Carroll, S.C., Rummel, D.R., and Segarra, E., 1993, Overwintering by the Boll Weevil (Coleoptera Curculionidae) in Conservation Reserve Program grasses on the Texas High Plains: Ecology and Behavior, v. 86, no. 2, p. 382-393.

The study objective was to determine if CRP grasses increased probability of development of resident boll weevil (Anthonomus grandis grandis) populations. CRP grasses furnished marginal over-wintering habitat for the species. Total winter survival and emergence of the species was consistently lower in CRP than recorded in native sand shinnery oak (Quercus havardii) habitats that served as a standard of comparison. Study results imply CRP grasses (weeping lovegrass, [Eragrostis curvula]) furnish marginal winter habitat for the boll weevil. Small numbers of the weevil did survive winter in CRP grasses; therefore, if surviving winter populations are large, potentially damaging populations could occur affecting adjacent cotton crops.

Cederbaum, S.B., Carroll, J.P., and Cooper, R.J., 2004, Effects of alternative cotton agriculture on avian and arthropod populations: Conservation Biology, v. 18, no. 5, p. 1272-1282.

Land devoted to cotton (Gossypium hirsutum) production is intensively managed with resultant poor habitat potential for wildlife. Application of pesticides is usually frequent and intensive. Under modern conventional methods of cotton production, lands devoted to this crop are of little value to wildlife. Sustainable farming methods of conservation tillage and intercropping hold promise as approaches to creating a more diverse agroecosystem and reducing costs for farmers. Report presents effects of clover (Trifolium spp.) strip cover cropping with conservation tillage with conventional methods of cotton production and conservation tillage methods on avian and arthropod species composition and field use in east-central Georgia. Fields where strip cover had been incorporated had higher densities of birds and higher relative abundance of arthropods than found within both conservation tillage and conventional fields. During periods of migration and breeding, total densities of birds on strip cover fields were 2-6 times and 7-20 times greater than on conservation tillage and conventional fields, respectively. Findings suggest both conservation tillage and strip cropping will improve avian habitat conditions in cotton production systems with strip cropping furnishing superior habitat. Reduction in inputs with clover systems could allow lower production costs by \$282-\$317/ac.
Davros, N.M., Debinski, D.M., Reeder, K.F., and Hohman, W.L., 2006, Butterflies and Continuous Conservation Reserve Program filter strips-Landscape considerations: Wildlife Society Bulletin, v. 34, no. 4, p. 936-943.

Paper describes investigation of effects of filter strips along southwestern Minnesota waterways on abundance and diversity of butterfly communities. Row crops dominated the study area accounting for an average of 85 percent of landscape cover. Herbaceous dominated cover accounted for 9 percent of landscape. Butterfly use of filter strips was influenced by local and landscape level variables. Butterfly abundance and density were generally positively associated with greater width of filter strips. Authors recommend establishment of filter strips of maximum width possible with plantings comprised of diverse species composition and structure.

Davis, S.S., 1998, Effects of prescribed fire on small mammal and beetle assemblages in Conservation Reserve Program (CRP) grasslands: Lubbock, Tex., Texas Technical University, M.S. thesis, $55 \mathrm{p}$.

Author examines effects of prescribed fire on small mammal and beetle populations in CRP fields dominated by weeping lovegrass (Eragrostis curvula) in Lynn County, Tex. Twelve sample sites were stratified by canopy cover of vegetation. Small mammal species collected included: deer mouse (Peromyscus maniculatus), hispid pocket mouse (Chaetodipus hispidus), Cotton rat (Sigmodon hispidus), western harvest mouse (Reithrodontomys megalotis), northern grasshopper mouse (Onychomys leucogaster) and, spotted ground squirrel (Spermophilus spilosoma). Results suggest that rodents living in weeping lovegrass monocultures select different cover based on microhabitat conditions. Lovegrass habitats following fire are continually being optimized by changing groups of rodents even when vegetative cover returns to pre-burn conditions. Although small mammals are typically not considered important in decisions for CRP management, their presence can be important by increasing diversity of wildlife and supporting avian and mammalian predators.

Sampling showed 13 different families of beetles present in lovegrass CRP fields. June and dung beetles (Scarabaeidae), darkling beetles (Tenebrionidae), and blister beetles (Meloidae) were not affected by fire. Ground beetles (Carabidae) and tiger beetles (Cicindelidae) beetles show population increase in response to fire. Author concludes beetle families most affected by fire are those dependent upon litter and detritus for suitable habitat. Author concludes species dependent on thick layer of litter are reduced by application of prescribed fire.

Dievert, E.J., and Utter, R.A., 2003, Earthworm (Lumbricidae) survey of North Dakota fields placed in the U.S. Conservation Reserve Program: Journal of Soil and Water Conservation, v. 58, no. 1, p. 39-45. 
Twenty-three sites in ND CRP fields (5-8 yr old) were surveyed for presence and type of earthworms. Sites with earthworms were associated with organic matter levels greater than 2.5 percent. Sites without earthworms were characterized as having high content of sand (67 plus or minus 13 percent) with soil containing sharp crystals or grains that might not be suitable for inhabitation by earthworms. Total earthworm population estimates from five sites average 6.3 million/ ha $(2.5 \mathrm{million} / \mathrm{ac})$. Presence of wetlands or tree-dominated habitats in fields could not be used as criteria for determining presence of earthworms.

Doxon, E.D., and Carroll, J.P., 2007, Vegetative and invertebrate community characteristics of Conservation Reserve Program fields relative to gamebirds in western Kansas: American Midland Naturalist, v. 158, no. 2, p. 243-249.

Vegetative and invertebrate characteristics are examined in Kansas CRP fields planted to: Native grass (CP2), Established Grass (CP10), and Rare and declining habitat (CP25). CP10 fields were $7-10$ yr old. CP2 and CP25 fields were 3-5 years old. None of the fields evaluated had been hayed, burned, or grazed in the $3 \mathrm{yr}$ previous to the study. Fields were planted to native grasses including western wheatgrass (Pascopyrum smithii), Indiangrass (Sorghastrum nutans), switchgrass (Panicum virgatum), sideoats grama (Bouteloua curtipendula), little bluestem (Schizachyrium scoparium), and big bluestem (Andropogon gerardii). CP2 fields were seeded with alfalfa (Medicago saliva). CP25 mixes were comprised of native grasses and wildflowers such as Maximilian sunflower (Helianthus maximiliani) purple prairie clover (Dalea purpurea), prairie coneflower (Ratibida columnifera), and Illinois bundleflower (Desmanthus illinoensis).

Wheat (Triticum aestivum) fields were found to support less invertebrate biomass than CRP fields. Bare ground in CRP fields averaged 10 percent while forb cover was generally less than 20 percent. Invertebrate abundances were not significantly different among the CRP types evaluated. Conservation practices that incorporated some forbs in the planting mix had more stable, even increases, in invertebrate biomass and abundances. Unharvested wheat and CP10 fields had the greatest number of insect-prey. CRP produced more quality insect-prey than did wheat except when compared to unharvested wheat fields. Because invertebrate abundance varied within field types throughout the growing season, the authors suggest a mix of CRP practices across the landscape. Most fields were believed to provide excellent brood-rearing and feeding opportunities for gamebird chicks.

Fox, T.B., Landis, D.A., Cardoso, F.F., and Difonzo, C.D., 2004, Predators suppress Aphis glycines Matsumura population growth in soybean: Environmental Entomology, v. 33, no. 3, p. 608-618.
The soybean aphid (Aphis glycines) is an invasive species first discovered in Wisconsin in 2000. Currently distributed across 19 states and parts of Canada, the species interacts with both native and naturalized predators present in soybean ecosystems. In the United States, populations of this aphid have been reported to cause up to 40 percent decline in seed yield and up to 50 percent reduction in photosynthetic rates for soybean leaves infested. The aphid can also introduce other diseases (for example, soybean dwarf, tobacco ringspot, and yellow mosaic viruses) into soybean fields. These aphids also cause indirect damage by excreting honeydew which promotes growth of molds that reduce productivity of plants.

The purpose of this investigation was to determine if native predators had an effect on population dynamics of this potentially economically significant invasive species. The evaluation shows natural predators play an important role in control of A. glycines. By attacking aphids before they reached high numbers even a low density of natural (native) predators was able to suppress this pest.

Although the authors do not specifically state this, the implication of this study is preservation of native vegetative communities that support indigenous invertebrate predatory species, interspersed with lands in soybean production can be an effective means to control this pest species.

Haysom, K.A., McCracken, D.I., Foster, G.N., and Sotherton, N.W., 2004, Developing grassland conservation headlands-Response of carabid assemblage to different cutting regimes in a silage field edge: Agriculture, Ecosystems and Environments, v. 102, p. 263-277.

European agricultural landscapes have experienced the same intensification of production as seen in the United States. Increased use of nitrogenous fertilizers, wide-scale application of pesticides, simplification of the agricultural landscape, and replacement of small scale mixed farming with larger specialized farming operations have had substantial impacts on availability of wildlife habitats and biodiversity in agriculturally dominated landscapes. Authors discuss development and implementation of conservation headlands in croplands and their relation to improving availability of invertebrate foods for avian species. Butterflies, small mammals and songbirds have also shown positive response to creation of headland habitats in arable fields. Authors evaluate and advocate use of headland concept in grass-dominated crop (pastures, silage) where margins of fields are established by sowing a grass/herb mix or allowing natural regeneration to proceed. In addition to changes in vegetation structure, frequent harvest of grass crops can modify substrate characteristics affecting invertebrate composition. Carabid beetle assemblages increased in uncut margins and in margins cut only once each summer. Result of low intensity management in margins was increase in effective area of intercrop habitat. Authors recommend use of headland concept in grass-dominated croplands is a useful tool for improvement of habitat quality in agriculturally dominated landscapes. 
Hendrix, P.F., Parmelee, R.W., Crossley Jr., D.A., Coleman, D.C., Odum, E.P., and Groffman, P.M., 1986, Detritus food webs in conventional and no-tillage agroecosystems: Bioscience, v. 36, no. 6, p. 374-380.

Conservation tillage-crop planting systems leave 30 percent or more of crop residues on soils surface. Area in conservation tillage is $24-36$ million hectares (9.4-14 million ac) or about one-third of the Nation's cropland. Conservation tillage creates conditions similar to those of undisturbed ecosystems when compared to conventional tillage. No-till soils usually are physically and chemically stratified with more nutrients near the surface. Plowed soils often show increased organic matter decomposition and nutrient mineralization. Nutrient uptake by crops and weeds is often higher in conventionally tilled systems. In natural ecosystems, both direct and indirect interactions among soil biota are involved in decomposition of organic matter. No-till abundance and activity of fungivorous fauna increase in surface layers, and mineralization proceeds more slowly, thereby enriching soil. Decomposing residue plus microbes and microconsumers serve as food for macroconsumers. Organic pool should grow larger over time under no-till management. No till appears to increase importance of fungi relative to bacteria as primary decomposers, which provide a resource base for the detritus food web. Plowing creates conditions favorable to bacteria based food webs composed of disturbance-adapted organisms with high metabolic rates causing faster decomposition of organic matter and nutrient mobility.

Hoernemann, C.K., Johnson, P.J., and Higgins, K.F., 2001, Effects of grazing and haying on arthropod diversity in North Dakota Conservation Reserve Program grasslands, in Proceedings of the South Dakota Academy of Science: Mitchell, S. Dak., South Dakota Academy of Science, v. 80, p. 283-308.

Authors report that the majority of arthropod fauna was not adversely affected in abundance or diversity when subjected to moderate levels of grazing or haying. Maintenance of diverse arthropod populations ensures food for wildlife species in CRP habitats and prevents population outbreaks by insect pest species. Results suggest that grazing and haying of CRP lands are viable post-contract uses with regard to maintaining diverse arthropod populations.

Hull, S.D., Robel, R.J., and Kemp, K.E., 1996, Summer avian abundance, invertebrate biomass, and forbs in Kansas CRP: Prairie Naturalist, v. 28, no. 1, p. 1-12.

Invertebrate biomass and avian abundance evaluated in six Kansas native grass CRP fields. Analysis did not detect a statistically significant relationship between forb abundance and invertebrate biomass or avian abundance. Avian community assemblages in CRP fields with low and high forb abundances were similar. Authors suggest that a lack of statistically significant relationship does not mean assumption of greater abundance of forbs relates to greater availability of food for avian species is invalid. Half of invertebrate biomass collected was grasshoppers but not identified as to being grass or forb-dependent species. None of sampled fields had forb coverage exceeding 24 percent, which may have been below canopy coverage threshold to detect significant differences. Authors conclude different results may have been found with a larger sample size and greater spread in forb canopy cover (for example, $0-80$ percent rather than $0-23$ percent). Future research should address these shortcomings.

Jonas, J.L., Whiles, M.R., and Charlton, R.E., 2002, Aboveground invertebrate responses to land management differences in a central Kansas grassland: Environmental Entomology, v. 31, no. 6, p. 1142-1152.

Invertebrate community diversity and dynamics are tightly associated with plant communities. Incorporation of invertebrate communities into assessment programs can enhance sensitivity at smaller spatial and temporal scales than can assessment for larger avian or mammalian species. Invertebrate diversity is often related to plant species diversity, structural diversity, patch size, and density. Author provides justification of why Coleoptera (beetles) and Orthoptera (grasshoppers, crickets, mantids, katydids, walkingsticks) are invertebrate groups with characteristics suitable for monitoring grasslands. Study objective was to examine responses of invertebrates to different land management practices in a Great Plains grassland system. Evaluation completed in smooth brome (Bromus inermis) and mixture of tallgrass and mixedgrass prairie and old-field sites. Dominant grasses in oldfield sites were Kentucky bluegrass (Poa pratensis) and big bluestem (Andropogon gerardii) in prairie sites. Forb species cover was 11 percent in brome, 15 percent in old fields, and 7 percent in prairie sites. Old-field sites had significantly higher plant species richness than brome or prairie sites.

Invertebrates in general and Orthoptera and Coleoptera responded to differential land use and appeared most related to plant structural diversity and native plant species abundance. Coleopteran richness and diversity were generally lowest in brome fields. Orthopteran abundance and diversity was negatively correlated to native plant species abundance. Author speculates orthopteran distribution patterns of distribution may be related to land use and mechanical disturbance. Grasshopper distribution may be more related to accumulated surface and standing plant litter than to plant species composition. All prairie sites in study had been annually hayed which greatly reduced vegetative litter that may have negatively affected habitat quality for eggs and early instar nymphs. Brome and old fields, where orthopteran values were greatest were not regularly hayed. 
Kremen, C. N., Williams, M., and Thorp, R.W., 2006, Crop pollination from native bees at risk from agricultural intensification: Proceedings National Academy of Science, v. 99, no. 26 , p. $16812-16816$.

Ecosystems services are critical to human survival, which often is a strong argument for preservation of biodiversity. However, economic and ecological benefits furnished by these services are poorly understood and rarely incorporated into landscape management plans. American farmers have been dependent upon European honey bees (Apis mellifera) to furnish pollination services in agricultural production. These colonies are becoming scarce due to diseases, pesticides, and other impacts. Native bees also provide essential pollination, but the amount provided and effects of land use are poorly defined. Native bees can provide full pollination services; however, diversity in landscape vegetation composition is essential for sustaining this service. Continued degradation of the agricultural and natural landscape interface will continue to have negative impact on the benefits brought by these species.

Animals, particularly bees, pollinate over 66 percent of the world's 1,500 crop species. Currently, agriculture relies on only 11 of the 20,000 to 30,000 species of bees worldwide. Economic worth of honey bee pollination in the United States is \$5-14 billion per year. Invasion by the Africanized race of A. mellifera continues to spread north, creating loss of efficiency and liability concerns for bee keepers.

Authors believe native bee communities can provide equivalent services to that of managed honey bees if habitats of sufficient quality and distribution are maintained in association with agricultural land use. Isolation of floral and nesting resources in wildlands (for example, non-cultivated) is likely a key factor affecting the numbers and distribution of native bees. Native bee diversity and abundance is significantly related to the proportional area of uncultivated habitat associated with agricultural land. Use of insecticides and herbicides in conventional agriculture are also likely to negatively impact bee populations. The preservation of native vegetation in small fragments of habitat within larger context of agricultural landscape would benefit bees as well as other insect species. Authors suggest the CRP could play a significant role in enhancement and lessening costs for provision of needed habitats for these species. Restoration of bees and their habitats could benefit native plants and promote conservation of biodiversity across the agro-natural landscape.

Landis, D.A., Wratten, S.D., and Gurr, G.M., 2000, Habitat management to conserve natural enemies of arthropod pests in agriculture: Annual Review Entomology, v. 45, p. $175-201$.

As a result of frequent disturbance, intensity of land use, and growing dependence on agrochemicals, agricultural landscapes are particularly difficult environments to maintain indigenous species furnishing biological control of cropland plant pests. This document furnishes a review of recent literature focused on management of vegetation covers to favor natural enemies of agricultural pests by integrating suitable covers spatially and temporally in agricultural landscapes. Manipulation favoring biological control is focused on provision of suitable covers to favor survival, fecundity, longevity, and behavior of natural predators to increase their effectiveness in control of crop pests. Management of habitats may occur at within-field, within-farm, or at landscape scales. Establishment of non-farmed sites supporting perennial flowering plant species interspersed with croplands is a fundamental concept in this approach to enhancing biodiversity and control of insect pests.

Simply increasing diversity of plant covers, however, can increase pest problems. Consequently, it is important to identify key elements of plant diversity needed by natural enemies of crop pests. Key elements include improving availability of alternative foods such as nectar, pollen, providing shelter or microclimates in which natural enemies overwinter, and furnishing habitats in which alternative hosts or prey can survive. Successful implementation of natural predator conservation involves evaluation of disturbance in agricultural landscapes. Cover cropping, intercropping, and reduced tillage are alternatives to lessening disturbance. Habitat management may not always require radical changes in farming practices and may not require taking land totally out of production. Alternatives and examples of approaches to enhance agricultural landscapes to make pest management more effective and production systems more sustainable are presented.

Lewis, T., 1969, The diversity of insect fauna in a hedgerow and neighboring fields: Journal of Applied Ecology, v. 6, no. 3 , p. $453-458$.

Hedgerows contribute to enriched insect fauna in neighboring fields. In terrestrial insect communities, diversity was greatest in hedge, lower in beans, and least in pasture. Diversity of aerial insects decreased in response to increasing distance from the hedge. Presence of hedge enriched aerial population for a distance from trees to 10 times tree height on downwind side and one to two times on upwind side of hedgerow.

Losey, J.E., and Vaughan, M., 2006, The economic value of ecological services provided by insects: Bioscience, v. 56, no. 4 , p. 311-323.

Authors estimate ecological services (dung burial, pest control, pollination, and nutrition for wildlife) provided by wild insects in the United States to be at least $\$ 57$ billion. Economic value estimates for each service are: dung burial $\$ 0.38$ billion, pollination $\$ 3.07$ billion, pest control, $\$ 4.49$ billion, and wildlife-related recreation $\$ 49.96$ billion. These are believed to be very conservative estimates of the ecological values furnished by insects within the United States. Other environmental services provided by insects include 
suppression of weeds and other exotic herbivorous species, facilitation of dead plant and animal decomposition, and improvement of soil condition. The correct value of any of these services could add billions of dollars to these estimates.

Economic and ecological benefits of dung beetles (primarily Scarabaeidae) are discussed with benefits including improvement in soil, volatilization of nitrogen, diminished fouling of forage and control of livestock parasites and pests. Pollination is the most widely known benefit of insects with 15 to 30 percent of the diet of U.S. citizens directly or indirectly dependent upon pollination by insects. Available information suggests that control of insect pests costs the U.S. economy billions of dollars each year, but this is only a fraction of the economic impact if beneficial insects did not keep most pests below economically damaging levels. U.S. citizens spend over $\$ 60$ billion a year on hunting, fishing and observing wildlife. Insects are a critical food source for much of this wildlife. The predominant benefit of insects is concentrating and moving nutrients through the food web.

The authors conclude annual investment of tens of billions of dollars could be economically justified to maintain services provided by insects. There has been a steady decline in beneficial insects associated with diminishing biodiversity accompanied by severe declines in the quality of environments heavily impacted by human activities. Authors recommend a diversity of plant species in restoration or conservation projects to support viable and diverse populations of insects. Authors recommend that USDA conservation programs pay specific attention to insects and the roles they play in ecosystem functioning. Insects and their needs should be considered in land-management decisions. A diverse community of forbs should be included with any restoration of habitat or riparian bank projects.

McIntyre, N.E., 2003, Effects of Conservation Reserve Program seeding regime on harvester ants (Pogonomyrmex), with implications for the threatened Texas horned lizard (Phrynosoma cornutum): The Southwestern Naturalist, v. 48, no. 2, p. 274-313.

Abundance of harvester-ant nest sites, primary prey for endangered Texas horned lizard, are evaluated in CRP grasslands and native prairie in Texas panhandle sites. CRP fields evaluated were planted to old world bluestem (Bothriochloa ischaemum), weeping lovegrass (Eragrostis curvula), or mixtures of native grasses with and without buffalograss (Buchloë dactyloides). Native grass CRP plantings were dominated by sideoats grama (Bouteloua curtipendula), blue grama (B. gracilis) and switchgrass (Panicum virgatum). (Estimates of field age, comparisons of density and other vegetation characteristics between seeded and native grasslands were not described). The fewest ant mounds were found within fields planted to old world bluestem. Native (ungrazed) grassland had highest density of ant mounds. However, no significant difference between abundance of ant mounds in native and exotic CRP plantings were reported. Author concludes there is no evidence CRP plots planted to exotic grasses are poorer habitat for Texas horned lizards in terms of ant abundance than are native plantings.

McIntyre, N.E., and Thompson, T.R., 2003, A comparison of Conservation Reserve Program habitat plantings with respect to arthropod prey for grassland birds: American Midland Naturalist, v. 150, no. 2, p. 291-301.

Authors compared arthropod abundance in four CRP cover types: lovegrass (Eragrostis curvula), old world bluestem (Bothriochloa ischaemum), mixed native grasses (primarily sideoats grama [Bouteloua curtipendula] and switchgrass [Panicum virgatum]) with and without buffalo grass (Buchloë dactyloides) and native shortgrass prairie (that is, non-CRP) in Texas panhandle. Sampling focus was on adult and juvenile spiders (Order Araneae), beetles (Coleoptera), grasshoppers and crickets (Orthroptera), and butterflies and moths (Lepidoptera). Arthropod diversity was higher on indigenous short grass prairie when compared to CRP. The highest diversity in arthropods was recorded in native short grass prairie plot, which had the greatest vegetative diversity of all study plots. There were no significant differences in arthropod richness or abundance between types of CRP grasslands. Report concludes that CRP grasslands are not equivalent to native prairie in terms of vegetation or arthropod diversity but CRP lands do support arthropod prey for grassland birds. Results indicate plantings established in early years of CRP (old world bluestem, weeping lovegrass), as well as, more recently established stands of native grasses provide arthropods and habitat for avian species.

Millenbah, K.F., 1993, The effects of different age classes of fields enrolled in the Conservation Reserve Program in Michigan on avian diversity, density, and productivity: East Lansing, Mich., Michigan State University, M.S. thesis, $138 \mathrm{p}$.

Avian communities and vegetative characteristics examined in 6 age-class fields (1-6 growing seasons) in central Michigan to determine relations between field age and characteristics of avian communities. Younger CRP fields, characterized by dominance of forbs and bare ground, supported greater avian densities and diversities than older fields. Older fields supported greater height of grasses and litter cover. Grassland birds may require a diversity of age classes of CRP fields in agricultural landscapes to meet habitat requirements. Results suggest relationship between age of field and relative avian abundance, diversity, and productivity. Younger fields supported greater diversity and density of avian species. Older fields with greater litter cover and grass cover supported the greatest productivity. One-year-old CRP fields had greatest diversity of avian species. As fields aged, avian diversities declined but productivity increased. Both the number of active nests and successful nests were greatest in older fields. Litter 
cover serves as mechanical barrier to seedlings, decreasing the amount of light energy available for growth. On new fields horizontal cover is sparse. As forb and grass cover increased through the fourth growing season, horizontal cover increased. As fields became more grass-dominated and sparser during years 5 and 6 , horizontal cover decreased.

Greater biomass and diversity of insects were available in younger fields. Few significant differences were found among field-age classes, but mean insect diversities and biomass generally decreased as fields aged with younger fields furnishing greater diversity. Seventy percent of surveyed landowners gave improvement of wildlife habitat at least some importance in enrollment into CRP. Authors recommend controlled disturbance in years 4-6 of typical CRP grassland contract. Disturbances that provide multiple successional stages may best provide for concurrent high density, diversity, and productivity of avian species.

Morandin, L.A., and Winston, M.L., 2006, Pollinators provide economic incentive to preserve natural land in agroecosystems: Agriculture, Ecosystems and Environment, v. 116, p. 289-292.

Globally, conversion of natural ecosystems to agriculture is a major cause for losses in biodiversity. While natural patches of vegetation within agricultural landscapes are often viewed as a source of weeds, pests, and a hindrance to farming operations, these areas furnish biodiversity refuges, habitat corridors, and source areas for pollinating insects. Despite their economic and environmental benefits, natural pollinators are rarely taken into consideration in landscape planning. The economic value of natural pollinators remains largely undefined. This paper describes an evaluation completed in Alberta, Canada, of wild bee populations on canola (Brassica napus) production and yield.

Bee abundance was greatest in canola fields having more uncultivated land within $750 \mathrm{~m}$ ( $820 \mathrm{yd}$ ) of field edges. Abundance of bees increased in response to weed cover within fields and in uncultivated areas around canola fields. The authors conclude that seed production and crop yield could be increased by greater amounts of uncultivated habitats within the vicinity of canola fields. Authors estimate that pollination by wild bees could account for up to 38 percent increase in profits. The importance of pollinating insects to crop yield is not unique to canola implying uncultivated land interspersed with cropland has substantial potential to enhance natural pollination, crop yields and ultimately economic profits to farm operators.

Ostman, O., Ekbom, B., Bengtsson, J., and Weibull, A., 2001, Landscape complexity and farming practice influence the condition of polyphagous carabid beetles: Ecological Applications, v. 11 , no. 2 , p. $480-488$.

Authors attribute design of landscape structure in farming ecosystems having an influence on abundance of carabid beetles and potential biological control of pests in crop fields. Carabid beetles are predators of cereal aphids. Increased abundance of these predatory species could decrease aphid abundance in crop fields. Large degree of variability in physical condition of these ground beetles can be attributed to landscape factors including perimeter-to-area ratio of cultivated fields. These findings could be due to better feeding conditions at field borders, which are relatively more abundant on farms with high perimeter-to-area ratio. Beneficial attributes include proximity to several alternative habitats. Field borders are important to overwintering success of these species. Superior overwintering sites may result in reduced energy use during winter, which may in turn affect physical condition of beetles the following spring and summer.

Phillips Jr., S.A., Brown, C.M., and Cole, C.L., 1991, Weeping lovegrass, Eragrostis curvula (Schrader) Nees Von Esenbeck, as a harborage of arthropods on the Texas High Plains: The Southwestern Naturalist, v. 36, no. 1, p. 49-53.

Evaluation completed in 1984-1985 to determine arthropod fauna harbored by weeping lovegrass due to concern insects associated with the grass species extensively planted under the CRP would be detrimental to local or adjacent cotton crops. Results indicate large-scale plantings of weeping lovegrass will not be detrimental to the agro-ecosystem and may be beneficial through provision of habitat for predators and parasitoids of cotton pests.

Reeder, K.F., Debinski, D.M., and Danielson, B.J., 2005, Factors affecting butterfly use of filter strips in Midwestern USA: Agriculture, Ecosystems and Environment, v. 109, p. $40-47$.

Authors report results of investigating butterfly abundance and diversity relations to vegetative variables in filter strips in an agriculturally dominated landscape in southwest Minnesota. Filter strips evaluated were 3-7 yr old and dominated by "non-native" species, switchgrass (Panicum virgatum), and native vegetation. Buffer strips were present on both sides of streams and bordered by corn, soybeans, or wheat. Variation in management of filter strips was not an issue; none were treated with insecticide or fertilized. Filter-strip width did not differ significantly among planting treatments and ranged from 18 to $167 \mathrm{~m}$ (20 to $183 \mathrm{yd}$ ) for all plantings. Diversity of butterflies was positively correlated with width of filter strips, but abundance was not. Abundance and species richness of habitat sensitive (area) was positively related to width of filter strips. Authors conclude species adapted to tallgrass prairie and sensitive to disturbance may not benefit from narrow filter strips. The majority of butterflies exhibited a positive relationship to coverage of forbs. Although narrow strips were used by butterflies wider planting supported a higher diversity and larger abundances of butterflies. Increasing height and vertical density of vegetation may also influence richness of habitat 
sensitive species. Authors believe control of Canada thistle (Cirsium canadensis) through use of broad-leaved herbicides kills other beneficial forbs having a negative effect on butterfly populations.

Ries, L., and Debinski, D.M., 2001, Butterfly responses to habitat edges in the highly fragmented prairies of central Iowa: Journal of Animal Ecology, v. 70, p. 840-852.

Remaining natural habitats continue to become fragmented by human activity elevating risks for animal populations occupying these areas to become more isolated and vulnerable to processes that may cause local extinctions. However, little is known about how animals move through diverse landscapes and features of habitat that can enhance movements. Prairie ecosystems are considered one of the most endangered in the United States with between 82 percent and 99 percent eliminated. Iowa has suffered from the greatest losses with less than 0.01 percent of tallgrass prairie remaining. Row crops, roads, or treelines border the majority of prairie remnants.

The authors use data collected on behavior of two butterfly species, a habitat specialist, Regal fritillaries (Speyeria idalia) and generalist, monarch (Danaus pexippus), in prairie cover types to determine the extent to which edges are barriers to emigration. Authors conclude edges between habitats can act as barriers to movement even when adjacent habitats are structurally similar. Prairie remnants in Iowa are small ranging from 1 to 10 hectares ( 0.4 to $4 \mathrm{ac}$ ) resulting in a high emigration rate of butterflies. Increased dispersal may have an overall negative effect resulting in drain on local populations. Consequently modification of edge structure to reduce dispersal may become an important management option but further evaluation is needed. Response of butterflies to prairie edges is highly variable dependent on species, edge characteristics and local environmental conditions. Management plans should be based on responses of several species.

Robel, R.J., Press, B.M., Henning, B.L., and Johnson, K.W., 1995, Nutrient and energetic characteristics of sweepnetcollected invertebrates: Journal Field Ornithology, v. 66, no. 1, p. $44-53$.

An evaluation of invertebrate production in CRP grasslands is provided, but authors conclude sweepnet samples do not represent an accurate picture of invertebrate biomass available to birds. They do, however, state that the samples reflect taxonomic heterogeneity of invertebrate biomass in vegetative canopy of grasslands. Efforts to understand interactions of food resources and reproductive strategies require more precise data. Food resources are highly variable depending on taxonomic composition of insect biomass. Factors that influence differences in nutrient and energy contents of invertebrate taxonomic groups include genera or species within the samples, proportion of adult and immature individuals in the sample, levels of nutrients in food substrate, and life-history characteristics of species within taxonomic group. Need to know year-to-year or site-to-site differences in characteristics of avian food source to define suitability of food resources and predict avian behavior.

Southwick, E.E., and Southwick Jr., L., 1992, Estimating the economic value of honey bees (Hymenoptera: Apidae) as agricultural pollinators in the United States: Journal of Economic Entomology, v. 85, no. 3, p. 621-633.

Economic value of honey bees (Apis mellifera) to pollination of agricultural crops are presented as are economic gains to consumers through lower prices for crops benefited by pollination. Annual social gains are estimated to range between $\$ 1.6$ and $\$ 5.7$ billion. Demand for pollination services is greatest in monoculture production and where hybrid seed is used. Important crops include vegetables, fruits, clovers, oilseeds, alfalfa, soybeans, hay, forage crops, nuts, and flowers. In addition to the introduced European honey bee, there are about 3,500 native species of bees in North America of which many play an important role in pollination. About 130 crops in the United States are dependent upon pollination by honey bees and other native species. It is believed production of fruit, seed and nut crops would decline by about 90 percent without the pollination services provided by honey bees. Honey bees are often credited for pollination actually performed by other bee species and insects but the economic value of these species remains unknown and largely underappreciated. In addition to the services provided to agricultural production, bees pollinate vegetation which enhances property values in wilderness, urban and watershed areas.

Several factors have, or will, influence honey bee population that include introduced mites parasitic to honey bees, spreading diseases affecting bee populations, northward movement of Africanized honey bees (A. m. scutellata), and the negative effects of increased use of pesticides.

Taylor, R.L., Maxwell, B.D., and Boik, R.J., 2006, Indirect effects of herbicides on bird food resources and beneficial arthropods: Agriculture Ecosystems \& Environment, v. 116, p. $157-164$.

This paper reports relations between agricultural herbicides and food webs and how changes in the plant community affect abundance of arthropods. The study focuses on insects eaten by ring-necked pheasant (Phasianus colchicus) and gray partridge (Perdix perdix) chicks as well as arthropods that prey on insect pests and weed seeds. Beneficial insects were more common in weedy vegetation communities found within monocultures. Study demonstrates herbicides do affect abundance of beneficial insects that are food for avian species and predators of less desirable species. The study confirms herbicides do reduce numbers and biomass of insects important to game species, as well as others dependent upon insects for food, by altering the beneficial effects of vegetation 
composition and diversity. Weedy plots contained 12 times the biomass of vegetation dwelling insects than did monocultures. Vegetation plots with intermediate diversity in vegetation held 8 times the biomass of insects found within monocultures. After spraying bromoxynil and imazamethabenz insect abundance in weedy plots was diminished to 3 and 2 times that recorded in monocultural plots. Authors advocate use of headlands, where herbicides are not used, interseeding, and greater use of narrow spectrum herbicides to lessen losses of beneficial insects in agroecosystems.

Thomas, M.B., Wratten, S.D., and Sotherton, N.W., 1991, Creation of island habitats in farmland to manipulate populations of beneficial arthropods-Predator densities and emigration: Journal of Applied Ecology, v. 28, no. 3, p. 906-917.

Replacement of natural vegetation by crop monocultures eliminates presence of many indigenous insects. Diversity in habitat structure on both macro and micro scales will enhance abundance and diversity of insect populations associated with agricultural ecosystems. Decrease in diversity of habitats resulting from larger fields results in lower density of insects in interiors of larger fields.

Whitmore, R., 1982, Insect biomass in agronomic crops as food for ring-necked pheasant chicks: Lincoln, Nebr., University of Nebraska Lincoln, Ph.D. Dissertation, 64 p.

Corn, soybeans, and alfalfa had significantly lower amounts of insect biomass than recorded in wheat, oats, sweetclover, and oats-sweetclover. Estimated numbers of chicks/ha supported by insect biomass found in specific crops: corn, 8; soybeans, 10; sweetclover, 64; oats, 86; and oatssweetclover, 106.

Weibull, A., Bengtsson, J., and Nohlgren, E., 2000, Diversity of butterflies in the agricultural landscape-The role of farming system and landscape heterogeneity: Ecogeography, v. 23, p. 743-750.

Variation in landscape heterogeneity is more important than composition of the farming system (organic vs. conventional) for butterfly diversity and abundance. Authors express the opinion that the belief that organic farming always enhances diversity is not necessarily true. Landscape structure, but not always farming, practices have effects on diversity. Farmers of all kinds should be encouraged to increase the small-scale diversity of vegetation associated with farming operations to enhance habitat/species diversity. Simple methods such as leaving small habitat islands or strips within and between fields, increasing area and distribution of field margins should be encouraged. (Study completed in Sweden).

\section{Mammals}

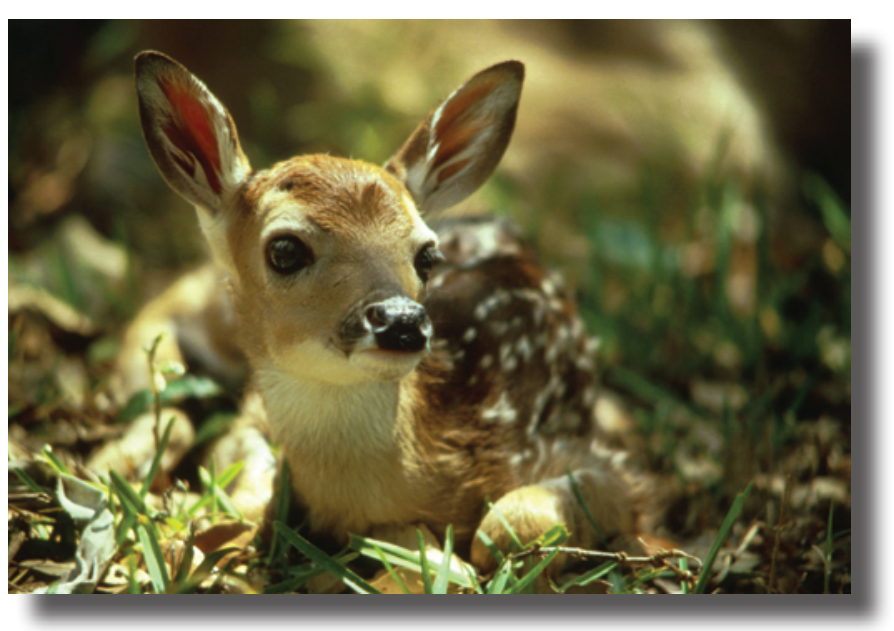

Photo credit: White-tailed deer fawn, Tom Stehn, U.S. Fish and Wildlife Service

Cline, G.A., 1988, Habitat relationships of bobwhite quail and cottontail rabbits on agricultural lands in Halifax County, Virginia: Blacksburg, Va., Virginia Polytechnic Institute and State University, M.S. thesis, 99 p.

Evaluation of a Habitat Suitability Index (HSI) model developed for assessment of bobwhite quail habitat. Wooded fallow fields, length of pasture/fallow, forest/forest edge, and total number of all edges present were positively related to quail presence. Management recommendations include maximizing the number of different edges and number of fallow fields in early successional stages. Cultivation of field borders, corners, waterways and other idle areas should be discouraged. A large number of small fields, each with a fallow or brushy border, are better than same acreage encompassed in only a few fields. Author concludes HSI model can correctly predict which habitats are preferred by bobwhite quail.

Davis, S.S., 1998, Effects of prescribed fire on small mammal and beetle assemblages in Conservation Reserve Program (CRP) grasslands: Lubbock, Tex., Texas Technical University, M.S. thesis, 55 p.

Author examines effects of prescribed fire on small mammal and beetle populations in CRP fields dominated by weeping lovegrass (Eragrostis curvula) in Lynn County, Tex. Twelve sample sites were stratified by canopy cover of vegetation. Small mammal species collected included: deer mouse (Peromyscus maniculatus), hispid pocket mouse (Chaetodipus hispidus), Cotton rat (Sigmodon hispidus), western harvest mouse (Reithrodontomys megalotis), northern grasshopper mouse (Onychomys leucogaster), and spotted ground squirrel (Spermophilus spiolsoma). Results suggest rodents living in weeping lovegrass monocultures select different cover based 
on microhabitat conditions. Lovegrass habitats following fire are continually being optimized by changing groups of rodents even when vegetative cover returns to pre-burn conditions. Although small mammals are typically not considered important in decisions for CRP management, their presence can be important by increasing diversity of wildlife and supporting avian and mammalian predators.

Sampling showed 13 different families beetles present in lovegrass CRP fields. June and dung beetles (Scarabaeidae), darkling beetles (Tenebrionidae), and blister beetles (Meloidae) beetles were not affected by fire. Ground beetles (Carabidae) and tiger beetles (Cicindelidae) beetles show population increase in response to fire. Author concludes beetle families most affected by fire are those dependent upon litter and detritus for suitable habitat. Author concludes species dependent on thick layer of litter are reduced by application of prescribed fire.

Evard, J.O., Snobl, D.A., Doeneir, P.B., and Dechant, J.A., 1991, Nesting of short-eared owls and voles in St. Croix County: The Passenger Pigeon, v. 53, no. 3, p. 223-226.

High concentration of meadow voles (Microtus pennsylvanicus) in CRP grasslands are attributed to attracting and supporting an elevated diversity of predators including shorteared owl (Asio flammeus), red fox (Vulpes vulpes), coyote (Canis latrans), and rough legged hawks (Buteo lagopus). Two nests of short-eared owls were found in CRP grassland. The species rarely has nested in Wisconsin. Presence of nests was attributed to CRP habitat supporting high density of meadow voles.

Furrow, L.T., 1994, The influence of field age on mammalian relative abundance, diversity, and distribution on Conservation Reserve Program lands in Michigan: Lansing, Mich., Michigan State University, M.S. thesis, 118 p.

Results suggest structure and composition of CRP grasslands in various age classes influence mammalian abundance, richness, and diversity. Reversion of CRP lands back to cropland may have significant impact on diversity of mammalian species depending on these grasslands for habitat. Results indicate leaving CRP fields undisturbed during the first $6 \mathrm{yr}$ may reduce plant and animal diversity as fields become less structurally complex. Author recommends disturbance at 3-6 yr after establishment of fields.

Gould, J., 1991, Seasonal use of Conservation Reserve Program fields by white-tailed deer in eastern South Dakota: Brookings, S. Dak., South Dakota State University, M.S. thesis, $40 \mathrm{p}$.

CRP lands used by white-tailed deer (Odocoileus virginianus) are recorded in greater proportion than availability of cover type during spring, summer, and fall. Deer selected CRP during active periods in the spring and summer and during bedding periods in summer and fall but avoided CRP during fall active periods. CRP land provides important forage and cover in all seasons. In most cases, maintenance, mowing, and weed control are detrimental to wildlife populations. CRP fields must have some type of disturbance every few years to maintain quality of habitat. Author recommended vegetation disturbance/management every 3-5 yr in late summer subsequent to avian nesting season (usually identified as after July 15). CRP may not be living up to expectations for provision of high quality habitat, however, in comparison with that furnished by actively farmed cropland, habitat quality is better than on most cropland.

Govenburg, T.W., Jacques, C.N., Klaver, R.W., and Jenks, J.A., 2010, Bed site selection by neonate deer in grassland habitats on the northern Great Plains: Journal of Wildlife Management, v. 74, no. 6, p. 1250-1256.

An investigation of white-tailed deer (Odocoileus virginianus) bed sites in South Dakota. Of all bed sites found 52.6 percent were in CRP dominated by western wheatgrass (Pascopyrum smithii), big bluestem (Andropogon gerardii), porcupine grass (Hesperostipa spartea), and little bluestem (Schizachyrium scoparium). Authors recommend management that encourages the tallest vertical height in grassland cover. They also express concern diminishing enrollment in CRP will lead to greater mortality of fawns.

Griffin, S.L., 1991, Pronghorn use of agricultural land in northwestern South Dakota: Brookings, S. Dak., South Dakota State University, M.S. thesis, 63 p.

Pronghorn (Antilocapra americana) observed within CRP grasslands 5 percent of monitoring time. CRP grasslands represented 4 percent of study area. Suggests that CRP grasslands may furnish high-quality foraging areas and program may result in reducing depredation on small grain and alfalfa croplands. Use of CRP by pronghorn was often highest in early summer and winter when potential for agricultural conflict was greatest. Future research should focus on better definition of pronghorn preferences for various grassland plantings permitted in CRP.

Hall, D.L., and Willig, M.R., 1994, Mammalian species composition, diversity, and succession in Conservation Reserve Program grasslands: The Southwestern Naturalist, v. 39, no. 1 , p. $1-10$.

Abundance of small mammals and species diversity compared between native shortgrass grasslands and CRP fields in southern high plains of Texas. CRP grasslands simulate shortgrass prairies in species diversity but not in species composition. CRP grasslands consist of introduced grasses, primarily weeping lovegrass (Eragrostis curvula), which allow CRP to 
accomplish soil erosion goals but not create "native habitat" with respect to plant or animal species composition. Successional changes in vegetational structure occurred in CRP sites. First-year sites on average contained more bare ground and less cover than older sites. Second-year sites were dense and almost homogenous with lovegrass. Third-year sites contained dense lovegrass, but it occurred in clusters, or bunches, interspersed with open spaces. CRP grasslands support as great a diversity of small mammals as do shortgrass prairie at least within initial three years following their establishment. Species composition may be highly dependent on specific physiognomic parameters that are not met in either agricultural sites or CRP grasslands. Endemic mammalian species composition may be restored if grazing or fire disturbance were incorporated into long-term management of CRP grasslands.

Horncastle, V.J., Hellgren, E.C., Mayer, P.M., Ganguli, A.C., Engle, D.M., and Leslie Jr., D.M., 2005, Implications of invasion by Juniperus virginiana on small mammals in the southern Great Plains: Journal of Mammalogy, v. 86, no. 4, p. 1144-1155.

Authors report changes in southern Great Plains landscape cover is changing in response to expansion and invasion of eastern red cedar (Juniperus virginiana) which is having effects on local vegetation composition and habitats for small mammals. Changes were investigated in tallgrass prairie, old field, and cross-timbers forest. In old field and tallgrass sites occurrence of grassland mammals decreased in response to increasing amounts of red cedar. Results suggest an increase in overstory cover from 0 to 30 percent can change species-rich prairie community to one dominated by one species (whitefooted mouse, [Peromyscus leucopus]). Losses in mammalian species diversity and changes in distribution parallel those reported for avian communities affected by invasion of red cedar. Authors believe this to be first study documenting impacts of red cedar on grassland mammalian communities adding to a body of literature describing negative consequences of invasion by this species. Once established, red cedar is difficult to remove. Prescribed fire may be best alternative but is limited in use due to costs and social concerns. Early detection and selective removal of young seedlings through cutting, mowing, or grazing may be most effective approach in controlling spread of red cedar.

Kamler, J.F., Ballard, W.B., Fish, E.B., Lemons, P.R., Mote, K., and Perchellet, C.C., 2003, Habitat use, home ranges, and survival of swift foxes in a fragmented landscapeConservation implications: Journal of Mammalogy, v. 84, no. 3, p. 989-995.

Study completed in north panhandle of Texas. Habitat loss attributed to be one of primary reasons for decline of the swift fox (Vulpes velox) in the western Great Plains. Results indicate swift foxes are specialized in habitat selection.
Protection of native shortgrass prairie may be necessary to support this species. Unlike habitat generalist species such as coyote (Canis latrans), red fox (V. Vulpes) and gray fox (Urocyon cinereoargenteus), which benefited from agricultural use and fragmentation of Great Plains habitats, swift fox range has declined. Study area composed primarily of irrigated cropland, native shortgrass prairie (grazed) and ungrazed grasslands enrolled in CRP. Shortgrass prairie was dominated by blue grama (Bouteloua gracilis) and buffalo grass (Buchloë dactyloides). CRP grasslands were planted to introduced old world bluestem (Andropogon spp.) and sideoats grama (Bouteloua curtipendula). Study results show swift foxes selected for shortgrass prairie and nearly completely avoided CRP grasslands. Although it represented 13-15 percent of study area, only 1 of 1,204 recorded locations of swift foxes were in CRP grassland. Avoidance of CRP by swift foxes attributed to their restricted mobility in taller, thicker vegetation (typical of ungrazed old world bluestem), reduced visibility, and possible lower abundance of prey in fields dominated by old world bluestem. Authors conclude planting of CRP fields to nonnative grasses and prevention of grazing of those grasslands may have further restricted available habitat for the swift fox.

Kamler, J.F., Ballard, W.B., Lemons, P.R., Gilliland, R.L., and Mote, K., 2005, Home Range and habitat use of coyotes in an area of native prairie, farmland, and CRP fields: American Midland Naturalist, v. 153, no. 2, p. 394-404.

Coyotes (Canis latrans) monitored in northwestern Texas to determine habitat use and home range patterns in a landscape dominated by native pasture, cropland and CRP grasslands. Native prairie cover types were dominated by blue grama (Bouteloua gracilis) and buffalograss (Buchlö̈ dactyloides) and moderately grazed by cattle. Primary crops on agricultural fields were corn and winter wheat. Most CRP fields in the study area were enrolled in 1985 and planted to warm season grasses dominated by old-world bluestem (Andropogon spp.) and sideoats grama (Bouteloua curtipendula). Study area defined by resident coyotes was 30 percent native prairie, 40 percent farmland, and 30 percent CRP. Habitat composition defined by transient coyote area of use was 33 percent native prairie, 48 percent cropland, and 19 percent CRP. Vegetation in CRP fields was thicker and taller than recorded in native prairie fields. Resident coyotes selected for native prairie sites whereas, transient coyotes selected for CRP fields. Resident coyotes used more native prairie and CRP and less cropland in winter than summer. Most ( 80 percent) natal dens found occurred in CRP fields. Resident coyotes may have selected native prairie because it is believed to contain a greater amount and diversity of prey species. CRP fields provided the only tall, permanent vegetation in study area therefore believed to furnish best available cover for transients. During winter resident coyotes selected more CRP than used in summer. Native prairie sites generally contained large numbers of cattle and had more human activity than did CRP fields. Authors conclude CRP provided important cover 
for coyotes because it was the only tall, permanent vegetation within the study area.

Kamler, J.F., Ballard, W.B., and Swepston, D.A., 2001, Range expansion of mule deer in the Texas panhandle: The Southwestern Naturalist, v. 46, no. 3, p. 378-379.

In contrast to population trends in other western states, mule deer (Odocoileus hemionus) populations in the Texas panhandle region are increasing and expanding. Over-hunting and loss of habitat decreased mule deer range substantially by the mid-1940s. By 1985, mule deer occurrence increased to 48 percent of the panhandle counties due to reintroductions of the species and limited natural expansion of range. The species was typically found along major drainages of the Canadian River and other steep rugged terrain. From 1985 to 2000, data show that mule deer populations expanded and nearly doubled distribution becoming present in 88 percent of panhandle counties. Authors believe expansion of deer is related to enrollment of crop fields into the CRP, which has provided higher vegetative cover, and greater distribution of suitable cover across relatively flat terrain otherwise dominated by cropland and shortgrass prairie. CRP fields provide permanent cover of relatively tall and dense grasses such as old world bluestem (Bothriochloa ischaemum). Because most CRP fields lie adjacent to croplands, mule deer have adequate cover adjacent to feeding areas. Authors believe availability and distribution of cover had been limiting mule deer distribution until advent of the CRP.

Kamler, J.F., Ballard, W.V., Wallace, M.C., and Gipson, P.S., 2007, Diets of swift foxes (Vulpes velox) in continuous and fragmented prairie in northwest Texas: The Southwestern Naturalist, v. 52, no. 4, p. 504-510.

A comparison of swift fox diets in a fragmented landscape (native prairie [40 percent], cropland [39 percent], CRP [21 percent]) and grazed native prairie dominated by blue grama (Bouteloua gracilis), and buffalograss (Buchloë dactyloides). CRP fields were recently enrolled and planted to warm-seasons grasses including sideoats grama (B. curtipendula), blue grama, sand dropseed (Sporobolus cryptandrus), and buffalograss. Older fields were planted to old world bluestem (Bothriochloa spp.). Swift fox diets were dominated by insects in the native prairie sites. The diet consisted of insects, birds, and mammals [primarily black-tailed jackrabbits (Lepus californicus) and cottontails (Sylvilagus spp.)] in the fragmented landscape. Greater edge and habitat diversity in the fragmented landscape enhanced habitat diversity and prey availability. The higher proportion of edge likely also benefited coyotes (Canis latrans) which can suppress swift fox populations.
Kaufman D.W., and Kaufman, G.A., 1989, Nongame wildlife management in central Kansas - Implication of small mammal use of fencerows, fields, and prairie: Transactions of the Kansas Academy of Science, v. 92, no. 3-4, p. 198-205.

Prairie-cropland ecotone provides suitable habitat for several native small mammals. Fencerows between prairie and cropland are potentially valuable habitats. Fencerows between prairie and cropland furnish better habitat than fencerows with similar cover type on both sides. Fencerows provide food, cover, and access to other cover types as well as dispersal corridors. Prairie-cropland fencerows supported an abundant, diverse assemblage of native small mammals. The association of these species was apparently dependent on tall, dense vegetation, deep litter, and ready access to food in crop fields. Interiors of cropland, even when fallow, were insufficient to support most species of small mammals. Small, ungrazed herbaceous and woody habitats scattered within a matrix of cultivated fields would maintain a higher density and diversity of small mammals than would be found if these cover types were removed.

Mankin, P.C., and Warner, R.E., 1999, Responses of eastern cottontails to intensive row-crop farming: Journal of Mammalogy, v. 80, no. 3, p. 940-949.

Eastern cottontail (Sylvilagus floridanus) home ranges averaged 2.3 times larger during growing season than in nongrowing season. During non-growing season farm homesteads were major component of home ranges. Homesteads were less than 2 percent of study area but comprised 23 percent of home ranges and 40 percent of rabbit locations. Declines in rabbit numbers have been most pronounced in intensively farmed regions where row crop agriculture has replaced pasture, other early successional permanent vegetation, forage crops, small grains, and miscellaneous uncropped land. Loss of cottontail habitat in Midwest is also attributed to greater use of herbicides and intensive fall tillage.

Phillips, M.L., Clark, W.R., Nusser, S.M., Sovada, M.A., and Greenwood, R.J., 2004, Analysis of predator movement in prairie landscapes with contrasting grassland composition: Journal of Mammalogy, v. 85, no. 2, p. 187-195.

An investigation of landscape influence on ability of predators to locate waterfowl nests focused on planted cover (CRP), pasture and hayland in North Dakota. Two 41.4 square kilometer $\left(\mathrm{km}^{2}\right)$ (25 square mile [ $\left.\left.\mathrm{mi}^{2}\right]\right)$ study areas - one of low-density grassland (15-20 percent grassland) and the other high-density (45-55 percent grassland) - were defined to investigate nightly movements of red foxes (Vulpes vulpes) and striped skunks (Mephitis mephitis). Authors conclude that heterogeneity of cover types at patch and landscape scales can affect predator movement. Fox movements were straighter 
across landscapes with low composition of grassland with direct movement between isolated patches of grassland cover. Movement of skunks did not differ between study areas with high and low density of grassland and were focused along wetland edges. Authors suggest a greater understanding of predator behavior in fragmented landscapes is essential for effective management of breeding habitat for grassland birds.

Sammon, J.G., and Wilkins, K.T., 2005, Effects of an invasive grass (Bothriochloa ischaemum) on a grassland rodent community: Texas Journal of Science, v. 57, no. 4, p. 371-382.

Rodent assemblages in native prairie in central Texas were compared to determine if non-native grassland supported a small mammal fauna different than found in grasslands dominated by native species. Past studies are cited that have shown lower diversity, richness, and relative abundance of small mammals in pure stands of grass than recorded in more dense native prairies. Rodent diversity generally correlates positively with plant diversity and cover. Introduced old-world bluestem tends to overwhelm and eliminate native species resulting in large homogenous stand of exotic grass. Exotic grasses often significantly increased the amount of litter present, reduced water loss from the soil, and diminished fluctuation in temperature by increasing insulation as a consequence of greater litter biomass. These changes often lead to establishment of exotic grasses over native grasses. Densities of hispid cotton rat (Sigmodon hispidus) were higher in habitats dominated by native grasses than recorded in stands of bluestem. The authors believe that further expansion of introduced grasses threaten to simplify remaining grassland habitats resulting in a system much different than native prairie.

Schroeder, M.A., and Vander Haegen, W.M., 2006, Use of CRP fields by greater sage-grouse and other shrubsteppe associated wildlife in Washington: Olympia, Wash., U.S. Department of Agriculture Farm Service Agency, Washington Department of Fish and Wildlife, 39 p.

The CRP is the largest effort to restore grassland and shrubsteppe habitat in the Columbia River Basin. About 1.5 million acres have been planted to CRP grasses in Washington. Unlike Midwestern CRP acreage established on land largely prairie prior to conversion to cropland, much of Washington CRP occurs on lands previously shrubsteppe prior to agricultural use. Declines in northwestern shrubsteppe habitats have coincided with declines in endemic populations of wildlife. Older CRP fields in the eastern Washington study areas were dominated by crested wheatgrass (Agropyron cristatum) while newer fields were dominated by the native Sandberg bluegrass (Poa ampla). Data suggest mule deer (Odocoileus hemionus) and jackrabbits (Lepus spp.) are using CRP fields with deer using newer fields and shrubsteppe to a greater degree than older CRP fields.
Schwartz, O.A., and Whitson, P.D., 1987, A 12-year study of vegetation and mammal succession on a reconstructed tallgrass prairie in Iowa: American Midland Naturalist, v. 117, no. 2 , p. 240-249.

The report documents successional changes in plant and small mammal communities in hayfield planted to five native grass species. Original field was dominated by foxtail (Setaria spp.) and alfalfa (Medicago sativa). Native grasses planted were big bluestem (Andropogon gerardii), little bluestem (Schizachyrium scoparium), Indiangrass (Sorghastrum avenaceum), sideoats grama (Bouteloua curtipendula), and switchgrass (Panicum virgatum). Three distinct developmental stages were recorded and discussed: herbaceous weed, perennial grassland, and early prairie. Reconstructed prairie furnished sub-optimal habitat for common prairie mammals due to low abundance of forbs, low diversity in vegetation, and high biomass of vegetation. As stand aged five perennial prairie grasses became dominant with few other herb, forbs, or woody plants present. Authors suggest development and management of seeded grasslands should incorporate techniques to balance native plant species diversity, especially forbs. High abundance of grasses, deficiency in forbs and lack of structural diversity furnish poor quality habitat for grassland species.

Seefeldt, S.S., Conn, J.S., Zhang, M., and Kaspari, P.N., 2010, Vegetation changes in Conservation Reserve Program lands in interior Alaska: Agriculture, Ecosystems and Environment, v. 135, p. 119-126.

Results of an investigation of plant communities within CRP fields established in Delta Junction, Alaska is presented. The CRP fields included in the study were originally planted to brome (Bromus inermis), red fescue (Festuca rubra), and the native common horsetail (Equisetum arvense). As time progressed, abundance of these species decreased being replaced by the native grass, bluejoint (Calamagrostis canadensis), native forbs, shrubs and tree species. Plant diversity in the CRP fields increased by more than 2 species per $1000 \mathrm{~m}^{2} /$ year. The authors conclude plant succession in the CRP fields is following patterns similar to that of natural systems despite multiple years of having been farmed. If these fields are left undisturbed the resultant plant community would be indistinguishable from surrounding undisturbed bottomland forest. As frequency and abundance of woody species increase through time it will be difficult to meet USDA compliance standard that CRP fields must be maintained in a condition that permits easy conversion to cropland. Authors believe these CRP fields will be non-compliant 32 years after establishment in CRP but the fields will be providing excellent erosion control and wildlife habitat. Although the CRP fields included in the study were not specifically evaluated for their quality as wildlife habitat, young CRP fields furnished "good" habitat for bison 
(Bison bison). The older, shrub-dominated fields were believed to furnish "good" habitat for moose (Alces alces).

Slade, N.A, and Crain, S., 2006, Impact on rodents of mowing strips in old fields of eastern Kansas: Journal of Mammalogy, v. 87, no. 1, p. 97-101.

Mowing was implemented in strips to prevent invasion of woody vegetation in old-field grass dominated covers. Effects on numbers and movements of five rodent species are described. Numbers of hispid cotton rats (Sigmodon hispidus) and prairie voles (Microtus ochrogaster) were reduced temporarily by mowing. Numbers of white-footed mice (Peromyscus leucopus) and deer mice (P. maniculatus), and western harvest mice (Reithrodontomys megalotis) were not significantly affected. Changes in numbers and movements were of short duration and authors conclude that mowing narrow strips when vegetation can recover rapidly had little sustained impact on rodent community. Deer mice showed almost no response to mowing. Negative effects on cotton rats lasted 4-5 months. Authors suggest mowing in narrow strips and early in the growing season should retain small mammal community.

Sirotnak, J.M., Reese, K.P., Connelly, J., and Radford, K., 1991, Effects of the Conservation Reserve Program (CRP) on wildlife in southeastern Idaho, project W-160-R-18, job completion report: Boise, Idaho, Idaho Department of Fish and Game, $45 \mathrm{p}$.

Lands enrolled in the CRP and used by mule deer (Odocoileus hemionus) and upland game birds. Continuation of CRP contracts was recommended to furnish continuing benefits to wildlife. Sharp-tailed grouse (Tympanuchus phasianel$l u s$ ) population benefited from the program in southeastern Idaho. Best-quality habitat was in fields with high levels of cover, diversity in vegetation species, and patches of native habitat or irregular borders increasing edge habitat. Authors concluded establishment of CRP may reduce depredation on forage crops by mule deer.

Stanley, T.R., 2010, Land use and small mammal predation effects on shortgrass prairie birds: Journal of Wildlife Management, v. 74, no. 8, p. 1825-1843.

An investigation of the potential effects of land use on small mammal (for example, thirteen-lined ground squirrel [Spermophilius tridecemlineatus], deer mouse [Peromyscus maniculatus]) predation on grassland bird nests is described. The author states, while benefits to mid- and tallgrass prairies are clear, it remains unclear if CRP provides suitable nesting habitat for shortgrass prairie birds. Also of interest was what effects elevated abundance of vegetation and seed sources furnished by CRP had on species richness of potential predators. Native grassland sites were dominated by buffalograss (Buchloë dactyloides), blue grama (Bouteloua gracilis) and plains pricklypear (Opuntia polyacantha). CRP fields in the northeastern Colorado study area were smooth brome (Bromus inermis) and wheatgrass (Agropyron spp.). Age of fields was not given. Land uses on shortgrass prairie are found to alter small mammal communities. Small mammal densities and richness were found to be greater along edges and on CRP compared to shortgrass sites. Survival of nests (artificial and natural) at edge and CRP sites did not differ from native sites. Small mammal communities were found not to affect nest survival.

\section{Non-Game Birds}

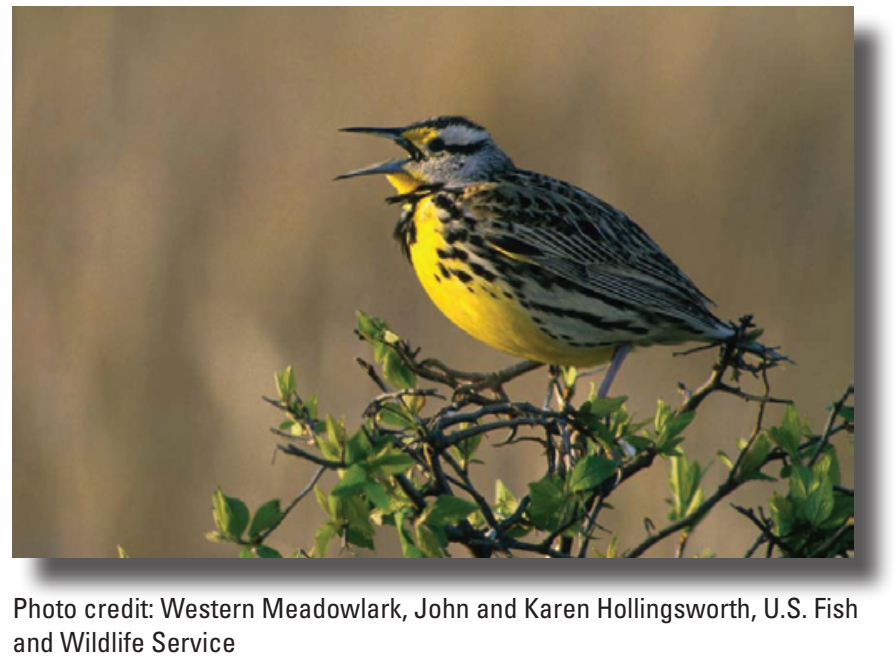

Allen, A.W., 1994, Conservation Reserve Program (CRP) contributions to avian habitat: Fort Collins, Colo., U.S. Fish and Wildlife Service Federal Aid Report, National Biological Survey, 19 p.

This report furnishes a summary of CRP contributions to distribution and quality of habitat for game and non-game birds affiliated with agricultural ecosystems. The report concentrates largely on species endemic to grassland ecosystems and decisions in CRP management that may favor endemic grassland species or species more typical of farmland habitats (for example, ring-necked pheasants [Phasianus colchicus]). The report provides a discussion of identification of CRP contracts furnishing greatest potential benefits, landscape planning, and management recommendations to enhance habitat quality.

Angelstram, P., 1986, Predation on ground-nesting birds' nests in relation to predator densities and habitat edge: Okios, v. 47, p. 365-373.

Author provides discussion of how predators utilize different habitats. As the size of habitat islands decrease the 
influences of surrounding cover become increasingly important. Since relative amount of edge increases as patch size decreases the predation rate should be inversely related to the size of patch. Permanently high densities of generalist predators are often a consequence of human activities especially where landscapes become fragmented in terms of cover type composition (for example, agriculture land use). The author concludes cover type edges in more productive habitats will experience greater rates of predation than edges in less productive habitats

Bakker, K.K. and Higgins, K.F., 2009, Planted grasslands and native sod prairie - equivalent habitat for grassland birds?: Western North American Naturalist, v. 69, no. 2, p. 235-242.

A comparison of species richness and density of grassland nesting birds in cool-season exotic grasses, warm-season monocultures/mixes, and native sod prairie in eastern South Dakota and western Minnesota is reported. Monocultures were switchgrass (Panicum virgatum) and intermediate wheatgrass (Thinopyrum intermedium). Warm season mixes contained 3 to 5 plant species (for example, big bluestem [Andropogon gerardii], Indiangrass [Sorghastrum nutans], switchgrass) while native sod tallgrass prairie contained as many as 119 plant species. Cool season mixes were dominated by exotic species including smooth brome (Bromus inermis) and yellow sweetclover (Melilotus officinalis). Planted fields were 4 to 9 yr old.

Preservation of native prairies furnished habitat not available in planted fields. Native sod prairies were found to support a richer grassland bird community and higher densities of several species. Planted cover types dominated by exotic species, intermediate wheatgrass monotypes, and cool-season mixes supported depleted grassland bird communities in comparison to native tallgrass prairie. Warm-season grass mixes came closest to approximating avian richness found in native prairie. Intermediate wheatgrass monocultures and exotic cool-season mixes contained 40 to 60 percent fewer bird species than did native prairie. Authors recommend including additional native plant species into grass plantings for production of biomass fuels or conservation purposes.

Bassett-Touchell, C.A., and Stouffer, P.C., 2006, Habitat selection by Swainson's warblers breeding in loblolly pine plantations in southeastern Louisiana: Journal of Wildlife Management, v. 70, no. 4, p. 1013-1019.

Swainson's warblers (Limnothlypis swainsonii) are typically associated with bottomland hardwood forests but also breed in even-age plantations of pine. Authors report investigation of Swainson's warbler use of loblolly pine (Pinus taeda) plantations of various age classes and management histories in southern Louisiana to determine stand structure preferences of the species. The warblers were found in pine stands that had well-developed canopy closure, abundant understory vegetation, and sparse ground cover. Swainson's warblers were recorded as using 7 to 24-yr-old, unthinned, even-aged loblolly pine stands as breeding habitat. Authors conclude that even-aged, thinned stands are not used as breeding habitat by this species. A mosaic of even-aged stands within a landscape is recommended to furnish habitats for avian species requiring early and mid-successional habitats. Use of pine plantations by Swainson's warblers is believed to begin when stands reach $7 \mathrm{yr}$ of age and use will continue only if the stands remain unthinned.

Berthelsen, P.S., 1989, Value of the Conservation Reserve Program to birds in the Texas southern high plains: Lubbock, Tex., Texas Technical University, M.S. thesis, 106 p.

The author believes the greatest potential benefit of the CRP to wildlife in the Southern High Plains is provision of secure, high quality nesting and winter cover for avian species. Bird-species composition on CRP lands was represented primarily by 2 to 3 dominant species. Seven of 13 species observed on CRP lands were considered migrants or winter residents. Fields of blue grama/kleingrass $(\mathrm{BG} / \mathrm{K})$ (Bouteloua gracilis/Panicum virgatum) produced high quality winter habitat. This cover type produced the greatest values for avian winter densities, avian biomass estimates, nest densities, number of birds observed, and winter cover quality for pheasants. $\mathrm{BG} / \mathrm{K}$ had highest numbers of avian species observed, followed by blue grama/sideoats grama (Bouteloua curtipendula) and blue grama/plains bluestem (Bothriochloa spp.). CRP may promote dispersal and increase survival of ring-necked pheasants (Phasianus colchicus) through provision of high-quality winter habitat more evenly dispersed over agriculturally dominated landscapes. CRP fields in vicinity of remaining grain crops may substantially enhance year round habitat quality. $\mathrm{BG} / \mathrm{K}$ grasslands will provide quality passerine habitat in southern high plains during winter and reproductive seasons. Greatest potential of CRP wildlife habitat in southern high plains is to produce secure, high quality, long-term nesting and winter cover for upland game birds. Nest success on CRP lands averaged 22 percent. There was no apparent difference in nest success between CRP covers. BG/K had highest production of cover types followed by $\mathrm{BG} / \mathrm{PB}$ and $\mathrm{BG} / \mathrm{SO}$. Study documents earlier initiation of pheasant nests in CRP than reported for the general area, which may be related to increase of available nesting habitat, more favorable weather, or hens entering breeding season in good physiological condition. CRP lands enable pheasants to distribute from formerly concentrated habitats, particularly playa wetlands often unsafe or unsuitable habitat due to seasonal flooding.

Benefits of CRP are dependent upon cover-management practices and political pressures. Approximately one-third of fields evaluated were hayed or mowed for weed control resulting in minimal to no value as habitat for upland nesting birds. Mowing of CRP fields for weed control was believed unnecessary. As stands age grasses will outcompete forbs and 
the weed issue will diminish. In addition, weed control may reduce compositional quality of vegetation in the field further affecting habitat quality.

Bertherlsen, P.S., and Smith, L.M., 1995, Nongame bird nesting on CRP land in the Texas Southern High Plains: Journal of Soil and Water Management, v. 50, no. 6, p. 672-675.

Evaluation of nongame bird nesting in the most common CRP cover types in Texas High Plains; blue grama/ sideoats grama (Bouteloua gracilis/Bouteloua curtipendula), blue grama/Kleingrass (Panicum virgatum), and blue grama/ plains bluestem (Bothriochloa spp.). Dominant avian species reported in the evaluation were western meadowlark (Sturnella neglecta), grasshopper sparrow (Ammodramus savannarum), Cassin's sparrow (Aimophila cassinii), and red-winged blackbird (Agelaius phoeniceus). Nest initiation for these species peaked in mid-May. Authors suggest because vegetative characteristics of fields change as CRP grasslands age their value as nesting habitat for nongame birds may decline as age of grasslands progress without disturbance to rejuvenate vegetation.

Best, L.B., Bergin, T.M., and Freemark, K.E., 2001, Influence of landscape composition on bird use of row crop fields: Journal of Wildlife Management, v. 65, no. 3, p. 442-449.

Bird species abundance in row crop fields was greater in landscapes with more grassland block cover and/or more wooded block-cover and strip cover. Avian habitat selection and use is a multi-scale phenomenon; therefore, landscape context should be considered when evaluating avian use and conservation management of agricultural ecosystems. Although few species nest in row crop fields (corn, soybeans) over 50 avian species have been documented to use these cover types during the breeding season. Avian species response to landscape composition varied. Habitat affinities of avian species influence use of specific habitat patches as well as landscape in which patches are located. Use of row crop fields by birds depends on within field features (for example, residue, crop type, and development) and landscape features in which fields are situated.

Best, L.B., Campa III, H., Kemp, K.E., Robel, R.J., Ryan, M.R., Savidge, J.A., Weeks Jr., H.P., and Winterstein, S.R., 1998, Avian abundance in CRP and crop fields during winter in the Midwest: American Midland Naturalist, v. 139, no. 2, p. 311-324.

This report contains results of 1992-1995 comparison of avian abundance and species composition in CRP and rowcrop fields during winter from Indiana, Iowa, Kansas, Michigan, Missouri, and Nebraska. Mean annual bird abundance ranged from 0.1 to 5.1 birds per $\mathrm{km}(0.62 \mathrm{mi})$ of transect in CRP fields and 0.1 to $24.2 / \mathrm{km}$ transect in row crop fields. Total number of species recorded in CRP fields ranged from 6 to 32 and 8 to 18 in row crop fields. Six of seven most abundant species observed in row crop fields are already abundant or experiencing long-term increases in populations. Variations in numbers and species recorded by state are reported. Total bird abundance in CRP and row crop fields was variable among states with no consistent pattern evident. A number of the most abundant avian species wintering in CRP fields have experienced long-term declines in populations. Authors document widespread use of CRP by birds in winter and conclude the program has potential to mitigate declines in avian populations.

Best, L.B., Campa III, H., Kemp, K.E., Robel, R.J., Ryan, M.R., Savidge, J.A., Weeks Jr., H.P., and Winterstein, S.R., 1997, Bird abundance and nesting in CRP fields and cropland in the Midwest - A regional approach: Wildlife Society Bulletin, v. 25, no. 4, p. 864-877.

Comparison of abundance and nesting success of avian species in CRP and row crop fields over 5 years (91-95) in 6 Midwest states (Indiana, Kansas, Missouri, Michigan, Nebraska, Iowa). Bird abundance was 1.4 to 10.5 times greater in CRP than found within row crop fields. Nests of 33 bird species found in CRP with nests of only 10 species in row crops. The number of nests found was 13.5 times greater in CRP than within row crops. Nest success was 40 percent in CRP. Nest success in row crops similar to that of in CRP, but total number of nests found in row crop was only 7.4 percent of that in CRP. Predation was greatest cause of nest failure. Long-term farm set-aside programs establishing perennial grass cover provide benefits for grassland birds including several species for which conservation is of substantial concern. Authors recommend further investigation of species-specific habitat requirements in relation to planting, management and spatial configuration of CRP.

Best, L.B., Freemark, K. E., Dinsmore, J.J., and Camp, M., 1995, A review and synthesis of habitat use by breeding birds in agricultural landscapes in Iowa: American Midland Naturalist, v. 134, no. 1, p. 1-29.

Data for this report was collected during breeding season (May-July). Total numbers of birds recorded were highest in floodplain and upland forests and lowest in small grain fields and fencerow dominated by herbaceous vegetation. Abundance of avian species was lowest in agricultural habitats (tilled row crops and small grains) and highest in narrow stripcover habitats (railroad rights-of-way, wooded fencerows and shelterbelts). Abundance patterns in natural habitats (forest, marsh, and prairie) were intermediate between agricultural and strip cover habitats. Bird species were more abundant in strip cover habitats. At least 30 percent of bird species using these habitats are common to very abundant. Abundance and diversity of arthropods was greater in uncropped strip cover habitats 
with perennial vegetation than recorded in cultivated cropland. Avian foraging was concentrated in and near such areas. Low abundance of birds was recorded in agricultural habitat due to repeated disturbance by tillage, planting, cultivation, pesticide/ fertilizer application, and mowing. These activities during breeding season destroy nests and adversely alter physical features of habitat causing disruption of site fidelity behavior by birds. Croplands characteristically have low species diversity and generally relatively simple physical structure. Acute or toxic exposure to toxic compounds or reduction in food sources also influences avian use of croplands.

Best, L.B., Whitmore, R.C., and Booth, G.M., 1990, Use of cornfields by birds during the breeding season-The importance of edge habitat: American Midland Naturalist, v. 123, p. 84-99.

Elimination of woody vegetation from fencerows and other habitats adjacent to crop fields will affect assemblage of bird species found within fields. The amount of linear edge relative to field area has a major effect on field use by birds. Larger fields are used proportionately less. The proportion of linear field edge decreases as fields become larger resulting in less overall use of cropland by birds. The trend in recent decades has been to consolidate fields and increase size of cropping units. Bird abundance was reported to be greater in wooded edges than in herbaceous edges. More bird species, and about five times more birds, used the perimeters of cornfields than the central area of fields. Continued land-use practices that increase field size and eliminate woody vegetation from edge habitats will affect both richness and abundance of avifauna affiliated with agricultural ecosystems.

Blackwell, B.F. and Dolbeer, R.A., 2001, Decline of the redwinged blackbird population in Ohio correlated to changes in agriculture (1965-1996): Journal of Wildlife Management, v. 65 , no. 4, p. 661-667.

Evaluation of breeding population data of red-winged blackbirds (Agelaius phoeniceus) showed decline with population indices decreasing by over 53 percent during period of evaluation (1966-1996). Although considered a pest, the decline is important from both ecological and damage control perspectives. Expansive upland grass dominated habitats furnish substantial potential for red-winged blackbird population growth. Decrease in area of non-alfalfa hay harvested likely has reduced availability of quality nesting habitat for this species. An associated increase in mechanized agricultural practices and use of chemicals in farming has resulted in a loss of traditional and non-traditional nesting habitats with resultant declines in grassland associated avian species. The agricultural practices that have resulted in decline of red-winged blackbirds likely have had more severe effects on other, less ubiquitous grassland species. Findings lend support to continuation of the CRP and other programs providing suitable habitat for grassland species. Management regimes should be modified by area, season, and crop rotation patterns to increase habitat opportunities for grassland avifauna.

Bock, C.E., Saab, V.A., Rich, T.D., and Dobkin, D.S., 1993, Effects of livestock grazing on neotropical migratory landbirds in western North America, in Finch, D.M., and Stangle, P.W., eds., Status and management of neotropical migratory birds: Fort Collins, Colo., USDA Forest Service General Technical Report RM-229, p. 296-309.

Authors advocate finding ways to make existing CRP grasslands economically valuable to owners, possibly encouraging moderate, periodic grazing by livestock or limited haying. Authors speculate CRP grasslands would be of greater benefit in some situations if they were coupled with creation of livestock exclosures in other areas such as National Grasslands. Also recommended by authors was an increase in the amount of public rangeland from which all livestock grazing is excluded.

Bohning-Gaese, K., Taper, M.L., and Brown, J.H., 1993, Are declines in North American insectivorous songbirds due to causes on the breeding range?: Conservation Biology, v. 7, no. 1, p. $76-86$.

Predation on breeding grounds in North America is believed to have played a larger role in the decline of migratory songbirds than deforestation on tropical wintering grounds. Predation pressure by terrestrial mammals is believed to have had a major impact on population trends of avian species. Vulnerability traits of low, open nests and high parasitism by brown-headed cowbirds (Molothrus ater) have additive negative effects on songbird populations. Authors suggest even a small effect of cowbird parasitism could be enough to push a songbird population experiencing substantial rate of predation to a negative replacement rate and decline in population.

Bollinger, E.K., and Gavin, T.A., 1989, Eastern bobolink populations - Ecology and conservation in an agricultural landscape, in Hagen, J.M., III and Johnston, D.W., eds., Ecology and conservation of neotropical migrant landbirds: Washington, D.C., Smithsonian Institute Press, p. 497-506.

Bobolink (Dolichonyx oryzivorus) abundance reported greatest in old hayfields. Abundance of species increased exponentially with size of hayfields. Conservation practices designed for grassland birds should concentrate on creating, or maintaining, large habitat patches which resemble old hayfields. Recommendations: create or maintain patches of relatively sparse grass-dominated cover with some broadleaf forbs. Fewer, larger patches tend to contain more breeding bobolinks than numerous small ones, because nest predation and parasitism by brown-headed cowbirds (Molothrus 
ater) tends to be higher in small patches of grassland cover. Management of grassland should focus on prevention of encroachment by woody vegetation. These practices should help populations of other declining grassland species as well. Eastern meadowlark (Sturnella magna), upland sandpipers (Bartramia longicauda), Henslow's sparrow (Ammodramus henslowii), and grasshopper sparrow (A. savannarum), were positively correlated with bobolink densities.

Boutin, C., Freemark, K.E., and Kirk, D.A., 1999, Farmland birds in southern Ontario-Field use, activity patterns and vulnerability to pesticide use: Agriculture, Ecosystems and Environment, v. 72, no. 2, p. 239-254.

Three factors are major determinants of bird distribution in agricultural land: type of crops grown, configuration and physical structure of adjacent non-crop cover types, and frequency and extent of agricultural practices (for example, tillage, pesticide application, crop harvest). A lack of data on avian use of croplands in dissimilar agricultural landscapes is a major obstacle in assessing effects of agriculture on wildlife in many areas of North America. Most species surveyed used edge habitat significantly more than expected. More arthropods are found in field edges than in interior areas of fields. Many field margins, or herbaceous borders, are either sprayed directly for control of pests or vulnerable to spray drift. Impacts of spraying on edges have diminished diversity of plants and insects important for young birds. The impacts of agrochemical spraying are especially detrimental in intensively farmed landscapes where vegetative diversity is already minimal.

Bowen, B.E. and Kruse, A.D., 1993, Effects of grazing on nesting by upland sandpipers in south central North Dakota: Journal of Wildlife Management, v. 57, no. 2, p. 291-301.

The study results suggest grazing during late spring and early summer has a detrimental effect on reproduction of upland sandpipers (Bartramia longicauda) in the northern Great Plains. Authors recommend delay of grazing until at least mid to late June. Traditional season-long grazing (JuneOctober) should be avoided. Autumn grazing at high stocking rates may be an acceptable alternative to season-long grazing. In the central Great Plains sandpipers nested in grazed fields rather than in ungrazed fields where vegetation was too tall.

Brady, S.J. and Flather, C.H., 1998, Agricultural land use patterns and grassland nesting birds: Gibier Faune Sauvage, v. 15 , p. $775-784$.

Paper documents association of grassland-nesting avian species with nonfederal rural land use and factors related to abundance of grassland birds. Natural Resources Conservation Service NRI data used to characterize land use patterns and BBS data. Authors conclude half of birds responded positively to the CRP, remainder of species investigated showed neutral response. Although the CRP has had a positive effect on grassland birds, the authors believe the program does not appear to be as important as are other habitats occurring on larger expanses of range and cropland. Effective management of wildlife habitat in agricultural ecosystems will occur only when management practices on all lands are taken into consideration on both local and regional levels. The species most associated with CRP were western meadowlark (Sturnella neglecta) ring-necked pheasant (Phasianus colchicus), lark bunting (Calamospiza melanocorys), and horned lark (Eremophila alpestris).

Brennan, L.A., and Kuvlesky Jr., W.P., 2005, North American grassland birds-An unfolding conservation crisis?: Journal of Wildlife Management, v. 69, no. 1, p. 1-13.

There is no single cause for declines of grassland birds but cumulative factors (afforestation in eastern United States, fragmentation and loss of prairie ecosystems with agriculture, and deterioration of western rangelands) are key factors in decline of these species. Authors believe economics of crop, fiber, and meat production have overwhelmed ethical use of land. Authors describe purpose of North American Bird Conservation Initiative as a potential solution for conserving grassland bird populations. Coordination of grassland bird conservation efforts with initiatives to increase upland game bird populations present additional opportunities to positively impact virtually all species of North American grassland birds.

Avian species with affinities for grassland and grassshrub habitats have been in continental-scale population declines for decades. Declines probably began about the time the steel plow first broke prairie sod in $19^{\text {th }}$ century. Since mid1800s, loss of grassland ecosystems in most of North America has exceeded 80 percent. Conversion of prairie ecosystems to agriculture remains a key part of problem facing grassland birds but problems extend far beyond prairie biome. Widespread deterioration in rangeland habitat quality and industrial silviculture that has replaced fire-maintained, open, park-like southern pine forests with dense plantations also have contributed to declines in grassland birds. Strategically adding CRP lands within highly fragmented agriculturally dominated landscapes would likely be of benefit to grassland species by reducing predation and brood parasitism rates associated with habitat edge. Restoration of ecosystem processes through use of fire, restoration of hydrological regime and control of invasive plant species will also be required to reverse declines in grassland birds. Stabilization and recovery of grassland bird populations will require healing of sick landscapes through adoption of the North American wildlife management model that has been so successful in recovery of other species in past decades.

Bryan, G.G., and Best, L.B., 1991, Bird abundance and species richness in grassed waterways in Iowa rowcrop fields: American Midland Naturalist, v. 126, p. 90-102. 
An evaluation of avian use of grassed waterways planted to smooth brome (Bromus inermis) in corn and soybean fields. Forty-eight avian species were recorded using grassed waterways compared to 14 species within croplands. No species exhibited exclusive use of croplands. Current mowing recommendations are to mow after July 15, however, 53 percent of all species observed and all of breeding species were recorded at peak abundance in waterways during 4-22 July. Authors recommend waterways be mowed in late August or early September to avoid detrimental effects on avian species. Mowing should not be undertaken after mid-September because mowing would reduce the amount of winter cover and residual vegetation required for early spring nesting. Unmowed waterways furnish important habitat for birds in mid-to-late summer because other grass dominated cover types have already been mowed, concentrating birds in limited remaining habitat.

Burger, L.D., Burger, L.W., and Faaborg, J., 1994, Effects of prairie fragmentation on predation of artificial nests, Journal of Wildlife Management, v. 58, no. 2, p. 249-254.

Artificial nests in smaller prairies were depredated more than those in larger prairies ( 37 percent vs. 13.9 percent). Although highest rates of predation were observed in smallest prairie size classes, proximity to woody cover was a more important factor affecting predation rates on artificial nests. Smallest prairies may have had higher predation rates due to higher proportion of area near woody cover. The potential effects of prairie size and woody vegetation on success of ground-nesting birds should be considered in decisions of acquisition and management of prairie habitats.

Chapman, R.N., Engle, D.M., Masters, R.E., and Leslie Jr., D.M., 2004, Tree invasion constrains the influence of herbaceous structure in grassland bird habitats, Ecoscience, v. 11, no. 1, p. 55-63.

Authors conclude trees and other woody plants diminish habitat quality for grassland-obligate birds as well as biological integrity of grassland ecosystems. Avian species associated with North American southern mixed grass prairies have declined in abundance while species associated with shrub-stage and woodland habitats have increased. Expansion of eastern redcedar (Juniperus virginiana) in southern Great Plains explains some of changes in avian assemblages in landscapes composed of grassland patches fragmented by cropland. As canopy cover of eastern redcedar increased variation in abundance of grassland birds decreased. Authors believe invasion of woody plants into grassland habitats will result in increasingly ineffective management of grassland bird abundance and nest success. Redcedar invasion also degrades grassland habitat by resulting in greater fragmentation of grasslands affecting area sensitive species. Although diversity in avian community may increase due to greater abundance of woody vegetation, it comes at the expense of the relatively few species endemic to grassland ecosystems.
Chapman, R.N., Engle, D.M., Masters, R.E., and Leslie Jr., D.M., 2004, Grassland vegetation and bird communities in the southern Great Plains of North America: Agriculture, Ecosystems and Environment, v. 104, p. 577-585.

Relations between structure and composition of vegetation and abundance of breeding birds in CRP fields seeded to old-world bluestem (Bothriochloa ischaemum) and native grasslands in Oklahoma are reported. Study fields were undisturbed, hayed or grazed. Authors conclude seeded grasslands were inferior to native mixed prairie in terms of diversity of plant species, however differences did not have a meaningful effect on vegetation structure that influenced habitat selection by breeding birds. Overlap in bird community composition showed disturbance (grazing, haying) rather than plant species composition creates habitat heterogeneity required to support a diverse assemblage of avian species. Authors conclude conservation programs that do not allow for suitable disturbance will benefit only a narrow suite of birds regardless of plant species composition.

Clawson, M.R., and Rotella, J.J., 1998, Success of artificial nests in CRP fields, native vegetation, and field borders in southwestern Montana: Journal of Field Ornithology, v. 69, no. 2 , p. $180-191$.

Artificial nests used to study relations between nest success in CRP, field borders/watercourses, and native vegetation. Nest success was higher in structurally more complex CRP fields than other grassland types. Results suggest nests surrounded by taller, thicker cover were more likely to survive than nests in vegetation furnishing less concealment. Field size was directly related to nest success in CRP fields but not in other grassland types.

Conover, R.R., Burger, L.W., Jr., and Linder, E.T., 2006, Winter avian community and sparrow response to field border width: Journal of Wildlife Management, v. 71, no. 6, p. 1917-1923.

The amount of strip cover, or linear cover, across the southeast has diminished. To compensate for these losses the national Conservation Buffer Initiative has promoted establishment of herbaceous field borders to enhance wildlife habitat quality. Effects of warm-season grass field borders on avian winter abundance in Mississippi are reported. Field borders were $400 \mathrm{~m}(1,312 \mathrm{ft})$ in length and planted to a mixture of Indiangrass (Sorghastrum nutans), little bluestem (Schizachyrium scoparium), big bluestem (Andropogon gerardii) partridge pea (Chamaecrista fasciculate), and Kobe pea (Lespedeza striata). Narrow borders were approximately $8 \mathrm{~m}$ (26 ft) in width while wider borders were approximately $30 \mathrm{~m}$ $(100 \mathrm{ft})$ wide.

Wide field margin borders enhanced overall abundance, richness and total avian conservation value over non-bordered fields and narrow field borders. Detailed information on 
habitat use by commonly observed avian species is presented. It is suggested wider borders furnish increased escape-cover quality or reduce predation pressure by increasing distance to avian predator perch sites in wooded edges. Field borders also enhanced greater use of crop fields by avian species for foraging. The authors conclude field borders performed well as winter habitat for birds in the Mississippi Alluvial Valley. The authors advocate establishment of field borders on production farms as a source of foraging, roosting and escape cover. Strip

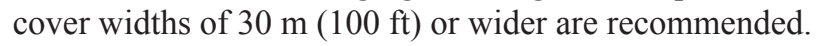

Conover, R.R., Burger Jr., L.W., and Linder, E.T., 2009, Breeding bird response to field border presence and width: Wilson Journal of Ornithology, v. 121, no. 3, p. 548-555.

Avian density, richness, and conservation value are

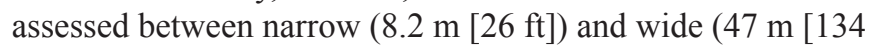
$\mathrm{ft}]$ ) field borders on intensively row-cropped field margins in the Mississippi Alluvial Valley. Field borders were $400 \mathrm{~m}$ $(1,312 \mathrm{ft})$ in length and planted to a mixture of Indiangrass (Sorghastrum nutans), little bluestem (Schizachyrium scoparium), big bluestem (Andropogon gerardii) partridge pea (Chamaecrista fasciculate), and Kobe pea (Lespedeza striata).

Wide field borders supported twice as many birds than did narrow borders, which supported six times as many birds as non-bordered fields. Seventy-eight bird species were observed in field borders during the study. Birds recorded and habitat associations are presented. Greater avian densities in and adjacent to wide field borders are attributed to increased vegetative diversity, lower perimeter to area ratio, and simply greater area of potential habitat. The authors believe greater emphasis on grassed borders is a more viable answer than whole field enrollment to declining grassland bird populations in intensively farmed areas as less land is taken out of production. Field borders should be as wide as possible to bring greater benefits to grassland birds.

Conway, W.C., Smith, L.M., and Ray, J.D., 2005, Shorebird habitat use and nest-site selection in the playa lake region: Journal of Wildlife Management, v. 60, no. 1, p. 174-184.

Playa lakes provide important habitats for wintering waterfowl as well as migrant and breeding shorebirds. Wetland scale habitat use and nest-site selection for four dominant species [American avocet (Recurvirostra americana), blacknecked stilt (Himantopus mexicanus), killdeer (Charadrius vociferus), snowy plover (C. alexandrinus)] nesting in playas, saline and man-created lakes, and riparian wetlands are described. Only avocets and killdeer nested in playas. No nests were found in created wetlands. Authors conclude created wetlands cannot compensate for loss of playa wetlands and urge greater conservation efforts be directed toward conservation of these natural wetlands. Protection of playa hydroperiod should be emphasized for breeding shorebird conservation. Most playas have cropland-dominated watersheds and have lost their natural vegetative communities. Prairies restoration around watersheds will decrease sedimentation rates and serve to restore playa hydrological cycles, which will benefit avian habitat quality and use.

Coppedge, B.R., Engle, D.M., Masters, R.E., and Gregory, M.S., 2001, Avian response to landscape change in fragmented southern Great Plains grasslands: Ecological Applications, v. 11 , no. 1 , p. $47-59$.

Avian community dynamics were investigated within fragmented grasslands in Oklahoma. Avian community structure shifted along gradients of increasing woody plant cover and levels of landscape fragmentation. The authors conclude invasion of woody plant species into grassland ecosystems already fragmented by agriculture represents a conservation dilemma because woody vegetation in remnant native prairies may provide habitat for some declining neotropical migrants while suitability is diminished for many endemic grassland birds. Native grassland area and landscape pattern, especially size of grassland patches, were negatively affected by encroachment of woody vegetation.

Authors believe although most of CRP in Oklahoma was planted to non-native grass monocultures (primarily old-world bluestem [Andropogon spp.] and lovegrass [Eragrostis spp.]) grassland avian species have benefited. But positive relations exhibited by some species were only in areas most affected by encroaching woody vegetation with the lowest levels of intact native grasslands leading authors to conclude benefits of the CRP may be relevant to and dependent upon, the context of the surrounding landscape. Authors recommend increased focus on grassland management and continuation of agricultural set-aside programs in areas where grasslands have been severely altered by woody vegetation and extensively fragmented by agricultural activity.

Coppedge, B.R., Fuhlendorf, S.D., Harrell, W.C., and Engle, D.M., 2008, Avian community response to vegetation and structural features in grasslands managed with fire and grazing: Biological Conservation, v. 141, p. 1196-1203.

The study reports management of tallgrass prairie in north central Oklahoma on avian community response. Grasses in the study area are dominated by perennial grasses including big bluestem (Andropogon gerardii), little bluestem (Schizachyrium scoparium), Indiangrass (Sorghastrum nutans), and switchgrass (Panicum virgatum). Portions of pasture were burned each year to create a mosaic of grassland patches of varying stages of recovery from disturbance. Results indicate that woody edges, ponds, and roads were more negative than positive influences on abundance of several grassland avian species. The study provides evidence of ecological advantages of rotating disturbance patterns in tallgrass prairie via patch-burning. Patch burning affected the avian community by decreasing abundance of the brownheaded cowbird (Molothrus ater), increased overall species richness, enhanced grassland obligate richness, and provided 
habitat for the Henslows's sparrow (Ammodramus henslowii) a species of management concern.

Cunningham, M.A., 2005, A comparison of public lands and farmlands for grassland bird conservation: The Professional Geographer, v. 57, no. 1, p. 51-65.

An assessment between avian songbird populations is made on southern Minnesota CRP fields and public lands to address relative effectiveness of public grasslands and private land for conserving songbird populations. Bird abundance and diversity were greater on CRP lands by providing more and better habitat for avian species. The author concludes USDA conservation programs and rules for implementation will strongly influence success of biodiversity conservation in the region.

Public lands investigated included restored prairies within state parks, waterfowl production areas (WPAs), wildlife management areas, and scientific and natural areas. The average number of birds observed on public lands was 9.8 pairs per eight hectare transect with a maximum of 22 and a minimum of 0 . On CRP fields the average number of pairs was $13 /$ transect with a maximum of 28 and minimum of 0 . Species richness was also greater on CRP fields than recorded within public lands. Public lands were richer in forbs than CRP fields but there were fewer birds found on the more forb-rich fields. CRP fields were dominated by a mix of brome (Bromus inermis) and alfalfa (Medicago sativa) or clover (Melilotus spp.) followed by monocultures of switchgrass (Panicum virgatum). Reed canarygrass (Phalaris arundinacea) and spotted knapweed (Centaurea maculosa), widespread invasive species in this region, were found more frequently on public lands than on CRP lands. Spatial indicators (mean patch size, proximity, and availability of core area) were substantially better for CRP lands than for public grasslands.

The author concludes CRP lands supported a greater abundance and diversity of birds than did public lands surveyed. While availability of habitat due to CRP is clearly a benefit the program's variable nature, subject to economic and political conditions poses difficulties for long-term management of wildlife and their habitats. Variable funding and relatively short (10 yr) contract period may make the CRP an unreliable source of habitat in the long-term. Conservationists and the public need to be aware of just how little public grassland acres exist and how important USDA conservation programs are for wildlife.

Davis, S.K., 2004, Area sensitivity in grassland passerinesEffects of patch size, patch shape, and vegetation structure on bird abundance and occurrence in southern Saskatchewan: The Auk, v. 121, no. 4, p. 1130-1145.

Information related to area sensitivity and consequences of habitat fragmentation on avian species has come largely from studies completed in forested and tallgrass-prairie habitats. Study reports findings of habitat fragmentation on abundance and occurrence of nine species of mixed-grass prairie passerines. Sprague's pipit (Anthus spragueii), Baird's sparrow (Ammodramus bairdii), grasshopper sparrow (A. savannarum), and chestnut-collared longspur (Calcarius ornatus) were determined to be area sensitive being more abundant or occurred more frequently in larger patches of mixed-grass prairie. The ratio of edge to interior habitat was a better predictor of areas sensitivity than patch size for these species in most cases. Horned lark (Eremophila alpestris), Savannah sparrow (Passerculus sandwichensis), clay-colored sparrow (Spizell pallida), western meadowlark (Sturnella neglecta), and brown-headed cowbirds (Molothrus ater) were insensitive to patch size.

Vegetation structure was found to be an important predictor of grassland-bird abundance and occurrence, explaining additional variation not accounted for by patch size or ratio of edge to interior habitat. While protection of large, contiguous tracts of habitat is essential to conservation of endemic grassland birds, the author concludes preservation of small patches of grassland with minimal edge also is vital for conservation of some grassland species. Grassland patches having a higher proportion of interior habitat relative to edge habitat are more attractive to area-sensitive species. Restoration efforts in grassland habitats should focus on increasing patch size and minimizing amount of edge but small patches of grassland should not be eliminated from consideration. Physiognomic features of habitat such as density of live and residual vegetation, vegetation height and shrub density also affect attractiveness of grasslands for avian species.

Davis, S.K., and Duncan, D.C., 1999, Grassland songbird occurrence in native and crested wheatgrass pastures of southern Saskatchewan: Studies in Avian Biology, v. 19, p. 211-218.

Songbird occurrence compared in native pasture and seeded pastures of pure crested wheatgrass (Agropyron cristatum) and crested wheatgrass/legume mix in southern Saskatchewan. Habitat variables associated with songbird occurrence differed among species. Authors conclude that vegetative structure is more important than is plant species composition in habitat selection for grassland birds. Pure stands of crested wheatgrass were found to be as attractive to many avian species as were native pastures. Because many species rarely inhabit cropland conversion to pure stands of crested wheatgrass can be beneficial to avian species if sufficient cover and structural diversity are furnished. Many avian species were more attracted to native pasture than stands of crested wheatgrass. Authors recommend preservation of existing native grasslands and restoration of grasslands that more closely mimic the structural diversity of native prairie community.

Delisle, J.M., and Savidge, J.A., 1997, Avian use and vegetation characteristics of Conservation Reserve Program fields: Journal of Wildlife Management, v. 61, no. 2, p. 318-325. 
Comparison of avian use of conservation practice CP1 (cool season grasses and legumes) and CP2 (warm-season, native grasses) in southeastern Nebraska. Total bird abundance did not differ between CP1 and CP2 fields. In winter and breeding season, CP2 fields had taller, denser vegetation than recorded in CP1 fields. Bobolinks (Dolichonyx oryzivorus) were more abundant in $\mathrm{CP} 1$ whereas common yellowthroats (Geothylpis poliocephala) and sedge wrens (Cistothorus platensis) more abundant in CP2 fields. American tree sparrows (Spizella arborea) and ring-necked pheasants (Phasianus colchicus) were the most abundant species recorded during winter with the highest numbers were associated with CP2. Meadowlarks (Sturnella neglecta) were most abundant in CP1. Sedge wrens preferred fields with structurally complex vegetation but disappeared after fields had been mowed or burned. Yellowthroats were associated with comparatively tall vegetation. Grasshopper sparrows (Ammodramus savannarum) disappeared from fields as litter depth increased and amount of dead vegetation accumulated. CP2 fields that maintained relatively consistent numbers of grasshopper sparrows were mowed 3 out of $4 \mathrm{yr}$. CP2 was preferred by pheasants for winter cover. Native plantings alone can provide habitat for all native birds if some fields were managed more intensively to simulate historical disturbances resulting from wildfire or grazing. CP1 generally furnished the best habitat for species which nest directly on ground and prefer low vegetation height and minimal depth of litter. CP2 grasslands were used predominantly by avian species that nest higher in vegetation and prefer denser growth.

Donald, P.F., Pisano, G., Rayment, M.D., and Pain, D.J., 2002, The common agricultural policy, EU enlargement and the conservation of Europe's farmland birds: Agriculture, Ecosystems and Environment, v. 89, p. 167-182.

Modern agriculture should be regarded as a major threat to biodiversity, comparable to global climate change and pollution in their potential to affect vast areas. Authors estimate one billion hectares in next $50 \mathrm{yr}$ will be converted to agriculture in developing countries resulting in doubling, or tripling, of chemical eutrophication of aquatic ecosystems and pesticide pollution. Data shows that declines in European birds have been most significant in EU countries with the most intensive agricultural production. Changes in agricultural production contributing to loss of avian numbers and biodiversity are attributed to increased use of pesticides, increase in highinput cereal farming, loss of lower-input grassland systems, increase in field size; loss of hedgerows and other "nonproductive" land, changes in times of sowing and harvesting, increased stocking levels of livestock, replacement of hay with silage, and abandonment of farmland. Data to support nonagricultural causes of avian population changes are generally weak or lacking.
Eggebo, S.L., 2001, Ring-necked pheasant and passerine abundance in Conservation Reserve Program grasslands of differing age-classes and cover types in eastern South Dakota, 1998-2000: Brookings, S. Dak., South Dakota State University, M.S. thesis, 96 p.

Old CRP grasslands (10-13 years old) had higher crowing count responses than recorded in young CRP fields (0-3 years old). Cool-season grasslands (tall or intermediate wheatgrass [Agropyron elongatum, A. intermedium], smooth bromegrass [Bromus inermis], and legumes) had higher crowing count responses than did warm-season mixes (switchgrass [Panicum virgatum], big bluestem [Andropogon gerardii], Indiangrass [Sorghastrum nutans]). Non-game bird grassland obligates were more abundant in CRP grasslands dominated by cool season grasses. Author concludes it takes at least 3 yr for CRP fields to provide suitable habitat for ring-necked pheasants (Phasianus colchicus). As CRP grasslands become older, they may lose some feeding qualities (for example, loss of legumes) but gain value as nesting habitat due to greater quality of cover. Overall, cool-season grassland generally furnished greater habitat quality than did grasslands dominated by warm-season species. Warm season grasses appeared to furnish better winter cover. The author recommends flexibility in CRP planting mixes with greater priority given to providing a mix of grassland types in administration of the CRP. Legume component may be critical component of the cool season mix.

Evard, J.O., Snobl, D.A., Doeneir, P.B., and Dechant, J.A., 1991, Nesting of short-eared owls and voles in St. Croix County: The Passenger Pigeon, v. 53, no. 3, p. 223-226.

Elevated concentration of meadow voles (Microtus pennsylvanicus) in CRP grasslands was attributed to attracting and supporting a diversity of predators including short-eared owl (Asio flammeus), red fox (Vulpes vulpes), coyote (Canis latrans), and rough legged hawks (Buteo lagopus). Two nests of short-eared owls were found in CRP grassland. The species rarely has nested in Wisconsin. Authors attribute presence of these nests to CRP grassland habitat supporting high density of prey species.

Fletcher Jr., R.J., and Koford, R.R., 2002, Habitat and landscape associations of breeding birds in native and restored grasslands: Journal of Wildlife Management, v. 66, no. 4, p. 1011-1022.

Evaluation of avian density and species richness in Iowa grasslands indicates restored grassland habitats contain bird communities generally similar to those in native prairie habitats. Therefore, restored grasslands may furnish similar habitat suitability for most grassland birds found in native grasslands. Although diversity of plants was much higher in native 
prairies, habitat structure was similar for many habitat variables. Primary exception was percent total cover and percent bare ground; both lower in restored grasslands. Restoration of grasslands in agricultural landscapes can provide suitable habitat for breeding grassland birds even if restoration does not mirror composition of native prairie. Habitat structure is important predictor of bird density in grasslands; consideration of landscape structure provides additional resolution. The amount of grassland in a landscape and its shape and structure should be important considerations in land acquisition, restoration, and management.

Fletcher Jr., R.J., and Koford, R.R., 2003, Changes in breeding bird populations with habitat restoration in northern Iowa: American Midland Naturalist, v. 150, no. 1, p. 83-93.

Although habitat restorations of grasslands and wetlands inevitably provide breeding habitat for declining avian species estimating how restoration efforts have enhanced populations and communities in fragmented landscapes is not easy or straightforward. Authors estimate many species of management concern have increased in response to restoration of habitat, but analysis of spatial processes could be important in determining habitat quality for avian species in agriculturally dominated landscapes. Temporal dynamics in avian populations can affect estimates of population change because populations can change among years. Some populations may exhibit changes at regional scales. Changes in restoration that restore grasslands from hayland and pasture will likely produce less change in avian populations than restoring lands in row crop agriculture. However, restoration of hayland and pasture will remain valuable because both grazing and mowing can have negative effects on avian populations.

Fletcher Jr., R.J., Koford, R.R., and Seaman, D.A., 2006, Critical demographic parameters for declining songbirds breeding in restored grasslands: Journal of Wildlife Management, v. 70 , no. 1 , p. $145-157$.

Planting and restoration under state and federal conservation programs are investigated to understand consequences on grassland bird (dickcissel [Spiza Americana], bobolink [Dolichonyx oryzivorus]) populations in northern Iowa. The study area was restored from row crop production using warmseason grasses ( 27.5 percent) and cool-season grasses ( 72.5 percent). Warm-season grasses were typically switchgrass (Panicum virgatum) or big bluestem (Andropogon gerardii). Cool-season plantings were dominated by smooth brome (Bromus inermis).

No evidence is found for planting type influencing rates of nest predation. The authors conclude management focused on increasing adult survival or decreasing nest predation could produce stable populations of these species. Data suggests grasslands in this Iowa study were likely sink habitats for dickcissels where populations were unsustainable without immigration. Bobolink population growth would occur only if annual survival is high. It is recommended conservation strategies should concentrate on lessening detrimental effects of nest predation. Larger size of fields and greater amount of grassland habitat in the landscape is recommended.

Frawley, B.J., 1989, The dynamics of nongame bird breeding ecology in Iowa alfalfa fields: Ames, Iowa, Iowa State University, M.S. thesis, 94 p.

Eight bird species (dickcissel [Spiza americana], red winged blackbird [Agelaius phoeniceus], western meadowlark [Sturnella magna], common yellowthroat [Geothlypis trichas], sedge wren [Cistothorus platensis], grasshopper sparrow [Ammodramus savannarum], mourning doves [Zenaida macroura] and vesper sparrow [Pooecetes gramineus]) established territories in alfalfa fields before mowing. Mowing reduced avian numbers and densities. Only dickcissels, grasshopper sparrows, western meadowlarks, and vesper sparrows attempted to nest in second growth alfalfa fields subsequent to mowing. Common yellowthroats selected the tallest, densest vegetation with relatively high coverage of grass. Grasshopper sparrows used areas of comparatively sparse vegetation. Western meadowlark abundance seemed unrelated to changes in vegetation.

The needs of ground nesting birds are difficult to integrate with forage management practices. Highest forage yields are obtained by harvesting alfalfa in early June in Iowa. Alfalfa is typically harvested two more times at $5 \frac{1}{2}$-week intervals. Forage production on private lands will continue to intensify with greater production, new cultivars, and earlier mowing. New species of cultivars have permitted earlier mowing while still maintaining high yields. CRP provides some compensation for losses of habitat in alfalfa. However, mowing of CRP in nesting season negates potential benefits of CRP.

Freemark, K.E., Probst, J.R., Dunning, J.B., and Heji, S.J., 1993, Adding a landscape ecology perspective to conservation and management planning, in Finch, D.M., and Stangle, P.W., eds., Status and management of neotropical migratory birds: Fort Collins, Colo., USDA Forest Service General Technical Report RM-229, p. 346-352.

Populations within individual habitat patches can decline, become extinct, and become reestablished by dispersal of individuals from other patches. The set of local populations, which interact through dispersal, is a meta-population. Within a landscape the probability of local extinction within a habitat patch is inversely related to size of the patch population, which is proportional to the size and habitat quality within the patch. Probability of re-colonization is proportional to proximity and connectedness to similar habitat patches and permeability 
of the intervening matrix of land cover and use. Effective conservation of neotropical migrant land birds may require preservation of suitable but intermittently unoccupied, habitat. Management plans should protect the diversity of habitats and landscapes used, not just where the species is most common.

Fritcher, S.C., Rumble, M.A., and Flake, L.D., 2004, Grassland bird densities in seral stages of mixed grass prairie: Journal of Range Management, v. 57, no. 4, p. 351-357.

Authors believe seral stages of grassland may have effects on declining bird populations in grassland ecosystems but resource managers lack sufficient information to assess how avian species are affected by changes in grassland composition. Report evaluates bird density, species diversity and species richness in 4 seral stages of western wheatgrass (Pascopyrum smithii), and green needlegrass (Nasella viridula) associations in central South Dakota. Species richness did not differ between seral stages but diversity was greater in early seral stages of grassland composition. Birds with habitat requirements of tall vegetation and residual cover were more abundant in later seral stages (for example, grasshopper sparrow [Ammodramus savannarum], bobolink [Dolichonyx oryzivorus]). Early seral stages were more beneficial to species needing short grass and sparse vegetative cover (for example, chestnut-collard longspur [Calcarius ornatus], horned lark [Eremophila alpestris]). Authors recommend management prescriptions furnishing a mosaic of seral stages to maximize grassland bird species diversity and abundance across the landscape. Authors conclude seral stage was an effective predictor of density for many grassland birds and assessment of seral stage can furnish a framework for development of management plans and prediction of effects of management decisions.

Gard. N.W., Hooper, M.J., and Bennett, R.S., 1993, Effects of pesticides and contaminants on neotropical birds, in Finch, D.M., and Stangle, P.W., eds., Status and management of neotropical migratory birds: Fort Collins, Colo., USDA Forest Service General Technical Report RM-229, p. 13-413.

The report provides a summary of potential effects of chemicals on migratory birds. More is unknown than known and problems or effects of chemical applications and pollution remain difficult to assess. Standardization of monitoring programs and selection of specific avian species as indicators is recommended.

Gill, D.E., Blank, P., Parks, J., Guerard, J.B., Lohr, B., Schwartzman, E., Gruber, J.G., Dodge, G., Rewa, C.A., and Sears, H.F., 2006, Plans and breeding bird response on managed Conservation Reserve Program grassland in Maryland: Wildlife Society Bulletin, v. 34, no. 4, p. 944-956.
A report on the first 6 years of studies in experimental CRP grasslands designed to evaluate how mixes affect local population of grassland obligate birds, appraise avian species response to vegetation management, and define desirable grassland management prescriptions. The investigation is based on evaluation of 92.4 hectares (232 ac) of CRP grassland in northeastern Maryland. CRP fields were planted to native grasses (CP2) in 1998. Designed as a replicable experiment, the ultimate management goal of these fields was reestablishment of grasslands similar to those dominant on the Atlantic seaboard pre-agriculture. Fields were planted to 8 native warm-season, and 2 cool-season grasses. Within several fields prairie flower seeds were added to the planting mix.

Study results demonstrate eastern native grasslands can be "reassembled" on heavily degraded lands within a time frame of 2 to 4 yr. Reassembled was, increasing species diversity in a managed habitat so the area becomes capable of supporting sustainable populations of plant and animal species. In six years of management (for example, mowing, burning) cumulative plant species richness increased. Several at risk bird species (for example, grasshopper sparrow [Ammodramus savannarum], dickcissel [Spiza americana]) colonized the restored grassland and established sustainable breeding populations. Large blocks of habitat were fundamental to the positive response by grassland obligate species in contrast to narrow linear grass-buffer strips (that is, CP21) which attracted very few grassland specialist bird species. Prescribed burning is identified as the least expensive management tool for maintaining grasslands. Switchgrass (Panicum spp.) was found to be too aggressive in this region and no longer recommended for native grassland seeding mixtures. Management of restored grasslands should include spatial and temporal rotation of prescribed fire and herbicide applications to sustain desirable vegetative physical structure rather than species composition.

The authors conclude mowing, during establishment, prescribed burning on a 3-yr rotation, and application of herbicides for noxious weed control established and maintained a species rich grassland habitat valuable to grasslandobligate species. Results of this study demonstrate many of the management prescriptions recommended by USDA and others work. Conservation effort of CRP and CREP are valid approaches to benefit multiple conservation objectives.

Granfors, D.A., 1992, The impact of the Conservation Reserve Program on eastern meadowlark production and validation of the eastern meadowlark habitat suitability index model: Lubbock, Tex., Texas Technical University, M.S. thesis, $98 \mathrm{p}$.

Eastern meadowlark (Sturnella magna) productivity was compared between CRP land and rangelands in Lyon county Kansas. Nests in CRP fields had lower parasitism by brownheaded cowbirds (Molothrus ater), larger clutch sizes, and 
higher hatch rates than nests in pastures. Cowbird parasitism appeared to be a major cause of lowered productivity of meadowlark nests. Eastern meadowlarks selected for less dense litter and more homogenous vegetation structure in both land use types. Nests in CRP fields had higher proportion of grass than available in random sites. Residual cover was greater near nests in CRP fields.

Relationships between HSI values and eastern meadowlark densities were poor due primarily to high densities of meadowlarks in fields with high coverage of forbs. Relationship improved when HSI values and densities were averaged over three years of the study. There appeared to be no discernible relationship between western meadowlark (S. neglecta) densities and the output of the eastern meadowlark HSI model.

Granfors, D.A., Church, K.E., Smith, L.M., 1996, Eastern meadowlark nesting in rangelands and Conservation Reserve Program fields in Kansas: Journal of Field Ornithology, v. 67, no. 2, p. 222-235.

Comparison of microhabitat, nest-site selection, and nest success on Kansas rangelands and CRP is described. Daily nest survival rates and numbers fledged per female did not differ significantly between land use types. Mowing CRP fields was source of nest failure and induced adults to abandon some fields. CRP had significantly higher values for depth and density of litter cover, taller herbaceous canopy, less herbaceous cover and more standing dead cover than recorded in rangelands. CRP has increased diversity of available nesting habitats. Eastern meadowlarks (Sturnella magna) selected sites with greater litter cover, higher proportion of grass, more uncompacted litter, and greater structural homogeneity than on recorded in random plots. Delay of mowing and burning was recommended to enhance and maintain habitat suitability in CRP fields.

Mowing caused undesirable buildup of litter and, depending on time of year, may cause abandonment of fields and direct failure of nests. Authors recommended partial mowing of fields over complete mowing. Spot mowing after July 15 was recommended as best management option. Disadvantage of grazing is increased probability of trampling and attracting brown-headed cowbirds (Molothrus ater). Prescribed burning can reduce litter and increase proportion and vigor of native grasses while decreasing percentage of cool-season grasses and forbs. Recommend spring burning every 3-4 yr. Prescribed burning may cause temporary early-season loss in habitat quality, but resultant increased cover of grass and reduction of litter should enhance habitat quality later in growing season and subsequent years.

Grant, T.A., Madden, E., and Berkey, G.B., 2004, Tree and shrub invasion in northern mixed-grass prairie-Implications for breeding grassland birds: Wildlife Society Bulletin, v. 32 , no. 3 , p. $807-818$.
Study reports results of investigation of invasion by woody plants aspen (Populus tremuloides), willow (Salix spp.) and others on avian grassland bird species in northcentral North Dakota. Grassland study area dominated by needlegrass-wheatgrass (Stipa-Agropyron) intermixed with smooth brome (Bromus inermis) and Kentucky bluegrass (Poa pratensis). Probability of occurrence of 11 of 15 species decreased as percent woodland, tall shrub, or brush cover increased. Grasslands became largely unsuitable for 9 species of grassland birds as woody cover exceeded 25 percent. Only vesper sparrow (Pooecetes gramineus), clay-colored sparrow (Spizella pallida), and common yellowthroat (Geothlypis trichas) occurred more frequently as woody cover increased. Savannah sparrow (Passerculus sandwichensis), bobolink (Dolichonyx oryzivorus) and grasshopper sparrow (Ammodramus savannarum) reached maximum probability of occurrence in open treeless grasslands with probability of occurrence declining to 50 percent when woody cover ranged from 10-25 percent. Number of species negatively affected by woody cover increased as vertical structure changed to tall shrub and aspen woodland.

Authors judge even nominal increases in woody vegetation compromise use of grasslands by several avian species. Occurrence of most woodland-sensitive species declined rapidly as woodland cover increased to only 5-20 percent. Recommend restoration efforts on grasslands be focused where woody cover is less than 20 percent for management to have most beneficial effects. Authors urge discontinuance of programs that encourage introduction of native and non-native trees and shrubs into northern Great Plains grasslands.

Graul, W.D., 1980, Grassland management practices and bird communities, in Management of western forests and grasslands for nongame birds: Ogden, Utah, USDA Forest Service General Technical Report INT-86, p. 38-47.

Grasslands contain relatively few bird species. However, within grasslands occur mosaics with different avian species restricted to subtypes. Consequently, a general habitat category of grassland can contain considerably more avian species than may be implied by categorization as a single type. Grassland bird communities tend to be numerically dominated by one or two abundant, widespread species. Grassland types may contain avian species with extremely restricted habitat needs. A viable approach to grassland management is to consider the habitat requirements of avian species with most restrictive needs and maintain enough suitable habitat to support substantial numbers of the species. This management strategy is based on assumption species with broader habitat requirements will find suitable habitat.

Helmers, D.L., 1992, Shorebird management manual: Manomet, Mass., Western Hemisphere Shorebird Reserve Network, $58 \mathrm{p}$. 
Disappearance or degradation of migratory stopover habitats (many of which are associated with agricultural ecosystems) may be detrimental to entire populations of shorebirds. Physically and chemically altered wetlands have resulted from drainage, impoundment, or alteration of watersheds and water regimes. Associated uplands used by nesting shorebirds are dominated by short, sparse vegetation. Twelve shorebird species breed within the Great Plains geographic region. Nest sites are often on bare sand or gravel substrates associated with fresh, alkaline, or saline wetlands. A mosaic of wetland types from ephemeral to semi-permanent interspersed with short to moderate height grasslands provide reproductive and brood rearing habitat for many of shorebirds utilizing the Great Plains.

Henningsen, J.C., and Best, L.B., 2005, Grassland bird use of riparian filter strips in southeast Iowa: Journal of Wildlife Management, v. 69, no. 1, p. 198-210.

Report documents results of investigation of breeding grassland bird use of 33, 3-4-yr-old CRP filter strips. Relative abundances of birds and nests were similar between coolseason and warm-season grass plantings. The most abundant avian species recorded were red-winged blackbird (Agelaius phoeniceus), dickcissel (Spiza americana), song sparrow (Melospiza melodia), and common yellowthroat (Geothlypis trichas). Nest success was generally low in all treatments evaluated with predation being the major cause of nest failure.

Several differences between vegetation characteristics in filter strips planted to cool-season (mixtures of brome [Bromus inermis], orchardgrass [Dactylis glomerata], and timothy [Phleum pratense]) and warm-season (switchgrass [Panicum virgatum]) were recorded. Generally, warm season planting had more vertically dense live vegetation, taller residual vegetation and greater plant species richness (forbs). Grass cover was greater on cool-season filter strips. Cool season grass and legume plantings are more horizontally dense and more resistant to encroachment from weedy plants. Proximity to woody vegetation influenced bird species richness, abundance, and nest abundance. Species richness was higher in non-wooded sites as grassland bird species tend to be less abundant, or less likely, to nest near wooded edges. Nest success estimates were generally low in all treatments (planting mixture, edge type) and were lower than nest success reported for block-shaped CRP fields in Iowa. Authors conclude presence of woody vegetation adjacent to filter strips has negative effects on use by grassland birds but if enhancement of the overall avian community is a goal establishment of filter strips adjacent to wooded riparian corridors is a reasonable management option. Greater filter strip width potentially can increase use by birds infrequently recorded in existing filter strips.

Herkert, J.R., 1994, The effects of habitat fragmentation on midwestern grassland bird communities: Ecological Applications, v. 4, no. 3, p. 461-471.
Breeding bird species richness patterns significantly increase with habitat fragment size. Eight of 15 bird species had distributions among fragments influenced by habitat area. Estimates of minimal area requirements for five area sensitive avian species range from 5 to 55 hectares (12.5 to 136 ac). Absence of area sensitive grassland bird species from small fragments may be a consequence of limited availability of habitat. Both area and vegetation structure significantly influence midwestern grassland bird populations. All five area sensitive species monitored in this study regularly avoided structurally suitable habitat on small grassland fragments. Habitat fragmentation is likely to have caused midwestern grassland bird declines especially for area-sensitive species. Management directed toward minimizing breeding season disturbances, controlling features attracting nest predators, reduction in amount of woody encroachment into grasslands, and attention to needs of area sensitive species would be major benefits to midwestern grassland birds. Local or regional extinctions are likely if loss and fragmentation of midwestern grassland habitat continues.

Large scale, diverse grassland management is needed to meet habitat needs of migratory grassland bird species of the greatest conservation concern in Midwest region. Habitats of highest management concern will vary regionally. Management should focus on providing habitat for large populations of area-sensitive species to increase the likelihood of longterm persistence of populations. An excellent discussion on effects of grazing and burning is presented. However, results can be highly variable depending on extent of management, season as well as species of management concern. Mosaic of burned and unburned, mowed, un-mowed grasslands provide full range of habitat preferences. There still are insufficient data regarding individual species and how they respond to differing management practices under varying conditions. Information on short-term responses is common but there is little available information on long-term effects of habitat management.

Herkert, J.R., 1994, Breeding bird communities of midwestern prairie fragments - The effects of prescribed burning and habitat area: Natural Areas Journal, v. 14, p. 128-135.

Study competed in Illinois comparing relative importance of habitat area and effects prescribed burning showed habitat area had greater influence on breeding bird community composition than prescribed burning. Large prairie fragments must be managed to provide a mosaic of burned and unburned areas to ensure availability of suitable habitat for species experiencing significant population declines and predominately restricted to large grassland areas. Benefits of burning include increase in aboveground plant biomass, which may provide greater concealment for nests thereby decreasing rate of nest predation. Higher densities of insects also present in burned prairies as compared to unburned sites. Management of large fragments of prairie is more complex than that of smaller 
fragments due to presence of sensitive avian species. The habitat requirements of these species can be addressed by providing a mosaic of habitat types. General guidelines: conduct prescribed burns on large prairie fragments (greater than 80 hectares [198 ac]) on rotation of 20-30 percent of area annually. On small fragments larger percentage may be burned but probably should not exceed 50-60 percent of area, especially if sensitive species are present.

Herkert, J.R., 1997, Population trends of the Henslow's sparrow in relation to the Conservation Reserve Program in Illinois, 1975-1995: Journal of Field Ornithology, v. 68. no. 2 , p. 235-234.

Spring bird count data suggests 78 percent population decline for the Henslow's sparrow (Ammodramus bairdii) in Illinois between 1975 and 1995. Analysis indicates grasslands established under CRP have been beneficial to the species. Population trends in counties with high enrollment in CRP were greater than trends in counties with little land enrolled in the program. Although the CRP has been beneficial, the positive change in populations of Henslow's sparrows has been insufficient to offset long-term, larger scale declines due to other factors, particularly loss of suitable habitat. Periodic management of CRP grasslands may be needed to maintain habitat quality for the species by reducing encroachment of woody vegetation into grasslands.

Herkert, J.R., 2007, Evidence for a recent Henslow's sparrow population increase in Illinois: Journal of Wildlife Management, v. 71, no. 4, p. 1229-1233.

Due to long-term declines in populations the Henslow's sparrow (Ammodramus henslowii) is of high management concern. Historical loss of habitat has been the underlying reason for the decline in numbers and distribution of the species. Using Illinois Spring Bird Count data, the author investigates relations between establishment of the CRP and population trends for the species. The CRP appears to have played a fundamental role in averting federal listing of the Henslow's sparrow in the United States. Data analysis shows populations of Henslow's sparrows in Illinois have increased substantially over the last 10 years. This increase is attributed to establishment of more than 400,000 hectares $(988,440 \mathrm{ac})$ of CRP grasslands within the state. Growing populations of the bird in other states (Iowa, North Dakota, South Dakota, Minnesota, Michigan, Missouri, and Indiana) also are attributed to increased distribution and quality of habitat brought by the CRP. Since haying and grazing diminish habitat quality, new USDA rules for allowing managed use of these fields may have detrimental effects on the species. Monitoring the effects of haying and grazing, especially on three year rotations, should be completed to assess impacts to Henslow's sparrow which generally do best within undisturbed grasslands.
Herkert, J.R., 2007, Conservation Reserve Program benefits on Henslow's sparrows within the United States: Journal of Wildlife Management, v. 71, no. 8, p. 2749-2751.

The Henslow's sparrow (Ammodramus henslowii) is one of America's fastest declining grassland songbirds. Establishment of the CRP has been associated with enhancement of habitat distribution and quality for this species. Breeding Bird Survey data are used to evaluate the impact CRP has had on the Henslow's sparrow throughout their breeding range. Data from 170 BBS routes in Illinois, Indiana, Iowa, Kansas, Kentucky, Maryland, Michigan, Minnesota, Missouri, New York, Ohio, Oklahoma, Pennsylvania, Virginia, West Virginia, and Wisconsin are used in the analysis. CRP data (total percentage land area in CRP) were at the county-level for the 2002 Census of Agriculture. The author finds Henslow's sparrow populations are influenced by the CRP with greatest increases in populations found in areas of high local enrollment in the program. This trend was evident throughout the breeding range. Prior to CRP populations of this species were declining at a rate of 6.5 percent $/ y$ r. Subsequent to establishment of CRP grasslands the species is believed to be increasing by 2.9 percent/yr. Population enhancements experienced by the Henslow's sparrow are at risk due to effects of high commodity prices and expiration of a large number of CRP contracts in upcoming years. If many of these lands return to production habitat and population gains experienced by this species will diminish. The effects of loss in CRP habitats on Henslow's sparrows should be monitored.

Herkert, J.R., 2009, Response of bird populations to farmland set-aside programs: Conservation Biology, v. 23, no. 4, p. 1036-1040.

The author states the role of agriculturally dominated landscapes in biodiversity conservation has been largely ignored. U.S. Department of Agriculture set-aside programs may offer the most promising conservation opportunities due to the large area devoted to these programs. (Note: only lands included in the CRP are included in this evaluation. Effects of other USDA/State set-aside programs are not addressed). The author provides an analysis of set-aside area and changes in avian populations following establishment of these programs. The assessment is focused on 12 north-central states (Illinois, Indiana, Iowa, Kansas, Michigan, North and South Dakota, Minnesota, Missouri, Nebraska, Ohio and Wisconsin). Within these states is found 62 percent of the total cropland in the United States and 6.7 million hectares (16.5 million ac) of land enrolled in the CRP (48 percent of total CRP area). The author used 21 years of BBS population trend data collected after establishment of the CRP to evaluate whether the program had influenced population trends of breeding birds within the north-central United States.

Results show an association between set-aside (that is, CRP) on local abundance and change in regional avian 
population trends following broad scale implementation of the CRP. Avian species whose abundance was most strongly influenced by CRP also tended to exhibit regional improvements in populations. Several grassland-obligate birds, whose populations were in long-term decline prior to the CRP, have had positive population response to the program. Grassland species with the greatest positive changes in population trends (bobolink [Dolichonyx oryzivorus], dickcissel [Spiza americana]) were also the most common grassland species in CRP fields within the region. The author provides a summary of population trends for 30 avian species prior to (1966-1986) and following initiation of the CRP (1987-2007). The author notes avian use of set-aside grasslands vary as vegetation structure and composition change through time consequently the influence of changes in habitat composition and response of bird populations deserves greater research attention. The author states there is increasing evidence CRP lands have provided population-level benefits for grassland birds. However, there is growing concern over the stability of lands devoted to the conservation program. Rising commodity prices may influence farm operators to return lands enrolled in the CRP to production. The author concludes new policy options may be needed to maintain the population profits to grassland birds brought by the CRP as acreage in the program declines.

Herkert, J.R., Sample, D.W., and Warner, R.E., 1996, Management of midwestern grassland landscapes for the conservation of migratory birds, in F.R. Thompson, III, ed., Management of midwestern landscapes for the conservation of neotropical migratory birds: St. Paul, Minn, USDA Forest Service General Technical Report NC-187, p. 89-116.

Avian species of high priority for conservation were associated with a variety of grassland habitats including dry prairies, pastures, old fields, hayfields, wet prairies, sedge meadows, and grasslands with interspersed shrubs. Diverse habitat associations of bird species with high management concern suggest problems facing grassland birds are widespread and involve variety of grassland habitats. One common feature was sensitivity to habitat fragmentation. Declines in grassland bird numbers significantly correlate with declines in regional acreage of pastures and hay fields. Grassland nest success highest 2-3 yr following prescribed fire. Mid-length (3-5) year rotational burn program appears to be optimum under most circumstances. A greater understanding of winter ecology and habitat requirements of grassland bird species is needed. Relatively few avian species use fields with monotypic grass cover. Pastures are most abundant grassland habitat in the Midwest accounting for 7.8 million hectares (19 or more million ac) (5.7 percent of land area). Pastures can furnish valuable habitat because, when not over-grazed they can support diverse assemblages of grassland bird species including those with declining populations. Area of pasture/hayfield reached peak in Midwest in early 1900s but have declined since then due to lower presence of farm animals and greater dependence upon confine feeding operations.
Hickman, K.R., Farley, G.H., Channell, R., and Steier, J.E., 2006, Effects of old world bluestem (Bothriochloa ischaemum) on food availability and avian community composition within the mixed-grass prairie: The Southwestern Naturalist, v. 51, no. 4, p. 524-530.

An investigation of relations between grassland vegetation structure and species composition in Old-world bluestem, native prairie, and CRP pasture to avian community species richness and species abundance is reported. The study was completed in southwestern Kansas. CRP pastures included in the study had expired from enrollment in the program and were grazed during the evaluation. Dominant grasses in the CRP pastures were sand bluestem (Andropogon hallii), little bluestem (Schizachyrium scoparium), Indiangrass (Sorghastrum nutans), switchgrass (Panicum virgatum), sideoats grama (Bouteloua curtipendula), and sand lovegrass (Eragrostis trichodes). Native pastures had never been under crop production with most common grasses being big bluestem (Andropogon gerardii), sideoats grama, Indiangrass, and little bluestem. Old-world bluestem pastures were monocultures planted to two cultivars of the species.

Study findings show abundance of individual bird species richness was significantly lower in old world bluestem than both native and CRP pastures. Fewer bird species were also recorded in the old world bluestem fields than within native fields. No difference in numbers of birds observed was recorded between CRP and old world bluestem pastures. Grasshopper sparrows (Ammodramus savannarum), dickcissels (Spiza americana), western meadowlarks (Sturnella neglecta), eastern meadowlarks (S. magna), and lark sparrows (Chondestes grammacus) were the most abundant species across all pastures.

Forb cover was found to be significantly greater in native rangelands compared to CRP and old world bluestem fields. The old world bluestem pastures had significantly shorter vegetation than recorded in other field types. CRP was found to have greater litter depth than recorded in old-world monocultures and native pastures. The authors conclude shorter vegetation heights and litter depths in old world pastures may not have provided sufficient vegetation structural diversity for some grassland birds to find suitable for use. Analysis of arthropod biomass indicated old world bluestem and CRP pastures lacked some attributes necessary to produce an abundance of arthropods. Shorter vegetative cover and low mean forb cover in old world bluestem supported lower arthropod biomass. In contrast, CRP pastures showed a positive relationship between amount of forbs present and arthropod biomass. Insect biomass increased with increasing abundance of forbs. Significantly less avian food, as defined by arthropod biomass, was found in old world bluestem fields than in native pastures. The authors consider the large area planted to old world bluestem monocultures in the southern Great Plains may be contributing to declining abundance of grassland birds. 
Horn, D.J., and Koford, R.R., 2000, Relation of grassland bird abundance to mowing of Conservation Reserve Program fields in North Dakota: Wildlife Society Bulletin, v. 28, no. 3, p. 653-659.

Evaluation of haying of CRP fields in central North Dakota. Study compared relative abundance of birds in idled and mowed portions of fields one year after mowing. Results are consistent with other evaluations which show bird species responding to differing characteristics of fields as defined by height and structure of vegetation. Some species were more abundant in idled portions of fields while others were more abundant in hayed portion of field. By late spring of the year following mowing portions of fields hayed had vegetation of equivalent height of non-mowed portions of fields. Authors recommend partial mowing of CRP fields to provide a mosaic of grassland habitats with different physical characteristics to meet needs of diverse populations of avian species.

Howard, M.N., Skagen, S.K., and Kennedy, P.L., 2001, Does habitat fragmentation influence nest predation in the shortgrass prairie?: The Condor, v. 103, p. 530-536.

Effects of habitat fragmentation and vegetation structure of shortgrass prairie and CRP land on predation rates on natural and artificial nests were investigated in northeastern Colorado. Vegetation seeded under CRP is taller than native shortgrass prairie species. Patch size, degree of fragmentation, and distance of nest from edge had no influence on mortality rates of artificial or natural nests. Vegetation structure did influence predation of artificial nests with predation decreasing with increasing height of vegetation, however, vegetation structure did not influence predation rates on natural nests. Mortality rates of artificial nests on CRP lands and shortgrass sites did not differ. Authors conclude habitat structure is a more important determinant of nest predation than is influence of landscape. Habitat fragmentation in study area did not result in increased predation in remaining patches of shortgrass prairie habitat.

Hughes, J.P., Robel, R.J., Kemp, K.E., Zimmerman, J.L., 1999, Effects of habitat on dickcissel abundance and nest success in Conservation Reserve Program fields in Kansas: Journal of Wildlife Management, v. 63, no. 2, p. 523-529.

CRP fields studied were dominated by Indiangrass (Sorghastrum nutans), big bluestem (Andropogon gerardii), little bluestem (Schizachyrium scoparium), sideoats grama (Bouteloua curtipendula), switchgrass (Panicum virgatum), and western wheatgrass (Agropyron smithii). These grasses comprised over 95 percent of all vegetation recorded in study fields. Dickcissel (Spiza americana) abundance was significantly associated with field-level vegetation characteristics, field edge characteristics, and land use surrounding CRP fields. Nest success was associated with field-level vegetation variables only, specifically vegetation volume. The species responded positively to increased litter cover but negatively to live and grass canopy covers. Forbs have been recognized as preferred nesting substrates for dickcissels. Forbs were relatively uncommon in CRP fields evaluated. Efforts to enhance dickcissel habitat should focus on modification of vegetation structure within fields by encouraging presence and abundance of forbs.

Hughes, J.P., Robel, R.J., and Kemp, K.E., 2000, Factors influencing mourning dove nest success in CRP fields: Journal of Wildlife Management, v. 64, no. 4, p. 1004-1008.

An evaluation of mourning dove (Zenaida macroura) nesting success in northeastern Kansas CRP fields. Daily nest survival rates were associated positively with height of live vegetation and negatively with percent grass cover and percent live vegetation cover. Management practices producing sparse but tall vegetation may increase success of mourning dove nests in CRP fields. Evaluated fields were planted to CP2 native warm season grasses (Indiangrass [Sorghastrum nutans], big bluestem [Andropogon gerardii], little bluestem [Schizachyrium scoparium], sideoats grama [Bouteloua curtipendula], switchgrass [Panicum virgatum], and western wheatgrass [Agropyron smithii]). Dove nests were found in 7 of 9 fields evaluated in 1994 and 8 of 9 fields in 1995. Nest success did not differ between years. Apparent nest success was 55.6 percent in both years, representing a superior success rate reported in other studies. Daily nest survival rates were influenced by field-level vegetation structure, but not field-edge characteristics or surrounding land-use variables. Doves appeared to have higher success in fields with tall, live vegetation and low amounts of grass and live vegetation cover. Authors recommend intermediate level of disturbance providing low amounts of live vegetation and grass cover but high height of vegetation. Recommend spring burning every $3 \mathrm{yr}$.

Hultquist, J.M., and Best, L.B., 2001, Bird use of terraces in Iowa rowcrop fields: American Midland Naturalist, v. 145, no.2, p. 275-287.

Bird abundance in terraces was less than recorded in other strip cover habitats such as grassed waterways and roadsides but greater than recorded in row crops. Authors conclude the relative contribution of terraces to grassland bird conservation is minor and changes in current management practices of terraces would not likely improve conditions for birds nor be economically acceptable. Dominant cover on terraces evaluated was smooth bromegrass (Bromus inermis), the species one recommended by NRCS for establishment on terraces. Bird species richness and abundance may be lower in terraces because terraces are narrower than other strip-cover habitats and vegetation is less diverse. Bird densities in terraces were higher than recorded in CRP because of greater concentration of birds in narrow strip covers than in block-cover CRP. 
Igl, L.D., and Johnson, D.H., 1995, Dramatic increase of Le Conte's sparrow in Conservation Reserve Program fields in the Northern Great Plains: Prairie Naturalist, v. 27, no. 2, p. 89-94.

Substantial increase in Le Conte's sparrow (Ammodramus leconteii) numbers in CRP recorded in 1994 compared to 1990-1993. Changes in habitat associated with drought from1989-1993 and above normal precipitation from mid1993 to mid-1994 likely produced favorable breeding conditions for this species in CRP fields. CRP may provide important habitat only under wet conditions. Influence of emergency mowing and grazing of CRP fields on breeding bird populations remains poorly understood.

Igl, L.D., and Johnson, D.H., 1999, Le Conte's sparrows breeding in Conservation Reserve Program fields-Precipitation and patterns of population change: Studies in Avian Biology, v. 19, p. 178-186.

Breeding Le Conte's sparrows (Ammodramus leconteii) studied in CRP grasslands from 1990 to 1996. Status changed from an uncommon breeding species to one of the most abundant species recorded in last two years of study. Results emphasize importance of range-wide conservation efforts and long-term observations of grassland birds. In 6-yr study period, 111 species of birds were recorded using CRP grasslands during the breeding season. Dramatic increase in populations of this sparrow coincided with occurrence of wet conditions in northern Great Plains. Authors believe geographically large conservation programs such as the CRP are important for long-term conservation of avian species in grassland ecosystems and attribute improvements in habitat quality and distribution furnished by the program as benefiting many species of grassland birds.

Johnson, D.H., Haseltine, S.D., and Cowardin, L.M., 1994, Wildlife habitat management on the northern prairie landscape: Landscape and Urban Planning, v. 28, p. 5-21.

A summary of European settlement impacts to northern prairie landscapes and wildlife habitats. Regional management of wildlife cannot be effective on public lands alone. Partnerships with private landowners need to be developed and expanded. Wildlife managers need to base management activities on explicit, quantifiable objectives that furnish measures of survival, reproduction, and distribution of species. Descriptions of potential landscape-level management options are presented.

Johnson, D.H., and Igl, L.D., 1995, Contributions of the Conservation Reserve Program to populations of breeding birds in North Dakota: Wilson Bulletin, v. 107, no. 4, p. 709-718.
An evaluation of projected changes in North Dakota breeding bird populations if CRP land was taken out of conservation covers and brought back to agricultural production is presented. Of 18 avian species common on CRP, crop fields, or both, 12 were more abundant in CRP. Six of these species had suffered significant decline in populations prior to implementation of the CRP. None of the species common in cropland cover types had declined significantly. Termination of CRP and return of lands to cultivation is projected to cause population declines for sedge wren (Cistothorus platensis), grasshopper sparrow (Ammodramus savannarum), savannah sparrow (Passerculus sandwichensis), dickcissel (Spiza americana) and lark bunting (Calamospiza melanocorys).

Johnson, D.H., and Igl, L.D., 2001, Area requirements of grassland birds-A regional perspective: Auk, v. 118, no. 1, p. 24-34.

Loss of grassland habitats is only one variable affecting avian breeding success. Degradation of remaining grasslands due to improper, or inadequate, management, disruption of natural disturbance regimes, encroachment of woody and exotic vegetation, and fragmentation are other key issues influencing habitat quality for these species. Three fragmentation factors affect avian grassland habitat quality: patch-size, edge, and isolation. The report provides an evaluation of the influence of fragmentation and isolation of CRP grassland fields for grassland breeding bird populations in the northern Great Plains. Fields were planted with perennial grasses and legumes usually wheatgrasses (Agropyron spp.), bromegrass (Bromus inermis), and alfalfa (Medicago sativa). Breeding bird assemblages associated with these fields were similar to those in idle native grasslands in the same region. Authors conclude locating a CRP field near existing grassland, or establishing one large CRP field would benefit more grassland bird species than would creating a larger number of small, isolated CRP fields.

Johnson, D.H. and Koford, R.R., 1995, Conservation Reserve Program and migratory birds in the northern Great Plains, in LaRoe, E.T., Farris, G.S., Puckett, C.E., Doran, P.D., and Mac, M.J., eds., Our living resources-A report to the Nation on the distribution, abundance, and health of U.S. plant, animal, and ecosystems: Washington, D.C., U.S. Department of the Interior, National Biological Service, p. 302-303.

A presentation of nest density and survival rate data for selected common birds and waterfowl nesting in North Dakota and Minnesota CRP fields, croplands, and WPAs. Data supports conclusion federal agricultural programs can have beneficial effects on wildlife resources over broad geographic areas. As CRP fields age their attractiveness to certain species may change. 
Johnson, G.J., and Temple, S.A., 1990, Nest predation and brood parasitism of tallgrass prairie birds: Journal of Wildlife Management, v. 54, no. 1, p. 109-111.

Rates of nest predation and brood parasitism of 5 avian species nesting in tallgrass prairie remnants in Minnesota were influenced by size of prairie fragment, distance to wooded edge, and number of growing seasons since vegetation around nest was last burned. Nest predation was lower on larger blocks of habitat, further from wooded edge, and in vegetation burned less than $3 \mathrm{yr}$ prior to observation. Management activities to maximize nest productivity should focus on provision of large fields regularly burned with no nearby wooded edges. Species investigated: clay-colored sparrow (Spizella pallida), savannah sparrow (Passerculus sandwichensis), bobolink (Dolichonyx oryzivorus), grasshopper sparrow (Ammodramus savannarum), and western meadowlark (Sturnella neglecta). Because of increased abundance of brown-headed cowbirds (Molothrus ater) and addition of wooded edges to prairie habitat nest productivity of prairie nesting birds may be declining. Recently burned prairie vegetation is usually tall and dense, which may restrict visibility to predators and predator activities. Production of seeds and insects was greater in recently burned areas permitting birds to spend less time foraging and greater amount of time protecting nests.

Kantrud, H.A., 1981, Grazing effects on avifauna of North Dakota: Canadian Field Naturalist, v. 95, p. 404-417.

Avian species richness tends to decrease in response to greater intensity of grazing, but total density of birds increased due to higher numbers of a few common species. Total bird density was always highest on idle or lightly grazed sites. In general, distribution and abundance of most grassland bird species in North Dakota have been negatively affected by agricultural activities. Fragmentation of grasslands by agriculture resulted in extirpation of some avian species but cultivation of eastern tallgrass prairie has destroyed habitat for more bird species than in the shorter, western grasslands. Protection should be given to larger remaining areas of grassland representative of various types found throughout state. Long-term preservation of grassland habitat quality will require periodic management of vegetation.

Kantrud, H.A., and Higgens, K.F., 1992, Nest and nest site characteristics of some ground-nesting, non-passerine birds of northern grasslands: Prairie Naturalist, v. 24, no. 2, p. $67-84$.

Fields with numerous wetlands were more attractive to upland-nesting shorebirds than were similar fields where wetlands were more distant. All species studied used native grassland for nesting. Fourteen species nested in seeded grasslands and croplands. Nest success rates did not differ among habitat types for any species. Except for killdeer (Charadrius vociferus), few nests were found in annually tilled croplands.

Current management practices on grasslands devoted to wildlife conservation would benefit from occasional management activities to maintain stand vigor. Results suggest about one third of bird species studied, mostly shorebirds, nested predominantly in shorter sparser cover of pastures rather than taller idle grasslands. Few species were attracted to recently burned fields. To maintain grassland bird species diversity and abundance large, scattered areas of grasslands in the northern Great Plains should be periodically disturbed to reduce vegetation height, litter, and the invasion of woody plants. Modern livestock grazing systems can increase habitat quality for many species of non-game birds on mixed-grass prairies in North Dakota. However, some species seem attracted to fields where vegetation height and density are reduced by grazing during one or more previous growing seasons even though these fields may be relatively unattractive when cattle are present.

Kantrud, H.A., and Kologiski, R.L., 1982, Effects of soils and grazing on breeding birds of uncultivated upland grasslands of the northern Great Plains: Washington, D.C., USDI Fish and Wildlife Service Wildlife Research Report 15, 32 p.

Livestock grazing on lands set aside for wildlife can be used as a management measure to increase populations of game species and increase diversity of plant or animal species. Light to moderate grazing resulted in increased species richness. However, heavy grazing in the northern Great Plains significantly reduced species richness. Grazing by domestic livestock generally decreased average vegetative height and increased exposure of bare soil. In lightly grazed plots height of vegetation seemed to decrease because of shading effect of large amounts of litter. Increased avian species richness was associated with plots in which height of vegetation was not appreciably reduced and percentage of bare soil was not greatly increased by excessive grazing.

Kimmel, R.O., Berner, A.H., Welsh, R.J., Haroldson, B.S., and Malchow, S.B., 1992, Population responses of grey partridge (Perdix perdix), ring-necked pheasant (Phasianus colchicus) and meadowlarks (Sturnella spp.) to farm programs in Minnesota, in Birkan, M., ed., Proceedings of Perdix VI, First International Symposium on Partridges, Quails, and Francolins: Gibier Fauna Sauvage, v. 9, p.797-806.

Impacts of farm programs on wildlife vary depending on vegetation planted, subsequent management of vegetation, and length of time cropland was removed from production. Spring and summer roadside counts were used to monitor changes in grey partridge, pheasant, and meadowlark population changes in 15 Minnesota study areas with varying amounts of land removed from production. Conservation lands included lands enrolled in CRP and Reinvest in Minnesota (RIM) program. At the time of evaluation approximately 96 percent 
of CRP land in Minnesota was planted to tame grasses and grass-legume mixtures (CP1 and $\mathrm{CP} 10)$. Native grass plantings (CP2) accounted for 4 percent of plantings. Grass covers planted on 80 percent of RIM lands were tame grasses and grass-legume mixtures. Authors estimate it would cost $\$ 200$ million/yr for state conservation agency to establish the number of acres of habitat furnished by the CRP. Authors conclude there was not an apparent response by gray partridge but the abundance of pheasants and meadowlarks was positively correlated with amount of land in CRP/RIM. Wildlife benefits of covers provided by conservation programs vary according to which habitat components are furnished and how these components affect existing conditions. If winter cover and feeding areas are inadequate, the benefits of added reproductive cover furnished by CRP/RIM may be reduced. Areas with existing low populations of grassland birds may take a longer period of time for population responses to improvement in habitat quality to be evident.

King, J.W., and Savidge, J.A., 1995, Effects of the Conservation Reserve Program on wildlife in southeast Nebraska: Wildlife Society Bulletin, v. 23, no. 3, p. 377-385.

Ring-necked pheasant (Phasianus colchicus) numbers in southeast Nebraska were higher in areas with approximately 20 percent of cropland in CRP than in areas with less than 5 percent of landscape in the program. Meadowlark (Sturnella neglecta) numbers and eastern cottontail rabbit (Sylvilagus floridanus) numbers did not differ between areas. No differences were found between numbers of birds or avian richness between cool-season grass and warm-season grass-cover types. Vegetation structure and amount of cover were more important in determining bird densities and richness than was diversity of vegetation species. No relationship between bird numbers and vegetation diversity was found suggesting structure may be more important than species composition. In general, vegetation was taller in warm-season grass fields than recorded within cool-season fields. Authors suggest burning grasslands every $3-5 \mathrm{yr}$ to rejuvenate fields. Fields seeded to single grass species generally become denser as they mature resulting in decline in habitat quality.

Klute, D.S., 1994, Avian community structure, reproductive success, vegetative structure, and food availability in burned CRP fields and grazed pastures in northeastern Kansas: Manhattan, Kans., Kansas State University, M.S. thesis, $168 \mathrm{p}$.

Thesis is focused on comparison of avian community structure, reproductive success, vegetative structure, and food availability in burned CRP fields with local dominant cover types, burned, grazed, native grass pastures. During summer, relative abundance of avian species was significantly greater in grazed pastures than in CRP fields. Differences were primarily due to vegetative structure. Vegetative height and biomass VOR was greater in CRP than grazed fields. Total invertebrate biomass during summer was significantly greater in grazed pasture than CRP. Greater forb coverage in grazed pastures may have contributed to higher biomass of invertebrate in grazed pastures over CRP. During winter relative avian abundance did not differ significantly between CRP and grazed pastures. Mean species richness was greater in CRP. Winter CRP fields had taller vegetation and more bare ground within grazed pastures. Total biomass of available seed did not differ significantly between CRP and grazed pastures, however, CRP contained more preferred seed for wintering birds. Author concludes CRP furnished better winter habitat than provided by other covers evaluated. Moderate grazing of CRP may contribute to reduced vegetative height, increased total canopy overage, and increased forb coverage, which should improve habitat for grassland birds over the long term.

Klute, D.S., and Robel, R.J., 1997, Will conversion of Conservation Reserve Program (CRP) lands to pasture be detrimental for grassland birds in Kansas?: American Midland Naturalist, v. 137, no. 2, p. 206-212.

Report describes comparison of avian use of CRP fields and pasture in eastern Kansas. Pastures had significantly greater vegetative cover while CRP fields had more bare ground. Vegetation was taller in CRP fields late in summer as compared to heights in pasture. Total avian abundance was greater in pasture than CRP fields. Reproductive success and rates of nest parasitism did not differ between cover types but nests were more numerous in grazed pasture. Authors conclude if CRP is converted to pasture it would probably not be detrimental to grassland bird populations but this is based on assumption that grazing does not exceed moderate levels.

Long-term moderate grazing tends to reduce vegetative height, increase basal cover of grass, decrease woody vegetation, increase vegetative heterogeneity, and increase forb cover. CRP fields included in study (6-7-yr-old CP2, native grasses) did not have these characteristics. Forb component of pastures (22.4 percent cover) was higher than recorded in CRP fields ( 6.4 percent). This difference was believed to be a key component in attraction of birds to the fields evaluated. More species of birds were observed in CRP fields than in pastures but they occurred at low abundances and more infrequently. Fewer avian species were observed in grazed pastures but at greater abundance and throughout breeding season. Authors conclude long-term changes in CP2 CRP fields have not been adequately documented and these fields are less suitable for grassland birds than moderately grazed pastures. This conclusion is based, however, on the abundance of only a small number of selected species (grasshopper sparrow [Ammodramus savannarum], dickcissel [Spiza americana], meadowlark [Sturnella neglecta], and upland sandpiper [Bartramia longicauda]). 
Knopf, F.L., 1994, Avian assemblages on altered grasslands: Studies in Avian Biology, v. 15, p. 247-257.

As a group, populations of endemic grassland bird species have declined more than any other group of avian species (including neotropical migrants) in the last quarter century. Unlike most forest species that winter in the neotropics, most birds breeding in North American grasslands winter in North America. Consequently problems driving declines in grassland species are associated almost entirely with North American processes. Eastern tallgrass prairie has been virtually obliterated while western shortgrass prairies continue to experience fragmentation. During the last 25 years, grassland species have shown steeper, more consistent and geographically widespread declines than any other behavioral or ecological guild of North American avian species.

Knopf, F.L., 1992, Faunal mixing, faunal integrity, and the biopolitical template for diversity conservation: Transactions of the North American Wildlife and Natural Resources Conference, 57, Charlotte, N.C., March/April 27-1, 1992, Proceedings: Washington, D.C., Wildlife Management Institute, p. 330-342.

Conservation biologists striving to protect a diversity of habitats and species in increasingly altered landscapes of North America do so primarily by protecting samples of the biota in natural preserves. At many locations, local species assemblages have been affected by addition of new species from contiguous or distant sites. Shifts in the composition of native biological diversity can lead to declines in regionally unique species. Often augmented faunas are viewed by the public and local Fish and Game agency personnel as indicative of good wildlife conservation. Future conservation of faunal integrity requires greater coordination among natural resource agencies. Faunal mixing presents a dilemma for biologists dedicated to protecting the integrity of native, endemic faunas. Traditional policies of natural resource agencies favor the spread of ecological-generalist species. Most popular game species are characteristic of early successional habitats and respond favorably to greater edge and diversity in cover composition. Enhancing species richness through fragmentation of landscapes is becoming less favored based on growing evidence that increasing the quantity of edge can harm composition of some wildlife communities. Ecological consequences of species substitutions are masked in management that focuses purely on species richness. Actions for conservation of biological diversity: minimize practices promoting site-specific diversity, emphasize between-habitat diversity on management units and implement a step-down (national/ regional/local) approach to conservation of biological diversity. Conservation of biological diversity must complement the conservation of endangered species. Despite the extinction of many species and a general decline in the biological diversity of North America, many local faunas contain more species today than present prior to European settlement.

Knopf, F.L., 1988, Conservation of steppe birds in North America, in Goriup, P.D., ed., Ecology and conservation of grassland birds: Cambridge, United Kingdom, Technical publication no. 7, International Council for Bird Preservation, p. 27-41.

Only 9 avian species are wholly endemic to the tall and short grass prairies. An additional 19 species have strong affinities to grasslands but also occur in adjacent vegetation types. Endemic species spend the entire year within the grassland while remaining species tend to migrate into brush land and other habitats in Mexico and central America. About 260 species of birds regularly breed in the grasslands of North America, however most are associated with wetlands or manaltered landscapes. Locally, bird communities within grassland average only three to five species during the breeding season with substantial seasonal and annual variation in densities. Conservation programs should identify needs of area-dependent stenotopic species for a locale when planning land purchases. Invasion by woody species provides habitat for birds more typical of eastern deciduous forests, which accelerate patterns of avifaunal mixing.

Knopf, F.L., 1986, Changing landscapes and the cosmopolitanism of the eastern Colorado avifauna: Wildlife Society Bulletin, v. 14, p. 132-142.

Development of riparian forests on the Great Plains has provided corridors for movement of forest birds across grasslands, which have historically served as an ecological barrier to dispersal. Movement of eastern, woodland species as a direct and indirect consequence of land use and modification illustrates relevance of current conservation theory to decisions on local management and the need for interstate rationalization of management plans intended for restoration or preservation of grasslands.

Knopf, F.L., and Samson, F.B., 1992, Conserving the biotic integrity of the Great Plains, in Johnson, S.R., and Bouzaher, A., eds., Conservation of great plains ecosystemsCurrent science, future options: Kluwer Academic Press, p. 121-133.

Despite relatively simplistic composition of endemic avifauna in the Great Pains, grassland-endemic species are currently showing steeper, more consistent, and geographically widespread declines than any other group of North American species. Of 32 grassland bird species, 10 declined at statistically significant rates from 1966-1991. Principle processes that shaped endemic plant and animal communities on the Great Plains have been drought, grazing, and fire. 
These factors favored broad expanses of monotypic vegetation with a minimization of ecological edges. Activities having universal effects on endemic diversity include fragmentation of grasslands, drainage of wetlands, invasion or introductions of alien and exotic species, and water development activities. Impoundments of rivers reducing natural variation in flow regimes and elimination of natural wildfire have had more severe consequences to native flora and fauna of the western Great Plains than has most agricultural production. Ninety percent of breeding bird species in northeastern Colorado did not breed there at the turn of the century.

Koford, R.R., 1999, Density and fledgling success of grassland birds in Conservation Reserve Program fields in North Dakota and west-central Minnesota: Studies in Avian Biology, v. 19, p. 187-195.

Fields planted to CRP grassland covers were suitable breeding habitat for several species whose populations declined prior to implementation of the conservation program. The habitat furnished by CRP appeared to be as secure as other suitable habitats in federal WPAs within these states. Additional cover provided by CRP may have lowered breeding densities in all habitats with possible benefits if reproduction is density dependent. Additional habitat associated with the CRP also may have allowed birds to breed that otherwise would not have bred, such as second year birds, thereby supporting higher growth of populations.

Koford, R.R., and Best, L.B., 1996, Management of agricultural landscapes for the conservation of neotropical migratory birds, in F.R. Thompson, III, ed., Management of midwestern landscapes for the conservation of neotropical migratory birds: St. Paul, Minn, USDA Forest Service General Technical Report NC-781, p. 86-88.

Thirty-eight neotropical migratory birds are common in Midwestern agricultural landscapes. Most species depend on herbaceous or wooded habitats that are declining as average size of farms increases. Management recommendations: minimize cultivation, encourage moderate grazing, delay spring mowing of hay, increase acres in grassed waterways and roadsides, avoid nighttime mowing, encourage longer intervals between mowings, avoid fall mowing and annual mowing of grassed waterways/roadsides, retain fencelines, maintain idle land, and change configuration of idle land to enhance species richness and nesting success. Immediate effect of tillage is exposure of arthropods and other prey to foraging birds and a long-term reduction in abundance of litter-dwelling arthropods. Conventionally tilled fields have lower arthropod abundance than no-till or idle areas. Herbicides can affect birds by reducing availability of seeds. Insecticides reduce abundance and diversity of foliage-dwelling arthropods. Strip cover (for example, grassed waterways, terraces, fencerows roadsides and windbreaks/shelterbelts) usually provides habitat more long-term than provided by areas enrolled in crop-retirement programs. Strip cover in agriculturally dominated landscapes has decreased in recent years. Orientation of crop rows relative to grassed waterway influenced disturbance intensity as nest densities were greater when rows parallel waterways.

Management objectives recommended include conservation of remnant prairie and savannah still in existence. Large-scale restoration of these habitats is often impractical but remnants of important cover types can be saved for education and research. Other recommendations provided include: increasing amount of crop residues available, maintaining CRP or other long-term programs, furnishing high-quality vegetative covers, minimizing tillage, encouraging greater diversification of crops, encouraging moderate grazing of pastures with prescription for species needs of those most at risk, delaying spring mowing of hay as long as possible, avoiding night mowing, increasing intervals between mowing, maintaining idle land in blocks rather than strips, increasing species composition of vegetation on terraces, and planting more diverse species mixes of vegetation. Farmers should be encouraged to not burn all ditches or roadside vegetation in the same year. Fencerows greater than $3 \mathrm{~m}$ (10 ft) wide should be encouraged.

Kurzejeski, E. W., 1996, Vegetation structure and avian species composition in diverted farmland: Jefferson City, Mo., Missouri Department of Conservation Final Report Federal Aid Project No W-31-R-05, 75 p.

Report provides a comparison of vegetative conditions, avian abundance, composition and productivity on CP1 (introduced grasses/legumes), CP2 (native grasses), and row crop fields in northern Missouri. Total bird abundance, grassland bird abundance, nest density, and number of nesting species were all lower on cropland than recorded in CRP fields. Bird community using crop fields differed from CRP fields with short grass and open-ground feeding birds, which are predominant species found on crop fields. The conservation value of CRP fields for declining grassland bird species was higher for CP1 fields than CP2 fields. Monotypic stands of both warmseason and cool-season grasses should be avoided to increase the potential wildlife benefits of CRP and other idle grassland habitats. Management recommendations: cost sharing of grass plantings should be limited to multi-species seedings. Periodic haying and grazing may increase habitat value of monotypic fields and non-game bird habitat. Mowing may effectively decrease height and density of vegetation, however, litter build-up and accelerated rate of grass succession may negatively affect wildlife values of fields where only mowing (residue is not removed) is implemented.

Leddy, K.L., Higgins, K.F., and Naugle, D.E., 1997, The importance of Conservation Reserve Program fields to breeding grassland birds at Buffalo Ridge, Minnesota: Proceedings of the South Dakota Academy of Science, v. 76, p. 105-111. 
Avian abundance and species composition were compared in CRP grasslands, pastureland, and cropland in southwestern Minnesota. CRP fields had higher vegetation measurements and supported higher densities of birds and species richness than did pasturelands and cropland. Majority of CRP fields evaluated were planted to smooth brome (Bromus inermis)/alfalfa (Medicago sativa) or to switchgrass (Panicum virgatum). Mean densities of birds (\#/100ha, [250ac]) in CRP were 312.5 compared to 166.7 in pasture and 9.0 in cropland. Grasslands established under CRP were an important habitat due to the presence of sedge wren (Cistothorus platensis), dickcissel (Spiza americana), and clay colored sparrow (Spizella pallida) not found in other covers evaluated. In contrast, croplands and pasture supported only generalist species.

Little, T., and Hill, R.A., 1993, CRP having an impact: Iowa Conservationist, v. Sept/Oct, p. 4-9.

Description of agricultural and settlement impacts to wildlife habitats and an overview of CRP benefits to wildlife in Iowa. Converting as little as 4 percent of county from row crops to CRP significantly increased numbers of ring-necked pheasants (Phasianus colchicus) recorded on survey routes. Higher numbers of pheasants were attributed to greater overwinter survival due to the elevated quality of grassland cover furnished by the CRP. More than 15 nests of non-game birds were recorded per 40 acres (16 hectares) of CRP, which compared to less than one nest in same area of row crops. Nest success of birds in CRP was 33 percent as compared to 20 percent in hay fields. Waterfowl nest success in CRP was believed to be as good, or better, than experienced in wildlife management areas.

Littlefield, C.D., and Johnson, D.H., 2005, Habitat preferences of migrant and wintering northern harriers in northwestern Texas: The Southwestern Naturalist, v. 50, no. 4, p. $448-452$.

Habitat preferences for northern harriers (Circus cyaneus) in four counties in the panhandle of Texas are described. The raptors hunted over a variety of habitats in the study areas but foraged mainly in CRP grasslands and vegetated playa basins. This area of the panhandle, as well as eastern New Mexico is recognized as a winter concentration area for the species. Within the study area land enrolled in the CRP accounted for 16 percent of land use. The balance of land use was cropland (63 percent), rangeland (16 percent), and playa lakes (less than 2 percent). Species compositions of CRP grasslands (for example, native species vs. introduced species [for example, old world bluestem, weeping lovegrass]) are not described.

CRP grasslands, playas, and native rangeland were used by harriers disproportionately more than availability. Winter wheat was used for foraging less than availability. Tilled stubble, cotton stubble, bare plowed fields, corn stubble, corn stubble planted to wheat, and plowed cotton received little use. Use of winter wheat increased as vegetation increased in height providing cover for prey species. Authors conclude further depletion of Ogallala aquifer may affect distribution of croplands in the region with potential benefits to harriers. CRP and playas supported 42 percent of harrier habitat use. With declines in irrigated cropland CRP enrollment may increase availability of grassland and protection of playas. If the dominant land-use reverts to grazing harriers may be impacted negatively as use of livestock grazed grasslands and playas have been shown to diminish pray availability.

Lloyd, J.D., and Martin, T.E., 2005, Reproductive success of chestnut-collared longspurs in native and exotic grassland: The Condor, v. 107, p. 363-374.

Population declines of grassland birds continue to be apparent in prairie ecosystems that remain relatively intact suggesting factors in addition to habitat loss and fragmentation are involved. Changes in breeding habitat quality may be related to declines in populations but few studies have examined habitat-specific demography of grassland birds. Report describes investigation of reproductive success of chestnut-collared longspurs (Calcarius ornatus) in grasslands composed of native mixed-grass prairie species (species composition and abundance were not identified) and crested wheatgrass (Agropyron cristatum) monocultures in eastern Montana. Conservation efforts targeted toward grassland birds must consider not only spatial relations between covers but vegetative composition and characteristics within patches of habitat.

Authors report that daily nest survival was 17 percent lower in crested wheatgrass plots than within native grassland. Lower predation rates in native prairie resulted in greater average number of young produced per nest. Nestlings in exotic grass also were found to gain mass more slowly, reflecting lower quality of the environment, leading to longer period in nest and greater susceptibility to predation. Fledgling mass in native grassland was approximately 9 percent greater than recorded in crested wheatgrass. There was no evidence longspurs preferred to nest in the native prairie with nest density similar in both habitat types. Results indicate introduction and spread of exotic grass have adverse fitness for this species highlighting the importance of maintaining grasslands comprised of native species. Land managers rarely can control spatial arrangement of habitats within a landscape but can influence changes in structure and composition of vegetation within patches (that is, fields). Authors conclude that changes in the structure and species composition of grassland vegetation can affect reproductive success of grassland birds and spread of exotic vegetation can have adverse fitness consequences for native wildlife. Authors believe the CRP can have greatest potential for endemic species of wildlife if native grasses are emphasized in conservation plantings.

Lokemoen, J.T., and Beiser, J.A., 1979, Bird use and nesting in conventional, minimum-tillage, and organic cropland: Journal of Wildlife Management, v. 61, no. 3, p. 644-655. 
Seasonal use by birds and nesting use was evaluated in fallow fields, sunflower (Helianthus spp.), and wheat fields among conventional farms, minimum tillage farms, reduced tillage, and organic farms (no synthetic pesticides). Spring bird densities were highest in minimum-tillage, fallow fields providing food and cover. No differences in bird densities were found among crops or field types in fall or winter but mean densities of avian species in summer were highest in fallow fields. Fallow fields also had greater mean number of nesting species and highest mean densities of nests, which may have been due to increased amounts of plant litter cover. Mean number of nesting species and nest densities were higher in minimum tillage and organic fields. Overall hatching success was low for waterfowl and shorebirds and low nest success for passerines. Nest losses were due to predation and farming activities. Hatch success higher in minimum tillage fields for passerines and wheat fields for shorebirds. Nest densities in CRP were 6 times larger than that found in minimum tillage stubble and organic fallow and 11 times larger than densities in other field types and crops.

Madden, E.M., Hansen, A.J., and Murphy, R.K., 1999, Influence of prescribed fire history on habitat and abundance of passerine birds in northern mixed grass prairie: Canadian Field-Naturalist, v. 113, no. 4, p. 627-640.

Linkages between disturbance regimes and vegetation response need to be more clearly defined to effectively manage grassland habitats and declining populations of prairie passerine birds. Avian-habitat relations are described on mixed-grass prairie in northwestern North Dakota in relation to history of prescribed fire. Post-fire succession characterized as short, sparse vegetation cover with few forbs and low amounts of litter immediately after burning to moderate amounts of forbs, litter, and shrubs $2-8$ yr following fire. Vegetation described as tall, dense, and shrubby with little forbs or litter understory when fire was excluded (greater than $80 \mathrm{yrs}$ ). Most grassland birds were absent from sites where fire had been excluded. Species richness and abundances of Baird's sparrow (Ammodramus bairdii), bobolink (Dolichonyx oryzivorus), grasshopper sparrow (A. savannarum), Le Conte's sparrow (A. leconteii), Sprague's pipit (Anthus spragueii), and western meadowlark (Sturnella neglecta) were positively related to application of fire. Common yellowthroat (Geothlypis trichas) and clay colored sparrow (Spizella pallida) were recorded at highest densities in unburned prairie.

Authors conclude many grassland birds in this region are strongly adapted to vegetation characteristics associated with relatively frequently burning (5-10 yr). A mosaic of habitats reflecting all temporal stages of succession following fire are recommended to provide suitable habitat for widest number of species. Recommended sizes and configurations for burned areas are not provided with authors suggesting need for further research. Recommendation for burning 20-30 percent of management area yearly is cited for Midwestern prairies. Authors suggest managers should furnish areas with short (2-4 yr) moderate (5-7 yr), and long (greater than 8-10 yr) fire intervals to provide maximum diversity in avian species and habitats. The authors caution, however, management prescriptions should take into account needs of other wildlife species (for example, invertebrates, amphibians) that may not benefit from frequent application of fire.

Madden, E.M., Murphy, R.K., Hansen, A.J., and Murray, L., 2000, Models for guiding management of prairie bird habitat in northwestern North Dakota: American Midland Naturalist, v. 144, no. 2, p. 377-392.

It remains difficult to summarize effects of vegetation management on individual bird species due to differences in environmental conditions (moisture, soils, plant species composition). Vegetation attributes are important determinants of grassland bird abundance. Vegetation structure, and to a lesser extent, composition, can be manipulated by managers. The report gives specific characteristics of vegetation (shrub cover, herb cover, VOR) believed important for a number of prairie bird species. Authors conclude most public grasslands devoted to wildlife traditionally have been managed to promote tall, dense, nesting cover for game birds. Some avian species of importance are most associated with native bunch grasses (for example, little bluestem [Schizachyrium scoparium], sideoats grama [Bouteloua curtipendula]) rather than the broad-leaved, exotic grasses often planted for duck nesting cover. Vegetation attributes preferred by these endemic species are characteristic of grasslands receiving periodic defoliations such as those produced by fire or grazing. A mosaic of available vegetation types is needed to maximize avian diversity. Visual obstruction, presence of grass, forb, or shrub covers were important features for all specialized avian species.

McCoy, T.D., 1996, Avian abundance, composition, and reproductive success on Conservation Reserve Program fields in northern Missouri: Columbia, Miss., University of Missouri, M.S. thesis, $226 \mathrm{p}$.

Grassland bird species richness was higher on structurally diverse $\mathrm{CP} 1$ (introduced grass/legume) fields than found in CP2 (native grass). Vegetation in CP2 fields evaluated was tall, dense monocultures of switchgrass (Panicum virgatum). In areas where grass monocultures exist disturbances to decrease height and density of vegetation and increase plant diversity may be beneficial. Provisions for periodic haying and grazing may enhance habitat value for many avian species.

McCoy, T.D., Ryan, M.R., Kurzejeski, E.W., and Burger, L.W., 1999, Conservation Reserve Program-Source or sink habitat for grassland birds in Missouri: Journal of Wildlife Management, v. 63, no. 2, p. 530-538.

Authors conclude that further documentation of CRP effects on bird populations are needed to maximize benefits 
of the program. The relative value of CRP can be evaluated by comparing reproductive habitat quality for avian species. However, data from CRP habitats are limited. Authors believe that claims that the CRP is a panacea for grassland wildlife are overstated, but the CRP likely has contributed to conservation of many species including several of special concern.

McCoy, T.D., Ryan, M.R., and Burger, L.W., and Kurzejeski, E.W., 2001, Grassland bird conservation-CP1 vs. CP2 plantings in Conservation Reserve Program fields in Missouri: American Midland Naturalist, v. 145, no. 1, p. 1-17.

A comparison of the relative value of different CRP plantings for breeding grassland and wintering birds in CP1 (introduced grasses/legumes) and CP2 (native grasses) fields in northern Missouri is provided. Differences in species abundance were evident between season, but overall species richness, abundance, and nesting success of grassland birds during the breeding season and total bird use in the winter did not differ between conservation practices. Structurally shorter, more diverse, cool-season grass fields were equal or better habitat than taller, more vertically dense switchgrass (Panicum virgatum)-dominated fields for grassland birds including several of high conservation concern. Authors recommend single species plantings of warm or cool season grasses should be avoided to maximize potential benefits of CRP to wildlife.

Authors concluded CP2 fields did not differ from CP1 fields in their value as reproductive and wintering habitat for birds. However, CP2s fields were switchgrass monocultures. Greater value as habitat may be realized with establishment of a mix of warm-season native species. Fields planted to CP1 fields were orchardgrass/lespedeza (Dactylis glomerata/ Kummerowia striata), or timothy/clover (Phleum pratense/ Trifolium spp.). Analysis of mowing in late summer and early fall indicated CP1 fields had sufficient regrowth of cool season grasses, legumes, and annual weeds to provide cover and food for wintering birds. In comparison, cover of warm-season grasses was reduced for at least the following two summers after $\mathrm{CP} 2$ fields were mowed resulting in minimal structural and vegetational diversity until switchgrass again dominated fields. Authors believe landowners are not likely to intensively manage CRP for wildlife unless this is a condition of the contract and/or there is a monetary incentive to do so.

McMaster, D.G., and Davis, S.K., 2001, An evaluation of Canada's permanent cover program-Habitat for grassland birds?: Journal of Field Ornithology, v. 72, no. 2, p. 195-210.

In the early 1990s, Agriculture Canada's Permanent Cover Program (PCP) converted over 445,000 hectares $(1,099,640 \mathrm{ac})$ of cropland to perennial vegetative cover. Permanent Cover Program sites supported higher avian species richness than cropland. Nine of ten commonly detected grassland bird species occurred at higher frequencies in PCP than cropland. Permanent Cover Program sites were characterized by taller, denser vegetation and less bare ground than recorded in cropland sites. Hayed and grazed PCP sites differed significantly in vegetative structure and avian community composition, but did not differ in species richness or evenness. Unlike the CRP, the PCP allows use of forage produced on program lands. Permanent Cover Program vegetation most commonly comprised of combinations or wheatgrass (Agropyron spp.), brome (Bromus inermis), alfalfa (Medicago sativa), and crested wheatgrass (A. cristatum). Habitat maintained in a mosaic of successional stages would provide for the richest diversity of grassland avian species.

McMaster, D.G., Devries, J.H., and Davis, S.K., 2005, Grassland birds nesting in haylands of southern SaskatchewanLandscape influences and conservation priorities: Journal of Wildlife Management, v. 69, no. 1, p. 211-221.

Authors conclude conversion of cropland to hayland provides significant benefits to grassland avian species, including some of conservation priority. Grassland species of conservation concern nested less frequently in hayland than recorded within native grassland. Because restoration of native prairie vegetation costs more to establish than does tame seeded grasses it is an option of limited availability. In contrast to the United States, where the CRP is generally restricted from annual use, grasslands established for conservation purposes in Canada's PCP differ in that producers are allowed to annually hay or graze the restored, or converted lands. Evaluation was conducted in the Missouri Coteau region of the province in lands converted from crop production to hayland. Semipermanent or permanent wetlands were within, or adjacent to, study fields. Study fields were at least 4 yr old and hayed the previous year. Haylands evaluated were seeded to alfalfa (Medicago spp.), and a combination of grasses typically crested wheatgrass (Agropyron cristatum), smooth brome (Bromus inermis), or Russian wild rye (Elymus junceus).

Because study fields were adjacent to wetlands, waterfowl represented a significant portion of nests located. Estimates of relative abundance for all species were approximately twice that recorded in rotational grazing systems of tame and native pastures but half that of waterfowl nests found in idle planted nesting cover. Residual vegetation is a major factor determining quality of habitat for waterfowl nesting cover. Study results show haylands are used for nesting by many species of grassland birds although relatively few may be present at high densities. Haylands are likely to attract fewer waterfowl than idle vegetation since the previous year's haying removes much of the residual vegetation. Nest success rates reported from this investigation are similar to those found in dense nesting cover and CRP (13-19 percent) and within range believed necessary to sustain populations (15-20 percent). Authors conclude conservation of native grassland in a mosaic of heavily to lightly grazed areas likely is the best method to meet habitat requirements of the entire grassland bird community and conversion of cropland to hayland 
greatest advantage may be to reduce grazing pressure on native pasture.

Millenbah, K.F, 1993, The effects of different age classes of fields enrolled in the Conservation Reserve Program in Michigan on avian diversity, density, and productivity: East Lansing, Mich., Michigan State University, M.S. thesis, $108 \mathrm{p}$.

Avian communities and vegetative characteristics were examined in 6 age-class fields (1-6 growing seasons) in central Michigan to determine relations between field age, vegetation characteristics, and avian communities. Younger CRP fields were characterized by higher amounts of forbs and bare ground and supported greater avian densities and diversities than older fields. Older fields supported greater height of grasses and more litter cover than did younger fields. Grassland birds may require a diversity of age classes of CRP fields in agricultural landscapes to meet habitat requirements. Results suggest relationship between age of field and relative avian abundance, diversity and productivity. Younger fields maintained the greater diversity and density of avian species. Older fields with greater litter and grass cover supported the greatest productivity. One-year-old CRP fields supported greatest diversity of avian species. As fields aged, diversity declined, but productivity increased. Both the number of active and successful nests was greatest in older fields. Litter cover serves as a physical barrier to seedlings decreasing the amount of light energy available for vegetative growth. On new fields horizontal cover is sparse. As forb and grass cover increased through the fourth growing season, horizontal cover increased. As fields became more grass-dominated and sparser during years 5 and 6 , horizontal cover decreased.

Greater biomass and diversity of insects were available in younger fields. Few significant differences were found among field age classes, but mean insect diversities and biomass generally decreased as fields aged. Younger fields supported greater diversity. Seventy percent of surveyed landowners gave improvement of wildlife habitat at least some importance in enrollment into CRP. Author recommends controlled disturbance in years 4-6 with the goal to provide multiple successional stages for simultaneous high density, diversity, and productivity of avian species.

Millenbah, K.F., Winterstein, S.R., Campa III, H., Furrow, L.T., and Minnis, R.B., 1996, Effects of Conservation Reserve Program field age on avian relative abundance, diversity, and productivity: Wilson Bulletin, v. 108, no. 4, p. $760-770$.

This report is an expansion of discussion on findings reported in 1993 thesis by Millenbah. The authors recommend implementing management of CRP between years 3-6 to set back succession of vegetation. CRP field are a unique vegetation type in the agricultural landscape consequently little is known about how disturbances will ultimately influence avian species using these fields. Additional information is needed on maintenance and rejuvenation methods for planted CRP grasslands. Authors recommend management activities be accomplished in as short a time period as possible to minimize detrimental effects to nesting species.

Murphy, M.T., 2003, Avian population trends within the evolving agricultural landscape of eastern and central United States: The Auk, v. 120 , no. 1, p. 20-34.

Author reports results of investigation between USFWS BBS and USDA statistics on changes in farmland structure and population trends of birds breeding in grassland and early successional (shrub-dominated) habitats in the central (Rocky mountains to Mississippi river) and eastern (Mississippi east) regions. Author reports changes in land use explained 25-30 percent of variation in avian population change. Grassland birds exhibited stronger declines in populations than did shrub-habitat-associated species. Strong association of declines in grasslands birds was evident regardless of migratory or nesting behavior, suggesting events on breeding grounds have driven declines in these species. Changes in landscape composition accounted for more variability in population trends for grassland species than for shrub-associated species. Most grassland species are short-distance migrants overwintering in agriculturally dominated landscapes within North America. Author believes these species are affected by changes in landscape and agricultural practices both during breeding and non-breeding seasons. Highly individualistic habitat needs of species suggest a complex mosaic of habitat types that must be furnished within agriculturally dominated ecosystems if a diverse avifauna is to be maintained.

In contrast to many other studies, this investigation reports a negative correlation between CRP and avian populations. Five of seven negative associations were for avian species associated with shrub-dominated habitats and the two negative relations for grassland species (common nighthawk [Chordeiles minor], Vesper sparrow [Pooecetes gramineus]) regularly nest in less densely vegetated covers including row crops. Author attributes inability to detect positive associations between birds and CRP possibly a consequence of the relatively small area of land devoted to the program and its uneven distribution in the United States.

Negus, L.P., Davis, C.A., and Wessel, S.E., 2010, Avian response to mid-contract management of Conservation Reserve Program fields: American Midland Naturalist, v. 164 , no. 2, p. 296-310.

Many CRP grasslands lose their value as avian habitat as they mature or become decadent or dominated by grass monocultures. The objectives of this study were to investigate effectiveness of disking and interseeding legumes as a midcontract management practice in northeastern Nebraska CRP 
fields. Vegetative response to management, grassland bird abundance and nest-productivity were evaluated in interseeded and disked CRP fields as well as control (unmanaged) fields. Study fields were 10-15 yr old and originally planted to smooth brome (Bromus inermis) as well as several species of legumes (Trifolium spp.). In the early years following planting these fields were characterized as providing excellent habitat for grassland birds. However, habitat quality declined as fields aged, became dominated by brome monocultures, and the legume/forb component diminished. Managed fields were lightly disked and interseeded with legumes. A portion of each field was disked in 2003 and 2004 with a total of 50-60 percent of each field treated.

Overall avian abundance in treated fields was $4.49 \mathrm{bird} /$ transect as compared to $2.93 \mathrm{birds} /$ transect in control fields. Avian species richness and diversity also were greater within treated fields as compared to untreated control fields. No difference in nest density or nest success was found between control and treated fields. Disked/interseeded portions of fields had higher maximum vegetation height, greater horizontal VOR and a higher percentage of bare ground than did control fields. Grass cover was greater within control fields than within treated fields. Responses of individual avian species (bobolink [Dolichonyx oryzivorus], dickcissel [Spiza americana], red-winged blackbird [Agelaius phoeniceus], common yellowthroat [Geothlypis trichas] and grasshopper sparrow [Ammodramus savannarum]) to the habitat management are discussed.

Oberheu, D., Mitchell, R., Dabbert, B., and Davis, S., 1999, Observations of avian nesting activity in burned and nonburned weeping lovegrass CRP: Texas Journal of Agriculture and Natural Resources, v. 12, p. 14-17.

More than 1 million acres of weeping lovegrass (Eragrostis curvula) has been planted in Texas as part of the CRP. The planting has been criticized as being of little value to wildlife. Although numbers of nests found were small this report documents nesting in weeping lovegrass by Cassin's Sparrow (Aimophila cassinii) a species in decline throughout its range. Nests of mourning doves (Zenaida macroura) and common nighthawk (Chordeiles minor) also were located in CRP lovegrass fields. Although not the best cover for wildlife due to a lack of structural diversity and insufficient thermal cover, weeping lovegrass may be the best multiple-use cover for soil conservation and forage production on sandy soils in the southern High Plains. Because nesting seemed to be inhibited for at least two seasons following burning, the authors suggest application of prescribe fire should be conducted in a mosaic fashion to maintain diversity in vegetative cover.

Owens, R.A., and Myres, M.T., 1973, Effects of agriculture upon populations of native passerine birds of an Alberta fescue grassland: Canadian Journal of Zoology, v. 51, p. 697-713.
Disturbance of fescue (Festuca sp) grasslands by mowing for hay or grazing by cattle reduced or eliminated Baird's sparrow (Ammodramus bairdii) and Sprague's pipit (Anthus spragueii) but permitted ingress of horned lark (Eremophila alpestris) and chestnut-collared longspur (Calcarius ornatus). Total elimination of native grassland by cultivation for cereal crops eliminated all passerine species except the horned lark. Disturbance of peripheral areas resulting from cultivation such as field boundaries and ditches may have benefited species occurring in edge habitats. Vegetation physiognomy is probably the key factor determining distribution of grassland passerine species. Prairie passerines, which evolved to exploit original grassland environments, have been forced to make use of various habitats created by agriculture. Species dependent upon dense-grass situations are largely eliminated when grazing is heavy. Variable grazing intensities will affect habitat distribution differently resulting in changes in composition of grassland bird community. Under grazing, prescriptions aimed at maintaining range in good condition will probably support the full range of prairie passerines. Under heavier grazing, avian species associated with short-grass conditions will predominate. Some species will be present under any grazing prescription (meadowlarks [Sturnella spp.]). This study suggests that passerine avifauna that evolved on the Great Plains is adapted to survive in habitats, which are the product of grazing by native ungulates and periodic fires. Therefore, areas managed to preserve grasslands and native avifauna must allow these factors to operate to create similar conditions.

Patterson, M.P., and Best, L.B., 1996, Bird abundance and nesting success in Iowa CRP fields-The importance of vegetation structure and composition: American Midland Naturalist, v. 135, p. 153-167.

Although many bird species frequent row-crop fields, their abundance within them is relatively low and few species nest there. Because of predation, parasitism, and farming activities, bird reproduction in row crops may be below levels needed to sustain populations. Establishment of the CRP likely has contributed to an increase in abundance of many bird species in central Iowa because permanent vegetative cover replaced row-crop habitats. Authors believe CRP fields furnish better nesting habitat for grassland birds than do roadsides, grassed waterways, and other non-farmed covers associated with Iowa agriculture. The presence of diverse vegetation structure and composition, large block nature, and reduced agricultural activity are believed to benefit avian species. Grass species planted on CRP fields should be selected based on structural and composition attributes to which birds respond. Mowing and spraying of CRP fields for weed control should be deferred until after July to permit maximum nest success. A variety of grass species should be planted. Grass monocultures should be avoided. Whole field enrollments should be encouraged. Effects of disturbances (disking, burning, grazing and interseeding) need to be evaluated in order to refine conservation policies and management guidelines. 
Peak, R.G., Thompson III, F.R., and Shaffer, T.L., 2004, Factors affecting songbird nest survival in riparian forests in a midwestern agricultural landscape: Auk, v. 121, no. 3, p. 726-737.

Physical factors affecting nest success of songbirds investigated in riparian forest and stream buffers in northeastern Missouri. Spatial characteristics of habitat assessed in three narrow (55-95 m, [180-312 ft]) and three wide (400-530 m $[1,312-1,739 \mathrm{ft}])$ riparian forests with adjacent grasslandshrub buffer strips and in three narrow and three wide riparian forests without adjacent grassland-shrub buffers. Riparian forests provided breeding habitat for area sensitive forest species (Acadian flycatcher [Empidonax virescens], wood thrush [Hyocichla mustelina], ovenbird [Seiurus aurocapillus]) and grassland-shrub nesting species (gray catbird [Dumetella carolinensis], Northern cardinal [Cardinalix cardinalis], and indigo bunting [Passerina cyanea]). Buffer strips furnished additional breeding habitat for grassland-shrub nesting species. When located in agriculturally dominated landscapes nest success may be marginal for these species even within wide riparian forests. Negative effects of predation were believed higher in narrow riparian buffers. However, as long as these "sink" habitats are balanced with other more productive habitat types, the authors suggest these types of habitats should be maintained as they may contribute to long-term viability for these species.

Peterjohn, B.G., 2003, Agricultural landscapes - Can they support healthy bird populations as well as farm products?: The Auk, v. 120, no. 1, p. 14-19.

Intensification of agricultural production appears to underlie most declines in grassland-bird species numbers and distribution. Conservation on local scale can reverse local negative trends, but changes necessary to address landscapelevel patterns of population decline will require solutions that remain undefined. Our understanding of ecology and habitat requirements of many farmland species during the non-breeding season remains rudimentary limiting the ability to develop effective conservation strategies. Until an understanding of the entire annual cycle related to habitat needs is provided, the risk of inefficient conservation strategies remains high. Singlespecies management may not be an effective approach for the entire farmland bird community but may be needed for avian species of immediate conservation concern. Effective conservation of avian species associated with agricultural landscapes will require innovative solutions based on compatibility with current agricultural practices. Reliance on reverting to less intensive agricultural practices across North America is an unrealistic expectation.

Some combination of variables, including grassland species composition, structural diversity, patch size, habitat fragmentation, and management activities, defines relations between grassland birds and their habitat. Each species responds differently. Studies at smaller spatial scales are needed to clarify these relationships. Simple, all-encompassing conservation solutions will not reverse all declines to farmland bird populations. Recent declines in grassland birds probably reflect factors other than habitat loss and include fragmentation, increased mowing and other detrimental practices associated with intensification of agricultural production. The negative relationship between population trends of avian species and CRP (see Murphy 2003 in Grassland Birds) is surprising and may reflect the fact that CRP fields constitute only 3.6 percent of the overall landscape and negative factors operating on remaining 96.4 percent of landscape have a greater influence on avian population trends. Five of seven negative associations reported by Murphy (2003) were for avian species associated with shrub-dominated habitats and the two negative relations for grassland species were for those that regularly nest in less densely vegetated covers including row crops. The relatively small area of land devoted to CRP and its uneven distribution in the U.S. probably also had an influence on this relationship.

Rahmig, C.J., Jensen, W.E., and With, K.A., 2009, Grassland bird responses to land management in the largest remaining tallgrass prairie: Conservation Biology, v. 23, no. 2, p. $420-432$.

This report provides an evaluation of avian community, population and demographic responses to grazing, and burning and haying of native tallgrass prairie and grasslands restored under the CRP. The study area was dominated by big bluestem (Andropogon gerardii), switchgrass (Panicum virgatum), little bluestem (Schizachyrium scoparium), and Indiangrass (Sorghastrum nutans). CRP fields were planted to native grasses. Grazed pastures and native prairie hayfields generally supported a more diverse assemblage of grassland birds than did CRP fields, especially burned CRP. The authors conclude, although CRP has benefited grassland birds in agriculturally dominated landscapes, CRP fields may have lower habitat value when within a matrix of native tallgrass prairie. Planted to native grasses, CRP fields differed structurally from native prairie hayfields or grazed pasture. Unburned CRP had higher standing crop biomass, more litter, greater amounts of dead standing grass, more forb cover, and higher diversity in structure. Dickcissels (Spiza americana) were the dominant species recorded in CRP fields. Grasshopper sparrows (Ammodramus savannarum) and eastern meadowlarks (Sturnella magna) were found in lowest numbers in CRP. The small size of CRP fields (12 hectares [30 ac]) also was identified as potentially limiting avian use in a grassland dominated landscape. Widespread grazing and annual burning in the Flint Hills study area has resulted in simplification of vegetative habitat diversity. Diversification of management practices is recommended to increase habitat diversity and conservation potential for Flint Hills' grassland birds.

Renfrew, R.B., Ribic, C.A., and Nack, J., 2005, Edge avoidance by nesting grassland birds - A futile strategy in a fragmented landscape: The Auk, v. 122, no. 2, p. 618-636. 
An evaluation of edge effects is described for avian species (Savannah sparrow [Passerculus sandwichensis], grasshopper sparrow [Ammodramus savannarum], bobolink [Dolichonyx oryzivorus] and meadowlark [Sturnella spp.]) in grazed pastures in Wisconsin. Authors conclude edge avoidance by grassland passerines will not necessarily reduce predation in actively grazed pastures within fragmented agricultural landscapes. Authors recommend larger patches with larger core area will likely enhance productivity of these species. Removal of trees and shrubby hedgerows is recommended when practical but this approach may be practical only when few wooded areas are nearby and removal increases connectivity of larger pastures or grassland covers. Covers of adequate height, density, and structural variability are believed key in conservation of grassland birds. Decreased rates of livestock stocking could favorably maintain vegetation height density making it more difficult for predators to locate nests. Proper management of cattle may have as much an effect on grassland bird populations as management of patch and landscape characteristics.

Reynolds, R.E., Shaffer, T.L., Sauer, J.R., and Peterjohn, B.G., 1994, Conservation Reserve Program - Benefit for grassland birds in the Northern Plains, in Transactions of the North American Wildlife and Natural Resources Conference, 59, Anchorage, AK., March 18-23, 1994, Proceedings: Washington, D.C., Wildlife Management Institute, p. 328-336.

The report concludes that CRP cover is providing benefits for some grassland nesting birds. Nest success for ducks in CRP covers estimated to be 6-18 percent higher than reported for planted cover in WPAs. Authors believe CRP provides substantial benefits for species restricted to grassland habitat during the breeding season. Population status of lark bunting (Calamospiza melanocorys) and grasshopper sparrow (Ammodramus savannarum) improved after establishment of CRP in North Dakota. Authors state conditions in wintering habitats, or along migration routes, may be influencing population trends of neotropical migrants that have not shown positive response to CRP.

Ribic, C.A., Guzy, M.J., and Sample, D.W., 2009, Grassland bird use of remnant prairie and Conservation Reserve Program fields in an agricultural landscape in Wisconsin: American Midland Naturalist, v. 161, no. 1, p. 110-122.

CRP grasslands provide surrogate grassland habitats previously furnished by pasture and hayfields that have declined across agricultural landscapes over the last 50 or more years. These agricultural fields became important to grassland obligate birds as native grasslands diminished to less than 1 percent of their original area. Less than 0.01 percent of native grasslands exist in Wisconsin today. Remnant prairies, agricultural set-aside lands (for example, CRP), and idle old fields consequently are valuable habitat for grassland birds. While alfalfa (Medicago sativa) and hay fields are used by grassland birds, they often become ecological traps because reproductive success is minimal due to haying during the nesting season. Successful management of grassland birds requires managers to assess conservation strategies on a larger landscape view of habitat conditions than individual properties or fields. The objective of this study was to understand how bird species use different grassland habitats by determining avian densities in CRP and remnant prairies compared to densities found in pastures, alfalfa hay and contour strip crop fields. Only habitat use by obligate grassland birds (bobolink [Dolichonyx oryzivorus], eastern meadowlark [Sturnella magna], grasshopper sparrow [Ammodramus savannarum], Henslow's sparrow [A. henslowii], and Savannah sparrow [Passerculus sandwichensis]) was evaluated.

Remnant prairies were associated with knobs, ridges, or slopes on ground too steep, rocky, or thin to plow. Virtually all had been grazed at some time. Most of these sites were surrounded by cool-season exotic grasses, most often smooth brome (Bromus inermis). Dominant native species included little bluestem (Schizachyrium scoparium), big bluestem (Andropogon gerardii), needle grass (Stipa spartea), Indiangrass (Sorghastrum nutans), sideoats grama (Bouteloua curtipendula) and panicgrass (Panicum spp.). Average heightdensity of vegetation in these sites was $18.4 \mathrm{~cm}$ (4.0 in). CRP fields included in the investigation were originally enrolled in the program in 1987 or 1988 and were generally $15 \mathrm{yr}$ old at the time of the study. Cool-season grasses dominated these fields, primarily smooth brome. Other grasses present included orchardgrass (Dactylis glomerata), timothy (Phleum pratense) as well as a wide variety of forbs. Many of the CRP fields had a scattering of woody vegetation present (for example, sumac [Rhus spp.]). The legume component, most often alfalfa, included in the original plantings of these fields was mostly absent. Average height-density of vegetation in CRP fields was $33.8 \mathrm{~cm}$ (13.3 in).

Habitat type was more important than landscape features in affecting grassland bird densities in this study completed in a largely grass-dominated landscape. Grasshopper sparrows were most abundant on remnant prairie. Savannah sparrows were found in greatest densities in pastures and hayfields, habitats that characteristically have annual disturbance. Henslow's sparrows were found in greatest density in CRP fields and rarely observed in pasture or hay fields. Bobolink densities were highest in hay fields followed by CRP. Meadowlark densities were greatest in CRP fields, remnant prairie and pastures. The authors conclude when managing for grassland birds across a single agricultural landscape with a large amount of grassland a continuum of habitat types will be necessary to benefit grassland birds as a group.

Riffell, S.D., Scognamillo, and Burger, L.W., 2008, Effects of the Conservation Reserve Program on northern bobwhite and grassland birds: Environmental Monitoring Assessment, v. 146, p. 309-323. 
Breeding Bird Survey and NRIdata are used to evaluate potential benefits of the CRP to grassland birds and northern bobwhite quail (Colinus virginianus). Regression models were developed for 15 avian species in seven ecological regions. Ecological regions were based on classification defined by the North American Bird Conservation Initiative. Obligate grassland birds included in the study were: horned lark (Eremophila alpestris), grasshopper sparrow (Ammodramus savannarum), dickcissel (Spiza americana), eastern meadowlark (Sturnella magna), and western meadowlark ( $S$. neglecta). Seven facultative grassland bird also were included in the evaluation: mourning dove (Zenaida macroura), eastern kingbird (Tyrannus tyrannus), loggerhead shrike ( Lanius ludovicianus), common yellowthroat (Geothlypis trichas), lark sparrow (Chondestes grammacus), red-winged blackbird (Agelaius phoeniceus), and eastern bluebird (Sialia sialis). The brown-headed cowbird (Molothrus ater), a nest parasite, and the indigo bunting (Passerina cyanea), a forest edge species, were also included in the analysis.

Mean abundance of birds was calculated over a 5-yr period (1995-1999) on routes sampled in three or more of the five years. The time period corresponds to the dates of best estimates of CRP coverage. Because 1997 was the year most CRP contracts (10-15 yr) would not yet have expired, 1997 was assumed to furnish the best cumulative estimates of CRP distribution. Land-use data was assessed in a $1,962 \mathrm{~km}^{2}(758$ $\mathrm{mi}^{2}$ ) area around each BBS used. CRP habitat comprised an average of 1.6 percent of the landscapes surrounding BBS routes. CRP grass habitats averaged 1.3 percent and CRP tree dominated covers accounted for an average coverage of 1.3 percent.

Analysis of data showed varying responses across ecological regions. Only the eastern meadowlark was positively related to CRP in all regions. The CRP was a strong predictor of bird abundance. The CRP, especially grass-legume was related to higher abundance of northern bobwhite across their breeding range. Populations of common yellowthroat, eastern meadowlark and indigo bunting were associated with higher amounts of CRP. Analysis of relationships between CRP for other avian species are presented and discussed.

The authors conclude that NRI data presently furnish relatively coarse-resolution information on CRP. More thorough investigations of relations between CRP and habitat quality for birds, as well as other species, could be possible if additional NRI data themes were available. These include, but are not limited to, spatial arrangement of fields, age of field, and specific conservation practices used. An ability to assess landscape configuration with variables such as edge density, patch size, and juxtaposition of cover types would greatly strengthen predictive capabilities of the data set. Availability of information on stand age, species composition, and successional stage would also be of benefit.

Robel, R.J., Hughes, J.P., Keane, T.D., and Kemp, K.E., 2003, Do artificial nests reveal meaningful patterns of predation in Kansas grasslands?: The Southwestern Naturalist, v. 48, no. 3 , p. $460-464$.
Fates of artificial and natural bird nests were determined in CRP fields planted to native grasses (Indiangrass [Sorghastrum nutans], big bluestem [Andropogon gerardii], little bluestem [Schizachyrium scoparium], sideoats grama [Bouteloua curtipendula], switchgrass [Panicum virgatum] and western wheatgrass [Agropyron smithii]). Artificial nests were intended to simulate those of the dickcissel (Spiza americana) the most common avian species nesting in northeastern Kansas CRP fields. Loss of artificial nests was only 9.8 percent $(\mathrm{n}=562)$ compared to 70.1 percent of 97 natural nests monitored. Consequently, authors conclude that depredation rates from artificial nests might not be representative of predation on natural nests. Authors attribute greater rates of predation on natural nests to the possibility of parental activity of adult birds, scent associated with incubated eggs, and heat associated with developing embryos, all of which could be factors affecting attraction of predators. Limitations associated with use of artificial nests in grasslands to determine predation rates need to be further investigated.

Robinson, S.K., Grzybowski, J.A., Rothstein, S.I., Brittingham, M. C., Petit, L.J., and Thompson, F.R., 1993, Management implications of cowbird parasitism on neotropical migrant songbirds, in Finch, D.M., and Stangle, P.W., eds., Status and management of neotropical migratory birds: Fort Collins, Colo., USDA Forest Service General Technical Report RM-229, p. 93-102.

Brown-headed cowbirds (Molothrus ater) benefit directly from human activities resulting in population increases potentially threatening populations of many neotropical migrant songbirds. Authors recommend development of landscape approaches to management such as consolidation of ownerships to preserve large tracts of land and minimize edge habitat. Larger tracts are preferable to smaller ones and compact shapes (square) are preferable to complex shapes with high ratios of edge to interior. Maintenance and restoration of extensive areas of contiguous grassland are recommended. Acquisition should focus on inholdings to minimize fragmentation. Woody fencerows, snags and corridors within and adjacent to prairie should be removed.

Rodenhouse, N.L., and Best, L.B., 1983, Breeding ecology of vesper sparrows in corn and soybean fields: American Midland Naturalist, v. 110, no. 2, p. 265-275.

Avian nesting success in corn and soybean fields is low with losses due primarily to agricultural operations and predation. Nest predation was higher near agriculturally nonproductive areas due to an increase in density and use by predators. On cultivated land, nest predators use linear non-cropped areas as travel lanes, thus higher predation can be expected near or within such areas. Breeding success would be greater if the number of tillage operations was reduced and crop residue was retained on the fields. 
Rodenhouse, N.L., Best, L.B., O’Connor, R.J., and Bollinger, E.K., 1993, Effects of temperate agriculture on neotropical migrant landbirds, in Finch, D.M., and Stangle, P.W., eds., Status and management of neotropical migratory birds: Fort Collins, Colo., USDA Forest Service General Technical Report RM-229, p. 280-295.

Ecology of neotropical migrant landbirds is reviewed for the purpose of developing management recommendations in agriculturally dominated landscapes. Migrants constitute about 71 percent of bird species using farmland and 86 percent of bird species nesting there. Number and abundance of avian migrants using farmland are greatest in uncultivated edges with trees and shrubs, less in uncultivated grassed areas, and least in row crops. Homogeneous landscapes with larger farms specializing in few commodities have created ecosystems lacking suitable interspersion of required habitats.

Most migrants using temperate farmland are field or edge species. Agriculture is implicated in decline of all nine neotropical migrants currently listed, or candidates, as threatened or endangered. The percentage of farmland in hay/ pasture or in uncultivated semi-natural habitat has decreased in proportion to increase in area of intensively cultivated row crops. Migrant richness and abundance are greater in wider strips of uncultivated edge vegetation. Uncultivated wooded areas include wooded fencerows or the edges of fields bordering woodland, grassed edge includes some fencerows, waterways, terrace berms, road edges, and most land in the CRP. Breeding productivity of migrants in farmland is often low relative to number of offspring estimated needed to balance adult and juvenile mortality. Percentage of county area in the CRP was positively associated with the abundance of 19 migrant species 12 of which were field species.

Areas in permanent cover, even if only grasses and no-till cropland, often support higher arthropod abundance than conventionally tilled fields. Arthropod abundance is greater near permanent vegetated field edges and greater in fields surrounded by complex habitats. Weed seeds are more abundant near uncultivated areas because seeds disperse from uncultivated areas and permanent vegetation concentrates wind dispersed arthropods and seeds. Homogenization of farmland lowers diversity and abundances of plants, seeds and arthropods within fields ultimately affecting the quality of the overall landscape as foraging habitat.

Lands in CRP covers were associated with significantly more migrant species than resident species. Migrants strongly dominate the bird communities of farmland and numerous major crops are positively associated with some migrant species. The presence of sheltering vegetation may be needed for some avian species especially edge-associated species, which use farmland during migration. Farmland landscape complexity has been declining in most agricultural regions due to increased use of large equipment requiring larger field size, producing/rotating fewer crops, and consolidation/increased average size of farms. All contribute to reduction in vegetation diversity across agriculturally dominated landscapes. The absence of safe nesting sites may be the factor most limiting reproduction and survival of migrants in cropland.

Future of agriculture: Long-term programs such as CRP are needed because they allow opportunities for research into more effective management of habitats in agroecosystems and lessen environmental impacts of agricultural production.

Management recommendations: The key issue in greater effectiveness and acceptance of wildlife/environmental management by landowners is recommendations which do not reduce, and perhaps enhance, farm profits. Management recommendations must consider farmland structure as well as agricultural practices and be approached in an interdisciplinary manner. Recommended agricultural practices include: maintenance of as much crop residue as possible on fields, use of integrated pest management, reduction in number of field operations (for example, tillage, chemical, and physical control of weeds) that destroy nests, delay spring mowing as long as possible, prevention of night mowing, and spacing of mowing operations as widely as possible in time to permit maximum success of nests. Considerations for improvement in farmland landscape structure include: encouragement of complex vegetation structure in uncultivated edges and idle nonfarmed areas, maintenance and enhancing overall diversity in cover types on farmland, increase diversity of crops produced, and reduction in field size. Advantageous uses of CRP land could be greater devotion of land to strip cover within fields or along field edges, and preservation of small wetlands with encircling, broad buffers of herbaceous vegetation.

Research needs: Long-term conservation programs such as the CRP are needed because they provide opportunities for research on bird response to evolving management of agricultural ecosystems. Greater attention should be given to getting understandable, technical information to users and landowners. Information simply cannot be restricted to technical or professional journals.

Rodgers, R.D., 2005, Conservation Reserve Program successes, failures, and management needs for open-land birds, in Allen, A.W. and Vandever, M.W., eds., The Conservation Reserve Program - Planting for the future - Proceedings of a National Conference, Fort Collins, Colo., June 6-9, 2004: Reston, Va., U.S. Geological Survey, Scientific Investigations Report 2005-5145, p. 129-134.

Author characterizes application of periodic management as a key factor in creation and longevity of vegetatively diverse CRP stands that furnish wildlife habitat of high quality. However, appropriate management of CRP grasslands through periodic disturbance has been inadequate throughout most of the history of the program. Absence of management (for example, grazing, fire) had permitted encroachment of woody vegetation into CRP grasslands (for example, eastern red cedar, Juniperus virginiana), which unchecked will ultimately negate habitat benefits of these grasslands for many species of grassland wildlife. Various conservation practices using grass buffers available through Continuous Conservation Reserve 
Program (CCRP) offer excellent opportunities to improve habitat in regions dominated by agricultural production but have been underused in the western and southern Great Plains.

The author furnishes the following recommendations for refinement in future management of the program to benefit grassland dependent avian species. No further planting of aggressive exotic grasses should be permitted. Emphasis must continue on provision of species diverse stands with a strong forb component. A greater proportion of program acres should be shifted to localities near existing native grassland habitats. Invasive trees on existing CRP grasslands must be eliminated. Impractical incidental grazing restrictions on in-field CCRP linear conservation practices (for example, cross wind strips, grassed terraces) should be discontinued. Consultation between USDA, state wildlife agencies, and non-government organizations must continue, and increase, if optimization of soil, water, and wildlife conservation is to be expected.

Ryan, M.R., Burger, L.W., and Kurzejeski, E.W., 1998, The impact of CRP on avian wildlife-A review: Journal of Production Agriculture, v. 11, no. 1, p. 61-66.

The report furnishes a review of quantitative data on grassland bird occurrence (species richness), abundance, and reproductive success in CRP during breeding season in the central United States. Over 90 avian species have been documented using CRP plantings during the breeding season. More than 40 avian species are recorded as nesting in CRP covers. Grasslands in CRP supported 1.4 to 10.5 times the number of individual birds as did crop fields. Nest abundance has been found to be from 8.8 to 27 times higher in CRP fields than recorded in crop fields. Overall, CRP produced about 14 times as many songbirds as did crop fields. Waterfowl nesting in CRP fields is believed to be comparable to covers specifically managed for waterfowl production (for example, USFWS WPAs). Numbers of ring-necked pheasants (Phasianus colchicus) are believed to be 3 to 5 times higher after CRP plantings were established. Nest success of pheasants in CRP was greater than necessary for maintenance of growth in populations. Although use of CRP by northern bobwhite quail (Colinus virginianus) is substantial, direct evidence of CRP contributing to growth of quail populations is lacking. Overall, the CRP has provided high-quality breeding habitat for many grassland birds, including several experiencing long-term declines in populations. Avian response to CRP is sufficient to justify efforts to maintain long-term set aside provisions in future federal legislation.

Sample, D.W., and Mossman, M.J., 1993, Habitat management guidelines for grassland birds on public and private land in Wisconsin: Monona, Wis., State of Wisconsin Memorandum Bureau of Research, 13 p.

The likely major cause of decline of grassland birds is loss of breeding habitat due to conversion of pasture to row crops and early, frequent mowing of alfalfa. Primary goal of habitat management for grassland birds should be to maximize diversity and viability of grassland bird populations statewide, or on a regional basis. Special attention should be given to identifying current or potentially large tracts suitable for management.

Schmutz, J.K., 1987, The effect of agriculture on Ferruginous and Swainson's hawks: Journal of Range Management, v. 40 , no. 5 , p. $438-440$.

Raptors are an important component of Great Plains ecosystems. This report furnishes a summarization of effects of cultivation and agricultural activity on hawk density in prairie region of Alberta. The density of ferruginous hawks (Buteo regalis) declined with increasing cultivation. In contrast, density of Swainson's hawks (Buteo swainsoni) was higher in areas of moderate cultivation (11-30 percent) than in grassland dominated areas (less than 10 percent cultivation). Swainson's hawks appeared to tolerate higher levels of cultivation. Ferruginous hawks have affinity for land with sparse and short vegetation and avoid areas where grasses are replaced by dense, tall crops. In contrast, Swainson's hawks are more adapted to smaller prey common in ungrazed grassy borders of ponds, roads, and farmsteads than in intensively grazed pastures. If small patches of natural or semi-natural cover containing trees or shrubs are strategically distributed in agricultural areas Swainson's hawks are likely to remain present in reasonable numbers. Ferruginous hawks require grassland and will be common only where this land use dominates the landscape.

Smith, M.D., Barbour, P.J., Burger Jr., L.W., and Dinsmore, S.J., 2005, Density and diversity of overwintering birds in managed field borders in Mississippi: Wilson Bulletin, v. 117 , no. 3, p. 258-269.

This paper describes potential value of field borders established under USDA National Conservation Buffer Initiative as habitat for wintering birds in Mississippi. Greater densities of several sparrow species were observed along transects established in association with field borders. Effects of borders differed by avian species and plant community types. Diversity, species richness, and relative conservation value were similar between bordered and non-bordered edges. Authors conclude that field borders are practical tools that can be used to address multiple environmental issues and enhance habitat quality for wintering bird populations in agricultural landscapes.

Within many intensively farmed landscapes buffers (grassed waterways, contour grass strips, filter strips, riparian buffers, crosswind trap strips, windbreaks, and shelterbelts) offer the only relatively permanent, non-disturbed covers. Field borders may be more broadly applied as they are not restricted to downslope field edges providing potentially important wintering habitat for avian species. Authors recommend field borders be maintained in early seral stages through periodic disturbance (for example, disking or fire) to furnish greater quantities of annual plant seeds during winter. Knowledge about avian and other wildlife use of habitats in winter 
within agricultural landscapes is lacking and needs greater attention to define optimal management practices for conservation in agricultural landscapes.

Stanley, T.R., 2010, Land use and small mammal predation effects on shortgrass prairie birds: Journal of Wildlife Management, v. 74 , no. 8, p.1825-1843.

An investigation of the potential effects of land use on small mammal (for example, thirteen-lined ground squirrel [Spermophilius tridecemlineatus], deer mouse [Peromyscus maniculatus]) predation on grassland bird nests is described. The author states, while benefits to mid- and tallgrass prairies are clear, it remains unclear if CRP provides suitable nesting habitat for shortgrass prairie birds. Also of interest was what effects elevated abundance of vegetation and seed sources furnished by CRP, had on species richness of potential predators. Native grassland sites were dominated by buffalograss (Buchloë dactyloides), blue grama (Bouteloua gracilis) and plains pricklypear (Opuntia polyacantha). CRP fields in the northeastern Colorado study area were smooth brome (Bromus inermis) and wheatgrass (Agropyron spp.). Age of fields was not given. Land uses on shortgrass prairie are found to alter small mammal communities. Small mammal densities and richness were found to be greater along edges and on CRP compared to shortgrass sites. Survival of nests (artificial and natural) at edge and CRP sites did not differ from native sites. Small mammal communities were found not to affect nest survival.

Swanson, D.A., Scott, D.P., and Risley, D.L., 1999, Wildlife benefits of the Conservation Reserve Program in Ohio: Journal of Soil and Water Conservation, v. 54, no. 1, p. 390-394.

Habitat use by grassland-dependent species was related to availability of CRP. More than half of fields sampled were mowed during the nesting season. Twenty-one of 40 fields were disturbed prior to August. On average, disturbed fields had 51 percent of acreage mowed or burned. Disturbed fields had significantly lower values for VOR, percent grass canopy cover, and mean herbaceous height than did nondisturbed fields. Mean age of fields was five years (2-7). Mean field size $20 \mathrm{ac}$ ( 8.1 hectares). Over 80 percent of fields sampled were dominated by timothy (Phleum pratense), orchardgrass (Dactylis glomerata) and clover (Trifolium spp.) Forty-three breeding bird species used CRP fields. Use by eastern meadowlarks (Sturnella magna) and bobolinks (Dolichonyx oryzivorus) significantly larger in CRP fields. All species were numerically more abundant in CRP fields contiguous with other grassland habitat than recorded in isolated fields.

Swengel, S.R., and Swengel, A.B., 2001, Relative effects of litter and management on grassland bird abundance in Missouri, USA: Bird Conservation International, v. 11, p. 113-128.
Bird surveys were conducted in 43 tallgrass prairie sites in southwest Missouri from 1992-1999. Relative importance of management type (rotational burning, rotational haying, or a combination of both) and litter volume on relative abundance of avian species was evaluated in relation to abundance of three declining grassland songbirds, Henslow's sparrow (Ammodramus henslowii), grasshopper sparrow (A. savannarum), and dickcissel (Spiza americana). Haying resulted in significantly higher abundance than burning for all species except dickcissel. Due to greater amounts of litter subsequent to management rotational haying should be employed more than burning in management of these declining birds. Midsummer haying was believed to have less impact on nest density and production of birds than did cool-season burning.

Thompson, F.R., Lewis, S.J., Green, J., and Ewert, D., 1993, Status of neotropical migrant landbirds in the MidwestIdentifying species of management concern, in Finch, D.M., and Stangle, P.W., eds., Status and management of neotropical migratory birds: Fort Collins, Colo., USDA Forest Service General Technical Report RM-229, p. 145-158.

Authors encourage ecosystem management to address needs of the many species of high management concern in midwestern states. Grasslands are only one of several habitats that deserve special management attention. Grassland species identified as special management concern in order of decreasing importance were; Bairds' sparrow (Ammodramus bairdii), dickcissel (Spiza americana), mountain plover (Charadrius montanus), bobolink (Dolichonyx oryzivorus), long-billed curlew (Numenius americanus), grasshopper sparrow (A. savannarum), lark bunting (Calamospiza melanocorys), upland sandpiper (Bartramia longicauda), burrowing owl (Athene cunicularia), scissor-tailed flycatcher (Tyrannus forficatus), Swainson's hawk (Buteo swainsoni), and lark sparrow (Chondestes grammacus).

Thompson, T.R., Boal, C.W., and Lucia, D., 2009, Grassland bird associations with introduced and native grass Conservation Reserve Program fields in the Southern High Plains: Western North American Naturalist, v. 69, no. 4, p. $481-490$.

Relative abundance of grassland birds is assessed within $\mathrm{CRP}$ fields planted to native grass mixtures and two introduced grass monocultures (weeping lovegrass [Eragrostis curvula], old world bluestem [Bothriochloa ischaemum]) in the shortgrass prairie region of the western Texas panhandle. Native grass CRP fields were mixes of sideoats grama (Bouteloua curtipendula), blue grama (B. gracilis), green sprangletop (Leptochloa dubia), switchgrass (Panicum virgatum) and buffalograss (Buchloe dactyloides). All fields included in the evaluation were at least $3 \mathrm{yr}$ old, approximately 65 hectares (160 ac) in size, and were considered to have been successfully established. Native grass fields were stratified into two types based on the presence of buffalo grass in the seeding mix. 
Sixteen bird species were identified in study fields during the breeding season. Species richness and abundance were similar among cover types. During the breeding season all fields were dominated by one or two bird species accounting for approximately 80 percent of all birds observed. Grasshopper sparrows (Ammodramus savannarum), Cassin's sparrows (Aimophila cassinii), and western meadowlarks (Sturnella neglecta) accounted for more than 90 percent of all birds observed. Twelve bird species were observed on study fields during winter. Winter species richness differed between introduced and native fields. Introduced fields had lower relative avian abundance than did fields planted to native grasses. Western meadowlarks, horned larks (Eremophila alpestris), and Savannah sparrow accounted for over 94 percent of winter observations. Greater numbers of horned larks were observed in the native grass fields containing buffalograss; they were not observed in the lovegrass fields. No differences were observed for Savannah sparrows or meadowlarks with both species being observed in all fields. However, when compared to other cover types, Savannah sparrows were more abundant in native fields without the buffalograss component.

The authors conclude no one CRP seeding type is most attractive to grassland passerines but the fields provide an important tool for conservation. Compared to monocultures of introduced grasses, CRP fields planted to mixtures of native grasses promote increased avian abundance, diversity and use. The authors believe the pooling of CRP grasslands only into broad categories of native or introduced grasses risks less meaningful detection of biological results when evaluating the use of these fields by avian species.

Veech, J.A., 2006, A comparison of landscapes occupied by increasing and decreasing populations of grassland birds: Conservation Biology, v. 20, no. 5, p. 1422-1423.

Twenty years of Breeding Bird Survey data were used to identify stable, increasing, and decreasing populations of 36 grassland bird species in relation to physical features of the landscape adjacent to survey routes using USDA NRI data. Populations increasing were associated with landscapes that contained significantly more restored grassland and rangeland but less forest land and urban land than landscapes inhabited by decreasing populations. There was no significant difference in proportion of cropland within landscape of increasing and decreasing population although cropland composed greater than 30 percent of many of these landscapes. Restored grassland typically was a very small proportion (less than 3.5 percent) of total land cover but was significantly more common in landscape of increasing than decreasing populations of grassland birds. Rangeland and CRP land held the greatest potential for having a positive effect on grassland birds. CRP was typically a low component of landscape composition (2.9-3.2 percent). Author concludes the amount of grassland habitat within a landscape can affect population trends in grassland birds regardless of spatial configuration of individual grassland parcels.
Vickery, P.D., and Herkert, J.R., 2001, Recent advances in grassland bird research-Where do we go from here?: Auk, v. 118 , no. 1, p. 11-15.

Although several species of grassland birds have shown benefits and positive response to the CRP, other species have shown continuing declines in populations. Unrelenting declines point to the complexities in diagnosing reasons behind diminishing avian populations. One or more of the following reasons may be the cause; CRP has not provided enough habitats to offset losses of grasslands, CRP fields may be too small, CRP grasslands are possibly population sinks, and/or problems affecting the species that continue to decline are not limited to the breeding grounds. More research needs to be directed toward definition of problems on wintering grounds.

Warner, R.E., 1992, Nest ecology of grassland passerines on road rights-of-way in central Illinois: Biological Conservation, v. 59 , no. 1 , p. $1-7$.

Availability of suitable grassland cover has decreased in response to an increase in row crop farming. Fescue (Festuca spp.) supported relatively few breeding birds. Where farming is diversified and habitat conditions are more favorable, road rights-of-ways and other linear habitats are used more extensively by birds. Use is influenced by habitat conditions in vicinity of strip and regional land use. Managed roadsides were important to passerine species even where hay was present because most nests in hay fields are destroyed during harvest. Management practices recommended to benefit grassland birds were described as: seed to brome/alfalfa (Bromus inermis/Medicago sativa) and or native grasses and forbs, delay mowing until after August 1, maximize strip habitat widths, and encourage establishment of shelterbelts and woody plants in some areas to enhance diversity of species attracted to strip vegetation.

Warren, K.A., and Anderson, J.T., 2005, Grassland songbird nest-site selection and response to mowing in West Virginia: Wildlife Society Bulletin, v. 33, no. 1, p. 285-292.

Former hayfields and pastures are becoming a more common component of the landscape in the eastern United States due to changing farming and land-use practices as well as purchase of farmland for other uses. Authors report investigation of grassland bird nest site selection and success between idle and mowed pastures and hayfields. Dominant vegetation on study fields included orchardgrass (Dactylis glomerata), mountain oatgrass (Danthonia compressa), sweet vernalgrass (Anthoxanthum odoratum), quackgrass (Elymus repens), and timothy (Phleum pratense). Avian nests monitored included bobolink (Dolichonyx oryzivorus), eastern meadowlark (Sturnella magna), red-winged blackbird (Agelaius phoeniceus), and savannah sparrow (Passerculus sandwichensis). 
Authors conclude management that increases vertical structure and density should be promoted for grassland birds through mowing, grazing, and prescribed burning to set back grassland succession. These management techniques are recommended to prevent encroachment of woody vegetation and too excessive litter layer from developing in undisturbed fields. Leaving blocks of cover idle for $1-4 \mathrm{yr}$ is recommended to maintain overall diversity in vegetation composition.

Wentworth, K.L., Brittingham, M.C., and Wilson, A.M., 2010, Conservation reserve enhancement program fields- Benefits for grassland and shrub-scrub species: Journal of Soil and Water Conservation, v. 65, no. 1, p. 50-60.

Between 2000 and 2004, almost 74,100 acres (30,000 hectares) of grassland were established in south-central Pennsylvania through the CREP. Avian surveys on 103 CREP fields found 32 species using these fields during the breeding season of which the red-winged blackbird (Agelaius phoeniceus) was the most abundant. The next most abundant species (song sparrow [Melospiza melodia], indigo bunting [Passerina cyanea], field sparrow [Spizella pusilla]) are typically associated with scrub-shrub habitats. Grassland obligate species (vesper sparrow [Pooecetes gramineus], savannah sparrow [Passerculus sandwichensis], grasshopper sparrow [Ammodramus savannarum], bobolink [Dolichonyx oryzivorus], eastern meadowlark [Sturnella magna]) were rare and most abundant in larger, cool-season dominated grass fields.

The CREP fields examined in this investigation lie within a forest-dominated landscape where fields tend to be small and irregularly shaped. Bird communities within this south-central Pennsylvania landscape differ from Midwest avian communities where the majority of studies on CRP avian use have been completed. Field size and within-field vegetation type had a strong influence on avian use. Grassland obligates were most abundant on larger fields with a lower density of vegetation. Avian species related with shrub-scrub dominated habitats were associated with smaller fields and a higher proportion of warm-season grasses. The authors conclude management of larger fields, to maintain less dense cool-season grass cover, and targeting smaller field adjoining woodlands may be an effective way to maximize the potential of CREP fields to provide habitat for a range of avian species in this region.

Wilson, J.D., Whittingham, M.J., and Bradbury, R.B., 2005, The management of crop structure-A general approach to reversing the impacts of agricultural intensification on birds?: Ibis, v. 147 , p. 453-463.

Across Europe and North America intensification in production of agricultural products has widely been identified with declines in populations of birds associated with these landscapes. A major cause of declines in habitat quality is simplification of cover type structure and diversity across the landscape. Reversal in trends of simplified, homogeneous cover type is believed to improve nesting and foraging habitat conditions for a wide range of avian species and may represent a cost-effective approach for further improvements in agroenvironmental conservation policies. Written mainly from a British perspective, the paper discusses effects of agricultural intensification of production, relations to avian habitat quality, and presents methods to reestablish diversity in agriculturally dominated landscapes.

Winter, M., Johnson, D.H., and Shaffer, J.A., 2005, Variability in vegetation effects on density and nesting success of grassland birds: Journal of Wildlife Management, v. 69, no. 1, p. 185-197.

The structure of grassland vegetation varies dramatically among years on the same sites and among regions with similar vegetation. Understanding of influence of variation in vegetation structure on bird density and nesting success is poorly understood because few studies have included sufficiently large temporal and spatial scale to capture variation in vegetation structure, avian density, or nesting success. Effects of vegetation structure on density and nesting success of three species (clay-colored sparrow [Spizella pallida], Savanna sparrow [Passerculus sandwichensis], and bobolink [Dolichonyx oryzivorus]) in northern tallgrass prairie are described.

Each species responded differently to vegetation variables. Because avian response varied among regions, years, and species, land managers need to furnish grasslands with differing types of vegetation structure as management guidelines based on small-scale, short-term studies may lead to misrepresentation of the needs of grassland avian species. High annual and regional variability in grassland systems requires studies on avian species extend over a wide geographic region and over several years. Management for several species requires establishment of a mosaic of management regimes that furnish various types of vegetation conditions across the landscape.

\section{Reptiles and Amphibians}

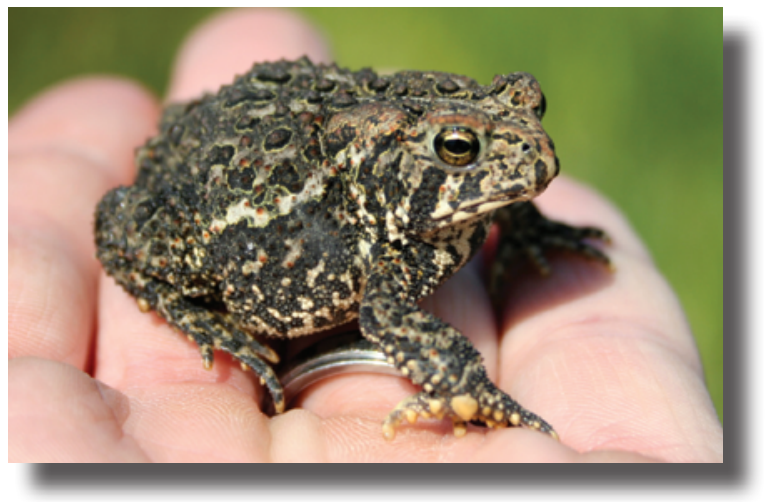

Burrow, A.L., Kazmaier, R.T., Hellgren, E.C., and Ruthven III, D.C., 2001, Microhabitat selection by Texas horned lizards in southern Texas: Journal of Wildlife Management, v. 65, no. 4 , p. $645-652$. 
Horned lizards (Phrynosoma cornutum) occur throughout Texas, Oklahoma, and parts of Kansas, Missouri, New Mexico, and Arizona. Loss of habitat, introduction of the fire ant (Solenopsis invicta) and use of insecticides have contributed to the declining abundance of the species throughout its range. Open habitats resulting from relatively frequent disturbance are thought to be prime habitats. The species requires variety in habitat structure since resource needs change throughout the day and season. Favored habitat includes a mosaic of bare ground, herbaceous, and woody vegetation in close proximity.

Donaldson, W., Price, A.H., and Morse, J., 1994, The current status and future prospects of the Texas horned lizard (Phrynosoma cornutum) in Texas: The Texas Journal of Science, v. 46 , no. 2 , p. $97-113$.

The Texas horned lizard is a threatened species in Texas and a Federal category 2 candidate species. Primary reasons for decline of species, are habitat alteration or destruction by agriculture and urbanization, use of insecticides on crops and direct and indirect effects of the imported red fire ant (Solenopsis invicta). Agriculture seems to be the primary factor in absence of horned lizard populations in Texas. Best conservation measures to restore populations of horned lizard would be re-establishment of native vegetation communities that remain unplowed and untreated with agrochemicals.

Forson, D.D., and Storfer, A., 2006, Atrazine increases Ranavirus susceptibility in the tiger salamander, Ambystoma tigrinum: Ecological Applications, v. 16, no. 6, p. $2325-2332$.

Pathogenic diseases and environmental contaminants are leading hypotheses for the decline in amphibian populations. Amphibians, because of their permeable skin and biphasic life history, are considered to be indicators of environmental quality. This report describes the influence of contaminants on susceptibility to disease in amphibians by determination of the effects of ecologically relevant doses of atrazine, sodium nitrate and in laboratory-bred tiger salamander to Ambystoma tigrinum virus (ATV). Atrazine and sodium nitrate significantly decreased peripheral leukocyte levels suggesting impacts on the immune system increasing susceptibility of larvae to ATV infection. Study results suggest ecologically relevant concentrations of atrazine have immunosuppressive effects possibly contributing to ATV epizootics.

Gray, M.J., and Smith, L.M., 2005, Influence of land use on postmetamorphic body size of playa lake amphibians: Journal of Wildlife Management, v. 69, no. 2, p. 515-524.

The densities, health, and survival of amphibians may be affected by alteration of wetland hydroperiods due to agricultural land use around wetlands. Effects of agricultural land use on spadefoot toad (Spea multiplicata), plains spadefoot toad (S. bombifrons), Great Plains toad (Bufo cognatus), and barred tiger salamander (Ambystoma tigrinum) surrounding playa wetlands are described. For most age classes of amphibians monitored, body size was 10-148 percent greater in playas surrounded by grassland than found within wetlands surrounded by crop production. Greater body size is related to greater survival. Study results suggest amphibian in playas surrounded by cultivated land may be smaller than those found in wetlands not affected by agricultural land use. Although other factors may influence survival (for example, hydroperiod, conspecific density, predators), restoration of grassland covers around playas is recommended to increase survival and habitat quality for these species.

Gray, M.J., Smith, L.M., and Brenes, R., 2004, Effects of agricultural cultivation on demographics of Southern High Plains amphibians: Conservation Biology, v. 18, no. 5, p. 1368-1377.

Few data exist on effects of agriculture of wetland watersheds on amphibian populations. Paper describes effect of cultivation of playa wetlands on demographics of amphibians (New Mexico spadefoot toad [Spea multiplicata], Plains spadefoot toad [S. bombifrons], Great Plains toad [Bufo cognatus], Woodhouse's toad [B. woodhousii], spotted chorus frog [Pseudacris clarkii], plains leopard frog [Rana blairi], and barred tiger salamander [Ambystoma tigrinum mavortium]) in the Southern High Plains of Texas.

Cropland playas had a higher abundance of amphibians than did grassland playas. No difference in mean daily diversity of the amphibian assemblage was detected between land use types. Abundance of spadefoot toads in cropland playas may be attributed to confinement of individuals in suitable habitat surrounded by cultivation. Geometric complexity and edge density were greater in cropland playas than within grassland playas. Roads and other habitat factors affecting movement and dispersal of spadefoot toads may have resulted in increased abundance in natal wetlands. Density of larval and neotenic barred tiger salamanders (a keystone predator of other amphibians in playas) was greater in playas surrounded by grassland than in cropland playas. Grassland playas generally have greater volume and longer hydroperiod than cropland playas allowing establishment of tiger salamander populations making other amphibian larvae more susceptible to predation in the wetlands more characteristic of non-agricultural conditions.

Other factors that may influence greater numbers of spadefoot toads in agricultural playas are greater plant diversity and structure in cropland playas, which could increase food resources, and escape cover for larvae. Nitrogen influx from fertilizers may increase food resources for larval amphibians in cropland playas. Pesticide drift and runoff into cropland playas may reduce density of aquatic insects, which can compete with amphibian larvae for food resources. However, authors believe these factors were not ultimate reasons affecting differences between disturbed and undisturbed wetlands. 
Authors conclude agricultural disturbance around wetlands may positively affect abundance of some amphibian species. Less vagile species are competitively dominant in absence of predation and may benefit most as a consequence of landscape cultivation. This does not, however, imply better conditions for amphibian populations. These populations may be less stable particularly if they exceed carrying capacity. Amphibian populations in cultivated landscapes also may function as ecological sinks more often than population sources resulting in these populations being more susceptible to local or metapopulation extinction than populations inhabiting more pristine habitats.

Kolozsvary, M.B., and Swihart, R.K., 1999, Habitat fragmentation and the distribution of amphibians - Patch and landscape correlates in farmland: Canadian Journal of Zoology, v. 77 , p. $1288-1299$.

The most important negative effects of humans on amphibian populations are modification and destruction of habitat. In the midwestern United States, much of the historic habitat modification has resulted from massive land clearing and drainage of wetlands for agricultural purposes. Amphibians requiring aquatic sites for breeding and moist upland sites for foraging, or hibernation, may be especially susceptible to agricultural fragmentation of the landscapes. Species with high vagility and broad environmental tolerance are less affected by fragmentation of the landscape. In contrast, species that have limited mobility, require large tracts of forest cover, or have specific requirements for seasonal habitats are more severely affected by fragmentation. Authors developed model furnishing general predictions concerning how amphibian distribution could be affected in an agriculturally fragmented landscape (west-central Indiana). Species exhibited a high degree of nestedness in the agricultural landscape, which has probably developed since massive land clearing, and alteration of wetlands and hydroperiods. Amphibian species richness was highest for sites dominated by seasonal and semipermanent wetlands or sites containing a mixture of wetlands with various water regimes. The ability of a species to move through a cropland matrix is believed to be critical to its persistence in farmland.

Langford, G.J., Borden, J.A., Major, C.S., and Nelson, D.H., 2007, Effects of prescribed fire on the herpetofauna of a southern Mississippi pine savanna: Herpetological Conservation and Biology, v. 2, no. 2, p. 135-143.

Little research is available describing effects of prescribed fire on herpetofauna in the Gulf Coastal plain. The southeast is one of the most fire-dependent regions in the United States, with prescribed fire becoming an increasingly important tool in habitat and ecosystem management. In absence of fire, hardwood species become dominant in pine communities. Species endemic to southeastern pine forests (for example, Flatwood salamander [Ambystoma cinculatum], Oak toad [Bufo quercicus]) suffer loss of habitat resulting from changes in structure and vegetation diversity. The study was conducted in a mosaic of pine flatwoods and southern wiregrass (Aristida beyrichiana) savanna with open canopies of slash pine (Pinus elliottii) dominant. Other representative pines included slash pine (P. elliottii) and longleaf pine (P. palustris). Overall the authors conclude prescribed fire had little, if any, effect on amphibians and reptiles in the study area. The study suggests low intensity prescribed fire increased the number of individual herpetofauna in study area pine savannas.

McIntyre, N.E., 2003, Effects of Conservation Reserve Program seeding regime on harvester ants (Pogonomyrmex), with implications for the threatened Texas horned lizard (Phrynosoma cornutum): The Southwestern Naturalist, v. 48 , no. 2, p. 274-313.

Abundance of harvester ant nest sites, primary prey for endangered Texas horned lizard, evaluated in CRP grasslands and native prairie in Texas panhandle sites. CRP fields evaluated were planted to Old World bluestem (Bothriochloa ischaemum), weeping lovegrass (Eragrostis curvula), or mixtures of native grasses with and without buffalograss (Buchloë dactyloides). Native grass CRP plantings were dominated by sideoats grama (Bouteloua curtipendula), blue grama ( $B$. gracilis), and switchgrass (Panicum virgatum). (Estimates of field age, comparisons of density, and other vegetation characteristics between seeded and native grasslands were not described). The fewest ant mounds were found within fields planted to Old World bluestem. Native (ungrazed) grassland had the highest density of ant mounds. However, no significant difference between abundance of ant mounds in native and exotic CRP plantings were reported. Author concludes there is no evidence CRP plots planted to exotic grasses are poorer habitat for Texas horned lizards in terms of ant abundance than are native plantings.

Newbold, T.A.S., 2005, Desert horned lizard (Phrynosoma platyrhinos) locomotor performance-The influence of cheatgrass (Bromus tectorum): The Southwestern Naturalist, v. 50 , no. 1, p. $17-23$.

An investigation of the influence of vegetation structure on the distribution patterns of desert horned lizards and the effect cheatgrass has on ability of the species to move through its habitat. Physical structure of vegetation has non-thermal effects on animals. Shrub and grass densities affect the amount of bare substrate and can have an influence on distribution patterns. Negative association between lizard scat abundance and cheatgrass cover suggesting the lizard avoids areas with higher density of cheatgrass. Results demonstrate negative effect of cheatgrass and the potential detrimental consequences of cheatgrass invasion on distribution patterns of the horned 
lizard. Altered soil properties and exclusion of native plants are consequences of cheatgrass dominance.

Relyea, R.A., 2005, The lethal impact of Roundup on aquatic and terrestrial amphibians: Ecological Applications, v. 15, no. 4, p. 1118-1124.

Although there is evidence pesticides may play a role in large-scale decline in amphibian populations few pesticides have been tested on these species. Author reports results of testing impact of Roundup overspray on leopard frogs (Rana pipiens), American toad (Bufo americanus), and gray tree frog (Hyla versicolor) tadpoles in outdoor pools. Roundup is a globally common herbicide widely thought to be nonlethal to amphibians. The herbicide is a glyphosate also sold under the brand names of Rodeo and Aqua Master. The herbicide is widely used to control weeds and often used in association with Roundup-ready corn and soybean production as well as in forestry, aquatic weed control, and residential applications. Roundup was the second most commonly used pesticide in 1999 in the United States with 30-33 million kg of active ingredient applied on over 8 million hectares (greater than 19 million acres).

The most striking result of this investigation is that a herbicide designed to kill plants had fatal results on almost all tadpoles within 3 weeks and 79 percent of all juveniles within one day. Three weeks after application of the herbicide 96-100 percent of larval amphibians exposed to Roundup died. Juvenile (post-metamorphic) anurans were exposed to direct overspray of the herbicide resulting in 68-86 percent mortality within one day. Cause of mortality appears to be from direct toxicity rather than reduction of algal food resources. Author concludes Roundup can cause extremely high rates of amphibian mortality resulting in declines in populations.

Semlitsch, R.D., and Bodie, J.R., 2003, Biological criteria for buffer zones around wetlands and riparian habitats for amphibians and reptiles: Conservation Biology, v. 17, no. 5, p. 1219-1228.

Often overlooked for their value to semiaquatic species, terrestrial habitats surrounding wetlands are important for more than just protection of water quality. A close dependence of semiaquatic reptiles and amphibians on terrestrial cover types in proximity to wetlands is exhibited for critical lifehistory functions such as foraging, overwintering, or nesting. Criteria by which to define habitat requirements for most species and associated regulations to protect spatial relations between wetlands and terrestrial habitats are lacking. Conservation and management plans must consider both local and landscape dynamics, however, core habitats for local populations of species must be defined before issues of wetland and terrestrial connectivity can be addressed.

Literature review by authors suggest overall core terrestrial habitat for amphibians ranged from 159 to $290 \mathrm{~m}$
(175 to $317 \mathrm{yd}$ ) and that of reptiles ranged from 127 to 289 $\mathrm{m}$ (140 to $316 \mathrm{yd}$ ) from edge of aquatic sites. While wetlands vary in many characteristics, the authors suggest a single allencompassing value for the size of core habitats can be used effectively. On private lands, or areas where sustainable land use is the priority, a stratified system of protection zones can minimize impacts to wildlife. Authors propose three terrestrial zones adjacent to core aquatic and wetland habitats: Zone 1, area immediately adjacent to wetland restricted from use and designed to buffer the core aquatic habitat; Zone 2, core terrestrial zone that encompasses the core terrestrial habitat defined by semiaquatic species of priority (for example, amphibians 159-290 m); Zone 3, beyond zone 2 serves to buffer the core terrestrial habitat from surrounding land use. Decisions on how restrictive each zone may be to land-use practices would depend on management goals and species of concern. Authors suggest buffers 15-30 m (16-33 yd) wide used to protect wetland species in many states are inadequate for amphibians and reptiles. A table providing summary data for movement data of reptiles from wetlands is furnished.

\section{Soils}

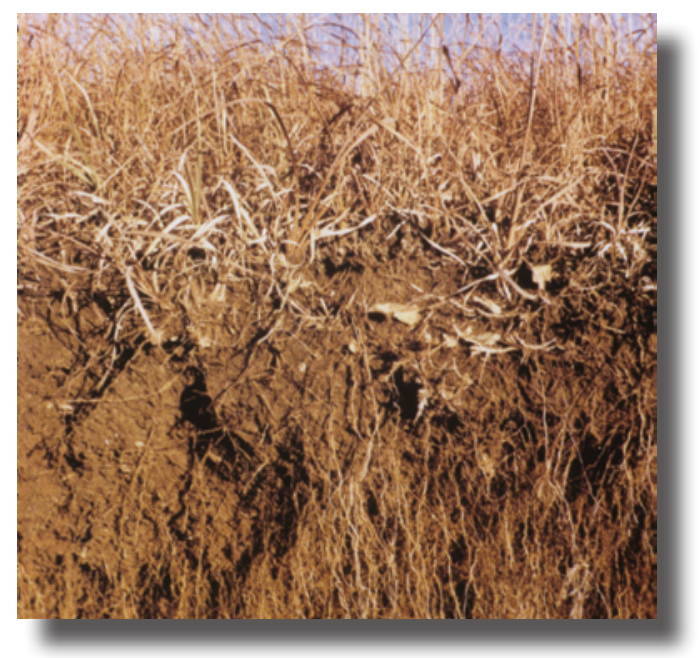

Baer, S.G., Rice, C.W., and Blair, J.M., 2000, Assessment of soil quality in fields with short and long term enrollment in the CRP: Journal of Soil and Water Conservation, v. 55, no. 2, p. 142-146.

Surface soil quality was examined in fields representing short and long-term enrollment in CRP. Total $\mathrm{C}$ and $\mathrm{N}$ amounts were similar in both types of enrollment but lower than recorded in native prairie. Measures of $\mathrm{C}$ and $\mathrm{N}$, however, did increase in response to greater time in the CRP. Long-term establishment of native grasses exhibited 141 percent and 93 percent greater microbial biomass $\mathrm{C}$ and $\mathrm{N}$ than soil recently enrolled in CRP. Putting land in CRP promotes soil restoration but 10 growing seasons (the typical enrollment period) are not adequate for recovery of total soil $\mathrm{N}$ and $\mathrm{C}$ pools. Soil organic 
$\mathrm{C}$ is estimated to have declined 24 to 60 percent in the Great Plains soils due to cultivation. Total $\mathrm{C}$ and $\mathrm{N}$ pools were not different between soils recently enrolled and those planted to CRP grasses for 10 years. The improvements in soil quality can decline rapidly on CRP lands if conventional tillage practices are resumed when contracts are terminated.

Burke, I.C., Lauenroth, W.K., and Coffin, D.P., 1995, Soil organic matter recovery in semiarid grasslands-Implications for the Conservation Reserve Program: Ecological Applications, v. 5, no. 3, p. 793-801.

There has been a modest amount of work completed on quantification of long-term recovery of soil organic matter and nutrient supply lost due to cultivation. Soil organic matter, silt content, microbial biomass, potentially mineralizable $\mathrm{N}$, and potentially respirable $\mathrm{C}$ were significantly lower in soils of cultivated fields than in fields of native grass. Abandoned fields were not significantly different from native fields with respect to microbial biomass, potentially mineralizable $\mathrm{N}$, or respirable C. Authors suggest $50 \mathrm{yr}$ is necessary for recovery of active soil organic matter and nutrient availability but recovery of total soil organic matter is a much slower process. Ultimately establishment of perennial grasses determines the rate of organic matter recovery.

Losses of soil organic matter in the central grassland region were attributed to cultivation and cropping effects that increase outputs from soil and decrease residue inputs. Tillage increased erosion and decomposition through physical mixing, degradation of soil aggregates, and enhanced contact of litter and soil organic matter with decomposing organisms. Annual crop plants have lower belowground biomass production than native perennial grasses. Decades of continuous cultivation have led to losses in surface soil organic matter $(0-20 \mathrm{~cm}[0-8$ in] depth) of between 20-40 percent. Historical losses of soil organic matter represent a significant transfer of $\mathrm{C}$ to the atmosphere as well as regional losses in production potential.

Study was conducted in northeast Colorado in shortgrass steppe blue grama (Bouteloua gracilis). Soils tilled for a longer period of time had greater decrease in silt content. Silt is the soil component most susceptible to wind erosion. Silt content significantly influences rate of recovery of blue grama in shortgrass ecosystems. A 10-percent reduction in silt content may reduce grass seedling establishment rates by 90 percent. Long-term losses of soil organic matter from cultivated fields represent a significant decline in soil fertility due to decreased availability of nutrients. Losses of fine soil particles and total soil organic matter are not likely to be recovered over human time scales. The carbon-capture rates from recovering fields in semiarid regions are extremely slow.

Fuhlendorf, S.D., Zhang, H., Tunnell, T.R., Engle, D.M., and Cross, A.F., 2002, Effects of grazing on restoration of southern mixed prairie soils: Restoration Ecology, v. 10, no. 2, p. $401-407$.
An analysis of grazing effects of cultivated lands reseeded to native grasses under CRP and native prairies never cultivated, but managed similarly, undertaken in Oklahoma. Vegetation monitored in study is typical of southern mixed prairie perennial species with dominant species varying depending on physical conditions and past land use. Common mid grasses were sideoats grama (Bouteloua curtipendula), purple threeawn (Aristida purpurea), and silver bluestem (Bothriochloa laguroides). Dominant short grasses included blue grama (B. gracilis) and hairy grama (B. hirsuta). Less common tall grasses included little bluestem (Schizachyrium scoparium), yellow Indiangrass (Sorghastrum nutans), and big bluestem (Andropogon gerardii).

Management of domestic livestock on rangelands, including land planted to grasses but no longer actively part of the CRP, can have variable effects on soil fertility, vegetation composition and structure thereby influencing the rate of recovery of restored grasslands. Grazing may also influence amounts, spatial pattern, and composition of nutrient accumulation in soil. Authors conclude that, regardless of cultivation history, soils and vegetation on heavily grazed sites differed significantly from that on moderately grazed sites. On restored (CRP) sites soil $\mathrm{N}$ and $\mathrm{C}$ were higher with moderate grazing than with heavy grazing. On native prairie sites grazing only minimally affected soil nutrients. Heavy grazing on former CRP sites reduced litter accumulation and abundance and increased bare ground, which led to reduction in accumulation of organic matter and nutrients. Results of this study suggest heavy grazing on native mixed prairie has little influence but heavy grazing on restored mixed grasslands (CRP) actually reduces rate of soil nutrient and organic matter accumulation. Authors state data support USDA policies of limited grazing on CRP grasslands if the objective is restoration of grassland ecosystems or building soil $\mathrm{C}$ pools.

Gebhart, D. L., Johnson, H.B., Mayeux, H.S., and Polley, H.W., 1994, The CRP increases soil organic carbon: Journal of Soil and Water Conservation, v. 49, no. 5, p. 488-492.

Replacement of cropland to perennial grassland associated with CRP may sequester atmospheric $\mathrm{C}$ back into the soil $\mathrm{C}$ pool, thereby changing cultivated soils from sources to sinks for atmospheric carbon. Soil organic $\mathrm{C}$ was evaluated in cropland, native pasture, and 5-yr-old CRP fields in Texas, Kansas, and Nebraska. Across all locations, soil organic $\mathrm{C}$ for cropland, CRP, and native pasture was 59.2, 65.1, and 90.8 metric ton C/ha $(2.5 \mathrm{ac})$ in upper $300 \mathrm{~cm}$ (118 in) of surface. CRP lands gained an average of 1.1 tons $\mathrm{C} / \mathrm{ha} / \mathrm{yr}(0.4$ ton/ac/ yr). Findings illustrate that agricultural $\mathrm{CO}_{2}$ emissions might be effectively controlled through changes in land use and management systems.

Many Great Plains soils have declined in organic C content and nutrient supplying capacity since initially cultivated. Losses of 24-70 percent are estimated from soils cultivated 30-43 years. Authors estimate cultivated croplands in U.S. lose about 2.7 million metric ton of $\mathrm{C}$ year (6 billion lbs/yr). An 
additional 35.4 million metric tons are released to the atmosphere yearly from agricultural fossil fuel use and manufacture of $\mathrm{N}$ fertilizers. CRP grasslands reduce atmospheric $\mathrm{CO}_{2}$ levels and increase soil organic $\mathrm{C}$ as a consequence of litter accumulation into surface soils and net primary production allocated to root growth. Recovery of soil organic $\mathrm{C}$ to pre-cultivation levels may take 50 or more years under perennial grasses.

Average soil organic C levels for CRP and cropland were significantly lower than those for native pasture indicating cultivation had markedly reduced pools of soil organic carbon. Depletion of soil organic $\mathrm{C}$ with initial cultivation was attributed to tillage-induced changes in plant species composition and inputs of $\mathrm{C}$ from roots to soils. Cultivation also increases soil temperature and microbial activity, which increase decomposition of organic matter and $\mathrm{C}$ content. Across all locations soil organic $\mathrm{C}$ levels in CRP were significantly greater than recorded in cropland to depth of $40 \mathrm{~cm}$ (16 in). After $5 \mathrm{yr}$ of perennial grass cover, only 21 percent of $\mathrm{C}$ lost during decades of intensive tillage had been replaced. Carbon was 34 percent greater in the $0-5 \mathrm{~cm}(0-2$ in) depth but amount of $\mathrm{C}$ decreased with increasing depth. Greater biomass of grass roots may also contribute to higher $\mathrm{C}$ content. Authors cite other studies that describe mean annual $\mathrm{C}$ inputs to grassland soils are 90 to 800 percent greater than inputs into cultivated soils. Authors speculate the 17 million hectares (42 million ac) of cropland enrolled in CRP may have potential to sequester about 45 percent of the 38.1 million metric tons of $\mathrm{C}$ released annually into the atmosphere by U.S. agriculture.

Gewin, V.L., Kennedy, A.C., Veseth, R., and Miller, B.C., 1999, Soil quality changes in eastern Washington with Conservation Reserve Program (CRP) take-out: Journal Soil and Water Conservation, v. 54, no. 1, p. 432-438.

Study results suggest a relative decrease of up to $10 \mathrm{mg}$ $\mathrm{CO}_{2}$-c10 $\mathrm{g}$ soil in readily mineralized $\mathrm{C}(\mathrm{RMC})$ results from conventional tillage. Most substantial decrease in $\mathrm{C}$ was immediately following tillage treatments. RMC represent the amount of $\mathrm{C}$ readily available to microbial communities. Fluctuations in amount of RMC result from soil disturbance and amount and species composition of ground cover. Crested wheatgrass (Agropyron cristatum) may reduce soil quality compared to native grasses species as a result of lower root exudates and unstable organic matter. Direct seed treatments were most similar to original CRP condition when compared to conventional tillage. No decrease in RMC was found with direct seeding. Direct seeding maintained soil quality conditions better than conventional practices.

Huang, X., Skidmore, E.L., and Tibke, G.L., 2002, Soil quality of two Kansas soils as influenced by the Conservation

Reserve Program: Journal of Soil and Water Conservation, v. 57 , no. 6 , p. $344-350$.

This evaluation compared soil chemical and physical properties after $10 \mathrm{yr}$ of enrollment in CRP to land continuously cropped. Improvements in soil quality attributed to CRP included reduction of soil acidification, less soil compaction, and reduction of topsoil erosion. When land in CRP was returned to crop production with conventional tillage total $\mathrm{C}$ in surface layer and aggregate stability gradually decreased. Significant recovery in obtaining higher levels of soil C levels would require more than the standard 10-year CRP contract. Authors suggest appropriate land management practices are needed to maintain residual benefits to soil quality derived from CRP enrollment.

Hughes-Popp, J.S., Huszar, P.C., and Hoag, D.L., 2000, Reducing wind erosion damages and the Conservation Reserve Program, in Napier, T.L., Napier, S.M., and Tvrdon, J., eds., Soil and water conservation policies and programs-Successes and failures: Washington, D.C., CRC Press, p. 143-154.

The CRP is an extension of soil conservation policies begun after the 1930s dust bowl by either purchasing or renting highly erodible land to retire it from production and susceptibility to erosion. Erosion is a significant problem in the U.S. with more than 2 billion tons of soil lost per year on non-federal cropland. Forty-four percent of this loss is due to wind. Over 770 million tons ( 80 percent of all erosion in the western United States) is caused by wind. This represents 36 percent of all soil erosion in the United States.

Authors conclude the CRP has not effectively addressed western soil-erosion issues. Greater benefits of the CRP may be realized by selecting program land not on the basis of greatest erosion rate but on combination of erosion rates, land location, and land use. On-site damages of wind erosion are much less than off-site damages. Proximity to large population areas largely defines the economic impact of wind erosion. Low estimates of economic benefits of CRP are due to land far from population centers being entered into the program. Authors conclude in New Mexico where only 3 percent of the land base is in cropland the CRP has had only minor benefits to reduction of the overall erosion rate. Effectiveness of the program could be enhanced by targeting lands with high rates of erosion regardless of present or past use (for example, cropland).

Karlen, D.L., Rosek, M.J., Gardner, J.C., Allan, D.L., Alms, M.J., Bezdicek, D.F., Flock, M., Huggins, D.R., Miller, B.S., and Staben, M.L., 1999, Conservation Reserve Program effects on soil quality indicators: Journal of Soil and Water Conservation, v. 54, no.1, p. 439-444.

Soil-quality indicators may be useful for evaluation of CRP effectiveness in meeting environmental objectives. The study focused on how CRP affected several physical, chemical, and biological indicators of soil quality. Overall, soil biological indicators showed more significant differences than either chemical or physical indicators. Results imply several soil quality indicators were improved by placing 
highly erodible cropland into perennial grass covers. Biological indicators were affected more quickly and to greater extent than chemical or physical indicators of soil quality. These indicators could be used to assess long-term impacts of agricultural management practices. Discussion of applicability physical and chemical indicators is provided. Authors recommend if CRP lands are returned to production, no-till or minimum tillage practices should be used to maintain environmental benefits.

McLauchlan, K.K., Hobbie, S.E., and Post, W.M., 2006, Conversion from agriculture to grassland builds soil organic matter on decadal timescales: Ecological Applications, v. 16 , no. 1, p. $143-153$.

Study results show soil C accumulates linearly for at least the first 40 years after conversion from cropland to grassland. Authors conclude Midwestern U.S. agricultural lands where grasslands have been reestablished can store additional soil C for 55-75 yr after termination of crop production but will not continue to accumulate $\mathrm{C}$ more than a century after conversion to grassland. Authors believe that substantial quantities of $\mathrm{C}$ can be stabilized in surface soils within decades after planting to grasslands, not centuries as has been suggested by other studies.

Robles, M.D., and Burke, I.C., 1997, Legume, grass, and Conservation Reserve Program effects on soil organic matter recovery: Ecological Applications, v. 7, no. 2, p. 345-357.

The active pool of soil organic matter can recover to levels indicative of undisturbed grassland on formerly cultivated fields if left undisturbed for approximately $50 \mathrm{yr}$. In the short term (less than $10 \mathrm{yr}$ ), recovery of organic matter and nutrient supply was highest in CRP fields containing a greater proportion of legumes. Net input of plant inputs and cessation of tillage generally increased pools of course particulate organic matter, $\mathrm{C}$, and $\mathrm{N}$ by factors of two to four relative to wheat-fallow fields but had negligible effects on amounts of soil organic matter. Endemic levels of organic matter are lower in highly disturbed soils as result of cultivation because plant inputs are reduced and erosion and decomposition are elevated. Reductions of 30-50 percent total soil $\mathrm{C}$ and $\mathrm{N}$ can occur during cultivation with even larger reductions in organic matter. These losses are greatest in lands managed on wheatfallow rotations. Plant life forms and relative plant densities can deferentially influence recovery of organic matter in soils depleted during long-term cultivation having important implications for conservation management.

After $6 \mathrm{yr}, \mathrm{C}$ and $\mathrm{N}$ levels are generally higher in CRP fields than in wheat-fallow indicating presence of perennial plants and lack of tillage leads to increased soil organic matter. Carbon and $\mathrm{N}$ levels can approach levels found in undisturbed conditions in $50 \mathrm{yr}$ in abandoned fields dominated by perennial bunch grasses. Grasslands produce 3-5 times more biomass than cultivated fields mainly because belowground biomass is higher. Coarse particulate organic matter (POM) appears to be a sensitive indicator of CRP management. Coarse POM was nearly twice as high in CRP fields 80/20 legume/grass than in 20/80. N-fixing species seeded in CRP fields played a significant role in enhancing $\mathrm{N}$ inputs. Nitrogen availability likely stimulated net primary productivity in CRP fields leading to increased soil organic matter.

Recovery of potential net $\mathrm{N}$ mineralization under legumes in CRP fields was higher than under rhizomatous grasses and higher than under bunch grasses in native fields. Legumes accelerate recovery of soil heterogeneity more than do rhizomatous grasses. Nitrogen transfer is highest when the proportion of legumes is maximized. Although changes in soil resource and nutrient availability in CRP fields were documented they are believed to probably have minimal effects on future potential crop yields. Enhanced mineralizable and coarse organic matter pools of $\mathrm{C}$ and $\mathrm{N}$ would be quickly exhausted if CRP grasslands were returned to conventional wheat-fallow tillage. The environmental benefits derived from retiring land from production dissipate quickly with a return to conventional cultivation.

Paustian, K., Killian, K., Cipra, J., Bluhm, G., Smith, J.L., and Elliott, E.T., 2001, Modeling and regional assessment of soil carbon- A case study of the Conservation Reserve Program, in Soil Carbon Sequestration and the Greenhouse Effect: Madison, Wis., Soil Science Society of America Special Publication no. 57, 410 p.

Modeling suggests CRP lands are sequestering $\mathrm{C}$ and regional differences in $\mathrm{C}$ storage rates are controlled by differences in primary production rates and secondarily by abiotic and soil factors influencing decomposition. Simulated rates of soil organic matter accumulation under CRP ranged from less than 10 to more than $40 \mathrm{~g} \mathrm{C} \mathrm{m(-1)} \mathrm{yr(-1).} \mathrm{Highest} \mathrm{estimated}$ rates are in the most humid regions. Predicted $\mathrm{C}$ increases for first 10-year period of CRP were on order of $10^{12}$ for soil organic matter C. Gains made in sequestered $\mathrm{C}$ on CRP grassland are vulnerable to loss with reversion to annual cropping.

Waisanen, P.J., and Bliss, N.B., 2002, Changes in population and agricultural land in conterminous United States counties, 1790 to 1997: Global Biogeochemical Cycles, v. 16, no. 4, p. 1137-156.

A data set of changes in population and agricultural land for the conterminous United States at the county level is provided and discussed. The data set furnishes more detail in spatial changes than previously available. The objective was to deliver data on timing of land conversion as input to models for estimation of changes in $\mathrm{C}$ due to alterations of land use, primarily conversion of native vegetation associations to agricultural production. However, the data have a variety of potential uses for physical, biological and social science applications. Data represent county-level information for each 
census year between 1790 and 1997 showing history of population and agricultural development.

Conversion of forest and grasslands to agriculture has stimulated the release of $\mathrm{C}$ from soils to the atmosphere. Estimates of declines in soil organic $\mathrm{C}$ range from 20 to 40 percent following cultivation with most of the loss occurring in the first $20 \mathrm{yr}$. Declines in soil C are most likely due to poor agricultural practices that did not maintain soil fertility or prevent erosion. Improved agricultural practices have maintained inputs from net primary production to allow some recovery of soil $\mathrm{C}$ on agricultural lands. Subsequent abandonment of cropland may enhance sequestration of $\mathrm{C}$ in the soil. Although regional variations exist, total U.S. land in farms peaked in 1940 declining ever since. Regional trends in farmland from 1850-1997 are presented, as are changes in non-farm grazing land, forestland, grassland, pasture, improved farmland, and harvested farmland.

Wu, J., Nellis, M.D., Ransom, M.D., Price, K.P., and Egbert, S.L., 1997, Evaluating soil properties of CRP land using remote sensing and GIS in Finney County, Kansas: Journal Soil and Water Conservation, v. 52, no. 5, p. 352-358.

The report discusses integration of remote-sensing technologies and GIS to evaluate present CRP in terms of soil conservation and recommendations for future management and land-use decisions. Results show soil erodibility index (EI) of CRP land was much lower than land used for corn, alfalfa or grass. It was also less than county average. About 75 percent of CRP land was in lower EI categories (less than 12) but about one-third of corn land had an EI greater than 30. The land with the highest potential for erosion was not included in the program. Authors conclude existing national rules governing CRP may not be appropriate for specific, local areas. Modification of local eligibility rules could result in more efficient targeting of the most environmentally sensitive land.

Zheng, F., Merrill, S.D., Huang, S., Tanaka, D.L., Darboux, F., Liebig, M.A., and Halvorson, A.D., 2004, Runoff, soil erosion, and erodibility of Conservation Reserve Program land under crop and hay production: Soil Science Society of America Journal, v. 68, p. 1332-1341.

There is concern that lands enrolled in CRP will experience increased soil erosion when returned to crop production. Authors report results of investigation comparing runoff, erosion, and erodibility on CRP land converted to hay production, crop production under conventional-till and no-till management. The study was completed in central North Dakota 6 yr after CRP land had been converted to hay and crop production. Authors conclude CRP land converted to crop production with a higher residue crop rotation and no-till management can possess the same low soil water erodibility as CRP land managed as hayed grassland. Erosion rates on no-till did not differ from pasture hayland. Erodibility on conventionally tilled land was six times greater than recorded in pasture/hayland. Erodibility of tilled no-till was significantly higher than recorded in tilled pasture/hayland showing higher inherent stability of grassland surface soil with its perennial plant root structures.

\section{Surveys, Landowner Opinions, and Public Attitudes}

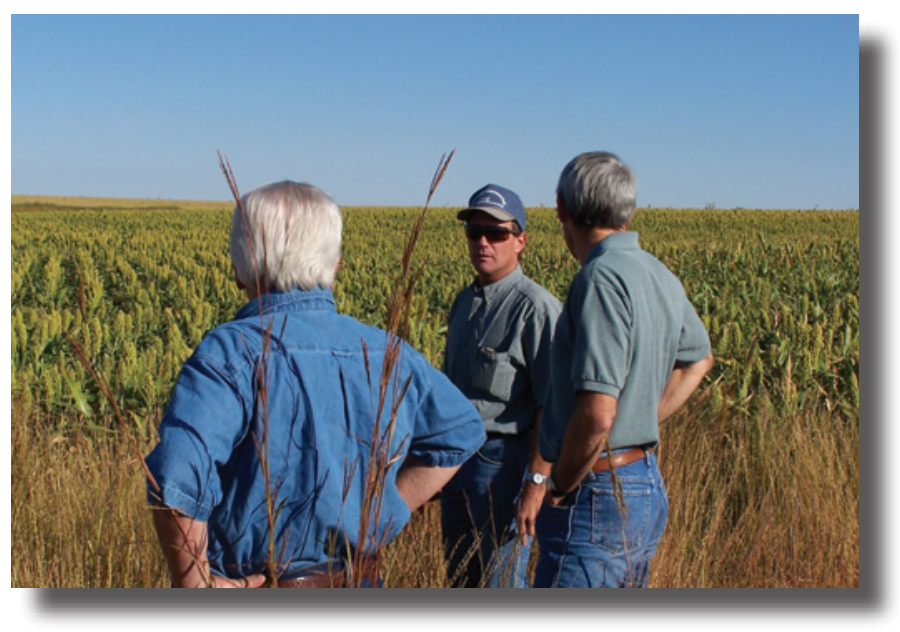

Allen, A.W., and Vandever, M.W., 2003, A national survey of Conservation Reserve Program (CRP) participants on environmental effects, wildlife issues, and vegetation management on program lands: Fort Collins, Colo., U.S. Department of the Interior, Geological Survey, Biological Science Report 2003-0001, 56 p.

A national survey of CRP contractees was completed to obtain information about environmental and social effects of the program on participants, farms, and communities. Of interest were observations concerning wildlife, attitudes about long-term management of program lands, and effectiveness of USDA assistance in relation to these issues. Surveys were delivered to 2,189 CRP participants of whom 64.5 percent responded. Retired farmers represented the largest category of respondents ( 52 percent). Enhanced control of soil erosion was the leading reported benefit of the CRP. Over 73 percent of respondents observed increased numbers of wildlife associated with lands enrolled in the program. The majority of respondents reported CRP benefits including increased quality of surface and groundwaters, improved air quality, control of drifting snow, and elevated opportunities to hunt or simply observe wildlife as part of daily activities. Income stability, improved scenic quality of farms and landscapes, and potential increases in property values and future incomes also were seen as program benefits. Negative aspects, reported by a smaller number of respondents, included seeing the CRP as a source of weeds, fire hazard, and attracting unwanted requests for trespass. 
Over 75 percent of respondents believed CRP benefits to wildlife were important. A majority of respondents ( 82 percent) believed the amount of assistance furnished by USDA related to planning and maintaining wildlife habitat associated with CRP lands was appropriate. Nearly 51 percent of respondents would accept incorporation of periodic management of vegetation into long-term management of CRP lands to maintain wildlife habitat quality. Provision of funds to address additional costs and changes in CRP regulations would be required to maximize long-term management of program lands. Additional, on-ground assistance related to management of CRP, and other agricultural lands, to maintain wildlife habitats was commonly identified as a need by survey respondents.

Andersen, C.B., and Polkinghorn, B., 1996, Geology as a social science-Addressing the complexity of human habits and values in water-quality conflicts: GSA Today, v. 6 , p. 36-38.

An interesting, honest analysis of why scientists sometimes fail in working with communities and the public. Different values create a competing set of emphasis on the way we perceive information pertaining to environmental conflict. The result is poor communication and misunderstanding which is often the result of an inability of scientists to listen to the concerns of the community and base their recommendations only upon data. Often individuals or groups are effective in identification of what others have done incorrectly but often do not recognize the effects of their habits and their contribution to the problem. Resolution of most environmental conflicts is top down but this approach often fails when the community as a whole contributes to the environmental issue. Often, the top-down approach results in the four Rs: regulation, resentment, resistance, and refusal. Scientists must begin to address the social realities of environmental issues. This can be done by listening to the concerns of the community and to use these perspectives of problems as the starting point for the search to a solution. An understanding of how the layperson views the problem is necessary. Scientists are trained to think the scientific method is nonnegotiable and is superior to values that may further anger the public. Values are intrinsic to the community and scientists trying to tell the public how to value the environment based only on data is an exercise doomed to failure. However, science can change what the community values by changing the community's perception of its relationship to the environment.

Scientists should listen and work with the community to develop common ground using data only as needed to address or answer questions. The scientist should be a conveyer of knowledge but the community must guide the discussion. If a scientist in not willing to learn how people solve problems and work together then they are not likely to be successful. If you do not possess basic communication skills beyond simple presentation of ideas they will not succeed. Solutions will come from basic understanding and incorporation of the human factor in decision-making.
Anderson, W.L., and David, L.M., 1992, Results of the 1991-1992 Illinois quail hunter survey: Chicago, Ill., Illinois Department of Conservation, Division of Wildlife Resources Administrative Report, 16 p.

An Illinois survey of 1,716 northern bobwhite quail (Colinus virginianus) hunters was completed with a 76 percent rate of response. Of the 34 percent of respondents who hunted on CRP, 63 percent believed habitat furnished by the program had helped quail populations. Survey results indicate more quail hunters hunted on CRP land than had ring-necked pheasant (Phasianus colchicus) hunters. Fewer quail hunters believed the CRP had a positive impact on quail populations than did pheasant hunters who saw improvements in the population of pheasants.

Belden, N., and Russonello, J., 1996, Human values and natures future - American attitudes on biological diversity: Washington D.C., Belden and Russonello Research and Communications, $24 \mathrm{p}$.

This national survey indicates only 19 percent of the American public had heard about loss of biodiversity. Although eighty percent of respondents had not heard about loss of biodiversity upon clarification of the concept, 48 percent of respondents thought it was important to maintain biodiversity. Nearly 50 percent of respondents strongly, or somewhat, agreed it was all right to eliminate some species in favor of saving jobs. The greatest concerns about environmental impacts are human health, consequences of pollution, and destruction of environmental components furnishing clean air and water. The dominant motivation expressed by respondents for biological diversity protection was having a healthy, pleasing environment for their existing and future family to live in.

Boody, G., Vondracek, B., Andow, D.A., Krinke, M., Westra, J., Zimmerman, J., and Welle, P., 2005, Multifunctional agriculture in the United States: Bioscience, v. 55, no. 1, p. 27-38.

Potential changes in farming practices are evaluated in two Minnesota watersheds to determine how changes in farm policy may affect environmental, social, and economic outcomes. Authors conclude environmental and economic benefits from farming can be attained through change in agricultural land management without increasing public costs. Benefits include improved water quality, healthier populations of fish, increased C sequestration, decreased greenhouse gas emissions, and greater farm profitability. Policies that emphasize environmental functions and products in addition to food production are essential. Suggestions for redirecting farm payments toward "green box" issues could lead to substantial environmental change and public benefits.

Minnesota residents indicate they are willing to provide incentives for significant changes in environmental benefits 
associated with agricultural production. Members of the public that were surveyed indicate a desire to develop public policy, research, education and marketing strategies to promote greater diversification of food and fiber production in ways that lead to environmental and social benefits. Many current government programs and land grant university systems focus too closely on too few crops and reinforce production of traditional commodities. Local institutions need to change along with farmers. Focus groups state present commodity program discourages diversification in farming. U.S. farm policy should support agricultural diversity and nonmarket ecosystem services. Future programs should reward farmers for environmental benefits. Authors conclude that we cannot afford to sacrifice future agricultural productivity for the sake of short-term increases in commodity production. Dealing with worldwide food shortages will require a future agriculture that produces rather than consumes ecosystem benefits.

Brook, A., Zint, M., and De Young, R., 2003, Landowners' responses to an endangered species act listing and implications for encouraging conservation: Conservation Biology, v. 17 , no. 6 , p. $1638-1649$.

The survey provides an examination of landowner responses to listing of the Preble's meadow jumping mouse (Zapus hudsonius preblei) under the Endangered Species Act (ESA). In the United States, more than 90 percent of federally listed species depend on non-federal land to meet a portion of their habitat needs. Fifty percent of these species depend entirely on nonfederal land. The authors conclude listing under ESA did not appear to improve likelihood of survival of the meadow jumping mouse on private land. In terms of land area owned, respondents who indicated they sought to harm the species or its habitat negated efforts of landowners who said they had tried to help the species. The majority (56 percent) of respondents to the survey had, or would not allow, a biological survey of their land to gather information on the species.

Landowner conservation decisions are influenced by aesthetic preferences, economics, availability of trusted information, amount of land owned, personal values, recreational opportunities, residence, and their amount of trust in the government. Conservation activities are more likely to be accepted when they are perceived to be financially beneficial. Conflicts and mistrust between conservation interests and landowners is a key factor in acceptance of conservation. The authors conclude the previously untested assumption that some landowners may act to limit, or harm, rare species on their property is supported by their research. Effective acceptance conservation by landowners will depend upon an increasing availability of information and countering information provided by those who discourage changes in land use (for example, farm supply companies) or overall lack of information. Distribution of information through social networks appears to be a more effective approach to getting information to landowners over mass media or direct mailings. Distrust between landowners and the government is a major issue limiting acceptance of conservation policies. Landowners must be respected partners in conservation and working relations have to be built on a foundation of collaborative decision-making. A sense of control is especially important to acceptance of conservation policies by landowners. Approaches that enhance landowner feelings of control and diminish perceptions of exploitation by regulators should be pursued to gain maximum acceptance of governmental conservation policies.

Cable, T.T., 2002, Beliefs of Kansas agricultural producers about riparian areas and wildlife conservation: Human Dimensions of Wildlife, v. 7, p. 141-142.

Kansas agricultural producers $(\mathrm{n}=909)$ were surveyed with a 39 percent response rate. The purpose of the survey was to assess beliefs about riparian lands and wildlife conservation on private lands. Agricultural producers have a crucial role in the preservation of riparian areas, but even with compensation, most appear to be ambivalent about riparian area conservation. About 40 percent of respondents had set aside land specifically to help wildlife but only about 20 percent would sign a 10-yr lease at current rental values to set aside riparian land for wildlife. Seventy-four percent of respondents were unwilling to lease land for conservation even at 125 percent of current rental value. Seventy percent of respondents said they would not lease riparian land for wildlife at any price. The survey showed less support for endangered species among agricultural producers compared to general public. Support for endangered species was low: 58 percent thought endangered animals should be protected, 43 percent favored protection of plants and only 16 percent favored acquisition of streamside land to protect fish species. About one quarter of respondents said they would not stop farming along a streamside to protect an endangered species of fish.

Carr, S., and Tait, J., 1991, Differences in the attitudes of farmers and conservationists and their implications: Journal of Environmental Management, v. 32, p. 281-294.

Despite being completed in the United Kingdom, results of two surveys reported here have direct applicability to issues in the United States. Farmer and conservation groups were queried in relation to opinions about conservation issues affecting agricultural production and landscapes. Authors conclude farmers' sympathy for conservation has been overestimated in previous studies. The significance of productivity and efficiency in motivation of farmer decisions generally override concerns about conservation. Farmer opinions about what constitutes an attractive landscape and wildlife habitat quality differ from those of conservationists; therefore, attitudes toward conservation and stewardship by the two groups likely also diverge. After decades of governmental policies encouraging production farmers now try to maintain income under policies encouraging reductions in production. Strategies on the part 
of farmers consequently tend to be short-term, exploitive, and extractive rather than conserving and sustainable. Although attitudes involving deeply held values might be resistant to change, beliefs can often be enhanced by providing new information about conservation or changing the institutional framework in which farmers operate.

Cooper, E.R., 2005, The attitudes and opinions of Pennsylvania Conservation Reserve Enhancement Program (CREP) participants towards riparian buffers and conservation easements: University Park, Pa., Pennsylvania State University, M.S. thesis, $108 \mathrm{p}$.

Thesis explores attitudes and opinions of CREP participants toward establishment and preservation of riparian buffers. Survey was mailed to 685 CREP participants across 20 Pennsylvania counties who had established forested riparian buffers. Many participants stated reasons to enroll in CREP were to practice good environmental stewardship. The majority of respondents ( 85 percent) said they were likely to leave buffers intact when contracts expires but are hesitant to commit to establishing permanent easements due to concern about forfeiture of property rights and allowing public access to their land. Financial issues and education affected willingness to establish conservation easements. Participants were generally satisfied with buffer rental payment but are unsure as to the future and hesitant to sign a contract into perpetuity. Landowners generally were unsure of future conditions with resultant hesitation about permanent loss of use of land in buffers. Education will play a major role in fostering acceptance of easement programs.

Despain, W., 1995, A summary of the SWCS Wetlands Reserve Program survey: Journal of Soil and Water Conservation, v. 50 , no. 6 , p. 632-633.

A summary obtained from three landowner focus groups held to define attitudes toward wetlands issues, the WRP, and ways WRP could be improved to increase landowner participation. Results suggest most farmers believed they were well informed about environmental benefits of wetlands. Those struggling financially tended to see wetlands in terms of how much crop they could potentially produce if the wetlands were drained and farmed. Participants in focus groups seemed generally well informed about federal wetland programs but less knowledgeable about state programs. Farmers tended to group all government programs together but did recognize particular environmental organizations such as the Nature Conservancy and Ducks Unlimited. Recognition depended upon how much promotion effort was put into program communication. The programs most favored by landowners were voluntary. Shortcomings of the WRP enrollment process and administration are discussed. Respondents generally favored programs focused on local conditions and issues. Farmers wanted more specific information on how land was chosen for potential enrollment in the WRP. Permanent easements remain a concern to landowners. Shorter-term easements were more acceptable but not at a lower price of payment. Most farmers indicated they would rather receive an offer on their land rather than having to make a bid for enrollment. Farmers thought they should be compensated for income and property taxes that would remain due on lands enrolled in WRP.

Diebel, P.L., Cable, T.T., and Cook, P.S., 1993, The future of Conservation Reserve Program land in Kansas-The landowner's view: Manhattan, Kans., Kansas State University, No. 94-45-S. 56 p.

The majority of survey respondents were satisfied with the CRP program and ranked potential declines in soil erosion as an important influence in their initial enrollment. Wildlife habitat considerations affected decisions by 67.7 percent of respondents. However, 57.6 percent of respondents said increases in wildlife populations were undesirable. Hunting was most frequent form of recreation allowed on CRP land (76.4 percent). Market prices for commodities, forage, and livestock prices were key factors in landowner decisions about future use of CRP land.

Duke, J.M., 2004, Participation in agricultural land preservation programs - Parcel quality and a complex policy environment: Agricultural and Resource Economics Review, v. 33, no. 1, p. 34-49.

Information on owner and land characteristics is used to analyze factors affecting landowner decisions in agricultural preservation programs in Delaware. Farmland preservation programs reduce farmer risk to lawsuits and reward multifunctional benefit which may have higher social values than do the commodities produced from the land. Effective programs based on purchase of agricultural conservation easements must consider what issues motivate landowners to participate. Landowners perceive a complex policy environment suggesting factors driving participation in one program may also drive participation in related programs. Participation may be greatest in areas receiving low development pressure and by use of personal contact as the source of information (as compared to information presented in newspapers). Owners tend to make conservation decisions in a complex policy environment with preservation and commodity programs that may work against one another in terms of environmental quality and development. Participation in environmental programs is preferred by landowners in areas further from cities. In areas under the most development pressure owners tend to reject preservation programs due to the potentially high return that could be received for sale of land. Part of the reason behind this lack of participation may be commodity programs that offer alternative to preservation without requirement of long-term commitment. 
Ervin, D.E., 1986, Constraints to practicing soil conservation-Land tenure relationships, in Lovejoy, S.B., and Napier, T.L., eds., Conserving soil-Insights from socioeconomic research: Ankeny, Iowa, Soil Conservation Society of America, p. 95-107.

Farmland tenancy in the United States experienced three major changes during the 1970s: percentage of total farmland owned by non-operator landlords rose, use of fixed-cash rental contracts increased, and landlords contributed a lesser share of total farm production and capital expenditure. These events imply increased separation of ownership from on-ground, daily management of farmland. The tenants only incentive is to invest in soil-erosion control if productivity benefits, or cost savings, outweigh erosion control expenses during time the land is rented. Landlords may under-invest in soil erosion control, because tenants who do not share in the costs will capture actual benefits. Unless tenant operators expect to rent land for an extended period of time, or intend to purchase the land, a program oriented to renters will miss the long-term incentives that owners have. Attempts to persuade landowners and tenants about conservation advantages without sound data may succeed in short run but will ultimately fail when real benefits and costs are realized. Forty percent of U.S. farmland is leased.

Forshay, K.J., Morzaria-Luna, H.N., Hale, B., and Predick, K., 2005, Landowner satisfaction with the Wetlands Reserve

Program in Wisconsin: Environmental Management, v. 36, no. 2, p. 248-257.

Social and political support for wetland protection has increased with recognition of the ecological services that wetlands provide. The WRP establishes conservation easements on agricultural wetlands in exchange for financial incentives. Administered by NRCS, the WRP provides an increase in wetland acreage, reduction of groundwater contamination from agricultural sources, flood prevention, increases in groundwater recharge, and wildlife habitats. The WRP began as a 9-state pilot program and expanded to all states in 1995. By the end of $2002,516,629$ hectares $(1,276,618$ acres $)$ were enrolled in the program. Three types of easements are offered: permanent easements where USDA pays 100 percent of agricultural value of the land and full cost for restoration; 30-year easements, 75 percent of restoration costs paid; and cost-share where the operator maintains restoration for $10 \mathrm{yr}$ and USDA pays 75 percent of restoration costs.

Authors report results of a four-county 2003 investigation of 25 percent of Wisconsin WRP contracts $(n=69$ after rejection of some contracts). Restoration and easement costs, NRCS monitoring records, and surveys of program participants were investigated. Average size of sites included in the assessment was 52 hectares (128 ac). Time since restoration was not a significant predictor of any ecological or social variables. The most common wetland community after restoration was fresh meadow. On 74 percent of sites, reed canarygrass (Phalaris arundinacea), an invasive species was present. Cost for restoration was $\$ 407 /$ ha (\$162/ac). Participant survey had an 80 percent response rate with an overall rating of 3.6 plus or minus 0.2 (1-5 scale with 5 being completely satisfied). Environmental protection was identified by 81 percent of respondents as primary reason to enroll in WRP, while 71 percent identified economic incentives and 60 percent indicated improvement in recreational opportunities drove their decision to enroll. New landowners were more likely to recreate on the WRP land than were original owners. Concerns expressed by WRP participants included restriction on establishment of permanent deer stands, increase in tax rate following restoration, limited communication with NRCS, and lack of participation in restoration process.

Authors conclude monitoring data on WRP projects is coarse and not collected with enough consistency to quantify change in biodiversity or wetland function. Data was only effective in tracking changes in area converted from agriculture to wetland. Authors recommend a more comprehensive monitoring program to furnish more quantifiable data on ecological issues related to restoration and assessing program outcomes. Results indicate satisfaction with the program by participants and that 89 percent planned to maintain the restorations. Satisfaction was largely driven by participation in the restoration process and economic incentives. Results indicate landowners derive nonmonetary benefits from their wetlands, chiefly recreation. Thirty-three percent of WRP sites surveyed changed ownership since placed in the program.

Authors make the following management recommendations related to the WRP. Management of invasive species should be a priority in the WRP. Monitoring of success and ecological functions of restored wetlands should be more rigorous and systematic over a longer time period (10-20 yr). Wetland Reserve Program sites should receive significant tax relief such as a full tax exemption following establishment of the easement. State tax assessments have increased for conservation easements because are classified as recreational land. This reduces property taxes for farmers but serves as a disincentive for restoration of wetlands. Communication between WRP participants and NRCS needs to be increased.

General Accounting Office, 2002, Agricultural conservationState advisory committees' views on how USDA programs could better address environmental concerns: Washington, D.C., U.S. General Accounting Office, 76 p.

Sixty-two percent of respondents indicated loss of wildlife habitat on farms and ranches was a moderate or major concern. Over half believed loss of native species was of moderate or major concern. Almost 50 percent felt CRP was very, to extremely, effective in addressing state environmental and resource concerns. Nearly 53 percent of respondents believed CRP was very, or extremely, effective in protecting or improving wildlife habitat. Over 35 percent felt there was enough NRCS technical assistance to meet program needs while 
58 percent believed there was less than enough assistance provided than needed. Fifty eight percent of respondents felt CRP had some very positive effects on the economy of rural communities while nearly 20 percent of respondents believed CRP had some very negative effects on local economies. Fifty percent of respondents believed CRP needs more emphasis on protecting or improving wildlife habitat.

Habron, G.B., 2004, Adoption of conservation practices by agricultural landowners in three Oregon watersheds: Journal of Soil and Water Conservation, v. 59, no. 3, p. 109-115.

Mail survey used to identify agricultural landowner participation in watershed conservation projects and determine characteristics of participating and non-participant landowners. Because sharing management decisions with a spouse increases probability of adopting both upland and riparian ecological practices, the author recommends that conservation programs fully involve the entire household and not target just male landowners. Agencies should expend more effort in providing information about other landowner conservation experiences as landowners are often a main source of information. Working with other landowners reduces landowner fears about having conservation-agency staff on site and potential implications of sanctions or forced adoption of conservation activities. To be most effective landowners need a non-threatening forum to learn from one another. Belief in scientific experimentation and a tendency to tell others about conservation also influenced adoption of conservation practices. Resource agencies and planners should not assume all landowners have identical concerns or that uniform solutions to problems will always be the answer to resource issues

Holsman, R.H., and Peyton, R.B., 2003, Stakeholder attitudes toward ecosystem management in southern Michigan: Wildlife Society Bulletin, v. 31, no. 2, p. 349-361.

The move to encourage better management of natural resources through ecosystem management is based on the assumption that the public values and supports the concept. Traditional demands on resource managers to produce recreational and other utilitarian benefits will continue and affect acceptance of stakeholders in ecosystem management. Redistribution of benefits makes it imperative that a solid understanding of public preferences is used to formulate ecosystem management plans. Increases in government regulation, impacts on economic development, and potential loss in property rights all have substantial influence on acceptance of ecosystem management goals by landowners. Public perceptions are diverse and actual understanding of ecosystem concepts and management objectives are low. While the public may, in principle, support ecosystem management many stakeholders remain focused on, and opt for, narrow preferences like management for single species and continuation of economic development. Attempts to measure public support for ecosystem management need to plainly define attributes and trade-offs involved in management options. Ecosystem management must be based on a clear and concrete vision, effective communication of expected benefits and costs, and building of strong relationships and trust between involved and affected groups.

Jensen, K., Clark, C.D., Ellis, P., English, B., Menard, J., Walsh, M., and de la Toree Ugarte, D., 2007, Farmer willingness to grow switchgrass for energy production: Biomass and Bioenergy, v. 31, p. 773-781.

A survey of farmers in Tennessee to determine willingness to grow switchgrass (Panicum virgatum) for potential energy markets is reported. In 2005, a survey was sent to 19,684 Tennessee farmers with a reported income of over $\$ 10,000$. Response rate was 23.9 percent. Of those responding 20.8 percent previously heard of growing switchgrass as an energy option. Only 29.6 percent of respondents indicated an interest in growing switchgrass if it were profitable. Producer opinions about switchgrass production are presented. Study results suggest many farmers are still not familiar with switchgrass opportunities. The availability of technical assistance and poorly defined markets were factors limiting adoption of the practice. Land owners with off-farm income were more likely to convert land to switchgrass production. Control of soil erosion had no influence in interest in growing switchgrass but improvement of wildlife habitat quality did.

Kurzejeski, E.W., Burger Jr., L.W., Monson, M.J., and Lenkner, R., 1992, Wildlife conservation attitudes and land use intentions of Conservation Reserve Program participants in Missouri: Wildlife Society Bulletin, v. 20, p. 253-259.

Sixty-two percent of respondents indicated wildlife was an important concern in their choice of farming practices. Only 9.4 percent of respondents enrolled land in conservation practices that furnished permanent wildlife habitat. Fifty-six percent of respondents indicated they were unaware of the availability and details about this practice. Increased educational efforts to promote wildlife management options are needed and should target both landowners and administering agencies.

Korsching, P.F., and Hoban, IV, T.J., 1990, Relationships between information sources and farmers' conservation perceptions and behavior: Society and Natural Resources, v. 3 , p. 1-10.

Traditional primary sources of information used by farmers to adopt new practices are, in order of importance, other farmers, local dealers of agricultural products, and local government agencies. Mass media sources were believed relatively unimportant. Results of this survey of 600 Iowa farmers indicate the top three sources of information are: farm 
magazines, other farmers, and the SCS (now USDA NRCS). Authors conclude the SCS was the primary source of trusted conservation information but mass media, particularly farm magazines and local papers, can be effectively used to educate and promote conservation issues for relatively little expense.

Lambert, D., Sullivan, P., Claassen, R., and Foreman, L., 2006, Conservation-Compatible Practices and Programs-Who Participates?: Washington, D.C., U.S. Department of Agriculture Economic Research Service Report No. 14, 43 p.

Recent years have brought increasing emphasis on conservation programs that reward good stewardship on working farmland. This report examines business, operator, and household characteristics of farms that have adopted conservation practices with and without financial assistance from government programs. Concerns related to succession in ownership, desires to limit time, cost and energy spent farming, and the need to stabilize income can all affect decisions about farming and conservation. Not all conservation practices have equal environmental impact and their applicability depends on farmland attributes, farming practices in place, commodities grown, and other physical factors. Different types of farmers adopt differing conservation practices. Operators of small farms and operators not primarily focused on farming are less likely to adopt conservation practices that are management intensive than are operators whose primary occupation is farming. Farmers have financial incentives to maintain the quality of their land by limiting soil erosion, avoiding excessive use of chemicals and protecting the productivity of their land. However, there is little financial motivation to reduce off-site impacts, consequently farming remains a source of sedimentation and nutrients in some watersheds. Results of this investigation suggest farm size, commodities produced, and operator motivations are all associated with decisions to use various types of conservation practices.

Conservation practices that provide environmental benefits without large costs have been adopted by farms of all sizes, often without direct financial assistance from conservation programs. Operators of smaller farms, focused on non-farm occupations are less likely to adopt practice requiring extra time or expense than those of large operations who depend upon farming for their livelihood. Conservation structures such as grass waterways, riparian buffers, and planting fields, or portions of fields, to grasses come at costs for installation and foregone income. Younger operators, who rely less on off-farm income, are more likely to install conservation practices compatible with production. Operators who plant conservation cover crops as part of cropland retirement consider themselves to be retired. Larger farm operators are more likely to participate in working-land conservation programs such as the EQIP. Intensive use of land retirement programs (for example, CRP) is more common with retired and "lifestyle" farms. Operators who replace income from production with CRP payments are generally older than other farmers and are more reliant upon non-farm income. Those who tend to retire selected fields, or portions of them, in CRP tend to have larger farms and consider farming as their primary occupation.

Authors conclude that both working-land and landretirement programs are needed to address diverse needs of conservation. If farm operators do not sufficiently benefit from adopting conservation practices, farming-related environmental problems are less likely to be addressed. Policies other than direct subsidies can furnish substantial environmental benefits. These options include conservation compliance regulations, technical assistance, and research to improve farming practices. Programs based on the assumption that long-term profit is the driving force behind farming practices will not appeal to all farmers. Larger farm operators who participate in commodity programs are more likely to have adopted conservationcompatible practices than those growing non-program crops and livestock. A sliding scale of payments accounting for higher cost of conservation for smaller farm operations could increase adoption of conservation. Working land programs (for example, Conservation Security Program) are likely to reach more farms than land retirement programs but may not furnish all environmental benefits typically attributed to retirement programs.

Lant, C.L., Kraft, S.E., and Gillman, K.R., 1995, The 1990 farm bill and water quality in Corn Belt watersheds-Conserving remaining wetlands and restoring farmed wetlands: Journal of Soil and Water Conservation, v. 50, no. 2, p. 201-205.

Report furnished results of two surveys addressing estimated potential enrollment of farmed wetlands in the CRP and WRP, and farmland owner attitudes toward Swampbuster. The primary reason some farmers choose not to enroll in wetland programs is economic concern. Operators did not want to forgo potential production of crops on wetland acres and 51 percent or respondents believed enrollment could leave them with too little flexibility to change use of land as economic conditions changed. Also of concern was the potential change in overall drainage characteristics and possible effects on farming operation resulting from restoration of wetlands. Respondents were concerned destruction of current drainage facilities would be difficult and maintaining wetlands would be too time consuming. In 1992 mean payment for Iowa WRP easement was $\$ 958 / \mathrm{ac}$ with a total of $\$ 233 / \mathrm{ac}$ for restoration, technical assistance, and settlement fees. Potential participation in wetland preservation programs increases with rising payment rates. Although these rental rates are high compared to typical CRP rental rates they are low compared to costs for other Federal wetland restoration programs.

Survey results indicate that Swampbuster is an unpopular program with only 30 percent of respondents believing it is a necessary, or fair, program. Nearly 70 percent of respondents believed Swampbuster was an infringement on property rights. Over 70 percent said permitting some economic use of wetlands (pasture, hay) would make the program more acceptable. 
Seventy five percent of respondents said wetlands enrolled in Swampbuster should be exempt from property taxes. The Swampbuster program could be made more acceptable to operators if wetland mapping issues are resolved, reduction in property taxes on farmlands subject to Swampbuster is accomplished, and limited, periodic, economic use of wetlands is allowed. In addition, if continued, Swampbuster needs consistent enforcement of regulations and constraints to prevent impression of favoritism and arbitrary enforcement perceived by some operators.

Leistritz, F.L., Hodur, N.M., and Bangsund, D.A., 2002, Socioeconomic impacts of the Conservation Reserve Program in North Dakota: Rural America, v. 17, no. 3, p. 57-65.

Results of personal interviews and a survey of community leaders, CRP contract holders in 16 North Dakota counties are presented. Survey of CRP contractees based on results of 3,150 questionnaires sent with a 32.3 percent rate of return. Ninety-two community leaders received surveys with a 62 percent response rate. Negative effects of the CRP described by community and agricultural leaders include reduced demand for agricultural inputs such fuel, fertilizer, and machinery leading to lost income to farm supply and service sector businesses. Positive aspects of the program described by both CRP contractees and community leaders included increased control of soil erosion, improved populations of wildlife, and economic benefits to local communities derived from CRPassociated hunting and recreational opportunities. Recreational spending was perceived to be positive for local business including motels, cafes, gas stations, and grocery stores. In some areas guide services, outfitters and bed and breakfast operations had grown and were attributed to greater recreational opportunities stemming from establishment of the CRP. Contract holders said the CRP has helped stabilize revenue during adverse weather and volatile market conditions.

Community leaders were concerned the CRP had contributed to farm consolidation, declining rural populations, and an increase in posting of land against hunting. However, results from CRP participants invalidate these concerns. About 61 percent of landowners lived in the county where their CRP tract was located, 16 percent lived in an adjacent county, and only 13 percent live outside the county. Wherever they were living, CRP survey respondents were typically long-term residents. Only 11 percent had lived in county of residence less than 10 years. Tracts enrolled in CRP were typically small and represented only a fraction of the land needed to support an economically viable farming unit. Seventy two percent of respondents indicated CRP participation had reduced their income risk. Only 4 percent of respondents felt opportunities to supplement income with hunting fees was important. Eighty-nine percent of CRP respondents indicated posting of their land had not changed since enrollment in the program. Only 4 percent did not allow hunting and only 1.6 percent of respondents indicated they lease, or charge a fee, for hunting on their CRP land.

Almost 82 percent of respondents believed the CRP had contributed to growing populations of upland game species. More than 90 percent of respondents said the program had helped populations of big game, and about 75 percent said the CRP had benefited waterfowl populations. Respondents also said the CRP had been a benefit to hunting and trapping in their county. Local leaders were less likely to think the CRP had positive effects and enrollment criteria should focus on farmland characteristics rather than wildlife or environmental values. The authors conclude, however, North Dakota communities should develop businesses focused on capitalization of the enhanced recreational and subsequent economic development opportunities furnished by the CRP.

Manfredo, M.J., Teel, T.L., and Bright, A.D., 2003, Why are public values toward wildlife changing?: Human Dimensions of Wildlife, v. 8, no. 4, p. 287-306.

Public values toward wildlife have changed dramatically over the last half of the 20th century away from traditional emphasis on use and management. This trend is one of the most influential factors affecting wildlife management as we enter the 21 st century. The shift is associated with declining hunting, growth of nongovernmental organizations placing emphasis on nontraditional views toward wildlife, and policy changes through ballot initiatives. Increasing public affluence, higher levels of education, urbanization, and a decline in residential stability are key variables driving changes in attitudes toward wildlife management. Barring environmentally or socially catastrophic events, the authors predict continuation of the decline in utilitarian attitudes toward wildlife. The shift toward a largely protectionist attitude toward wildlife is founded within the growth of protectionist views toward the environment. Authors suggest environmental protection values will deepen and wildlife protection values will follow. It is important for managers and policy makers to understand shifting values within the public sector to guide program planning and implementation. Ultimately, success of conservation efforts will depend upon compatibility with cultural values.

McCann, M.J., Nunez, J.T., and Nowack, P.J., 2006, What we don't know can hurt us-Adoption of animal waste management strategies: Journal Soil and Water Conservation Society, v. 61, no. 1, p. 30-33.

With manure management as a focus, the authors describe social and research barriers to adoption of conservation practices. The discussion is applicable to farmer adoption of conservation practices in general. Adoption of manuremanagement strategies has been disappointing, particularly by smaller operators. Economic and social barriers to adoption are identified and described. Varying values of farmers, goals, previous investments are among those discussed. Given the 
variability in operators, farms, and physical characteristics of farm locations a one-size-fits-all policy is not appropriate. Barriers to adoption include profitability, cost of equipment, uncertainty of potential costs and benefits, and complexity of regulations. Solutions discussed include greater availability of information and well developed channels of communication. Policy focused research needs to take into account factors affecting adoption behavior to formulate policies that are flexible, effective, and have low costs.

McCann, E., Sullivan, S., Erickson, D., and DeYoung, R., 1997, Environmental awareness, economic orientation, and farming practices-A comparison of organic and conventional farms: Environmental Management, v. 21, no. 5, p. $747-758$.

The farm population in the last half of the 20th century changed radically from a relatively homogeneous group of small and medium-sized family farms to larger, specialized operations. Young people continue to leave the farming industry as economic risks of farming continue to grow. When farming is no longer of interest to the next generation, family farmland almost always goes to bigger farmers with the machinery and capitol to make the land profitable. Although many of the farmers participating in this study stated love, respect, and an understanding of nature, they feel obligated to preserve the economic stability of the operation that has sustained their family and lifestyle. Based on a survey of 25 farmers in Michigan, the authors conclude organic farmers show a greater awareness of and concern for environmental problems than do conventional farmers. Although conventional farmers perceive themselves as people of the land, they frequently sacrifice the health of the land in the interest of continued farming. However, both groups of farmers express concern about economics and the health of the land. Both organic and conventional farmers are dependent on an economic structure largely beyond their control. Higher debt burdens and a governing economic orientation toward agriculture make large farms less likely to be concerned about and adopt practices of environmental protection. The authors conclude that governmental conservation programs have been successful in increasing awareness about soil erosion issues and should be expanded to address other environmental concerns. An understanding of farmers' attitude and behaviors toward conservation vary but is essential for identification and implementation of effective conservation objectives.

McGranahan, D.A., and Beale, C.L., 2002, Understanding rural population loss: Rural America, v. 17, no. 4, p. 2-11.

More than 25 percent of rural counties lost population between 1990 and 2000. Loss rates often were greater than 5 percent. Many of these counties were agricultural and have been losing population for decades. Distance away from metro areas, low population density, and few natural amenities (favorable climate, topographic diversity, and presence of surface waters) are identified as factors affecting population loss in these counties. Population loss was most pronounced in the center of the country as well as scattered areas in the Northeast and South. Rural life for most people is improved by access to doctors, schools, stores, and restaurants. The problem with access to services has increased as health, education and retail services have consolidated. Frontier counties (less than 10.1 persons $/ \mathrm{mi}^{2}$ ) were much more likely to lose population than were other more densely populated counties putting greater strain on services in counties least able to bear the consequences of declining population.

People who move to or stay in rural areas generally enjoy a slower pace of life, less congestion, community centered life, and the outdoors. Areas dominated by farming tend to be flat, have low density of surface waters (lakes, ponds), and have wetter winters and hotter summers resulting in low rates of natural amenities that attract people. Three of four counties classified as frontier having below average natural amenities are farming dependent. Population loss in the 1990s was strongly related to availability of natural amenities and frontier status. Nearly 70 percent of frontier counties lost at least 5 percent of their population. Frontier counties without natural amenities have not attracted manufacturing with low labor markets and low paying jobs remaining prevalent. These counties also tend to have older populations with death rates exceeding birth rates. Industrial agricultural (large confined animal operation, meat packing plants), casinos and prisons have brought increases in populations but with low-paying, unskilled jobs. The authors conclude low-amenity frontier counties will face difficult choices. Unless these counties can develop a recreational industry they must deal with either industrial agriculture or continued declines in population comprised largely of immigrants accepting low paying, non-skilled jobs.

McLeod, D.M., Miller, S.F., and Perry, G.M., 1996, North Central Oregon Conservation Reserve Program Survey-A summary of results: Corvallis, Oreg., Oregon State University Special Report 959, 46 p.

At the time that this report was written, Oregon had 530,766 acres in CRP (1.5 percent of national total). A survey was administered to CRP participants in the north central and northeastern regions of state in six counties where the majority of the CRP is enrolled. The survey was sent to $670 \mathrm{CRP}$ contract holders with 505 responding ( 75 percent response rate). For the entire study area (county by county results are also presented) 73 percent of contractees were owner operators and 19 percent renters. Nine percent of respondents committed 100 percent (whole farm) of their land to the CRP. Over half of the acreage enrolled represented less than 25 percent of the whole farm. Fifty-two percent of respondents indicated they were currently raising livestock. Primary reasons given for participation in CRP were: land of low yield/soil quality, 70 percent; 
provision of stable income, 77 percent; leaving farming, 12 percent; retirement, 17 percent; furnish wildlife habitat, 62 percent; and soil protection, 84 percent. Average age of CRP survey respondents was 57 . The typical respondent was an owner-operator of a 2,000-acre operation with 500 acres in the CRP. Upon expiration of the CRP contract, water and fencing costs to make land suitable for conversion to a grazing operation was estimated to be over $\$ 10,000$.

Nassauer, J.I., 1989, The aesthetic benefits of agricultural land: Renewable Resources Journal, v. 7, p. 17-18.

Author puts forth argument that failure to address aesthetic values of farmland to operators and the public in general has been a shortcoming of farm legislation. Management of agricultural land under the CRP and other USDA programs could be accomplished so that it appears attractive and helps to convey the message of environmental quality. Both rural and urban public receive satisfaction from how the rural landscape looks, sounds, and smells. Lands can be attractive because they are scenic or show good stewardship. Farm Bill programs should protect scenic rural landscapes and create more attractive landscapes by making American farmland a more vivid demonstration of good stewardship. Accomplishing these goals may enhance participation in conservation programs, assist in improvement of biodiversity, help to support rural economies, and preserve open space in proximity to urban areas.

Nassauer, J.I., 1995, Messy ecosystems, orderly frames: Landscape Journal, v. 14, no. 2, p. 161-170.

Ecological functions are not always recognizable to those not educated in a way to see or appreciate it. Ecologically beneficial land use and cover types may be perceived to be messy and uncared for. This may be a problem in convincing landowners to adopt conservation practices if they believe their neighbors see them as uncaring or sloppy managers of their land. The author addresses the issue that the appearance of indigenous ecosystems and wildlife habitats may violate cultural norms for the neat appearance of landscapes and how these obstacles can be addressed.

People often do not know how to see ecological quality directly but only through our cultural experience. What is good may not look good and what looks good may not be good. The author states that the difference between the scientific concept of ecology and the cultural concept of nature is the difference between function and appearance. This difference demonstrates that applied landscape ecology is essentially a design problem. While a neat and orderly landscape is often seen as a sign of hard work and pride, such a landscape seldom enhances ecological functions. The design of ecosystems (for example, incorporation of viable conservation practices into agriculturally dominated landscapes) may depend upon including cues of human intention that lead to understanding the land is not neglected or awaiting development.

The naturalness that Americans appreciate is more closely related to $18^{\text {th }}$ century perceptions of beauty than ecological function. Wetlands are often modified, prairies planted to trees, and dead wood removed in an effort to meet cultural expectations. People tend to perceive landscapes that furnish biodiversity as messy, weedy, and unkempt. Farmers see beauty in straightness of rows, even green color, and neatly kept roadsides. These images represent care, pride, and the work ethic associated with successful farming. People who have "unattractive" landscapes are often seen as not caring, having a negative personality, or lacking resources to manage their land properly; ultimately they are often perceived as not being good neighbors.

Mowing strips along the margins of buffers, bird nest boxes, bold strip patterns of conservation covers, and use of seed mixes heavy in native forbs, with large flowers (plants with small flowers are often perceived to be weeds), are identified as methods to make conservation practices more acceptable to farm operators.

Mehmood, S., Zhang, D., and Armstrong, J, 2003, Factors associated with declining hunting license sales in Alabama: Human Dimensions of Wildlife, v. 8, no. 4, p. 243-262.

Report documents factors associated with declining hunting license sales, which include lack of time, deficiency in availability of public hunting areas, aging, and loss of interest. Former and active hunters did most hunting on private lands. Size of area available for hunting, abundance of game, travel distance, and accessibility were important factors in choosing hunting sites. Majority of active hunters responding to survey said they traveled less than $50 \mathrm{mi}$ to a hunting area. Authors conclude once hunters quit the sport there is no policy within power of state wildlife agencies that can bring these persons back to the sport. Furthermore, agencies should increase efforts to retain interest of existing hunters by providing opportunities for hunting rather than trying to recruit new, or bring back former, hunters.

Miller, E.J., 1989, Wildlife management on Virginia Conservation Reserve Program land-The farmers' view: Blacksburg, Va., Virginia Polytechnic Institute and State University, M.S. thesis, $91 \mathrm{p}$.

Seventy-two percent of survey respondents indicated they wanted to improve wildlife habitat on retired farmland. However, most respondents said they had not been informed about improving habitat on CRP land. Respondents identified USDA personnel as the primary source of habitat information for program participants. Only 5 percent of land was planted to permanent wildlife habitat. Mowing of entire CRP acreage was primary means of weed control. Leasing of CRP land to hunters was uncommon. Results indicate a high level of 
interest in wildlife and a need for getting more detailed information to landowners from USDA and wildlife agencies.

Miller, E.J., and Bromley, P.T., 1989, Wildlife management on Conservation Reserve Program Land- The Farmer's view, in Transactions of the North American Wildlife and Natural Resources Conference, 54, Washington, D.C., March 17-22, 1989, Proceedings: Washington, D.C., Wildlife Management Institute, p. 377-381.

Survey results from CRP participants in Iowa and Virginia are presented. Results indicate CRP participants have a high level of interest in improving wildlife habitat. However, a lack of information and educational opportunities about how to specifically improve lands for wildlife appeared to be an important limitation. Objection to regulations and red tape may constrain acceptance of programs to stimulate improvement in habitat quality. Improvements in wildlife issues on CRP lands will require aggressive information and education efforts by wildlife agency staff (rather than USDA county staff) that can furnish precise information useful for improvement in habitat quality.

National Environmental Education \& Training Foundation, 2001, Lessons from the Environment, Why 95 percent of adult Americans endorse environmental education, in Ninth Annual National Report Card on Environmental Attitudes, Knowledge and Behaviors: Washington. D.C., National Environmental Education \& Training Foundation, 46 p.

A survey taken in 2000 confirms widespread environmental illiteracy persists within American population. However, there is an increasing public concern about pollution of the environment. Americans endorse government programs to protect water and air from pollution. Eighty-six percent of those surveyed believed government agencies should support educational programs addressing environmental issues. Majority of Americans believe environmental protection and economic development are compatible and environmental quality will increasingly play an important role in the nation's economic future.

Although there is a persistent and pervasive lack of environmental knowledge among Americans, a strong level of support for environmental education is apparent. The majority of the public still cannot identify leading causes of water pollution, air pollution, and issues related to disposal of solid waste. There is, however, an increasing level of public concern about environmental issues and Americans endorse governmental environmental protection programs. There is strong public support for governmental and corporate involvement in environmental education for adults. Americans believe a balance between the environment and economy is required for continued prosperity. Many believe environmental quality will be an important factor in the nation's economic future. When asked to choose between environmental protection and economic development, 71 percent of those surveyed said they would choose the environment. While there is general support for environmental quality, a lack of specific knowledge on environmental issues limits the public from taking effectual protective actions.

Newton, B.J., 2001, Environmental education and outreachExperiences of a federal agency: Bioscience, v. 51, no. 4, p. 297-299.

Conservation of natural resources is inextricably bound to public attitudes and opinions. Recommendations for making environmental messages and information effective: keep message simple, make information directly relevant to the individual, ask individuals to do something, develop sense of trust, focus outreach on events, allow for public discussion and input, or localize identification of issues and potential solutions as much as possible.

Pocewicz, A., Nielsen-Pincus, M., Goldberg, C.S., Johnson, M.H., Morgan, P., Force, J.E., Waits, L.P., and Verling, L., 2008, Predicting land use change-Comparison of models based on landowner surveys and historical land cover trends: Landscape Ecology, v. 23, p. 195-210.

To make informed decisions, potential effects of policies on land use must be evaluated. A mail survey of private landowners was used to develop a survey-based landowner decision model to describe future land-use changes. The study was conducted in northwest Idaho. A large amount of marginal agricultural land in this region has been enrolled in the CRP. The mail survey of questions focused on land-use plans was sent to 442 owners of privately owned land greater than 0.8 hectares $(2.0 \mathrm{ac})$. The survey had a 54 percent rate of response.

The analysis leads the authors to conclude that nonmetropolitan growth rates will continue to grow based on an increasing importance of amenity-driven migration and economic mobility. Both forest harvesting and residential development on private lands were projected to grow as a consequence of harvest constraints on public lands. Agricultural land is projected to decrease over the next decade. The authors attribute loss of agricultural land mostly to enrollment in CRP and residential development. Analysis indicates policies designed to attract participation in the CRP would be very successful in the study area. The authors conclude the surveybased model is a useful approach for understanding landscapescale impacts of land management policies.

Rhoads, B.L., Urban, M., and Herricks, E.E., 1999, Interaction between scientists and nonscientists in community-based watershed management-Emergence of the concept of stream naturalization: Environmental Management, v. 24, no. 3, p. 297-308.

Environmental management in watersheds is based on science and engineering but must first be perceived as a 
social process. More than ever before, approaches to environmental decision making must be based on an understanding and respect for social interaction and input from those most directly affected by programs. Local people often discount scientific information if they perceive the bearer of information as an outsider insensitive to the rituals and practices that make up their cultural identity. Scientists must develop personal relations with nonscientists based on trust and a mutual exchange of information and understanding. An important challenge for technical experts and scientists is appreciation for sincere, genuine understanding of the perspectives of local stakeholders. The biophysical environment is valued in different ways by people within the community, which ultimately shapes a community's reaction to environmental issues and regulations. Failure to take into account local knowledge and values often leads to the perception of top-down intervention which can reinforce existing social barriers, generate mistrust, and strengthen the perception of the scientist as an outsider with little understanding of local values or concerns.

Based on restoration of stream ecosystems in Illinois, the authors conclude the transformation of the fluvial environment occurred largely prior to collection of detailed environmental data and so widespread that predisturbance condition are largely unknown to local inhabitants. Watershed scale restoration is impractical because most rural communities are primarily concerned about maintaining high levels of production and land is too valuable for large tracts to be taken out of production.

An approach described as "Naturalization" is advocated by the authors as an alternative to restoration for watersheds situated in landscapes characterized by intensive human modification. The concept is based on recognition that natural is a social construct that each community negotiates as an appropriate mix of human and biophysical components. The goal of naturalization is to establish sustainable, morphologically, and hydraulically varied stream systems capable of supporting biologically diverse, healthy aquatic ecosystems. The approach described is based on scientifically informed views that acknowledge importance of social and economic concerns yet also preserves or enhances biophysical features of the system. The approach accommodates a shift away from purely utilitarian perspectives toward a view that incorporates the importance of environmental sustainability. Management prescriptions must address social and economic concerns based, in part, that human intervention in biophysical systems is part of the current "natural" dynamics of modern ecosystems.

Riddle, M, Skold, M.D., and Trock, W.L., 1994, The future of the Conservation Reserve Program in Colorado: Fort Collins, Colo., Department of Agricultural and Resource Economics, Colorado State University, Technical Report TR94-5, $41 \mathrm{p}$.

A survey of Colorado CRP contractees to ascertain expectations related to future of land use and the program. Respondents indicated that the most important reason for enrolling land in CRP was income brought by the program. Soil conservation also was identified an important consideration. These results led authors to conclude if the program expired, about 38 percent of land would return to production. About the same amount of expiring CRP land would remain in grass. Because the lands have been in crop production, infrastructure needed to accommodate livestock use (for example, fencing, water) is generally not available on CRP grasslands. New fences and development of water resources would be needed to convert CRP grassland to grazing.

Ryan, R.L., Erickson, D.L., and De Young, R., 2003, Farmers' motivations for adopting conservation practices along riparian zones in a mid-western agricultural watershed: Journal of Environmental Planning and Management, v. 46, no. 1, p. 19-37.

Report describes motivations of 268 farmers in a typical mid-western watershed for adopting conservation practices, current management practices, and future plans for management. Authors conclude farmers are motivated to practice conservation as a consequence of attachment to their land rather than receiving economic compensation. Farmers are more likely to become involved with conservation practices that make their farm appear well managed. Authors believe protection of riparian resources in agricultural watersheds requires an approach that respects farmers' attachment to their land and desire to practice good stewardship.

Conservation practices generally require a long-term investment with little or no short-term benefits. Understanding landowner motivation for adopting conservation is vital for success in promotion of widespread environmental protection and enhancement. Attachment to the land and protection of it for future generations are underlying motivations for farmers to participate in conservation activities. Emphasis on farmers' concern about environmental effects on downstream neighbors may be a new approach to convince farmers to engage in conservation practices. The social aspects of conservation behavior are worth further investigation in environmental planning and policy research. Authors suggest adoption of conservation practices may be more likely when supported by a range of motivations (social, aesthetic, and economic) rather than just economic incentives.

Aesthetic qualities of conservation practices are important but full-time farmers, in particular, did not perceive maintaining woody riparian cover as giving the appearance of good stewardship. Apparently, farmers are hesitant to allow acreage enrolled in government programs to revert to woody vegetation because the programs are generally perceived as being too short in duration and unpredictable. Grass-dominated cover is much easier to convert back to production if necessary. This investigation showed that no-till farming and grass buffer strips were the most commonly practiced management options in the watershed.

Findings imply farm structure (percent of income derived from farming) was important in determining types of 
conservation practices adopted. Part time farmers were more likely to maintain woody vegetative buffers along streams. As farm income continues to decline in relation to off farm income the number of part-time farmers will grow providing further opportunities to diversify programs. Authors believe part time farmers represent an underserved portion of the agricultural population likely to adopt more environmentally beneficial practices if government programs were structured to take advantage of their desires and limitations.

Soil and Water Conservation Society, 2001, Seeking common ground for conservation: Ankeny, Iowa, Soil and Water Conservation Society, $58 \mathrm{p}$.

Soil and Water Conservation Society staff interpretation of input provided by private interests, farmers and resource professionals obtained from five workshops sponsored by the agency to solicit input on conservation provisions for the 2002 Farm Bill. Specific recommendations are presented describing hopes and concerns of workshop participants. The report concludes that weakness in the nation's technical services infrastructure is the single greatest impediment to meeting the conservation needs of producers. The public desires improvement in environmental quality, but lack of funding for existing technical and financial assistance programs remains the greatest barrier to progress in conservation and environmental management. Most of new investment in conservation should be used to reach those producers who want to keep working the land rather that retire it from production. Report advocates continuation of existing conservation programs including the CRP. Findings imply state and local leaders need greater authority over the way USDA programs operate on local level. A farm program based on stewardship rather than commodity production will bring a needed balance to farm programs. Farm Bill programs should be broadly available, prevent conservation problems before they require treatment, achieve widespread enhancement to the environment, emphasize transition to production systems that enhance not just protect environment, and emphasize development of innovative practices that integrate conservation directly in production systems.

Recommendations ranging from more funding for existing conservation programs to creating a new overall vision for farm policy based on a foundation of land stewardship are furnished. (See report for 22 specific recommendations.) Specific to CRP, the report advocates expansion of the program, including lands that do not have cropping history, and integration of economic use, which may include managed haying, grazing, or other compatible economic use at reduced rental or easement payment rates.

The authors conclude more emphasis on monitoring and evaluation of USDA program performance is needed to furnish timely, accurate information upon which to base enhancement of program delivery. A lack of knowledge, rather than cost, is identified as the primary barrier to adoption of effective conservation systems. Recommendations based on basic and applied research are needed to formulate specific guidelines for conservation planning, systems design, and implementation. Policy makers could improve priority setting by making a portion of CCC funding available to support monitoring, assessment, and evaluation of programs. The development of reliable and consistent tools to estimate environmental benefits of programs is needed and should be a high priority.

\section{Tarrant, M.A., Overdevest, C., Bright, A.D., Cordell, H.K., and English, D.B.K., 1997, The effects of persuasive com- munication strategies on rural resident attitudes toward ecosystem management: Society\& Natural Resources, v. 10, p. $537-550$.}

The purpose of this study was to examine ways of generating more favorable attitudes on the part of rural residents toward environmental management. Results show although rural residents generally have low knowledge of environmental management, messages can be developed that significantly improve attitudes toward such policies. Generally, there is little knowledge of ecosystem concepts and management by rural residents. The most favorable attitudes toward ecosystem management were associated with messages containing strong arguments in favor of such a policy. Poor public knowledge and weakly developed opinions are, in part, based on an inadequate understanding due to the complexity of many natural resource issues. A lack of knowledge often equates to absence of support. Arguments containing aspects of high personal relevance produced the most favorable attitudes and responses on the part of rural residents. Managers and those who formulate policies need to understand their target audience. Key questions to address include whether or not the audience considers environmental management as highly relevant and if they hold general knowledge about what the concept entails. Messages should include not only facts about an issue but information that would increase relevance of the issue to the target audience. Managers should develop strong arguments for the strategy being proposed, emphasize how the issue is personally relevant to the audience, and furnish additional, information to persons already knowledgeable about the topic.
Troy, A.R., Strong, A.M., Bosworth, S.C., Donovan, T.M., Buckley, N.J., and Wilson, M.L., 2005, Attitudes of Ver- mont dairy farmers regarding adoption of management practices for grassland songbirds: Wildlife Society Bulletin, v. 33 , no. 2 , p. $528-538$.

A survey of 131 dairy farmers in Vermont's Champlain Valley was completed to determine attitudes toward habitat management for grassland birds. Results show a trend toward earlier and more frequent harvest of hayfields with operators indicating they have little flexibility to alter timing of harvest. Forty-nine percent of respondents indicated willingness to adopt alternative management on at least a small portion of their land to benefit avian species. It is believed operators with smaller dairy herds were more likely to devote a greater 
percentage of their land to alternative management prescriptions. Hayfield management is increasingly incompatible with reproductive cycle of grassland birds due to early June harvest, which is well before grassland birds can successfully fledge nestlings. Only small amounts of land are enrolled in USDA conservation programs in the northeast. Dairy farmers have increased intensity of hayfield harvest therefore it appears grassland songbirds depend upon the degree to which these operators have the ability and willingness to reduce management intensity on their hayfields. Authors believe study results have relevance to dairy farms across northern-tier dairy states (Wisconsin, Minnesota, Michigan, Ohio, Pennsylvania, New York). Authors conclude most farmers are unlikely to delay first cutting of hay because of the financial loss and reduced protein content of later cuttings. Results suggest smaller sized operators are more likely to alter management on a larger portion of their land than those with larger sized herds. Efforts to target large-lot landowners (non-farmers) are suggested as an alternative for enhancing avian reproductive habitat in the region.

Valdiva, C., and Polulos, C., 2009, Factors affecting farm operators' interest in incorporating riparian buffers and forest farming practices in northeast and southeast Missouri: Agroforestry, v. 75, p. 61-71.

Authors report the strongest positive factor in increasing Missouri farmers to adopt riparian buffers and forest farming is enhancing knowledge about the conservation practices. How farmers value the environment and future generations was reported as one of the strongest effects on interest in the practices. CRP payments had no effect on interest in enrollment. The authors conclude values and attitudes of landowners appear to be good indicators of interest in both practices. Older farmers were found to be less interested in the practices. For practices not perceived as commercial, or as a sole or important source of income, non-monetary motivations may be a driving force in interest and adoption of practices. In other words, environmental concerns have value in farmer decisions.

Vandever, M.W., and Hoag, D.L., 2006, Stakeholder opinions regarding management of Conservation Reserve Program lands to address environmental and wildlife issues: Human Dimensions of Wildlife, v. 11, p. 147-149.

Results of a survey completed by attendees at a national conference on the CRP (see Allen and Vandever in the Agricultural Conservation Policy Section of this bibliography) are presented. This preliminary analysis of the survey focuses on issues related to wildlife management and the CRP. Of 213 official participants at the conference 124 (58 percent) completed the questionnaire. Of those providing responses, 54 percent categorized themselves as employed by state or federal agencies, 20 percent were employed by agribusiness or commodity/producer groups, 16 percent represented conservation organizations, and 6 percent were affiliated with academia. Four percent categorized themselves as being in the "other" classification.

In relation to management and disturbance of CRP lands, 71 percent of respondents believed periodic disturbance of CRP lands would best be administered (for example, identification of priorities, frequency of disturbance, methods) at the state or local levels. Twenty-one percent thought these issues were more appropriately identified at the regional level, while 7 percent thought the national level was most appropriate. Over half (53 percent) of the respondents believed wildlife priorities were adequately represented by the EBI used to rank lands being evaluated for potential inclusion in the program. However, 29 percent of respondents believed the EBI did not adequately address needs of wildlife associated with the CRP.

In relation to the 2007 Farm Bill, 52 percent of respondents wished to see continued emphasis of conservation priority areas and 44 percent identified monitoring of wildlife / environmental impacts of the CRP as being a priority. Only 2 percent of respondents believed wildlife issues were not a priority in definition of future management of CRP lands. Nearly two thirds (65 percent) of respondents indicated wildlife and management issues were of great concern and many believed only slight modifications of administration of the CRP were needed to maximize benefits.

Vandever, M.W., Allen, A.W., and Sexton, N.R., 2002, Selected effects of the Conservation Reserve Program on program participants-A report to survey respondents: U.S. Geological Survey, Fort Collins Science Center, Fort Collins, Colo., Open File Report 02-476, 21 p.

The report is a brief summary of survey results to respondents of a nationwide survey of participants in USDA's CRP. Focus of survey was program participant perceptions about wildlife issues and environmental effects of the CRP. Of interest were observations concerning wildlife, attitudes about long-term management of program lands, and effectiveness of USDA assistance in relation to these issues. Surveys were delivered to 2,189 CRP participants with a response rate of 64.5 percent. This report provides only brief discussion of management and administrative implications of respondent opinions. A more thorough presentation of analysis of survey results is presented in Allen and Vandever 2003 presented above.

Wagner, M.M., 2005, Watershed-scale social assessment: Journal of Soil and Water Conservation, v. 60, no. 4, p. 177-186.

Issues and potential products (for example, clean water) are unique to each watershed based on the geographic region, issues, and planning participants. Effective watershed-scale planning integrates place-based social information and physical landscape data to determine solutions for local 
communities. To be successful watershed projects need leadership from watershed residents, a fundamental requirement for understanding difference in goals between planners and residents. Implementation of watershed planning in agriculturally dominated regions requires effective communication and collaborative decision making between planners and residents. Because residents are unlikely to participate actively in decision making if technical data are not understood it is essential they be involved in the decision process from the beginning. Planning and land management outcomes reflect value systems that can be quite different between planners and residents. This report describes experiences and makes recommendation on watershed planning based on experiences in the Cedar Lake region of Iowa.

Watershed and agricultural policies are largely based on the assumption farmers will respond to incentive-based, voluntary programs. Factors that influence farmer participation include aesthetics, economic incentives, farm structure/ size and concern for the environment. Often a combination of social, economic, and aesthetic factors influences decisions. Attributes identified that influence how quickly new ideas may be adopted include its advantage over established practices, compatibility with existing values, complexity, the degree the practice can be implemented, and the amount to which results of the innovation are observable.

White, D.D., and Hall, T.E., 2006, Public understanding of science in Pacific Northwest salmon recovery policy: Society and Natural Resources, v. 19, p. 305-320.

Public opinion increasingly influences governmental policy which has an effect on inefficiency and controversy in formulation of resource policies. This paper, although focused on salmon recovery in the Pacific Northwest, has implications for formulation of governmental policies and effectively addressing stakeholder inputs and concerns about the validity of scientific information and guidance. Factors that complicate formulation and implementation of natural resource policies include competing social values, divergent institutional priorities, and entrenched bureaucracies that limit coordinated, effective efforts to address issues. Many in the policy community, including Congress, advocate basing decisions on more and better scientific input, but there are also demands to increase citizens' input more thoroughly in policymaking. Because scientists and members of the general public have divergent ways of relating to, and discussing, issues this presents problems. While many in the public have faith in science a growing percentage of the citizenry are suspicious of the motives of scientists and untrusting of scientific expertise, often seeing science as not being "policy neutral." Also, some involved in policy formulation consciously exploit uncertainty and gaps in scientific knowledge to influence policymaking, most often as a method to stall decisions.

Authors conclude science should be demystified to ensure public values are not overridden. It should not be taken for granted more science will lead to more acceptance by the public. Scientists must be sensitive to how their input is relevant to public concerns. Authors believe citizen stakeholders often become involved in resource issues when a sense of injustice is perceived. Citizens are more astute about science and its use than often depicted and should not be treated as ignorant or unwilling to accept scientific evidence.

Wimberley, R.C., Reynolds, W.N., Vander Mey, B.J., Wells, B.L., Ejimakor, G.D., Bailey, C., Burmeister, L.L., Harris, C.K., Lee, M.A., McLean, E.L., Molnar, J.J., Ohlendorf, G.W., Tomazic, T.J., and Wheelock, G., 2004, Food from our changing world-The globalization of food and how Americans feel about it: Raleigh, N.C., North Carolina State University, accessed June, 2005, at http://faculty.chass.ncsu. edu/wimberley/Global-Food/foodglobal.pdf

Results are presented from a 2001-2002 survey by scientists from 11 universities of 819 U.S. adults to determine how globalization affects our food, communities, and quality of life. Fifty-seven percent of respondents worry about health problems stemming from American farming methods. Sixty eight percent say they would pay more for safe foods grown in America. Over 70 percent said they would pay more for food grown locally. Seventy percent of respondents trust farmers while only 11 percent trust business executives and only 20 percent trust elected officials. Eighty-two percent trust USDA, while 10 percent distrust the agency. Ninety-one percent of respondents (following 9/11) were somewhat, or very, concerned about the safety of the American food supply. Three fourths of respondents were concerned about environmental effects of farming methods in other countries and 61 percent were concerned about environmental consequences in the U.S. industry. Ninety-four percent of respondents believe farmers have responsibilities to protect resources for future generations and 56 percent believe farmers who fail to adopt needed conservation practices should be financially penalized. Seventyone percent said they would be willing to pay more for food if it were produced in ways to protect the environment while 81 percent said they would pay more for food grown on farms using beneficial environmental practices. Seventy-six percent of respondents believe government policies should focus on helping small, family owned farms. Only 25 percent believe corporate farms should get government help. Nearly 60 percent believe family farms should be supported even if it means higher prices for food.

Witter, D.J., 2006, High Plains landowner survey 2006-

Farmers, ranchers, and conservation: Mishawaka, Ind., D.J.

Case \& Associates, Playa Lakes Joint Venture, accessed

November, 2010, at http://www.pljv.org/.

A survey of 1,800 High Plains landowners in Colorado, Kansas, Nebraska, New Mexico, Oklahoma, and Texas was completed in early 2006 with a 26 percent response rate. About 50 percent of the farmers and ranchers responding 
had heard the term "playa." Approximately 50 percent of respondents did not know playas were useful for restoration of groundwater recharge of the Ogallala Aquifer. Respondents indicated a support for more conservation measures to protect the Ogallala Aquifer as well as to continue the CRP. Twenty eight percent of respondents were highly willing and 46 percent moderately willing to plant native grass buffers around playas if offered economic incentives. Of those respondents who said they had playas on their lands, 68 percent indicated the wetlands had a positive effect while 25 percent saw playas as a negative feature of the landscape. A major benefit of playas was seen as their attraction to wildlife followed by groundwater recharge, improvement in groundwater quality, and availability of water for livestock. Factors identified as having a negative influence associated with playas was reduction of land available for production, flooding, and the potential negative effects of state or federal regulation associated with use of these lands. Landowners indicated their preferred source of information about conservation options was from federal and county agricultural sources. Non-governmental groups were ranked lowly as a source of potential information.

Wright, B.A., Kaiser, R.A., and Nicholls, S., 2002, Rural landowner liability for recreational injuries-Myths, perceptions, and realities: Journal of Soil and Water Conservation, v. 57 , no. 3, p. $183-191$.

Liability for recreational injuries has been a particularly worrisome problem for landowners. Article describes analysis of state-level recreation-use statutes intended to protect landowners from legal obligations tied to injuries sustained on their land. Data from over 600 appellate court cases involving recreational injuries are analyzed. Authors conclude fears on part of landowners about liability appear to be greater than actual risk. State recreation-use statutes generally provide significant liability protection for landowners. The exceptions generally occur when landowners charge fees for access. In free access states landowners are required to make a choice between income generation and state provided liability protection. Resource professionals and landowners are generally not fully aware of the significant liability protection furnished by state recreation-use statutes.

Zepeda, L., and Kim, J., 2006, Farm parents' views on their children's labor on family farms - A focus group study of Wisconsin dairy farmers: Agriculture and Human Values, v. 23 , p. 109-121.

An examination of parents' perspectives on their children's working on family dairy farms in Wisconsin is presented. All participants in the study felt pressured as a consequence of U.S. agricultural policy to enlarge their operations in order to keep the farm financially viable. But focus group participants believed further expansion of their operation would overextend family labor and force the hiring of outside labor. This would change the operation and it would no longer be a "family farm." Participants believed if agricultural programs were decoupled from production, farmers would not have incentives to expand operation. The study points to income supports, access to health care, or other options as alternatives to production supports. These actions were beveled to lessen the need for parents, particularly mothers, to find off-farm employment, which provides more time for supervision of children and reduce the need for children to devote so much labor to the farm operation. The investigation also suggests agricultural policies should target farm practices, safety training and alternatives to mechanization in improving family and social conditions on family farms.

\section{Upland Game Birds}

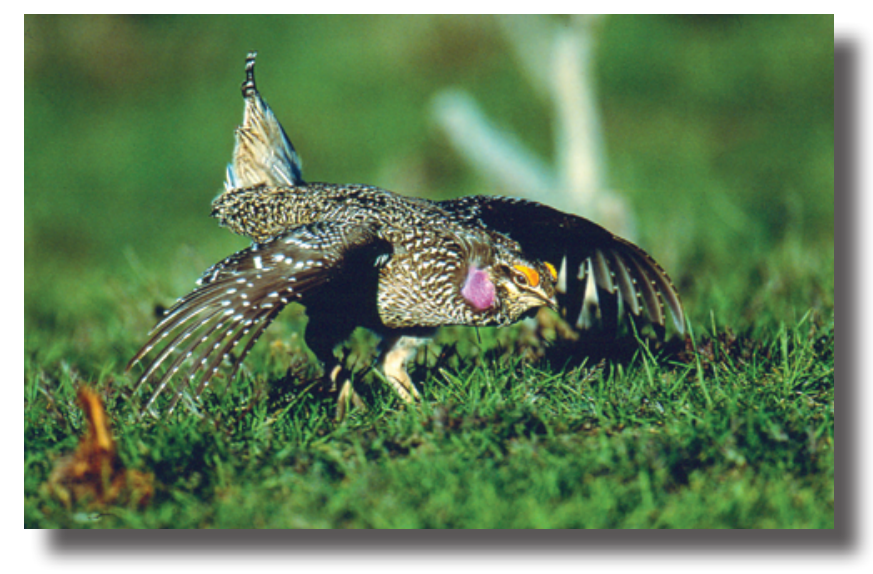

\section{Northern Bobwhite Quail}

Barnes, T.G., Madison, L.A., Sole, J.D., and Lacki, M.J., 1995, An assessment of habitat quality for northern bobwhite in tall fescue-dominated fields: Wildlife Society Bulletin, v. 23, no. 2, p. 231-237.

This report presents an evaluation of tall fescue (Festuca arundinacea) fields as potential habitat for northern bobwhite quail (Colinus virginianus) in Kentucky. Fescue fields were characterized by dense vegetation, little bare ground, and low diversity of plant species. Tall fescue was characterized as marginal habitat for bobwhite quail due to unsuitable vegetation structure, poor floristic composition, and insufficient availability of food. Tall fescue is grown extensively for stock feed, turf, and soil-conservation purposes. Fescue is an excellent pasture grass and the dominant grass seeded in most southeastern CRP fields. Aggressive domination of fields planted to tall fescue may reduce plant species diversity resulting in lower quality of habitat for quail. Infection of endophytic fungus (Acremonium coenophialum), which can result in fescue toxicosis, reproductive disorders in mammals, and reduced fertility and hatching success in quail has been documented. 
Brennan, L.A., 1991, How can we reverse the northern bobwhite population decline?: Wildlife Society Bulletin, v. 19, no. 4, p. 544-555.

Northern bobwhite quail (Colinus virginianus) populations have declined at an alarming rate over the past 3 decades. Every population index for the species indicates significant downward trends in greater than 75 percent of the states within geographic range of species. The most precipitous declines have occurred in the southeastern region of the United States. Clean farming practices and forest management systems focused on maximizing basal area and yield of wood products are the most obvious causes. More intensive management of farmland, including an increasing size of farms and fields, has eliminated weedy fencerows and overall diversity in vegetative composition of agricultural landscapes. Many marginal farmlands in the southeast have been converted to pine plantations eliminating needed cropland and overall habitat diversity. Pesticides have been implicated as a possible mortality factor affecting bobwhite populations, however, indirect effects of pesticides on quail are poorly understood. Agricultural chemicals indirectly affect populations by suppressing arthropod populations, a fundamental and essential food resource for broods. Weeds provide food and feeding substrates essential for growth and development of chicks.

The potential for CRP to enhance habitat for quail is far from being realized. Required mowing for weed control during peak nesting season is a major problem. Conversion of cropland to pine plantations also has had significant impacts to habitat quality and availability. Periodic disturbance of CRP is essential to maintain annual species of vegetation and vegetative diversity. Strip disking is recommended as a viable management option to set back vegetation succession in CRP grasslands and early stages of pine plantations.

Brennan, L.A., 1993, Future directions for bobwhite quail and wildlife research in the southeastern United States, in 1993 Tall Timbers Game Bird Seminar, Tallahassee, Fla.,1993, Proceedings: Tallahassee, Fla., Tall Timbers Research Station, $60 \mathrm{p}$.

An increase in arthropod abundance was recorded in response to burning and strip disking. Herbicide applications affect quail populations through disruption of the food chain by elimination of vegetation strata thereby limiting populations of needed insects. Widespread application of herbicides suppresses weed populations so well that sufficient insect populations are not available for hens and chicks. Suggested modification of herbicide application includes adoption of Conservation Headlands which have been documented to have substantially increased production of gray partridge (Perdix perdix) in Great Britain. Application of headland concept and elimination of pesticide applications in field borders has potential for befitting quail and other wildlife associated with agricultural landscapes.
Brennan, L.A., 1993, Strategic plan for quail management and research in the United States - Introduction and background, in Quail III-National Quail Symposium, Kansas City, MO, July 1992, Proceedings: Pratt, Kans., Kansas Department of Wildlife and Parks, p. 160-169.

Habitat management by the private sector is apparently having little broad-scale impact on northern bobwhite quail (Colinus virginianus) populations. Leadership from professionals with creative vision for solving problems caused by changing land use patterns is needed. Evidence of growing interest in quail by the public as well as concerned landowners supports a greater management emphasis toward quail. Detrimental effects of existing federal agricultural policies include: annual spring burning, summer mowing, continued emphasis on planting cool-season grasses (for example, tall fescue [Festuca arundinacea], smooth bromegrass [Bromus inermis]), extensive stands of monoculture pine, and lack of flexibility in management are severely limiting value of CRP as a means to improve habitat conditions for quail. The paper provides detailed recommendation for modification of Federal agricultural policies to improve habitat quality for quail.

Burger Jr., L.W., Kurzejeski, E., Daily, T.V., and Ryan, M.R., 1990, Structural characteristics of vegetation in Conservation Reserve Program fields in northern Missouri and their suitability as bobwhite habitat, in Transactions of the North American Wildlife and Natural Resources Conference, 55, Denver, Colo., March 16-21, 1990, Proceedings: Washington, D.C., Wildlife Management Institute, p. 74-83.

Vegetation established under the CRP may provide both nesting and winter roosting habitat for northern bobwhite quail (Colinus virginianus) in northern Missouri. However, clipping, haying, or disking disturbed 50 percent of all fields sampled as part of this investigation. Thirty four percent of fields provided potential roosting habitat. Fields where establishment of permanent native grass (CP2) and permanent wildlife habitat (CP4) were planted were most likely to provide early season nesting habitat needed by quail. Disturbance, primarily for weed control was the primary factor limiting the potential value of CRP fields as winter roosting and nesting cover.

Burger Jr., L.W., McKenzie, D., Thackston, R., and Demaso, S.J., 2006, The role of farm policy in achieving large-scale conservation-Bobwhite and buffers: Wildlife Society Bulletin, v. 34, no. 4, p. 986-993.

Payments to farm operators under USDA conservation programs far outweigh the collective investment of the North American Wetlands Conservation Act, Endangered Species Act, Pittman Robertson Act, and Conservation Investment Act with resultant potential to alter land use and bring improvements to wildlife habitat quality on large spatial scales. Past effectiveness of programs has varied by program, practice, 
region and wildlife species affected with effects ranging from positive to negative. These programs can be more effective if explicit goals are identified as part of large-scale conservation initiative such as the North American Waterfowl Plan and the Northern Bobwhite Conservation Initiative. While USDA conservation programs have been designed to achieve broad conservation objectives, available policy options often have not been designed to address specific wildlife goals identified in comprehensive, multi-agency regional and national initiatives. In the 1996 Farm Bill, wildlife was elevated to co-equal status with soil erosion and water quality but still wildlife issues do not carry equivalent weight of other objectives in relation to conservation compliance. An overview of how the Conservation Reserve Program, specifically Conservation Practice 33 (Habitat Buffers for Upland Birds) is being used to address specific goals and objectives to enhance habitat for these species is presented.

The authors describe the Northern Bobwhite Conservation Initiative as a case study for refinement of USDA conservation programs to achieve specific wildlife goals. The goal is to restore range-wide populations to an average density equivalent to that which existed in 1980 which would require management on 32.8 million hectares (81 million ac) of farm, forest, and rangeland. Recommended management practices would change primary use on only $6-7$ percent of land. The underlying assumption upon which this initiative is based is that insufficient native herbaceous grasses and forbs (primary covers for nesting and brood habitat) limit bobwhite populations across their range. Conservation buffers and field borders in uplands were identified as primary practices that could achieve this goal in agricultural ecosystems. Conservation Practice 33 was the first continuous CRP practice specifically designed to meet habitat and population goals under a national species recovery plan. It was also the first CRP practice to specifically require monitoring to determine population response. Habitat buffers are typically $30-120 \mathrm{ft}$ wide and planted to native warm-season grasses, legumes, and shrubs or are allowed to regenerate through natural succession. Contracts are $10 \mathrm{yr}$ in length and require periodic disturbance through disking, prescribed fire or application of selective herbicides. In the first year 29,588 hectares $(73,113 \mathrm{ac})$ were enrolled in 35 states. CP33 will likely succeed because it addresses producer economic needs, provides multiple wildlife and environmental benefits and is based on goals identified in large-scale conservation initiatives.

Burke, J.D., Chamberlain, M.J., and Geaghan, J.P., 2008, Effects of understory vegetation management on brood habitat for northern bobwhites: Journal of Wildlife Management, v. 72 , no. 6 , p. $1361-1368$.

Conversion of potential habitat to pine forest and exclusion on fire from pine dominated landscapes are attributed to be part of the reason for long-term declines in northern bobwhite quail (Colinus virginianus) populations across the southeast. Understory vegetation response to management is evaluated in relation to arthropod abundance in commercially managed pine forest in Louisiana. Study forests were 25- to 40-yr-old, even-aged, short-rotation loblolly pine (Pinus taeda) stands. Primary overstory trees were loblolly pine and shortleaf pine (P. echinata), red maple (Acer rubrum), water oak (Quercus nigra), southern red oak (Quercus flacata), and sweetgum (Liquidambar styraciflua). Understory vegetation consisted of blackberry (Rubus spp.), greenbrier (Smilax spp.), poison ivy (Toxicodendron radicans), sumacs (Rhus spp.), lespedezas (Lespedeza spp.), and beggarweeds (Desmodium spp.). Management practices evaluated included mowing, prescribe fire only, imazapyr application in conjunction with fire, and control (no treatment).

Percentage of forbs was 2 times greater in burn-herbicide plots relative to all other practices. Mowed plots contained the greater percentages of grass, whereas burn and burn-herbicide plots contained 10 times the amount of bare ground. Arthropod abundance and diversity were greatest in plant communities managed using prescribed fire and imazapyr. Orthoptera abundance was greatest in burn-herbicide plots. Quail chicks had the greatest foraging success in the burn-herbicide treated areas. Management prescriptions intended to enhance habitat quality for the federally endangered red-cockaded woodpecker (Picoides borealis) were found to benefit brood habitat quality for quail. To encourage more favorable vegetative conditions for quail brood habitat application of imazapyr in combination with a 2-yr burn rotation is recommend. The authors suggest more intensive management of understory vegetation may be necessary to achieve high-quality habitat in loblolly pine habitats.

Cline, G.A., 1988, Habitat relationships of bobwhite quail and cottontail rabbits on agricultural lands in Halifax county, Virginia: Blacksburg, Va., Virginia Polytechnic Institute and State University, M.S. thesis, 99 p.

An evaluation of a HSI model for assessment of northern bobwhite quail (Colinus virginianus) habitat is described. Wooded fallow fields, length of pasture/fallow, forest/forest edge, and total number of all edges were positively related to quail presence. Management recommendations are to maximize the number of different edges and number of fallow fields in early successional stages. Cultivation of field borders, corners, waterways and other idle areas should be discouraged. A large number of small fields, each with a fallow or brushy border, are better than equivalent acreage in only a few fields. Authors concluded that the model can correctly predict which habitats are preferred by bobwhite quail.

Cox, S.A., Guthery, F.S., Lusk, J.J., Peoples, A.D., DeMaso, S.J., and Sams, M., 2005, Reproduction by northern bobwhites in western Oklahoma: Journal of Wildlife Management, v. 69, no. 1, p. 133-139. 
A 10-yr evaluation of northern bobwhite (Colinus virginianus) reproduction suggests lower clutch size later in nesting season. Availability of early-season nesting cover is limiting and a management concern. Authors conclude high success of nests is possible in absence of predator suppression where significant high quality habitat supports abundant nests established across the landscape. Authors believe early nesting by the species and availability of an abundance of cover early in spring can support greater reproductive success. Consequently, management should focus on availability high quality cover in the early nesting season.

Doxon, E.D., and Carroll, J.P., 2008, Feeding ecology of ringnecked pheasant and northern bobwhite chicks in Conservation Reserve Program fields: Journal of Wildlife Management, v. 74, no. 2, p. 249-256.

In spite of programs like the CRP, northern bobwhite (Colinus virginianus) and ring-necked pheasant (Phasianus colchicus) continue to decline in some regions. These declines have been attributed to fewer insects in agricultural ecosystems, continued loss in amount and quality of habitat, and declining survival of chicks in agricultural and CRP fields. Four conservation practices were evaluated in relation to invertebrate availability: CP10 warm-season grass mix, improved CP10 which had less than 10 percent of the field interseeded with alfalfa (Medicago sativa), CP2 warm season grasses with a forb mix included, and CP25 warm season grasses with Maximilian sunflower (Helianthus maximiliani) purple prairie clover (Dalea purpurea), prairie coneflower (Ratibida columnifera) and Illinois bundleflower (Desmanthus illinoensis) added to the planting mix. Winter wheat was also sampled as part of the investigation.

Many fields, especially CP10 averaged less than 5 percent bare ground cover. Study fields with the highest percentage of bare ground (CP25 and CP2) produced some of the highest foraging and mobility rates for pheasant and quail chicks. The more open ground enabled chicks to move more easily and experience higher foraging rates. The amount of bare ground was found to have a significant impact on insect selection and accessibility by the chicks. The authors conclude brood habitat quality in CRP fields could be greatly improved by practices that increase bare ground cover, such as light disking or burning. Data suggest, at least for this region of Kansas, disturbance every 4 to 5 years as grass growth in 5 to 7 year old fields had become too dense to furnish suitable conditions for foraging by quail and pheasant chicks.

Greenfield, K.C., Burger Jr., L.W., Chamberlain, M.J., and Kurzejeski, E.W., 2002, Vegetation management practices on Conservation Reserve Program fields to improve northern bobwhite habitat quality: Wildlife Society Bulletin, v. 30 , no. 2 , p. $527-538$.

Habitat quality for early successional and grassland species of wildlife may decline as CRP grasslands mature if they are not subjected to disturbance. Effects of strip disking on vegetation structure, composition, and soil erosion were evaluated in Missouri stands of tall fescue (Festuca arundinacea) and orchardgrass (Dactylis glomerata). Fall discing generally increased percentage of bare ground and plant diversity and decreased litter cover and depth. Habitat quality gains in fescue fields were short lived but of longer duration in orchardgrass fields. Vegetative response to disking diminished by the second growing season following treatment, especially in fescue. Soil losses within treated areas were estimated to be well within USDA tolerable limits. Authors recommend disking intensity on CRP fields could be increased and be implemented on a 2- to 3-yr rotation to maintain early succession plant communities in Midwestern and Southeastern CRP fields.

Greenfield, K.C., Chamberlain, M.J., Burger Jr., L.W., and Kurzejeski, E.W., 2003, Effects of burning and discing Conservation Reserve Program fields to improve habitat quality for Northern bobwhite (Colinus virginianus): American Midland Naturalist, v. 149, no. 2, p. 344-353.

Evaluation of burning and light disking of strips in Mississippi CRP fields planted to fescue (Festuca arundinacea). This report is a companion study to Missouri results described above in Greenfield and others, 2002. Fall disking generally increased percentage bare ground and plant diversity with corresponding declines in plant litter cover and depth. Effects of fall light disking diminished by the second growing season. Burning increased plant diversity and improved habitat quality for northern bobwhite quail (Colinus virginianus). Erosion impacts of light discing were within tolerable soil erosion limits therefore more intensive disking was recommended to extend benefits of management action.

Madison, L.A., Barnes, T.G., and Sole, J.D., 2001, Effectiveness of fire, disking, and herbicide to renovate tall fescue fields to northern bobwhite habitat: Wildlife Society Bulletin, v. 29, no. 2, p. 706-712.

Fields dominated by tall fescue (Festuca arundinacea) furnish poor habitat for northern bobwhite quail (Colinus virginianus) due to unsuitable vegetation structure, a lack of diversity in vegetation composition, and absence of suitable food. Tall fescue forms a dense sod and furnishes little bare ground, which may prevent bobwhite from efficient movement and foraging. The paper reports results of an examination of the effectiveness of controlled burning, disking, and Round-up to improve habitat quality for quail. Spring application of herbicide was most effective method in reduction of fescue coverage. Fescue cover was reduced for one year following disturbance by fall, spring and summer disking but became similar to undisturbed control plots and pre-treatment conditions by the second year post-treatment. Fall, spring, and summer burning did not prove to be effective in reduction of fescue. 
Riffell, S.K, and Burger, L.W., 2006, Estimating wildlife response to the Conservation Reserve Program-Bobwhite and grassland birds: Washington D.C., USDA Farm Service Agency, Department of Agriculture, Farm Service Agency, Acquisition Management Branch, Special Projects Section, Report FSA-R-28-04DC, 49 p.

A retrospective analysis of relationships among land use and cover type, CRP habitats, and indices of grassland bird populations is described. USDA NRI data and Common Land Unit (CLU) data were used on differing spatial scales to describe relations between land use, conservation practice, and estimates of avian populations. Conclusions drawn from use of NRI data indicate that CRP habitat was overwhelmingly associated with a higher abundance of obligate and facultative grasslands birds. Significant relations between CRP and grassland birds were more prevalent in ecological regions where the majority of the landscape was covered by forest and little cropland was present. Bobwhite quail (Colinus virginianus) were associated with both tree and grass based conservation practices. Common Land Unit data (from Kansas, Nebraska, and Missouri) indicated bobwhite were positively related to the density (\# patches $/ \mathrm{km}^{2}$ ) of grass dominated CRP less than $4 \mathrm{yr}$ old. Bobwhite were believed to benefit from increasing density of grass-dominated CRP and application of midcontract management to furnish earlier successional characteristics of vegetation composition and structure in older CRP fields. The authors conclude knowledge of conservation practice type, configuration, and age are key factors in determination of potential habitat quality. Simple, generic classifications of lands enrolled in the CRP are of limited utility in determination of program influences on quail habitat distribution and quality. Authors conclude their analysis consistently pointed to widespread positive effects of the CRP on grassland birds.

Riffell, S., Scognamillo, D., and Burger, L.W., 2008, Effects of the Conservation Reserve Program on northern bobwhite and grassland birds: Environmental Monitoring Assessment, v. 146 , p. 309-323.

Breeding Bird Survey and NRI data are used to evaluate potential benefits of the CRP to grassland birds and northern bobwhite quail (Colinus virginianus). Regression models were developed for 15 avian species in seven ecological regions. Ecological regions were based on classification defined by the North American Bird Conservation Initiative. Obligate grassland birds included in the study were; horned lark (Eremophila alpestris), grasshopper sparrow (Ammodramus savannarum), dickcissel (Spiza americana), eastern meadowlark (Sturnella magna), and western meadowlark ( $S$. neglecta). Seven facultative grassland bird also were included in the evaluation; mourning dove (Zenaida macroura), eastern kingbird (Tyrannus tyrannus), loggerhead shrike (Lanius ludovicianus), common yellowthroat (Geothlypis trichas), lark sparrow (Chondestes grammacus), red-winged blackbird
(Agelaius phoeniceus), and eastern bluebird (Sialia sialis). The brown-headed cowbird (Molothrus ater), a nest parasite, and the indigo bunting (Passerina cyanea), a forest edge species, were also included in the analysis.

Mean abundance of birds was calculated over a 5-yr window (1995-1999) for routes sampled in three or more of the five years. The time period corresponds to the dates of best estimates of CRP coverage. Because 1997 was the year most CRP contracts (10-15 yr) would not yet have expired 1997 was assumed to furnish the best cumulative estimates of CRP distribution. Land use data was assessed in a $1,962 \mathrm{~km}^{2}$ $\left(758 \mathrm{mi}^{2}\right)$ area around each BBS used. CRP habitat comprised an average of 1.6 percent of the landscapes surrounding BBS routes. CRP grass habitats averaged 1.3 percent and CRP tree dominated covers accounted for an average coverage of 1.3 percent.

Analysis of data showed varying responses across ecological regions. Only the eastern meadowlark was positively related to CRP in all regions. CRP was a strong predictor of bird abundance. The CRP, especially grass-legume, was related to higher abundance of northern bobwhite across their breeding range. Populations of common yellowthroat, eastern meadowlark and indigo bunting were associated with higher amounts of CRP. Analysis of relationships to CRP for other avian species are presented and discussed.

The authors conclude that NRI data presently furnish relatively coarse resolution information on CRP. More thorough investigations of relations between CRP and habitat quality for birds, as well as other species, could be possible if additional NRI data themes were available. These include, but are not limited to, spatial arrangement of fields, age of field, specific conservation practices used. An ability to assess landscape configuration with variables such as edge density, patch size and juxtaposition of cover types would greatly strengthen predictive capabilities of the data set. Availability of information on stand age, species composition, and successional stage would also be of benefit.

Roseberry, J.L., and David, L.M., 1994, The Conservation Reserve Program and Northern bobwhite population trends in Illinois, in Transactions of the Illinois State Academy of Science 87 (1 \& 2): Edwardsville, Ill., Illinois State Academy of Science, p. 61-70.

Authors conclude contributions of the CRP to improvements in Illinois quail habitat have been less than expected. Lands enrolled in CRP have positively contributed to local habitat quality but in some situations the CRP has had neutral or negative effects. Overall, CRP land composes only a small proportion of total habitat base in the state. CRP contributions to the quality of quail habitat could be improved if there is less mid-summer mowing, weedier early successional vegetation was furnished as a consequence of strip disking and burning, and less emphasis was placed on planting of cool-season grasses (for example, smooth bromegrass [Bromus inermis]). 
Stauffer, D.F., Cline, G.A., and Tonkovich, M.J., 1990, Evaluating potential effects of CRP on bobwhite quail in Piedmont Virginia, in Transactions of the North American Wildlife and Natural Resources Conference, 55, Denver, Colo., March 16-21, 1990, Proceedings: Washington, D.C., Wildlife Management Institute, p. 75-76.

Although authors believed that conversion of cropland to permanent herbaceous cover is likely to have a positive effect on the quality of quail habitat, the beneficial effects are liable to exist only while a suitable grass-forb mixture is maintained. If grasses such as tall fescue (Festuca arundinacea) dominate planting, dense sods will form and habitat benefits will be reduced. As croplands are converted to pine plantations, the quality of habitat for quail will decline as the stands mature. For the first 5-7 yr after conversion, plantations typically furnish suitable herbaceous cover. As pines mature and the canopy begins to close, the quality of bobwhite quail habitat will diminish due to declining understory vegetative cover needed for nesting, brood rearing, and food.

When conversion of cropland to CRP increases overall diversity in vegetation covers adding habitat components previously lacking (for example, brood cover), an increase in quail populations can be expected. However, when overall diversity is reduced, quail populations are likely to decline. The large amount of CRP being placed in pine plantations is likely to cause substantial local declines in quail populations. The addition of woody cover in pine plantations will lower overall habitat diversity in areas where woodlands already are a large component of the landscape. Consideration needs to be given to juxtaposition and interspersion of CRP with other cover types and land uses. A large amount of cropland converted to CRP may not be beneficial to quail if large fields are converted to grass cover. Converting many smaller fields rather than fewer large fields will create more diversity resulting in better quail habitat.

Weber, W.L., Roseberry, J.L., and Woolf, A., 2002, Influence of the Conservation Reserve Program on landscape structure and potential upland wildlife habitat: Wildlife Society Bulletin, v. 30, no. 2, p. 888-898.

An evaluation and quantification of CRP effects on Illinois agricultural landscape composition within northern bobwhite quail (Colinus virginianus) range (southwestern and southern Illinois). Considering all land-cover types, CRP landscapes had smaller patches than non-CRP landscapes. CRP landscapes were characterized by higher patch density of grassland and by woodland which compared to landscapes without CRP. Edge density of row crop, grassland, and woodland cover types was greater within CRP landscapes in contrast to non-CRP landscapes. Farmland enrolled in CRP tended to be located in areas with proportionately less row crop and more grassland and woodland than non-CRP landscapes. Landscapes surrounding CRP fields were more diverse than
non-CRP landscapes. Enrollment criteria required CRP to be located in areas less productive than cropland and more likely to have smaller patch size and greater diversity than general landscape. Multiple fields enrolled by landholders also might account for some of aggregation. Results support conclusion the CRP is being established in landscape that already contained grassland and woodland cover types.

Williams, C.F., and Mjelde, J.W., 1994, Conducting a financial analysis of quail hunting within the Conservation Reserve Program: Wildlife Society Bulletin, v. 22, p. 233-241.

The upsurge in outdoor recreation by the American public has strained the public land system. Public hunting lands remain in short supply and are receiving increasing amounts of demand for use. The greatest opportunities to supply quality hunting lies in the development of recreational opportunities associated with private land.

Williams, C.K., Lutz, R.S., Applegate, R.D., and Rusch, D.H., 2000, Habitat use and survival of northern bobwhite (Colinus virginianus) in cropland and rangeland ecosystems during the hunting season: Canadian Journal of Zoology, v. 78 , p. $1562-1566$.

Authors suggest landowners on rangeland could reduce natural mortality of bobwhite quail populations by taking advantage of state and federal programs and non-government organizations to increase woody cover suitable for quail. Woody, brushy cover is the primary escape cover for quail. The lack of such cover may cause higher levels of natural mortality primarily by affecting fall-winter survival. To decrease predation in rangeland ecosystems, authors encourage creation of more woody escape cover by protecting existing cover from development, allowing natural succession to establish cover, and use of USDA conservation programs to plant new cover where it does not presently exist.

Williams, C.K., Guthery, F.S., Applegate, R.D., and Peterson, M.J., 2004, The northern bobwhite decline-Scaling our management for the twenty-first century: Wildlife Society Bulletin, v. 32, no. 3, p. 861-869.

Although the northern bobwhite (Colinus virginianus) is one of the most broadly researched and intensively managed species in North America, current and traditional management principles are incompatible with spatial scales needed to adequately address the nationwide, long-term decline (greater than 3 percent/yr from 1966-2001 in 25 of 34 states) of the species. Management of habitat must become focused on regional assessment and management (joint ventures between agencies, landowners) of habitat needs rather than fine-scale approach (edge, disked strips, food plots). Within regional areas, harvest management must become more focused and adapted to local trends in bird numbers. Bobwhite 
numbers have varied with some western and northern populations increasing or stable but southeastern numbers have been in decline.

Changes in the agricultural industry continue to decimate broad-scale suitability of wildlife habitats, but approaches to addressing the issue remain focused on fine-scale, site-specific approaches to meeting wildlife needs. Because of the general failure of fine-scale habitat management, it has become apparent that the quantity and quality of habitat must be addressed on larger spatial scales (for example, multi-farm communities of landowners, physiographic regions). Regions with large amounts of suitable, useable space should be protected from future development while areas with potential for rehabilitation should be the primary focus of management activities. While management of habitat is believed to be the most critical component for recovery of bobwhite populations, harvest policies affect population dynamics and may need regional or local refinements. Fine-scale properties of habitat have potential to affect local population processes ultimately affecting year-to-year survival with implications for refinement of harvest guidelines through "risk-sensitive harvest strategies." These strategies should be flexible allowing spatially variable levels of harvest, including no harvest, depending on local quality and distribution of habitat. This concept will require a shift away from maximizing recreational opportunities to maximizing biological potential.

\section{Prairie Grouse, Sage Grouse}

Boisvert, J.H., 2002, Ecology of Columbian sharp-tailed grouse associated with Conservation Reserve Program and reclaimed surface mine lands in northwestern Colorado: Moscow, Idaho, University of Idaho, M.S. thesis, 184 p.

Author concludes that CRP lands furnish variable benefits to Columbian sharp-tailed grouse (Tympanuchus phasianellus) in Colorado. CRP grasslands provide habitat characteristics preferred for lek establishment but do not furnish suitable nesting or brood rearing habitat. The absence of suitable nesting and brood habitat contributes to low survival and productivity. Nor did the CRP provide suitable winter habitat. To provide appropriate habitat, CRP fields must provide adequate shrub cover and residual vegetation during spring. Plant species diversity must be increased, (author recommends approximately 7 species within a $1-\mathrm{m}$ radius), greater than 30 percent grass cover, greater than $50 \mathrm{~cm}$ (20 in) vertical cover, and 20 percent forb cover during nesting and brood rearing seasons. Ideally, CRP fields should be near shrub-dominated native habitats. The CRP fields included in study were originally planted to non-native mixture (CP-1) primarily of smooth bromegrass (Bromus inermis), timothy (Phleum pratense), pubescent wheatgrass (Agropyron trichophorum), and alfalfa (Medicago sativa).
Boisvert, J.H., Hoffman, R.W., and Reese, K.P., 2005, Home range and seasonal movements of Columbian sharp-tailed grouse associated with Conservation Reserve Program and mine reclamation: Western North American Naturalist, v. 65 , no. 1 , p. $36-44$.

Columbian sharp-tailed grouse (Tympanuchus phasianellus columbianus) use of CRP and reclaimed mine lands in northwest Colorado is reported. (Vegetative composition of CRP and reclaimed lands were not provided.) Sharp-tailed grouse have been documented using CRP and mine-reclamation lands for breeding, nesting, and brood-rearing. Findings suggest a $2.0 \mathrm{~km}(1.25 \mathrm{mi})$ radius around leks is suitable for assessment of breeding habitat for grouse in reclaimed mine lands and CRP. Home ranges of grouse associated with CRP (112 hectares [277 ac]) were larger than those of grouse in reclaimed mine lands.

Davis, C.A., Riley, T.Z., Smith, R.A., Suminski, H.R., and Wisdom, M.D., 1979, Habitat evaluation of lesser prairie chickens in eastern Chaves County, New Mexico-Final report: Las Cruces, N. Mex., Department of Fish and Wildlife Science, $141 \mathrm{p}$.

Authors recommended 160-acre minimum area of block habitat to insure sufficient area for winter cover and nesting habitat for lesser prairie chickens (Tympanuchus pallidicinctus).

Fields, T.L., White, G.C., Gilgert, W.C., and Rodgers, R.D., 2006, Nest and brood survival of lesser prairie-chickens in west central Kansas: Journal of Wildlife Management, v. 70, no. 4, p. 931-938.

Authors report habitat use and other sources of variation of survival affecting lesser prairie chicken (Tympanuchus pallidicinctus) and greater prairie chicken (T. cupido) nests and broods. Age of the nest and brood, timing during the season, age of the brooding female, and precipitation during brooding were predictors of survival. Nest survival and survival of chicks were identified as the most critical parameters associated with population size of prairie grouse. In Kansas, grass height and sagebrush density/height were described as the most important vegetation characteristics influencing nest success. Evidence suggests that lesser prairie chicken populations have remained stable or increased in western Kansas, which is probably related to the presence of large acreage enrolled in CRP. Authors recommend provision of heterogeneous habitat providing year round diverse opportunities for food and cover to counterbalance mechanisms reducing survival of nests and broods. Of 59 nests monitored, 69 percent were located in CRP fields either dominated by grasses or enhanced with additional seeding of forbs. Twenty-seven percent of nests were located in native rangeland, while 3 percent were found in cropland. CRP fields in the study area were planted to little 
bluestem (Schizachyrium scoparium), sideoats grama (Bouteloua curtipendula), big bluestem (Andropogon gerardii), switchgrass (Panicum virgatum), western wheatgrass (Pascopyrum smithii), blue grama (Bouteloua gracilis), buffalograss (Buchloë dactyloides), and Indiangrass (Sorghastrum nutans). Subsequent to 1997, selected CRP fields were interseeded with white sweetclover (Melilotus alba), yellow sweetclover (M. officinalis), as well as several varieties of wildflowers. The number of prairie chickens nesting in CRP indicates that preservation of CRP will benefit persistence of the species in the region. Authors conclude the brooding period may be the most critical parameter defining population health.

Giesen, K.M., 2000, Population status and management of lesser prairie-chicken in Colorado: Prairie Naturalist, v. 32, no. 3, p. 137-148.

There have been modest increases in population of prairie chickens (Tympanuchus pallidicinctus) in Colorado since the 1960s. Continued restoration and management of degraded habitats and transplants of birds into suitable habitats could result in substantial increases in distribution and populations. The effects of CRP on prairie chicken populations in Colorado are unknown. Prairie chicken populations have not increased in Baca County since initiation of CRP despite fact that onethird of former cropland in the county is enrolled in program. There are no documented leks in CRP fields in Colorado, but evidence suggest that some use of CRP has occurred for roosting.

Jarnevich, C.S., and Laubhan, M.K., 2011, Balancing energy development and conservation-A method utilizing species distribution models: Environmental Management, v. 47, p. $926-936$.

Authors modeled LPC (Tympanuchus pallidicinctus) habitat suitability using Maximum Entropy (Maxent) as a tool to assist energy development in Kansas. The LPC has experienced loss of habitat and population decreases and is considered an indicator of grassland conditions. Kansas is ranked third in potential wind energy and companies have established 6 wind facilities and proposed 44 more facilities. Avoidance from further negative impacts to wildlife (habitat loss and fragmentation) in areas developed for energy production are needed but agencies often do not have the resources to delineate distribution of wildlife or suitable habitat at necessary scales.

Authors identified two land use and land cover classes (grasslands, CRP), areas of topographic relief, and anthropogenic variables (highways, transmission lines, etc.) as inputs. Grasslands represented pasture, rangeland, and lands with greater than 50 percent cover of trees or grasslands. Normalized difference vegetation index (NDVI) was used to provide estimates of vegetation productivity (low values indicative of fallow cropland, high values indicative of lush vegetation).
Lek locations of both LPC and GPC (T. cupido) were collected by Kansas Wildlife and Parks and incorporated into the model.

Lek habitat suitability was positively correlated with increasing land use and land-cover classes. Average NDVI was the best indicator of habitat suitability across all models. Low NDVI values correlated with greater lek habitat suitability. Elevation was the third most important variable in all models except for mixed lek (LPC and GPC) models. Mixed leks models that included anthropogenic features showed distance from roads more important than standard deviation in elevation. Anthropogenic variables increased uncertainty in the models but generally had low relative contributions to habitat suitability.

Maxent models do not determine causal relationships, and, while evidence of relationship between habitat suitability and anthropogenic variables exist and aid in siting energy development, the authors caution that additional testing is needed to confirm causal relationships.

Jensen, W.E., Robinson Jr., D.A., and Applegate, R.D., 2000, Distribution and population trend of lesser prairie chicken in Kansas: Prairie Naturalist, v. 32, no. 3, p. 169-175.

There appears to be an overall decline in lesser prairie chickens (Tympanuchus phasianellus) in Kansas. However, local variation in lek and individual count indices may be attributable to large blocks of grassland established under CRP. The lesser prairie chicken appears to occupy a large portion of its former range in the state but to be declining throughout its breeding range. The overall decline in prairie chicken populations in recent decades likely is due to loss, fragmentation, and deterioration of habitat. Fragments of grassland with and without extensive sand sagebrush (Artemisia filifolia) patches exist as potential breeding habitat in southwestern Kansas and should be maintained as a safeguard against a further decline of the species.

Lupis, S.G., Messimer, T.A., and Black, T., 2006, Gunnison sage-grouse use of Conservation Reserve Program fields in Utah and response to emergency grazing - A preliminary evaluation: Wildlife Society Bulletin, v. 34, no. 4, p. 957-952.

Use of CRP grasslands by Gunnison sage grouse (Centrocercus minimus) is reported. The study area was a mosaic of CRP grassland and sagebrush (Artemisia tridentata and A. nova). CRP fields comprised 60 percent of the study area. Fields grazed under emergency release, due to drought, supported crested wheatgrass (Agropyron cristatum), pubescent wheatgrass (Thinopyrum intermedium), alfalfa (Medicago spp.), and sagebrush. Most sage grouse locations were reported in CRP covers but the authors find no statistical evidence for preference of CRP cover. However, the authors believe CRP provides critically important habitat for sage grouse. CRP provided roosting cover and foraging habitat. CRP may furnish a greater number and diversity of critical 
arthropods because of higher grass and forb cover compared to adjacent rangelands. Avoidance of fields by grouse during emergency grazing was believed to be more in response to the presence of cattle than in response to impacts to vegetation. The grazing was of short duration and high intensity. Grouse frequently returned to previously grazed fields. Long-term enrollment of CRP is critical for establishment of sagebrush to take place within enrolled fields. If CRP acreage is regionally reduced or replaced by agriculture, an immediate loss of habitat will occur. If grazing is allowed on CRP lands, or former lands, it should be conducted in a deferred-rotation with nonuse areas available to grouse in the spring and summer.

Robel, R.J., Harrington, Jr., J.A., Hagen, C.A., Pitman, J.C., and Reker, R.R., 2005, Effect of energy development and human activity on the use of sand sagebrush habitat by lesser prairie chickens in southwestern Kansas, in Transactions North American Wildlife and Natural Resources Conference, 69, Spokane, Wash., March 16-20, 2004, Proceedings: Washington, D.C., Wildlife Management Institute, p. 251-266.

Lesser prairie chickens (Tympanuchus pallidicinctus) occupy xeric grasslands across much of the southern Great Plains dominated by sand sagebrush (Artemisia filifolia) or shinnery oak (Quercus havardii). In southwestern Kansas, populations have generally declined due to deterioration of sandsage habitat largely due to conversion to center-pivot irrigation for production of corn. While most of this development occurred in mid 1980s, populations continue to decline. Low nest success and survival of chicks appear to be factors contributing to decline. Authors conclude the presence of anthropogenic features (for example, buildings, roads, wellheads, electric transmission lines) have reduced suitability of habitat beyond direct loss of habitat area. Vegetative characteristics between used and non-used areas were identical. Avoidance of habitat is believed to be associated with movement and noise from infrastructure related to energy development and agriculture. Adult birds used habitat near roads, wellheads, buildings, and transmission lines less than areas further from those features. Negative impacts for buildings and transmission lines were greater than those of wellheads and roads. Estimates of buffers around roads and energy features where habitat use is affected are given. Buffered areas representing habitat of lower quality represents 58 percent of the sand sagebrush habitat remaining in 2001. Loss of suitable habitat for nesting is believed to be even greater leaving only 26 percent of remaining habitat available for nesting.

Rodgers, R.D., 2005, Conservation Reserve Program successes, failures, and management needs for open-land birds, in Allen, A.W. and Vandever, M.W., eds., The Conservation Reserve Program- Planting for the future-Proceedings of a National Conference, Fort Collins, Colo., June 6-9, 2004: Reston, Va., U.S. Geological Survey, Biological Resources Discipline, Scientific Investigations Report 2005-5145, p. 129-134.
The author characterizes periodic management as a key factor in creation and longevity of vegetatively diverse CRP stands to furnish habitat of high quality. However, appropriate management of CRP grasslands through periodic disturbance has been inadequate throughout most of the history of the program. Absence of management (for example, grazing, fire) has permitted encroachment of woody vegetation into CRP grasslands (for example, eastern red cedar, Juniperus virginiana), which unchecked will ultimately negate habitat benefits of these grasslands for many species of grassland wildlife. Various conservation practices using grass buffers available through CCRP offer excellent opportunities to improve habitat in regions dominated by agricultural production but have been underused in the western and southern Great Plains.

The author furnishes the following recommendations for refinement in future management of the CRP to benefit grassland dependent avian species: (1) No further planting of aggressive exotic grasses should be permitted; (2) Emphasis must continue on provision of species diverse stands with a strong forb component; (3) A greater proportion of program acres should be shifted to localities near existing native grassland habitats; (4) Invasive trees on existing CRP grasslands must be eliminated; (5) Impractical incidental grazing restrictions on in-field CCRP linear conservation practices (for example, crosswind trap strips, grassed terraces) should be discontinued; and (6) Consultation between USDA, state wildlife agencies, and non-government organizations must continue, and increase, if optimization of soil, water, and wildlife conservation is to be expected.

Rodgers, R.D. and Hoffman, R.W., 2005, Prairie grouse population response to Conservation Reserve Program Grasslands-An overview, in Allen, A.W. and Vandever, M.W., eds., The Conservation Reserve Program-Planting for the future-Proceedings of a National Conference, Fort Collins, Colo., June 6-9, 2004: Reston, Va., U.S. Geological Survey, Biological Resources Discipline, Scientific Investigations Report 2005-5145, p. 120-128

Authors describe population responses of greater prairie chicken (Tympanuchus cupido), lesser prairie chicken (T. pallidicinctus), and sharp-tailed grouse (T. phasianellus) to establishment of CRP grasslands in Colorado, Illinois, Kansas, Minnesota, Missouri, Nebraska, North Dakota, and South Dakota. Generally the greatest benefits to prairie grouse occurred where CRP stands were established near pre-existing grasslands augmenting coverage and habitat diversity of the grassland complex. Common issues are associated with success and failure of prairie grouse populations in their response to the CRP. CRP grasslands 12-30 in in height appear most valuable to prairie grouse. Stands less than 12 in generally furnish inadequate concealment and protection from the weather. Grass stands greater than 30 in in height do provide thermal cover but such stands are often otherwise avoided. Multispecies plantings that are structurally diverse in height and growth are grasslands of the greatest value to these species. 
Presence of a high diversity of forbs, particularly legumes, greatly enhances the quality of grasslands as habitat for prairie grouse. Native grasses furnish habitat of greater quality than do stands dominated by introduced species. Recommendations for management of individual grassland stands and landscapelevel management are presented.

Salter, G.C., Robel, R.J., and Kemp, K.E., 2005, Lesser prairie-chicken use of harvested corn fields during fall and winter in southwestern Kansas: The Prairie Naturalist, v. 37, no. 1, p. $1-8$.

Lesser prairie chicken (Tympanuchus pallidicinctus) populations have declined in numbers in Kansas primarily due to conversion of sand sagebrush (Artemisia filifolia) to cropland. Fall and winter foraging by lesser prairie chickens is common on waste grain in harvested cornfields adjacent to prairie fragments. No significant relationship between numbers of bird locations and amount of waste grain in cornfields was found. Harvested fields with relatively low amounts of grain on the ground had sufficient amounts of food available. Authors conclude there is no need to develop supplemental food sources for wintering lesser prairie chicken populations and efforts to enhance habitat quality for this species would be better directed at preservation of sand sagebrush habitats.

Schroeder, M.A. and Vander Haegen, W.M., 2006, Use of CRP fields by greater sage-grouse and other shrubsteppe associated wildlife in Washington: Olympia, Wash., U.S. Department of Agriculture Farm Service Agency, Washington Department of Fish and Wildlife, 39 p.

The CRP is the largest effort to restore grassland and shrubsteppe habitat in the Columbia River Basin. About 1.5 million acres have been planted to CRP grasses in Washington. Unlike Midwestern CRP acreage established on land that was largely prairie prior to conversion to cropland, much of Washington CRP occurs on lands previously shrubsteppe prior to agricultural use. Declines in northwestern shrubsteppe habitats have coincided with declines in endemic populations of wildlife that include sage grouse (Centrocercus urophasianus), sage thrashers (Oreoscoptes montanus), and Brewer's sparrow (Spizella breweri). Between 1992 and 1997, 89 sage grouse nest sites were monitored. Although more nests were in shrubsteppe during the study the proportion of nests in CRP increased (31 to 50 percent) in response to maturation of CRP grasses characterized by increased height and cover of perennial grass and invasion by big sagebrush (Artemisia tridentata). Nest success in both shrubsteppe and CRP was similar. In north central region of Washington where CRP comprised 17 percent of occupied area by sage grouse data imply a sight reversal of grouse population decline. In south-central Washington, where CRP represented 2 percent of occupied area, the long-term decline of this grouse population continued.

Numbers of passerine birds using CRP were comparable to those recorded in shrubsteppe although species composition differed. Grassland birds as a group were more abundant in CRP and cropland cover types. Shrubsteppe birds were more abundant in old CRP than in newer fields using CRP fields only when sagebrush was present. Older CRP fields were dominated by crested wheatgrass (Agropyron cristatum) while newer fields were dominated by the native Sandberg bluegrass (Poa ampla). Data suggest that mule deer (Odocoileus hemionus) and jackrabbits (Lepus spp.) are using CRP fields. Mule deer used newer fields and shrubsteppe to a greater degree than they did older CRP fields.

Other significant findings include the conclusion shrubsteppe birds are benefiting from establishment of CRP through creation of suitable nesting habitat and development of a more contiguous non-cropland dominated landscape. CRP is of greatest benefit in this region when it contains sagebrush and is located in a previously shrubsteppe-dominated landscape. As sagebrush matures, CRP is gaining importance as nesting, brooding, and wintering habitat for sage grouse. CRP does not appear to be important in provision of lek sites. Authors attribute greater use of CRP by sage grouse to increasing size and abundance of big sagebrush in CRP fields, increasing cover of perennial grasses, growing success of nesting attempts in CRP, and possibly the recognition by sage grouse of CRP as suitable nesting habitat. The presence of CRP next to shrubsteppe habitat appeared to improve quality of CRP for sage grouse. Authors conclude sage grouse population would be severely impacted in Washington if the CRP were discontinued.

\section{Silvy, N.J., and Hagen, C.A., 2004, Introduction-Manage- ment of imperiled prairie grouse species and their habitat: Wildlife Society Bulletin, v. 32, no. 1, p. 2-5.}

This is an introductory presentation to a special coverage section of the Bulletin containing 11 papers on prairie grouse and their habitats. The papers are a result of a special symposium held at the 9th Annual Conference of The Wildlife Society held in Bismarck, N. Dak. in 2002. Titles of papers are: "Great plains ecosystems: Past, present, and future"; "The cause and the decline of pinnated grouse: The Texas example"; "Weather and prairie grouse: Dealing with effects beyond our control"; "Parasites and infectious diseases of prairie grouse: Should managers be concerned?"; "Evaluation of the lekcount index for greater sage-grouse"; "Guidelines for managing lesser prairie-chicken populations and their habitats"; "Private-land habitat opportunities for prairie grouse through federal conservation programs"; "Adaptive management of prairie grouse: How do we get there?"; "Assuring the future of prairie grouse: Dogmas, demagogues, and getting outside the box"; "Federal listing of prairie grouse: Lessons from the Attwater's prairie-chicken"; "Summary remarks and personal observations of the situation by an old hunter and researcher"; and "Epilogue: The ghosts of prairie grouse past."

Authors in this introductory chapter conclude that most non-grouse biologists are unaware of the recent decline in populations and habitats of these species. The public is even more uninformed of the plight of these species. Papers 
address changes in habitat availably and quality, limiting factors to populations, monitoring and management of grouse populations, opportunities provided by federal conservation programs, and advantages/disadvantages of federal listing. A summary by R. Robel presents the recommendation that an aggressive plan must be implemented soon to reverse the downward trend in grouse if we expect to have large, viable populations of these species. He recommends implementation of large-scale experiments to define best-management practices to increase nest success and survival; flexible rangewide management plans with economic incentives to induce landowner participation; and aggressive large-scale $(80,000+$ ha $[197,000 \mathrm{ac}])$ restoration of prairie habitats within the next $10 \mathrm{yr}$ for each species.

Sirotnak, J.M., Reese, K.P., Connelly, J., and Radford, K., 1991, Effects of the Conservation Reserve Program (CRP) on wildlife in southeastern Idaho, project W-160-R-18, job completion report: Boise, Idaho, Idaho Department of Fish and Game, $45 \mathrm{p}$.

Report documents use of CRP lands by mule deer (Odocoileus hemionus) and upland game birds. Authors recommend continuation of CRP contracts to furnish wildlife benefits. Columbian sharp-tailed grouse (Tympanuchus phasianellus) experienced the greatest benefits of the program in the southeastern part of the state. The best fields for wildlife were described as having high levels of cover, high vegetative diversity, patches of native vegetation interspersed with CRP covers, and irregular borders providing an increased amount of edge habitat. The authors believed establishment of CRP may reduce depredation on forage crops by mule deer.

Wachob, D.G., 1997, The effects of the Conservation Reserve Program on wildlife in southeastern Wyoming: Laramie, Wyo., University of Wyoming, Ph.D. dissertation, 123 p.

This dissertation provides an evaluation of CRP effects on wildlife from 1993-95. It contains descriptions of vegetation and spatial characteristics of CRP influencing habitat use by non-game birds, small mammals, sharp-tailed grouse (Tympanuchus phasianellus), raptors, and big-game in Laramie, Platte, and Goshen Counties (southeastern Wyoming). Vegetation species richness, height, standard deviation of vegetation cover, and area were significant predictors of small-mammal use of CRP. All grouse nests located were in larger CRP patches. Hen grouse used CRP with a broad-leafed weed component and annual grasses more often than CRP without these features. Avian use of CRP was higher in fields with alfalfa than in fields without alfalfa. The CRP was determined to be vital reproductive habitat for sharp-tailed grouse in southeast Wyoming. Leks were located closer to CRP compared to entire study area. Landscape analysis indicated species richness increased rapidly as CRP coverage increased from 0-15 percent. Sharp-tailed grouse were rare to absent in study area prior to implementation of CRP. Author recommends CRP should be retained at numerous patches of 200-400 hectares (495-988 ac).

Woodward, A.J.W., and Fuhlendorf, S.D., 2001, Influence of landscape composition and change on lesser prairie chicken (Tympanuchus pallidicinctus) populations: American Midland Naturalist, v. 145 , no. 2, p. 261-274.

Declining populations of lesser prairie chickens were associated with landscapes characterized by greater rates of total landscape change (11 percent per decade) and loss of shrubland cover types compared with landscapes in which populations did not decline. Amount of cultivation was not associated with population trends for 13 populations monitored in Texas, New Mexico, and Oklahoma. Smaller land ownerships in Oklahoma increased the potential for more variable management and greater amounts of landscape change. Landscapes that have undergone the most rapid change over the past several decades also had the most intensive settlement patterns resulting in smaller land holdings. Management should focus on maintaining stability of land use and continuity of shrublands within $4.8 \mathrm{~km}$ ( $3 \mathrm{mi}$ ) of active leks.

\section{Ring-Necked Pheasant}

Applegate, R.D., Flock, B.E., Gipson, P.S., McCoy, M.W., and Kemp, K.E., 2002, Home ranges of ring-necked pheasants in northwestern Kansas: The Prairie Naturalist, v. 34, no. $1 / 2$, p. 21-29.

Home ranges of hen ring-necked pheasants (Phasianus colchicus) varied from an average of 127 hectares (314 ac) in high-density ( 25 percent) CRP areas to 155 hectares (383 ac) on low-density (8-11 percent) CRP areas. Home ranges for males were greater in high-density CRP areas than within low-density areas. During the brooding season, home range size on low-density CRP site was more than double that of home ranges on high-density areas suggesting amount of CRP available may have affected home range size at least during this season.

Berner, A.H., 1988, Federal pheasants-Impact of federal agricultural programs on pheasant habitat, 1934-1985, in Hallett, D.L., Edwards, W.R., and Burger, G.V., eds., Pheasants - Symptoms of wildlife problems on agricultural lands, in Midwest Fish and Wildlife Conference, 49, Milwaukee, Wis., 8 December 1987, Proceedings: Minneapolis, Minn., p. 45-93.

Federal agricultural programs designed to assist farmers through cropland diversion and deficiency payment programs have significantly impacted the amount and quality of 
ring-necked pheasant (Phasianus colchicus) habitat over the last 50 yr. Pheasant populations have generally responded positively to multi-year cropland diversion programs but negatively to annual set-aside programs that allow poor cover management and require periodic disturbance of vegetative covers. Agricultural conservation programs requiring annual set-aside of land for control of commodity production (for example, Feed Grain Program and Wheat Production Program) resulted in habitat destruction for pheasants and other wildlife. Although potentially beneficial to some species, early destruction of cover prior to seed-head development greatly reduced value of set-aside lands as safe nesting and broodrearing cover. In Minnesota, data on pheasant populations indicate annual set aside lands have a pronounced negative influence on populations. Beneficial or negative effects of these programs are largely a function of if the cover is left through the nesting season and summer. The majority of fields enrolled in annual programs have been fallow or lightly seeded to small grains in early June and destroyed by July 15. Nesting cover on set aside lands was absent, poor, or fair on about 80 percent of lands while good to excellent only on about 20 percent of evaluated fields. Hunting cover and winter cover were 4.4 percent fair, 7.4 percent good, and 2.8 percent excellent. Proper management of set-aside lands with a focus on maintenance of high quality vegetative cover could greatly benefit game and non-game populations of wildlife in agricultural ecosystems.

Berthelsen, P.S., Smith, L.M., and George, R.E., 1990, Ringnecked pheasant nesting ecology and production on CRP lands in the Texas southern High Plains, in Transactions North American Wildlife and Natural Resources Conference 55, Denver, Colo., March 16-21, 1990, Proceedings: Washington, D.C., Wildlife Management Institute, p. 46-56.

In the Texas panhandle, high-quality nesting habitat for ring-necked pheasants (Phasianus colchicus), upland nesting waterfowl, and non-game birds has been furnished by CRP fields planted to blue grama/Kleingrass (Bouteloua gracilis/ Panicum coloratum), blue grama/sideoats grama (B. curtipendula), and blue grama/plains bluestem (Bothriochloa ischaemum). Introduction of the CRP to the panhandle region is projected to greatly benefit pheasants due to greater availability of cover which will enable birds to disperse from existing refuge covers (for example, playa lake basins). Prior to implementation of the CRP high quality, year-round cover was uncommon and isolated. One third of fields in study had CRP cover effectively eliminated as wildlife habitat due to emergency haying or weed control.

Bogenschutz, T.R., Hubbard, D.E., and Leif, A.P., 1992, Corn and sorghum as a winter food source for ring-necked pheasants: Journal of Wildlife Management, v.59, no. 4, p. $776-784$
Corn and sorghum furnish higher-quality winter food for pheasants than do natural wild foods and soybeans. Natural foods typically are high in fiber and low in digestible energy. Soybeans contain digestive inhibitors that lower the metabolically useable energy content of the diet. Female pheasants feeding on food plots (corn and mixed plots) had larger lipid reserves than females feeding on control and sorghum plots. Sorghum provides better winter cover due to vegetative structure. The best option, in most cases, would be to include both corn and sorghum in food plots. If winter cover is not limiting corn is a better option. If little to no winter wheat is nearby, food plots dominated by sorghum are preferred.

Clark, W.R., and Bogenschutz, T.R., 1999, Grassland habitat and reproductive success on ring-necked pheasants in northern Iowa: Journal of Field Ornithology, v. 70, no. 3, p. $380-392$.

Study of ring-necked pheasant (Phasianus colchicus) reproductive success in northern Iowa finds nest success averaged 62.3 percent in undisturbed blocks of habitat such as provided by CRP and 44.8 percent in small, linear, or disturbed cover types. The study reaffirms importance of a diversified agricultural landscape with large blocks of undisturbed cover to maintain suitable levels of pheasant reproduction. Populations cannot increase rapidly in landscapes providing small, linear or disturbed habitats due to greater occurrence of nest failures associated with such configurations of habitat.

Clark, W.R., Schmitz, R.A., and Bogenschutz, T.R., 1999, Site selection and nest success of ring-necked pheasants as a function of location in Iowa landscapes: Journal of Wildlife Management, v. 63, no. 3, p. 976-989.

Authors recommend managers should provide undisturbed grassland in blocks of greater than 15 hectares ( $40 \mathrm{ac}$ ) for nesting ring-necked pheasants (Phasianus colchicus). Nest success was highest in fields greater than $160 \mathrm{ac}$. Establishment of cover in several blocks is better than one large block of equivalent area. Both nest-site selection and success are influenced by habitat configuration within 1 home range radius of nest site. Specific vegetation type at nest location was not predictive of nest site selection or success. Authors conclude biologists must understand how landscape configuration is influenced by agricultural policy if they are to enhance wildlife populations.

Doxon, E.D., and Carroll, J.P., 2008, Feeding ecology of ringnecked pheasant and northern bobwhite chicks in Conservation Reserve Program fields: Journal of Wildlife Management, v. 74, no. 2, p. 249-256.

In spite of programs like the CRP, northern bobwhite (Colinus virginianus) and ring-necked pheasant (Phasianus colchicus) continue to decline in some regions. These declines have been attributed to fewer insects in agricultural 
ecosystems, continued loss in amount and quality of habitat, and declining survival of chicks in agricultural and CRP fields. Four conservation practices were evaluated in relation to invertebrate availability: CP10 warm-season grass mix; improved CP10 which had less than 10 percent of the field interseeded with alfalfa (Medicago sativa); $\mathrm{CP} 2$ warm season grasses with a forb mix included; and CP25 warm season grasses with Maximilian sunflower (Helianthus maximiliani) purple prairie clover (Dalea purpurea), prairie coneflower (Ratibida columnifera) and Illinois bundleflower (Desmanthus illinoensis) added to the planting mix. Winter wheat was also sampled as part of the investigation.

Many fields, especially CP10, averaged less than 5 percent bare ground cover. Study fields with the highest percentage of bare ground (CP25 and CP2) produced some of the highest foraging and mobility rates for pheasant and quail chicks. The more open ground enabled chicks to move more easily and experience higher foraging rates. The amount of bare ground was found to have a significant impact on insect selection and accessibility by the chicks. The authors conclude brood habitat quality in CRP fields could be greatly improved by practices that increase bare ground cover, such as light disking or burning. Data suggest, at least for this region of Kansas, disturbance every 4 to $5 \mathrm{yr}$ as grass growth in 5 -to 7 -yr-old fields had become too dense to furnish suitable conditions for foraging by pheasant and quail chicks.

Eggebo, S.L., Higgens, K.F., Naugle, D.E., and Quamen, F.R., 2003, Effects of CRP field age and cover type on ringnecked pheasants in eastern South Dakota: Wildlife Society Bulletin, v. 31, no. 3, p. 779-785.

An evaluation of CRP grassland species composition and field age related to ring-necked pheasant (Phasianus colchicus) abundance, habitat use, and productivity in the northern Great Plains. Fields $(n=42)$ were stratified by species composition (CP1; cool season/introduced species, CP2; warm-season natives) and stand age (old: $10-13 \mathrm{yr}$, new: $1-3 \mathrm{yr}$ ). CP1 fields were planted primarily to tall wheatgrass (Agropyron elongatum), or intermediate wheatgrass (A. intermedium) and smooth bromegrass (Bromus inermis). Some CP1 fields also contained alfalfa (Medicago sativa) and sweetclover (Melilotus officinalis). CP2 fields were dominated by switchgrass (Panicum virgatum), big bluestem (Andropogon gerardii), and Indiangrass (Sorghastrum nutans). Field age and cover-type effects on pheasant abundance and productivity were primarily a consequence of differences in vegetative structure among fields. Greater numbers of crowing pheasants were recorded in association with CRP cool season grasses than any other cover type. Higher numbers of broods were recorded in association with cool season than warm season CRP grasslands. Authors conclude cool season grass-legume mixtures should be given equal or higher ratings than warm-season stands of grass in establishment of new fields or preservation of established fields due to higher use by pheasants.
Vegetation structure, as measured by VOR and litter depth, increased with age in both cool and warm season grassland. Vegetation height/density and litter depth increased more rapidly in cool season than within warm-season grasslands. Litter depth was greatest in cool-season grasslands but increased in all fields as they aged. Authors conclude that cool-season CRP grasses furnish better nesting and brood-rearing cover than do warm-season CRP grasses of comparable age in eastern South Dakota. Authors recommend USDA provide more flexible criteria upon which potential, or renewed, CRP contracts are evaluated. The authors propose because cool season grasses become established more quickly and are less expensive to establish than warm-season natives, equal priority should be given to planting and maintenance of coolseason grasses. However, because cool-season grasses are more likely to become lodged or flattened during winter and do not consistently furnish quality winter cover, the authors recommend maintenance of a mosaic of both cool and warm season grasses of various age classes.

Eggebo, S.L., 2001, Ring-necked pheasant and passerine abundance in Conservation Reserve Program grasslands of differing age-classes and cover types in eastern South Dakota, 1998-2000: Brookings, S. Dak., South Dakota State University, M.S. thesis, 96 p.

Old CRP grasslands (10-13 yr old) had higher crowing count responses than recorded in young CRP fields ( $0-3 \mathrm{yr}$ old). Cool-season grasslands (tall or intermediate wheatgrass [Agropyron elongatum, A. intermedium], smooth bromegrass [Bromus inermis], and legumes) had higher crowing count responses than did warm-season mixes (switchgrass [Panicum virgatum], big bluestem [Andropogon gerardii], Indiangrass [Sorghastrum nutans]). Non-game bird grassland obligates were more abundant in CRP grasslands dominated by cool-season grasses. Author concludes it takes at least 3 yr for CRP fields to provide suitable habitat for ring-necked pheasants (Phasianus colchicus). As CRP grasslands become older, they may lose some qualities of dependable feeding cover (for example, loss of legumes) but gain value as nesting habitat due to greater quality of cover. Overall, the investigator concluded cool-season grassland generally furnished better habitat quality than did grasslands dominated by warm-season species. However, warm-season grasses appeared to furnish better winter cover. The author recommends flexibility in CRP planting mixes with greater priority given to providing a mix of grassland types in administration of the CRP. Legume component may be critical component of cool-season grass mix.

Gabbert, A.E., Leif, A.P., Purvis, J.R., and Flake, L.D., 1999, Survival and habitat use by ring-necked pheasants during two disparate winters in South Dakota: Journal of Wildlife Management, v. 63, no. 2, p. 711-722. 
Severe winter weather can alter availability of winter cover and affect mortality of ring-necked pheasants (Phasianus colchicus). Pheasant habitat use and survival were monitored in South Dakota in the second most severe winter in since 1892 as well as a milder, more typical winter. Mortality due to predation exceeded mortality due to weather in both winters. Mortality due to weather did not differ between winters but severe weather increased vulnerability to predation. Authors conclude shelterbelt and food plot habitats are essential to pheasant survival during extreme weather conditions.

When wind driven snow inundates herbaceous dominated covers and makes them unavailable for use woodland and food plot habitats are essential to the winter survival of pheasants. Authors conclude cattail- (Typha spp.) dominated wetlands, stands of grass greater than $25 \mathrm{~cm}$ tall, and food plots were important for pheasant survival in severe winters. Authors recommend managers should develop dense woody habitat, particularly shrubs and coniferous species near areas of high density pheasant populations but the potential negative effects to native flora and fauna should be taken into consideration when these habitat features are introduced into unfragmented landscapes.

Gatti, R., 1992, Nest cover for pheasants and ducks: Madison, Wis., Wisconsin Department of Natural Resources, Final Report, Study No. 127, Project W-141-R, 51 p.

Nest success is not consistently related to field size, shape, distance to water, cover height density, plant diversity, or cover type. Nest success was lower for nests closest to edges of cover types. Duck nest density was negatively related to plant diversity and positively related to height/ density of residual cover. Ring-necked pheasant (Phasianus colchicus) habitat use was higher in fields with lower diversity of plant species, greater structural diversity, more irregular in shape, and further from water. Widespread establishment of switchgrass (Panicum virgatum) nest cover and management of existing duck nest cover towards monotypic stands of switchgrass is not justified based on costs, use, or nest success. Authors recommend management for diversity of cover types.

Haroldson, K.J., Kimmel, R.O., Riggs, M.R., and Berner, A.H., 2006, Association of ring-necked pheasant, gray partridge, and meadowlark abundance to Conservation Reserve Program grasslands: Journal of Wildlife Management, v. 70, no. 5 , p. $1276-1284$.

Relations between amount of land in CRP habitats in 15 agriculturally dominated landscapes in Minnesota and a 10 -yr assessment of relative abundance of ring-necked pheasants (Phasianus colchicus), gray partridge (Perdix perdix), and meadowlarks (Sturnella spp.) are described. For each 10 percent increase in areas of grass in the landscape, numbers of pheasants counted on survey routes increased by an average of 12.4 birds in spring and 32.9 birds in summer. Meadowlark indices increased by an average of 11.7 birds per route in summer for each 10-percent increase in grassland area. Regardless of the amount of grass added to the landscape, partridge numbers declined throughout the investigation. Authors conclude that conversion of cropland to CRP grassland is associated with higher population indices of pheasants and meadowlarks.

Authors recommend the effectiveness of long-term conservation programs should be monitored over periods of at least $5 \mathrm{yr}$ to account for natural fluctuations in wildlife populations that occur without apparent changes in habitat quality or abundance. Continuation of CRP and other programs that restore idle grasslands in agriculturally dominated landscapes is recommended. These grasslands should be minimally disturbed during the primary nesting season.

Hubbard, M.W., 1991, Habitat changes in central Iowa and their relationship to ring-necked pheasant populations, 1981-1990: Ames, Iowa, Iowa State University, M.S. thesis, $64 \mathrm{p}$.

A HSI model was evaluated by relating outputs to numbers of ring-necked pheasants (Phasianus colchicus) numbers. Study area encompassed 133,000 hectares. Pheasant numbers were negatively related to alfalfa/hay acreage and positively related to pasture lands. Only area in roadside and spring VOR was positively related to pheasant numbers. Other influences affected relationships between model output and estimated number of birds (for example, weather, population numbers). Pheasant populations have undergone widespread declines in the Northern Plains states since mid-1960s as consequence of habitat loss due to increased mechanization and conversion of non-crop acreage to croplands. The original HSI model appeared to lack a component to assess important sources of winter food for pheasants. Three variables disked corn, chiseled corn and disked soybeans were incorporated into the model in an effort to improve performance. The model source is not described, nor is the model presented.

Kimmel, R.O., Berner, A.H., Welsh, R.J., Haroldson, B.S., and Malchow, S.B., 1992, Population responses of grey partridge (Perdix perdix), ring-necked pheasant (Phasianus colchicus) and meadowlarks (Sturnella spp.) to farm programs in Minnesota, in Birkan, M., ed., Proceedings of Perdix VI, First International Symposium on Partridges, Quails, and Francolins: Gibier Fauna Sauvage, v. 9, p.797-806.

Impacts of farm programs on wildlife vary depending on vegetation planted, subsequent management of the vegetation, and length of time cropland was removed from production. Spring and summer roadside counts were used to monitor changes in grey partridge, pheasant, and meadowlark population changes in 15 Minnesota study areas with varying amounts of land removed from production. Conservation lands included lands enrolled in CRP and Reinvest in Minnesota (RIM) program. At the time of the evaluation approximately 
96 percent of CRP land in Minnesota was planted to tame grasses and grass-legume mixtures (CP1 and CP10). Native grass plantings (CP2) accounted for 4 percent of plantings. Grass covers planted on 80 percent of RIM lands were tame grasses and grass-legume mixtures. Authors estimate it would cost $\$ 200$ million/yr for state conservation agency to establish the number of acres of habitat furnished by the CRP. Authors conclude there was not an apparent response by grey partridge but the abundance of pheasants and meadowlarks was positively correlated with amount of land in CRP/RIM. Wildlife benefits of covers provided by conservation programs vary according to which habitat components are furnished and how these components affect existing conditions. If winter cover and feeding areas are inadequate, the benefits of added reproductive cover furnished by CRP/RIM may be reduced. Areas with existing low populations of grassland birds may take a longer period of time for population responses to improvement in habitat quality to be evident.

Leif, A.P., 2003, Survival, spatial ecology and habitat use of male ring-necked pheasants in South Dakota: Pierre, S. Dak., South Dakota Department of Game, Fish and Parks Pittman-Robertson Completion Report 2003-08, 64 p.

Study results are based on movements and habitat use of radio tagged male ring-necked pheasants (Phasianus colchicus) monitored over a 5-yr period in eastern South Dakota. Lower rates of survival following severe winters were attributed to flattening of herbaceous cover in idle cover types and the drifting in and filling of wetlands with snow. Better habitats were associated with perennial cover that included grasses and forbs not mowed or grazed in the previous growing season. Use of perennial cover harvested previous growing season increased when new growth produced sufficient cover to provide concealment and protection from predators. Complexes of undisturbed herbaceous (wetlands with emergent cover or CRP plantings) and woody cover will maximize landscape capability to support territories of male pheasants.

Leif, A.P., 2005, Spatial ecology and habitat selection of breeding male pheasants: Wildlife Society Bulletin, v. 33, no. 1 , p. 130-141.

Based on work completed in South Dakota, the author concludes susceptibility of ring-necked pheasants (Phasianus colchicus) to predation may decrease where shrubs border idle herbaceous cover types. Woody cover with high groundlevel stem density will enhance habitat suitability for breeding pheasants. Idle herbaceous habitats are essential to ringnecked pheasants regardless of the life-cycle requirements (for example, display, nesting, escape/winter cover) that this habitat type may fulfill. Grass species with stems that retain vertical structure in spring (for example, warm-season native grasses) offer superior protective cover compared to species that are prone to lodge under snow and not return upright when snow melts. However, cool season grasses furnish food and preferred nesting cover therefore both types of cover should be established within management units. Dense monocultures of any grass should be avoided.

Presence of low growing woody shrubs reduced size of breeding area required by cocks and served to reduce size of pheasant territories. Male pheasants with access to woody habitat appeared to experience lower rates of depredation. Managers should maximize amount of idle herbaceous cover on the landscape. Placement of narrow bands of shrub (2-3) rows along idle cover edges will furnish attractive and beneficial component of habitat. Wide shelterbelts were identified as crucial cover for winter survival during the most severe conditions. Author recommends distance between shelterbelts of 2.5 to $5 \mathrm{~km}$ (1.5 to $3 \mathrm{mi})$ and placement near idle cover (wetlands with emergent vegetation or CRP grasslands) and food sources.

Little, T., and Hill, R.A., 1993, CRP having an impact: Iowa Conservationist, v. Sept/Oct, p. 4-9.

This article provides a description of agricultural and settlement impacts to wildlife habitats in Iowa with an overview of CRP benefits to wildlife largely based on results reported from other studies. Converting as little as 4 percent of row crop area to CRP significantly increased numbers of ring-necked pheasants (Phasianus colchicus) seen on survey routes. Higher numbers of pheasants were attributed to greater overwinter survival due to the high quality of winter cover furnished by the CRP. More than 15 nests of non-game birds per 40 acres of CRP were recorded compared to less than one in same area of row crops. Nest success of birds in CRP was estimated at 33 percent as compared to 20 percent in hay fields. Waterfowl nest success in CRP was believed to be as good, or better, than that found within established wildlife management areas.

Nielson, R.M., McDonald, L.L., Sullivan, J.P., Burgess, C., Johnson, D.S., Johnson, D.H., Bucholtz, S., Hyberg, S., and Howlin, S., 2008, Estimating the response of ringnecked pheasants (Phasianus colchicus) to the Conservation Reserve Program: The Auk, v. 125, no. 2, p. 434-444.

Associations between CRP and ring-necked pheasant populations were assessed using BBS data from 1987-2005 from BBS routes in nine states. Land use and CRP habitat type data within a 1,000-m buffer around each survey route were compared to population counts. On average, a positive association between ring-necked pheasant counts and the amount of CRP herbaceous vegetation within the 1,000-m buffer was found. Authors conclude the analysis shows a positive association of ring-necked pheasants along BBS routes with larger amounts of CRP enrollment. This association was consistent across broad geographic regions. The statistical and modeling methods used for this analysis are believed a useful 
tool for further evaluation of CRP effects on other avian species and regions.

Nomsen, D.E., 2005, The Conservation Reserve Program Wildlife Legacy - Continuing and strengthening the U.S. Department of Agriculture's most successful wildlife conservation program, in Allen, A.W., and Vandever, M.W., eds., The Conservation Reserve Program-Planting for the Future-Proceedings of a National Conference, Fort Collins, Colo., June 6-9, 2004: U.S. Geological Survey, Scientific Investigations Report 2005-5145, p. 53-55.

Perspectives of Pheasants Forever (PF) in relation conservation successes of the 2002 Farm Bill and the future of the CRP are presented as are descriptions of how PF has been involved in on-ground and policy refinement of conservation provisions affecting the CRP. Excerpts from letters from 10 Great Plains and Midwestern (Idaho, Illinois, Iowa, Kansas, Minnesota, Montana, Oklahoma, South Dakota, Texas, Washington) states describing the wildlife benefits brought by the CRP are presented.

Riley, T.Z., 1995, Association of Conservation Reserve

Program with ring-necked pheasant survey counts in Iowa: Wildlife Society Bulletin, v. 23, no. 3, p. 386-390.

Ring-necked pheasant (Phasianus colchicus) numbers in Iowa are believed to have increased 30 percent during first $5 \mathrm{yr}$ of CRP compared to a similar period prior to program. Numbers increased 34 percent in counties with greater than 70 percent of cropland and 26 percent in counties with 50-70 percent cropland. Increases were not detected in counties with less than 50 percent of their area in cropland. Although pheasant numbers were positively related to CRP area, numbers apparently also were influenced by percent cropland and cumulative snowfall. Positive association between pheasant survey counts and CRP land enrollment may have resulted from an increase in nesting and winter cover. The addition of idle grass-forb fields provided by the CRP may have improved survival of females and enhanced reproductive success by increasing amount and dispersion of roosting and nesting cover. Association of pheasant counts with percent area in CRP probably a function of percent cropland. Value of existing grass cover and that added by CRP may have been reduced by the persistence of snow cover.

Robertson, P.A., 1996, Does nesting cover limit abundance of ring-necked pheasants in North America?: Wildlife Society Bulletin, v. 24, no. 1, p. 98-106.

Based on a review of literature, the author concludes availability of attractive nesting cover is a major factor limiting ring-necked pheasant (Phasianus colchicus) density in North America. Although secure nesting cover can increase the chance of an individual hen successfully hatching a clutch, availability of nesting cover does not necessarily lead to longterm increases in overall density of birds. Author concludes that territory cover, a mixture of many habitat types, may be limiting in many parts of North America. Creation of habitats that support new territories could reduce spring dispersal and increase local breeding density. Predation, availability and quality of winter cover, and suitable cover for broods all can have important influences on quality of pheasant habitat and should be addressed in landscape-level development of pheasant habitat.

Rodgers, R. D., 1999, Why haven't pheasant populations in western Kansas increased with CRP?: Wildlife Society Bulletin, v. 27, no. 3, p. 654-665.

Pheasant (Phasianus colchicus) populations in western Kansas declined an average of 65 percent from 1966 to1975 and 1986 to 1995 . Declines were particularly strong in the 1980s. Over 680,000 acres of CRP were added to the regional landscape since 1985, but pheasant populations have not shown a significant increase in population numbers. Although summer observations show that CRP was used proportionally more than availability by pheasant broods, over-winter use of CRP was only 37 percent of weedy wheat stubble, a habitat being lost in the region. Increased use of herbicides, which results in less cover and lowering the quality of wheat stubble as habitat for pheasants represents an overwhelming loss of habitat for which CRP cannot compensate. Also, the author attributes a lack of vegetative diversity in early CRP plantings as further limiting their benefits to pheasants. Poor maintenance of stands and the large size of fields enrolled in the CRP is also believed to have limited benefits of the program to pheasants. The quality of pheasant habitat could be improved if perennial legume and other forbs were interseeded into recently burned stands and grass-legume strips were interspersed within intensively farmed landscapes. The lack of brood habitat and the failure of the CRP to improve availability of brood habitat are also attributed to the lack of response by pheasants. Nesting habitat, largely furnished by winter wheat, is not believed to be limiting in the region.

Use of weedy wheat stubble by pheasants was higher than use recorded in CRP grasslands. Nighttime roosting composed much of the pheasant use of CRP with only limited use during daytime. Native grasses typical of CRP plantings in the region furnish minimal food sources for pheasants as compared to waste grain and weed seeds in weedy wheat stubble. Excessive litter in unmanaged CRP also may restrict movement and use of these fields by pheasants. Though useful, CRP has not compensated for the loss in quality of habitat provided by weedy wheat stubble in western Kansas. But benefits of CRP habitats may have compensated for loss of wheat stubble habitats and associated impacts on pheasant populations preventing even further declines in populations. Greater use of linear conservation features (for example, grassed terraces, crosswind trap strips) interspersed with cropland is strongly advocated to enhance habitat quality for pheasants. 
Schmitz, R.A., and Clark, W.R., 1999, Survival of ring-necked pheasant hens during spring in relation to landscape features: Journal of Wildlife Management, v. 63, no. 1, p. 147-154.

Density of edge between grassland and other habitats was predictive of the hazard rate and odds of mortality, which increased 2 percent for every $10 \mathrm{~m} / \mathrm{ha}(33 \mathrm{ft} / 2.5 \mathrm{ac})$ of additional edge in the home range. Management to reduce vulnerability to predation should be targeted to areas with high measures of edge. Reduction in edge density by increasing field size of permanent cover would increase spring survival. Managers need to estimate how landscape changes at the township $\left(36 \mathrm{mi}^{2}\right)$ scale if full advantages of agricultural policies and conservation practices are to be expected.

Snyder, W.D., 1985, Survival of radio-marked hen ring-necked pheasants in Colorado: Journal of Wildlife Management, v. 49 , no. 4 , p. 1044-1050.

The lowest monthly survival of hen ring-necked pheasants (Phasianus colchicus) occurred in April. Predation was primarily due to predation by avian species. Great horned owls (Bubo virginianus), Cooper's hawks (Accipiter cooperii), and prairie falcons (Falco mexicanus) were primary avian predators. Coyote (Canis latrans) and feral house cats (Felis silvestris) were the principle mammalian predators. The presence of trees interspersed, or in close association, with grassland covers contributed to high rates of avian predation. Concealment quality of early spring residual cover in grassland was important for survival of hens. Study area contained extensive tree and shrub plantings attracting both wintering pheasants and avian predators. Pheasants associated with grasslands containing trees suffered a higher rate of avian predation than their counterparts in habitats not containing trees.

Taylor, M.W., Wolfe, C.W., and Baxter, W.L., 1978, Land use change and ring-necked pheasants in Nebraska: Wildlife Society Bulletin, v. 6, no. 4, p. 226-230.

Positive relationships were reported between spring densities of hen ring-necked pheasants (Phasianus colchicus) to kilometers $(\mathrm{km})$ of fencerows, hectares $(\mathrm{ac})$ of pasture/hay, and wheat and wheat stubble. Pheasant numbers were inversely related to area of row crops, percent of land fall-tilled, and amount of area irrigated. Irrigation generally involves extensive land leveling, or clearing, which eliminated idle areas, fencerows, old farmsteads, wetlands, and other vegetative covers of high value. Tillage of crop residue in fall, especially wheat stubble, reduced cover for wildlife. An interspersion index useful for predicting pheasant habitat quality and density of birds is presented.

Taylor, R.L., Maxwell, B.D., and Boik, R.J., 2006, Indirect effects of herbicides on bird food resources and beneficial arthropods: Agriculture Ecosystems \& Environment, v. 116, p. $157-164$.
This paper reports on an investigation of relations between agricultural herbicides, food webs, and how changes in the plant community affect abundance of arthropods. The study focuses on insects eaten by ring-necked pheasant (Phasianus colchicus) and gray partridge (Perdix perdix) chicks as well as arthropods that prey on insect pests and weed seeds. Beneficial insects were more common in diverse communities of vegetation than within monocultures. Study demonstrates that herbicides do affect abundance of beneficial insects that are food for avian species and predators of less desirable species of insects. The study confirms herbicides do reduce numbers and biomass of insects important to game species, as well as others dependent upon insects for food, by altering the beneficial effects of vegetation composition and diversity. Weedy plots contained 12 times the biomass of vegetation dwelling insects than did monocultures. Plots with intermediate diversity in vegetation held 8 times the biomass of insects than did monocultures. After spraying bromoxynil and imazamethabenz, insects in weedy plots diminished by more than 50 percent compared to that recorded in monocultures. Authors advocate use of headlands (where herbicides are not used), interseeding, and greater use of narrow spectrum herbicides to lessen losses of beneficial insects in agroecosystems.

Trautman, C.G, 1982, History, ecology and management of the ring-necked pheasant in South Dakota: Pierre, S. Dak., South Dakota Department Game, Fish, and Parks, 118 p.

Winter concentrations of ring-necked pheasants (Phasianus colchicus) invariably are near weed patches, grain stubble, cornfields and other food sources. Distances traveled rarely exceed $1 / 4 \mathrm{mi}$. The nearness to available food is dominant factor in choice of winter roosting sites. Marshlands provide high quality winter cover. The document provides a detailed presentation of ring-necked pheasant history, ecology and management in South Dakota.

Warner, R. E., 1994, Agricultural land use and grassland habitat in Illinois-Future shock for midwestern birds: Conservation Biology, v. 8, no. 1, p. 147-156.

During the period of most intensive agricultural production, grasslands were present only as linear edges with resultant low density and diversity of grassland nesting birds. Nest densities and species diversity were highest where grassland was nearby cover types heterogeneous and where corridors connected grasslands in the surrounding landscape. Nest destruction is high in years when both predators and nesting ring-necked pheasants (Phasianus colchicus) were concentrated in relatively little remaining grassy cover. The percentage of pheasant nests hatched annually from 1973 to 1981 was positively correlated with the amount of grassland per hen in spring where grassland consisted of both edge habitats (including roadsides) and fields of hay and small grain. Landscape characteristics associated with use of edges by nesting birds 
increased reproductive success. Nest densities and species diversity increased relative to the degree of spatial heterogeneity and to how well plots were connected to surrounding landscape by corridors. There is potential for enhancing use of grassy farmland edges by establishing filter strips, field borders, and improving cover in existing edges, and by locating hay and small grains near existing wider grassland corridors. It is too simplistic to conclude all linear habitats are predator traps. Predation rates vary with predatory-prey assemblages, density of birds in nesting covers, and the extent to which other cover and prey attract predators away from relatively attractive linear nesting sites. Author concludes landscapelevel phenomena affecting habitat use and predator relations are poorly understood at this time.

Warner, R.E. and Etter, S.L., 1985, Farm conservation measures to benefit wildlife, especially pheasant populations, in Transactions of North American Wildlife and Natural Resource Conference, 50, Washington, D.C., March 15-20, 1985, Proceedings: Washington, D.C., Wildlife Management Institute, p. 135-141.

Three spatial factors are key variables in understanding interaction of agriculture and ring-necked pheasants (Phasianus colchicus), FIELD: primary site for particular biological needs; FARM: represents a unit of land management and describes cover types near sites of biological activity; REGIONAL: mosaic of cover over an extended area that encompasses several farms. All three scales are significant to occurrence, location, and outcome of specific events in the life of pheasants. Scales vary in importance from season to season depending upon weather, type of farming, and biological activity. Regional scale is important to movement during crop harvest, fall tillage, winter grouping and spring dispersal. The farm scale is more important during brood rearing and establishment of territories. Field-scale characteristics are most relevant to nest success, roosting, and predation. To be effective, management practices should extend over several contiguous townships. Management across a large spatial scale permits movements of birds from farm-to-farm in response to individual management activities and availability of habitat. Conservation measures must be extensive and of significantly long-term to benefit pheasant populations. Addressing factors that are critical during the reproductive season are typically of first priority (suitable undisturbed vegetative cover of sufficient area).

Warner, R.E. and Etter, S.L., 1989, Hay cutting and the survival of pheasants-A long-term perspective: Journal of Wildlife Management, v. 53, no. 2, p. 455-461.

Tracts of undisturbed nest cover placed near forage crops do not have to be extensive to benefit ring-necked pheasants (Phasianus colchicus). Grassed terraces, filterstrips, and other linear covers can furnish important nesting cover.
Mortality rates of hens and nests are high when hay cutting coincides with late stages of incubation. Data suggests mortality of pheasants due to haying operations is increasing due to earlier cutting.

Warner, R.E., David, L.M., Etter, S.L., and Joselyn, G.B., 1992, Costs and benefits of roadside management for ringneck pheasants in Illinois: Wildlife Society Bulletin, v. 20, p. 279-285.

Mitigating the effects of agricultural land use on upland wildlife remains a significant challenge to resource agencies. Successful habitat programs in agriculturally dominated environments are most likely those that are relatively compatible with farming operations. The success of habitat initiatives is rarely evaluated relative to response by target species, economics, or perceptions of cooperating landholders. Roadside right-of-ways frequently are mowed during the growing/nesting season consequently they have little habitat value for nesting ring-necked pheasants (Phasianus colchicus). The paper summarizes economic costs and benefits of roadside seeding and maintenance in relation to improved habitat availability and production of pheasants.

Warner, R.E., Hubert, P., Mankin, P.C., and Gates, C.A., 2000, Disturbance and the survival of female ring-necked pheasants in Illinois: Journal of Wildlife Management, v. 64, no. 3, p. 663-672.

The paper reports results of an investigation in eastcentral Illinois in an intensively farmed landscape: 93 percent row crops (corn and soybeans in equal proportion). Hen ringnecked pheasants (Phasianus colchicus) exhibiting disturbance-avoidance (farm operations, hunting, weather) behavior were associated with extended movements and coped well with hazards except during nesting. Relatively long-lived birds made extensive use of corn and soybeans while minimizing use of cover traditionally considered attractive to pheasants. Nesting season was associated with high death rates. Primary nest cover in the study area was annual set-aside land planted to temporary cover crops (wheat, oats). Significant improvements in availability and permanence of quality cover must occur on numerous individual farms over larger space and time scales to improve survival rates and population stability in intensively farmed landscapes.

To further enhance benefits of the CRP, land managers and wildlife biologists must collaborate to identify objectives and maximize landscape level approaches to cover management. As enrollment criteria presently exist, opportunities to improve wildlife habitat are limited. Communication and information exchange between USDA NRCS personnel and program participants needs improvement. Administration of CRP, as well as other conservation programs, needs greater emphasis on landscape level planning to meet wildlife objectives. 
Whitmore, R., 1982, Insect biomass in agronomic crops as food for ring-necked pheasant chicks: Lincoln, Nebraska, University of Nebraska Lincoln, Ph.D. dissertation, 64 p.

Corn, soybeans, and alfalfa had significantly lower amounts of insect biomass than wheat, oats, sweetclover, and oats-sweetclover. Estimated number of chicks/ha (2.5 ac) supported by insect biomass: corn, 8 ; soybeans, 10; sweetclover, 64; oats, 86; oats-sweetclover, 106.

Wooley, J.B., George, J. R., Ohde, B., and Rybarczyk, W., 1982, Nesting evaluations of native grass pastures and narrow-row soybeans, in Dahlgren, R.B., Proceedings of Midwest Agricultural Interfaces with Fish and Wildlife Resources Workshop, Ames, Iowa, University of Iowa, 1-2 June 1982: Ames, Iowa, Iowa Cooperative Research Unit, p. 5-6.

Native grasses have a dense growth form similar to other types of ring-necked pheasant (Phasianus colchicus) nest cover and are unlikely to be mowed or grazed until after most eggs hatch. Leaving the recommended 20-25 cm (8-10 in) stubble to ensure optimum plant growth should provide residual cover for nesting the following spring. Pheasant-nest densities were high in switchgrass (Panicum virgatum) and little bluestem (Schizachyrium scoparium). Success was greatest in switchgrass. Mowing operations in early June destroyed all nests and killed 8 of 11 hens nesting in alfalfa/orchardgrass (Medicago sativa/Dactylis glomerata). Pheasant and passerine nest success was higher in switchgrass that was not grazed or mowed the previous summer. Greater residual cover presumably was more attractive to nesting females and resulted in greater numbers of successful nests. Switchgrass managed for nest cover should be left undisturbed.

\section{Waterfowl and Shorebirds}

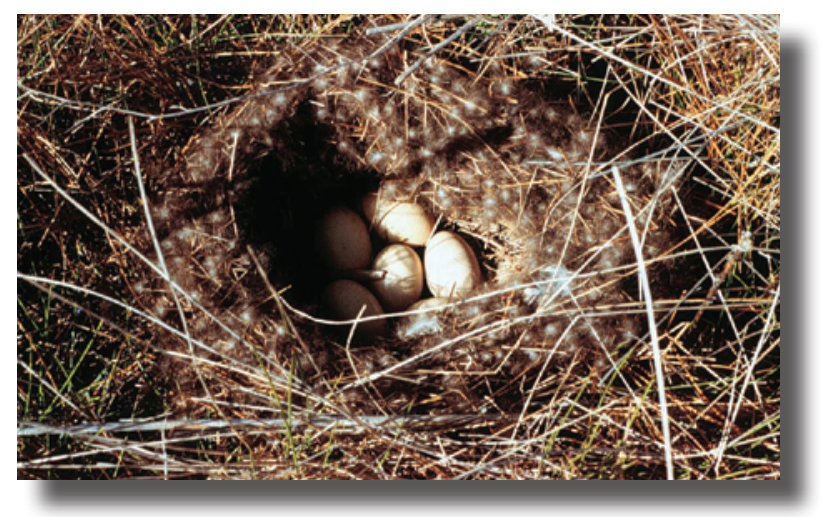

Abraham, K.F., Jefferies, R.L., and Alisauskas, R.T., 2005, The dynamics of landscape change and snow geese in midcontinent North America: Global Change Biology, v. 11, p. 841-855.
The mid-continent population of the lesser snow goose (Chen caerulescens caerulescens) has increased 5-7 percent annually since the late 1960 s to 1990 s due to the positive effect of agricultural crops (corn, rice, wheat) along flyways and wintering grounds. While the increased availability of agricultural foods has increased survival, substantial negative effects on arctic breeding grounds have resulted due to increased numbers of birds. Foraging by high numbers of birds has led to loss of coastal vegetation, adverse changes in soil properties, and exposed sediments which will take decades to recover, assuming populations are reduced through natural or human influences. The changes displayed by snow geese reflect alteration in agricultural production which potentially affects other wildlife associated with seasonal or year-round use of agricultural lands.

Large-scale changes in agricultural practices and creation of refuges have altered patterns of land use, feeding habits, survival, and migratory patterns of waterfowl (Anatidae). Changes in habitat use and negative effects on arctic ecosystems by snow geese are described which largely are in response to a shift from historical winter use of salt and brackish marshes of the Gulf of Mexico to use of irrigated rice in Texas and Louisiana. The mid-continent population of snow geese now is dependent upon these rice fields as well as other agricultural crops farther north during migration and wintering. While land area plated to corn and wheat had not changed during last $50 \mathrm{yr}$, production yields have increased. Area devoted to rice increased from 1950 to 1975. Area in soybeans has risen threefold over the same period. While little use of soybeans is recorded for geese, this crop accounts for a large proportion of weeds and weed seeds on these lands may be consumed by the species. Waste (spilled corn) is a primary food source of lesser snow geese. Creation of Federal and State wildlife refuges coincide with major changes in agricultural practices and production, which have created landscapes highly favored by snow geese. Agricultural changes in land use have led to shift in migratory patterns on both local and regional scales. Availability of refuges and cropland foods have resulted in more frequent stopovers and reduced direct, non-stop migration between breeding and wintering grounds.

Agricultural policies will continue to influence numbers of waterfowl as a consequence of crop production. Weed production associated with agricultural production is expected to decline in response to greater dependence on genetically modified, herbicide ready crops (see Krapu and others, 2004, below). This development can have potentially large-scale negative effects on waterfowl and other wildlife dependent upon weeds and their seeds as a food source. Increased efficiency of harvest, resulting in less waste grain, may also have negative consequences for wildlife in agriculturally dominated ecosystems. The lack of green, weedy forages; decline in availability of spilled/waste grains; and greater area in soybeans are believed to have negative effects on wildlife foods sources in agriculturally dominated landscapes. 
Ball, I.J., Eng, R.J., and Ball, S.K., 1995, Population density and productivity of ducks on large grassland tracts in northcentral Montana: Wildlife Society Bulletin, v. 23, no. 4, p. $767-773$.

An analysis of variation in duck productivity associated with habitat size and differing effects of red fox (Vulpes vulpes) and coyotes (Canis latrans) is presented. Productivity of dabbling ducks on large grassland tracts with relatively low populations of predators was higher than recorded where habitat fragmentation was more extensive and high populations of predators were present. Authors conclude that attempts to improve nest success at an inappropriately small scale may be counterproductive if hens and predators are attracted to same limited area. Increasing surface water area where low rates of nest success prevail attracts pairs to areas where mortality exceeds recruitment. Due to foraging strategies and prey preferences, productivity of upland-nesting ducks can be expected to be higher in large grassland tracts where coyotes are primary predator. More fragmented habitats where red fox is the dominant predator will have lower productivity of upland nesting waterfowl due to foraging strategies and prey preferences by red foxes.

Clark, R.G. and Nudds, T.D., 1991, Habitat patch size and duck nesting success-The crucial experiments have not been performed: Wildlife Society Bulletin, v. 19, no. 4, p. 534-543.

Authors state that there is conflicting evidence concerning relations between patch size and nest success of upland nesting birds. Some studies show nest success increases with greater area and lower density of nests while others indicate there is no positive relationship between area and success. More information about relations between habitat patch size and composition of managed habitats to duck nesting success is needed. Key questions include: what kind of cover needs to be planted and how much; are ducks doing better in managed habitats than in unmanaged habitats, what is the most viable standard of comparison (for example, nest success, duckling survival), and are management programs cost effective? The review of literature presented does not clearly support or refute the hypothesis that duck nesting success should be greater in larger patches and questions the rationale of establishing relatively small (less than 300 hectares [741 ac]) areas of cover. The authors suggest it might be better to redirect efforts and limited funds to programs or management alternatives that could direct changes in agricultural policy influencing overall land use.

Cowardin, L.M., Sargent, A.B., and Duebbert, H.F., 1983, Low waterfowl recruitment in the prairies - the problem, the reasons, and the challenge to management, in Boyd, H., ed., First western hemisphere waterfowl and waterbird symposium: Slimbridge, England, International Waterfowl Research Bureau, p. 16-18.
Waterfowl nest success estimates for the northern United States are in the range of 5-15 percent, although two studies in western North Dakota demonstrated success rates of 38 percent and 42 percent. Variation in success reflects differences in quality of habitat and predator populations. The lowest success rates were observed in areas of intensive agriculture. The highest nest success for mallards (Anas platyrhynchos) was in grassland and lowest in cropland. Data demonstrate a serious problem of low recruitment resulting from destruction of habitat and increased predation rates in remaining suitable habitat. Intensification of agricultural production has decreased both the availability of nesting cover and habitat available to resident prey species. The result is a concentration of nesting ducks and foraging predators in remaining untilled grassland or other non-farmed covers. Key management strategy is to separate nest predators from nesting waterfowl. Habitat preservation is essential but also requires management of predator populations.

Cowardin, L.M., Gilmer, D.S., and Shaiffer, C.W., 1985, Mallards and agricultural programs, in Transactions of North American Wildlife and Natural Resource Conference, 50, Washington, D.C., March 15-20, 1985, Proceedings: Washington, D.C., Wildlife Management Institute, p.132-140.

Prior to and at the time of this report, the declining quality of wildlife habitat has not been considered an issue of high priority by ASCS (FSA) committees charged with allocating funds for agricultural conservation programs. Prior to the 1985 Farm Bill biologists from 12 midwestern states documented declines in habitat quality due to changing land use and agricultural practices. A summary of species-population data revealed estimated declines of 91 percent for ring-neck pheasant (Phasianus colchicus), a 72 percent decline in eastern cottontail (Sylvilagus floridanus) populations, and 83 percent decline in northern bobwhite quail (Colinus virginianus) populations. Declines in these species, traditionally associated with diverse agricultural land use, were attributed to the large increase in row crop acreage. More land devoted to row crops has come at the cost of area in high quality nonfarmed nesting cover, small grains, pasture, and other cover types. More intensive use of agricultural lands has resulted in an overall loss of edge between different covers due to larger size of farms and individual fields, destruction of old farmsteads, drainage of wetlands, and fewer non-disturbed idle areas. Recent decades have seen a major shift from diversified farms to monoculture-agricultural landscapes dominated by operations that continue to get larger by absorbing the lands of surrounding less successful farmers. The report provides summary of weak points of agricultural programs (for example, Payment in Kind) and basic wildlife recommendations for 1985 Farm Bill.

Cox Jr., R.R., Johnson, D.H., Johnson, M.A., Kirby, R.E., Nelson, J.W., and Reynolds, R.E., 2000, Waterfowl research priorities in the northern Great Plains: Wildlife Society Bulletin, v. 28, no. 3 , p. 558-564. 
A Waterfowl Working Group identified high priority issues for future research in Northern Great Plains. (1) Determine effects of landscape factors on demographics and recruitment of ducks in Prairie Pothole region. Studies are needed to quantitatively assess landscape characteristics influencing breeding pair density, spring summer survival, and recruitment rates. (2) Develop and improve estimates of important parameters used in models for management and planning. Refinement in variables describing habitat characteristics related to preference for various cover types and corresponding nest success rates are needed for species other than the mallard (Anas platyrhynchos). (3) More Evaluations of waterfowl management activities at regional scales are needed. Greater attention needs to be focused on large-area applications of management treatments corresponding to large-scale management plans (for example, Prairie Habitat Joint Venture, North American Waterfowl Management Program). (4) Direct studies on species of concern are needed. Some species have shown little response to increased presence of wetlands in recent years (for example, Northern pintail [Anas acuta], lesser scaup [Aythya affinis]). Studies are needed to identify factors limiting populations of these species as is evaluation of the applicability of bird-conservation area concept to waterfowl production. The assumption that core areas of excellent habitat will maintain viable populations of breeding birds needs to be evaluated as it applies to waterfowl. Population source and sink habitats and how they may be configured or manipulated to benefit ducks need further investigation.

Farmer, A.H., and Parent, A.H., 1997, Effects of the landscape on shorebird movements at spring migration stopovers: The Condor, v. 99, no. 3, p. 698-707.

The authors report associations between pectoral sandpiper (Calidris melanotos) habitats that furnish stopover sites are a crucial link between wintering and breeding areas for migratory birds. Stop-over habitats provide foods and energy needed for continued movements and nutritional reserves that may be essential for successful reproduction on the breeding grounds. Agricultural development has had a major impact on presence and quality of wetland habitats across the Great Plains raising concerns about maintenance of an adequate network of stopover wetland habitats needed by migratory species. The authors describe several types of stopover habitats furnishing both short-term and extended nutritional and habitat needs. These habitats are affected by spatial scales and biological organization.

Authors report landscape pattern has a significant influence on bird movements independent of wetland quality potentially accounting for up to 46 percent of variance in movement. A highly connected landscape, in terms of wetland abundance and quality, allows shorebirds to exploit higher quality food patches while minimizing the energetic costs of searching. As wetlands become isolated, distances moved by sandpiper decline. Over-use of remaining habitats constrains feeding opportunities as foods become depleted.
Individual wetlands, and food sources contained within them, must be distributed so individual birds can achieve relatively high ingestion rates at low energetic costs. Important stopover habitats are defined as having sufficient food (that is, wetlands) for the population of birds using the site. The food must be distributed at a relatively small scale to meet needs of individual birds. While shorebird stopover sites receiving the most conservation attention have been those where large numbers of shorebirds are observed, such sites may not furnish sufficient food resources to meet population needs. Conservation focused on small, closely spaced wetlands may be just as important to some shorebird species as are larger wetlands. Smaller, diverse wetlands in close proximity may furnish perpetuation of greater diversity in foods and foraging opportunities than do larger wetlands.

Fox, A.D., Madsen, J., Boyd, H., Kuijkens, E., Norriss, D.W., Tombre, I.M., and Stroud, D.A., 2005, Effects of agricultural change on abundance, fitness components and distribution of two arctic-nesting goose populations: Global Change Biology, v. 11, p. 881-893.

Although the paper focuses on two largely European arctic nesting geese (pink-footed goose [Anser brachyrhynchus] and Greenland white-fronted goose [A. albifrons flavirostris]) effects of changes in agricultural land use on avian habitat use and distribution are analogous to North American agricultural/ conservation issues. The increase in agricultural production has replaced many natural habitats but has benefited some avian species. Improvement in grass cultivars has enhanced grass quality by elevating crude protein content, increasing digestibility and prolonging growing seasons. Large-scale patterns of cultivation have created extensive areas of uniform, intensively managed areas of grassland and cereals. These changes have increased carrying capacity for true grazing birds. Several species of northern nesting geese have shown dramatic spatial redistribution and increases in population size in response to changes in agricultural production. In Europe geese have become highly dependent on the agricultural landscape as "survival habitat." Implications of changing agricultural production and policies on these species are discussed.

Gatti, R., 1992, Nest cover for pheasants and ducks: Madison, Wis., Wisconsin Department of Natural Resources, Final Report, Study No. 127, Project W-141-R, 51 p.

Nest success was not consistently related to field size, shape, distance to water, cover height density, plant diversity, or cover type. Nest success was, however, lower for nests closest to cover edges. Duck-nest density was negatively related to plant diversity and positively related to height and density of residual cover. Ring necked pheasant (Phasianus colchicus) use was higher in fields with lower diversity of plant species, greater structural diversity, more irregular in shape, and further from water. Widespread establishment of switchgrass 
(Panicum virgatum) nest cover and management of existing duck nest cover towards monotypic stands of switchgrass are not justified based on costs, use, or nest success. Management for diversity of cover types to achieve better nesting success is recommended.

Horn, D.J., Phillips, M.L., Koford, R.R., Clark, W.R., Sovada, M.A., and Greenwood, R.J., 2005, Landscape composition, patch size, and distance to edges-Interactions affecting duck reproductive success: Ecological Applications, v. 15, no. 4, p. 1367-1376.

An investigation of grassland-landscape characteristics influencing nest success of upland nesting ducks is described. Study areas composed of 15-20 percent grassland and 45-55 percent grassland in North Dakota were used to investigate relations between duck reproduction, field size, and distance to nearest field and wetland edges. Nest survival rates were higher in 45-55 percent grassland study area. Nest survival rates were highest in small and large fields and lowest in fields of moderate size. Study results support conclusion that both landscape composition and configuration affect success of ground-nesting birds. Authors conclude clustering of moderately sized patches of nesting habitat in agriculturally dominated landscapes have low nest success. Higher nest success in high-grassland study area may be due to greater probability of nest hatching when farther from field edges. Nest success was highest in small and large fields and lower in fields of intermediate size. Differences in success between field sizes were attributed to differences in predator activity. Authors believe predators rarely visit small patches of cover and predator activity in large fields reflects inability for predators to effectively search the entire field. Medium sized fields are believed to be those most thoroughly searched by predators (for example, red fox [Vulpes vulpes], striped skunk [Mephitis mephitis]) as they spend proportionally more time within fields in this size category.

Hurley, T.M., Babcock, B.A., Reynolds, R.E., and Loesch, C.R., 1996, Waterfowl populations and the Conservation Reserve Program in the Prairie Pothole Region of North and South Dakota: Ames, Iowa, Center for Agricultural and Rural Development, Iowa State University, Working Paper 96-WP 165, 30 p.

Authors estimate that the density of waterfowl breeding pairs under current distribution of CRP land is only 12.5 percent greater than what would have been realized had land been randomly enrolled in program. Authors believe initial enrollment rules for CRP did a relatively poor job of including the best waterfowl habitat and suggest improved targeting to higher quality habitat for waterfowl. These changes could potentially double density of breeding pairs. Further improvement in pair density may be realized if CRP lands were associated with existing Wetland/waterfowl Management Districts that furnished better quality habitat. It is also suggested it is more important to focus enrollment targeting within adjacent county regions rather than between regions. The benefits of such planning would extend to wildlife species other than waterfowl.

Ignatiuk, J.B., and Duncan, D.C., 2001, Nest success of ducks on rotational and season-long grazing systems in Saskatchewan: Wildlife Society Bulletin, v. 29, no. 1, p. 211-217.

Rotational grazing systems intended to increase duck production in the Canadian prairie pothole region have had only limited success. A comparison of waterfowl production recorded in once-over rotational systems and season-long pastures in Saskatchewan failed to reveal differences in nest survival between grazing systems. Rotational systems could be more beneficial if they preserve or improve grassland areas, attract more ducks from less productive habitats, or increase duck survival. Strong evidence that pastures have higher nest success compared to most other habitat types including small plots of planted cover. Conversion of cropland to pasture and retaining existing pastures was recommended to improve duck production.

Kantrud, H.A., 1993, Duck nest success on Conservation Reserve Program land in the prairie pothole region: Journal of Soil and Water Conservation, v. 48, no. 3, p. 238-242.

Duck nest success was found to be higher (23.1 percent) on tracts of CRP than on WPAs (8.2 percent). Larger size of fields, greater distance from water, lower densities of nests, and high quality of vegetative cover on tracts of CRP were key factors believed to contribute to lower rates of predation and higher production of waterfowl.

Krapu, G.L., Brandt, D.A., and Cox Jr., R.R., 2004, Less waste corn, more land in soybeans, and the switch to genetically modified crops - Trends with important implications for wildlife management: Wildlife Society Bulletin, v. 32, no. 1, p. $127-136$.

Growing efficiency in corn harvest (greater than 99 percent under ideal conditions) and widespread replacement of corn and other crops by soybeans less capable of supplying nutritional needs of wildlife represents a growing risk to wildlife dependent upon waste grain for energy and weeds for the foods and cover they provide. Nearly 25 percent of total cropland in the United States is used to produce soybeans. In 2002, approximately 75 percent of soybean crop was planted to GM herbicide resistant types. Increased efficiency of weed control results in decline in amount of weeds present representing decline in foods and cover for wildlife in agricultural landscapes. Implications may be particularly severe on seeddependent wildlife of lower mobility and smaller home ranges and on migratory species with seasonally high nutritional 
needs. Prior to development of GM strains, herbicides were less efficient or selective resulting in some weed species continuing to thrive in cropland. Genetically modified crops appear to be on verge of greater acceptance by farm operators and industry broadening negative impacts on wildlife dependent upon weeds. Aggressive control of weeds in CRP fields and other private lands further impacts seed-eating wildlife when the availability of weed seeds and other high quality grain foods are becoming less available across agriculturally dominated landscapes.

Authors suggest more research is needed to determine impacts of weed control on CRP and other lands as well as studies to better document effects of GM crops on quality of wildlife habitat across regions. Authors believe the beneficial effects of the CRP in providing perennial cover for wildlife may be negated by more highly efficient and intensive weed control on lands remaining in production as well in CRP covers. It is suggested producers could be offered incentives to grow high-energy food plots, intentionally leave greater crop residues, and use less intensive weed-control methods to ensure that adequate sources of food are available for wildlife in areas dominated by row crop production.

Luttschwager, K.A., 1991, Effects of two haying provisions on duck nesting in Conservation Reserve Program (CRP) fields in South Dakota: Brookings, S. Dak., South Dakota State University, M.S. thesis, 51 p.

This report provides an evaluation of 1988 and 1989 release of eastern South Dakota CRP fields' effects for emergency haying on duck-nest density and success. Nest densities in idled (non-hayed) strips and fields were significantly greater than recorded within hayed strips. Nest densities in idled and hayed blocks were similar. Nest success was lowest in idled strips, which apparently attracted predators as well as ducks. To lessen predation, the author recommends leaving a minimum of 25 percent of hayed fields in non-hayed cover in contiguous blocks rather than strips.

Luttschwager, K.A., Higgens, K.F., and Jenks, J.A., 1994, Effects of emergency haying on duck nesting in Conservation Reserve Program fields, South Dakota: Wildlife Society Bulletin, v. 22, no. 3, p. 403-408.

Authors report comparison of upland nesting duck nest densities and nest success among hayed, idled strips, and blocks of CRP grassland hayed under authorized emergency use. CRP haying provisions that left 10 percent of fields in idled (non-hayed) strips resulted in nest success of mallards (Anas platyrhynchos) and blue-winged (A. discors) teal below levels necessary to sustain their populations in areas where CRP fields constitute a major portion of available nesting habitat. Haying provisions requiring at least 25 percent of field be left standing supported sufficient reproduction to maintain or increase populations. The authors recommend CRP emergency haying be completed in blocks rather than strips. At least 25 percent of a hayed field is recommended to be left standing, in a contiguous block, to maintain nesting habitat. Residual vegetation was attractive during the early part of the nesting season. Nest densities in idled strips, unharvested blocks, and CRP fields were 4 times greater than recorded in hayed strips or hayed blocks.

Reynolds, R, 1992, Evaluation of the effect of CRP on duck recruitment in the prairie pothole joint venture area of FWS, Regions 6: U.S. Fish and Wildlife Service Progress Report: Bismarck, N.D., 6 p.

Report documents results of 1992 pilot effort to evaluate waterfowl production in Montana, North Dakota, and South Dakota. Duck nest success was estimated to be 2 to 3 times higher in CRP grasslands than recorded in established WPAs.

Reynolds, R.E., Shaffer, T.L., Loesch, C.R., and Cox Jr., R.R., 2006, The Farm Bill and duck production in the Prairie Pothole Region-Increasing the benefits: Wildlife Society Bulletin, v. 34, no. 4, p. 963-974.

Two key provisions of the Food Security Act of 1985 benefited waterfowl in the PPR: the CRP and Swampbuster. The CRP furnished attractive, secure nesting cover for upland ducks while Swampbuster served to protect wetlands vital to breeding ducks. With concerns about future availability of habitat brought by these programs, breeding duck population data and wetland habitat surveys were used to develop models for five species of upland-nesting ducks. Habitat quality assessment was completed for mallard (Anas platyrhynchos), gadwall (A. strepera), blue-winged teal (A. discors), northern shoveler (A. clypeta), and northern pintail (A. acuta). These models were applied to more than 2.6 million wetlands to evaluate where cover would be accessible to the greatest number of nesting hens. These data were compared to the distribution of current CRP contracts relative to distribution of upland-nesting ducks. The study area was the portion of North and South Dakota east of the Missouri River, known as the glaciated PPR and glacial Lake Agassiz plain.

Analysis of data indicates that 75 percent of CRP contracts (as of 2005) included in the study area were accessible to high numbers of ducks. The authors present a method to prioritize extension, or reenrollment, of CRP contracts, as well as new lands suitable for inclusion in these programs, to maintain or increase duck populations. The approach described is applicable to determine the availability of habitat and to target desirable lands for inclusion in conservation programs in other regions of the country. To maintain the current potential of the PPR to produce ducks, the CRP and wetland-protection elements of the farm-conservation programs must be maintained. The authors conclude that if Swampbuster protection were eliminated and protected wetlands were drained, waterfowl 
production would decline by 37 percent in this region of the PPR.

Reynolds, R.E., Shaffer, T.L., Renner, R.W., Newton, W.E., and Batt, B.D., 2001, Impact of the Conservation Reserve Program on duck recruitment in the U.S. prairie pothole region: Journal of Wildlife Management, v. 65, no. 4, p. 765-780.

Authors conclude the CRP has furnished substantial benefits to upland nesting waterfowl during 1992-97 study period. Estimated nest success and recruitment rates for 5 waterfowl species (mallard [Anas platyrhynchos], gadwall [A. strepera], blue-winged teal [A. discors], northern shoveler [A. clypeata], and northern pintail $[A$. acuta]) were respectively 46 and 30 percent higher than estimated for non-CRP covers within study area. Estimates of daily survival rates were positively related to the percent of perennial grass cover on $4 \mathrm{mi}^{2}(10.4$ $\mathrm{km}^{2}$ ) study plots. The authors contribute significant benefits to populations of upland nesting ducks in the Prairie Pothole region to the CRP through provision of attractive, secure nesting cover. Authors estimate that 12.4 million additional ducks were produced in study area between 1992-97 than would have been produced if CRP had not been implemented.

Renner, R.W., Reynolds, R.E., and Batt, B.D.J., 1995, The impact of haying Conservation Reserve Program lands on productivity of ducks nesting in the Prairie Pothole region of North and South Dakota in North American Wildlife and Natural Resources Conference, 60, Proceedings: Washington, D.C., Wildlife Management Institute, p. 221-229.

Report provides a comparison of duck nest success and production in hayed versus non-hayed portions of CRP fields. Duck production was higher on non-hayed portions of CRP fields. Authors suggest haying effects on litter depth and vegetation structure may have detrimental effects on quality of nesting cover through entire year following haying of CRP cover. The report recommends haying be allowed no more than once every $5 \mathrm{yr}$ to maintain vegetation quality, habitat diversity and quality of nesting cover.

Skagen, S.K., and Knopf, F.L., 1992, Toward conservation of midcontinental shorebird migrations: Conservation Biology, v. 7 , no. 3 , p. 533-541.

Successful transcontinental migrations of the highly diverse group of shorebirds are dependent upon dynamic freshwater wetlands for stopover resources essential of replenishment of fat reserves and completion of migration. Patterns of shorebird distribution and habitat use vary geographically and take advantage of uniquely different regions. Smaller species and Neotropical migrants primarily move across the Great Plains, whereas larger species and North American migrants predominantly use the intermountain west for migration.
Transcontinental migrants disperse and use wetlands opportunistically; this highlights the need to develop a large-scale, coordinated regional management effort based on recognition of the dynamic nature of wetlands across the Great Plains.

Smith, L.M., Haukos, D.A., and Prather, R.M., 2004, Avian response to vegetative pattern in playa wetlands during winter: Wildlife Society Bulletin, v. 32, no. 2, p. 474-480.

Cover to water ratios were manipulated in Texas playa lakes to determine avian response during winter. Cover was managed to yield (cover:water) 75:25, 50:50, and 25:75 ratios. Playa vegetation was dominated by barnyardgrass (Echinochloa crusgalli), smartweed (Polygonum spp.), and curly dock (Rumex crispus). Lakes were surrounded by cropland. Greatest bird richness and waterfowl numbers were recorded in 50:50 cover/water ratio wetlands. Authors attribute increased edge and habitat diversity to greater use and numbers of avian species. Management of playas to furnish 50:50 ratio of cover to water and moist soil management is recommended to maximize habitat availability and wetland bird diversity during winter.

Sovada, M.A., Zicus, M.C., Greenwood, R.J., Rave, D.P., Newton, W.E., Woodward, R.O., and Beiser, J.A., 2000, Relationships of habitat patch size to predator community and survival of duck nests: Journal of Wildlife Management, v. 64 , no. 3, p. 820-831.

This report provides an evaluation of duck-nest success and the composition of predator community in relation to size of discrete patches of nesting cover in the Prairie Pothole region. The study focused on CRP grasslands in Minnesota, North Dakota, and South Dakota. Activity patterns of red fox (Vulpes vulpes), badger (Taxidea taxus), striped skunks (Mephitis mephitis), coyotes (Canis latrans), and Franklin's ground squirrels (Spermophilus franklinii) were related to habitat patch size and daily survival rate of upland duck nests. Estimated annual mean daily survival rates were generally greater in larger habitat patches. Although authors believe a positive relationship between habitat patch size and nest success probably exists, they conclude that absolute proof remains elusive.

Stephens, S.E., Rotella, J.J., Lindberg, M.S., Taper, M.L., and Ringleman, J. K., 2005, Duck nest survival in the Missouri coteau of North Dakota-Landscape effects at multiple spatial scales: Ecological Applications, v. 15, no. 6, p. 2137-2149.

Over the past century the PPR landscape has been dramatically altered by agriculture. Remaining grasslands have become fragmented or lost to agriculture. Authors believe species composition of nest predators present in a given landscape may be influenced by the amount of grassland present which 
in turn may affect waterfowl nest survival rates. Design of successful habitat-management programs requires understanding of how predators respond to habitat features. Structure and configuration of landscape features may have an important influence on predation rates and nest success. Determination of what scale to measure landscape-level variables may be as important as is identification of individual variables.

Study results indicate that large, intact grassland areas should be maintained and grasslands should be restored to achieve high nest survival for upland nesting ducks. Sites with larger, intact grasslands had high nest survival rates even in a year with poor overall nest survival. Intermediate levels of edge resulted in the lowest nest survival rates. The number of wetland basins was negatively related to nest survival. Authors suggest that long-term research is needed to better understand factors affecting nest survival across landscapes that include investigation of the relations between predators, alternate prey, and waterfowl nest success.

Taft, O.W., and Haig, S.M., 2005, The value of agricultural wetlands as invertebrate resources for wintering shorebirds: Agriculture, Ecosystems and Environment, v. 110, p. 249-256.

In the Willamette valley of Oregon, significant populations of wintering shorebirds (Charadriiformes) regularly use hundreds of dispersed wetlands on agricultural lands. However, agricultural landscapes have received little recognition of the habitat and food resources they provide. Although not quantified, benthic invertebrates associated with these wetlands furnish critical resources necessary for survival of these species. Shorebirds in this region rely principally on privately owned agricultural wetlands. Left in agricultural production, wetlands in crop fields have the capacity to produce invertebrate food sources. The authors suggest, but do not describe, active restoration and enhancement of these wetlands and management of their vegetation and hydrology may increase invertebrate production within these wetlands. Density, biomass, and general community composition of invertebrates were quantified in Willamette valley sites during a dry and wet winter. Invertebrate densities ranged from 173 to 1,925 individuals $/ \mathrm{m}^{2}$ in a wet winter to 214 to 3,484 individuals $/ \mathrm{m}^{2}$ in the dry winter. Estimated biomass ranged from 35 to $652 \mathrm{mg} /$ $\mathrm{m}^{2}$ in the wet winter and 85 to $1,405 \mathrm{mg} / \mathrm{m}^{2}$ in the dry year.

van Eerden, M.R., Zijlstra, M., van Roomen, M., and Timmerman, A., 1996, The response of Anatidae to changes in agricultural practice-Long-term shifts in the carrying capacity of wintering waterfowl: Gibier Faune Sauvage, v. 13 , p. $681-706$.

Written from a European (Netherlands) perspective, this report describes effects of change in agricultural production on waterfowl populations and habitat use. Both changes in the past and potential future changes are described with implications having application for North America. Herbivorous waterfowl have benefited from changes in agricultural production as a consequence of improved digestibility, protein, and longer growing seasons of grassland crop types. However, conversion to production of row crops and reduction in number of cattle grazing in natural areas may have negative effects on waterfowl along migratory routes and in wintering habitats.

Description of the effects of historical changes in land use, use of fertilizer, resulting in extended growing seasons, expansion of cattle and dairy production, and increased availability of "waste" grains/crops are provided, as are descriptions of waterfowl response to availability of stubble fields and expansion of grass dominated covers. Authors report negative effects of increased nutrient loads on water quality causing decline in populations of macrophyte dependent species of waterfowl. Use of agricultural land by waterfowl is related to body size with larger species spending more time on agricultural habitats than smaller species. Spatial relations between natural wetland habitats, agricultural land, and species response are discussed.

\section{Wetlands, Aquatic Ecosystems}

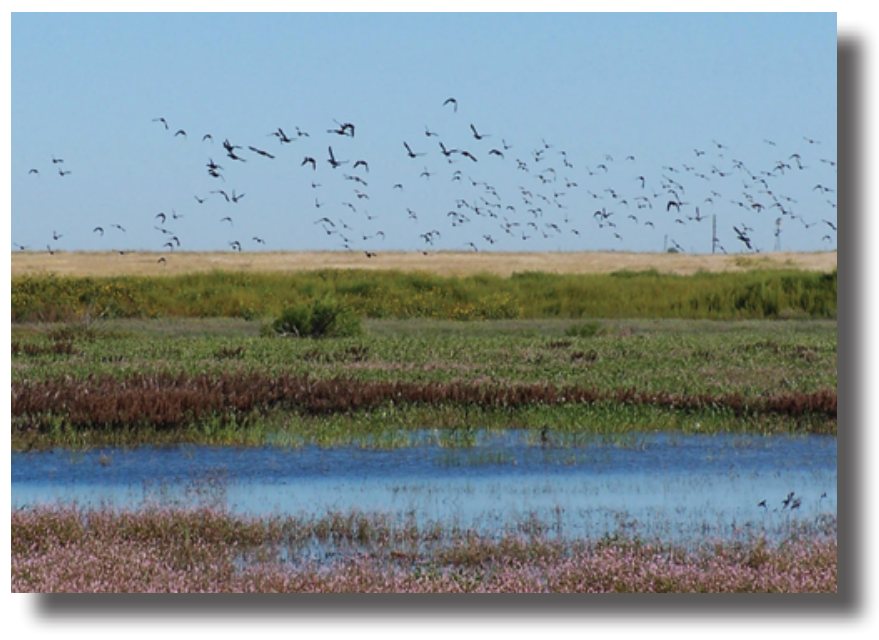

Allan, J.D., 2004, Landscapes and riverscapes-The influence of land use on stream ecosystems: Annual Review Ecology and Evolution Systematics, v. 35, p. 257-284.

Biological diversity and habitat quality in riverine systems is strongly influenced by landform and land use within the surrounding valley at multiple scales. Empirical relations between land use and stream response are difficult to define due to variance of anthropogenic and natural gradients, existence of multiple, scale-dependent mechanisms, nonlinear responses, and difficulties in separating present-day influences from those of the past. Human actions at the landscape scale are the principal threat to the ecological integrity of riverine ecosystems, affecting habitat, water quality, and associated biota via numerous and complex pathways. 
The author provides a comprehensive review of studies describing effects of agricultural practices shown to affect water quality, habitat value, and biological assemblages as the extent of agriculture increases. Higher inputs of sediments, nutrients, and pesticides accompany greater agricultural use affecting riparian and stream channel habitats. Streams in landscapes dominated by agriculture tend to have poor-quality habitat, which is reflected by declines in habitat indices and bank stability as well as greater deposition of sediments. Storm flows commonly increase in magnitude and frequency where land clearing, drainage ditches, subsurface drains, and loss of wetland area are extensive. Base flows often decline in agriculturally dominated basins due to reduced infiltration resulting in instream habitats with shallow water which is susceptible to greater levels of warming.

Discussions of urban land use, management applications, and approaches to assessment of environmental impacts are presented. The author concludes knowledge of pathways and mechanisms of land use affecting stream ecosystems is extremely limited, particularly in relation to prescriptive management. The author recommends greater emphasis on examination of sensitive indicator species response to management practices intended to offset impacts of intensive land use on stream habitat quality.

Bolen, E.G., Smith, L.M., and Schramm, H.L., Jr., 1989, Playa lakes - Prairie wetlands of the southern high plains: Bioscience, v. 39, no. 9, p. 615-623.

When inundated, playas form shallow lakes and wetlands that significantly increase plant and animal diversity in intensively cultivated landscapes. With rare exceptions, each playa and its watershed is a closed system. Avifauna dominates the vertebrate animal life associated with playas, but lagomorphs can reach high densities in playa habitats. Playas developed for agriculture have lower insect production than do unmodified basins due to reduction in fluctuation of water level. The value of playas as habitat lies in the diversity of vegetation and associated fauna. Playas receiving irrigation runoff had increased interspersion of vegetation and open water resulting in higher habitat quality. Cultivation of playas decreases their value as wildlife habitat. Reduction of vegetation surrounding playas can influence water quality. Establishment of pits within playas reduces the abundance and diversity of vegetation that requires alternating wet and dry periods. Majority of phytoplankton associated with aquatic vegetation is important for production of macroinvertebrates and forage for wintering waterfowl. Pits diminish value of lakes as waterfowl habitat; waterfowl often prefer densely vegetated sites. Losses of vegetation in littoral zones and interior islands of vegetation reduce nesting habitat and waterfowl production associated with these habitats. The loss of food production associated with modification of playas affects habitat quality for breeding, wintering, and migrating waterfowl and shorebirds. Loss of tall emergent and woody vegetation reduces roosting and nesting habitat for other birds. Conversely, modified playas hold water during dry seasons and may support greater plant biomass and diversity. Modified playas may provide high quality habitat particularly during periods of drought. However, wildlife benefits remain contingent on the extent of the modification and on temporal aspects of water-level fluctuations.

Buck, O., Niyogi, D.K., and Townsend, C.R., 2003, Scaledependence of land use effects on water quality of streams in agricultural catchments: Environmental Pollution, v. 130, p. 287-299.

Although completed in New Zealand, this investigation provides an excellent summary of the influences of temporal and spatial scales on water quality and assessments and implies that water monitoring needs to be sensitive to scale of catchments under evaluation. Different processes may occur at different scales, and understanding cumulative contributions of land uses is vital to successful monitoring. Authors conclude that rigid sampling of water quality at fixed time intervals does not provide sufficient information. Seasonal changes in nutrient export and fluxes during flood events need to be incorporated into sampling schemes. Data on local land use are important in small headwater streams while total influence of land use in whole basin provides better assessment of water quality in larger streams.

Conway, W.C., Smith, L.M., and Ray, J.D., 2005, Shorebird habitat use and nest-site selection in the playa lake region: Journal of Wildlife Management, v. 60, no. 1, p. 174-184.

Playa lakes provide important habitats for wintering waterfowl as well as for migrant and breeding shorebirds. Wetland-scale habitat use and nest-site selection for four dominant species (American avocet [Recurvirostra americana], black-necked stilt [Himantopus mexicanus], killdeer [Charadrius vociferus], snowy plover [C. alexandrinus]) nesting in playas, saline and man-created lakes, and riparian wetlands are described. Only avocets and killdeer nested in playas. No nests were found in created wetlands. Authors conclude that created wetlands cannot compensate for loss of playa wetlands and urge that greater conservation efforts be directed toward conservation of natural wetlands. Protection of playa hydroperiod should be emphasized for breeding shorebird conservation. Most playas have cropland-dominated watersheds and have lost their natural vegetative communities. Prairie restoration around watersheds will decrease sedimentation rates and restore playa hydrological cycles, which will benefit avian habitat quality and use.

Cooper, C.M., 1993, Biological effects of agriculturally derived surface water pollutants on aquatic systems - A review: Journal of Environmental Quality, v. 22, p. 402408.

Agricultural contaminants are most noticeable when they produce immediate, toxic effects on aquatic life, but more 
subtle, sub-lethal, chronic effects may be just as damaging over long periods. While suspended sediment represents the largest volume of aquatic contaminant, pesticides, nutrients, and enrichment due to the input of organic materials are major stressors of aquatic systems affected by agriculture. The demise of buffers along streams accelerates effects of pollutants. Author believes that protection of habitat is the single most effective means of conserving biological diversity in aquatic systems.

Two systems, based on input from the surrounding landscape, represent aquatic systems. Primary receivers include wetlands, small streams, and impoundments that receive runoff and contamination directly from the land. Secondary receivers include downstream rivers and larger lakes that receive inflow from multiple tributaries as well as limited direct runoff from the landscape. Ecological stressors, including physical and chemical inputs from agriculturally dominated landscapes, increase susceptibility of aquatic organisms to disease and parasites. In-stream suspended sediments and bedload, by volume, are the largest pollutants in the United States. Effects of sediments on benthic organisms, habitat composition, and aquatic productivity are discussed, as are effects of nutrients, organic contamination, pesticides, and metals.

Sediment-related contamination is best prevented by practices that prevent erosion or trap sediments. Use of cover crops, conservation tillage, grassed waterways, terraces, filter strips, preservation and creation of riparian zones, contour farming, and water and sediment control basins are recommended approaches to lowering sediment input to aquatic systems. Many of the management practices designed to reduce sediment input help to lower nutrient input. Protection of aquatic systems must be based on a watershed management approach.

Council for Agricultural Science and Technology, 1999, Gulf of Mexico hypoxia - Land and sea interactions: Ames, Iowa, Task Force Report 134, 44 p.

Agriculture is the leading source of impairment to rivers and lakes that supply nutrients to marine ecosystems. Hypoxia (oxygen deficiency) may be the most widespread anthropogenically induced effect in estuarine and marine environments worldwide. No other environmental parameter of such ecological importance to coastal marine ecosystems has changed so drastically in such a short period of time. In 1998, the hypoxic zone in the Gulf of Mexico covered 12,400 km² (4,800 $\left.\mathrm{mi}^{2}\right)$. Nitrogen export from the Mississippi River Basin has increased 2 to 7 fold over the last century. Sedimentation of marine organic matter from increased nutrients is the principal cause of hypoxia in the Gulf. The majority of Mississippi River N originated from agricultural practices (estimated contribution 2 to 3 $\mathrm{lbs} / \mathrm{ac} / \mathrm{yr}$ ). Estimated annual contribution to Gulf of agricultural $\mathrm{N}$ is approximately 2 million tons.

Factors that cause hypoxia are: water-column stratification, preventing mixing of waters, and decomposition of organic matter. The zone of hypoxia in the Gulf is now the largest in the western hemisphere and coincides with some of the nation's most productive and important fishing waters. The hypoxic zone is most persistent, widespread, and severe from June to August. Sedimentary records document eutrophication and increased marine-origin organic sedimentation in bottom waters that are positively correlated with increasing $\mathrm{N}$ loads and oxygen stress. Coastal phytoplankton productivity has increased due to enriched nutrient conditions. There have been increasing noxious phytoplankton blooms of algae, generally less edible by zooplankton. Suggestions that hypoxia has increased in response to long-term increases in water flow are not valid. Changes are due to water quality fueled by riverine nutrients. Total $\mathrm{N}$ export from Mississippi prior to human settlement estimated at $0.16 \mathrm{~kg} / \mathrm{ha} / \mathrm{yr}$. Estimates of current discharge are $5.7 \mathrm{~kg} / \mathrm{ha} / \mathrm{yr}$. Fifty-five percent of net $\mathrm{N}$ is attributable to agricultural fertilizers.

Decline in agricultural nutrient input can be accomplished by current technology and knowledge. Practices such as buffer strips within, and adjacent to, croplands and natural/ restored/constructed wetlands can contribute to lower $\mathrm{N}$ inputs to the river system. Alterations in seasonal application of fertilizers, soil testing to avoid over-application, and alternative tillage regimes to decrease sedimentation need to be adopted. Alteration of cropping strategies would have costs to producers and consumers, but in the long-run would yield larger benefits to society.

Cowx, I.G., and Van Zyll De Jong, M., 2004, Rehabilitation of freshwater fisheries-Tales of the unexpected: Fisheries Management and Ecology, v. 11, p. 243-249.

In recent years, there have been many attempts to restore and rehabilitate aquatic environments to address declines in biodiversity and fisheries. Many of these efforts have been on a small scale with fragmented approaches with resulting low rates of success. Often fisheries are not enhanced as expected and improvement gained is not justified by the costs. Authors conclude restoration of stream habitats to pristine conditions is a utopian goal. In most cases river basins have undergone extensive changes in land use with the most dramatic effects stemming from deforestation and intensification of agricultural activities. Many rehabilitation efforts are localized addressing issues on only small sections of the aquatic habitat or ignore problems associated with adjacent land uses. Rehabilitation success requires a catchment perspective requiring strategic planning. It is essential post-project monitoring must be undertaken and results disseminated widely to enhance future restoration efforts.

Davie, D.K., and Lant, C.L., 1994, The effect of CRP enrollment on sediment loads in two southern Illinois streams: Journal of Soil and Water Conservation, v. 49, no. 4, p. 407-412.

Relations between CRP enrollment and changes in stream-sediment load were evaluated in southern Illinois. CRP 
enrollment of 15.6 and 26.5 percent of all cropland in Big Creek and Cypress Creek watersheds resulted in estimated 24 and 37 percent reduction in erosion. Declines in erosion due to land management practices do not always result in immediate decline in suspended sediment load. Length of time between management action and reduction in sediment load is affected by many variables, including character of sediments, changes in basin hydrological response, timing of flood events, and spatial distribution of conservation practices. Authors conclude CRP enrollment within the two watersheds failed to produce a significant decrease in suspended sediment loads. Authors believe that reductions in suspended sediment in response to CRP enrollment are likely to be delayed as in and near-stream sediments are remobilized. In addition, few fields enrolled in CRP were in near-stream locations where they would be most effective in trapping upstream and upslope sediments.

Demissie, M., Keefer, L., Slowikowski, J., and Stevenson, K., 2006, Evaluating the effectiveness of the Illinois River Conservation Reserve Enhancement Program in reducing sediment delivery, in Sediment dynamics and the hydromorphology of fluvial systems: Dundee, United Kingdom, International Association of Hydrological Sciences p. 295-303.

A CREP was initiated in 1998 to address sedimentation and water-quality issues in the Illinois River, a tributary of the Mississippi. A major objective is to reduce sediment delivery by 20 percent by protecting and restoration of the flood plain corridor of the river and its tributaries. Between 1998 and $2004,110,854$ acres have been enrolled in the program. This paper describes the establishment of a monitoring program established by the state of Illinois and collection of baseline data to describe effects of the program. Methods of data collection, modeling, and monitoring are described.

Dodds, W.K., Gido, K., Whiles, M.R., Fritz, K.M., and Matthews, W.J., 2004, Life on the edge-The ecology of Great Plains prairie streams: Bioscience, v. 54, no. 3, p. 205-216.

Great Plains streams represent an important component of an ever-dwindling North American supply of unpolluted freshwater resources and furnish habitat to a number of threatened or endangered species. Most areas of the Great Plains were formerly prairie but are now heavily affected by agriculture or urbanization resulting in pollution, hydrologic disturbance, and physical modification of habitats. Large areas of groundwater (for example, Ogallala-High Plains aquifer) have been overexploited. Climatic variation and thunderstorms result in highly variable runoff patterns resulting in common patterns of flooding and drying and the intermittent pattern of flow characteristic of many of these streams. Great Plains streams have an important role in ecosystems services: many now support unique and endangered biota. There is, however, little published research available for these streams. Many of the streams that were meandering through grassland ecosystems now are not much more than straight ditches through drainagetiled, repeatedly tilled cropland. Such streams are often heavily sedimented and contain high concentrations of nutrients. The future for prairie streams and historically associated fauna appears bleak unless conservation provisions can be applied to large tracts of land, especially at the watershed scale. Authors furnish discussions of roles of hydrologic disturbances in prairie streams with a focus on microbial processes, macroinvertebrates, and fish fauna.

Forshay, K.J., Morzaria-Luna, H.N., Hale, B., and Predick, K., 2005, Landowner satisfaction with the Wetlands Reserve Program in Wisconsin: Environmental Management, v. 36, no. 2, p. 248-257.

Social and political support for wetland protection has increased with recognition of the ecological services that wetlands provide. The WRP establishes conservation easements on agricultural wetlands in exchange for financial incentives. Administered by NRCS, the WRP provides an increase in wetland acreage, reduction of groundwater contamination from agricultural sources, flood prevention, increases in groundwater recharge, and wildlife habitats. The WRP began as a 9-state pilot program and was expanded to all states in 1995. By the end of 2002, 516,629 hectares $(1,276,618$ acres) were enrolled in the program. Three types of easements are offered: permanent easements where USDA pays 100 percent of agricultural value of the land and full cost for restoration; 30 -yr easements, 75 percent of restoration costs paid; and cost-share where the operator maintains restoration for $10 \mathrm{yr}$ and USDA pays 75 percent of restoration costs.

Authors report results of a four-county 2003 investigation of 25 percent of Wisconsin WRP contracts ( $\mathrm{n}=69$ after rejection of some contracts). Restoration and easement costs, NRCS monitoring records, and surveys of program participants were investigated. Average size of sites was 52 hectares (128 ac). Results include the conclusion that time since restoration was not a significant predictor of any ecological or social variables. The most common wetland community after restoration was fresh meadow. On 74 percent of sites reed canarygrass (Phalaris arundinacea), an invasive species was present. Cost for restoration was $\$ 407 / \mathrm{ha}$ (\$162/ac). Participant survey had an 80 percent response rate with an overall rating of 3.6 plus or minus $0.2(1-5$ scale, with 5 being completely satisfied). Environmental protection was identified by 81 percent of respondents as primary reason to enroll in WRP, while 71 percent identified economic incentives and 60 percent indicated improvement in recreational opportunities drove their decision to enroll. New landowners were more likely to recreate on the WRP land than were original owners. Concerns expressed by WRP participants included restriction on establishment of permanent deer stands, increase in tax rate following restoration, limited communication with NRCS, and lack of participation in restoration process.

Authors conclude that monitoring data on WRP projects is coarse and not collected with enough consistency to 
quantify changes in biodiversity or wetland function. Existing monitoring was only successful in tracking changes in area converted from agriculture to wetland. Authors recommend that a more comprehensive monitoring program should be established to furnish more quantifiable data on ecological issues related to restoration and assessing program outcomes. Results indicate satisfaction with the program by participants and that 89 percent planned to maintain the restorations. Satisfaction was largely driven by participation in the restoration process and economic incentives. Results indicate landowners derive nonmonetary benefits from their wetlands, chiefly recreation. Thirty-three percent of WRP sites surveyed changed ownership since placed in the program.

Authors make the following WRP management recommendations. Management of invasive species should be a priority in the WRP. Monitoring of success and ecological functions of restored wetlands should be more rigorous and systematic over a longer time period (10-20 yr). WRP sites should receive significant tax relief, such as a full tax exemption, following establishment of the easement. State level tax assessments increase for conservation easements classifying them as recreational land. This reduces property taxes for farmers but serve as a disincentive for restoration or wetlands. Communication between WRP participants and NRCS needs to be increased.

General Accounting Office, 2004, Watershed managementBetter coordination of data collection efforts needed to support key decisions: Washington D.C., U.S. General Accounting Office, GAO-04-382, 145 p.

GAO concludes that almost all federal and state agencies contacted believe coordination of water quality data is poor. Reasons for poor coordination include differing objectives for collection of data, inconsistencies in data collection protocols, unawareness of other agencies and their data collection efforts, and overall low priority given to collection of data. GAO recommends designation of a lead organization to coordinate data collection. Those agencies responsible for gathering of water quality data concur that overall shortage of data was a more serious problem than is lack of coordination about knowledge of what information is available.

Genito, D., Gburek, W.J., and Sharpley, A.N., 2002, Response of stream macroinvertebrates to agricultural land cover in a small watershed: Journal of Freshwater Ecology, v. 17, no. 1, p. 109-119.

An evaluation of aquatic macroinvertebrate community structure in watersheds affected by agriculture is reported. Macroinvertebrate samples were collected on first- to thirdorder streams in central Pennsylvania. Taxonomic richness of macroinvertebrates (mayflies [Ephemeroptera], caddisflies [Trichoptera]) was lower in streams draining watersheds with a high percentage of agricultural land. Habitat quality decreased as percentage of agricultural land cover increased. Authors conclude that a high percentage of agricultural land in a watershed reduced the number of sensitive macroinvertebrate taxa resulting in a community that reflects altered habitat quality.

Common macroinvertebrate community responses to agriculturally derived pollution include decreases in overall species diversity, loss of sensitive taxa, and increased abundance of tolerant taxa. Macroinvertebrate communities varied in structure and function in relation to the amount of upstream land in agriculture and site-specific habitat quality. Sites with less agricultural activity upstream had higher total taxa richness. Habitat quality for sampled species decreased when agricultural land use reached approximately 40 percent of the watershed.

Gilley, J.E., Patton, B.D., Nyren, P.E., Simanton, J.R., 1996, Grazing and haying effects on runoff and erosion from a former Conservation Reserve Program site: Applied Engineering in Agriculture v. 12, no. 6, p. 681-684.

Comparisons of runoff and erosion are made from a former CRP field with treatments including undisturbed CRP, twice-over rotational grazing, season-long grazing, haying, and burning. The experimental field was formerly in CRP and planted to 40 percent intermediate wheatgrass (Agropyron intermedium), 50 percent smooth brome (Bromus inermis) and 10 percent alfalfa (Medicago sativa). Runoff and erosion were based on simulated rainfall. No significant difference was found between season-long grazing and burned treatments. Similar amounts of erosion were recorded from twice over rotational grazing, season-long grazing, and hayed treatments. Use of CRP for grazing or haying resulted in a significant increase in runoff when compared to leaving the site in undisturbed CRP cover. Grazing and haying operations resulted in significantly reduced infiltration rates for surface waters. The authors determine, however, that grazing and haying of this CRP site would not result in "excessive" erosion if adequate canopy and soil surface cover were maintained.

Harding, J.S., Benfield, E.F., Bolstad, P.V., Helfman, G.S., and Jones III, E.B.D, 1998, Stream biodiversity-The ghost of land use past: Proceedings of the National Academy of Sciences of the United States of America, v. 95, p. 1484314847.

The study focuses on an investigation of relations between land use and invertebrate and fish diversity in streams. Findings lead authors to conclude that past land use, particularly agriculture, may result in long-term modification to and reductions in aquatic diversity, regardless of revegetation in riparian zones. Preservation of only fragments in a watershed may not be sufficient to recover, or maintain, natural diversity. Although recovery of physical habitat is often possible, the degree to which biological communities can 
recover from long-term disturbance is relatively unknown. By emphasizing the restoration of riparian zones, land managers assume stream conditions can be mitigated by attention only to land adjacent to the stream. Findings indicate that largescale and long-term agricultural disturbances in a watershed limit recovery of stream diversity for many decades. Current stream-restoration philosophy and policy supports the assumption that recovery of stream fauna can occur relatively rapidly after short-term natural and human disturbances are addressed by restoring vegetation. Authors conclude that recovery may take decades. These findings challenge assumptions about both maintenance and future recovery of biodiversity in disturbed stream ecosystems. High or sustained impacts (that is, agriculture) profoundly alter biotic communities and effects of such disturbance persist across decades.

Heimlich, R.E., Wiebe, K.D., Classen, R., Gadsby, D., and House, R.M., 1998, Wetlands and agriculture-Private interests and public benefits: Washington, D.C., USDA Economic Research Service Agricultural Economic Report No. 765,94 p.

This report furnishes an analysis of wetland-policy questions in the context of private landowner and public interests. Although society values wetlands, private landowners usually cannot benefit from them economically unless they are converted to other than natural use (for example, agriculture or development). New incentive programs encourage landowners to make socially acceptable use of wetlands. Federal and State conservation programs are partly responsible for the decrease in wetland conversion over the past $25 \mathrm{yr}$ but falling commodity prices also contributed to reduction in wetland conversion. The share of wetlands converted to agricultural uses declined from more than 80 percent in 1954-74 to 20 percent from 1982 to 1992 . Elimination of current wetland preservation programs would likely increase wetland conversion rates. Preservation and improvement in quality of remaining wetlands is an important goal because fully functioning wetlands provide environmental services highly valued by society. Wetland issues will remain important in agricultural conservation policy requiring continued research to support refinement of policy issues and program administration.

Hodne, C.J., 2005, Concentrating on clean water-The challenge of concentrated animal feeding operations: Mount Vernon, Iowa, The Iowa Policy Project, accessed online

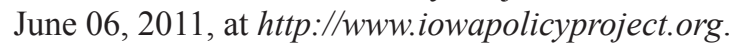

Agricultural industrialization has resulted in large numbers of animals in confinement on a minimal amount of land with external sources of grain used as feed. These operations are commonly referred to as concentrated animal feeding operations (CAFOs). Large amounts of CAFO-generated manure are not readily usable and can exceed needed nutrient levels when applied to surrounding lands. CAFOs are disconnected from crop production and an integrated land base. Areas of high levels of CAFO production experience substantial risks of water pollution. Large-scale, vertically integrated CAFOs have taken over livestock production with all aspects of production, processing, and distribution coordinated through common ownership and management. Although often seen as a way to save small family farms, over time farmers' entrepreneurial, management, and marketing autonomy is diminished with operators often becoming contract farmers to large corporations. CAFOs annually produce approximately 575 billion pounds of manure. The main components of CAFO manure potentially affecting water quality are $\mathrm{N}, \mathrm{P}$, potassium, ammonia, bacteria, feed additives, antibiotics, hormones, salts, trace elements, organic matter, and solids. Contamination can stem from lagoon spills, discharges, seepage, discharge of pollutants to air, and deposition to water and soil. Shallow, private wells used in rural areas are especially vulnerable to contamination by CAFOs.

The author concludes that some policy makers, development planners, and rural residents assume that rural residents need to sacrifice healthy environments for the benefits of local economic growth from CAFOs. Many studies suggest this is an illusory trade-off and rural quality of life is often lost without the promised gain in economic benefits. Large CAFOs are being given advantage over diversified, family farm operations through government subsidized inexpensive grain, tax exemptions, poor environmental regulatory enforcement, and weak control over CAFO siting.

The author makes the following recommendations. A sustainable livestock-production industry requires research, producer education, equitable producer consumer relations, and effective environmental regulation. Improvements can be made through enhanced economic health of livestock producers with moderately sized, diversified operations. There are rising demands for political and social response from domestic and global consumers for safer, healthier meats; restoration and protection of water quality; soil health; and improvements in the general environment. Iowans should have the option to reverse policies that favor unsustainable practices in livestock production. Greater local control over regulatory processes and siting would likely increase local water quality

Knopf, F.L., and Scott, M.L., 1992, Altered flows and created landscapes in the Platte River Headwaters, 1840-1990, in Sweeney, J.M., ed., Management of dynamic ecosystems: West Lafayette, Ind., North Central Section, The Wildlife Society, p.70-74.

Impoundments have altered Platte River flow dynamics, which has affected annual runoff peaks and severe reductions in total discharge. Deciduous gallery forest associated with the river provides local habitats for more wildlife species than currently occur elsewhere, or historically, in the headwaters. Stabilization of hydrodynamics regimes in headwater streams has drastically altered the characteristic fluvial processes that shaped these ecosystems. Unique characteristics of riparian ecosystems are the pulsed flow resulting from spring runoff 
and linear connectively across elevational gradients in the basin. Annual floods tend to maintain wide, shallow, and active river channels with high sediment loads. Changes in hydrology can be attributed to removal of beaver (Castor canadensis), water development/diversion for agriculture, municipal, and industrial use. Woody vegetation on pristine rivers occurred as widely scattered stands of cottonwood (Populus spp.) and willows (Salix spp.). Hydrologic conditions controlled the patterns of establishment and growth of woody riparian species. Crop irrigation recharge to the river raised local water tables and a perennial, lower-flow regime. The ecological consequences of more permanent, but low, summer flows have been the driving ecological force in Platte Rivers and have enabled dramatic movements of faunal assemblages at local and regional levels. Connectivity provided by the riparian corridor established as a consequence of altered flow regimes has allowed western expansion of species such as white-tailed deer (Odocoileus hemionus), fox squirrel (Sciurus niger), and numerous small mammals and avian species to move westward from eastern ecosystems.

Knutson, M.G., Richardson, W.B., Reineke, D.M., Gray, B.R., Parmelee, J.R., and Weick, S.E., 2004, Agricultural ponds support amphibian populations: Ecological Applications, v. 14 , no. 3. p. 669-684.

This report describes an assessment of small, constructed ponds in southeastern Minnesota which were studied to determine their value as breeding sites for amphibians. Small agricultural ponds furnished habitat for at least 10 species of amphibians. Species richness and reproductive success were more closely associated with pond characteristic than those of the surrounding landscape. Ponds surrounded by cropland had similar species richness and reproductive success to ponds surrounded by non-grazed pasture. Ponds used by livestock showed a trend toward lower reproductive success due to higher levels of $\mathrm{P}$ and higher turbidity. Authors conclude that properly managed small ponds may help sustain amphibian populations where natural wetland habitat is rare. Authors recommend limiting access by livestock, reduction of $\mathrm{N}$ inputs by establishing grass-dominated buffers, and avoiding introduction of fish to favor establishment and inhabitation by amphibians.

Lant, C.L., Kraft, S.E., and Gillman, K.R., 1995, The 1990 farm bill and water quality in Corn Belt watersheds - Conserving remaining wetlands and restoring farmed wetlands: Journal of Soil and Water Conservation, v. 50, no. 2, p. 201-205.

This report furnishes results of two surveys addressing estimated potential enrollment of farmed wetlands in the CRP and WRP and farmland-owner attitudes toward Swampbuster. The primary reason some farmers choose not to enroll in wetland programs is economic concern as operators did not want to forgo potential production of crops on wetland acres.
Fifty-one percent of respondents believed enrollment in the wetland programs could leave them with too little flexibility to change use of land as economic conditions changed. Also of concern was the potential change in overall drainage characteristics and possible effects on farming operation resulting from restoration of wetlands. Respondents were concerned destruction of current drainage facilities would be difficult and maintaining wetlands would be too time consuming. In 1992, mean payment for Iowa WRP easement was \$958/ac with \$233/ac for restoration, technical assistance, and settlement fees. Potential participation in wetlandpreservation programs increases with rising payment rates. Although these rental rates are high compared to typical CRP rental rates, they are low compared to costs for other Federal wetland-restoration programs.

Survey results indicate that Swampbuster is unpopular, with only 30 percent of respondents believing it is a necessary or fair program. Nearly 70 percent of respondents believed Swampbuster was an infringement on property rights. Over 70 percent said permitting some economic use of wetlands (pasture, hay) would make the program more acceptable while, 75 percent said wetlands enrolled in Swampbuster should be exempt from property taxes. The Swampbuster program could be made more acceptable to operators if wetland-mapping issues are resolved; property taxes on farmlands subject to Swampbuster are reduced; and limited, periodic, economic use of wetlands is permitted. In addition, if continued, Swampbuster needs consistent enforcement of regulations and constraints to prevent impression of favoritism and arbitrary enforcement perceived by some operators.

Lowe, W.H. and Likens, G.E., 2005, Moving headwater streams to the head of the class: BioScience, v. 55, no. 3 , p. 196-197.

Conservative estimates indicate headwater streams account for more than 70 percent of stream-channel length in the United States. However, because of their typical small size, these streams are often not addressed in natural-resources management. The effects of land use on headwater streams affects many valued ecosystem services including clean water, recreation, nutrient removal, and biodiversity. Growing evidence that the overall health of freshwater systems depends on functions and quality of environmental conditions in headwater streams. Headwater streams are characterized by strong and vital interactions with the systems that surround them. The high sensitivity of ecological processes and natural communities in headwater streams to atmospheric and terrestrial disturbances lead to low thresholds of impact. There is growing evidence that in-stream processes play a significant role in modifying $\mathrm{N}$ input-output balance of headwater watersheds.

Luo, H., Smith, L.M., Allen, L.B., and Haukos, D.A., 1997, Effects of sedimentation on playa wetland volume: Ecological Applications, v. 7, no. 1, p. 247-252. 
Playas within a surrounding cultivated watershed contained more sediments than those within rangeland watershed. On average, playas in cultivated watersheds lost all of their original volume whereas playas within rangeland dominated watershed had lost only about one third of volume. Sedimentation was found to be greater in medium-texture soil than within fine-texture soils. Authors recommend continuation of the CRP and management to address sedimentation be focused on coarser areas of soils and permanent vegetative cover (buffers planted to perennial native grasses) be established around playa wetlands to reduce further loss in volume and changes in hydroperiod. Research is needed to determine the optimum size of buffers. Removal of sediments from playas may be feasible to restore playas deemed of critical value to wildlife.

Marshall, D.W., Fayram, A.H., Panuska, J.C., Baumann, J., and Hennessy, J., 2008, Positive effects of agricultural landuse changes on coldwater fish communities in southwest Wisconsin streams: North American Journal of Fisheries Management, v. 28, no. 3, p. 944-953.

An investigation of relations between CRP enrollment and effects on fish community structure in coldwater streams in southwestern Wisconsin is described. An index of biotic integrity (IBI) for coldwater fish and species richness in streams in areas of relatively high CRP enrollment (21.3 percent of land area) and comparatively low CRP enrollment (12.3 percent of land area) were compared. All streams were sampled prior to implementation of the CRP in the 1970s. Streams were resampled in the same locations in 2000 and 2005 after CRP lands were established.

Fish-community health is often negatively correlated with intensive agricultural land use. In Wisconsin, high runoff associated with intensive farming and steep topography has degraded streams that historically supported salmonids and smallmouth bass (Micropterus dolomieu). Rare non-game fish populations have also become imperiled. High concentration of $\mathrm{P}$ (attributed to agricultural land-use) results in oxygen depletion stemming from excessive primary production in aquatic ecosystems. The goals of this investigation were to determine whether biotic integrity, species diversity, and estimated $\mathrm{P}$ loading in streams differed prior to and after adoption of CRP land practices. Significant acreage was regionally enrolled in the CREP, one result of which was riparian buffer zones were enlarged to $305 \mathrm{~m}$ ( $333 \mathrm{yd}$ ) from stream channels.

The authors found that coldwater fish IBI score increased and the mean number of fish species per stream decreased over time in the high-CRP area relative to the low-CRP area. Mean IBI score in low-CRP streams was 7.2 before CRP implementation and 16.1 after the CRP was established. Within the high-CRP area, mean IBI score increased from 21.7 (poor environmental habitat range) to 56.8 (good environmental habitat range) following CRP establishment. The mean number of species declined over time in streams within the high-CRP area. Predicted $\mathrm{P}$ loading rate declined in both areas over time as agricultural production intensity diminished with greater area devoted to conservation practices. The decline in $\mathrm{P}$ loading was greater within the high-CRP area than within the low-CRP area. Greater responses in the fish community were recorded in the high-CRP area as stenothermal, cool water species (mottled sculpin [Cottus bairdii], brown trout [Salmo trutta]) became dominant. In the low-CRP area, eurythermal species, tolerant of a wider range in water temperatures, dominated both pre- and post-CRP implementation. These species (johnny darters [Etheostoma nigrum], central stonerollers [Campostoma anomalum], and fantail darters [E. flabellare]) declined in abundance within both study areas. The continued dominance of eurythermal fish species in the low-CRP streams presumably reflected continued effects of $\mathrm{P}$ and sediments.

Within the high-CRP area, stream improvements occurred at the watershed scale with fish communities favoring stenothermal species that serve as indicators of more desirable trout streams. This response did not occur within streams in the low-CRP area. The authors concluded the more favorable shift to stenothermal species was attributable to CRP borne from beneficial water and environmental changes at the watershed scale. The improvement in water/habitat quality improved even as instream and riparian habitats in this area continued to degrade from excessive woody shading. Too much growth by boxelders (Acer negundo) inhibited grass and other vegetative growth along streambanks, important habitat for brown trout.

The authors conclude by noting that productive farms remain in operation in the high-CRP area. Most farms historically were in dairy production but many now blend production of row crops, hay, beef cattle, sheep, CRP, and woodlands. This analysis stands as convincing evidence that the current balance of agricultural production and CRP are beneficial to stream ecosystems bringing desirable changes in aquatic habitat quality.

Marty, J.T., 2005, Effects of cattle grazing on diversity in ephemeral wetlands: Conservation Biology, v. 19, no. 5, p. $1626-1632$.

Conservation of rare habitats depends not only on avoiding development but on implementation of appropriate management regimes. In regions lacking native wild grazers, cattle may produce the type of disturbance that helps to maintain diverse communities. Assessment of grazing effects was completed on 72 vernal pools in the Central Valley of California. After $3 \mathrm{yr}$ of treatment, ungrazed pools had 88 percent higher cover of exotic annual grasses and 47 percent lower relative cover of native species. Species richness of native plants declined by 25 percent and aquatic invertebrate richness was 28 percent lower in ungrazed wetlands compared to wetlands with continuously grazed treatment. The absence of grazing reduced the vernal pool inundation period by 50 to 80 percent. Primary cause of decrease in hydroperiod may be due to increased evapotranspiration rates resulting from greater abundance of vegetation in absence of grazing. Decline in invertebrate taxa richness was attributed to altered hydrology. Author concludes the debate over grazing needs to move 
beyond simple conclusions that it is either good or bad. Effects of the grazing needs to be properly evaluated through experimental studies of practical management alternatives.

McCauley, L.A., and Jenkins, D.G., 2005, GIS-based estimates of former and current depressional wetlands in an agricultural landscape: Ecological Applications, v. 15, no. 4, p. 1199-1208.

Wetland drainage of agriculturally dominated landscapes has been extensive and well documented. Current and future efforts to restore wetlands would benefit from information describing historical (that is, pre-settlement) wetland distribution. Shallow, small, depressional wetlands accounted for the majority of wetlands lost; consequently, they should be a priority in restoration. Authors describe several models using hydric soils as input but analyzed by Digital Raster Graphic, Digital Elevational models, or Digital Orthophotography Quarter Quadrangles. Model output varied, but for the study area (Champaign County, Ill.), estimates of wetlands lost ranged from 1,077-4,090 depressional wetlands; this represents a 78 to 92 percent loss of wetlands in the county. Authors conclude wetland losses hold substantial potential to negatively affect species that evolved with a more diverse, numerous wetland complex. Restoration efforts should give priority to wetlands in proximity to other wetlands and seek to restore wetland complexes consistent with former wetland distributions.

Mitsch, W.J., Day, J.W., Jr., Gilliam, J.W., Groffman, P.F., Hey, D.L., Randall, G.W., and Wang, N., 1999, Reducing nutrient loads, especially nitrate-nitrogen, to surface water, groundwater, and the Gulf of Mexico-Topic 5 Report for the Integrated Assessment of Hypoxia in the Gulf of Mexico: Silver Spring, Md., NOAA Coastal Ocean Program, Decision Analysis Series No. 19, 111 p.

Over-enrichment by nutrients is one of the major stresses on coastal ecosystems. A large area (13,000 to $20,000 \mathrm{~km}^{2}$ [5,020 to 7,722 $\left.\mathrm{mi}^{2}\right]$ ) of the Gulf of Mexico suffers from a seasonally depleted oxygen level (less than $2 \mathrm{mg} / \mathrm{l}$ ) due to nutrient-induced eutrophication. Most aquatic species cannot survive at such low levels of oxygen. This hypoxia zone forms in the middle of the most important commercial and recreational fisheries region in the conterminous United States.

The goal of the report is to identify and evaluate approaches for solving the Gulf of Mexico hypoxia problem. Methods for controlling nutrient input, particularly nitratenitrogen, into waterways are reviewed. Among recommendations made are several on-farm practices that include reduction of $\mathrm{N}$ fertilizer application, optimum timing of fertilizer application, and use of alternative crops. The report recommends efforts be increased to restore, or create, 24 million acres (3.4 percent of Mississippi River basin) of riparian zones and wetlands which may reduce $\mathrm{N}$ inputs by 40 percent. Also recommended is restoration of flood prone lands in the Upper Mississippi River Basin to natural wetland vegetation and functions. Additional recommendations are provided. A comprehensive evaluation and monitoring of practices to reduce $\mathrm{N}$ inputs are presented.

Mitsch, W.J. and Gosselink, J.G., 2000, The value of wetlands - Importance of scale and landscape setting: Ecological Economics, v. 35, no. 1, p. 25-33.

Wetlands have value because their functions are useful to humans. The reason wetlands are often legally protected has to do with their values to society, not with intangible ecological processes that occur in wetlands. Wetland value increases with increased use and greater scarcity. Wetlands function best in landscapes as spatially distributed systems. Wetland values are defined by where wetlands are found in the landscape allowing hydrologic and biological fluxes to operate with other systems. Authors suggest that 3-7 percent of temperate-zone watersheds should be in wetlands to provide desirable flood control and water-quality values.

Wetlands are multiple-value systems that perform many processes. Optimization of one function generally comes at expense of other functions. The most valuable product of wetland is public amenities. Once wetlands are lost, restoration of their functions and values is often impossible. At the ecosystem scale, wetlands provide environmental services because they are most effective when abiotic and biotic parts of the ecosystem are synchronized. The term "value" depends on human perceptions. In the absence of human population, or in situations where population is so dense as to make wetlands nonfunctional, wetland value is low to zero. Marginal value of wetlands increases with human development only to a point as wetland functions begin to be lost. Wetland value appears to be maximized when distributed across the landscape and balanced with natural services and human enterprises.

Moore, A.A., and Palmer, M.A., 2005, Invertebrate biodiversity in agricultural and urban headwater streams-Implications for conservation and management: Ecological Applications, v. 15 , no. 4, p. 1169-1177.

Urbanization of agricultural land is the dominant pattern of land use in developed countries leading to agricultural land preservation programs and riparian restoration and protection. Ecological benefits of such efforts are poorly understood and have yet to be fully explained. This paper describes an investigation of stream macroinvertebrate community structure along a gradient of agriculture to urban development in headwater streams with varying amounts of intact riparian buffers in four watersheds near Washington D.C. Without direct analysis between farming practices and macroinvertebrate, diversity results lead to the conclusion that conservation practices implemented on agricultural lands have had positive environmental impacts. 
Macroinvertebrate richness was strongly related to land use with the highest diversity associated with streams in agriculturally dominated landscapes. Agricultural headwater streams were not only more diverse than urban headwaters but levels of macroinvertebrate diversity were high compared to other studies published for agriculturally dominated landscapes. Authors believe that higher richness values may be due to widespread use of "Best Management Practices" (for example, no-till farming, contour farming, grassed waterways, establishment of buffers) in the region that may alleviate stressors caused by cultivation. Authors suggest these practices help protect headwater streams from sediment and chemical inputs to aquatic systems and recommend further research to better understand how specific farming practices influence stream ecosystems.

Mushet, D.M., Euliss Jr., N.H., and Shaffer, T.L., 2002, Floristic quality assessment of one natural and three restored wetland complexes in North Dakota, USA: Wetlands, v. 22, no. 1 , p. 126-138.

Although it has received little rigorous evaluation, floristic quality assessment is a potentially important method for conservation efforts. Relying upon coefficients assigned to each plant species in a region's flora, the authors conclude coefficients assigned subjectively by expert botanists furnish adequate information to perform accurate floristic quality assessments. This method is based on a system where each native plant species is assigned a coefficient of 0 to 10 , where 0 represents species that tolerate almost any disturbance and can be found in almost any habitat. Species with a value of 10 have very low tolerance to disturbance and high fidelity to habitat integrity. Species falling between the two extremes are assigned appropriate coefficients based on professional judgment of botanists familiar with the area. This method was used to assess the quality of plant communities on one natural and three restored wetland complexes in North Dakota. Authors conclude that the floristic quality method provides means to identify high-quality wetlands based on vegetation present. The method provides a means to evaluate restoration efforts, compare plant communities among different sites, monitor change over time, and evaluate response of plant communities to management.

Rabalais, N.N., Turner, R.E., Dortch, Q., Justic, D., Bierman Jr., V.J., and Wiseman Jr., W.J., 2002, Nutrient-enhanced productivity in the northern Gulf of Mexico-Past, present, and future: Hydrobiologia, v. 475-476, no. 1, p. 39-63.

Nutrient over-enrichment is having pervasive effects on coastal ecosystems around the world. The largest zone of oxygen-deplete coastal waters in the entire western Atlantic Ocean is in the northern Gulf of Mexico on the Louisiana/Texas continental shelf influenced by the Mississippi discharge. Nutrient concentration and loading have changed in the last half of the 20th century with average annual nitrate concentration doubling. Estimated affected area in 1993-2001 was $20,700 \mathrm{~km}^{2}$ $\left(8,000 \mathrm{mi}^{2}\right)$. With increase in world population, concentration of populations in coastal areas, agricultural expansion in major river basins and increased energy consumption eutrophication has become a major environmental problem in coastal waters throughout the world. The seasonally hypoxic zone associated with the Mississippi River is among the largest in world's coastal oceans.

Authors conclude that nutrient loading and hypoxic zone can be diminished, but response time would be years. Beneficial changes in marine ecosystem may also have a response time of years. Nutrient management activities and landscape alterations that reduce flux of dissolved $\mathrm{N}$ from the Mississippi watershed are necessary for a reduction in $\mathrm{N}$ load entering Gulf of Mexico. Nitrogen-reduction goals have been successful in Chesapeake Bay, Long Island Sound, and other regions of the world and can be realized in Gulf of Mexico with societal and political will.

Rankin, E.T., and Armitage, B.J., 2004, Protection, restoration, and aquatic life potential in Nature Conservancy areas in the agricultural Midwest-French Creek (New York), St. Joseph River and Fish Creek (Indiana, Michigan and Ohio), and the Mackinaw River (Illinois) - A report prepared for the Nature Conservancy, Indiana Chapter: Columbus, Oh., Midwest Biodiversity Institute, not paginated.

Report documents results of three watershed studies to determine efficacy of various management practices and increase awareness of the importance of watershed management to improve water quality in agricultural watersheds. Knowledge of stressors and limiting factors at watershed and regional scales can help to interpret success or failure of management at smaller scales. Analysis indicates ranges of biological response to nutrient changes resulting from application of best management practices (BMPs) likely are small in short term at local scale. Data at watershed scale illustrate that biological changes that influence populations of sensitive species are related to cumulative impacts. Local projects may not be failures if biological responses are not strong, but should be considered incremental responses to larger scale cumulative impacts at watershed scale.

Instream habitat quality is critical for maintenance of the biotic integrity of stream ecosystems. A framework for successful management of watershed should include application of BMPs in uplands, riparian, and in-channel habitats. It is important to consider watershed and regional conditions before implementing BMPs at local level. Pre-management conditions must be known and post-management monitoring over extended periods of time is essential for refinement and documentation program benefits. Evaluations in watersheds with good water and instream habitat quality are needed to serve as examples and benchmarks for guiding restoration in impaired watersheds. 
This investigation shows that with proper effort, agricultural BMPs can be implemented and changes in biological and chemical patterns can be detected. Habitat restoration in streams is an emerging science that needs more complete integration of geomorphic and ecological principles. Many methods of restoration, large to small, are considered experimental due to lack of information derived from long-term monitoring. Focus of restoration should be on headwater (smaller) streams because they are more manageable and represent the predominant interface between aquatic and upland systems. Multiple approaches are required to protect and restore high quality watersheds. Headwater streams offer the greatest potential for restoration and where BMPs would be most effective especially for nutrient and sediment control. Headwater streams may themselves be relatively low in biodiversity but serve to control ecological functions that strongly influence downstream biodiversity.

Richards, R.P, and Grabow, G.L., 2003, Detecting reductions in sediment loads associated with Ohio's Conservation Reserve Enhancement Program: Journal of the American Water Resources Association, v. 39, no. 5, p. 1261-1268.

The purpose of this study was to determine if minimum detectable change analysis could determine the amount of change in concentrations of water quality constituents needed to be considered statistically significant in Lake Erie CREP. Authors conclude minimum detectable changes for sediment loads were around 6 percent. Changes in load smaller than 10 percent are unlikely to be detectable except when intense sampling over a relatively long period of time (greater than a decade) before and after implementation of conservation practices is completed.

Shields, F.D., Jr., Langendoen, E.J., and Doyle, M.W., 2006, Adapting existing models to examine effects of agricultural conservation programs on stream habitat quality: Journal of the American Water Resources Association, v. 42, no. 1, p. 25-33.

Although conservation funding for agriculture increased about 80 percent in the 2002 Farm Bill, environmental benefits of these programs remain largely unquantified. Authors believe watershed models used in current evaluations (for example, CEAP) which are focused on water quantity and quality are insufficient to assess changes in the quality of aquatic habitats. Current models are hydrologic simulation models which have minimal habitat simulation capability and even more limited links to ecological condition. This is due to the fact that habitat has rarely been considered in design of these models. Impairment to habitat quality in many watersheds are physical degradation of habitat not water quality issues. Existing models used for CEAP emphasize simulation only.

Threats to stream corridors and aquatic habitats in agricultural landscapes are severe. The major hazard in many watersheds is degradation of the physical habitat. Sedimentation and habitat degradation accounted for 53 percent of impaired river and stream miles in the 2000 National Water Quality Inventory. Declines in stream habitat quality threaten 85 percent of the 2,500 plant and animal species listed as imperiled, while only 25 percent are threatened by pollution.

This paper describes specific components that should be added to permit assessments of stream-habitat quality as part of efforts to evaluate effectiveness of farm conservation programs. At a minimum, six additional variables are suggested for use in examination of ecological impacts: land use, streamflow, water temperature, streambed material type, large woody debris, and hydrologic conditions at base flow. Discussions of the implications of each of these variables to quality of aquatic habitats are presented. All of these variables are influenced by presence, location, and quality of riparian buffers. Incorporation of the above variables may substantially contribute to more effective evaluation of conservation programs. Authors conclude more detailed analysis of capabilities of existing models to simulate effects of land retirement, conservation buffers, and management of stream habitats is needed but existing models do provide a wealth of information. The authors advocate additional research to refine combination of simulated or measured habitat quality parameters into methods for assessment of stream habitat quality. Adaptations to methods currently used in the CEAP are presented.

Smith, L.M., and Haukos, D.A., 2002, Floral diversity in relation to playa wetland area and watershed disturbance: Conservation Biology, v. 16, no. 4, p. 964-974.

Within the intensively cultivated Southern Great Plains are 25,000 to 30,000 playa wetlands. Report describes results of plant-community composition in 224 playas and relations to wetland area and watershed characteristics. Playas in cropland-dominated watersheds had more exotic species, higher diversity, and fewer perennial species than playas within grassland-dominated watersheds. Cultivated watersheds contributed to playas dominated by annual and exotic vegetation species. Playas often function as island refuges in a region dominated by agriculture. Consequently, their preservation is important to maintenance of biodiversity for the entire shortgrass plains ecoregion where playas account for only 2 percent of landscape area. Most playas (greater than 75 percent) exist within cultivated watersheds. Cultivation contributes to increased sedimentation of basins, alteration of hydroperiod, and an increase in presence of exotic species as a consequence of greater input of nutrients. Protection of the native shortgrass prairie surrounding playas is fundamental to maintaining playa wetland ecosystem functions. Restoration of playas should focus first on upland watershed then on removal of sediment to restore a more natural hydroperiod.

Smith, L.M., Haukos, D.A., and Prather, R.M., 2004, Avian response to vegetative pattern in playa wetlands during winter: Wildlife Society Bulletin, v. 32, no. 2, p. 474-480. 
Cover to water ratios were manipulated in Texas playa lakes to determine avian response during winter. Cover was managed to yield (cover:water) 75:25, 50:50, and 25:75 ratios. Playa vegetation is dominated by barnyard grass (Echinochloa crusgalli), smartweed (Polygonum spp.), and curly dock (Rumex crispus). Lakes were surrounded by cropland. Greatest bird richness and waterfowl numbers were recorded in 50:50 cover/water ratio wetlands. Authors attribute increased edge and habitat diversity to greater use and numbers of avian species. Management of playas to furnish 50:50 ratio of cover to water and moist soil management is recommended to maximize wetland bird diversity during winter.

Vaché, K.B., Miller, J.M., and Santelmann, M.V., 2002, Water quality modeling of alternative agricultural scenarios in the U.S. corn belt: Journal of the American Water Resources Association, v. 38, no. 3, p. 773-787.

Report documents results of changes in land use and management on water quality in two Iowa watersheds using the simulation model Soil Water Assessment Tool. The objective was to evaluate effects of agriculture on water quality at the watershed scale and provide quantitative estimates of how landscape and management changes may affect water quality. Despite an increase in understanding of physical processes and sources of agriculturally derived nonpoint source pollution and application of BMPs, aquatic systems associated with agriculturally dominated regions continue to receive high loadings of agricultural pollutants. Significant changes in water quality improvement, on order of 50-percent reduction in loading reduction, will require development of integrated watershed plans including innovative land use and management practices. Because these changes in management of agricultural landscapes will be economically costly, public support will be required.

Results imply that restoration of water quality through reduction in nutrient export will require major reconsideration of conservation approaches. Scenarios that included widespread reduction of $\mathrm{N}$ application (10 to 33 percent reduction) along with implementation of other BMPs can result in diminished reduction of $\mathrm{N}$ export by 50 percent or more. Conversion to no-till cultivation and residue management across large areas is an effective approach to reduction in $\mathrm{N}$ export. Decreased production of row crops and wider riparian buffers may reduce $\mathrm{N}$ export by up to 65 percent.

Wang, L., Lyons, J., Kanehl, P., and Gatti, R., 1997, Influences of watershed land use on habitat quality and biotic integrity in Wisconsin streams: Fisheries, v. 22, no. 6, p. 6-12.

Report documents analysis of relations between watershed land use, habitat quality, and biotic integrity for 134 sites in 103 streams throughout Wisconsin. Habitat quality and biotic integrity scores were positively correlated with amount of forested land and negatively correlated with amount of agricultural land in entire watershed and in $100 \mathrm{~m}$ wide buffer along streams. Correlations were generally stronger for entire watersheds than buffers. Decline in habitat quality and integrity scores were apparent in agricultural watersheds only when agricultural land exceeded 50 percent. High rates of urban land use were strongly associated with poor biotic integrity and poor aquatic habitat quality. Levels of urbanization in watershed beyond 10-20 percent consistently had low values.

Generally, land use within the 100-m buffers was similar to the amount of land use for the entire watershed. For urban land, use values in the buffer were almost identical with values for the entire watershed. The amount of agricultural land upstream tended to be inversely related to habitat quality and biotic integrity. Watershed agricultural land use was negatively correlated with the biotic integrity score. When agricultural land use exceeded 50 percent, the integrity and habitat scores decreased. Results demonstrate strong effects of upstream land uses on stream ecosystems. Agricultural land use often increases runoff; destabilizes flow, temperature, and channel morphology; as well as reducing the supply of coarse organic materials. Urban-land uses expand areas of impermeable land surface with substantially increased watershed runoff. With increased runoff, the equilibrium between watershed and stream channel breaks down, causing major change in stream morphology, bank erosion and, degradation in water and habitat quality.

Authors conclude watershed land-use patterns were generally a better predictor of habitat quality and biotic integrity than were riparian land-use patterns. Watershed landforms and distribution of land use within a watershed may be as important as the amount of land used is in influencing stream ecosystems.

Yates, A.G., Bailey, R.C., and Schwindt, J.A., 2006, No-till improves stream ecosystem quality: Journal of Soil and Water Conservation, v. 61, no. 1, p. 14-19.

Authors report increased use of no-till cropping systems has a positive effect on quality of stream habitats in agroecosystems. Measures of stream habitat and water quality in 32 small sub-watersheds show increased use of no-till resulted in improvement in habitat and water quality and benthic macroinvertebrate communities. As a consequence of environmental and economic benefits, no-till cropping has become common across North America over the past two decades. In addition to being the best management practice for maintaining soil productivity, the practice(s) are often recommended as a method for limiting sediments entering surface waters. This investigation examines a gradient of tillage systems with the objective of determining relations between tillage methods and three measures of stream ecosystem quality (water, habitat, and benthic macroinvertebrates). Improvement in stream quality was attributed to reduced amounts of fine sediments in streams as proportion of cropland under no-till increased. Notill systems did indicate a tendency to lead to higher levels of 
nitrates in stream water than reported for conventional tillage. Authors conclude increasing no-till is an effective mitigation tool where sediment and sediment-associated stressors are of primary concern.

Zimmerman, J.K.H., Vondracek, B., and Westra, J., 2003, Agricultural land use effects on sediment loading and fish assemblages in two Minnesota (USA) watersheds: Environmental Management, v. 32, no. 1, p. 93-105.

Agricultural practices have affected stream ecosystems by increasing sediment and nutrient loads; raising stream temperature; and altering channel morphology, hydrological regime, and composition and abundance of riparian vegetation. In the midwestern United States, row-crop agriculture is the leading source of water pollution resulting in 70 percent of streams being classified as "impaired." Changes in structure and function of stream as a consequence of land use often result in reduced diversity of fish, less complex size/age structure of fish populations, higher relative abundance of herbivorous/detritivorous fish, and greater variability in abundance of fish. Simplification of aquatic habitat diversity, such as loss of deep pools or decreased complexity of stream substrates, is the root cause of changes in composition of fish population diversity and structure. Fish assemblages can also be affected by sublethal and lethal effects of suspended sediment resulting in greater abundance of species more tolerant to silt introduced into the aquatic system. Warm water fish species are more sensitive to suspended sediment levels than are salmonid species. These are the species most often associated with intensively farmed agricultural landscapes.

This report discusses findings from field-scale estimates of sediment loss and fish life-history data analysis using simulation models to investigate changes in lands use in two Minnesota watersheds. The purpose of the data analysis was to estimate potential changes in fish assemblages as land use shifts away from conventional row-crop agriculture to include a greater proportion of conservation tillage, riparian buffers, permanent cover crops, and grass. Land-use changes led to reductions in sediment loading of up to 84 percent in one watershed and 49 percent in the other. Reduction in sediment loading may be directly related to reduction in runoff by about 35 percent. A 98-percent reduction in lethal concentrations of suspended sediment was estimated in Wells Creek as a consequence of greater use of conservation tillage, riparian buffers, and permanent vegetation cover.

\section{Buffers and Filter Strips}

Atwill, E.R., Tate, K.W., Pereira, M.D.G.C., Bartolome, J., and Nader, G., 2006, Efficacy of natural grassland buffers for removal of Cryptosporidium parvum in rangeland runoff: Journal of Food Production, v. 69, no. 1, p. 177-184.
Authors report results of an investigation to determine effectiveness of grass buffers to reduce the input of animal (cattle) waste carrying Cryptosporidium parvum into surface waters. Cryptosporidium parvum is a zoonotic protozoal parasite of heightened public health concern due to its ability to enter surface waters used for municipal and recreational purposes. Authors conclude grass buffers retain C. parvum oocysts from cattle manure from entering surface waters potentially contaminating drinking and irrigation water supplies. Results suggest strategically placed buffers can be a beneficial management practice that will minimize risk of waterborne contamination of surface water supplies.

Daniels, R.B. and Gillam, J.W., 1996, Sediment and chemical load reduction by grass and riparian filters: Soil Science Society of America Journal, v. 60, no. 1, p. 246-251.

Authors report results from an investigation of the amount of nutrients and sediment removed by natural and planted filter strips in North Carolina Piedmont. Effectiveness of vegetated filter strips varies with watershed erosiveness and storm intensity but across a wide range of rainfall filter strips reduce sediment load 60-90 percent. Runoff nutrient loads are reduced less than sediment load. Ephemeral riparian channels need a continuous vegetative cover to be effective filters, which is generally not possible under a closed-tree canopy. Forested buffers were effective sediment sinks during dry season but were ineffective during large storm events because of little ground vegetation and resistance to flow. Total sediment decrease through grass and riparian filters was about 80 percent. High volume flows commonly overwhelmed both grass and riparian filters next to cultivated fields.

Das, C., Capehart, W.J., Mott, H.V., Zimmerman, P.R., and Schumacher, T.E., 2004, Assessing regional impacts of Conservation Reserve Program-type grass buffer strips on sediment load reduction from cultivated lands: Journal of Soil and Water Conservation, v. 59, no. 4, p. 134-142.

Paper describes a method to determine regional estimates of CRP area needed to achieve a given percentage reduction of agricultural sediment yield into surface waters. Simulations using Universal Soil Loss Equation (USLE) and Water Erosion Prediction Project (WEPP) model provide estimates of grass buffer strip areas required to achieve targeted reductions of sediment yield

Dillaha, T.A. III, Sherrard, J.H., and Lee, D., 1989, Long-term effectiveness of vegetative filter strips: Water, Environment and Technology, v. 1, p. 418-421.

Report furnishes a summary of filterstrip effectiveness. Taller weeds shaded desirable grasses and reduced filterstrip effectiveness. Mowing, herbicides, and reseeding or combinations of the three could improve effectiveness 
of this conservation practice. Grazing by cattle generally decreases the quality of vegetation cover and effectiveness of filter strips.

Dodds, W.K. and Oakes, R.M., 2006, Controls on nutrients across a prairie stream watershed-Land use and riparian cover effects: Environmental Management, v. 37, no. 5, p. 634-646.

This paper presents a discussion on understanding the scale at which land use influences nutrient loading to define management recommendations and policies to improve water quality. Relations between land use and stream nutrients in a first-order intermittent stream in a prairie watershed (Kansas) are discussed. Total N, nitrate, and $\mathrm{P}$ concentrations were greater in lower portions of the watershed mirroring increased density of row crop agriculture. Land use in the entire watershed had a large influence on downstream water quality; this suggests that nutrient criteria may not be met by addressing land-use issues associated only with permanently flowing streams.

Intermittent streams in grassland-dominated ecosystems and relations to water quality are at present poorly known. Areas formerly in grassland but now dominated by row-crop agriculture contribute substantially to eutrophication problems in the Gulf of Mexico. Nutrient concentrations were found to closely reflect increasing level of agricultural intensity from headwaters to lower reaches. Authors recommend protected riparian zones, including intermittent streams, may help to lessen land- use impacts in the midwestern United States.

Ducros, C.M. and Joyce, C.B., 2003, Field-based evaluation tool for riparian buffer zones in agricultural catchments: Environmental Assessment, v. 32, no. 2, p. 252-267.

Report presents and describes a method to evaluate characteristics and effectiveness of riparian buffers in agricultural landscapes. Based on criteria developed from literature and peer review, a method of scoring perceived effectiveness of buffer zones is provided. The method could be useful for guiding the establishment of riparian buffers and monitoring their effectiveness in furnishing environmental enhancement and improvements in habitat quality. The method is based on physical, hydrological, and vegetative criteria that can be easily collected in the field. Although the authors suggest the method needs further refinement and testing, they believe the procedure is a rapid, relatively simple, and inexpensive method for assessment of the quality and effectiveness of riparian buffers in agricultural ecosystems.

Henningsen, J.C., and Best, L.B., 2005, Grassland bird use of riparian filter strips in southeast Iowa: Journal of Wildlife Management, v. 69, no. 1, p. 198-210.

This report documents results of investigation of breeding grassland bird use of 33, 3-4 year-old CRP filter strips.
Relative abundances of birds and nests were similar between cool-season and warm-season grass plantings. The most abundant avian species recorded were red-winged blackbird (Agelaius phoeniceus), dickcissel (Spiza americana), song sparrow (Melospiza melodia), and common yellowthroat (Geothlypis trichas). Nest success was generally low in all treatments evaluated, with predation being the major cause of nest failure.

Several differences between vegetation characteristics in filter strips planted to cool-season (mixtures of brome [Bromus inermis], orchardgrass [Dactylis glomerata] and timothy [Phleum pratense]) and warm-season (switchgrass [Panicum virgatum]) were recorded. Generally, warm-season planting had more vertically dense live vegetation, taller residual vegetation, and greater plant-species richness (forbs). Grass cover was greater on cool-season filter strips. Cool season grass and legume plantings are more horizontally dense and more resistant to encroachment from weedy plants. Proximity to woody vegetation influenced bird species richness, abundance, and nest abundance. Species richness was higher in non-wooded sites as grassland. Bird species tend to be less abundant, or less likely to nest, near wooded edges. Nest-success estimates were generally low in all treatments (planting mixture, edge type) and were lower than nest success reported for blockshaped CRP fields in Iowa. Authors conclude that the presence of woody vegetation adjacent to filter strips has negative effects on use by grassland birds, but if enhancement of the overall avian community is a goal, establishment of filter strips adjacent to wooded riparian corridors is a reasonable management option. Greater filter strip width potentially can increase use by birds infrequently recorded in existing filter strips.

Johnson, L.B., Breneman, D.H., and Richards, C., 2003, Macroinvertebrate community structure and function associated with large wood in low gradient streams: River Research and Applications, v. 19, no. 3, p. 199-218.

An assessment of the role of large woody debris and macroinvertebrate communities in central Michigan and southeastern Minnesota agricultural regions is described in this report. Although wood was not abundant in these streams and small in size, wood is an important habitat in these aquatic systems. Eighty-six and 95 percent (in Michigan and Minnesota, respectively) of total taxa encountered were found in association with wood. Presence of wood increased average taxa richness by 15 and 10 taxa in Michigan and Minnesota, respectively. Wood in stream systems increases flow heterogeneity by retarding flow and creating plunge pools, changing channel depth and form, and increasing retention of organic/ inorganic matter. Woody material also contributes to shelter for fish species, perching/foraging habitat for higher species of wildlife, and provides food for invertebrates. Despite low abundance of large woody material in streams within developed landscape, the material provides important habitat. Management practices in agriculturally dominated landscapes remove wood and other structures that obstruct flow. These features, however, provide important habitat and contribute to 
diversity in stream ecosystems often lacking in agriculturally dominated regions. Authors suggest that stream clearing practices that result in reduction of diversity in stream and bank structure should be moderated.

Lee, K.H., Isenhart, T.M., Schultz, R.C., and Mickelson, S.K., 1999, Nutrient and sediment removal by switchgrass and cool-season grass filter strips in central Iowa, USA: Agroforestry Systems, v. 44, no. 2-3, p. 121-132.

In the short-term, switchgrass (Panicum virgatum) and cool-season grass filter strips (smooth bromegrass [Bromus inermis], timothy [Phleum pratense], fescue [Festuca arundinacea]) removed about the same amount of sediment. Long-term effectiveness of cool-season grass-filter strips may be limited, however, due to sediment accumulation in this typically low-stature, less-resilient vegetation. Switchgrass may offer higher long-term effectiveness because it produces large amount of litter, has stiff stems, strong root systems, and a growth pattern more uniform and erect than cool-season grasses.

Lovell, S.T., and Sullivan, W.C., 2006, Environmental benefits of conservation buffers in the United States-Evidence, promise, and open questions: Agriculture, Ecosystems and Environment, v. 12, no. 4, p. 249-260.

Conservation buffers can have large environmental benefits by reducing erosion, improving water quality, enhancing biodiversity, and providing habitats for wildlife. However, buffers have yet to be fully accepted by landowners and those who forge agricultural policies in the United States. The authors furnish a review of why buffers have not been accepted as a viable conservation practice, environmental benefits of buffers, and the importance of the correct design of buffers in agroecosystems. Many questions related to design and management of buffers remain unanswered. The recommendations provided include modification of policies to better reflect landowner desires, assessment of buffers at watershed scales, and designing buffers based on aesthetic preferences and regional variation.

The underlying goal of buffers of all types is to enhance environmental quality by impacting ecological health on and beyond the farm by reducing soil loss due to wind and water erosion. Properly maintained, buffers have been shown to remove up to 97 percent of soil sediment prior to runoff entering surface waters. Removal of $\mathrm{N}$ has been shown to range between 40 to 94 percent with 50-percent removal more likely. Buffers have been shown to furnish environmental benefits at specific sites, but much remains to be known about effects at larger spatial scales. Questions about buffer effectiveness as a consequence of their spatial placement, effectiveness and movement corridors for wildlife, and influence on biodiversity at watershed scales are yet to be answered. Long-term management of buffers may be critical to their ultimate success in addressing environmental issues. Regional differences in buffer design and functions need to be addressed. Social and economic constraints affecting landowner acceptance of these conservation options must be addressed as well.

Economic, social, and environmental benefits of buffers are diverse, but farmers are often driven by short-term economic considerations rather than long-term benefits. Costs incurred by landowners have an important impact on the willingness of landowners to change land-use patterns. Although economic incentives may be substantial, many operators are hesitant to participate in governmental programs because they do not want to forgo control of their land, work with the federal government, or are concerned about loss of future economic income.

An issue affecting effectiveness of governmental programs, including buffer initiatives, is a lack of coordination between and within agencies. Goals are often unclear or, to farmers, appear to be inappropriate. The lack of information on long-term management of buffers also appears to have an effect on the adoption of these practices. Design and aesthetic characteristics of landscape buffers have received too little attention. Findings suggest that conservation buffers should be designed so they convey a sense of stewardship and visible signs of care to receive greatest acceptance by farmers.

Authors conclude that, by working at watershed scale, buffer systems could be made more efficient and interconnected, thereby providing greater environmental and social benefits. They also believe greater attention needs to be directed toward correct species composition of vegetation used, appropriate management activities, education, and aesthetic qualities of buffers. Recommendations made to those who direct formulation of policy include greater emphasis on the role of visual quality of buffers to increase public support and consideration of the best approaches to receive the greatest economic benefits to society (for example, purchase vs. easement). Conventional approaches to agricultural policy need to be challenged to create a more sustainable agricultural system.

Lynch, L., and Brown, C., 2000, Landowner decision making about riparian buffers: Journal of Agricultural and Applied Economics, v. 32, no. 3, p. 585-596.

Understanding farmer decision making with regards to property and conservation practices is crucial to implementation of effective conservation programs. Determination of conditions that influence farmer decisions when most benefits accrue to society (for example, establishment of riparian buffers) and not to the landowner is important in setting program incentives and policies. Authors conclude that non-agricultural opportunity costs affect decisions and will be required if environmentally sensitive but high-value land is desired for enrollment additional incentives. Up-front costs for adoption were important determinants in land-owner decisions. Farmers were more sensitive to the relative cost-share rates to establish conservation practices than to relative incentive rates. Authors conclude increasing cost-share rates may be more effective in 
increasing enrollment, or participation in specific conservation practices, than would be increasing rental rates. Up-front signing bonuses encourage more participation than does an increase in annual rental payments. Land values, rental rates, and crop prices affect farmer decisions about participation. In areas with high land values or low rental rates additional incentives such as higher annual incentive rates or signing bonuses may be needed to achieve enrollment goals.

Lyons, J., Trimble, S.T., and Paine, L.K., 2000, Grass versus trees-Managing riparian areas to benefit streams of central North America: Journal of American Water Resources Association, v. 36, no. 4, p. 919-930.

Authors provide a review and comparisons of advantages and disadvantages of wooded and grass/herbaceous dominated riparian buffers. Comparisons are presented on effects of grassed riparian areas on bank stability, erosion, channel morphology, cover for aquatic species, hydrology, water temperature, organic matter inputs, primary production, and macroinvertebrates. Grass-dominated riparian cover may be more effective in reducing bank erosion and trapping suspended sediments than are riparian areas dominated by woody species. Maintenance of grassy riparian vegetation usually requires management, as succession tends to ultimately favor woody vegetation.

Mankin, P.C., Kammin, L.A., Hoffman, C.L., Hubert, P.D., Teisberg, J.E., and Warner, R.E., 2005, Management of conservation buffers for upland wildlife in Illinois: Springfield, Ill., Illinois Department of Natural Resources, Federal Aid in Wildlife Restoration Act Project P-R W-144-R., 72 p.

As of July 2005, 514,877 acres (208,370 hectares) of filter strips had been established in the Midwest, 29 percent $(149,314 \mathrm{ac})$ of which were established in Illinois. This document reports findings on an investigation of Illinois filter strips established under the CRP describing habitat characteristics and use by birds and mammals. Authors find that CRP plantings in the eastern Corn Belt have been minimal and the relatively small amount of CRP has tended to be in covers other than large blocks (that is, whole fields). Grassland birds experiencing the greatest declines in this region were not found to be nesting in filter strips in central Illinois. Authors speculate the filter strips were too narrow to attract these species.

The authors report that most filter strips evaluated were successfully established at first planting, but approximately 20 percent in 2001 and 2003 were not designed adequately for filtering sediments. Unapproved uses of filter strips were documented that included use as driving lanes, farmequipment storage, food plots, junk storage, deposit of dredge spoils, and as a shooting range. By 2003, filter strips included in the evaluation began to decline in quality as a consequence of unapproved uses and poor management (primarily mowing during the nesting season) and invasion by undesirable vegetation. The authors believe that with no provision for follow-up consultation or compliance checks the habitat quality of filter strips will continue to decline. Limited technical assistance, including landowner education, will be required over many years to optimize habitat quality.

Avian use of filter strips was evaluated in fall, winter, and spring/summer. In winter, the number of birds observed did not differ based upon type of grass (cool vs. warm season), but more birds were observed where grass filter strips contained, or were adjacent to, a tree line. Nesting studies were sampled on representatives filter strips $(n=62)$ where 743 nests were found. Overall, nest success was extremely low. Of 521 nests found in herbaceous cover, 82 percent were depredated. Brown-headed cowbirds (Molothrus ater) parasitized 5 percent of nests.

Biomass (relative abundance) of small mammals in conservation buffers was low and species richness was high. Small mammals were more abundant in warm-season grass filter strips than within those planted to cool-season grasses. Authors conclude widespread adoption of conservation tillage and filter strips has benefited mammal species in agriculturally dominated ecosystems and fields where these conservation practices are used may host source populations that spread into more intensively farmed fields or less optimal habitats.

Although filter strips are likely sinks for nesting birds, they do furnish birds, mammals, and reptiles with cover and forage that would not exist in crop fields. Vegetation structure and plant-species composition seem to have more influence over nest-site selection than does the type of grass (cool vs. warm season). Filter strip plantings should be multi-species rather than monocultures. Forbs should be encouraged. The mandate to control weeds should be balanced with recognition that some of these "weed" species (for example, cow parsnip [Heracleum lanatum] and Canada thistle [Cirsium arvense]) are desirable components of habitat for some species of wildlife. Mowing of filter strips should be restricted to occur only after the breeding season. Driving on filter strips and using filter strips as turn-arounds should be prohibited. Authors believe there is no evidence to suggest removal of treelines and woody vegetation would increase use of filter strips by grassland birds in Illinois. It is likely that too narrow a width is the factor limiting use of filter strips by grassland bird species of priority in this region. A width of $100 \mathrm{ft}(30 \mathrm{~m})$ for filter strips is recommended. Finally, authors recommend a focus on establishing blocks of grassland habitat, as filter strips alone cannot stem the decline in grassland birds in this region. Filter strips will have their greatest value to wildlife when used in association with blocks of grassland cover that include pastures, hay fields, and CRP planted to grass in whole field enrollments.

Mayer, P.M., Reynolds Jr., S.K., Canfield, T.J., and McCutchen, M.D., 2006, Riparian buffer width, vegetative cover, and $\mathrm{N}$ removal effectiveness-A review of current science and regulations: Cincinnati, Ohio, U.S. Environmental Protection Agency, EPA/600/R-05/118, 27 p. 
A synthesis of existing literature on effectiveness of riparian buffers to improve water quality by removal of $\mathrm{N}$ from surface and groundwaters is provided. The authors conclude there remains no consensus for what constitutes optimal riparian buffer design or width to achieve maximum effectiveness in removal of $\mathrm{N}$ from surface and groundwaters. The report attempts to identify generalizations and trends described in published literature for improving decisions about establishing, maintaining and restoring riparian buffers. Nitrogen removal effectiveness varied widely among buffers studied. Subsurface removal of $\mathrm{N}$ did not appear to be related to buffer width. Surface-water removal was partly related to buffer width but generally inefficient in removing only a small amount of total nitrogen. In some cases, narrow buffers actually contributed greater amounts of $\mathrm{N}$ into riparian zones. Buffers of various vegetation compositions were equally effective at removing $\mathrm{N}$ in the subsurface but not in surface flow. Soil types, watershed hydrology, and subsurface biogeochemistry may be more important in defining $\mathrm{N}$ concentration. The authors found state and federal guidelines for buffer width varied widely but were generally consistent with published literature recommending buffers 7 to $100 \mathrm{~m}(8$ to $110 \mathrm{yd})$ in width. Proper placement and protection of buffers from soil compaction, loss of vegetation, and stream incision are critical to the effectiveness of buffers. Buffers around stream headwaters will likely be most effective at maintaining overall quality of watersheds and will be most effective when used in conjunction with control of point and nonpoint sources of $\mathrm{N}$ inputs. Riparian buffers are often used to achieve multiple environmental goals which in some cases may require greater width, specific types of vegetation, and incorporation of other special considerations and designs.

Mersie, W., Seybold, C.A., McNamee, C., and Lawson, M.A., 2003, Abating endosulfan from runoff using vegetative filter strips-The importance of plant species and flow rate: Agriculture, Ecosystems and Environment, v. 97, no. 1-3, p. 215-223.

Endosulfan, a chlorinated cyclodiene insecticide, is used extensively on cropland, particularly on east and west coast vegetable crops, to control insects. The presence of endosulfan in surface water is of concern due to adverse impact on human and aquatic life. The pesticide is known to cause metabolic and reproductive disorders in fish and grass shrimp (Palaemonetes pugio), which is a key component of the food chain in estuarine marsh ecosystems. Data on performance of vegetative filter strips in reduction of pollutant loads reaching surface waters is scant, as is information related to the effectiveness of different species of grass used in filter strips. Study compares performance of switchgrass (Panicum virgatum) and tall fescue (Festuca arundinacea) in removal of dissolved endosulfan. Performance of the two species varied with flow rate. At slow flow, tall fescue was more effective than switchgrass in removal of endosulfan. At relatively fast flow, there was no difference between the two grasses. Efficiency of grass filter strips in removing endosulfan declined as flow rate increased but both grasses were more effective than bare ground in abating endosulfan from a fast flowing runoff.

Osborne, L.L., and Kovacic, D.A., 1993, Riparian vegetated buffer strips in water quality restoration and stream management: Freshwater Biology, v. 29, p. 243-258.

Authors furnish a review on effectiveness and limitations of vegetated buffer strips for improving water quality. Riparian zones link aquatic systems with terrestrial catchment and have an influence on physical and chemical substance input to stream ecosystems. In small to mid-size streams, forested riparian zones can moderate temperatures, reduce sediment input, stabilize stream banks, and provide organic inputs. Forested and grass buffers reduced nitrate concentrations in shallow groundwater by up to 90 percent. On an annual basis, forested buffers were more effective in reducing nitrate concentrations than were grassed buffers but were less effective in retaining dissolved phosphorus. Vegetated buffer strips were not as effective in areas where fields are drained by tiles. Alternative practices, such as discharging tiles into constructed wetlands, may be a more effective means of controlling nonpoint source inputs in these situations.

Both forested and grass buffers will require periodic maintenance to sustain maximum performance. Failure to maintain shallow sheet flow and promote infiltration will reduce effectiveness of buffers to trap sediments. Vegetation in intermediate successional conditions is believed to be optimum for sediment capture. Vegetative composition can have an influence on buffer strips effectiveness but selection of appropriate species will be dependent upon specific water quality issue to be addressed. Authors conclude grass buffer strips are generally more socially acceptable in agricultural areas.

Peak, R.G., Thompson III, F.R., and Shaffer, T.L., 2004, Factors affecting songbird nest survival in riparian forests in a midwestern agricultural landscape: Auk, v. 121, no. 3, p. 726-737.

This report provides a discussion of physical factors affecting nest success of songbirds investigated in riparian forest and stream buffers in northeastern Missouri. Spatial characteristics of habitat assessed in three narrow (55-95 m [60-104 yd]) and three wide (400-530 m [438-580 yd]) riparian forests with adjacent grassland-shrub buffer strips and in three narrow and three wide riparian forests without adjacent grassland-shrub buffers. Riparian forests provided breeding habitat for area-sensitive forest species (Acadian flycatcher [Empidonax virescens], wood thrush [Hyocichla mustelina], ovenbird [Seiurus aurocapillus]) and grassland-shrub nesting species (gray catbird [Dumetella carolinensis], Northern cardinal [Cardinalix cardinalis], and indigo bunting [Passerina cyanea]). Buffer strips furnished additional breeding habitat 
for grassland-shrub nesting species. When located in agriculturally dominated landscapes, nest success may be marginal for these species even within wide riparian forests. Negative effects of predation were believed higher in narrow riparian buffers. However, as long as these "sink" habitats are balanced with other more productive habitat types, the authors suggest these types of habitats should be maintained as they may contribute, in some years, to long-term viability for these species.

Richards, C., Johnson, L.B., and Host, G.E., 1996, Landscapescale influences on stream habitats and biota: Canadian Journal of Fisheries and Aquatic Science, v. 53, no. S1, p. 295-311.

Authors describe results of investigation between influences of geologic versus human-induced (anthropogenic) effects on stream ecosystems and macroinvertebrate assemblages in 45 central-Michigan river catchments. Row-crop agriculture and the presence of wetlands were the most important land-use variables influencing amounts of woody debris. Stream buffers were more important than whole catchment data for predicting sediment-related habitat related variables. Authors believe catchment-wide geology and land use may be more important than stream buffers for maintaining and restoring stream ecosystems. The proportion of permanent vegetation in a catchment was vital for mediating land-use impacts on stream habitats. Row-crop agriculture is a major determinant of stream condition. The presence of wetlands influences surface water flow and hydrology affecting morphological development of stream channels. Substrate characteristics and bank erosion were strongly related to factors influenced by stream buffers. Authors conclude influence of landscape cover throughout the drainage basin may be as important as is riparian vegetation in understanding stream ecosystems.

Stauffer, J.C., Goldstein, R.M., and Newman, R.M., 2000, Relationship of wooded riparian zones and runoff potential to fish community composition in agricultural systems: Canadian Journal of Fisheries and Aquatic Science, v. 57, p. 307-316.

An analysis of fish-community composition to riparian cover and runoff potential in 20 Minnesota River Basins streams highly affected (greater than 50 percent area) by agriculture is discussed. Streams with wooded riparian zones had higher biological integrity, species richness, diversity, and percentage of benthic organisms than did streams with open riparian zones. Streams with low runoff potential had higher biological integrity scores and species richness than streams with high runoff potential. Amount of riparian cover influenced fish community composition more than did runoff potential. Authors conclude that, in the Minnesota River Basin, the local riparian zone condition has more influence on fish-community composition than the broad-scale watershed runoff potential. Streams without wooded riparian zones usually lacked instream woody debris and sufficient habitat for a diverse fauna of fish. Authors conclude that, in intensively farmed areas, protection and restoration of riparian vegetation may greatly benefit fish communities.

Semlitsch, R.D., and Bodie, J.R., 2003, Biological criteria for buffer zones around wetlands and riparian habitats for amphibians and reptiles: Conservation Biology, v. 17, no. 5, p. 1219-1228.

Often overlooked for their value to semiaquatic species, terrestrial habitats surrounding wetlands are important for more than the protection of water quality. A close dependence of semiaquatic reptiles and amphibians on terrestrial cover types in proximity to wetlands is exhibited for critical life-history functions such as foraging, overwintering, or nesting. Criteria by which to define habitat requirements for most species and associated regulations to protect spatial relations between wetlands and terrestrial habitats are lacking. Conservation and management plans must consider both local and landscape dynamics; however, core habitats for local populations of species must be defined before issues of wetland and terrestrial connectivity can be addressed. Authors suggest that overall core terrestrial habitat for amphibians ranged from 159-290 $\mathrm{m}(175-317 \mathrm{yd})$ and that of reptiles ranged from $127-289 \mathrm{~m}$ (139-316 yd) from the edge of aquatic sites.

While wetlands vary in many characteristics, the authors suggest that a single, all-encompassing value for the size of core habitats can be used effectively. On private lands, or areas where sustainable land use is the priority, a stratified system of protection zones can minimize impacts of wildlife and desired land uses. Authors propose three terrestrial zones adjacent to core aquatic and wetland habitats: Zone 1: area immediately adjacent to wetland restricted from use and designed to buffer the core aquatic habitat; Zone 2: core terrestrial zone that encompasses the core terrestrial habitat defined by semiaquatic species of priority (for example, amphibians 159-290 m [175-317 yd]); and Zone 3, beyond zone 2 serves to buffer the core terrestrial habitat from surrounding land use. Decisions on how restrictive each zone may be to land-use practices would depend on management goals and species of concern. Authors suggest buffers $15-30 \mathrm{~m}$ (16-33 yd) wide used to protect wetland species in many states are inadequate for effectively protecting habitat for amphibians and reptiles. A table providing summary data for movement data of reptiles from wetlands is furnished in the report.

Teels, B.M., Rewa, C.A., and Myers, J., 2006, Aquatic condition response to riparian buffer establishment: Wildlife Society Bulletin, v. 34, no. 4, p. 927-935.

Authors describe the assessment of changes in condition of aquatic resources resulting from establishment of riparian buffers established under the CREP in northern Virginia. A fish IBI and Stream Visual Assessment Protocol (SVAP) are used 
to determine changes in aquatic condition. Improvements in stream condition were recorded at some sites within one year of buffer establishment. While not all sites evaluated indicated positive trends mean SVAP and IBI scores for buffered sites increased while results on control sites showed no change or were downward. Authors conclude buffers alone cannot be expected to protect streams. Riparian restoration should be planned in concert with other conservation practices applied at the watershed scale to optimize effectiveness of buffers.

Buffer establishment improved stream bank cover, decreased sedimentation, decreased manure/nutrient inputs, and improved appearance of water. Positive results from restoration were most evident at the most degraded sites, leading to the conclusion that unless upstream influences are overwhelming, the greatest response to establishment of buffers can be expected at sites with a high level of degradation. Smaller than average drainage areas (less than $58.8 \mathrm{~km}^{2}[22$ $\left.\mathrm{mi}^{2}\right]$ ) also may be expected to exhibit the greatest observable response. The authors conclude implementation of a single practice (such as buffers) should not be expected to protect streams and their biota from all adverse impacts that occur at the landscape scale. They also caution that ecological response cannot always be expected to occur rapidly and some functions may take years to respond (for example, growth of trees to sufficient height to affect aquatic habitat variables).

Valdivia, C., and Poulos, C., 2009, Factors affecting farm operators' interest in incorporating riparian buffers and forest farming practices in northeast and southeast Missouri: Agroforestry, v. 75, no. 1, p. 61-71.

Authors report that the strongest positive factor in increasing Missouri farmers to adopt riparian buffers and forest farming is enhancing knowledge about the conservation practices. How farmers value the environment and future generations was reported as one of the strongest effects on interest in the practices. CRP payments had no effect on interest in enrollment. The authors conclude values and attitudes of landowners appear to be good indicators of interest in both practices. Older farmers were found to be less interested in the practices. For practices not perceived as commercial, or as a sole or important source of income, non-monetary motivations may be a driving force in interest and adoption of practices. In other words, environmental concerns have value in farmer decisions.

Wenger, S., 1999, A review of the scientific literature on riparian buffer width, extent, and vegetation: Athens, Ga., University of Georgia, Office of Public Service \& Outreach, Institute of Ecology, 59 p.

The author provides a document to establish a defensible basis for determination of riparian buffer size and vegetation composition based on his review of more than 140 relevant documents and publications. Although buffers as narrow as $4.6 \mathrm{~m}(15 \mathrm{ft})$ have been shown to be effective in trapping sediment and reducing channel erosion, long-term studies suggest much wider buffers are more effective and needed. An absolute minimum width of $9 \mathrm{~m}(30 \mathrm{ft})$ is suggested. To be most effective buffers must extend along all streams including intermittent and ephemeral channels. Buffer widths in relation to phosphorous and nitrate control are discussed as are recommendations for enhancement of aquatic terrestrial habitat quality. The report focuses mainly on southeastern ecosystems and restoration of wooded vegetation in buffers.

\section{Woodland Management}

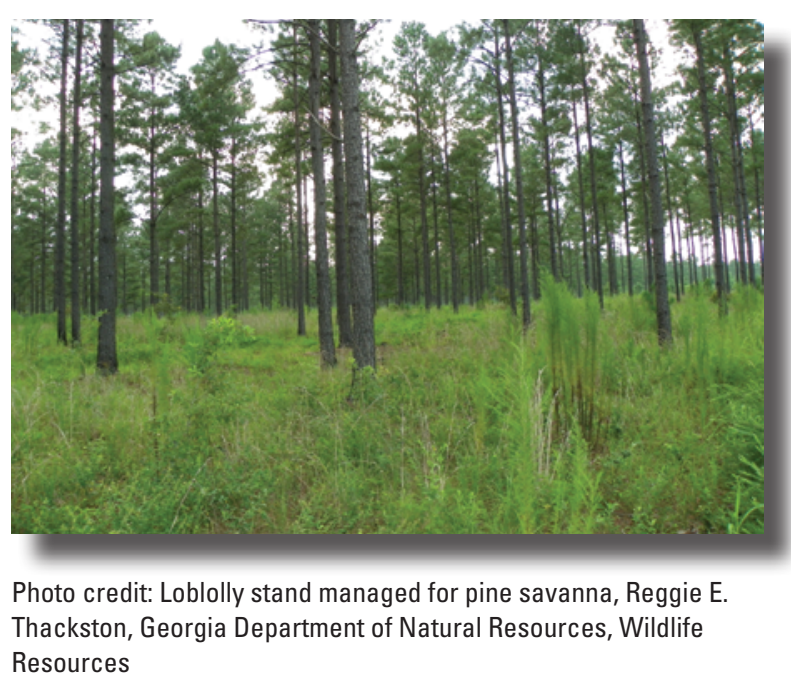

Allen, A.W., 1995, Agroforestry and wildlife-Alternatives and opportunities, in Rietveld, W.J., Proceedings of agroforestry, sustainable agriculture symposium, 7-10 August, 1994: Fort Collins, Colo., U.S. Forest Service General Technical Report RM-GTR-261, p.67-73.

This report provides a discussion of integration of agroforestry practices into existing farming operations to benefit wildlife. Presentation of spatial design considerations of tree-dominated cover types within agricultural ecosystems to benefit selected species of wildlife. A discussion of potential negative effects of tree/shrub-dominated covers to endemic avian grassland species is presented.

Allen, A.W., Bernal, Y.K., and Moulton, R.J., 1996, Pine plantations and wildlife in the southeastern United States-An assessment of impacts and opportunities: Washington, D.C., U.S. Department of the Interior National Biological Service, Information and Technology Report 3, $32 \mathrm{p}$.

This report documents growing dependence on southeastern forest products and the major role private lands will play in provision of timber resources in future decades. However, the priorities of owners of non-industrial, private, 
forests (NIPF) suggest nontimber-related financial investment, recreation, and aesthetic considerations will increasingly define acceptable management goals. Wildlife is a principal factor affecting management on a growing number of privately owned forestlands. Within the next $50 \mathrm{yr}$, the area of even-aged pine plantations, including CRP, on southeastern NIPF lands is projected to exceed 20 million acres $(809,356$ hectares). Silvicultural prescriptions applied influence wildlife habitat quality within, as well as across, stand boundaries and may potentially influence habitat distribution on a landscape scale. Various alternatives in physical design, location, and management of pine plantations are presented to mitigate negative effects of large-scale dependence of even-aged forest management on wildlife habitat.

Bassett-Touchell, C.A., and Stouffer, P.C., 2006, Habitat selection by Swainson's warblers breeding in loblolly pine plantations in southeastern Louisiana: Journal of Wildlife Management, v. 70, no. 4, p. 1013-1019.

Swainson's warblers (Limnothlypis swainsonii) are typically associated with bottomland hardwood forests but also breed in even-age plantations of pine. Authors report investigation of Swainson's warbler use of loblolly pine (Pinus taeda) plantations of various age classes and management histories in southern Louisiana to determine stand structure preferences of the species. The warblers were found in pine stands that had well-developed canopy closure, abundant understory vegetation and sparse ground cover. Swainson's warblers were recorded as using 7- to 24-yr-old, unthinned, even-aged loblolly pine stands as breeding habitat. Authors conclude that even-aged, thinned stands are not used as breeding habitat by this species. A mosaic of even-aged stands within a landscape is recommended to furnish habitats for avian species requiring early and mid-successional habitats. Use of pine plantations by Swainson's warblers is believed to begin when stands reach $7 \mathrm{yr}$ of age. Use will continue only if the stands remain unthinned.

Cable, T.T., 1991, Windbreaks, wildlife, and hunters, in Rodiek, J.E., and Bolen, E.G., eds., Wildlife and habitats in managed landscapes: Washington, D.C., Island Press, p. $35-55$.

Even though their value is widely recognized, windbreaks continue to be lost due to removal for farming. Windbreaks deteriorate in condition and quality as they become decadent. As trees and shrubs die over time, less protective cover is furnished. Hedgerows in five midwestern states are being lost at a rate of 0.6 to 3.1 percent/yr. The degree of importance of windbreaks varies according to needs of specific wildlife species; however, they are important to resident species as well as migrants. Less than 3 percent of Great Plains is forested. Although woodland habitats are scarce, woodland birds account for 46 percent of avifauna in western Kansas.
Functions of windbreaks as wildlife habitat include reproductive, escape, and protective cover. Windbreaks are particularly important to many wildlife species during severe winter weather. Shelterbelt presence may result in higher rates of predation on ground nesting birds in vicinity of wooded cover. Shelterbelts provide additional sources of food (both seed and insects). The number of species and individuals completely or partially insectivorous increased as the size of the windbreak increased. Windbreaks serve as wooded islands in agricultural landscape that can serve as travel corridors and dispersal habitat between riparian habitats and other wooded covers. The value of shelterbelts to wildlife is typically a function of size, number of rows, plant diversity, and height. In general, windbreaks furnish greater benefits to wildlife if located in, or adjacent to, grain fields rather than grazed pasture.

Carmichael Jr., D.B., 1997, The Conservation Reserve Program and wildlife habitat in the southeastern United States: Wildlife Society Bulletin, v. 25, no. 4, p. 773-775.

Author presents a discussion focused on the lack of significant wildlife benefits of CRP in southeastern states compared to those benefits realized in Midwest and Great Plains states. A discussion of limitations and negative effects of pine plantations and tall fescue (Festuca arundinacea) as CRP covers in southern states is presented. Pine plantations ultimately represent loss of early successional and agricultural habitats. Fescue forms dense sod impenetrable by smaller animals. Both practices have provided only limited benefits to wildlife. The report provides a summary of recommendations to improve new CRP and argues for FSA and wildlife professionals to commit to improvement in regional conservation policies.

Frey, G.E., Mercer, D.E., Cubbage, F.W., and Abt, R.C., 2010, Economic potential of agroforestry and forestry in the Lower Mississippi Alluvial Valley with incentive programs and carbon payments: Southern Journal of Applied Forestry, v. 34 , no. 4 , p. $176-185$.

Conversion of bottomland hardwood forests in the Lower Mississippi Alluvial Valley (LMAV), the historical floodplain of the Mississippi river below the confluence of the Ohio River, to agricultural production has brought loss of ecosystem services. Conversion of these lands to agriculture and other uses has reduced the original bottomland hardwood forest ecosystem to only 25 percent of its original extent. What remains suffers from fragmentation, altered hydrology, excessive sedimentation, water pollution, invasive exotic plants, and indiscriminant harvest of timber. Consequently there has been significant reduction in wildlife habitat, flood mitigation, groundwater recharge, nutrient uptake, sediment deposition, and $\mathrm{C}$ sequestration. Some of these services could be enhanced through establishment of forested conservation buffers on agricultural land through enrollment-conservation programs that include the CRP and WRP. Forestry and agroforestry on these 
sensitive lands may assist other efforts to restore bottomland hardwood forests in the LMAV. Adoption of these programs by landowners depends on sufficient financial returns at least equal to what could be produced by agricultural crops. This study investigates private profitability of agroforestry, production forestry, and annual cropping to evaluate the economic incentives for landowners to adopt agroforestry systems in the LMAV. Analysis was based on expert panels (Delphi technique), government databases, and input from regional agricultural and forestry institutions.

The authors find that, without governmental incentive payments, agroforestry and forestry conservation practices are unlikely to be adopted by landowners over much of the LMAV. Only pine silvopasture, production of cottonwood (Populus deltoides), sawtimber, and cottonwood alley cropping were competitive with potential income from agriculture and then only on the most marginal lands. The WRP and CRP Conservation Practice 22 (riparian buffers) were found to be economically competitive only in limited areas, with both generally falling below agriculture in profitability. Interest by landowners in adopting forestry/agroforestry may increase if markets for $\mathrm{C}$ sequestration and biomass production become practical. However, recent increases in commodity prices make adoption of forestry practices even less appealing to agricultural producers. The authors conclude that more direct payments from governmental programs and conservation organizations will be required for landowners to convert agricultural lands to uses that restore depleted ecosystem services in the LMAV.

Hoefer, P.J., Fechner, G.H., and McDonald, S.E., 1990, Trees are the answer-42nd Annual Meeting, Forestry Committee, GPAC—June 1990, Colorado Springs, Colorado: Colorado Springs, Colo., Great Plains Agricultural Council Publication 132, $112 \mathrm{p}$.

The central theme of federal agricultural policy has been control of variability in agricultural production and prices. During first 150 years of American history, federal policy successfully promoted expansion of United States farmland. Current policy is shifting focus to supply management by placing restrictions on resource use rather than just land use. The greatest need for education and research rests with integrating conservation practices with cropping systems. The 1980s may be viewed as a transitional decade for agricultural policy shifting focus from production control to production management. The environmental impacts of alternative agricultural production-control policies have been considered during the development and implementation of legislation. Since the 1930s, agricultural policies have sought to modify farmers' allocation of resources almost exclusively through use of positive and negative incentives. The peak of U.S. farmland acreage occurred in the early 1950s when acreage devoted to crops peaked at nearly 395 million acres. Total production of basic commodities has grown rapidly since the 50 s as technology brought increases in productivity. Federal policies designed to boost agricultural output through research and extension continues to achieve this goal.

Jones, P.D., Mixon, M.R., Demarais, S., 2009, Habitat quality following mid-rotation treatment in Conservation Reserve Program Pines: Journal of Wildlife Management, v. 73, no. 7 , p. 1166-1173.

Mid-rotation pine plantations often have a hardwood midstory that limits development of early succession habitats important to white-tailed deer (Odocoileus virginianus), northern bobwhite quail (Colinus virginianus), as well as other grass-dependent species. Imazapyr herbicide and prescribed burning were applied to 13-22-yr-old loblolly pine (Pinus taeda) plantations in southeastern Mississippi to determine effects on creation of earlier succession habitat supporting greater abundance of grasses and forbs. Each plantation had been thinned once between years 12 and 16. Dominant woody competitors were sweetgum (Liquidambar styraciflula) and Chinese privet (Ligustrum sinense). All fields were enrolled in CRP or the Forestry Incentives Program. Herbicides were applied October-December, and prescribed burns were completed January-March.

Application of herbicides and prescribed fire created a two-layered forest structure potentially benefiting wildlife species associated with pine-grassland communities. The herbicide/fire treatment resulted in a more open understory with greater coverage of debris and herbaceous plants than recorded in non-treated plots. Autumn and winter food plant coverage for quail was not different between treatments but accessibility was improved in treated plots. Nesting cover was improved in treated plots. Increased coverage of forbs furnished a more diverse forage base for deer. The authors suggest mid-rotation pine plantations enrolled in cost-share programs should be treated with selective application of herbicide followed by periodic prescribed fire and thinning to maintain early succession conditions.

Londo, A.J., Traugott, T.A., Dicke, S.G., and Roberts, S.D., 2002, How to determine when your Conservation Reserve Program (CRP) pine plantation is ready to thin, in Proceedings of the Eleventh Biennial Southern Silvicultural Research Conference, 11, Knoxville, Tenn., 20-22 March 2001: Asheville, N.C., USDA Forest Service General Technical Report SRS-48, p. 159-162.

In Mississippi alone, 308,000 acres of pine plantations have been established under the CRP. Over 1.2 million acres have been established under the program overall. At the time of this report, the authors suggest many plantations in Mississippi will be ready for initial thinning. Timing and frequency of first thinnings should be determined by site quality and landowner objectives. The authors conclude, however, that initial thinning of pine plantations is often considered to be as income source for landowners and not a method for 
improvement of the stand. The authors present criteria upon which to base pine-management decisions that include: stand density, natural pruning height, average diameter of trees, height of dominants and codominants in stand, and basal area growth rate. Recommendations are made from a silvicultural perspective to determine optimum time for first thinning of loblolly pine (Pinus taeda) plantations.

Mixon, R.M., Demarais, S., Jones, P.D., and Rude, B.J., 2008, Deer forage response to herbicide and fire in mid-rotation pine plantations: Journal of Wildlife Management, v. 73, no. 5 , p. $663-668$.

Mid-rotation pine plantations enrolled in cost-share programs (for example, CRP) often have a substantial hardwood mid-story that limits desirable understory growth for whitetailed deer (Odocoileus virgininaus). Application of imazapyr herbicide and prescribed fire effects on understory composition in 13-22-yr-old loblolly pine (Pinus taeda) plantations in Mississippi is reported. Evaluation was undertaken 1 and $2 \mathrm{yr}$ post-treatment. Deer foraging habitat was improved by greater growth of nutritious forbs following treatment. Results support the use of selective herbicide and prescribed fire to improve deer foraging habitat in pine plantations enrolled in conservation cost-share programs. In addition to improvements in deer habitat, enhancement of habitat for avian species of conservation concern was also noted. It has been shown that control of woody understory vegetation in pine plantations substantially improves pine growth making the management financially viable over the long-term.

Nuttle, T., and Burger, L.W., 1996, Response of breeding bird communities to restoration of hardwood bottomlands, in Annual Southeastern Association Fish and Wildlife Agencies, 50, Hot Springs, Ark., October 5-9, 1996, Proceedings: Tallahassee, Fla., Southeastern Association Fish and Wildlife Agencies, p. 228-236.

Bird-community response in relation to restoration of bottomland hardwoods is reported. Stands sampled included hardwood plantations that ranged from $0-4,7-15$, and $21-27$ yr old and natural sawtimber (greater than 50 yrs old) stands. Oaks commonly planted in plantations sampled included cherrybark (Quercus pagoda), Nuttall (Q. nuttallii), and water $(Q$. nigra) and willow oaks ( $Q$. phellos). Mean number of avian species increased with stand age. Plantations in the 21-22 and $7-15$ age classes supported a substantial portion of the potential forest avian community but lacked area-sensitive and selected late-successional species. Young plantations provided temporary habitat for regionally declining grassland bird species.

Authors suggest that management prescriptions for hardwood plantations that mimic natural succession (such as planting of multiple hardwood species and thinning) may enhance restoration efforts. Because oaks are slow growing, inclusion of faster-growing species in addition to oaks may enhance structural diversity of plantations at a quicker rate benefiting avian species. Thinning of hardwood plantations $20-25 \mathrm{yr}$ after establishment was recommended to allow development of ground and midstory vegetation to enhance structural and habitat diversity.

O'Leary, C.H., and Nyberg, D.W., 2000, Treelines between fields reduce the density of grassland birds: Natural Areas Journal, v. 20, no. 3, p. 243-249.

Fragmentation of grassland by fencerows could be a factor contributing to decline of grassland birds. Avian species sensitive to area of available habitat may be especially affected by introduction of wooded covers into grassland habitats. Recommendations to maintain habitat quality for grassland birds are furnished that include: reduce woody vegetation within fields, replace woody vegetation separating fields with grass, and connect fields to furnish larger interior area.

Okwudili, O.O., and Wheelock, G.C., 1999, Assessing the retention potential of Conservation Reserve Program practices in Alabama: Southern Journal of Applied Forestry, v. 23 , no. 2 , p. $83-87$.

CRP participants were surveyed to determine potential utilization of CRP acres if contracts expired without opportunities to re-enroll in the program. Survey results imply that 90 percent of lands planted to CRP trees would be retained after contract expiration, thus providing continuing environmental benefits. However, 60 percent of lands planted to grasses would be converted back to row-crop production. Authors suggest that, to maintain soil loss benefits and reduction in excess production, tree planting should be encouraged on new enrollments in CRP.

Pienaar, L.V., and Shiver, B.D., 1993, Early results from an old-field loblolly pine spacing study in the Georgia Piedmont with competition control: Southern Journal of Applied Forestry, v. 17, no. 4, p. 193-196.

Information is presented in this report on yield potential of improved loblolly pine (Pinus taeda) on marginal cropland with control of herbaceous competition. Early growth rates of seedlings exceeded those recorded in plantations without vegetation control. After $8 \mathrm{yr}$, average tree height, average diameter at breast height, and basal area/acres were more than twice the average growth rate in plantations without herbicide treatment.

Pierce II, R.A., Farrand, D.T., and Kurtz, W.B., 2001, Projecting the bird community response resulting from the adoption of shelterbelt agroforestry practices in eastern Nebraska: Agroforestry Systems, v. 53, p. 333-350. 
The purpose of this investigation was to develop a methodology for the evaluation of changes in wildlife habitat occurring as a consequence of conservation practices at the farm level. More specifically, the objective was to project changes occurring within avian communities as a consequence of establishing shelterbelts at the farm landscape level. The Habitat Analysis and Modeling System (HAMS) was used to project composition and spatial patterns resulting from the establishment of shelterbelts with resultant impacts on associated avian communities. Policies promoting shelterbelts create edge habitats which ultimately favor avian species associated with forest edge. Avian species associated with grassland habitats would potentially be negatively affected.

The authors note that little research has been completed to assess wildlife habitat changes resulting from adoption of agricultural policies promoting agroforestry. Appraisal of wildlife habitats within agroecosystems requires an ability to accurately forecast consequences of land-use changes. The ability to conduct such research has been enhanced with technological advances in remote sensing, geographical information systems, and methods to quantify spatial attributes of the landscape. Because agricultural policies affect species across broad scales it is important to assess interrelationships of land management on large regional scales when developing agricultural conservation policies.

Rutledge, B.T., and Conner, L.M., 2002, Potential effects of groundcover restoration on breeding bird communities in longleaf pine stands: Wildlife Society Bulletin, v. 30, no. 2, p. 354-360.

An investigation of how disturbed vs. undisturbed ground cover in Georgia longleaf pine (Pinus palustris) forest may have on distribution and abundance of ground nesting birds is reported. Investigation was in area of longleaf pine forest where historical agricultural use resulted in disturbed ground cover. Undisturbed sites were dominated by native vegetation, chiefly wiregrass (Aristida beyrichiana). Prescribed fire has been applied to these sites on a 2-yr rotation. Undisturbed sites were used as a surrogate for nonexistent restored longleaf pine stands.

Although differences in abundance of some species were recorded, the authors conclude that avian species richness and diversity within disturbed and native groundcovers were very similar. Discussion of avian species' relations with both cover types is presented. The authors suggest that breeding birds may be more influenced by the presence of an herbaceous understory than by restoration of specifically native vegetation species. Over the long term, it is believed breeding bird communities will be relatively similar regardless of if native ground cover is established in the restoration of longleaf pine stands. However, from a management perspective, native groundcover restoration will enhance the ability to apply prescribed fire as a tool in stand development and maintenance.
Sladek, B., Burger, L., and Munn, I., 2008, Avian community response to mid-rotation herbicide release and prescribed burning in Conservation Reserve Program plantations: Southern Journal of Applied Forestry, v. 32, no. 3, p. 111-119.

Due to widespread changes in land use and control of wildfire, early successional plant communities are declining in the forest-dominated Southeast. In this region, shrubdependent birds associated with early successional habitats have experienced a 0.99 percent decline per year from 1966 to 2004. Approximately 1.6 million acres of CRP pine plantations have been established across the southeast. Given this vast area, the potential to manage these habitats to benefit species of management concern is significant. The 2002 Farm Bill permits mid-contract management on CRP plantations that include: thinning, prescribed burning, disking, and use of herbicides. If managed with appropriate disturbance regimes, pine plantations established under the CRP have potential to furnish habitat for declining pine/grassland and shrub-successional bird species. Both prescribed fire and herbicides are used to reduce hardwood midstory trees and encourage enhanced growth of grasses, forbs, and other seed-bearing plants characteristic of more open, early successional habitats. Reduction of midstory vegetation in wooded environments typically results in a change in the avian community from dominance of forestinterior species to those more associated with grassland and early successional habitats.

This report focuses on the effects of the herbicide Imazapyr and prescribed burning on avian-community characteristics and pine growth in thinned, midrotation loblolly pine (Pinus taeda) CRP plantations in the Upper and Lower physiographic regions of Mississippi. The pine plantations included in the study were 15-18 yr old and recently thinned. Dominant understory vegetation in study sites were Chinese privet (Ligustrum sinense) and sweetgum (Liquidamber styraciflua). Treated sites were applied with $0.2 \mathrm{~kg}(7 \mathrm{oz})$ imazapyr and a nonionic surfactant in 75.7 1 (19.8 gal) of total spray solution per hectare $(2.5 \mathrm{ac})$. Prescribed burns were applied in January-February.

One year following treatment, understory hardwood and woody shrub basal area was reduced by 69 percent. Two years following treatment, percent midstory hardwood canopy differed significantly between treated and control (untreated) plots. Mean growth increments (mean diameter, total height, and basal area) of pine trees did not differ between treated and control sites. In both years following treatment, early successional and shrub-associated avian species richness was significantly greater within treated plots than in control plots. Of four early successional/shrub associated species (common yellowthroat [Geothlypis trichas], indigo bunting [Passerina cyanea], downy woodpecker [Picoides pubesens], summer tanager [Piranga rubra]), all were more abundant in treated plots. Because control plots favored habitat for several forestinterior species of management concern (hooded warbler [Wilsonia citrine], Kentucky warbler [Oporonis formosus], and 
white-eyed vireo [Vireo griseus]), the authors recommend that forest management maintain a mosaic of hardwood midstory control rather than broad-scale application of midstory thinning in CRP pine plantations. Detailed discussion of avian species and community level response to habitat management are presented in the report.

Twedt, D.J., Somershoe, S.G., Hazler, K.R., and Cooper, R.J., 2010, Landscape and vegetation effects on avian reproduction on bottomland forest restorations: Journal of Wildlife Management, v. 74, no. 3, p. 423-436.

Restoration of forests has taken place on over 200,000 hectares $(494,220$ acres) of agricultural land in the Mississippi Alluvial Valley. Decisions on where to restore bottomland forests ultimately depend on landowner objectives. Ecologists have advocated planting a diverse mix of densely spaced, fast-growing tree species for forest-restoration projects in this region. Planted in areas adjacent to existing forest land, this procedure has benefited area-sensitive forest-dependent birds. The effectiveness of this policy was assessed on 36 bottomland sites. Restoration sites evaluated ranged from 2-15 yr old. The majority of sites (25) were on private land and enrolled in the WRP. Most sites had been planted to water oak (Quercus nigra), willow oak ( $Q$. phellos), Nuttall's oak ( $Q$. nuttallii), green ash (Fraxinus pennsylvanica), sweet pecan (Carya illinoinensis), and bald cypress (Taxodium distichum).

Avian densities and breeding-bird abundance were influenced by landscape composition and vegetation structure on restoration sites. Detailed avian habitat relationships found for grassland, shrub-scrub, and slow and fast growing tree-associated species are presented. Bottomland restoration sites planted to slow-growing species retain grassland like habitat conditions for up to $10 \mathrm{yr}$ following planting. Such sites, with shorter and sparser tree cover, attracted bird species characteristic of grassland habitats. Due to low reproductive success, these sites were determined to be population sinks for these species. Restoration sites with taller trees and higher stem densities were found to support species characteristic of shrub-scrub and forested habitats. Compared to sites in agriculturally dominated landscapes, restoration plantings adjacent to existing forest experienced increased invasion rates of woody plants supporting greater bird densities and nest success. To maximize avian benefits, the authors' recommend restoration efforts are within largely forested landscape of at least 8,000 hectares (19,760 acres). Planting recommendations for bottomland sites should be at least $1,000 \mathrm{stems} / \mathrm{ha}$ (400 stems/acres). Forty to seventy percent of these trees should be a mixture of light-seeded, soft-mast bearing, fast-growing tree species.

Twedt, D.J., Wilson, R.R., Henne-Kerr, J.L., and Grosshuesch, D.A., 2002, Avian response to bottomland hardwood reforestation-The first 10 years: Restoration Ecology, v. 10 , no. 4, p. 645-655.

Bottomland hardwood forests were established on agricultural cropland in Mississippi and Louisiana with either oak (Quercus spp.) or eastern cottonwood (Populus deltoides) planted. Avian colonization was evaluated at years 2 and 10 subsequent to planting. Rapid growth of cottonwood resulted in forest structure supporting greater species richness of breeding birds and greater avian density than recorded on oak-dominated sites. Fourteen species of shrubscrub species and early successional forest birds were characteristic of cottonwood sites 5 to $9 \mathrm{yr}$ after planting. Authors recommend reforestation for avian conservation should include a high proportion of fast-growing species (such as cottonwood) to allow for earlier colonization by avian species during the period when slower-growing hardwoods are gaining height and structural diversity. Cottonwood is relatively short lived with other hardwood species replacing it in dominance over time

Van Lear, D.H., Carroll, W.D., Kapeluck, P.R., and Johnson, R., 2005, History and restoration of the longleaf pinegrassland ecosystem-Implications for species at risk: Forest Ecology and Management, v. 211, p. 150-165.

At the time of European discovery, the longleaf pinegrassland (Pinus palustris-Poaceae) ecosystem is believed to have occupied over 30 million hectares (greater than 12.1million acres) which was sustained by frequent low- to moderate-intensity surface fires preventing lands from reaching eventual succession to domination by mixed hardwood forests. The ecosystem has experienced loss to only about 1.2 million hectares $(485,000 \mathrm{ac})$ due to disruption of natural fire regimes, land conversion, urbanization, as well as other factors. Due to habitat loss and fragmentation of remaining stands, many species dependent upon this ecosystem are rare or in decline. Key factors affecting restoration include understanding the historical condition of the longleaf ecosystem, initiation and expansion of an appropriate fire regime, management of herbaceous diversity, continued research, and encouragement of multi-ownership to conservation approaches and responsibilities. 


\section{Relevant Books and Publications}

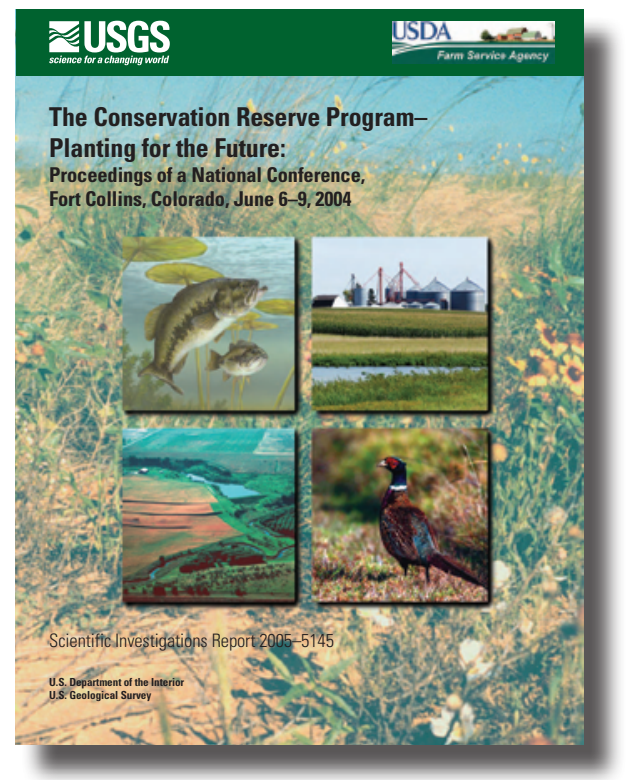

\section{Agricultural and Conservation Policy}

Albrecht, D.E., and Murdock, S.H., 1990, The sociology of U.S. agriculture-An ecological perspective: Ames, Iowa, Iowa State University Press, 249 p.

Allen, A.W. and Vandever, M.W., eds., 2005, The Conservation Reserve Program-Planting for the Future-Proceedings of a National Conference, Fort Collins, Colo., June 6-9, 2004: U.S. Geological Survey, Scientific Investigations Report 2005-5145, 248 p.

Aillery, M.P., Bertels, P., Cooper, J.C., Moore, M.R., Vogel, S.J., and Weinberg, M., 1996, Salmon recovery in the Pacific Northwest-Agricultural and other economic effects: Washington, D.C., USDA Economic Research Service, Natural Resources and Environment Division, Agricultural Economic Report No. 727, 72 p.

Anderson, M., and Magleby, R., 1997, Agricultural resources and environmental indicators, 1996-97: Washington, D.C., USDA Economic Research Service, Agricultural Handbook No. 712, 347 p.

Blatz, C.V., 1991, Ethics and agriculture-An anthology on current issues in world context: Moscow, Idaho, University of Idaho Press, $674 \mathrm{p}$.

Browne, W.P., Skees, J.R., Swanson, L.E., Thompson, P.B., and Unnevehr, L.J., 1992, Sacred cows and hot potatoesAgrarian myths in agricultural policy: Boulder, Colo., Westview Press, $150 \mathrm{p}$.

Brouwer, F., and Crabtree, B., 1999, Environmental indicators and agricultural policy: New York, N.Y., CABI Publishing, $305 \mathrm{p}$.
Council for Agricultural Science and Technology, 1990, Ecological impact of federal conservation and cropland reduction programs: Ames, Iowa, Council for Agricultural Science and Technology, Report No. 11, 28 p.

Center for National Policy, 1991, U.S. Agriculture- Myth, Reality and National Policy: Washington, D.C., Center for National Policy, 76 p.

Claassen, R., Hansen, L., Peters, M., Breneman, V., Weinberg, M., Cattaneo, A., Feather, P., Gadsby, D., Hellerstein, D., Hopkins, J., Johnson, P., Morehart, M., and Smith, M., 2001, Agri-environmental policy at the crossroads - Guideposts on a changing landscape: Washington, D.C., USDA Economic Research Service, Agricultural Economic Report No. 794, 66 p.

Claassen, R., Breneman, V., Bucholtz, S., Cattaneo, A., Johansson, R., and Morehart, M., 2004, Environmental compliance in U.S. agricultural policy_Past performance and future potential: Washington, D.C., USDA Economic Research Service, Agricultural Economic Report No. 832, $50 \mathrm{p}$.

Cochrane, W.W., 1993, The development of American agriculture-A historical analysis: Minneapolis, Minn., University of Minnesota Press, $500 \mathrm{p}$.

Cochrane, W.W., 2003, The curse of American agricultural abundance-A sustainable solution: Lincoln, Neb., University of Nebraska Press, 154 p.

Cochrane, W.W., and Runge, C.F., 1992, Reforming farm policy-Toward a national agenda: Ames, Iowa, Iowa State University Press, 279 p.

Ervin, D., Algozin, K., Carey, M., Doering, O., Frerichs, S., Heimlich, R., Hrubovcak, J., Konyar, K., McCormick, I., Osborn, T., Ribaudo, M., and Shoemaker, R., 1991, Conservation and environmental issues in agriculture-An economic evaluation of policy options: Washington, D.C., USDA Economic Research Service, Staff Report No 9134, $62 \mathrm{p}$.

Ervin, D.E, and Smith, K.R., 1996, What it takes to "Get to Yes" for whole farm planning policy: Greenbelt, Md., Henry A. Wallace Institute for Alternative Agriculture, Policy Studies Report No. 5, 42 p.

Feather, P., Hellerstein, D., and Hansen, L., 1999, Economic valuation of environmental benefits and the targeting of conservation programs-The case of the CRP: Washington, D.C., USDA Economic Research Service, Agricultural Economic Report No. 778, 56 p.

Freyfogle, E.T., 2003, The land we share-Private property and the common good: Washington D.C., Island Press, $336 \mathrm{p}$. 
General Accounting Office, 1995, Conservation Reserve Program-Alternatives are available for managing environmentally sensitive cropland-Report to the Committee on Agriculture, Nutrition, and Forestry, U.S. Senate: Washington, D.C., GAO/RCED-95-42, 68 p.

General Accounting Office, 2003, Agricultural ConservationSDA needs to better ensure protection of highly erodible croplands and wetlands - Report to the ranking Democratic member, Committee on Agriculture, Nutrition, and Forestry, U.S. Senate: Washington D.C., GAO-03-418, 106 p.

Gardner, B.L., 2002, American agriculture in the twentieth century-How it Flourished and What It Cost: Cambridge, Mass., Harvard University Press, 388 p.

Gerard, P.W., 1995, Agricultural practices, farm policy, and the conservation of biological diversity: Washington D.C., U.S. Department of the Interior, National Biological Service, Biological Science Report 4, 28 p.

Hallberg, M.C., 2001, Economic trends in U.S. agriculture and food systems since World War II: Ames, Iowa, Iowa State University Press, $179 \mathrm{p}$.

Haufler, J.B., ed., 2005, Fish and wildlife benefits of Farm Bill conservation programs - 2000-2005 update: Bethesda, Md., The Wildlife Society Technical Review 05-2, 205 p.

Heard, L.P., Allen, A.W., Best, L.B., Brady, S.J., Burger, W., Esser, A.J., Hackett, E., Johnson, D.H., Pederson, R.L., Reynolds, R.E., Rewa, C., Ryan, M.R., Molleur, R.T., and Buck, P., 2000, A comprehensive review of Farm Bill contributions to wildlife conservation, 1985-2000: Madison, Miss., USDA Natural Resources Conservation Service, Wildlife Habitat Management Institute, Technical Report USDA/NRCS/WHMI-2000, 208 p.

Heimlich, R.E., Wiebe, K.D., Classen, R., Gadsby, D., and House, R.M., 1998, Wetlands and agriculture-Private interests and public benefits: Washington, D.C., USDA Economic Research Service Agricultural Economic Report No. 765,94 p.

Hughes, J.S., Hoag, D.L., and Nipp, T.E., 1995, The Conservation Reserve-A survey of research and interest groups: Ames, Iowa, Council for Agricultural Science and Technology, $44 \mathrm{p}$.

Jack, Z.M., 2005, Black earth and ivory tower-New American essays from farm to classroom: Columbia, S.C., University of South Carolina Press, 312 p.

Kuntson, R.D., Penn, J.B., and Boehm, W.T., 1990, Agricultural and food policy: Englewood Cliffs, N.J., Prentice Hall, $437 \mathrm{p}$.

Lockeretz, W., 1996, Environmental enhancement through agriculture: Medford, Mass., Tufts University, Center for Agriculture, Food and Environment School of Nutrition Science and Policy, $334 \mathrm{p}$.

Licht, D.S., 1997, Ecology and economics of the Great Plains: Lincoln, Neb., University of Nebraska Press, 225 p.
McKenzie, D.F., and Riley, T.Z., eds., 1995, How much is enough? A regional wildlife habitat needs Assessment for the 1995 Farm Bill: Washington, D.C., Wildlife Management Institute, $30 \mathrm{p}$.

Napier, T.L., Napier, S.M., and Tvrdon, J., 2000, Soil and water conservation policies and programs - Successes and failures: Washington, D.C., CRC Press, 608 p.

National Research Council, 1989, Alternative agriculture: Washington, D.C., National Academy Press, 448 p.

National Research Council, 2010, Toward sustainable agricultural systems in the 21 st century: Washington, D.C., National Academy Press, $570 \mathrm{p}$.

Nowak, P., and Schnepf, M., Managing agricultural landscapes for environmental quality II-Achieving more effective conservation: Ankeny, Iowa, Soil and Water Conservation Society, $168 \mathrm{p}$.

Office of Technology Assessment, 1995, Agriculture, trade, and environment-Achieving complementary policies: Washington, D.C., U.S. Congress Office of Technology Assessment OTA-ENV-617, $241 \mathrm{p}$.

O'Riordan, T., and Stoll-Kleemann, S., 2002, Biodiversity, sustainability and human communities: Cambridge, U.K., Cambridge University Press, 317 p.

Olson, R.K., 1992, Integrating sustainable agriculture, ecology, and environmental policy: New York, N.Y., Food Products Press, $161 \mathrm{p}$.

Opie, J., 1994, The law of the land-Two hundred years of American farmland policy: Lincoln, Neb., University of Nebraska Press, 253 p.

Potter, C., 1998, Against the Grain-Agri-environmental reform in the United States and the European Union: New York, N.Y., CAB International, $194 \mathrm{p}$.

Pyle, G., 2005, Raising less corn, more hell-The case for the independent farm and against industrial food: New York, N.Y., Public Affairs, 229 p.

Risley, D.L., 1995, Farm Bill-Wildlife options in agricultural policy: Bethesda, Md., The Wildlife Society Technical Review 95-1, 24 p.

Solbrig, O.T., and Solbrig, D.J., 1994, So shall you reapFarming and crops in human affairs: Washington, D.C., Island Press, $284 \mathrm{p}$.

Schnepf, M., and Cox, C., 2007, Managing agricultural landscapes for environmental quality - Strengthening the science base: Ankeny, Iowa., Soil and Water Conservation Society, $196 \mathrm{p}$.

Thu, K.M., and Durrenberger, E.P., 1998, Pigs, profits, and rural communities: Albany, N.Y., State University of New York Press, $208 \mathrm{p}$.

Thurman, W.N., 1995, Assessing the environmental impact of farm policies: Washington, D.C., AEI Press, 79 p. 
Uri, N.D., 1999, Agriculture and the environment: New York, Nova Science Publishers, Inc., 277 p.

U.S. Department of Agriculture, 2001, Food and agricultural policy-Taking stock for the new century: Washington, D.C., U.S. Department of Agriculture, 120 p.

U.S. Department of the Interior, 1988, The impact of federal programs on wetlands, Volume 2-The Lower Mississippi Alluvial Plain and the Prairie Pothole Region: Washington, D.C., U.S. Department of the Interior, 114 p.

U.S. Department of the Interior, 1994, The impact of federal programs on wetlands, Volume 2- The Everglades, Coastal Louisiana, Galveston Bay, Puerto Rico, California's Central Valley, Western Riparian Areas, Southeastern and Western Alaska, Delmarva Peninsula, North Carolina, Northeastern New Jersey, Michigan, and Nebraska: Washington, D.C., U.S. Department of the Interior, $333 \mathrm{p}$.

Worster, D., 1979, Dust bowl-The Southern Plains in the 1930s: New York, Oxford University Press, 277 p.

\section{Wildlife Habitat}

Bonney, R., Pashley, D.N., Cooper, R.J., and Niles, L., eds., 2000, Strategies for bird conservation-The partners in flight planning process: Fort Collins, Colo., USDA Forest Service Proceedings RMRS-16, 281 p.

Dumke, R.T., Burger, G.V., and March, J.R., eds., 1981, Wildlife management on private lands - Proceedings of Symposium -Wildlife Management on Private Lands May 3-6, 1981 Milwaukee, WI: Madison, Wis., Wildlife Society of Wisconsin, $568 \mathrm{p}$.
Flather, C.H., Brady, S.J., and Knowles, M.S., 1999, Wildlife resource trends in the United States - A technical document supporting the 2000 USDA Forest Service RPA Assessment: Fort Collins, Colo., USDA Forest Service General Technical Report RMRS-GTR-33, 79 p.

Finch, D.M., ed., 1996, Ecosystem disturbance and wildlife conservation in western grasslands - A symposium proceedings: Albuquerque, N.M., USDA Forest Service General Technical Report RM-GTR-285, 82 p.

Finch, D.M., and Stangle, P.W., eds., 1992, Status and management of neotropical migratory birds: Fort Collins, Colo., USDA Forest Service General Technical Report RM-229, $422 \mathrm{p}$.

Hallett, D.L., Edwards, W.R., and Burger, G.V., 1988, Pheasants - Symptom of wildlife problems on agricultural lands: Bloomington, Ind., North Central Section of the Wildlife Society, $345 \mathrm{p}$.

Jackson, D.L., and Jackson, L.L., 2002, The farm as natural habitat-Reconnecting foods systems with ecosystems: Washington, D.C., Island Press, 297 p.

Payne, N.F., and Bryant, F.C., 1994, Techniques of wildlife habitat management of uplands: New York, McGraw-Hill, Inc., 840 p.

Thompson, F.R., III, ed., 1995, Management of midwestern landscapes for the conservation of neotropical migratory birds: St. Paul, Minn., USDA Forest Service General Technical Report NC-187, 207 p.

Whitney, G.C., 1994, From coastal wilderness to fruited plain-A history of environmental change in temperate North America from 1500 to the present: New York, Cambridge University Press, $451 \mathrm{p}$.

Publishing support provided by:

Denver Publishing Service Center

For more information concerning this publication, contact:

Center Director, USGS Fort Collins Science Center

2150 Centre Ave., Bldg. C

Fort Collins, CO 80526-8118

(970)226-9398

Or visit the Fort Collins Science Center Web site at:

http://www.fort.usgs.gov/ 
